Carlos German Massone

\title{
Avaliação da distribuição de hidrocarbonetos em matrizes ambientais e avaliação crítica das ferramentas de diagnóstico de fontes
}

\author{
Tese de Doutorado
}

Tese apresentada como requisito parcial para obtenção do grau de Doutor em Química pelo Programa de Pós-graduação em Química da PUC-Rio.

Orientadora: Profa. Angela de Luca Rebello Wagener Coorientadora: Profa. Adriana Gioda 
Carlos German Massone

\begin{abstract}
Avaliação da distribuição de hidrocarbonetos em matrizes ambientais e avaliação crítica das ferramentas de diagnóstico de fontes
\end{abstract}

Tese apresentada como requisito parcial para obtenção do grau de Doutor em Química pelo Programa de Pós-graduação em Química da PUC-Rio. Aprovada pela Comissão Examinadora abaixo assinada.

Profa. Angela de Luca Rebello Wagener Orientadora Departamento de Química - PUC-Rio

Profa. Adriana Gioda Coorientadora Departamento de Química - PUC-Rio

Prof. Annibal Duarte Pereira Netto UFF

Profa. Graciela Arbilla de Klachquin UFRJ

Prof. Jose Marcus de Oliveira Godoy Departamento de Química - PUC-Rio

Dr. Arthur de Lemos Scofield Departamento de Química - PUC-Rio

Prof. José Eugenio Leal Coordenador Setorial do Centro Técnico Científico - PUC-Rio

Rio de Janeiro, 06 de setembro de 2013 
Todos os direitos reservados. É proibida a reprodução total ou parcial do trabalho sem a autorização da universidade, do autor e dos orientadores.

\section{Carlos German Massone}

Oceanógrafo formado pela Universidade do Estado do Rio de Janeiro com mestrado em Geociências (Geoquímica) pela Universidade Federal Fluminense. Participou de ativamente de programas de monitoramento ambiental e na análise de contaminantes.

Ficha Catalográfica

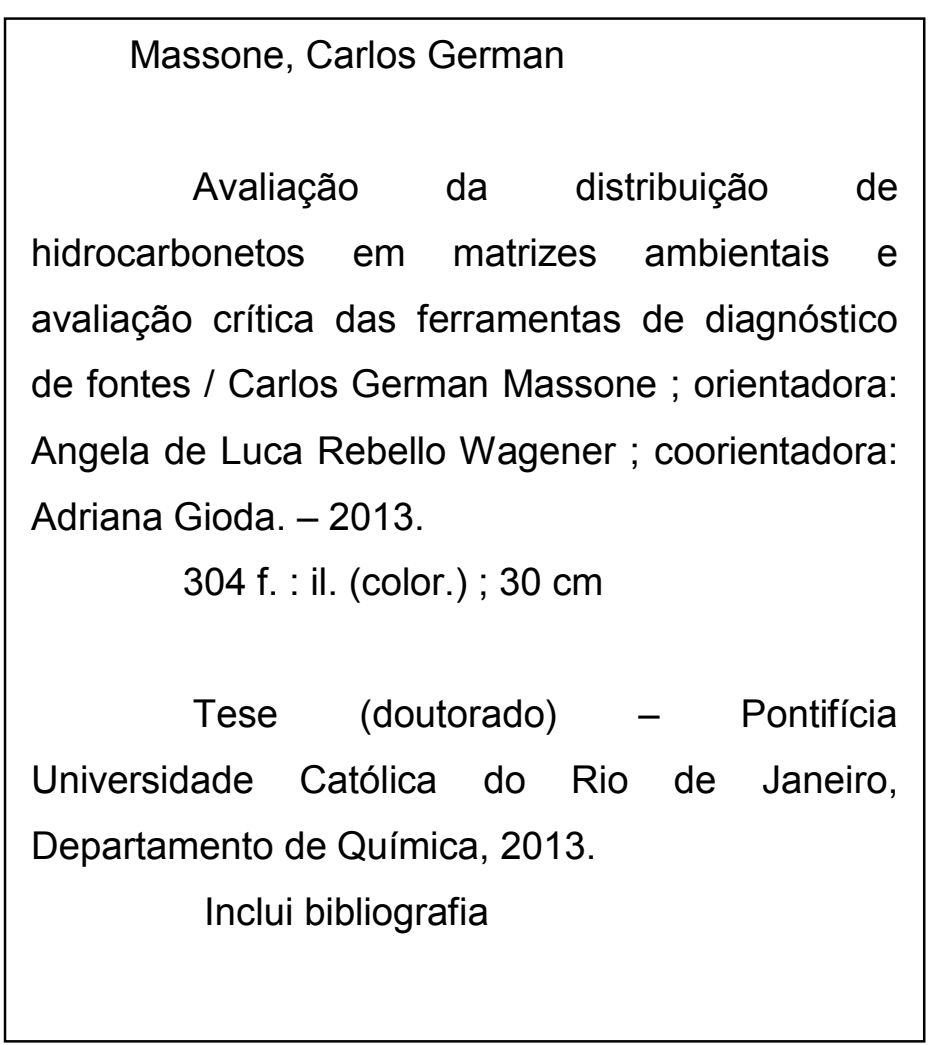


A minha família, agora maior, pelo apoio incondicional. $E$ as pessoas boas e ruins que cruzaram meu caminho, com seus respectivos exemplos, pois todos me ensinaram a ser um ser humano e profissional melhor. 


\section{Agradecimentos}

A minha orientadora Angela de Luca Rebello Wagener, pelo apoio, orientação e pela coragem de assumir um trabalho imenso, tendo como único fomento sua infinita curiosidade e incansável vontade de aprender.

A minha coorientadora Adriana Gioda pelas dicas, objetividade, orientação e ajuda ao longo desta jornada.

A meus pais e irmão pelo apoio e carinho contínuo.

A Thaís Pedrete Massone, minha esposa, por tornar os momentos difíceis mais amenos com um simples gesto. Não poderia pedir esposa mais amável ou amiga mais fiel. Agradeço também o companheirismo em finais de semana de trabalho intenso no laboratório.

Aos meus sogros pelo carinho e ajuda em todos os momentos.

Ao estagiário e colega Henrique pela ajuda e dedicação ao trabalho.

A PUC-RIO, pelos auxílios concedidos.

Ao Arthur de Lemos Scofield, cujo conhecimento e humildade sempre me fazem pensar se tive mais sorte em conhecê-lo como pessoa ou como pesquisador.

Ao Instituto Estadual do Ambiente (INEA) por ceder as amostras e tornar este trabalho possível.

Ao Centro de Pesquisas Leopoldo Américo Miguez de Melo (CENPES) pelo apoio em ceder as amostras de petróleo e produtos de petróleo.

A equipe do Labmam por prestarem ajuda além das funções que Ihe são atribuídas. Este trabalho existe graças ao comprometimento, dedicação e profissionalismo de todos. Não tenho como agradecer todo o empenho que tiveram com problemas que, na realidade, não eram seus. 
Ao Instituto de Estudos do Mar Almirante Paulo Moreira por seu apoio na realização deste trabalho.

Aos amigos e colegas de trabalho do IEAPM Pedro Paulo, Tereza e Fernanda pela amizade, ajuda nos momentos difíceis, e por sempre me lembrarem de que a vida não deve ser levada tão a sério e que somos capazes de rir de nossas próprias adversidades.

A Cláudia Hamacher, primeira orientadora e responsável pela minha ida ao mundo da oceanografia química.

A Cássia Farias, amiga de todas as horas, pela amizade e excelente convívio profissional que sempre carrego comigo como exemplo a ser seguido.

Aos eternos amigos do CENPES, Marcus, Gleidice, Rafael Encantado, Bruno, Fabiana, Gilson, Lili, Fabinho, André e todos os demais que não cabem nesta folha pelas lições profissionais e de vida, mas principalmente por provarem que trabalhar com alegria não é sinônimo de desordem, é uma benção.

A Fátima, pela inestimável ajuda na secretaria e por ouvir os problemas de cada aluno com o profissionalismo que lhe é característico, agregado a compreensão, bondade e acima de tudo a paciência de uma mãe. 


\section{Resumo}

Massone, Carlos German; Wagener, Angela de Luca Rebello (orientadora). Avaliação da distribuição de hidrocarbonetos em matrizes ambientais e avaliação crítica das ferramentas de diagnóstico de fontes. Rio de Janeiro, 2013. 304p. Tese de Doutorado - Departamento de Química. Pontifícia Universidade Católica do Rio de Janeiro.

A Baía de Guanabara é um ecossistema costeiro cujas alterações na bacia de drenagem ao longo dos anos levaram a sua condição atual de degradação ambiental. As razões diagnósticas e abordagens para a diferenciação de fontes de hidrocarbonetos baseiam-se em dados da literatura e a aplicação destas ao ambiente de estudo é de difícil extrapolação. Este estudo objetiva uma avaliação crítica destas ferramentas através da análise de dois tipos de aportes, o material particulado atmosférico $\left(\mathrm{PM}_{2,5}\right)$ da Região Metropolitana do Rio de Janeiro e amostras de petróleo e seus produtos de origem brasileira, interpretando os resultados separadamente e relacionando-os aos dados obtidos em amostras de sedimentos desta mesma baía. A concentração de hidrocarbonetos na atmosfera é considerada baixa, onde a precipitação mostrou-se o principal fenômeno atmosférico a influenciar na concentração de material particulado e de hidrocarbonetos. As emissões veiculares, principalmente derivadas de veículos a gasolina, são a principal fonte de hidrocarbonetos para a atmosfera. A concentração de hidrocarbonetos em sedimentos corrobora o forte aporte crônico ao qual a baía está sujeita, sendo a fonte antrópica a principal responsável pelos níveis encontrados. Muitas das razões diagnósticas e seus limites estabelecidos em literatura não correspondem aos valores encontrados nas diferentes matrizes analisadas, existindo também sobreposição de valores entre estas. Os sedimentos da Baía de Guanabara encontram-se em um estado elevado de degradação que interfere na quantificação de fontes e avaliação de aportes. A análise de componentes principais realizada com a proporção relativa dos HPAs em relação aos compostos de mesma massa mostrou-se a metodologia mais adequada para a avaliação de aportes. Os hidrocarbonetos policíclicos aromáticos normalmente não quantificados em estudos ambientais, especialmente os de massa 278 e 276, mostraram maior capacidade em 
discriminar e separar as amostras geograficamente em relação à origem da contaminação.

\section{Palavras-Chave}

Baía de Guanabara; matrizes ambientais; fontes de hidrocarbonetos; particulado atmosférico; sedimentos. 


\section{Abstract}

Massone, Carlos German; Wagener, Angela de Luca Rebello (advisor). Evaluation of hydrocarbons distribution in environmental matrices and critical appraisal of diagnostics source tools. Rio de Janeiro, 2013. 304p. DSc. Thesis - Departamento de Química. Pontifícia Universidade Católica do Rio de Janeiro.

Guanabara Bay is a coastal ecosystem where changes in the drainage basin over the years led to its current condition of environmental degradation. The diagnostic reasons and approaches for differentiating hydrocarbon sources are based on literature data and their application in the environment is difficult to extrapolate. This study aims a critical evaluation of these tools by analyzing two types of contributions, the atmospheric particulate matter $\left(P M_{2,5}\right)$ in the Metropolitan Region of Rio de Janeiro and samples of petroleum and their products of Brazilian origin, interpreting the results separately and linking them to data obtained in sediment samples from the same bay. The hydrocarbons concentration in the atmosphere is relatively low, where precipitation proved to be the main atmospheric phenomena to influence the concentration of particulate matter and hydrocarbons. The vehicular emissions, mainly derived from gasoline of vehicles, are the main source of hydrocarbons to the atmosphere. The concentration of hydrocarbons in sediments corroborates the intense chronic contribution which the bay is subject, presenting the anthropogenic source as the main cause of levels detected. Many of the diagnostic reasons and limits established in the literature do not correspond to the values found in different matrices analyzed, there is also overlap between these values. The sediments of Guanabara Bay are in a high state of degradation that interferes with the sources quantification and assessment of contributions. A principal component analysis performed with the PAHs relative proportion in relation to the compounds with the same molecular mass proved to be the most appropriate methodology for evaluating contributions. The polycyclic aromatic hydrocarbons not usually quantified in environmental studies, especially the ones with mass 278 and 276 , demonstrated greater ability to discriminate and separate samples geographically regarding the contamination origin. 


\section{Keywords}

Guanabara Bay; environmental matrices; hydrocarbons sources; atmospheric particulate; sediments 


\section{Sumário}

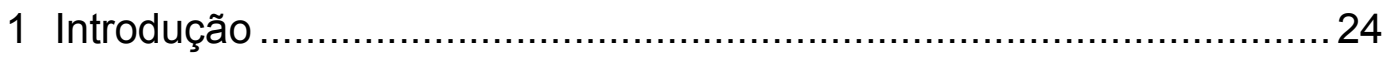

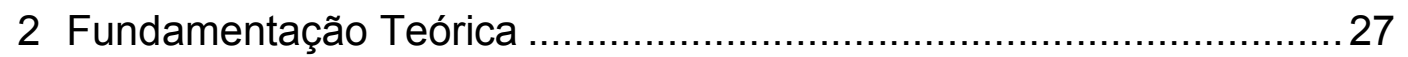

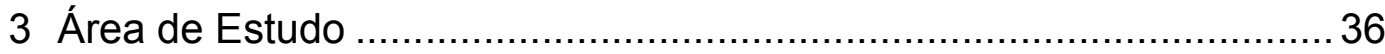

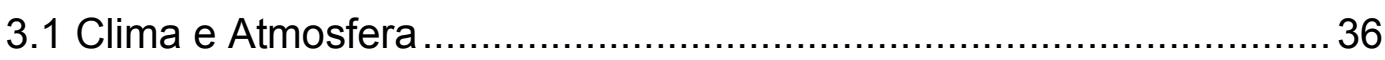

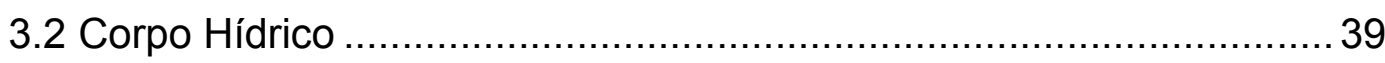

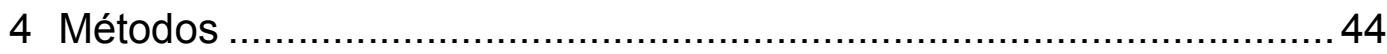

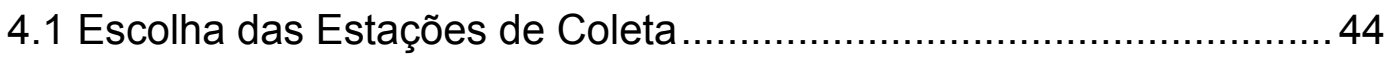

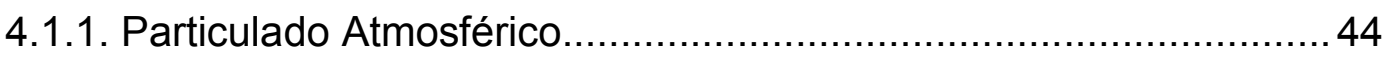

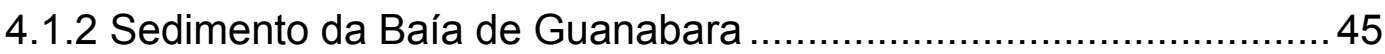

4.1.3 Amostras de petróleo e produtos de petróleo.................................. 46

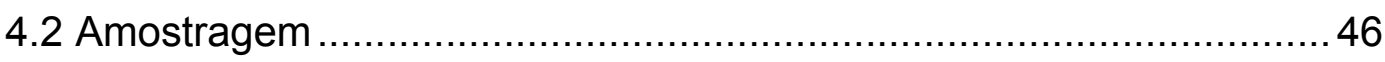

4.3 Aquisição e seleção de dados climatológicos e meteorológicos ........47

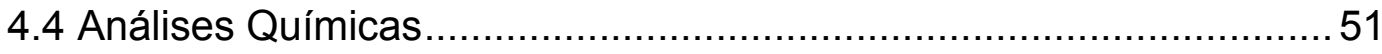

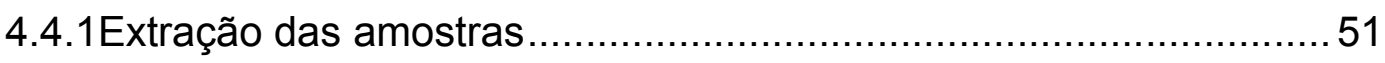

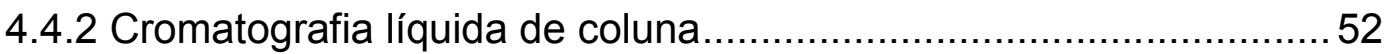

4.4.3Quantificação dos Hidrocarbonetos Alifáticos ..................................53

4.4.4Quantificação dos Hidrocarbonetos Aromáticos................................ 54

4.4.5 Análise de Carbono Orgânico nos sedimentos da Baía de

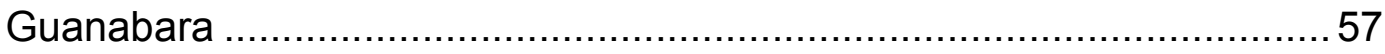

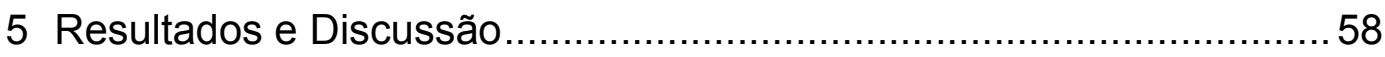

5.1 Dados complementares - Clima e Meteorologia da área de estudo .. 58

5.2 Caracterização das Amostras de Petróleo e Produtos de Petróleo.... 63

5.3 Concentração de hidrocarbonetos em amostras de material

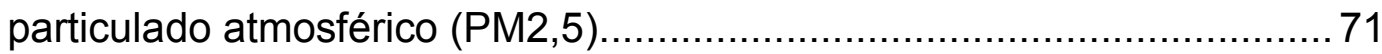

5.4 Relação entre a concentração de hidrocarbonetos em amostras de material particulado atmosférico (PM2,5) e variáveis complementares. .. 80 
5.5 Distribuição de hidrocarbonetos em particulado atmosférico e sua relação com fontes emissoras........................................................ 100

5.5.1 Origem dos hidrocarbonetos alifáticos ...................................... 100

5.5.2 Origem dos hidrocarbonetos aromáticos................................... 111

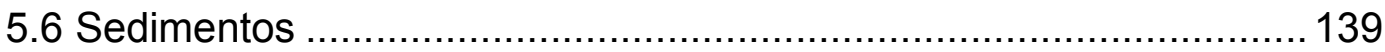

5.6.1 Carbono Orgânico ............................................................ 139

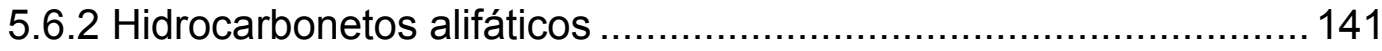

5.6.3 Hidrocarbonetos aromáticos.................................................... 148

6 Conclusões e Considerações........................................................177

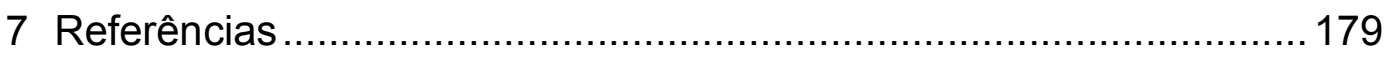

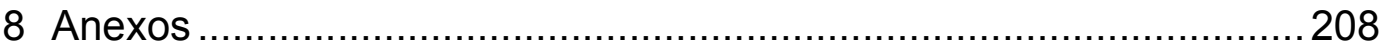




\section{Lista de abreviaturas}

ACP - Análise de Componentes Principais

AT - Alifáticos Totais

C - Estação de coleta do Centro

CAPES - Coordenação de Aperfeiçoamento de Pessoal de Nível Superior

CE - Estação de coleta de Campos Elíseos

CENPES - Centro de Pesquisas Leopoldo Américo Miguez de Mello

CP - Estação de coleta de Copacabana

GEO-RIO - Fundação Instituto de Geotécnica do Município do Rio de Janeiro

HPAs - Hidrocarbonetos Policíclicos Aromáticos

HR - Hidrocarbonetos Resolvidos

INEA - Instituto Estadual do Ambiente

INFRAERO - Empresa Brasileira de Infraestrutura Aeroportuária

INMET - Instituto Nacional de Meteorologia

IPC - índice de preferência de Carbono

MCNR - Mistura Complexa Não Resolvida

NT - Estação de coleta de Niterói

$\mathbf{P M}_{10}$ - Material Particulado atmosférico até $10 \mu \mathrm{m}$.

$\mathbf{P M}_{2,5}$ - Material Particulado atmosférico até 2,5 $\mu \mathrm{m}$.

SE - Estação de coleta de Seropédica

SJ - Estação de coleta de São João de Meriti

UFF - Universidade Federal Fluminense 


\section{Lista de figuras}

Figura 1 - Equação do Índice de Preferência de Carbono (IPC), onde a e b são n-alcanos com número par de carbonos (Cooper;Bary, 1963).

Figura 2 - Desenho esquemático de amostras de óleo cru (I), óleo intemperizado (II) e contribuição natural terrestre (III) (Massone, 2004).

Figura 3 - Resumo do processo de diagênese do Fitol (Modificado de Killops;Killops, 1993)

Figura 4 - Abundância relativa de compostos parentais e alquilsubstituídos como influência da temperatura de formação. (Modificado de NRC, 1985)

Figura 5 - Demonstração do Intemperismo do óleo. (a) e (c) são amostras de óleo e (b) e (d) são os produtos degradados e (e) são razões observadas ao longo do tempo . (Modificado de Page et al., 1993)

Figura 6 - Normais climatológicas dos dados do INMET para o Rio de Janeiro no período de 1961 a 1990. Precipitação acumulada (a) e temperatura média mensal (b). (INMET, 1992).

Figura 7 - Malha atual de monitoramento do INEA

Figura 8 - (a) Relevo do fundo da Baia de Guanabara em 3 dimensões (Torres et al., 2001 apud Guimarães, 2005) e (b) batimetria oficial (Modificado de Carta Náutica 1501-DHN)

Figura 9- Classificação de qualidade de água (Modificado de Mayr et al., 1989) 
Figura 10 - Taxa de sedimentação para diferentes áreas da Baía de Guanabara (Modificado de Godoy et al., 1998) - Localização aproximada dos pontos.

Figura 11 - Localização das estações de coleta deste estudo e malha de amostragem disponível pelo INEA.

Figura 12 - Localização das estações de coleta de Sedimento na Baía de Guanabara

Figura 13 - Mapa das estações de coleta de Material Particulado (PM2.5), estações meteorológicas do INMET, Aeroportos e estações do Sistema Alerta Rio.

Figura 14- Link para download dos dados de ventos de aeroportos. Especificação para o aeroporto do Galeão no período de 01 de janeiro a 31 de dezembro do ano de 2011

Figura 15 - Dados de direção (origem) e intensidade dos ventos para a estação do INMET de Copacabana para o mês de março de 2011 ...... 50

Figura 16 - Dados de chuva acumulada $(\mathrm{mm})$ e temperatura média pra a estação de Copacabana do INMET no ano de 2011.

Figura 17 -HPAs complementares identificados e quantificados nas amostras de material particulado atmosférico, sedimentos da Baía de Guanabara e amostras de petróleo e produtos de petróleo.

Figura 18 - Variação anual da temperatura média $\left({ }^{\circ} \mathrm{C}\right)$ e da chuva acumulada $(\mathrm{mm})$ para o ano de 2011 nas estações de suporte aos dados e estações complementares

Figura 19 - Precipitação máxima acumulada para o período 25 a 27 de abril nas estações de monitoramento da Prefeitura da Cidade do Rio de Janeiro (GEO-RIO/DEP/GPE, 2012).

Figura 20 - Variação anual da velocidade média mensal dos ventos $\left(\mathrm{m} \mathrm{s}^{-1}\right)$ para os dados das estações de Copacabana, Seropédica, 
Aeroporto Internacional Antonio Carlos Jobim (Galeão) e do Aeroporto Santos Dumont.

Figura 21 - Variação anual média para os dados de Umidade Relativa $(\%)$

Figura 22 - Variação anual média para os dados Radiação Global (KJ $\left.\mathrm{m}^{-2}\right)$

Figura 23 - Resultados para as análises em duplicata do produto de identificação FF nas quantificações de (a) hidrocarbonetos alifáticos e (b) hidrocarbonetos aromáticos

Figura 24 - Distribuição em Box-plot e percentual médio para as 32 amostras analisadas em duplicata da concentração de (a) n-alcanos, hidrocarbonetos resolvidos (HR) e Mistura Complexa Não Resolvida (MCNR) e (b) da concentração de Hidrocarbonetos Policíclicos Aromáticos (HPAs).

Figura 25 - Gráfico da razão C2Fe / C2DBT com a razão C3Fe / C3DBT

Figura 26 - Box-plot das razões diagnósticas de HPAs aplicadas às amostras de óleo, com a respectiva dispersão dos dados.

Figura 27 - Histogramas do percentual de recuperação dos compostos subrogados adicionados às amostras de material particulado atmosférico - (a) nC30d62 - (b) p-terfenil-d 14.

Figura 28 - Comparação das concentrações de hidrocarbonetos alifáticos entre as estações para amostras de material particulado atmosférico $\left(\mathrm{PM}_{2.5}\right)$ coletadas em 2011

Figura 29 - Comparação das concentrações de hidrocarbonetos alifáticos entre as estações para amostras de material particulado atmosférico $\left(\mathrm{PM}_{2.5}\right)$ coletadas em 2011. Foram excluídos os dados extremos para melhor visualização. 
Figura 30 - Comparação da concentração total de hidrocarbonetos policíclicos aromáticos (HPAs) em amostras de material particulado no mundo e no Brasil (Ln ([HPAs]+1) $\mathrm{ng} \mathrm{m}^{-3}$ ) e apenas no Brasil ([HPAs] $\mathrm{ng} \mathrm{m}^{-3}$ ).

Figura 31 - Concentração de HPAs entre os pontos amostrados de material particulado atmosférico $\left(\mathrm{PM}_{2.5}\right)$ no ano de 2011 e diferença honestamente significativa das médias dos locais amostrados pelo Teste de Tukey.

Figura 32 - Variação anual da precipitação acumulada da Estação do Sistema Alerta Rio de Irajá (A), concentração do material particulado para a Estação de Campos Elíseos (B) e box-plot da concentração de material particulado em relação a ocorrência de chuvas considerando o período de 48 horas anterior ao fim da amostragem (C)

Figura 33 - Box-plot da concentração de material particulado em relação a ocorrência de chuvas considerando o período de 48 horas anterior ao fim da amostragem para Copacabana

Figura 34 - Relação entre o material particulado fino $\left(\mu \mathrm{g} \mathrm{m}^{-3}\right)$, e a concentração dos parâmetros alifáticos $\left(\mathrm{ng} \mathrm{m}^{-3}\right)$ para os dados de 2011 da estação do Centro

Figura 35 - Relação entre o materital particulado atmosférico $\left(\mathrm{PM}_{2,5}\right)$ e a cncentração dos 16 HPAs prioritários (EPA) e o total de HPAs Quantificados para as estações do (a) Centro; (b) Campos Eliseos e (c) São João Meriti

Figura 36 - Concentração dos 16 HPAs prioritários (EPA) e da soma dos 38 HPAs quantificados para períodos sem e com ocorrência de chuva.

Figura 37 - Distribuição dos HPAs em amostras do Centro do Rio de Janeiro para o ano de 2011 entre dias normais e eventos de precipitação. 
Figura 38 - Distribuição dos HPAs em amostras de Copacabana para o ano de 2011 entre dias normais e eventos de precipitação

Figura 39 - Box-plot da concentração total de HPAs por mês e precipitação acumulada mensal para o ano de 2011 na estação de São João de Meriti.

Figura 40 - Box-plot da concentração de HPAs de 2 e 3 anéis por mês e precipitação acumulada mensal para o ano de 2011 na estação do Centro.

Figura 41 - Box-plot da distribuição de n-alcanos no material particulado atmosférico $\left(\mathrm{PM}_{2.5}\right)$, sem ouliers, amostrado durante o ano de 2011 nas estações do Centro, Campos Elíseos e Copacabana.

Figura 42 - Box-plot da distribuição de n-alcanos no material particulado atmosférico ( $\mathrm{PM}_{2.5}$ ), sem outliers, amostrado durante o ano de 2011 nas estações de Niterói, Seropédica e São João de Meriti.

Figura 43 - Resultados dos Índices de Preferência de Carbono, Cálculo da contribuição natural de vegetais superiores (WNA \%) e da razão entre a Mistura Complexa Não Resolvida e os Hidrocarbonetos Resolvidos (MCNR/HR) para as estações de coleta no ano de 2011 ... 105

Figura 44 - Gráfico log-log da concentração da concentração de Hidrocarbonetos Resolvidos (HR) e da Mistura Complexa Não Resolvida (MCNR)

Figura 45 - Box-plot da tipologia de HPAs no material particulado atmosférico $\left(\mathrm{PM}_{2.5}\right)$, eliminados os outliers, amostrado durante o ano de 2011 nas estações do Centro, Campos Elíseos e Copacabana.

Figura 46 - Box-plot da tipologia de HPAs no material particulado atmosférico ( $\mathrm{PM}_{2.5}$ ), eliminados os outliers, amostrado durante o ano de 2011 nas estações de Niterói, Seropédica e São João de Meriti. .....113 
Figura 47 - Box-plot das razões $\mid \mathrm{Pi} /(\mathrm{IPi}+\mathrm{BPe})$ e $\mathrm{Fl} /(\mathrm{Fl}+\mathrm{Pi})$ para o material particulado das estações de coleta.

Figura 48 - Box-plot das razões $\mathrm{BaA} /(\mathrm{BaA}+\mathrm{Cr})$ e $\mathrm{BaPi} /(\mathrm{BaPi}+\mathrm{Cr})$ para o material particulado das estações de coleta

Figura 49 - Box-plot das razões $\mathrm{BbFl} / \mathrm{BkFI}$ e $\mathrm{BaPi} / \mathrm{BPe}$ para o material particulado das estações de coleta.

Figura 50 - Box-plot da razão CHPAs / 16 HPAs para o material particulado das estações de coleta.

Figura 51 - Box-plot das razões de $\mathrm{BaPi} /(\mathrm{BaPi}+\mathrm{BePi})$ e $\mathrm{A} /(\mathrm{Fe}+\mathrm{A})$ para as diferentes estações amostradas durante o ano de 2011

Figura 52 - Variação anual da razão $\mathrm{BaPi} /(\mathrm{BaPi}+\mathrm{BePi})$ para as estações de Campos Elíseos e São João de Meriti.

Figura 53 - Gráfico log-log da concentração da concentração de HPAs de 3 a 6 anéis e da soma das 5 séries de HPAs alquilados

Figura 54 - Distribuição dos Fatores para a ACP realizada com a concentração relativa das amostras de particulado atmosférico da Região Metropolitana do Rio de Janeiro.

Figura 55 - Resultado da ACP para a distribuição relativa dos HPAs entre as estações

Figura 56 - Loadings dos 5 fatores extraídos da ACP para serem aplicado no Modelo Linear de Regressão Multipla

Figura 57 - Gráfico da concentração mensurada versus prevista; Contribuição média de cada fator para a concentração média das estações e desvios relativos da concentração prevista em relação à mensurada para cada estação de amostragem.

Figura 58 - Resultado dos demais HPAs quantificados para as estações de coleta de material particulado atmosférico $\left(\mathrm{PM}_{2,5}\right)$ 
Figura 59 - Razões diagnóstico de fontes baseadas em outros HPAs.. 137

Figura 60 - Distrubuição espacial da concentração de Carbono Orgânico (\%) em sedimentos da Baía de Guanabara.

Figura 61 - Distribuição dos n-alcanos, HR, MCNR e Alifáticos Totais (AT) em amostras de sedimento da Baía de Guanabara.

Figura 62 - Comparação entre as matrizes analisadas para a variação em escala logarítima da relação entre MCNR e HR e do índice de Preferência de Carbono (IPC)

Figura 63 - Variação especial da relação MCNR/HR para as amostras de sediment da Baía de Guanabara.

Figura 64 - Gráfico log da relação entre os hidrocarbonetos resolvidos (HR) e a Mistura Complexa Não Resolvida. (P7 e P8 não utilizados no cállculo de regressão).

Figura 65 - Distribuição dos HPAs em amostras de sedimento da Baía de Guanabara.

Figura 66 - Gráfico cruzado de razões diagnósticas de fontes aplicadas aos dados de Sedimento da Baía de Guanabara

Figura 67 - Gráfico log-log da concentração da concentração de HPAs de 3 a 6 anéis e da soma das 5 séries de HPAs alquilados para amostras de sedimento da Baía de Guanabara.

Figura 68 - Factor Loadings resultantes de ACP nos dados de concentração dos sedimentos

Figura 69 - Distribuição dos HPAs entre as estações de sedimento Gráficos na mesma escala

Figura 70 - Distribuição dos Carregamentos e Escores resultantes da ACP com Rotação Varimax nos dados de distribuição relativa. 
Figura 71 - Resultado da Análise Hierárquica de Agrupaento nos dados de distribuição relativa de HPAs em sedimentos

Figura 72 - Resultados obtidos no método de Análise de Componentes Principais associado a Regressão Múltipla Linear (ACP-MLR).

Figura 73 - Contribuição média e desvio-padrão da distribuição relativa das 11 amostras de sedimento da Baía de Guanabara

Figura 74 - Distribuição espacial da concentração total de HPAs em sedimentos

Figura 75 - Razões diagnóstico de fontes aplicadas a diversas matrizes estudadas.

Figura 76 - Resultado dos demais HPAs quantificados para as estações de sedimento da Baía de Guanabara 169

Figura 77 - Comparação das razões diagnóstico de fontes baseadas em outros HPAs para as amostras de aerossóis e sedimentos.

Figura 78 - Distribuição dos Carregamentos e Escores resultantes da ACP com nova normalização dos dados

Figura 79 - Resultado da Análise Hierárquica de Agrupamento (AHA) a partir da nova normalização dos dados. 


\section{Lista de tabelas}

Tabela 1 - Resultados do cálculo da estabilidade relativa para HPAs com múltiplos isômeros usando diferentes modelos. (Modificado de Yunker et al., 2000)

Tabela 2 - Escolha da base de dados disponíveis para interpretação dos resultados das estações de amostragem do material particulado ..... 48

Tabela 3 - Condições cromatográficas para determinação de hidrocarbonetos alifáticos.

Tabela 4 - Condições instrumentais para determinação de HPAs individuais.

Tabela 5 - Concentração média, desvio padrão, mediana e faixa de concentração dos parâmetros da fração alifática, em $\mathrm{ng} \mathrm{m}^{-3}$, para o particulado atmosférico $\left(\mathrm{PM}_{2,5}\right)$ da Região Metropolitana do Rio de Janeiro no ano de 2011

Tabela 6 - Concentração média, desvio padrão, mediana e faixa de concentração dos HPAs, em $\mathrm{ng} \mathrm{m}^{-3}$, da Região Metropolitana do Rio de Janeiro no ano de 2011

Tabela 7 - Correlação de Spearman $\left(r_{s}\right)$ entre a quantidade de material particulado $\left(\mu \mathrm{g} \mathrm{m}^{-3}\right)$ e os hidrocarbonetos $\left(\mathrm{ng} \mathrm{m}^{-3}\right)$. Valores estatisticamente significantes destacados em negrito e itálico

Tabela 8 - Concentração de Carbono Orgânico em amostras de sedimento da Baía de Guanabara

Tabela 9 - Resultados obtidos da fração alifática para amostras de sedimento da Baía de Guanabara

Tabela 10 - Resultados obtidos da fração aromática para amostras de sedimento da Baía de Guanabara 
"Vivamos de tal forma que, quando morrermos, até o agente funerário sinta saudades."

(Mark Twain) 


\section{Introdução}

A Baía de Guanabara tem sido um dos ecossistemas costeiros mais estudados nos últimos anos (Christensen et al., 2010; Wagener et al., 2012; Wagener et al. 2010; Luz, 2007; Soares-Gomes et al., 2010; Meniconi et al., 2002, Meniconi, 2007; Brito et al., 2006; Azevedo et al., 2004; Carreira et al., 2002). As alterações na bacia de drenagem iniciaram-se no início do século 19 levando a condição atual de elevada eutrofização, altas taxas de sedimentação e alterações das comunidades pelágicas e bênticas (Hamacher, 1996; Lima, 1996; Ribeiro, 1996; Amador, 1997; Feema, 1998; Valentin et al., 1999). Desde a intensificação das atividades offshore no início dos anos 90 este ecossistema está sob maior influência das atividades inerentes a esta indústria.

Os hidrocarbonetos são compostos presentes em petróleo e resíduos de combustão. Os hidrocarbonetos policíclicos aromáticos (HPAs), compostos formados pela fusão de dois ou mais anéis aromáticos, recebem maior atenção dado seus reconhecidos efeitos tóxicos, mutagênicos e carcinogênicos. Tais compostos encontram-se espalhados por todo o mundo, cuja distribuição em concentração reflete a proximidade a centros urbanos (Laflamme \& Hites, 1978). A concentração destes compostos em registros sedimentares tem demonstrado a elevação de sua concentração ao longo do tempo em consequência da atividade humana (Silliman et al., 2001), refletindo o aporte antropogênico crescente desde o século 19 (Pereira et al., 1999, Borges et al., 2009).

Os hidrocarbonetos produzidos por diferentes fontes possuem características próprias que podem ser usadas como ferramentas para determinar a origem destes compostos no ambiente (Cooper \& Bray, 1963; Clark \& Blumer, 1967; Blumer et al., 1971; Simoneit, 1985; Youngblood \& Blumer, 1975; Wakeham et al., 1980a; Wakeham et al., 1980b; Wakeham et al., 1980c; Boehm e Farrington, 1984; Benner et al., 1990; Benner \& Gordon, 1989; Prahl \& Carpender, 1983; Gschwend \& Hites, 1981; Sicre et al., 1987; Baumard et al., 1998). Entretanto a diversidade de fontes associada à complexidade natural do ambiente em diversas ocasiões não permitem um quadro claro para este tipo de avaliação. 
O entendimento das ferramentas adequadas para determinar a origem dos hidrocarbonetos, especialmente os aromáticos, é essencial para a avaliação ambiental e propostas de manejo e utilização dos recursos. Embora o uso destas ferramentas seja amplamente difundido em literatura, sua aplicabilidade e capacidade discriminatória de fontes parecem incertas. Uma das premissas deste tipo de abordagem é considerar que cada razão diagnóstica tem um valor específico em cada tipo de fonte, e que este se mantém estável desde sua emissão ou origem até o destino final. Uma vez que este pressuposto não é robusto o suficiente a combinação de diversas razões é utilizada para uma avaliação mais acurada.

Dada a complexidade ambiental e incerteza de cada ferramenta diagnóstica de fontes diversos métodos multivariados tem sido aplicados como proposta suplementar as indicações obtidas pelas razões (Li et al., 2012; Wagener et al., 2012; Christensen et al., 2010; Chen et al., 2012; Barakat et al., 2011). Os métodos mais frequentemente utilizados são a análise de componentes principais (ACP) e a análise hierárquica de agrupamento (AHA), ou Cluster Analysis.

O maior problema da aplicabilidade de todos os recursos encontrados na literatura é que os mesmos foram criados e estabelecidos a partir de estudos em zonas temperadas, cujas características dos produtos e condições ambientais são de difícil extrapolação ao ambiente encontrado na Baía de Guanabara. Esta discrepância existe desde a caracterização de petróleo e produtos de petróleo, e é especialmente preocupante na caracterização das emissões veiculares e queima de biomassa, cujas propriedades diferem das características encontradas no Brasil. Portanto os limites das razões diagnósticas de fontes merecem uma revisão crítica, assim como sua aplicação em ambientes costeiros.

Para tal finalidade foram analisadas amostras de petróleo e produtos derivados, assim como aerossóis $\left(\mathrm{PM}_{2,5}\right)$ de diferentes partes da Região Metropolitana do Rio de Janeiro ao longo de um ano, e amostras de sedimento marinho da Baía de Guanabara. As duas primeiras matrizes tratam de fontes distintas de hidrocarbonetos, produtos de petróleo e emissões atmosféricas, enquanto o sedimento é considerado o compartimento integrador de todas as fontes e processos atuantes no sistema. Além dos hidrocarbonetos usualmente utilizados em avaliações ambientais este estudo também avaliou outros compostos com potencial capacidade discriminatória de fontes nestas matrizes. 
Apesar de existirem vários estudos sobre a distribuição de hidrocarbonetos em aerossóis na Região Metropolitana do Rio de Janeiro (Fernandes et al., 2002; Lima, 2006; Quitério et al., 2005; Azevedo et al. 1999; Pereira Netto et al., 2002, 2001; Machado et al., 2009; Dayse et al., 1987; Marques et al., 2009; Lopes \& Andrade, 1996) os mesmos foram realizados em períodos, locais, metodologias e tamanhos de partículas diferentes. Soma-se a isto a descontinuidade temporal das análises e as mudanças na frota, especificação e uso de combustíveis fósseis. Todos estes fatores tornaram necessária a coleta de amostras em uma área ampla a fim de comparar os dados aos estudos pretéritos e às demais matrizes analisadas.

Desta forma o objetivo geral do trabalho é relacionar as características das fontes de hidrocarbonetos à sua deposição final na Baía de Guanabara através da caracterização de três diferentes matrizes e suas respectivas razões diagnósticas, buscando novos compostos para auxiliar nesta tarefa.

Os objetivos específicos deste estudo são:

- caracterizar a distribuição de hidrocarbonetos em amostras de petróleo, produtos de petróleo, aerossóis $\left(\mathrm{PM}_{2,5}\right)$ e sedimentos;

- Avaliar o grau de contaminação e as principais fontes de hidrocarbonetos para a atmosfera do Rio de Janeiro e dos sedimentos da Baía de Guanabara;

- Verificar a aplicabilidade das razões diagnósticas de fontes as diferentes matrizes e a relação entre estas, assim como avaliar o uso das análises estatísticas normalmente aplicadas aos dados, e;

- Buscar novos marcadores com maior capacidade de discriminar as diversas fontes de hidrocarbonetos. 


\section{2 \\ Fundamentação Teórica}

A identificação da origem de hidrocarbonetos no meio ambiente não é trivial, pois além das diversas fontes antrópicas, há também contribuições de fontes naturais ao ambiente. De maneira geral a diferenciação de fontes baseiase em princípios simples, mas de complexa aplicação a situações reais de aportes múltiplos. A distribuição de n-parafinas em amostras sem aporte antropogênico, por exemplo, difere daquela reportada sob influência de petróleo e seus derivados. No primeiro existe predominância de n-parafinas com número ímpar de carbonos e no petróleo não há predomínio de pares ou ímpares (Cooper \& Bray, 1963; Clark \& Blumer, 1967; Laws, 1993).

Hidrocarbonetos naturais produzidos por plantas marinhas e terrestres são normalmente encontrados a níveis traço, com componentes característicos ou distribuição refletindo a sua origem (Sicre et al., 1987). Blumer et al. (1971) analisaram o conteúdo de hidrocarbonetos de vinte e três algas pertencentes a nove classes diferentes constatando a predominância de hidrocarbonetos ímpares lineares, alcenos e alguns monometilalcanos. Estes autores constataram que algas são caracterizadas pela presença de relativamente poucos hidrocarbonetos, em pequena concentração.

Youngblood \& Blumer (1973) confirmam a predominância de npentadecano em algas marrons e n-heptadecano em algas vermelhas. São antigos os registros da produção de hidrocarbonetos pelo fitoplâncton, zooplâncton e algas bênticas (Clark \& Blumer, 1967; Avigan \& Blumer, 1968; Youngblood \& Blumer, 1973; Blumer et al., 1971).

Amostras com contribuição terrestre também são evidenciadas pela presença de n-alcanos ímpares, mas ocupando outra faixa de distribuição. Neste tipo de aporte a distribuição dos n-alcanos ímpares ocorre na faixa de n-C23 a $\mathrm{nC} 35$, enquanto a contribuição marinha é caracterizada pela faixa de nC15-nC21 (Bouloubassi \& Saliot, 1993; Volkman et al., 1992; Kranz et al., 1960; Cooper \& Bray, 1963; Sicre et al., 1987; Volkman et al., 1980).

O aporte de petróleo, diferentemente das contribuições anteriores é caracterizado pela presença de n-alcanos abrangendo uma ampla faixa de peso 
molecular sem preferência de números de carbonos pares ou ímpares (Farrington \& Tripp, 1977).

Esta diferença na distribuição dos n-alcanos subordinada as suas origens pode ser utilizada para inferir fontes em amostras ambientais (Clark \& Blumer, 1967). A relação entre compostos pares e ímpares é expressa pela equação do Índice de Preferência de Carbono (IPC), onde valores próximos a um indicam aporte por petróleo ou produtos de petróleo (Cooper \& Bray, 1963; Laws, 1993). Valores elevados desta razão indicam aporte natural, tanto marinho quanto terrestre, dependendo da faixa de distribuição.

$$
I P C_{a} \longrightarrow_{b}=0,5 x\left[\frac{\sum_{a+1}^{b-1} \text { impares }}{\sum_{a}^{b-2} \text { pares }}+\frac{\sum_{a+1}^{b-1} \text { impares }}{\sum_{a+2}^{b} \text { pares }}\right]
$$

Figura 1 - Equação do Índice de Preferência de Carbono (IPC), onde a e b são n-alcanos com número par de carbonos (Cooper \& Bray, 1963).

Outro componente dos hidrocarbonetos encontrado na fração saturada que auxilia na identificação de fontes é a Mistura Complexa Não Resolvida (MCNR). Esta é definida como uma variedade de compostos ramificados e cíclicos que não podem ser resolvidos por cromatografia. É um dos mais convincentes indicadores de contaminação por petróleo e é caracterizada pela elevação da linha base do cromatograma. (Volkman et al. 1992; Simoneit, 1986). Os componentes da Mistura Complexa Não Resolvida apresentam maior resistência à degradação e conseqüentemente se acumula em sedimentos marinhos (Volkman et al., 1992).

O intemperismo do material petrogênico diminui a concentração de nalcanos, mais lábeis, enquanto a concentração de MCNR permanece praticamente inalterada (Figura 2). A relação entre a MCNR e a fração resolvida $(\mathrm{HR})$ do cromatograma é utilizada como indicador de aporte petrogênico não recente (Mazurek \& Simoneit, 1984) e intemperismo (Wang et al., 1999).

Também são utilizados na diferenciação de fontes os compostos pristano e fitano. Fitano é um isoprenóide comum do óleo cru enquanto o Pristano, embora presente no petróleo, também tem origem biogênica, ocorrendo na biota e 
sedimentos recentes como produto de degradação do Fitol (Steinhauer \& Boehm, 1992; Steinhauer et al., 1994).
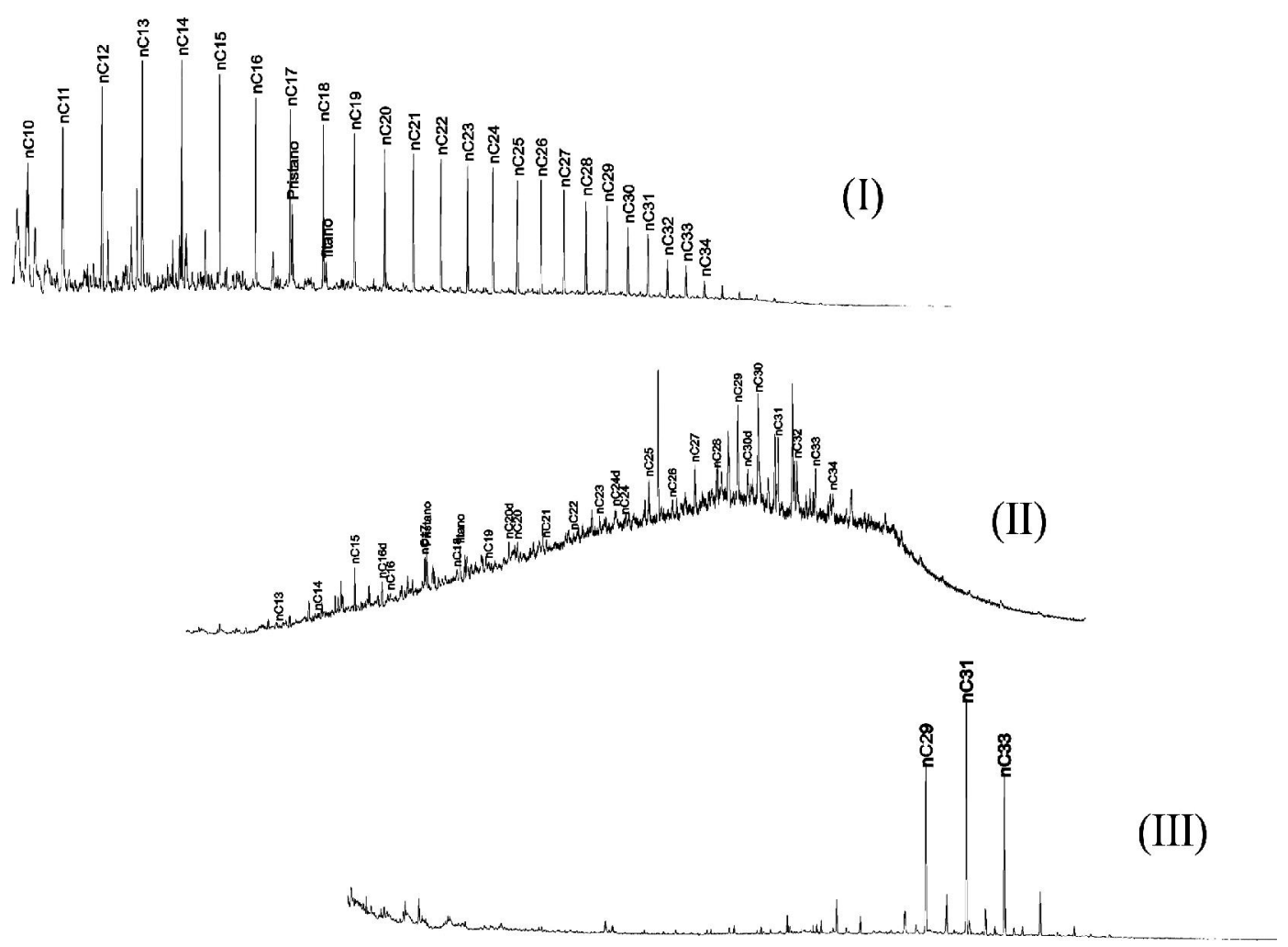

Figura 2 - Representação de cromatogramas de óleo cru (I), óleo intemperizado (II) e contribuição natural terrestre (III) (Massone, 2004).

Quando utilizamos os dois compostos juntos obtemos a razão pristano/fitano. Em sedimentos considerados limpos valores maiores que 1, entre 3 e 5, são normalmente encontrados e esta razão também pode ter utilidade na verificação das condições redox em sedimentos durante a diagênese ou na diferenciação entre dois tipos de petróleos (Killops \& Killops, 1993; Steinhauer et al., 1994; Powell, 1998). A diagênese de Pristano ou Fitano depende das condições sobre as quais esta ocorre (Steinhauer \& Boehm, 1992; Killops \& Killops, 1993). Sobre condições óxidas, o fitol, um composto C20 encontrado na clorofila, pode originar, através de uma série de processos, o pristano, um composto $\mathrm{C}_{19}$ (Figura 3 ). Entretanto, se $\mathrm{o}$ ambiente possui condições desfavoráveis de oxigênio teremos a formação do fitano, um composto $\mathrm{C}_{20}$.

Os copépodos são também uma importante fonte de pristano para o ambiente marinho e servem de elo na cadeia trófica marinha, sendo a síntese de 
pristano uma das mais importantes fontes de hidrocarboneto, tanto em tecido animal quanto em formações geológicas (Avigan \& Blumer, 1968).

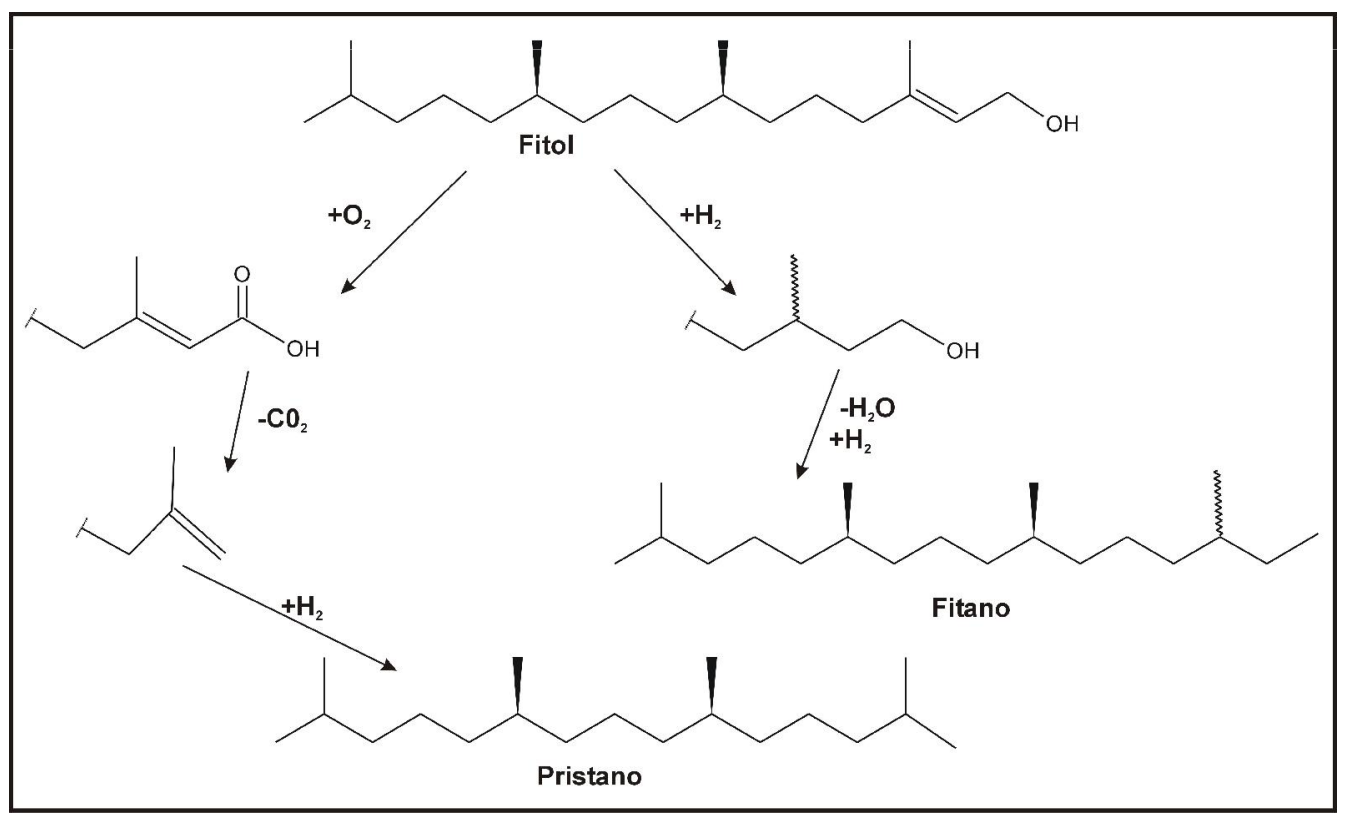

Figura 3 - Resumo do processo de diagênese do Fitol (Modificado de Killops \& Killops, 1993)

Os isoprenóides também são mais resistentes à degradação, fazendo com que sua relação com os $\mathrm{n}$-alcanos $\mathrm{nC} 17$ e $\mathrm{nC} 18$ possa ser utilizada como indicativo de degradação (Colombo et al., 1989), uma vez que existe um crescimento relativo ao longo do tempo do composto menos degradável (Pristano e Fitano) em relação ao mais degradável (nC17 e nC18).

Apesar do uso de hidrocarbonetos saturados para inferência de aportes a classe de hidrocarbonetos mais utilizada para a diferenciação de aportes são os hidrocarbonetos policíclicos aromáticos (HPAs). Sua aplicação como indicador baseia-se no fato de que sua distribuição reflete as condições ou processos nas quais são gerados. O petróleo dentro de sua constituição contém uma mistura bastante variada de HPAs decorrentes dos precursores que os originaram e das condições de maturação ao longo do tempo, cujas características diferem dos HPAs de origem pirolítica (Wakeham et al., 1980a).

Pode-se afirmar que HPAs originários de combustíveis fósseis possuem (a) relativa abundância de naftalenos alquilados e (b) maior abundância relativa de alquilados de fenantreno quando comparados ao composto não-alquilado (Boehm et al., 1984). 
Compostos de 1 a 3 anéis aromáticos tendem a predominar no petróleo, assim como seus homólogos alquilados (Neff, 1979). Já os HPAs mais abundantes derivados de combustão são o fluoranteno, pireno, benzo(a)antraceno, criseno, benzofluorantenos, benzo(e)pireno, benzo(a)pireno, indeno(1,2,3-cd)pireno e o benzo(ghi)perileno (Bouloubassi \& Saliot, 1993). Através de estudo de emissões de HPAs durante a queima de combustível fóssil, Benner et al. (1990) observaram que a queima produz menos HPAs que o óleo cru. Estes autores observaram que $90 \%$ dos HPAs no produto original tinham 3 anéis enquanto o conteúdo de HPAs nas emissões foi distribuído igualmente entre compostos de 3 anéis e os demais de maior peso molecular. As concentrações de HPAs com 5 ou mais anéis, que incluem benzo(a)pireno, foram de 10 a 20 vezes maiores em amostras de fuligem que no óleo original.

Em contraste com as condições brandas durante a formação do petróleo, as quais tendem a gerar hidrocarbonetos aromáticos alquilados, processos de combustão a temperaturas relativamente altas favorecem a formação de hidrocarbonetos policíclicos não alquilados (GESAMP, 1993), como observado na Figura 4.

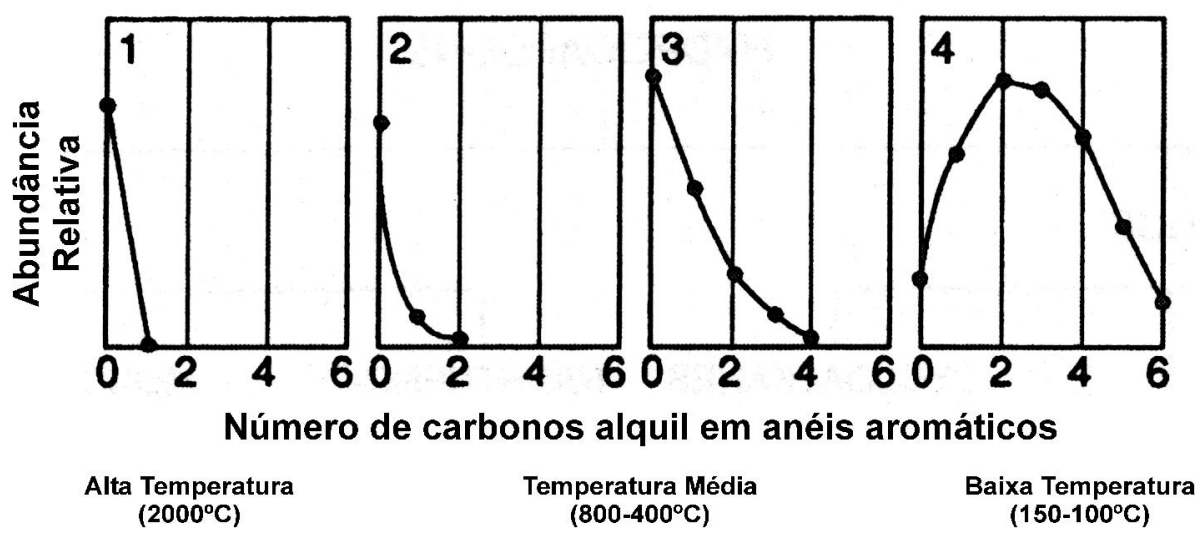

Figura 4 - Abundância relativa de compostos parentais e alquil-substituídos como influência da temperatura de formação. (Modificado de NRC, 1985)

Os compostos da combustão de combustível fóssil ou madeira, além de apresentarem preferencialmente anéis sem alquilação, mostram maior abundância de compostos mais pesados (maior número de anéis), característicos da alta temperatura de formação (Simoneit, 1985; Bouloubassi \& Saliot, 1993, Benner \& Gordon, 1989). Assim, uma maior abundância de 
compostos mais pesados, ou seja, maior número de anéis, seria um indicativo de processos de combustão e pode ser usado para identificação de fontes.

Todos os processos de combustão produzem hidrocarbonetos policíclicos aromáticos. Benner \& Gordon (1989) observaram que a concentração das espécies alquiladas aumenta relativamente em relação aos compostos não alquilados à medida que a temperatura de combustão decresce. Assim, índices baseados na abundância de alquilados, como a razão entre a soma dos fenantrenos alquilados e o fenantreno não alquilado (Prahl \& Carpender, 1983) ou o "índice pirolítico" (Wang et al., 1999a), são ferramentas para identificação de fontes de HPAs no ambiente. Este último se baseia na razão entre a soma da concentração de 14 HPAs não-alquilados e soma das 5 séries de HPAs alquilados.

Além do grau de alquilação dos compostos, existem outras propriedades que são utilizadas na diferenciação de fontes. Razões envolvendo compostos não-alquilados de mesma massa mas de diferente estabilidade termodinâmica, como fenantreno e antraceno (Gschwend \& Hites, 1981), fluoranteno e pireno (Sicre et al., 1987; Baumard et al., 1998) e benzo(a)antraceno e criseno (Gschwend \& Hites, 1981) também são ferramentas empregadas na distinção de fontes.

O uso destas razões decorre do fato de que a abundância relativa dos compostos de mesma massa reflete o mecanismo de controle da reação predominante, cinético ou termodinâmico, que os origina. Quando a reação de formação predominante destes compostos é controlada termodinamicamente, como na formação do petróleo, os compostos mais estáveis são mais abundantes. Quando o mecanismo de controle da reação é predominantemente cinético, como na combustão de materiais, é favorecida a formação de compostos menos estáveis. Para HPAs não alquilados de mesma massa, fontes de combustão são inferidas pelo aumento da proporção do menos estável, isômero "cinético", relativo ao mais estável, isômero "termodinâmico" (Yunker et al., 2002, Yunker et al., 2000).

A estabilidade dos HPAs de diferentes massas pode ser visualizada na Tabela 1. Dentro dos compostos de massa 178 o fenantreno é mais estável que o antraceno. Logo, em amostras de petróleo a proporção relativa de fenantreno para antraceno deve ser maior que em amostras de combustão, onde a formação do antraceno é mais favorecida. O mesmo princípio se aplica aos demais isômeros de diferentes massas. Assim, uma maior abundância de fluoranteno (massa 202), benzo(a)antraceno (massa 228) e indeno(1,2,3- 
cd)pireno (massa 276) relativo aos isômeros de mesma massa é indicativo de contribuição de HPAs originados por combustão. Uma menor contribuição destes compostos é então característica de aporte de petróleo ou derivados.

Tabela 1 - Resultados do cálculo da estabilidade relativa para HPAs com múltiplos isômeros usando diferentes modelos. (Modificado de Yunker et al., 2000)

\begin{tabular}{|c|c|c|c|c|}
\hline \multirow{2}{*}{ Composto } & \multicolumn{2}{|c|}{$\begin{array}{l}\text { Modelo AM1 } \mathrm{H}_{\mathrm{f}} \\
\text { (kcal/mol) }\end{array}$} & \multicolumn{2}{|c|}{ Modelo PC $\mathrm{H}_{\mathrm{f}}$} \\
\hline & AM1 $\left(H_{f}\right)$ & $\begin{array}{c}\text { Diferença } \\
\mathbf{H}_{\mathrm{f}}\end{array}$ & $\mathrm{PC}\left(\mathrm{H}_{\mathrm{f}}\right)$ & $\begin{array}{c}\text { Diferença } \\
\mathbf{H}_{\mathrm{f}}\end{array}$ \\
\hline \multicolumn{5}{|l|}{ Massa 178} \\
\hline Fenantreno & 57,1 & 0 & 49,7 & 0 \\
\hline Antraceno & 62,6 & 5,5 & 56,1 & 6,4 \\
\hline \multicolumn{5}{|l|}{ Massa 202} \\
\hline Pireno & 67,0 & 0 & 57,8 & 0 \\
\hline Fluoranteno & 87,6 & 20,6 & 71,0 & 13,2 \\
\hline Acefenantrileno & 95,6 & 28,6 & 77,6 & 19,8 \\
\hline \multicolumn{5}{|l|}{ Massa 228} \\
\hline Trifenileno & 75,1 & 0 & 67,8 & 1,1 \\
\hline Criseno & 75,8 & 0,7 & 66,6 & 0 \\
\hline Benzo(a)Antraceno & 77,9 & 2,8 & 68,6 & 2,0 \\
\hline \multicolumn{5}{|l|}{ Massa 252} \\
\hline Benzo(e)Pireno & 83,6 & 0 & 73,5 & 0 \\
\hline Benzo(a)Pireno & 87,1 & 3,5 & 76,3 & 2,8 \\
\hline Perileno & 88,9 & 5,3 & 80,0 & 6,5 \\
\hline Benzo(b)Fluoranteno & 102,8 & 19,3 & 83,7 & 10,2 \\
\hline Benzo(j)Fluoranteno & 104,7 & 21,1 & 86,6 & 13,1 \\
\hline Benzo(k)Fluoranteno & 108,7 & 25,1 & 89,7 & 16,2 \\
\hline \multicolumn{5}{|l|}{ Massa 276} \\
\hline Benzo(ghi)perileno & 90,9 & 0 & 77,9 & 0 \\
\hline Antantreno & 99,0 & 8,1 & 87,0 & 9,1 \\
\hline Indeno(1,2,3-cd)Pireno & 115,9 & 25,0 & 94,5 & 16,6 \\
\hline Indeno(7,1,2,3,-cdef)Criseno & 131,2 & 40,3 & 104,1 & 26,2 \\
\hline \multicolumn{5}{|l|}{ Massa 278} \\
\hline Dibenzo(a,h)Antraceno & 93,7 & 0 & 81,9 & 0 \\
\hline Piceno & 93,9 & 0,2 & 82,8 & 0,9 \\
\hline Dibenzo(a,j)Antraceno & 93,9 & 0,2 & 82,3 & 0,4 \\
\hline Dibenzo(a,c)Antraceno & 95,1 & 1,4 & 86,2 & 4,3 \\
\hline Benzo(b)Criseno & 97,2 & 3,5 & 86,5 & 4,6 \\
\hline Pentafeno & 97,9 & 4,2 & 86,6 & 5,0 \\
\hline
\end{tabular}

Nota : A diferença $\mathrm{H}_{\mathrm{f}}(\mathrm{Kcal} / \mathrm{mol})$ é a diferença de energia para cada isômero relativo ao isômero mais estável de mesma massa 
Outro processo importante na distribuição de HPAs em sedimento marinho é o intemperismo. Este processo inicia-se com a perda de compostos de baixo peso molecular por evaporação e dissolução, o predomínio de homólogos alquilados do fenantreno e dibenzotiofeno e o aumento da importância relativa de compostos naftênicos e nafteno-aromáticos (não resolvidos) (Bouloubassi \& Saliot, 1993). A degradação microbiana e a foto-oxidação atuam sob os hidrocarbonetos alquil-substituídos em preferência aos compostos parentais (Davies \& Tibbets, 1987; Ehrhardt et al., 1992). Os efeitos combinados do intemperismo (dissolução, biodegradação, fotoxidação) em petróleo encontramse sumarizados na Figura 5.

As mudanças mais marcantes do intemperismo na distribuição de HPAs, de acordo Page et al. (1993), são:

- Decréscimo acentuados de naftalenos $(\mathrm{N})$ relativo aos demais HPAs, que ocorre rapidamente nos primeiros dias.

- Desenvolvimento do perfil para cada grupo petrogênico de acordo com a distribuição: Parental $(\mathrm{C} 0)<\mathrm{C} 1<\mathrm{C} 2<\mathrm{C} 3$.

- Decréscimo gradual da abundancia relativa de fenantrenos, dibenzotiofenos e aumento gradual do criseno. Isto porque por sua baixa solubilidade em água, resistência à degradação biológica o criseno tem maior crescimento relativo dentro dos HPAs.

Compostos aromáticos formados naturalmente (diagênese) que recebem maior atenção são o reteno e o perileno. Os prováveis compostos precursores do perileno e a condições favoráveis à sua formação é uma discussão que gera controvérsias e pode ser encontrada sumarizada no trabalho de Venkatesan (1988). O perileno já foi encontrado associado à contribuição terrestre e posterior deposição em condições redutoras (Ainzenshat, 1973; Wakeham, 1977) sendo freqüentemente associado ao aporte de rios e estuários (La Flamme \& Hites, 1978; Baumard, 1998; Venkatesan \& Kaplan, 1982).

Apesar disto, concentrações reduzidas de perileno podem ser encontradas em sedimentos superficiais óxidos (Silliman et al., 1998), associadas à matéria orgânica marinha (Wakeham et al., 1979) e conseqüentemente a precursores aquáticos. Pode-se afirmar que os precursores deste composto estão presentes tanto em detritos terrestres quanto aquáticos (Venkatesan, 1988), além de serem encontrados no petróleo e em produtos de queima. Silliman et al. (1998) 
sugerem que o controle dos processos microbiológicos in situ de materiais orgânicos é mais importante na formação do perileno do que a disponibilidade de materiais precursores. O composto reteno é reportado principalmente à contribuição de angiospermas, com pequena relevância para outros tipos de aportes (Simoneit, 2002; Bi et al., 2003; Shen et al., 2012).

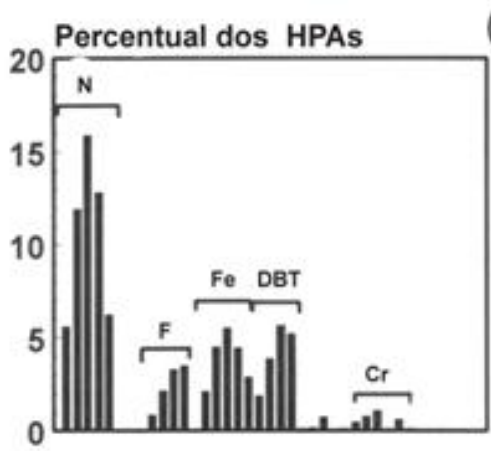

(a)

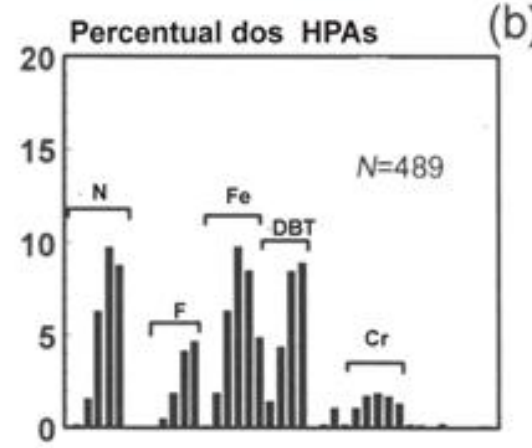

(b)

Hidrocarbonetos Policíclicos Aromáticos
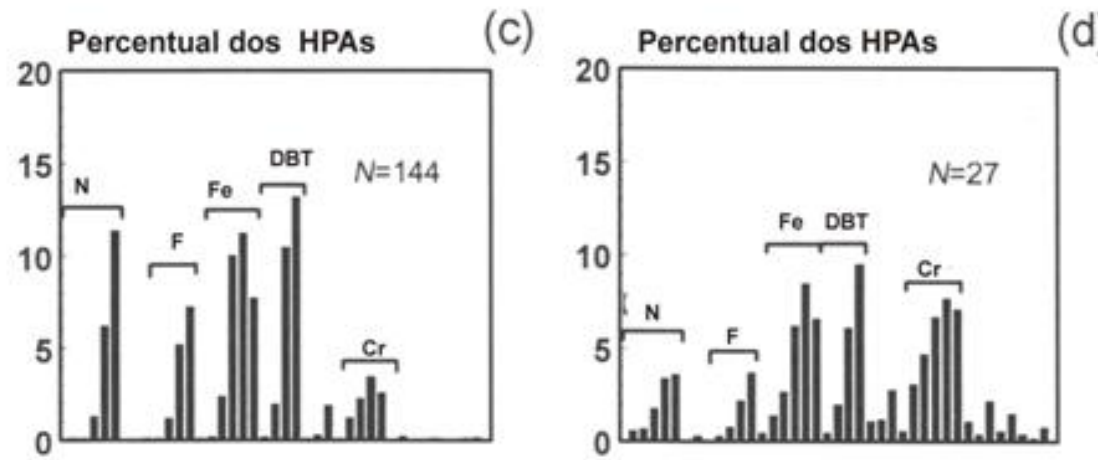

(d)

Hidrocarbonetos Policiclicos Aromáticos

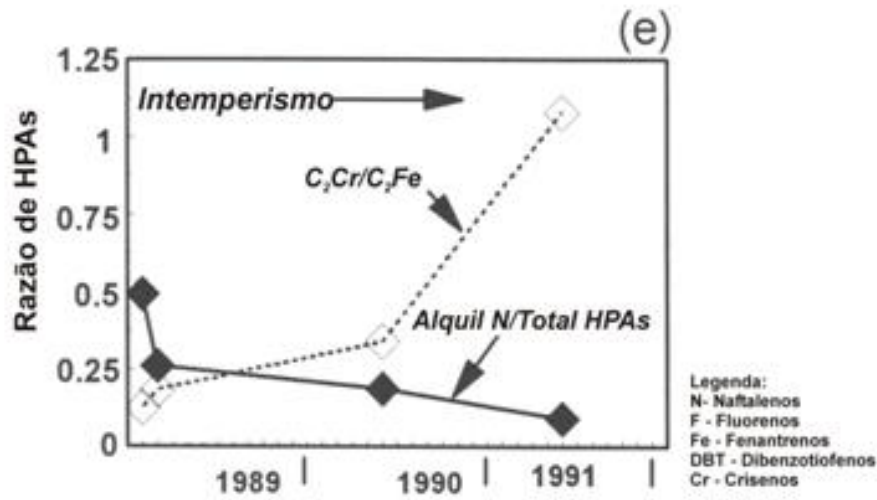

Figura 5 - Demonstração do Intemperismo do óleo. (a) e (c) são amostras de óleo e (b) e (d) são os produtos degradados e (e) são razões alteradas ao longo do tempo. (Modificado de Page et al., 1993) 


\section{Área de Estudo}

\section{1}

\section{Clima e Atmosfera}

A região de estudo apresenta clima tropical úmido com temperatura média anual de $23,7^{\circ} \mathrm{C}$, estação seca entre junho e agosto e alto índice pluviométrico anual (1100 a $2100 \mathrm{~mm}$ ) nas regiões próximas à Serra do Mar (Amador, 1997). Os meses mais chuvosos vão de dezembro a abril, com médias mensais acima de $100 \mathrm{~mm}$, enquanto que os mais secos são junho, julho e principalmente agosto, com médias mensais em torno de 50 mm (Filippo, 1997).
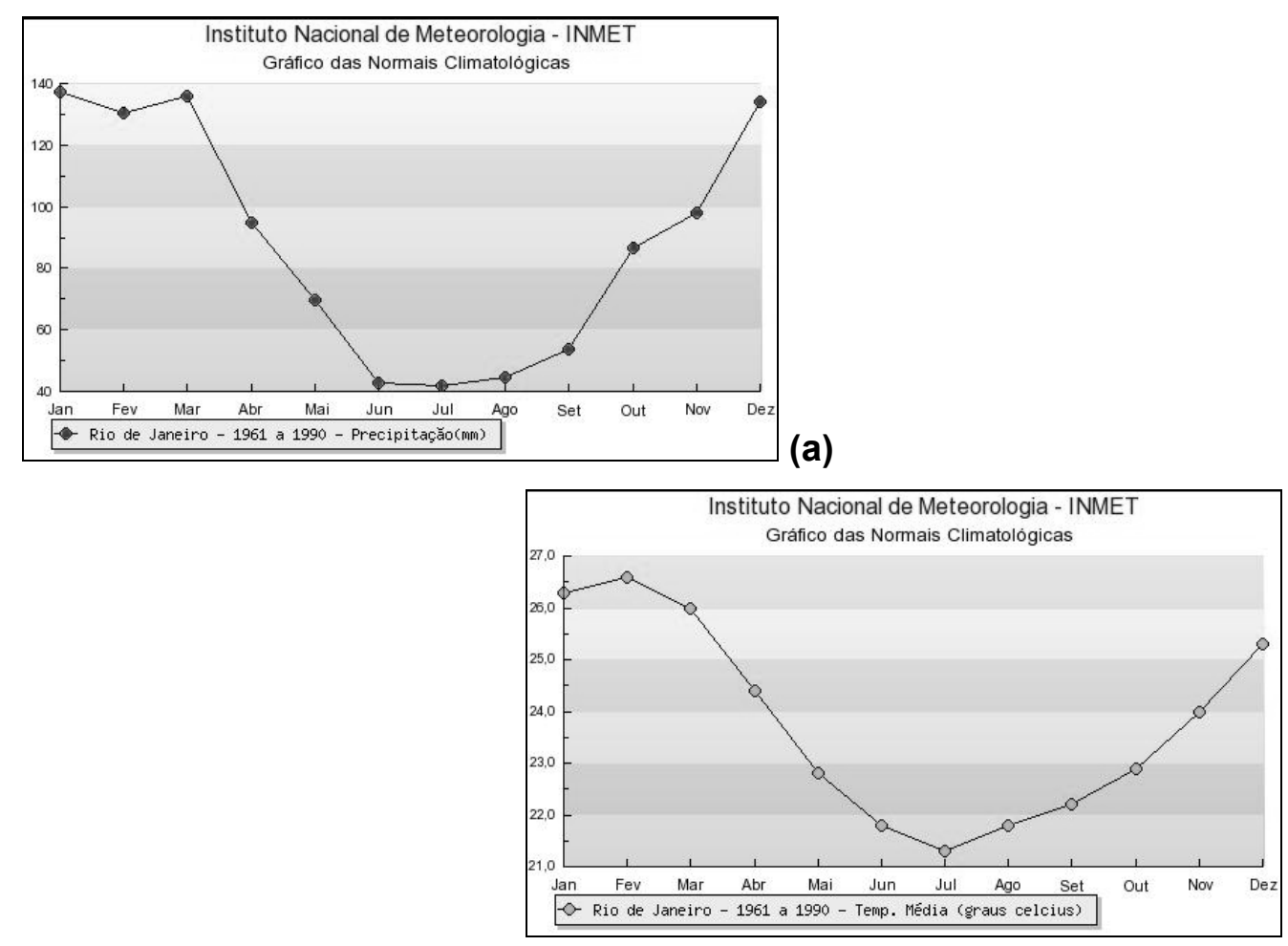

(b)

Figura 6 - Normais climatológicas dos dados do INMET para o Rio de Janeiro no período de 1961 a 1990. Precipitação acumulada (a) e temperatura média mensal (b). (INMET, 1992)

Segundo Barbiére \& Kronemberger (1994), os ventos predominantes são de Sul com velocidade média de $4,7 \mathrm{~m} \mathrm{~s}^{-1}$. Estes ventos apresentam maior freqüência na primavera e no verão. Nestas duas estações podem representar 
até $28 \%$ da freqüência total. Os autores destacam, para o período analisado (1978-1987), a importância dos ventos de sudeste, sul e norte no outono e sul e norte no inverno.

Fillipo (1997) aponta padrões similares no período subsequente de 1989 a 1993. Os ventos mais freqüentes foram norte e o sul, com intensidade média mensal de $5,0 \mathrm{~m} \mathrm{~s}^{-1}$. Em relação à direção, os ventos de sul predominam sobre os de norte na maior parte do ano, tanto em freqüência quanto em intensidade, existindo certo equilíbrio apenas durante o outono. $O$ vento sul, além do sudoeste, também está associado à entrada de frentes frias na região. Nestes eventos a velocidade dos ventos pode chegar a valores superiores a $10 \mathrm{~m} \mathrm{~s}^{-1}$, dependendo da intensidade da frente.

A qualidade do ar na região metropolitana do Rio de Janeiro é estudada desde 1967, quando foram instaladas as primeiras estações de monitoramento no então Estado da Guanabara. A rede atual de monitoramento do Instituto Estadual do Ambiente (INEA) prioriza a avaliação de um grupo seleto de poluentes. São estes: dióxido de enxofre $\left(\mathrm{SO}_{2}\right)$, partículas totais em suspensão (PTS), partículas inaláveis (PI), monóxido de carbono (CO), oxidantes fotoquímicos expressos como ozônio $\left(\mathrm{O}_{3}\right)$, hidrocarbonetos totais $(\mathrm{HC})$ e óxidos de nitrogênio $(\mathrm{NO})$. Apesar das ações desenvolvidas para melhoria da qualidade do ar ao longo do tempo, alguns parâmetros obtidos ainda superam os limites da legislação (CONAMA 03) na maioria das áreas monitoradas (INEA, 2009).

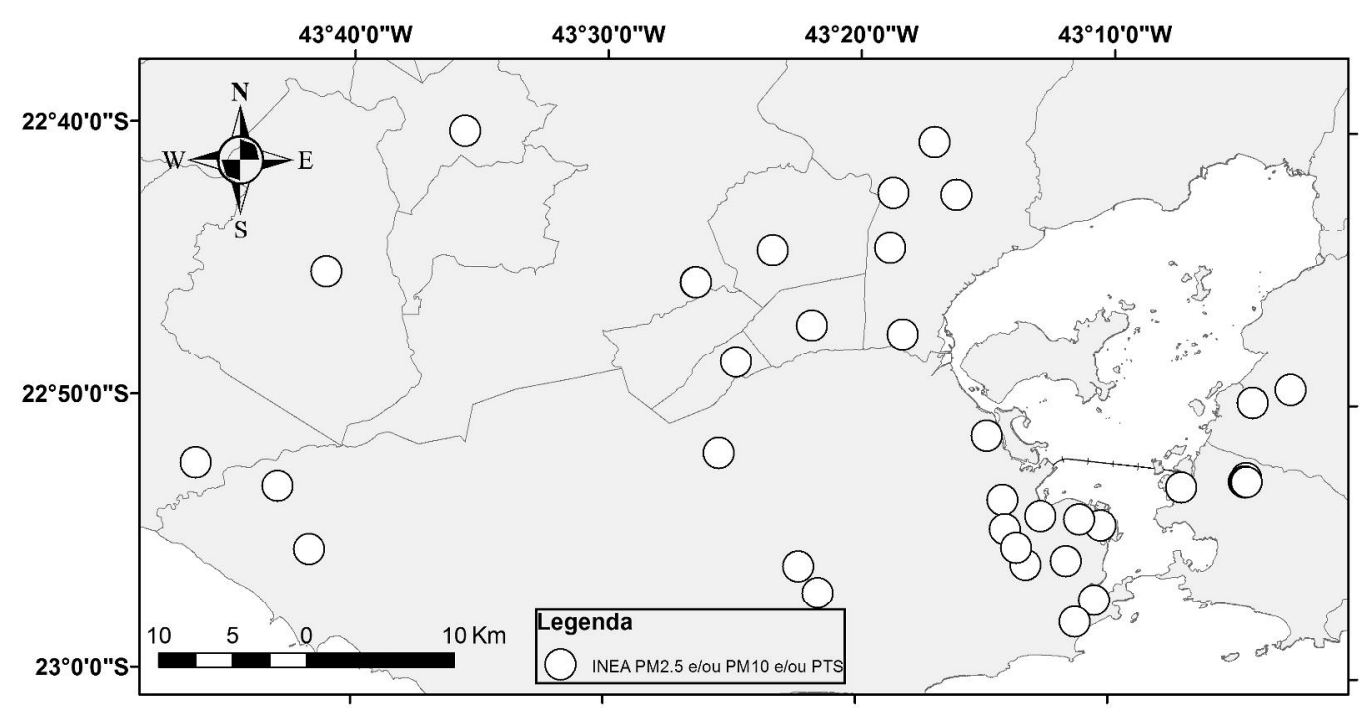

Figura 7 - Malha atual de monitoramento do INEA. 
Registros históricos de chumbo na atmosfera do Rio de Janeiro chegaram a estar diretamente relacionados à quantidade de aditivo chumbo tetraetila anteriormente agregado ao combustível (Trindade et al., 1981; Trindade \& Pfeiffer, 1982).

Souza et al. (2013) calculam que no Estado do Rio de Janeiro, veículos são responsáveis por $55 \%$ das emissões de CO, $61 \%$ das emissões de hidrocarbonetos totais e $91 \%$ das emissões de aldeídos. A gasolina contribui com $74 \%$ da emissão de CO e o diesel com $91 \%$ da emissão de material particulado. Os autores ressaltam que a emissão veicular de $\mathrm{CO}$ e material particulado nesta é $12 \%$ e $59 \%$ menor, respectivamente, comparada a média nacional.

Godoy et al. (2009) observaram que as fontes antropogênicas das emissões veiculares constituem um alto percentual relativo da massa de aerossóis finos. Estas emissões são a principal via de entrada de hidrocarbonetos aromáticos para atmosfera das cidades do Rio de Janeiro (Fernandes et al., 2002) e Niterói (Lima, 2006). Quitério et al. (2005) reporta altos valores para fatores de enriquecimento de metais diretamente associados às emissões antrópicas em sete distritos da baixada fluminense.

Há na região uma relação direta entre a intensidade do tráfego de veículos e a concentração de poluente. Azevedo et al. (1999) observaram o decréscimo de contaminação atmosférica por hidrocarbonetos desde áreas de maior fluxo de veículos até a Floresta da Tijuca. Fernandes et al. (2002) relacionam o nível de hidrocarbonetos em um determinado sítio à distância das rodovias. Carneiro et al. (2008), além de destacar a importância das emissões veiculares, enfatiza a poluição adicional causada pela deterioração de conversores catalíticos automotivos, caracterizada pelas concentrações de $\mathrm{Mo}, \mathrm{Pb}$ e Rh.

Além da distância da fonte de emissão, outros estudos enfatizam a influencia das condições climáticas. No período de maio a setembro, devido à atuação dos sistemas de alta pressão que dominam a região, ocorrem com freqüência situações de estagnação atmosférica e elevados índices de poluição (INEA, 2009). A variação do material em suspensão já foi relacionada à variação climática, com maiores valores para o período seco (Trindade et al., 1980; Trindade et al.,1981; Trindade \& Pfeiffer, 1982). Zeri et al. (2011) verificaram o domínio de eventos de escala temporal entre 1-8 dias como, por exemplo, a passagem de frentes frias, sobre a variação da temperatura e concentração de $\mathrm{PM}_{10}$. A concentração de espécies inorgânicas solúveis em água no material particulado atmosférico é quase duas vezes maior no período seco (Mariani \& 
Mello, 2007). Quitério et al. (2005) e Pereira Netto et al. (2001, 2002), entretanto, não conseguiram estabelecer uma relação clara entre a concentração de poluentes em particulado atmosférico e a sazonalidade.

\section{2}

\section{Corpo Hídrico}

A bacia da Guanabara esta localizada entre os paralelos $22^{\circ} 24^{\prime}$ e $22^{\circ} 57^{\circ}$ de latitude sul e entre os meridianos $42^{\circ} 33^{`}$ e $43^{\circ} 19^{\prime}$ de longitude oeste. A área de drenagem continental abrange aproximadamente $4080 \mathrm{~km}^{2}$ e o espelho d'água $350 \mathrm{~km}^{2}$ (Amador, 1997). Cerca de 55 rios e riachos deságuam na baía a uma taxa aproximada de $125 \mathrm{~m}^{3} \mathrm{~s}^{-1}$ (Kjerfve et al., 1997).

A entrada da Baía de Guanabara é estreita, com aproximadamente 1,6 km entre as pontas de São João e de Santa Cruz. A extensão em seu maior eixo, de direção norte-sul, corresponde a $30 \mathrm{Km}$. No fundo da baía ocorre um alargamento na direção leste-oeste, chegando a $28 \mathrm{Km}$ em largura (Quaresma 1997, Kjerfve et al., 1997). O perímetro da baía é de $153 \mathrm{~km}$ e sua área total é de $396 \mathrm{~km}^{2}$ que, descontando-se as áreas das ilhas, fornece o espelho d'água supracitado de $350 \mathrm{~km}^{2}$. Seu relevo é bastante irregular e a batimetria assemelha-se a uma concha em leque, mais profunda na porção mais estreita (Figura 8).

A baía pode ser classificada como um estuário tropical de águas parcialmente misturadas. Não apresenta, portanto, gradiente salino bem definido em duas camadas, uma menos salina (superior) e uma mais salina (inferior), com uma zona de mistura entre estas. O regime de marés é classificado como semi diurno, sendo de pequena amplitude e de tipo irregular.

O regime de micro marés tem uma altura média de $0,7 \mathrm{~m}$ que, em conjunto com o aporte proveniente dos rios, resulta em valores de salinidade na ordem de 29,5 \pm 4,8 (Quaresma, 1997). Esta baía é estruturalmente controlada por um canal central de maior profundidade com sedimentos arenosos próximos a entrada que refletem a ação das ondas e a forçante da maré (Kjerfve et al., 1997). As correntes de maré seguem o alinhamento do canal central e seus canais secundários (Oliveira, 1996 apud Amador, 1997). As velocidades destas correntes são de 20 a $30 \mathrm{~cm} \mathrm{~s}^{-1}$ na região mais interna, de 30 a $50 \mathrm{~cm} \mathrm{~s}^{-1}$ no canal central próximo a llha de Paquetá, podendo alcançar $150 \mathrm{~cm} \mathrm{~s}^{-1}$ na entrada da baía (Jica, 1994). 


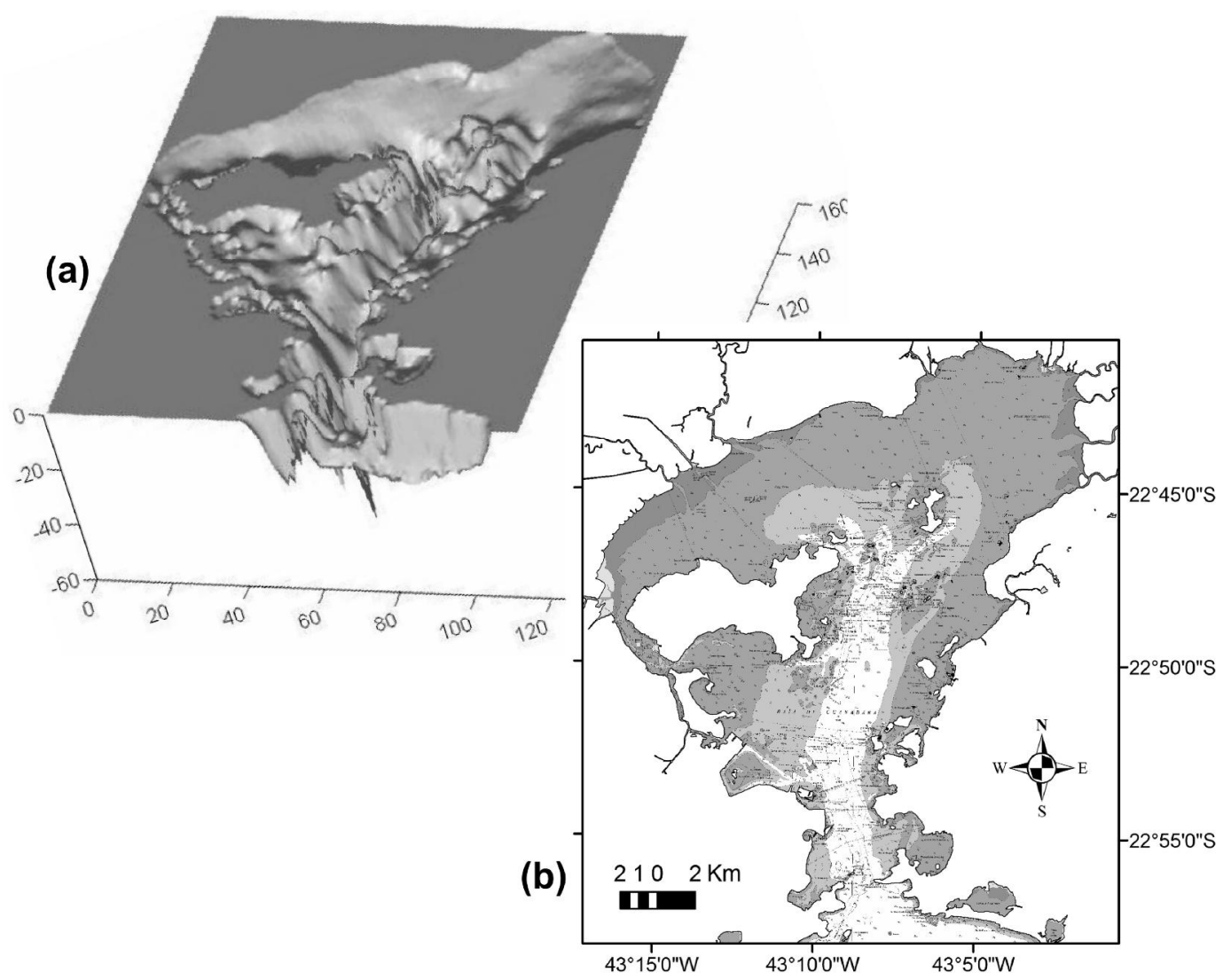

Figura 8 - (a) Relevo do fundo da Baia de Guanabara em 3 dimensões (Torres et al., 2001 apud Guimarães, 2005) e (b) batimetria oficial (Modificado de Carta Náutica 1501-DHN)

$\mathrm{Na}$ região metropolitana do Rio de Janeiro há aproximadamente 11 milhões de habitantes, dos quais 7,8 milhões produzem esgotos domésticos que são lançados diretamente nas águas da baía. Esta região, tal como considerada pelo IBGE, ostenta um PIB em torno de R $\$ 172$ bilhões, constituindo o segundo maior pólo de riqueza nacional. Concentra $70 \%$ da força econômica do estado e $8 \%$ de todos os bens e serviços produzidos no país (INEA, 2009).

As alterações na bacia de drenagem iniciadas no início do século dezenove levaram a um quadro de alta eutrofização, altas taxas de sedimentação, concentração elevada de metais e hidrocarbonetos nos sedimentos e trocas nas comunidades pelágicas e bênticas (Villac et al., 1991; Hamacher, 1996; Lima, 1996; Ribeiro, 1996; Amador, 1997; Feema, 1998; Valentin et al., 1999; Wagener et al., 2012; Meniconi, 2007).

A evolução do número de indústrias no Rio de Janeiro mostra que, em 1920, existia cerca de 2000 estabelecimentos. Este número evoluiu para 4000 
em 1940 e atingiu, em 1960, a cifra de 5500 indústrias. Em 1980 existia de cerca de 10000 indústrias, principalmente nas áreas de construção naval, têxtil, petroquímica, farmacêutica e material elétrico e mecânico, sendo aproximadamente 5000 significativamente poluidoras (Feema, 1991).

Apesar de ser um dos ecossistemas costeiros com o maior número de informações no Brasil (Niencheski e Baumgarten, 1999) é difícil compreender e caracterizar detalhadamente as alterações ambientais ocorridas ao longo das décadas. É enorme a complexidade deste sistema, com um padrão de circulação de água diversificado e múltiplas fontes de contaminantes, distribuídas de forma irregular em sua bacia somado à falta de estudos contínuos de longa duração (Farias, 2006).

Entre as fontes potenciais de poluição para a baía se destacam as indústrias, lançamento de esgotos domésticos sem tratamento, terminais marítimos de petróleo, 2 portos comerciais, 32 estaleiros e mais de 1000 postos avançados de combustível, responsáveis pela introdução crônica de quantidades significativas de petróleo cru e derivados, além de outros contaminantes. Somam-se a isto introduções através de derrames de óleo, como o acidente de 18 de janeiro de 2000. As principais fontes pontuais de contaminação encontram-se na região noroeste da baía, a qual recebe aportes de rios contaminados por efluentes derivados de depósitos municipais de lixo, da indústria petroquímica, refino do petróleo, de curtumes, metalúrgicas, indústria alimentícia e de outras atividades industriais.

Pela classificação de Mayr et al. (1989) pode-se dividir a área de estudo em 5 seções segundo a qualidade de água. A região noroeste apresenta o pior quadro ambiental, com melhoria em direção a margem leste e, principalmente, em direção à entrada da barra. Na Figura 6 estão expostas as 5 divisões, assim caracterizadas:

1. Canal principal de navegação - onde são encontradas as melhores condições de qualidade de água em função da grande contribuição oceânica.

2. Entrada da baía - cidades do Rio de Janeiro e Niterói, com poluição doméstica.

3. Caracterizada por forte deterioração ambiental.

4. Seção nordeste - região de aporte de rios menos poluídos

5. Seção noroeste - área mais deteriorada em função das diversas fontes de poluição 


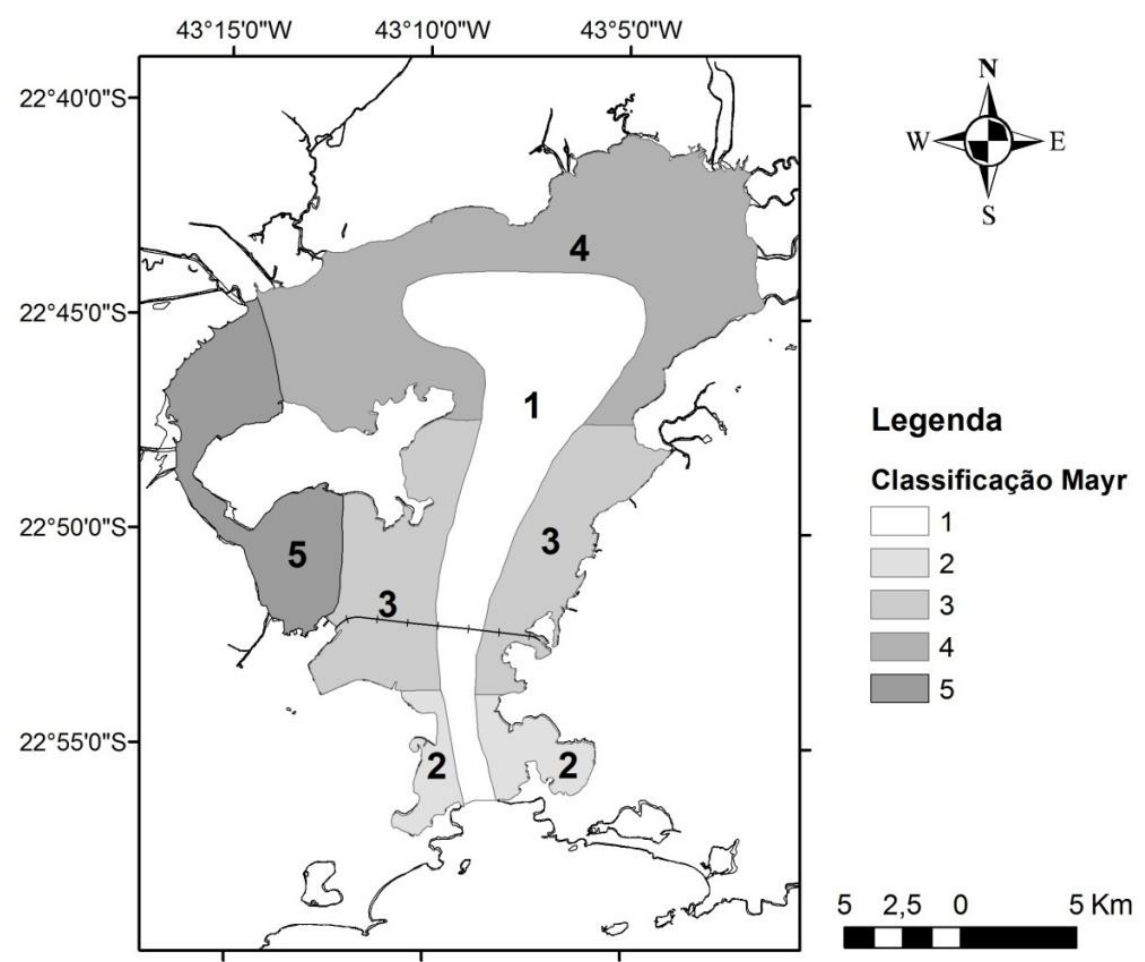

Figura 9- Classificação de qualidade de água (Modificado de Mayr et al., 1989)

Azevedo (1998) e Hamacher (1996), seguindo as recomendações internacionais da FAO contidas no trabalho de Abdullah et al. (1994), consideraram a água superficial da Baía de Guanabara como não poluída por hidrocarbonetos poliaromáticos (concentração $<2 \mu \mathrm{g} \mathrm{L}^{-1}$ ) à exceção da área próxima ao Porto do Rio de Janeiro.

Godoy et al. (1998), pela datação de testemunhos por ${ }^{210} \mathrm{~Pb}$ em cinco diferentes estações, determinaram a taxa de sedimentação para a baía entre 1 e $2 \mathrm{~cm}$ ano-1 $^{-1}$ (Figura 10). Os autores destacam a elevação desta taxa nos 40-50 anos anteriores à realização do estudo, que era entre 0,14 e $0,2 \mathrm{~cm}^{2} \mathrm{ano}^{-1}$, e a correspondência entre os perfis de metais pesados e o histórico de ocupação urbana e industrial. As altas taxas de sedimentação obtidas para a porção noroeste da baía corroboram a estimativa anterior $\left(2 \mathrm{~cm}^{2 n o^{-1}}\right)$, de Wilken et al. (1986), e refletem o histórico de poluição crônica de seu entorno.

Borges et al. (2009) também relacionam o histórico de ocupação humana à uma acentuada elevação (9x) no fluxo de fósforo para testemunho de manguezal da Baía de Guanabara, comparando dados atuais à registros sedimentares de 1800. 


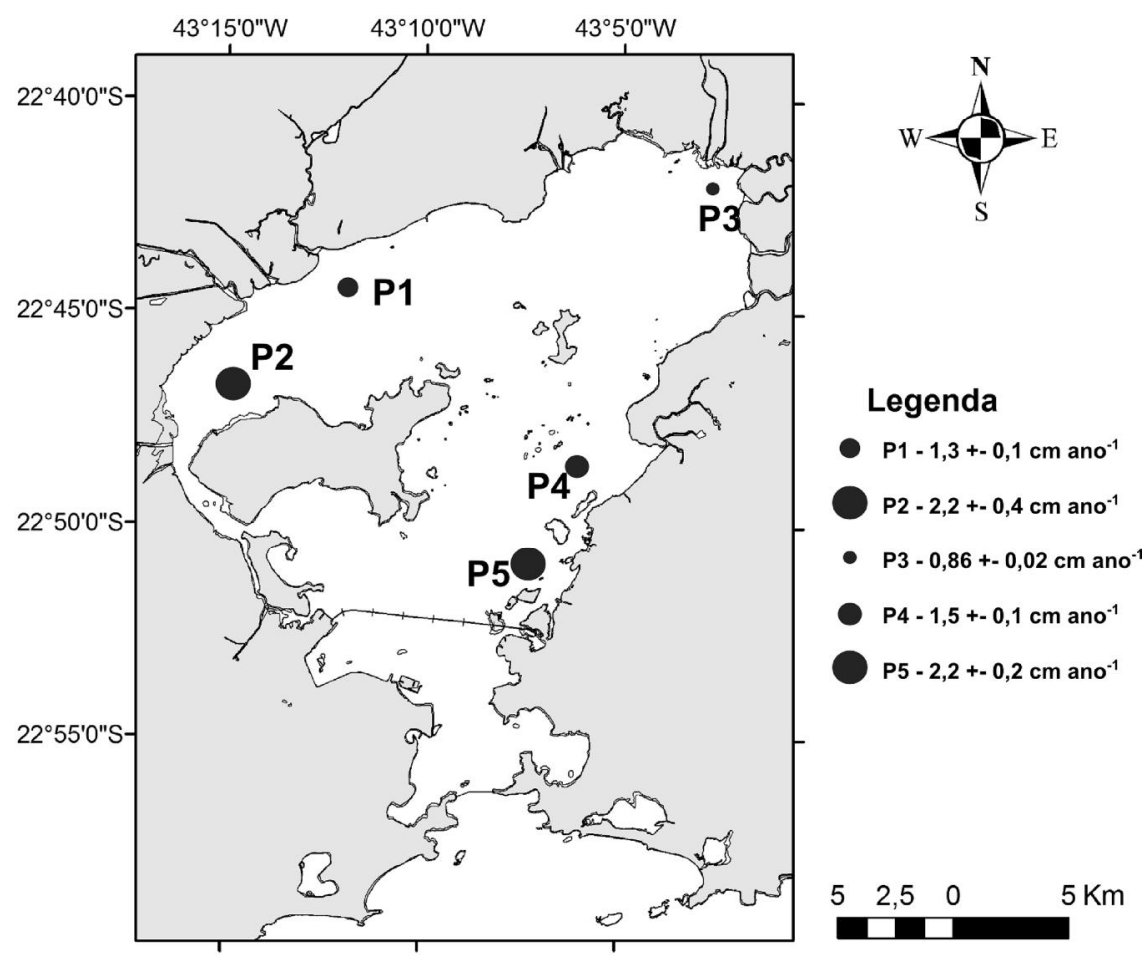

Figura 10 - Taxa de sedimentação para diferentes áreas da Baía de Guanabara (Modificado de Godoy et al., 1998) - Localização aproximada dos pontos.

A partir da avaliação geocronológica do aporte de HPAs, Lima (1996) evidencia o crescimento substancial da contaminação por hidrocarbonetos em sedimentos, principalmente a partir da década de 60. A autora observou o mesmo padrão para áreas consideradas menos alteradas, como as proximidades da Área de Proteção Ambiental (APA) de Guapimirim. Dados de Hamacher (1996), Meniconi (2007) e Wagener et al. (2012) para hidrocarbonetos em sedimentos superficiais corroboram o quadro de elevada contaminação da baía.

Meniconi (2007) e Wagener et al. (2012) utilizando de ferramentas para diferenciação de fontes tentaram estabelecer as principais contribuições de HPAs para a Baía de Guanabara. Todos os autores apontaram os sedimentos da região do Porto do Rio de Janeiro como severamente contaminados e relatam a complexidade em estabelecer claramente as fontes de HPAs devido às múltiplas entradas crônicas de contaminantes. 


\section{Métodos}

\section{1}

\section{Escolha das Estações de Coleta}

\subsection{1.}

\section{Particulado Atmosférico}

As estações de coleta foram definidas com base na malha amostral disponibilizada pelo Instituto Estadual do Ambiente (INEA) e exposta na Figura 11. Seis pontos de coleta de material particulado atmosférico fino $\left(\mathrm{PM}_{2,5}\right)$ que melhor representassem a distribuição atmosférica dos contaminantes foram selecionados, considerando as diferentes feições existentes no entorno da Baía. Foram definidas as seguintes estações: (1) Seropédica, considerada como ponto controle; (2) Centro da cidade do Rio de Janeiro; (3) Copacabana; (4) São João de Meriti; (5) Campos Elíseos e; (6) contemplando a parte leste da baía, a estação de Niterói. Ao todo, considerando ausências durante o período de amostragem, foram analisadas 236 englobando estas seis estações.

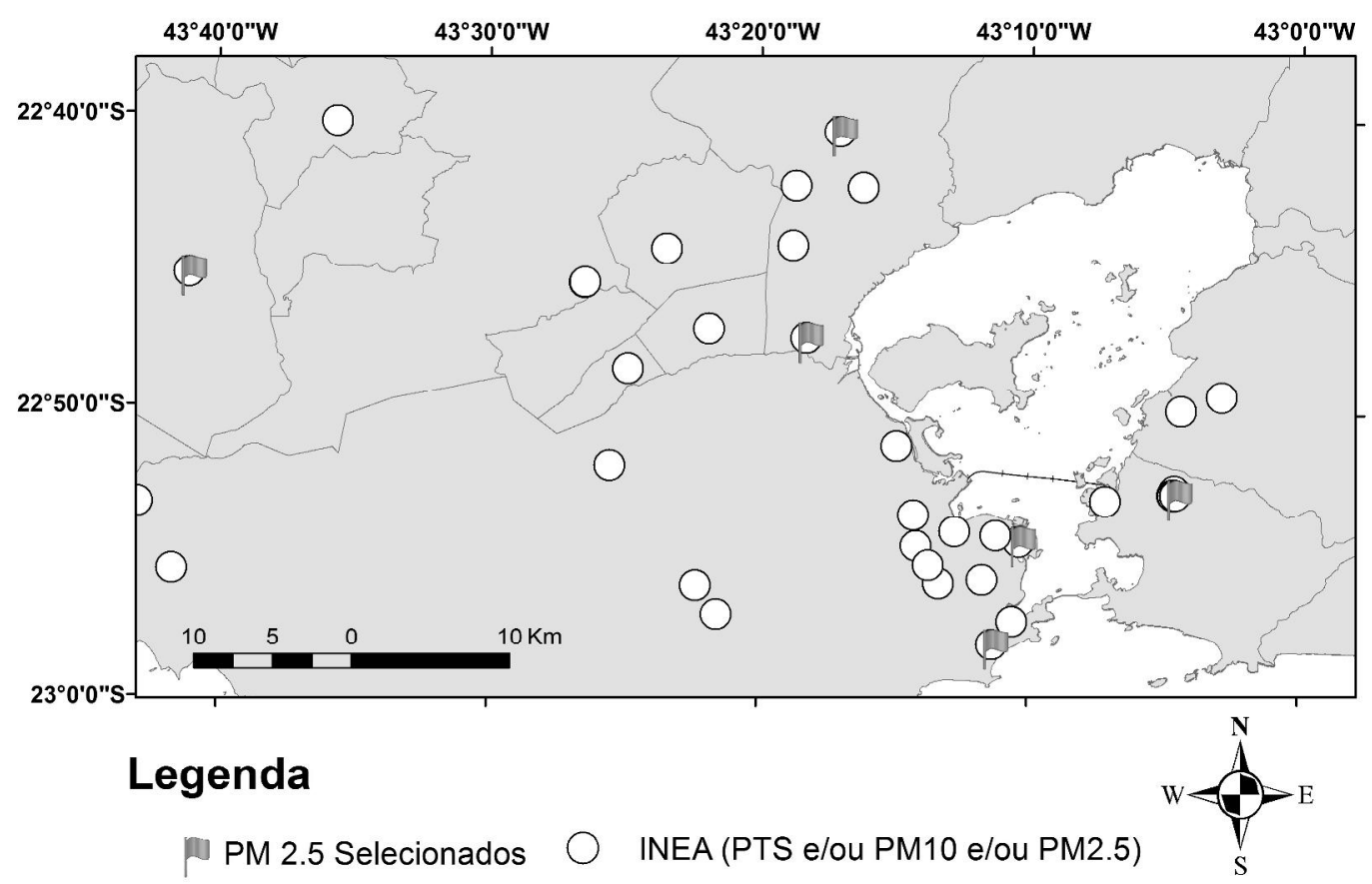

Figura 11 - Localização das estações de coleta deste estudo e malha de amostragem disponível pelo INEA. 


\subsection{2}

\section{Sedimento da Baía de Guanabara}

A escolha das estações de coleta de sedimento buscou contemplar toda a área da baía com os diferentes usos do solo e atividades de seu entorno. Consideraram-se também as avaliações pretéritas existentes. Alguns destes dados são anteriores ao derrame de combustível marítimo (MF-380) em 18 de janeiro de 2000 (Hamacher, 1996; Lima, 1996). Outros, posteriores ao acidente, provém de avaliações pontuais (Meniconi et al., 2002, Meniconi, 2007) e de dois anos de amostragem semestral em programa de monitoramento ambiental (Wagener et al., 2012).

Desta forma, além de investigar a fonte de hidrocarbonetos para os sedimentos da Baía de Guanabara, contribui-se para a manutenção de uma série histórica de dados. (Figura 12).

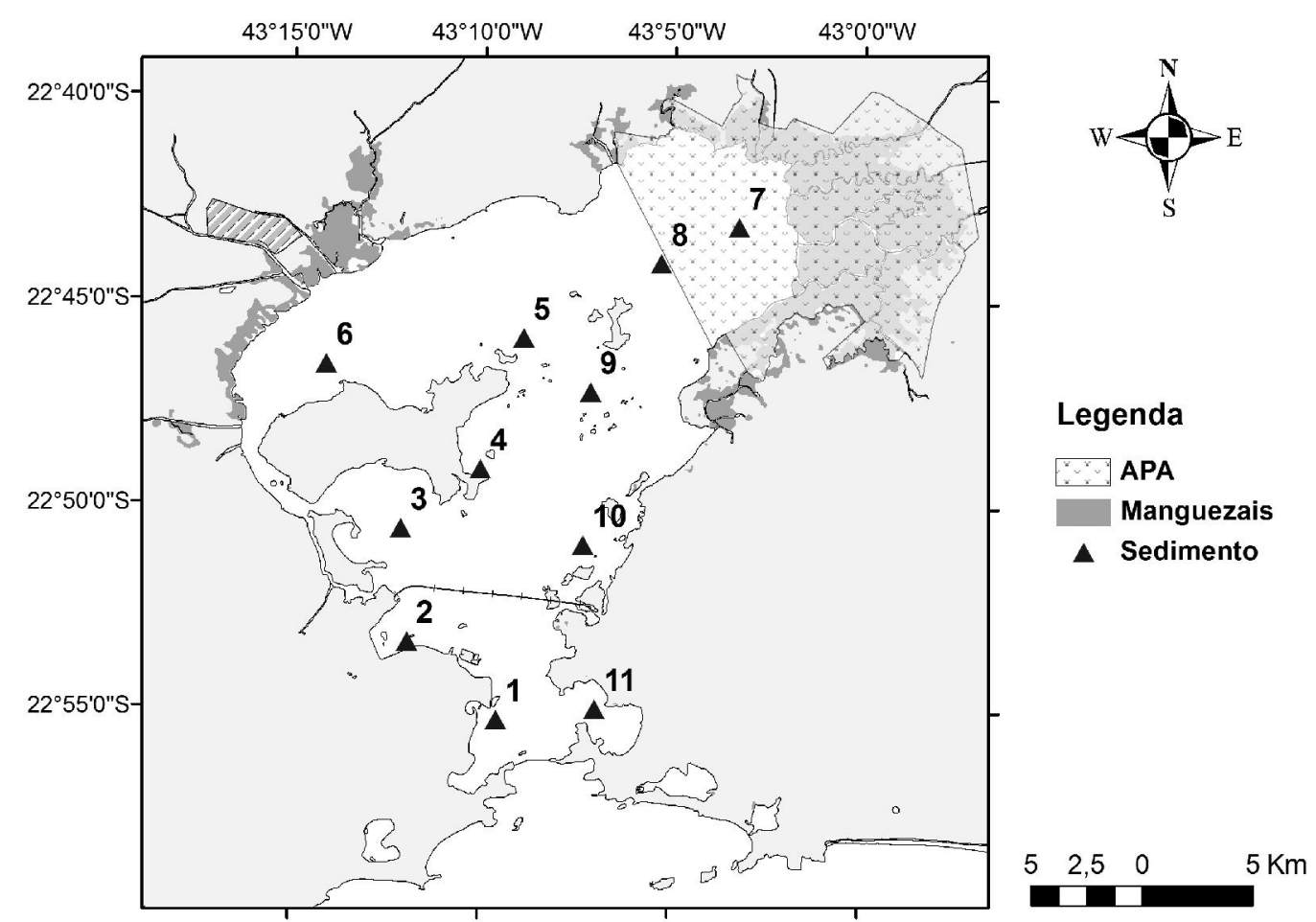

Figura 12 - Localização das estações de coleta de Sedimento na Baía de Guanabara 


\subsection{3}

\section{Amostras de petróleo e produtos de petróleo}

O Centro de Pesquisas Leopoldo Américo Miguez de Mello (CENPES), pertencente à empresa Petróleo Brasileiro SA (PETROBRAS), forneceu 31 amostras não identificadas de petróleo e produtos de petróleo de origem e ou uso no Brasil. Todas as amostras foram fornecidas em frascos de $250 \mathrm{~mL}$ e codificadas. A codificação das amostras foi acordada com a empresa para manter a sigilo requerido por esta quanto à origem dos produtos fornecidos.

\section{2 \\ Amostragem}

As amostras de material particulado atmosférico $\left(\mathrm{PM}_{2.5}\right)$ foram coletadas e cedidas pelo Instituto Estadual do Ambiente (INEA). A amostragem ocorreu conforme a norma ABNT -NBR 13412/95, de janeiro a dezembro de 2011. O período médio de coleta é de 24 horas, realizado a cada 6 dias utilizando filtros de fibra de vidro (Millipore) e vazão média de 1,13 metros cúbicos $\left(\mathrm{m}^{3}\right)$ por minuto.

As amostragens foram realizadas com Amostrador de Grande Volume (AGV MP 2,5) da marca Energética. O princípio de funcionando do aparelho é por impactação, onde a cabeça $\mathrm{PM}_{2,5}$ Andersen é dotada de um conjunto de 40 boqueiras que aceleram o ar de coleta para dentro de uma câmara. Esta, chamada de câmara de impactação, é onde as partículas maiores que 2,5 $\mu \mathrm{m}$ ficam retidas. A fração de ar com partículas menores que 2,5 $\mu \mathrm{m}\left(\mathrm{PM}_{2,5}\right)$ é carreada para fora da câmara e dirigida para um filtro de coleta (fibra de vidro ou micro-quartzo).

Também foi de responsabilidade do INEA a pesagem dos filtros, calibração do equipamento de coleta e entrega das amostras ao laboratório. A massa do material particulado coletado sobre o filtro de fibra de vidro foi obtida por análise gravimétrica em balança analítica (Mettler, $\pm 0,0002 \mathrm{~g}$ ). As concentrações de $\mathrm{PM}_{2.5}$, em $\mu \mathrm{g} \mathrm{m}^{-3}$, foram determinadas considerando-se a diferença de massa, a vazão e o tempo de amostragem.

Os filtros chegaram ao Laboratório de Química Atmosférica (LQA) em pacotes com lacre e número de identificação. Uma fração destes, de aproximadamente um sexto (1/6), foi retirada para as análises deste trabalho e armazenada em freezer. 
A coleta de sedimento da Baía de Guanabara ocorreu no dia 13 de abril de 2012 com auxílio de uma lancha rápida. Utilizou-se uma draga tipo Van Veen de pequeno porte. Esta, ao retornar a embarcação após a amostragem, foi aberta sobre uma bandeja de alumínio e, com o auxílio de uma espátula, retirada a camada superficial do sedimento (aproximadamente $2 \mathrm{~cm}$ ).

As amostras foram armazenadas em quentinhas de alumínio previamente descontaminadas e mantidas em gelo durante a coleta até a chegada ao laboratório. Os sedimentos foram então guardados em freezer para congelamento e preservação até a posterior etapa de liofilização.

\section{3}

\section{Aquisição e seleção de dados climatológicos e meteorológicos}

Para auxiliar na interpretação dos resultados utilizaram-se os dados meteorológicos e climatológicos compilados das redes de monitoramento do Instituto Nacional de Meteorologia (INMET), do Sistema Alerta Rio da Prefeitura do Rio de Janeiro (GEO-RIO) e os dados dos aeroportos Santos Dumont e Antonio Carlos Jobim (Galeão).

Os critérios para utilização dos dados neste estudo foram à proximidade com a estação de coleta de material particulado atmosférico e padrão climático e meteorológico condizente com a mesma. Pode ser visualizado na Figura 13 a localização das estações de amostragem e coleta de dados que subsidiaram estas escolhas. A Tabela 2 apresenta o resultado final deste processo de seleção.

Os dados meteorológicos dos aeroportos Santos Dumont e Galeão foram obtidos através da página da Empresa Brasileira de Infraestrutura Aeroportuária (INFRAERO). O download dos dados é possível através do link exposto na Figura 14, especificando o código do aeroporto e o período de interesse. Os dados surgem na tela do navegador como texto contínuo com o período desejado, divididos por dia e hora de cada observação. Neste texto as observações são separadas pelo caractere ponto-e-vírgula (;). Os dados foram copiados para um editor de texto e extraídas as informações de direção e velocidade dos ventos. A velocidade do vento é fornecida em nós e a direção em graus. 
Tabela 2 - Escolha da base de dados disponíveis para interpretação dos resultados das estações de amostragem do material particulado

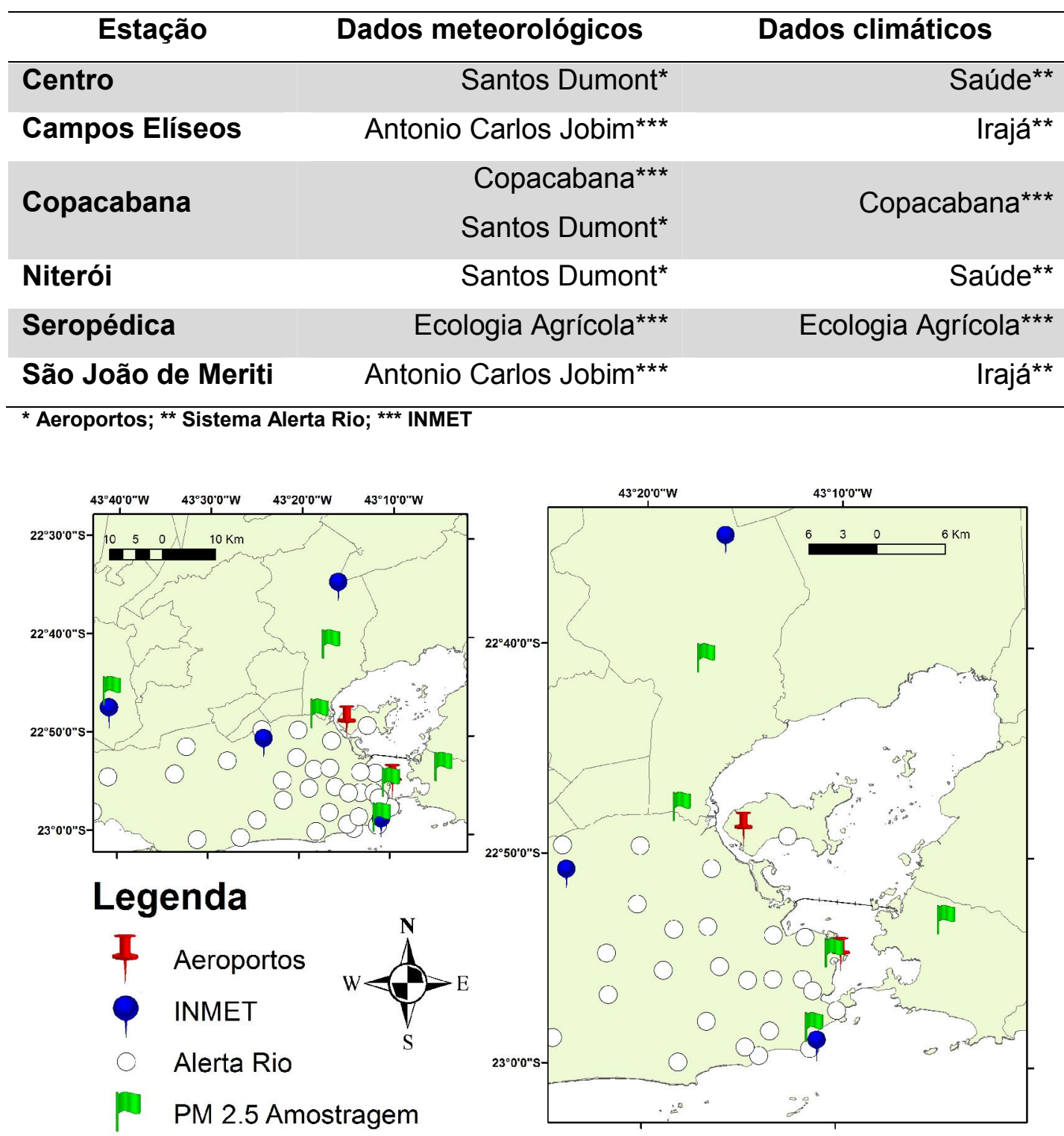

Figura 13 - Mapa das estações de coleta de Material Particulado $\left(\mathrm{PM}_{2.5}\right)$, estações meteorológicas do INMET, Aeroportos e estações do Sistema Alerta Rio.

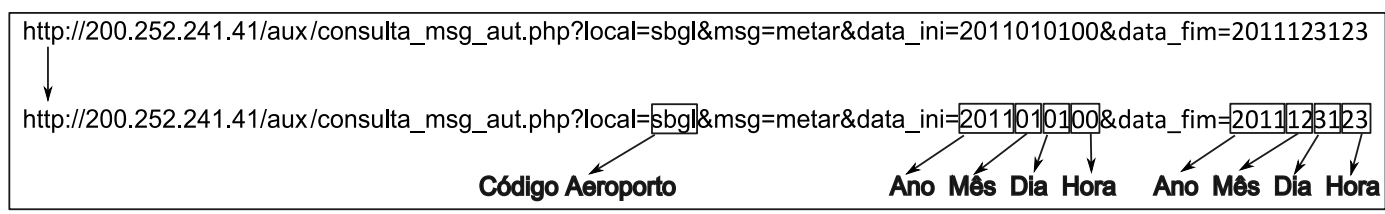

Figura 14- Link para download dos dados de ventos de aeroportos. Especificação para o aeroporto do Galeão no período de 01 de janeiro a 31 de dezembro do ano de 2011. 
Solicitou-se ao Instituto Nacional de Meteorologia (INMET) os dados das estações de interesse localizadas no Estado do Rio de Janeiro. O mapa com a localização e o nome das estações de monitoramento disponíveis no Brasil pode ser consultado na página do Instituto (http://www.inmet.gov.br/portal). A solicitação foi realizada por e-mail ao departamento competente, a Seção de Armazenamento de Dados Meteorológicos - SADMET/INMET, conforme procedimento descrito no site. A entrega dos dados foi autorizada sem ônus pelo Coordenador-Geral de Agrometeorologia. A direção do vento é fornecida em graus, com maior precisão comparada aos dados dos aeroportos, e sua intensidade é indicada em $\mathrm{m} \mathrm{s}^{-1}$.

Outra fonte de dados disponível encontra-se na prefeitura da cidade do Rio de Janeiro através da Fundação Instituto de Geotécnica do Município do Rio de Janeiro (GEO-RIO). Esta disponibiliza através da internet as informações meteorológicas e climáticas das estações que compõem o Sistema Alerta Rio (http://www0.rio.ri.gov.br/alertario/?page id=796). Embora existam três estações com dados meteorológicos para download, os mesmos não foram utilizados dada a melhor localização das estações do INMET em relação aos pontos de amostragem de material particulado. Soma-se a este fato a ausência de dados meteorológicos para as estações do Sistema Alerta Rio em alguns períodos do ano de 2011. Foi observado, por exemplo, a ausência de dados para os meses de janeiro e fevereiro na estação meteorológica de São Cristovão, alternativa próxima para a estação de coleta de material particulado do centro da cidade.

Utilizou-se apenas as informações climáticas das estações de Saúde e Irajá do Sistema Alerta Rio. A utilização destes dados decorre da maior precisão comparados aos dados disponíveis nos aeroportos. A chuva em aeroportos é indicada qualitativamente na linha de dados por um código demonstrando apenas a ocorrência da mesma.

Desta forma, os dados de ventos do Aeroporto Santos Dumont foram utilizados para as estações do Centro e de Niterói, associados aos dados de climatológicos da estação Saúde do Sistema Alerta Rio.

Os dados meteorológicos do Aeroporto Antonio Carlos Jobim, o Galeão, foram utilizados para as estações de São João de Meriti e Campos Elíseos. Para estas estações os dados climatológicos utilizados foram os da estação do Sistema Alerta Rio de Irajá. Apesar da estação do INMET localizada no Município de Xerém ser geograficamente mais próxima a estação de coleta de material particulado de Campos Elíseos, optou-se por não utilizar seus dados. A estação do INMET apresentou um padrão diferente das demais, possivelmente 
por sua localização no sistema da Serra do Mar. Optou-se, portanto, em utilizar os dados estação de Irajá, mais condizentes em relação á localização da estação de Campos Elíseos.

Os dados meteorológicos e climatológicos da Estação Agrícola do INMET, localizada em Seropédica, foram utilizados no ponto considerado controle. Os dados da estação do INMET de Copacabana foram utilizados na estação de amostragem de material particulado de Copacabana. Infelizmente nesta estação existe uma ausência de dados desde meados de setembro até o final do ano e, para este período, foram utilizados de maneira complementar os dados de ventos do Aeroporto Santos Dumont.

Soma-se a malha de dados demonstrada na Figura 13 a opção de download de dados do Sistema de Alerta de Cheias do Instituto Estadual do Ambiente (http://inea.infoper.net/inea/?p=historico). Apesar da malha do referido Instituto ser ampla e contemplar a porção leste da Baía de Guanabara, com duas estações em Niterói para download, os dados do ano de 2011 não se encontravam disponíveis. Esta base de dados não foi utilizada neste estudo, mas é uma opção complementar as demais bases de dados disponíveis em estudos futuros.

Após aquisição e seleção dos dados, os mesmos foram separados por mês e criados gráficos para melhor visualização e interpretação. Para os dados de ventos foram criados três gráficos mensais. São estes: (1) gráfico polar para distribuição da direção e intensidade dos ventos, utilizando o pacote plotrix do software R (Lemon, 2006); (2) freqüência da direção do vento para melhor visualização da direção predominante e; (3) velocidade média do vento por direção (Figura 15). Para os dados climatológicos foi calculada a média mensal da temperatura e a chuva acumulada para cada mês, demonstrando a variação anual de cada estação como exposto na Figura 16.
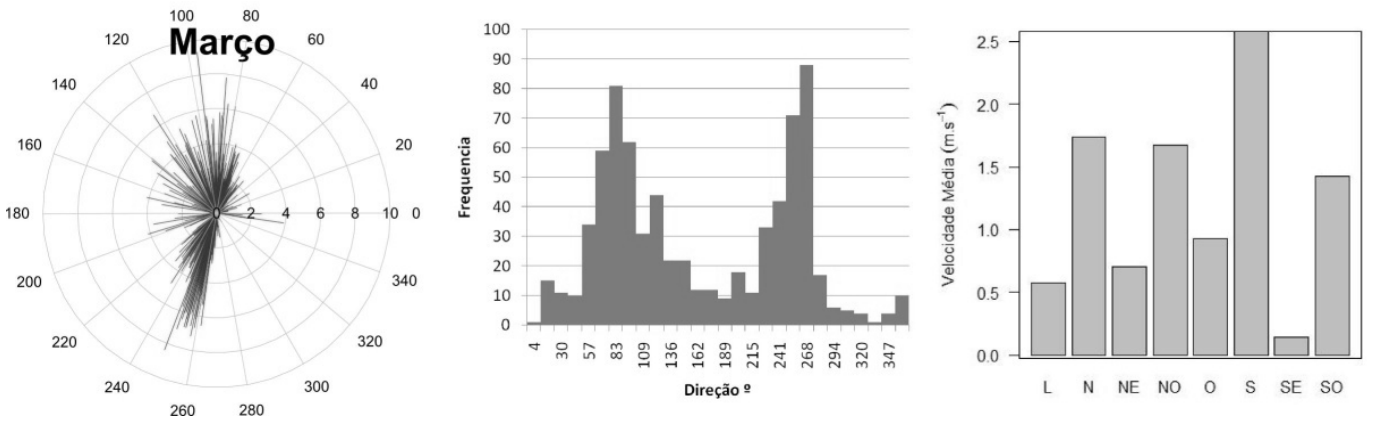

Figura 15 - Dados de direção (origem) e intensidade dos ventos para a estação do INMET de Copacabana para o mês de março de 2011. 


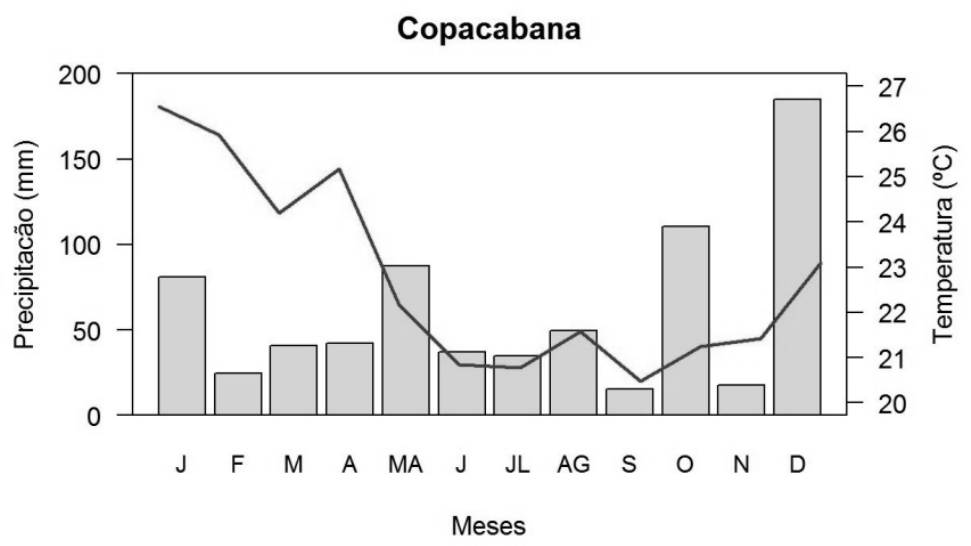

Figura 16 - Dados de chuva acumulada $(\mathrm{mm})$ e temperatura média pra a estação de Copacabana do INMET no ano de 2011.

Além das estações selecionadas para este estudo, quando necessário, dados de outras estações foram tratados e interpretados para corroborar as tendências observadas e os critérios de seleção utilizados.

\section{4 \\ Análises Químicas}

\subsection{1}

\section{Extração das amostras}

Previamente a extração as amostras de sedimentos foram liofilizadas (liofilizador ModulyoD da Thermo) para retirada da umidade. As amostras de sedimento e os filtros de particulado atmosférico foram extraídos em Sohxlet por 24 horas em diclorometano, seguindo a metodologia EPA 3540. Optou-se em seguir a mesma metodologia nas duas matrizes para melhor comparação de resultados.

Cada amostra de sedimento foi extraída duas vezes. Para primeira extração pesou-se aproximadamente $5 \mathrm{~g}$ e, na segunda extração, $2 \mathrm{~g}$. Este procedimento foi adotado para corroborar os resultados encontrados e verificar a variabilidade do método.

Para o controle da recuperação de todo o procedimento analítico utilizaram-se padrões deuterados, conhecidos como compostos subrogados, adicionados às amostras na etapa de extração. Para a determinação da recuperação nos hidrocarbonetos alifáticos utilizou-se os padrões deuterados 
$n C 16 d_{34}$ e $n C 30 d_{62}$. Para a fração aromática o padrão deuterado utilizado foi o pterfenil- $\mathrm{d}_{14}$.

Após a extração, o volume do extrato foi reduzido no concentrador de amostras TURBOVAP II, efetuando-se a troca de solvente para n-hexano, prérequisito para o fracionamento da amostra.

Para as amostras de petróleo e produtos de petróleo pesou-se aproximadamente $10 \mathrm{mg}$ de cada amostra em duplicata. Estas foram diluídas em n-hexano e diretamente inseridas no topo da coluna de vidro para fracionamento por cromatografia líquida em coluna aberta.

Todas as matrizes analisadas foram acompanhadas de análises em branco. Também foram realizados ensaios em branco com alguns filtros cedidos pelo INEA, utilizados para coleta de material particulado atmosférico.

\subsection{2 \\ Cromatografia líquida de coluna}

A separação das frações alifática e aromática a partir do extrato bruto foi realizada por cromatografia em coluna aberta. Utilizou-se uma coluna de vidro de $30 \mathrm{~cm}$ de comprimento e 1,3 cm de diâmetro interno, preenchida com alumina e sílica (7 g de alumina desativada a $2 \%$ e $10 \mathrm{~g}$ de sílica desativada a 5\%). A fração de hidrocarbonetos alifáticos (F1) foi obtida por eluição com $35 \mathrm{~mL}$ de nhexano. A fração contendo os HPAs (F2) foi eluída em seguida pela adição de $75 \mathrm{~mL}$ de uma solução n-hexano:diclorometano (1:1).

Tanto a F1 (alifáticos) como a F2 (aromáticos) para as amostras de material particulado e sedimento foram concentradas no TURBOVAP \| a $1 \mathrm{~mL}$, adicionados os respectivos padrões internos, e transferidas aos frascos correspondentes para injeção.

As amostras de petróleo e produtos de petróleo seguiram outro procedimento. Para estas, por apresentarem elevada concentração de hidrocarbonetos, o volume final de extrato foi de $50 \mathrm{~mL}$, sendo retirado $1 \mathrm{~mL}$ para adição de padrão interno e posterior injeção. 


\subsection{3 \\ Quantificação dos Hidrocarbonetos Alifáticos}

Nos hidrocarbonetos alifáticos são quantificados os compostos resolvidos e não-resolvidos, cujo somatório representa os hidrocarbonetos alifáticos totais. Os alifáticos resolvidos incluem os n-alcanos individuais ( $\mathrm{n}-\mathrm{C} 12$ ao $\mathrm{n}-\mathrm{C} 34)$, os isoprenóides pristano e fitano e outros picos identificados no cromatograma, mas que não podem ser relacionados a um composto específico. Os compostos denominados não-resolvidos são identificados no cromatograma por uma elevação da linha base, compondo a mistura complexa não resolvida (MCNR).

A quantificação foi baseada no método EPA 8015B. Os hidrocarbonetos alifáticos contidos nesta fração (F1) foram identificados e quantificados por cromatografia em fase gasosa com detector de ionização por chama (CG/DIC), utilizando as condições resumidas na Tabela 3.

A identificação dos n-alcanos individuais (n-C12 a n-C40) baseou-se no tempo de retenção de cada composto, verificado pela injeção de mistura-padrão $\left(0,05,0,25,0,5,1,2\right.$ e $\left.5 \mu \mathrm{mL}^{-1}\right)$.

Tabela 3 - Condições cromatográficas para determinação de hidrocarbonetos alifáticos.

\begin{tabular}{|c|c|}
\hline Equipamento & GC - Thermo Scientific modelo FOCUS Trace GC Ultra \\
\hline Coluna: & $\mathrm{HP}-5(30 \mathrm{~m} \times 0,25 \mathrm{~mm} \times 0,25 \mu \mathrm{m})$ \\
\hline \multicolumn{2}{|l|}{ Gases: } \\
\hline Carreador: & Hélio: $2 \mathrm{~mL}$ min $^{-1}$ (pressão: 5 psi a $60^{\circ} \mathrm{C}$ ) \\
\hline Make-up: & Nitrogênio: 33 mL min-1 \\
\hline Detector: & Ar: $360 \mathrm{~mL} \mathrm{~min}{ }^{-1}$; Hidrogênio: $33 \mathrm{~mL} \mathrm{~min}{ }^{-1}$ \\
\hline \multicolumn{2}{|l|}{ Temperatura: } \\
\hline Injetor: & $290^{\circ} \mathrm{C}$ \\
\hline Detector: & $310^{\circ} \mathrm{C}$ \\
\hline Coluna: & 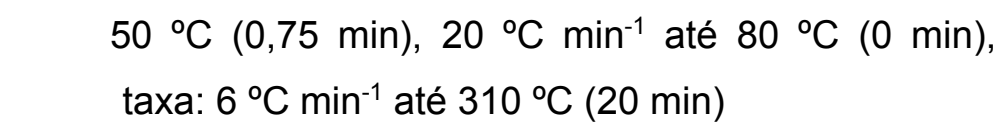 \\
\hline
\end{tabular}

Os demais picos resolvidos presentes no cromatograma da amostra, mas sem padrão que torne possível sua identificação, foram somados aos compostos identificados para determinar o total de hidrocarbonetos resolvidos (HR). 
A quantificação baseou-se nos cálculos os fatores de resposta dos nalcanos individuais relativos ao $\mathrm{n}-\mathrm{C} 24 \mathrm{~d}$ (FRR). Os FRRs foram determinados pela equação 1, após injeção da mistura-padrão usada para determinação do tempo de retenção de cada composto. A MCNR foi quantificada pelo FRR médio de todos os n-alcanos.

$$
F R R=\frac{A_{c}}{A_{p i}} \times \frac{C_{p i}}{C_{c}}
$$

onde:

Ac e Cc = área e concentração, respectivamente, do composto em questão.

Api e Cpi = área e concentração, respectivamente, do padrão interno (n-C24d).

O limite de detecção do método já estabelecido no laboratório corresponde a $25 \mathrm{ng} \mathrm{mL} \mathrm{m}^{-1}$. O limite de quantificação é considerado como igual à menor concentração utilizada na curva de calibração, ponderando-se a quantidade amostrada. Este limite nas amostras foi de $10 \mathrm{ng} \mathrm{g}^{-1}$ para $\mathrm{n}$-alcanos individuais no sedimento, aproximadamente $0,18 \mathrm{ng} \mathrm{m}^{-3}$ em particulado atmosférico e 250 $\mu \mathrm{g} \mathrm{g}^{-1}$ em amostras de petróleo e produtos de petróleo.

Os valores médios dos brancos analíticos expressos em massa de $n$ alcanos e MCNR foram descontados dos valores obtidos para cada amostra.

\subsection{4 \\ Quantificação dos Hidrocarbonetos Aromáticos}

A fração contendo os HPAs (F2) foi analisada por cromatografia em fase gasosa acoplada a espectrometria de massas (CG/EM), sob as condições resumidas na Tabela 4. Os hidrocarbonetos aromáticos considerados nesse trabalho são: naftaleno, acenaftileno, acenafteno, fluoreno, fenantreno, antraceno, fluoranteno, pireno, benzo(a)antraceno, criseno, benzo(b)fluoranteno, benzo(k)fluoranteno, benzo(a)pireno, indeno(1,2,3-c,d)pireno, dibenzo(a,h)antraceno, benzo(ghi)perileno, dibenzotiofeno, perileno e benzo(e)pireno. Somam-se a estes compostos ainda a quantificação dos seguintes homólogos alquilados: C1 a C4 naftalenos, C1 a C3 fluorenos, C1 a C3 dibenzotiofenos, C1 a C4 fenantrenos, C1 e C2 pirenos, e C1 e C2 crisenos. O protocolo analítico utilizado baseou-se no método EPA-8270D. 
Tabela 4 - Condições instrumentais para determinação de HPAs individuais.

\begin{tabular}{|c|c|}
\hline \multirow[t]{2}{*}{ Equipamento } & EM - Thermo Scientific modelo ITQ - Ion Trap \\
\hline & GC - Finnigan modelo TraceGC \\
\hline Coluna & $\begin{array}{l}\text { DB5-MS (30 m, 0,25 mm de diâmetro interno e 0,25 } \\
\mu \mathrm{m} \text { de filme) }\end{array}$ \\
\hline Programa de & $50^{\circ} \mathrm{C}$ durante $5 \mathrm{~min}$ \\
\hline \multirow[t]{3}{*}{ temperatura } & $50{ }^{\circ} \mathrm{C} \min ^{-1}$ até $80^{\circ} \mathrm{C}$ \\
\hline & $6{ }^{\circ} \mathrm{C} \min ^{-1}$ de $80^{\circ} \mathrm{C}$ a $280^{\circ} \mathrm{C}$ \\
\hline & $280{ }^{\circ} \mathrm{C}$ durante $25 \mathrm{~min}$ \\
\hline Gás de arraste & hélio $1,2 \mathrm{~mL} \mathrm{~min} \mathrm{~m}^{-1}$ \\
\hline Volume de Injeção & $1,4 \mu \mathrm{L}$ \\
\hline
\end{tabular}

Para a quantificação dos HPAs utilizou-se como padrão interno uma mistura contendo naftaleno- $d_{8}$, acenafteno- $d_{10}$, fenantreno- $d_{10}$, criseno- $d_{12}$ e perileno- $d_{12}$. O equipamento foi calibrado através de nove soluções-padrão $(2,5$, $10,20,50,100,200,400$ e $1000 \mathrm{ng} \mathrm{mL}^{-1}$ ) contendo todos os HPAs não alquilados, o padrão subrogado, e os padrões internos deuterados. Estes últimos, utilizados na quantificação, injetados na mesma concentração em todos os níveis da curva (100 $\left.\mathrm{ng} \mathrm{mL}^{-1}\right)$.

$\mathrm{Na}$ busca de novos indicadores que possam ser utilizados neste estudo foram identificados e quantificados de maneira complementar outros HPAs. São estes: acefenantrileno; benzo(c)fenantreno; dibenzo(a,j)antraceno; pentafeno; benzo(b)criseno; piceno e; indeno(7,1,2,3-cd)pireno.

A identificação dos compostos baseou-se no trabalho de Yunker et al. (2002) e nos trabalhos de Wise et al. (1988) e Wise et al. (1986) sobre o padrão de referência para queima de carvão (SEM 1597), utilizado na comparação dos cromatogramas. Estimou-se também o tempo de retenção de cada composto baseado em seu índice de retenção. A estimativa foi feita por comparação com os valores de tempo e índice de retenção dos compostos mais próximos existentes na curva de calibração. O resultado pode ser visualizado na Figura 17. A quantificação procedeu usando como base a curva do composto de mesma relação massa/carga $(\mathrm{m} / \mathrm{z})$ com o tempo de retenção mais próximo. Para a quantificação do Reteno, um $\mathrm{C}_{4}$ Fenantreno, além do espectro e do índice de retenção foi utilizado um padrão para verificação do tempo de retenção. 


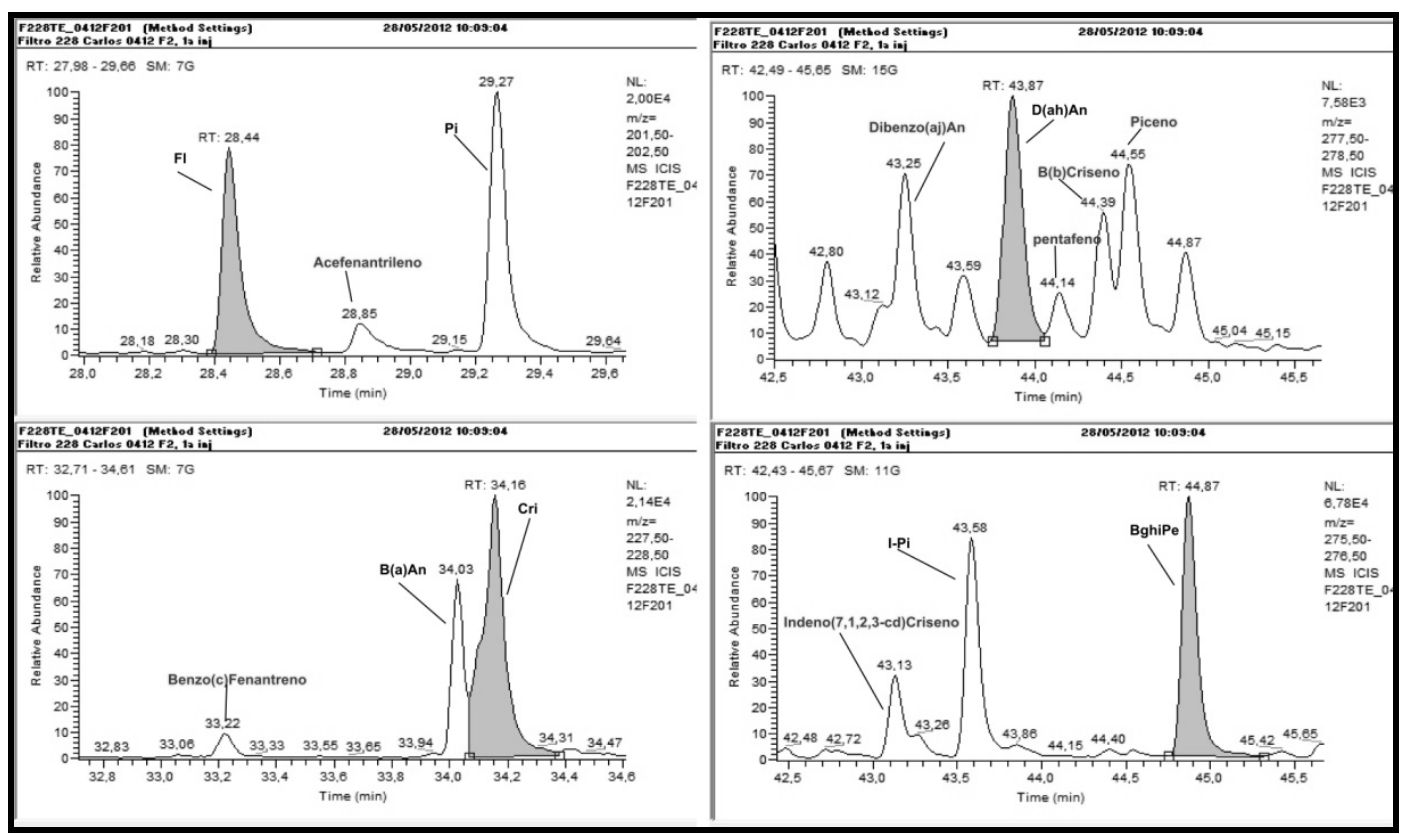

Figura 17 -HPAs complementares identificados e quantificados nas amostras de material particulado atmosférico, sedimentos da Baía de Guanabara e amostras de petróleo e produtos de petróleo.

Para a quantificação dos compostos alquilados, foram utilizadas as curvas de calibração de seus homólogos não alquilados. As curvas de calibração obtidas apresentaram coeficientes de correlação sempre superiores a 0,990 para todos os compostos.

O limite de quantificação do método foi considerado como igual à menor concentração utilizada na curva de calibração, ponderando-se a quantidade amostrada. Este limite para as amostras foi de $0,4 \mathrm{ng} \mathrm{g}^{-1}$ em sedimentos, aproximadamente $0,007 \mathrm{ng} \mathrm{m}^{-3}$ em particulado atmosférico e $10 \mathrm{\mu g} \mathrm{g}^{-1}$ em amostras de petróleo e produtos de petróleo.

Em algumas amostras houve a necessidade de diluir o extrato. Este ajuste foi adotado quando o resultado da quantificação excedia o maior valor de concentração da curva. A concentração de sedimento reportada neste estudo refere-se, preferencialmente, à extração de maior massa $(5 \mathrm{~g})$ por apresentar menor interferência da matriz. Em determinadas amostras, entretanto, foi necessário diluir o extrato para adequação da faixa analítica. Nestes casos optou-se por utilizar o resultado da amostra de menor massa extraída (2 g), cujo extrato não precisou ser diluído ou requisitou menor diluição para adequação da curva. 


\subsection{5}

\section{Análise de Carbono Orgânico nos sedimentos da Baía de Guanabara}

As análises de carbono orgânico foram realizadas em acordo com o Departamento de Geoquímica da Universidade Federal Fluminense (UFF) dentro do Projeto PROMAR, financiado pela CAPES (Coordenação de Aperfeiçoamento de Pessoal de Nível Superior). As amostras seguiram os procedimentos de descarbonatação e análise por analisador elementar.

Efetuou-se a descarbonatação através da adição de $\mathrm{HCl}$ 1,0 N diretamente nas amostras dentro dos frascos de análises. Este procedimento foi repetido por duas vezes sendo as amostras secas em estufa a $60{ }^{\circ} \mathrm{C}$ por $12 \mathrm{~h}$. A determinação dos teores de carbono nos sedimentos foi realizada no Analisador Elementar CHNS/O Perkin Elmer (2.400 Series II). Os valores foram expressos em percentual (\%), sendo a precisão obtida com três repetições, realizadas a cada 20 amostras. O nível de reprodutibilidade analítica dentro da mesma amostra foi a partir de 90 \%. Os testes de exatidão para C total e C orgânico realizados com padrão certificado marinho NIST 2702 foram realizados e revelaram recuperações acima de $95 \%$. O limite de detecção para C foi de $0,05 \%$. 


\section{Resultados e Discussão}

\section{1 Dados complementares - Clima e Meteorologia da área de estudo}

Neste subitem serão apresentadas as tendências gerais dos parâmetros climatológicos e meteorológicos obtidos no ano de 2011 nas estações de monitoramento escolhidas. Estes dados serão usados como subsídio à interpretação dos resultados analíticos. Em algumas ocasiões os dados de outras estações são apresentados, de maneira complementar, para corroborar as observações da estação de interesse. A utilização das informações, em média ou pontualmente a cada período de amostragem, será discutida durante a análise e interpretação de sua relação com os resultados analíticos.

As variações anuais da temperatura $\left({ }^{\circ} \mathrm{C}\right)$ e da pluviosidade acumulada $(\mathrm{mm})$ se encontram ilustrados na Figura 18. A oscilação dos dados seguiu o padrão esperado para a área de estudo, caracterizado por um clima tropical com as estações seca e chuvosa bem definidas.

Os maiores valores de precipitação acumulada, observados para o mês de abril advêm de um destacado evento pluviométrico. O registro da estação de Saúde entre os dias 24 e 27 de abril de 2011 para precipitação acumulada foi de 151,6 mm. Este valor corresponde a aproximadamente $81 \%$ da pluviosidade para o mês de abril e $19 \%$ do total anual desta estação. Altos valores de precipitação para o mesmo período foram obtidos nas estações de São Cristovão $(211 \mathrm{~mm})$ e Vila Militar (193 mm). Este evento é reportado com destaque entre os 23 eventos pluviométricos significativos em 2011 na Região Metropolitana do Rio de Janeiro (GEO-RIO/DEP/GPE, 2012). Os valores de pluviosidade nas estações de Copacabana e Seropédica para o mesmo período não foram tão elevados.

A distribuição de chuvas ocorre de forma irregular na área, como pode ser observado no Relatório Anual de Chuvas de 2011 (GEO-RIO/DEP/GPE, 2012), exemplificado na Figura 19 para o evento descrito anteriormente. A distribuição irregular das chuvas, assim como a variabilidade dos demais parâmetros obtidos, pode ocasionar variações espaciais nos registros de poluente atmosféricos. Ressalta-se, portanto, a importância da estação de monitoramento ser o mais próximo possível da estação de coleta de material particulado. Uma 
das limitações deste trabalho foi à necessidade de extrapolar as informações das estações de Saúde e Santos Dumont para Niterói e das estações de Irajá e Galeão para os pontos de coleta de São João de Meriti e Campos Elíseos.

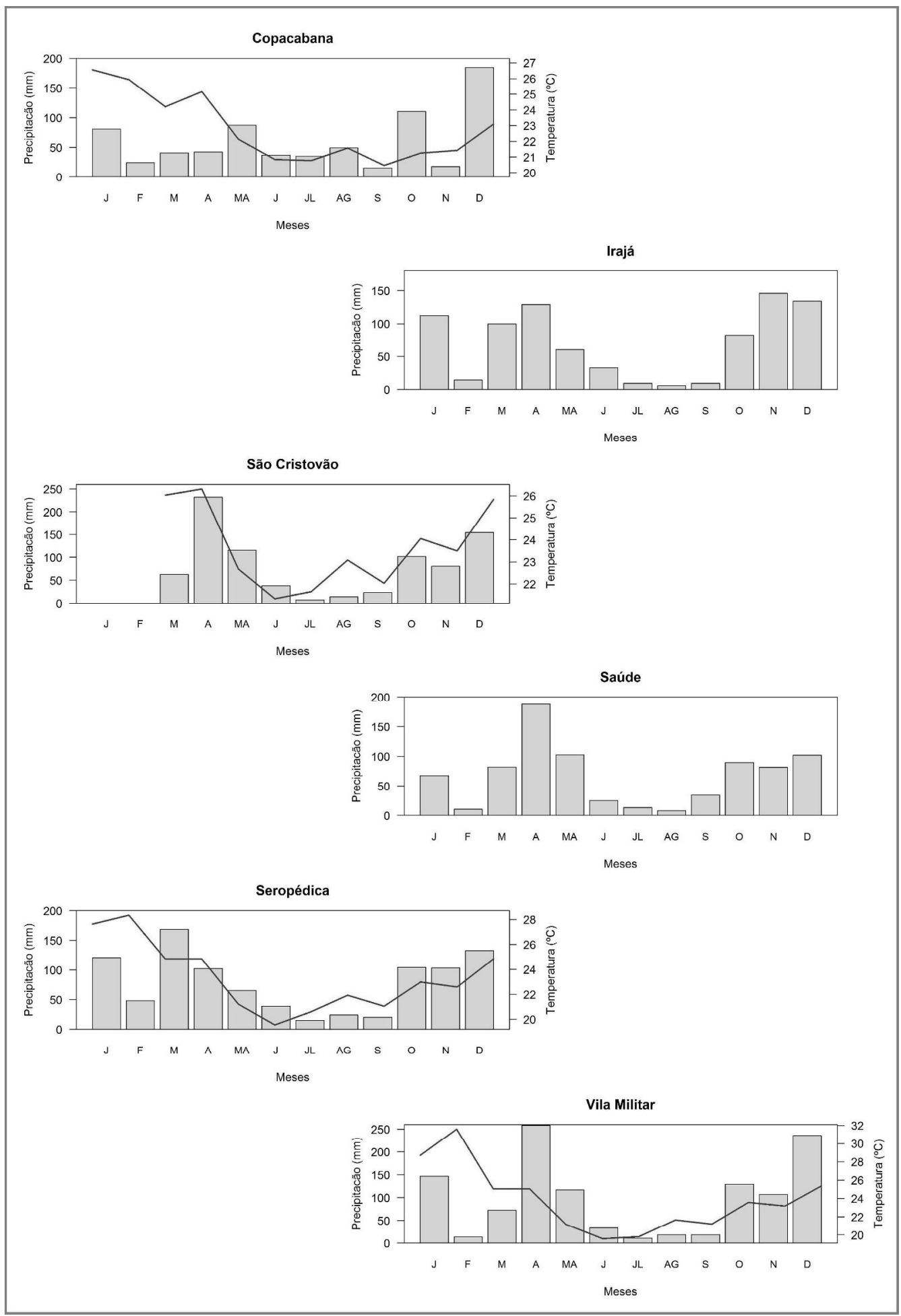

Figura 18 - Variação anual da temperatura média $\left({ }^{\circ} \mathrm{C}\right)$ e da chuva acumulada (mm) para o ano de 2011 nas estações de suporte aos dados e estações complementares. 


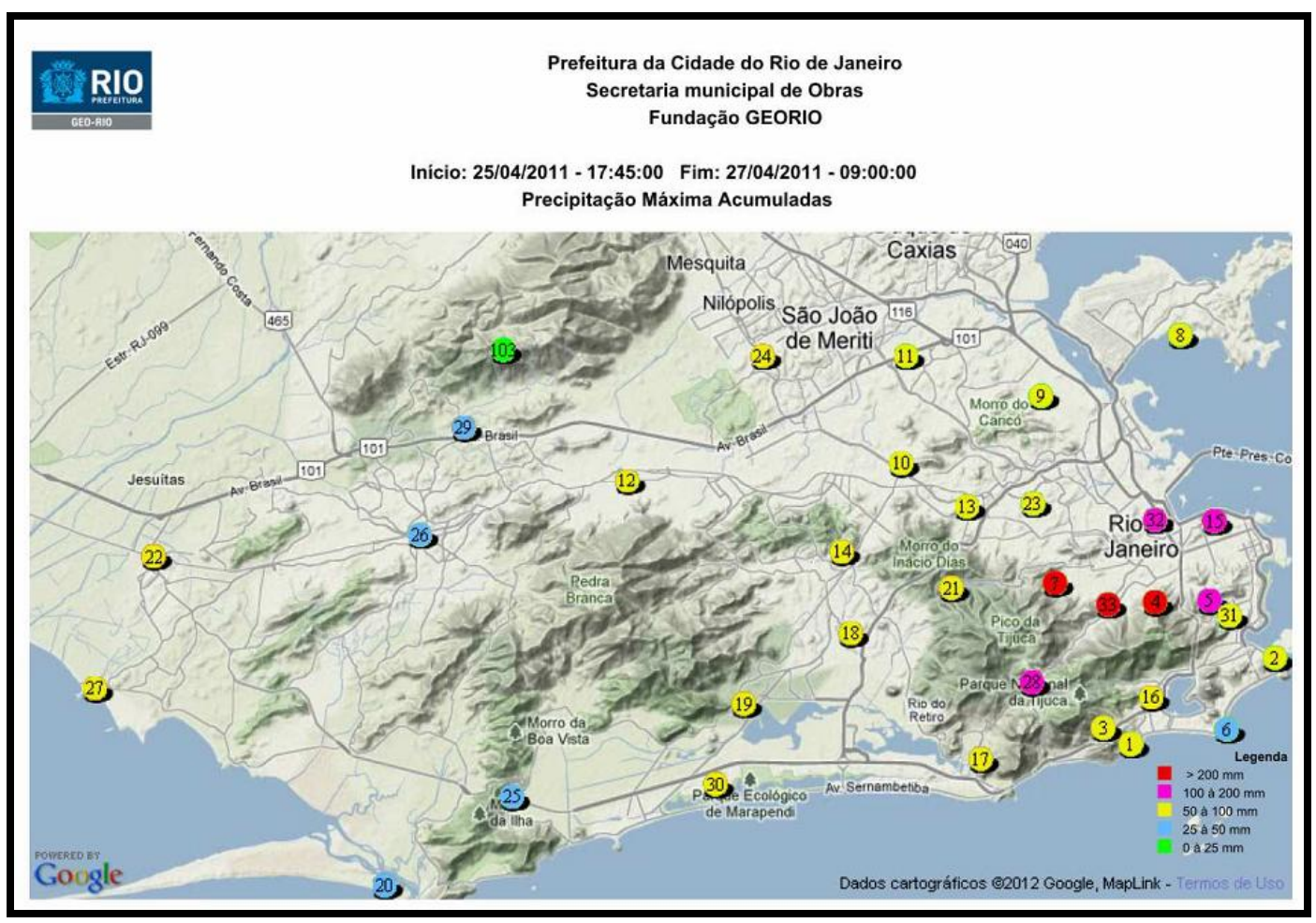

Figura 19 - Precipitação máxima acumulada para o período 25 a 27 de abril nas estações de monitoramento da Prefeitura da Cidade do Rio de Janeiro (GEORIO/DEP/GPE, 2012).

Os dados da estação de Seropédica, denominada pelo INMET de Ecologia Agrícola, apresentam uma distribuição bimodal da direção dos ventos, praticamente homogênea durante todo o ano. As maiores freqüência observadas são de ventos das direções leste-sudeste e oeste-sudoeste.

A estação de dados meteorológicos do Galeão apresentou maior freqüência de ventos de direções noroeste $(\mathrm{NO})$ e oeste $(\mathrm{O})$ durante todo o ano, principalmente noroeste. Uma maior incidência de ventos de sul (S) e sudeste (SE) surgiu no período de maio a setembro. Os dados do Santos Dumont também indicam a predominância dos ventos de NO e O. Nesta estação os ventos de S e SE aparecem com maior freqüência de abril a agosto.

Os dados meteorológicos da estação de Copacabana indicaram ventos mais freqüentes de $\mathrm{N}$ e $\mathrm{NO}$ de janeiro a maio, com aumento gradativo da influência de ventos de S e SE ao longo deste período. De junho a setembro a distribuição dos ventos se modifica, alternando a direção preferencial. Existem diferenças no padrão de ventos entre esta estação e a do Aeroporto Santos Dumont, além das já citadas para a precipitação. Estas diferenças são, provavelmente, relacionadas à localização das estações e feições geográficas associadas. O relevo da região é formado por maciços costeiros que funcionam 
como barreiras e influenciam a dinâmica de ventos. A estação de Copacabana encontra-se de frente para o mar e a do Santos Dumont protegida dentro da baía. Este quadro não permite a utilização da série de dados do Aeroporto Santos Dumont para complementar a ausência de informações na estação de Copacabana, do período de meados de setembro a dezembro. Para este período a relação entre os dados obtidos e os resultados analíticos de Copacabana ficou restrita às variáveis climatológicas.

Apesar das particularidades observadas na direção dos ventos entre as estações, todas apresentaram variação similar na intensidade. Os ventos mais intensos foram medidos nos meses de setembro e outubro, seguindo o padrão sazonal descrito para a região (Filippo, 1996; Amador, 1997; Barbiére \& Kronemberger, 1994). As menores intensidades médias foram observadas para os meses de maio e julho nos dois aeroportos e em Seropédica. Para a estação de Copacabana as menores intensidade foram observadas no mês de março (Figura 20).
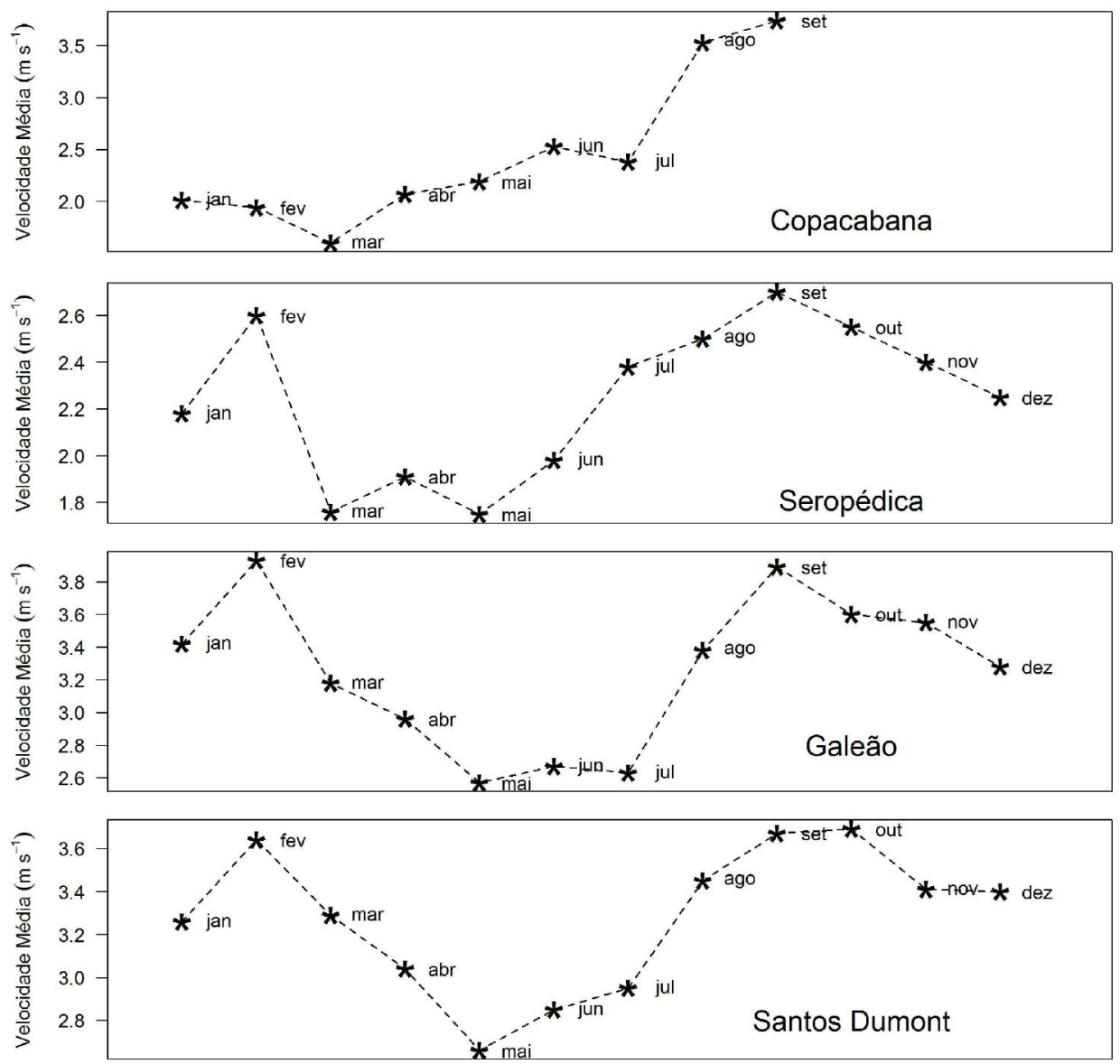

Figura 20 - Variação anual da velocidade média mensal dos ventos $\left(\mathrm{m} \mathrm{s}^{-1}\right)$ para os dados das estações de Copacabana, Seropédica, Aeroporto Internacional Antonio Carlos Jobim (Galeão) e do Aeroporto Santos Dumont. 
Os dados de umidade relativa do ar (\%) e radiação global monitorados pelas estações do INMET encontram-se expostos na Figura 21 e na Figura 22.
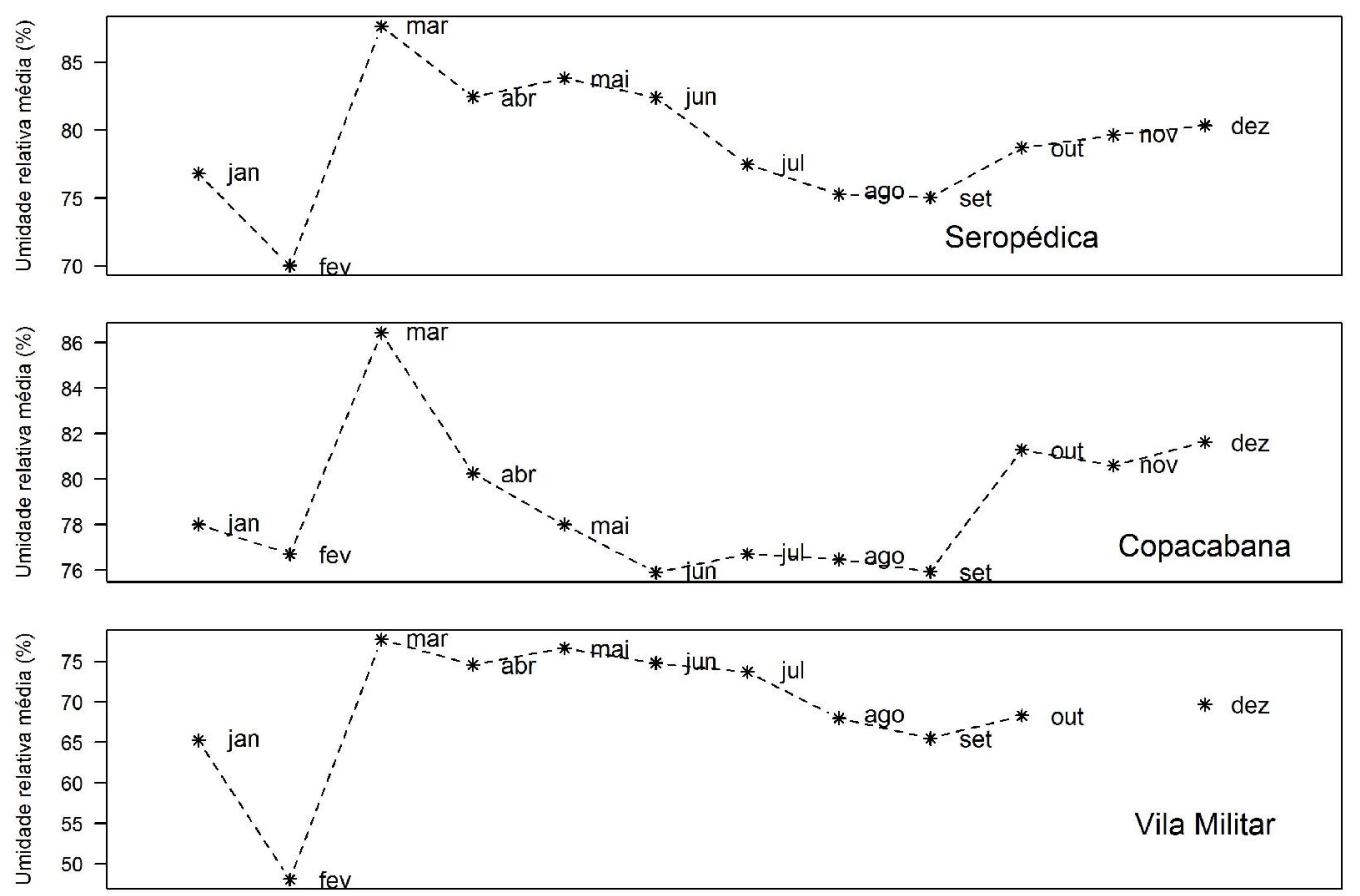

Figura 21 - Variação anual média para os dados de Umidade Relativa (\%).
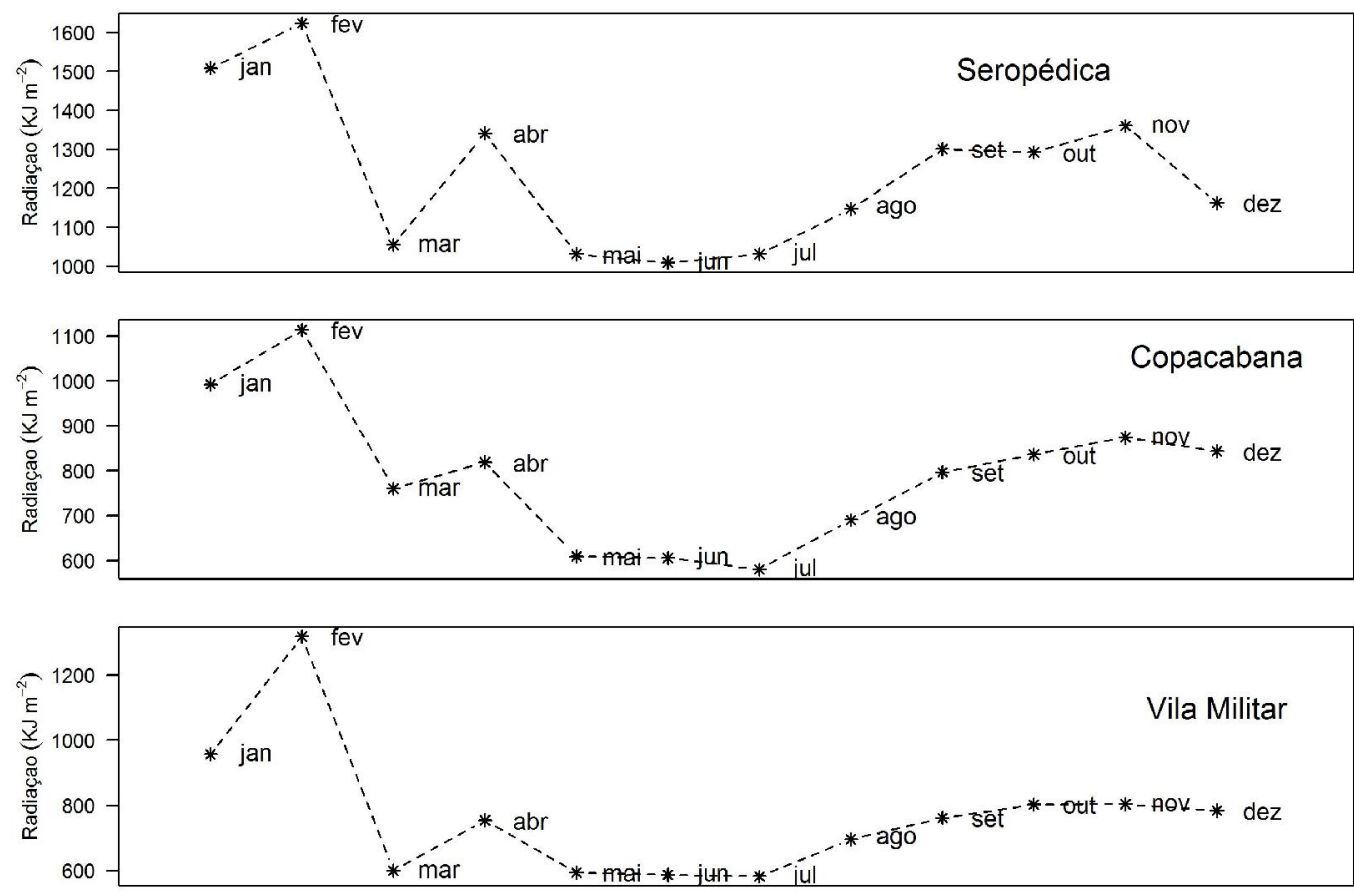

Figura 22 - Variação anual média para os dados Radiação Global (KJ m²)

Os maiores valores médios seguiram o padrão sazonal esperado com maiores valores no verão e menores no inverno. Os valores de umidade relativa variaram bastante entre as estações seguindo o mesmo comportamento observado para a pluviosidade acumulada. 


\section{2}

\section{Caracterização das Amostras de Petróleo e Produtos de Petróleo}

As tabelas contendo os resultados das amostras de petróleo e produtos de petróleo encontram-se em anexo. A variação da concentração reportada entre as replicatas foi pequena, como pode ser visualizado no exemplo a seguir (Figura 23). A concentração dos ensaios em branco foi proporcionalmente menor que $0,01 \%$ da concentração total determinada nos extratos desta matriz.

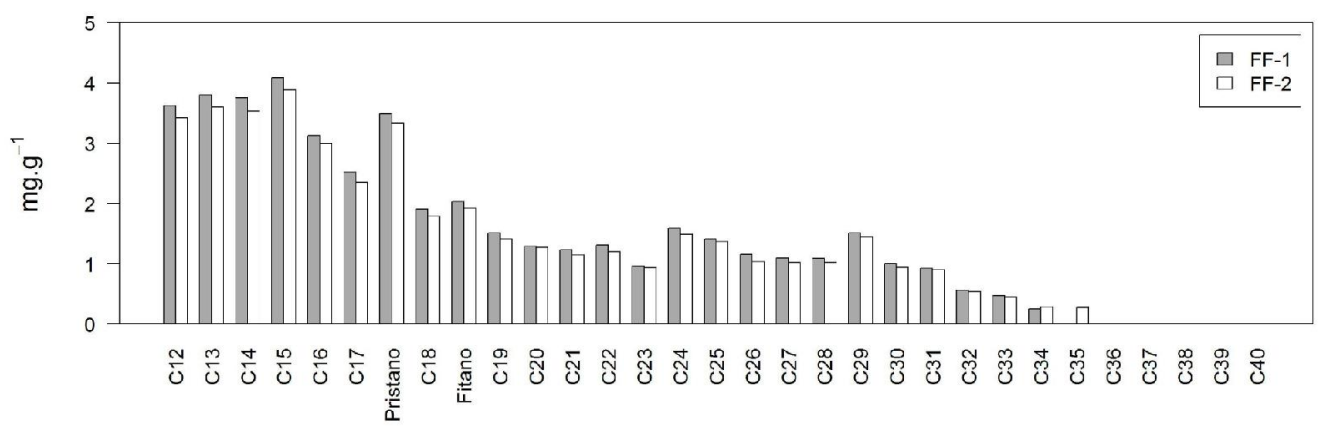

(a)

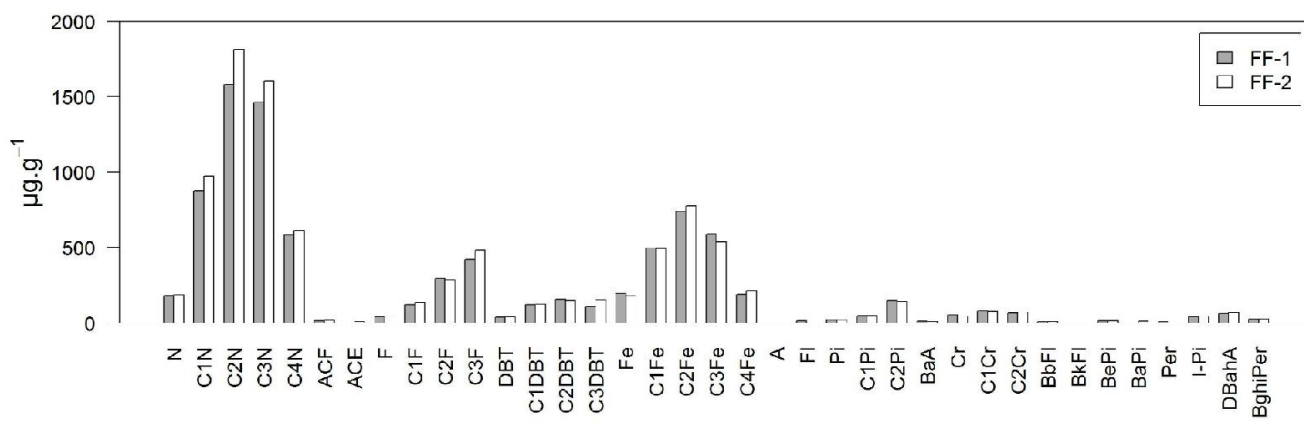

(b)

Figura 23 - Resultados para as análises em duplicata do produto de identificação FF nas quantificações de (a) hidrocarbonetos alifáticos e (b) hidrocarbonetos aromáticos.

A distribuição dos compostos nas frações alifática e aromática, assim como a distribuição relativa média por classes, encontra-se exposta na Figura 24. Os dados da distribuição relativa dos compostos aromáticos e alifáticos variou dentro da faixa esperada (Page et al., 1993; Wang et al., 1999a; Wang et al., 1999b; Wang et al., 2003; Readman et al., 2002; Volkman et al., 1992; Simoneit, 1986; NRC, 1985; Laws, 1993; Clark \& Blumer, 1967; Farrigton \& Tripp, 1997). Observa-se para os $n$-alcanos a contribuição mais significativa de compostos com menor peso molecular. Alguns dados considerados outliers no gráfico são derivados da mistura de produtos fornecidos. As amostras analisadas apresentam, em sua maioria, características de petróleo bruto. Algumas amostras têm uma distribuição de n-alcanos diferente que, ao agrupar-se no 
gráfico, produzem os referidos dados fora da distribuição. Isto pode ocorrer pela presença, por exemplo, de amostras de óleo combustível ou diesel, caracterizada pela distribuição de outliers entre o C18 e o C31. Em quatro amostras fornecidas ( $\mathrm{H}, \mathrm{I}, \mathrm{A}$ e $\mathrm{EE})$ os n-alcanos quase não foram detectados e em outras duas ( $V$ e $B B$ ) a ausência destes compostos é total.
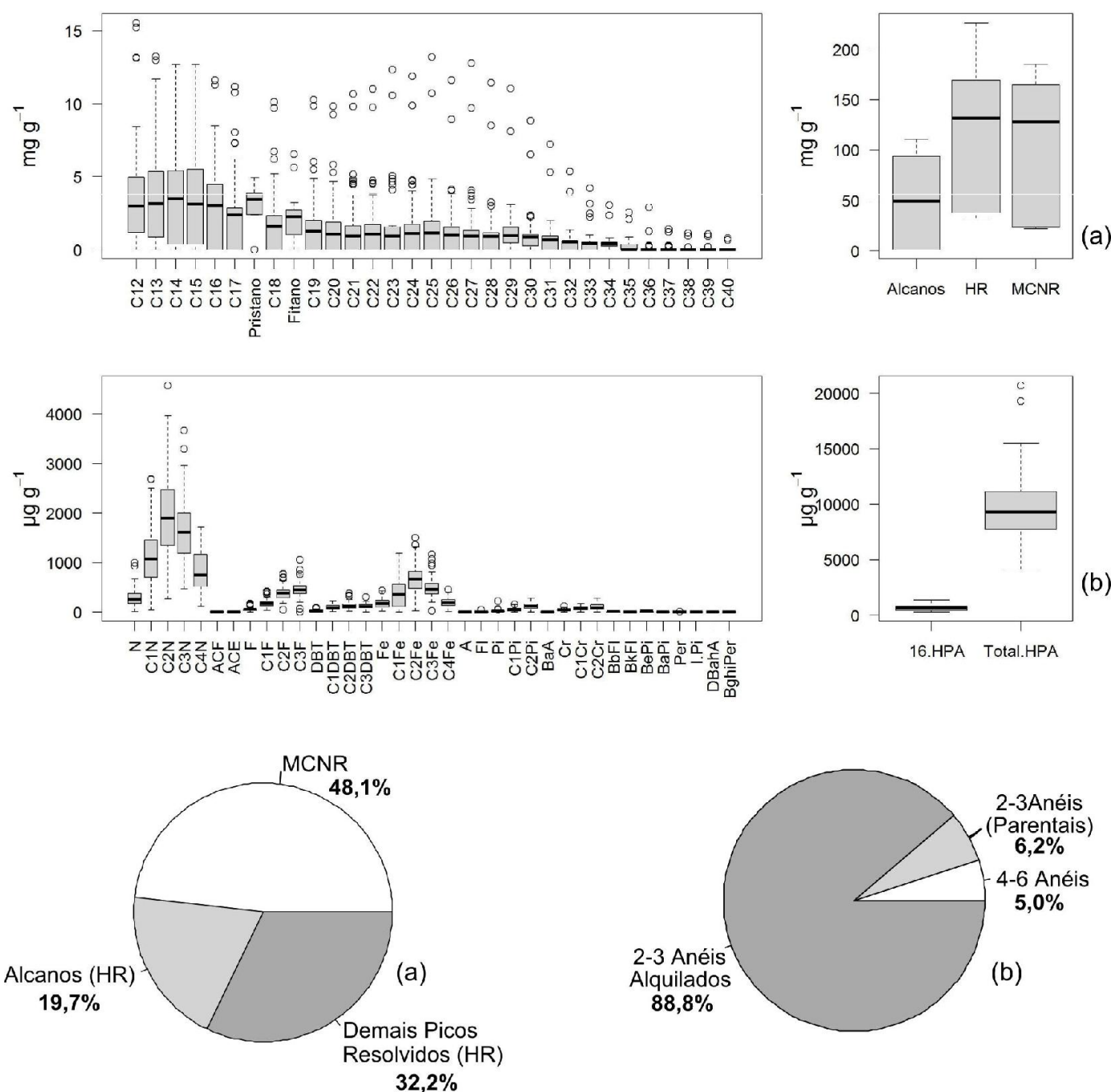

Figura 24 - Distribuição em Box-plot e percentual médio para as 32 amostras analisadas em duplicata da concentração de (a) n-alcanos, hidrocarbonetos resolvidos (HR) e Mistura Complexa Não Resolvida (MCNR) e (b) da concentração de Hidrocarbonetos Policíclicos Aromáticos (HPAs).

Os picos resolvidos constituem, em média, $51,9 \%$ do total da fração alifática sendo o restante $(48,1 \%)$ caracterizado por uma elevação da linha de base do cromatograma, a Mistura Complexa Não Resolvida. Dentro da parcela 
de picos resolvidos os n-alcanos contribuem com aproximadamente $34,8 \%$, ou $19,7 \%$ considerando o total de alifáticos.

O valor médio da razão entre a Mistura Complexa Não Resolvida e os hidrocarbonetos resolvidos $(H R)$ foi de $1,15 \pm 0,90(0,37-5,67)$. Apenas uma das réplicas da amostra $\mathrm{BB}$ apresentou razão superior a 4 . Esta amostra, como discutido anteriormente, apresenta características distintas do petróleo, com ausência de n-alcanos. As discrepâncias observadas são normalmente decorrentes da variedade de produtos fornecidos.

Em geral, valores da razão $M C N R / H R$ superiores a 4 são atribuídos a presença de material petrogênico degradado (Readman et al., 2002; Wang et al., 1999a; Volkman et al., 1992) e, conseqüentemente, indicam aporte de óleo ao ambiente. A presença da MCNR por si só já é considerada marcador de contaminação por petróleo (Volkman et al. 1992; Simoneit, 1986). Embora se considere que a presença desta mistura possa ocorrer naturalmente (Venkatesan \& Kaplan, 1982), esta contribuição em ambientes costeiros é relativamente muito inferior à contribuição petrogênica (White et al., 2013).

A média do índice de preferência de carbono para estas amostras foi de $1,17 \pm 0,37(0,84-2,84)$. Como esperado os valores mantiveram-se próximos a 1, com baixa dispersão, já que nesta matriz não existe predominância de compostos com número ímpar ou par de átomos de carbono (Clark \& Blumer, 1967; Farrigton \& Tripp, 1997; Wang et al., 1999a).

A média da relação entre os compostos Pristano e Fitano foi de 1,52 $\pm 0,30$ $(0,68$ - 2,31), da relação C17/Pristano foi de 1,24 $\pm 0,71(0,24-3,25)$ e da relação C18/Fitano foi de $1,48 \pm 0,97(0,29-4,37)$. Embora as razões envolvendo os compostos pristano e fitano ainda sejam usadas para indicar a contaminação por petróleo e o grau de intemperização de uma amostra, estudos realizados há mais de duas décadas já questionavam seu uso dada a quantidade de fontes destes compostos na natureza (Colombo et al., 1989; Powell, 1988).

No ambiente, as razões desenvolvidas para alcanos e isoprenóides mudam com o tempo. Por esta razão Wang et al. (2013) questionam a validade das mesmas para identificação de fontes oleosas e sugerem a utilização de biomarcadores e razão isotópica dos n-alcanos individuais.

Para os hidrocarbonetos aromáticos, assim como na fração alifática, existe um predomínio de compostos leves. A maior contribuição provém do naftaleno e seus homólogos alquilados, seguidos dos compostos de 3 anéis aromáticos. $A$ contribuição de compostos de 2-3 anéis corresponde a 95,0\% do total de HPAs 
nas amostras. Subtraídos os compostos parentais, o percentual de alquilados de 2-3 anéis sobre a concentração total é de $88,8 \%$. A concentração dos 16 HPAs considerados pela agência ambiental americana (EPA) como prioritários contribuem apenas para $7,0 \%$ da concentração total destas amostras.

Estimativas próximas a estas são reportados por Wagener et al. (2012) na análise da constituição de óleos utilizados na área da Baía de Guanabara (Al1, Al2, diesel, Combustível Marítimo MF-380) e outras fontes petrogênicas (Bence et al., 1996; Wang et al., 1997; Page et al., 1998). Os autores observaram que a soma das 5 séries de HPAs alquilados correspondem, em média, a 99,5\% da concentração total de HPAs. Neste estudo a contribuição média das 5 séries de HPAs alquilados foi de $97,1 \%$. A pequena diferença observada entre os trabalhos é provavelmente oriunda da maior número de produtos analisados neste estudo (31 amostras).

A variabilidade de amostras fornecidas fica evidenciada pela relação exposta na Figura 25. O gráfico das razões C2Fe / C2DBT e C3Fe / C3 DBT não é considerado uma ferramenta para diferenciação das fontes petrogênicas daquelas de combustão, ou naturais. A sua proposta é identificar se amostras de petróleo e produtos de petróleo apresentam ou não a mesma origem. Baseia-se no princípio que a proporção entre os compostos é única entre as amostras e, por possuírem propriedades químicas semelhantes, sua razão é praticamente constante ao longo do intemperismo (Douglas et al., 1996). Este tipo de avaliação é muito utilizada em derrames (Wang et al.,. 1999a, 1999b; Wang \& Fingas, 2003; Bence et al., 1996) quando a área atingida sofre aportes crônicos de hidrocarbonetos ou já foi objeto de liberações de outro tipo de petróleo ou produto.

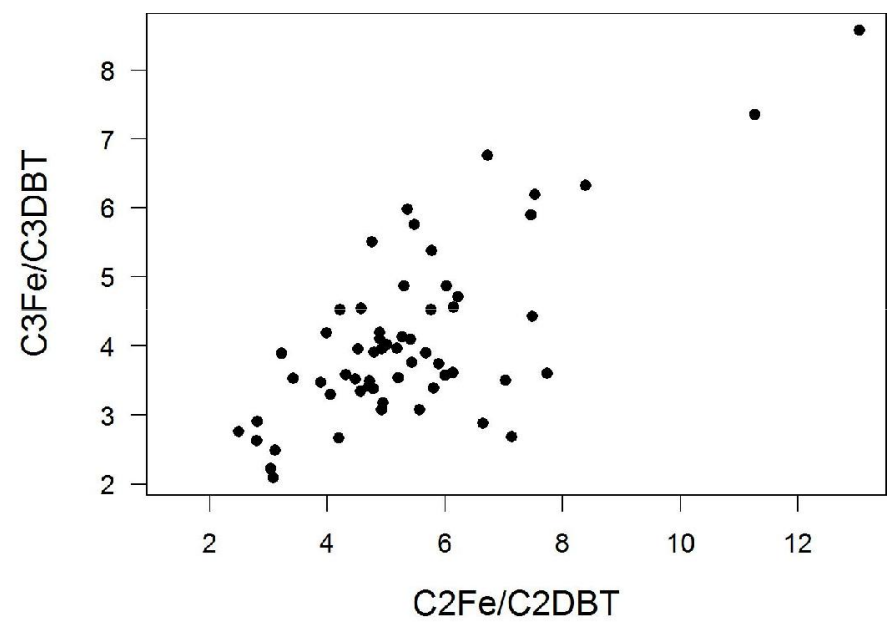

Figura 25 - Gráfico da razão C2Fe / C2DBT com a razão C3Fe / C3DBT 
O resultado das razões diagnósticas calculadas para os HPAs encontramse resumidas na Figura 26. Nesta figura também pode ser observado os limites determinados na literatura para estas razões.

Nem sempre foi possível realizar o cálculo das razões diagnósticas de fontes para as amostras. Compostos de maior peso molecular são menos abundantes nesta matriz e, na maioria das amostras, sua quantificação destes ocorreu próximo ao limite de detecção do método. Quando um dos compostos, ou ambos, apresentava-se abaixo do limite de detecção, a razão diagnóstica de fonte não pode ser calculada. $\mathrm{Na}$ razão $\mathrm{IPi} /(\mathrm{IPi}+\mathrm{BPe})$ todos os compostos estiveram abaixo do limite de quantificação. O composto Benzo(k)Fluoranteno não foi detectado em nenhuma amostra, o que não permitiu o cálculo da razão $\mathrm{BFI} /(\mathrm{BFI}+\mathrm{BePi})$.

$\mathrm{Na}$ relação $\mathrm{BaA} /(\mathrm{BaA}+\mathrm{Cr})$, por exemplo, espera-se que entre os compostos de massa 228 o mais estável termodinamicamente $(\mathrm{Cr})$ tenha maior abundância no petróleo em relação ao seu isômero menos estável (BaA) (Yunker et al., 2002; Gschwend \& Hites, 1981; Yunker et al., 2000). A quantidade de Criseno nas amostras analisadas foi adequada à quantificação. Infelizmente o mesmo não ocorreu com o Benzo(a)Antraceno, que mostrou com frequência valores abaixo do limite de quantificação, comprometendo o cálculo. Este mesmo padrão foi observado na avaliação das razões $A$ / $(F e+A), F I /(F I+P i)$, $\mathrm{BFI} /(\mathrm{BFI}+\mathrm{BePi})$ e $\mathrm{CO} /(\mathrm{CO}+\mathrm{C} 1) \mathrm{Fe} / \mathrm{A}$.

A maioria das razões só pode ser calculadas para menos de $50 \%$ das amostras analisadas. O problema no estabelecimento de índices nesta matriz, decorrente da escassez de determinados compostos, já foi observado por Wang et al. (1999b) e por Wagener et al. (2012) que propõem ferramentas alternativas para identificar e extrapolar a contribuição petrogênica a amostras ambientais.

O Índice Pirolítico, proposto por Wang et al. (1999a), foi o único a gerar resultados perfeitamente de acordo com os valores estabelecidos para esta matriz e foi calculado para todas as amostras. Segundo Wang et al. (1999a, 1999b) esta razão apresenta-se igual ou menor a 0,05 em materiais petrogênicos. A adequação para o cálculo, que constituiu em substituir os valores abaixo do limite de quantificação por zero, não comprometeu os resultados para o índice. Isto ocorre dada a grande diferença entre a concentração dos compostos de menor peso molecular e o limite de quantificação. Não se observa diferenças no gráfico que utiliza este índice ao optar por substituir o valor abaixo do limite de quantificação pelo valor do próprio limite. 

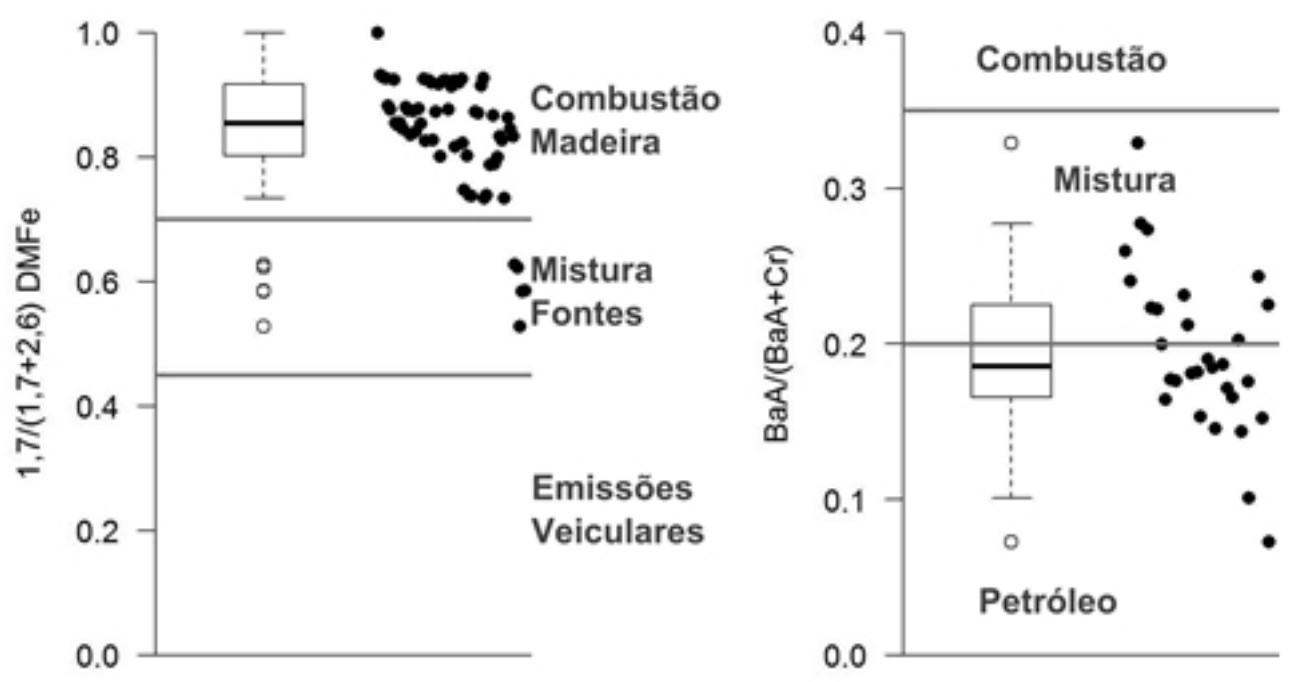

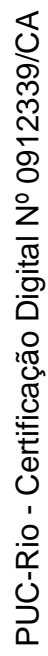
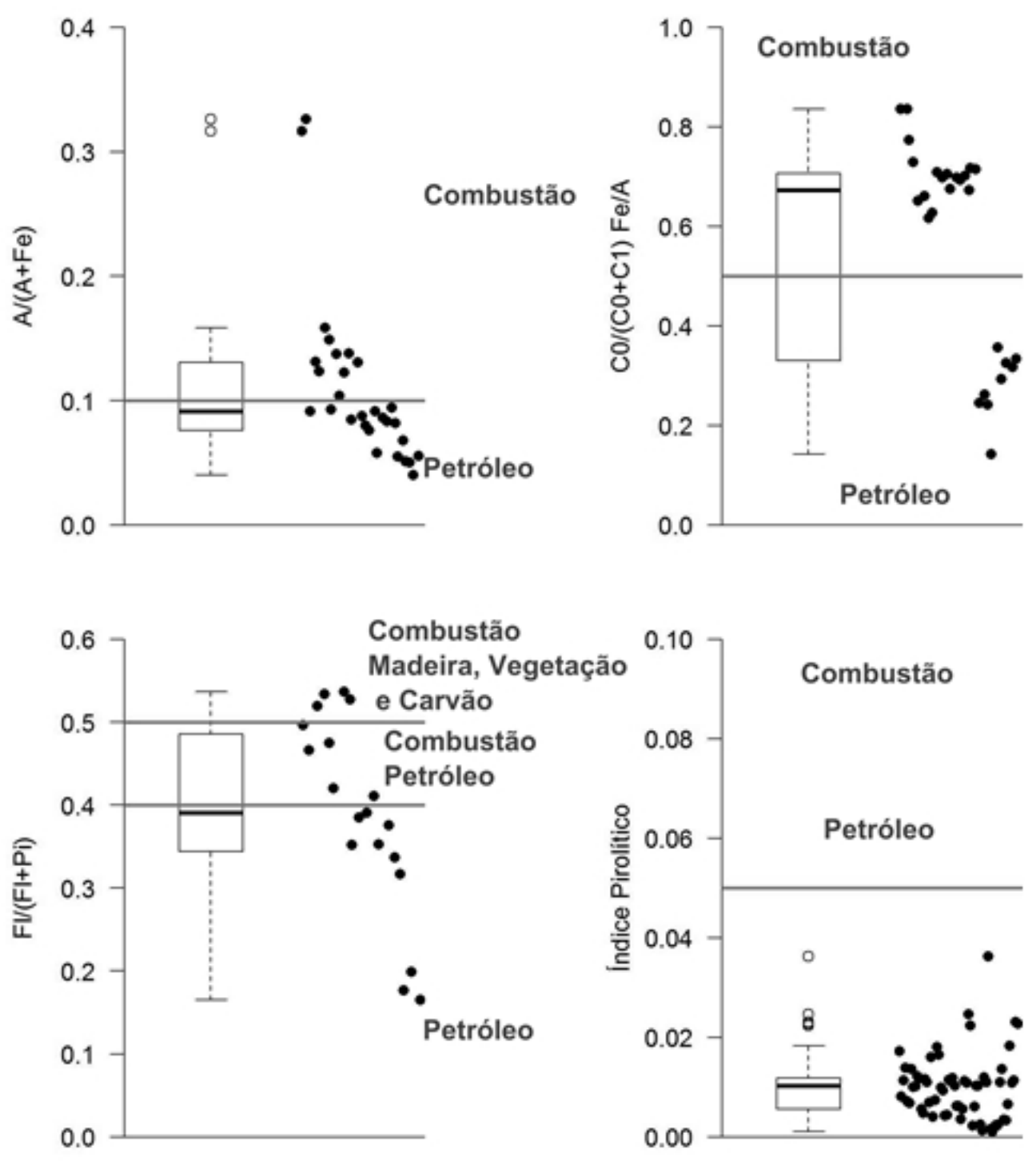

Figura 26 - Box-plot das razões diagnósticas de HPAs aplicadas às amostras de óleo, com a respectiva dispersão dos dados. 
Esse índice, diferente das demais razões diagnósticas de fontes, utiliza uma ampla gama de compostos e, segundo o autor (Wang et al., 1998), maior exatidão e menor incerteza do que as razões que utilizam compostos individuais. O índice pirolítico estaria menos sujeito a erros por flutuações de concentrações de um único composto dentro da série de HPAs. Ressalta-se que resultados obtidos são de amostras de petróleo e produtos de petróleo, sem qualquer efeito do intemperismo ao qual as mesmas estariam sujeitas no ambiente. Considerações sobre a dinâmica dos hidrocarbonetos no meio ambiente devem ser efetuadas

A razão $\mathrm{BaA} /(\mathrm{BaA}+\mathrm{Cr})$ para a maioria das amostras apresentou-se dentro do limite proposto por Yunker et al. (2002) para classificação de contribuição petrogênica $(<0,2)$. Os autores, baseados em 37 trabalhos diferentes envolvendo petróleo, produtos de petróleo, amostras de combustão e amostras ambientais, ajustam alguns limites pré-estabelecidos para as razões diagnósticas de fontes. Segundo este critério, sete observações aqui registradas, encontram-se na faixa de mistura entre petróleo e combustão (entre 0,2 e 0,35). Valores maiores que 0,5 para a razão $\mathrm{Fl} /(\mathrm{FI}+\mathrm{Pi})$ são considerados como indicativos de resíduos de combustão (Sicre et al., 1987; Baumard et al., 1998; Budzinski et al.,1997). Yunker et al. (2002) adequaram a faixa indicadora de resíduos de combustão de petróleo para valores a partir de 0,4 enquanto valores superiores a 0,5 foram tomados como indicativos de combustão de madeira, vegetação e carvão. Os produtos analisados neste estudo apresentaram valores nas três classes possíveis. Apenas nove dentre 19 observações realizadas mostraram-se fora dos limites estabelecidos para contribuição petrogênica $(<0,4)$.

A razão $A /(A+F e)$ apresentou valores superiores a 0,1 , indicando combustão em 11 de 29 determinações. Razões envolvendo os compostos de massa 178 (Fenantreno e Antraceno) tendem a ser menos efetivas na determinação de fontes de HPAs dada a pequena diferença termodinâmica entre seus constituintes (Yunker et al., 2000; Yunker et al., 2002).

A relação $\mathrm{C0} /(\mathrm{CO}+\mathrm{C} 1) \mathrm{Fe} / \mathrm{An}$ mostrou 9 das 29 determinações abaixo do limite de 0,5 , caracterizadas assim como petróleo. A razão $1,7 /(1,7+2,6)$ dimetilfenantreno indica majoritariamente combustão de madeira para as amostras.

Encontra-se na literatura exemplos de discrepâncias entre os limites estabelecidos e a matriz de análise, inclusive no Brasil. Meniconi et al. (2002) reportam valores inferiores a dez para a razão Fenantreno/Antraceno (Fe/A) em combustível marítimo (MF-380), do derrame de janeiro de 2000 na Baía de 
Guanabara. Os mesmos autores reportam valor maior que 1 para a razão Fluoranteno/Pireno (Fl/Pi) em óleo cru colombiano. Segundo a literatura a razão Fenantreno/Antraceno deve ser maior que 15 e razão Fluoranteno/Pireno menor que 1 para refletir a origem petrogênica (Sicre et al., 1987; Baumard et al., 1998; Gschwend \& Hites, 1981). Wang et al. (2001) reportaram em amostras de derrame valores para as razões de Fe/A e Benzo(a)Antraceno/Criseno que seriam erroneamente interpretados como provenientes de combustão. Calculando-se a razão $\mathrm{Fl} /(\mathrm{Fl}+\mathrm{Pi})$ nos dados do efluente da Estação de Tratamento de Efluentes (ETE) de Cabiúnas (Petrobras, 2002) obtêm-se valor superior a 0,5.

Ao extrapolar os limites das razões determinadas em petróleos e seus produtos derivados para o meio ambiente o problema se agrava. Os hidrocarbonetos podem ser introduzidos de várias maneiras e a assinatura de uma determinada fonte pode mascarar ou diluir outra (Wang et al., 1999a). Somam-se a isto as alterações decorrentes do intemperismo, que ocorre de maneira diferenciada entre os compostos. 


\section{3 \\ Concentração de hidrocarbonetos em amostras de material particulado atmosférico $\left(\mathrm{PM}_{2,5}\right)$.}

Os resultados da quantificação dos hidrocarbonetos alifáticos e aromáticos encontram-se detalhados em anexo. A recuperação média das extrações foi de $77,6 \pm 18,5 \%(40-143,8 \%)$ para o $\mathrm{nC} 30 \mathrm{~d}_{62}$ e de $91,1 \pm 17,5 \%(51,5-148 \%)$ para o p-terfenil- $d_{14}$. Nos poucos casos em que houve recuperações abaixo de $40 \%$ o resultado foi descartado. Nas recuperações acima de $120 \%$ observou-se a coeluição do padrão subrogado com compostos provenientes da amostra.

Nestes casos, para a fração alifática verificou-se a recuperação pelo segundo padrão subrogado adicionado, o $\mathrm{nC} 16 \mathrm{~d}_{34}$. Enquanto que para os HPAs foi verificado o espectro no tempo de retenção do composto subrogado, corroborando a coeluição. A variação da recuperação das amostras consideradas para este trabalho encontra-se na Figura 27. O percentual médio de hidrocarbonetos nos extratos dos ensaios em branco em relação ao extrato das amostras de particulado atmosférico foi de 1,08 $\pm 1,62 \%$. Devido a problemas na amostragem em alguns períodos do ano, o número de amostras por estação não é exatamente o mesmo.
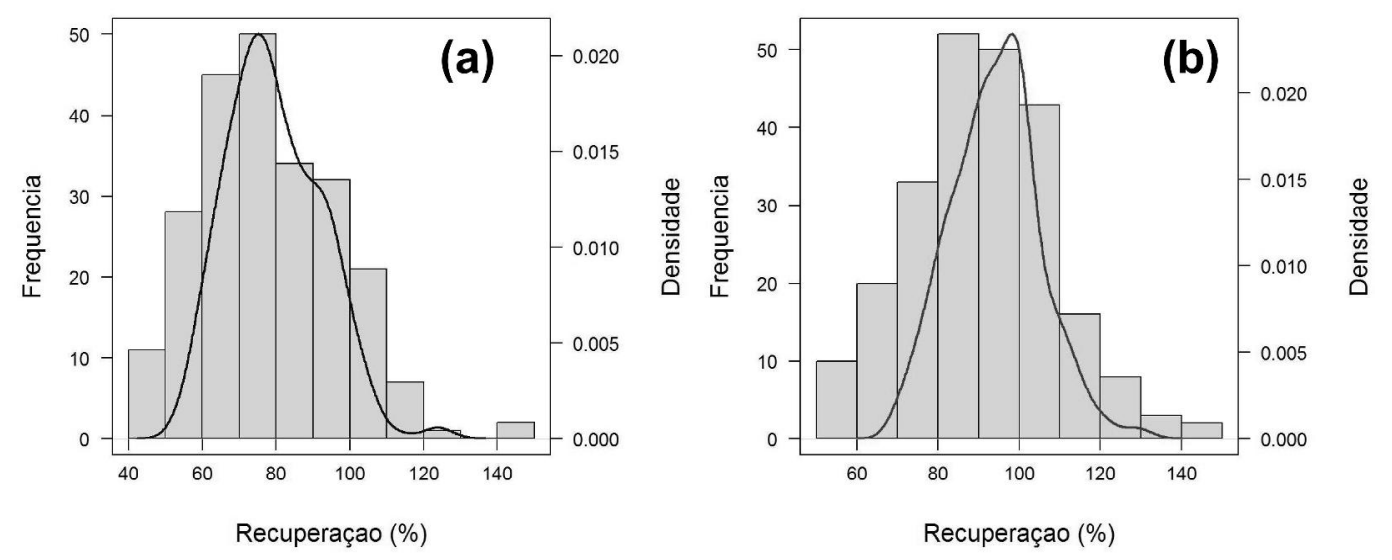

Figura 27 - Histogramas do percentual de recuperação dos compostos subrogados adicionados às amostras de material particulado atmosférico - (a) nC30d $_{62}$ - (b) p-terfenil- $d_{14}$.

A concentração média, desvio padrão, mediana e faixa de concentração dos parâmetros da fração alifática estão sumarizados na Tabela 5. Os dados encontrados estão dentro da faixa de outros estudos no Brasil. Azevedo et al. (1999) reportam valores de alifáticos totais para a atmosfera do Rio de Janeiro 
entre 58 e $581 \mathrm{ng} \mathrm{m}^{-3}$, com maior contribuição da Mistura Complexa Não Resolvida. Souza (2006) descreve médias sazonais da soma de n-alcanos para a Região Metropolitana de São Paulo de 10,7 a 34,7 $\mathrm{ng} \mathrm{m}^{-3}$. Vasconcellos et al. (2010) reporta, para cada um dos dois anos de amostragem, valores médios da soma de n-alcanos de 36,4 e 67,3 $\mathrm{ng} \mathrm{m}^{-3}$ para a cidade de São Paulo, 67,8 e $35,1 \mathrm{ng} \mathrm{m}^{-3}$ para Piracicaba e $289 \mathrm{ng} \mathrm{m}^{-3}$ para estação localizada na Mata Atlântica amostrada em um único período. Azevedo et al. (2002) encontraram na área do Município de Campos dos Goytacazes concentrações de hidrocarbonetos alifáticos entre 7,33 e $180 \mathrm{ng} \mathrm{m}^{-3}$.

Tabela 5 - Concentração média, desvio padrão, mediana e faixa de concentração dos parâmetros da fração alifática, em $\mathrm{ng} \mathrm{m}^{-3}$, para o particulado atmosférico $\left(\mathrm{PM}_{2,5}\right)$ da Região Metropolitana do Rio de Janeiro no ano de 2011.

\begin{tabular}{lcccc}
\hline & Média & Desvio Padrão & Mediana & Faixa \\
\hline n-alcanos & 27,8 & 60,34 & 12,4 & nd -697 \\
HR & 91,3 & 230 & 42,3 & nd - 2935 \\
MCNR & 299 & 596 & 174 & nd - 7935 \\
Alifáticos Totais & 390 & 769 & 225 & $0,4316-9413$
\end{tabular}

Para comparação dos dados de diferentes localidades da América do Sul podem-se usar as concentrações médias de n-alcanos reportada por Vasconcellos et al. (2011) para a cidade de São Paulo $\left(67,3 \pm 40,2 \mathrm{ng} \mathrm{m}^{-3}\right)$, Bogotá $\left(37,6 \pm 38,9 \mathrm{ng} \mathrm{m}^{-3}\right)$ e Buenos Aires $\left(229 \pm 47,4 \mathrm{ng} \mathrm{m}^{-3}\right)$. Cincinelli et al. (2007) obtiveram valores para a soma de n-alcanos entre 48,9 e $276 \mathrm{ng} \mathrm{m}^{-3} \mathrm{em}$ amostras de Prato, Itália. Pietrogrande et al. (2011) reportam para Augsburg, Alemanha, a variação do total de n-alcanos de 0,65 a $82 \mathrm{ng} \mathrm{m}^{-3}$.

Locais que conhecidamente apresentam pior qualidade do ar contêm concentrações em outra ordem de grandeza. Li et al. (2013) encontraram médias sazonais para a soma de n-alcanos entre 543,9 e $851,7 \mathrm{ng} \mathrm{m}^{-3}$ em Pequim, China. Xie et al. (2009), também na China, reportam em Baoji concentração de $\mathrm{n}$-alcanos na faixa de 232 a $3583 \mathrm{ng} \mathrm{m}^{-3}$ no inverno e, para a primavera, de 124 a $1160 \mathrm{ng} \mathrm{m}^{-3}$.

Há particularidades a considerar em qualquer comparação de dados, especialmente na matriz atmosférica. Um número de amostras maior, contemplando todo um ano de coleta, proporciona maior probabilidade de observação de um evento esporádico de maior concentração. Poucos estudos, 
especialmente no Brasil, apresentam um número tão elevado de amostras distribuídas ao longo de um ano de coleta, como é o caso do presente trabalho.

Nem todos os trabalhos utilizados nas comparações seguiram a norma ABNT e, portanto, outras frações de material particulado podem ter sido coletadas, interferindo no resultado. A maioria dos estudos de hidrocarbonetos na atmosfera encontrados para o Brasil analisaram frações de MP de tamanhos maiores do que a analisada neste estudo.

Particularidades sobre o local e período de amostragem também são importantes. Uma das estações de coleta de Azevedo et al. (1999), por exemplo, foi no Túnel Rebouças. As condições particulares de qualidade do ar e circulação nesta estação não podem ser extrapoladas a áreas abertas. Souza (2006) analisou 54 amostras na Região Metropolitana de São Paulo em um período que vai de 2001 a 2004, enquanto no presente estudo foram realizadas aproximadamente 240 observações distribuídas em seis estações ao longo de um único ano. Estudos pontuais como os de Azevedo et al. (1999) e de Azevedo et al. (2002) se prestam à comparação de faixas, mas, além das diferenças entre a frações amostradas, o período e freqüência não são equivalentes.

A variação da concentração dos parâmetros por ponto de amostragem pode ser visualizada na Figura 28 e na Figura 29. Em todas as estações amostradas existem eventos de maior concentração que se destacam da maioria das observações (Figura 28). Estes dados extremos (outliers) são os responsáveis pelo alto desvio padrão e pelas diferenças entre as médias e medianas.

Os dados considerados outliers, apesar de sua influência, não foram retirados durante os tratamentos estatísticos. Entende-se que eventos de maior concentração ocorrem periodicamente no ambiente e fazem parte do histórico do ponto amostrado. Todas as considerações estatísticas de significância apresentadas neste estudo referem-se a 0,05 como valor de $\alpha$, ou $1-\alpha=0,95$.

O primeiro passo da análise estatística constituiu em verificar a normalidade da distribuição da soma de n-alcanos, Hidrocarbonetos Resolvidos, Mistura Complexa Não Resolvida e Alifáticos Totais nas estações de coleta. Após observar-se que os parâmetros não apresentaram distribuição normal optou-se por modificar os dados pela Transformação de Box-Cox (Box e Cox, 1964). Este procedimento é uma das possíveis formas de contornar o problema de dados que não obedecem aos pressupostos da análise de variância (Aitchison, 2003). 

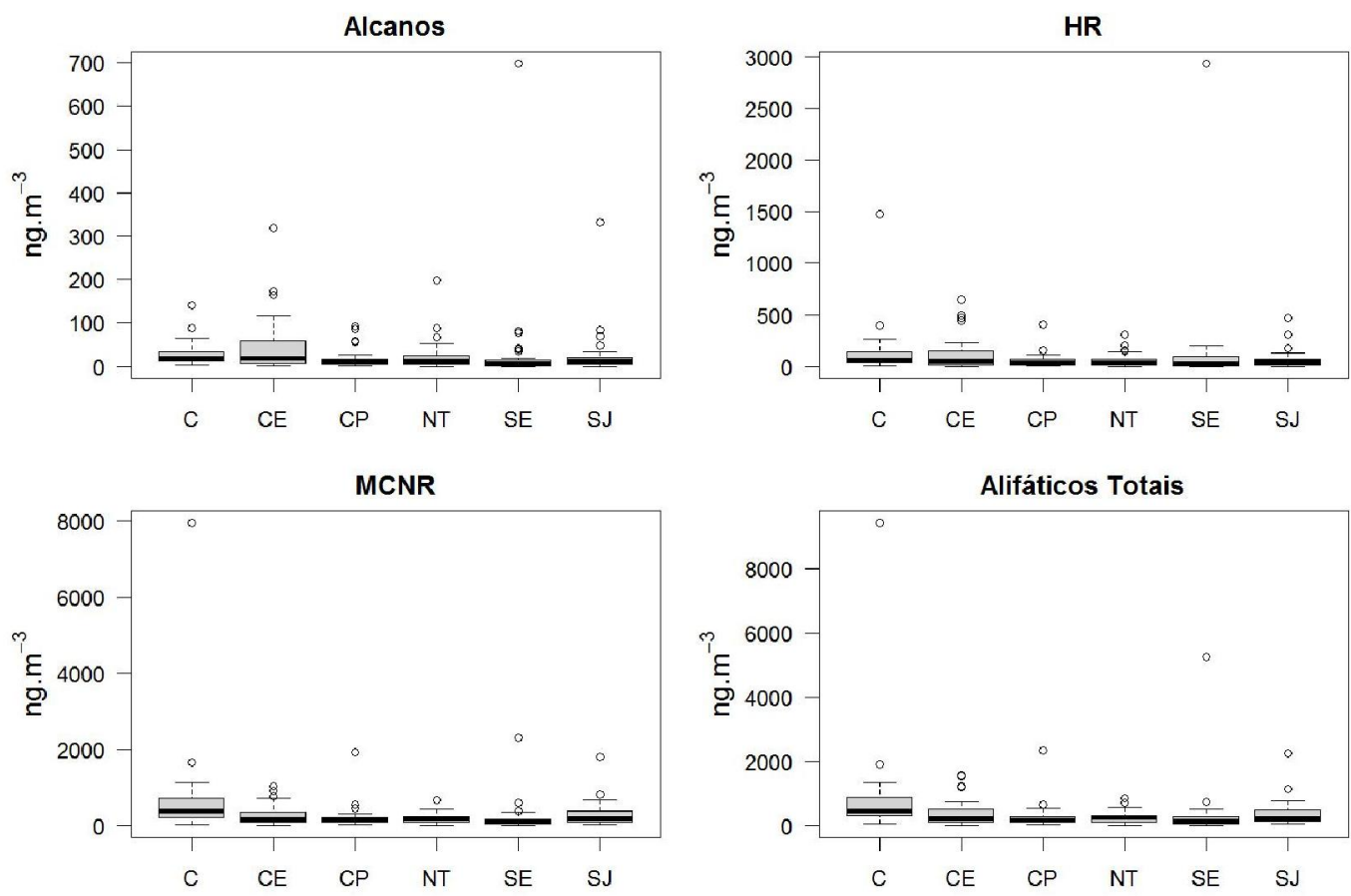

Figura 28 - Comparação das concentrações de hidrocarbonetos alifáticos entre as estações para amostras de material particulado atmosférico $\left(\mathrm{PM}_{2.5}\right)$ coletadas em 2011
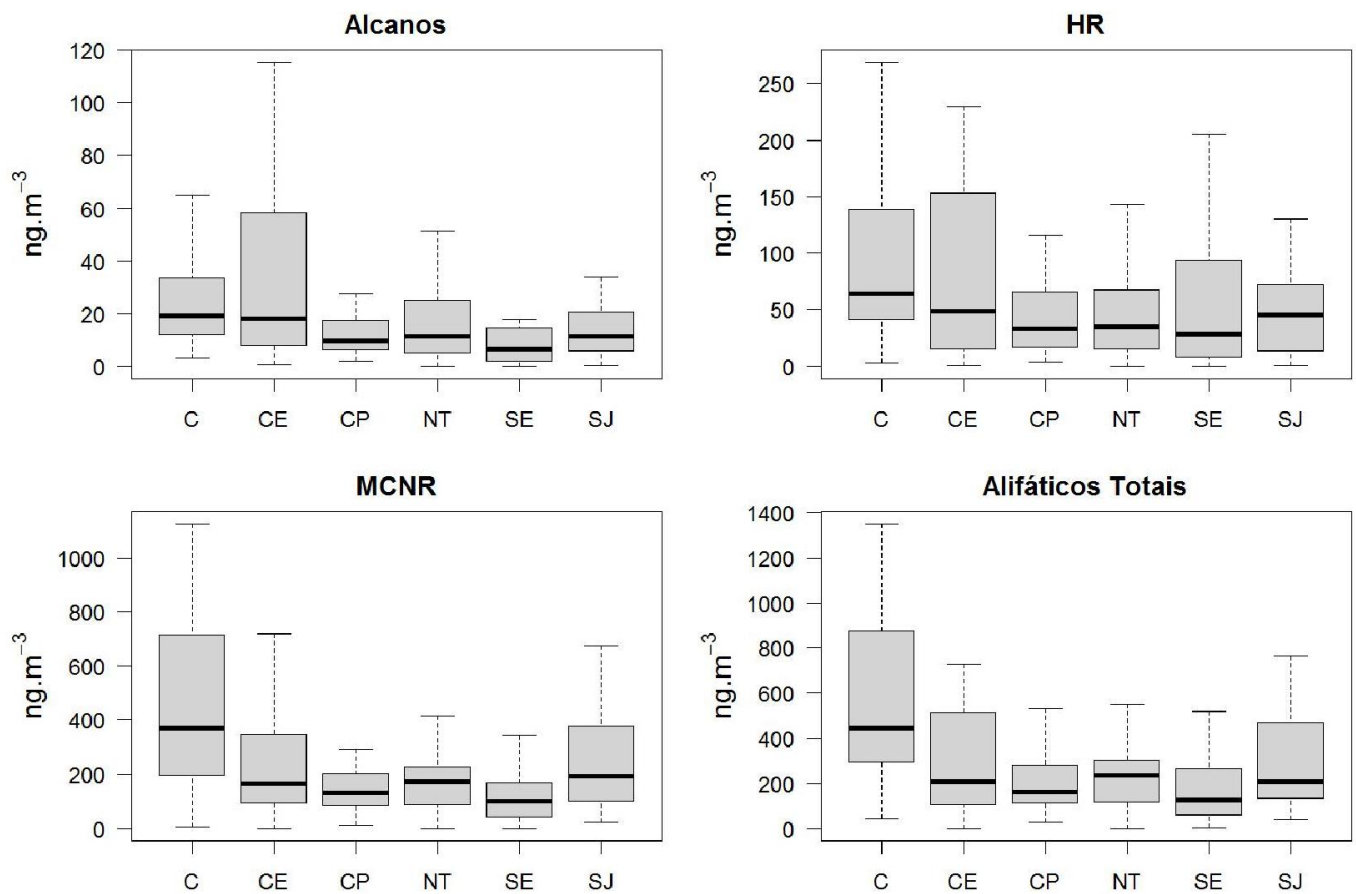

Figura 29 - Comparação das concentrações de hidrocarbonetos alifáticos entre as estações para amostras de material particulado atmosférico $\left(\mathrm{PM}_{2.5}\right)$ coletadas em 2011. Foram excluídos os dados extremos para melhor visualização. 
O teste de normalidade aplicado aos dados após a transformação manteve as indicações anteriores e conseqüentemente, foi aplicada a estatística nãoparamétrica aos dados brutos da fração alifática. Considerando, portanto, que as amostras apresentam tamanhos diferentes, não são pareadas, são independentes e não seguem a distribuição normal, utilizou-se o teste de Kruskal-Wallis (Kruskal \& Wallis, 1952), cuja equivalência paramétrica é o teste ANOVA. Neste, a hipótese nula é que as populações a partir da qual as amostras se originam têm a mesma mediana. As comparações entre a soma de n-alcanos, a concentração de Hidrocarbonetos Resolvidos (HR), Mistura Complexa Não Resolvida (MCNR) e Alifáticos Totais apresentaram diferença estatística entre as estações. Isto significa que pelo menos uma das estações é diferente de outra, sem indicar onde as diferenças ocorrem ou quantas diferenças de fato ocorrem.

Para determinar as diferenças entre estações adotou-se como teste posthoc ao Kruskal-Wallis as comparações múltiplas pelo Teste Wilcoxon da Soma dos Pontos, também chamado de Wilcoxon-Mann-Whitney. É um teste de permutação que usa a soma das posições ordenadas, testando a igualdade das medianas. O valor de $\mathrm{p}$ (probabilidade) obtida pelo teste foi ajustado pelo método de Bonferroni (Dunn, 1959; Dunn, 1961).

Um dos problemas decorrentes dos testes de comparações múltiplas é que se aumenta a chance de rejeitar a hipótese nula quando esta é verdadeira, o erro tipo I (Sousa et al., 2012). A correção de Bonferroni é um dos métodos usados para contornar este problema e, além de ser um dos mais simples, também é considerado o mais conservativo (Aickin \& Gensler, 1996).

Os resultados encontrados indicaram diferenças para o total de alifáticos e MCNR entre a estação do Centro (C) e todas as demais. Para estes dois parâmetros também foram observadas diferenças entre as estações de São João de Meriti (SJ) e Seropédica (SE). Para a soma de n-alcanos a estação de Seropédica (SE) apresenta diferenças em relação ao Centro (C) e Campos Elíseos (CE). Os hidrocarbonetos resolvidos (HR) possuem diferenças estatísticas entre a estação do Centro $(\mathrm{C})$ e às estações de Copacabana $(\mathrm{CP})$, Niterói (NT) e Seropédica (SE).

As diferenças obtidas comprovam que as estações do Centro e São João de Meriti, sujeitas a um tráfego mais intenso, destacam-se das demais. Especialmente considerando comparações em relação à estação de Seropédica, considerada como controle pela menor influência antrópica. Nestas duas estações é especialmente marcante a maior presença da Mistura Complexa Não 
Resolvida em relação a todas as demais, o que acarreta uma distribuição similar para os alifáticos totais.

As concentrações nas estações de Niterói, Copacabana e Seropédica são praticamente equivalentes. Em Campos Elíseos (CE), apesar das maiores concentrações de n-alcanos e Hidrocarbonetos Resolvidos, há uma menor concentração de Mistura Complexa Não Resolvida quando comparada às estações do Centro (C) e São João de Meriti (SJ). Esta estação só mostrou diferença estatisticamente significante para a soma de n-alcanos em relação à estação controle, Seropédica. Azevedo et al. (1999) em estudo na cidade do Rio de Janeiro já relacionavam a intensidade do fluxo de veículos à concentração de hidrocarbonetos alifáticos, com alta contribuição da MCNR.

Deve-se considerar que a comparação entre as estações engloba todos os dados para o ano de 2011. Em cada estação, como será demonstrado ao longo do trabalho, houve períodos em que não ocorreu coleta de amostras. Estes períodos não foram os mesmos nas diferentes estações de coleta e tampouco o número total de amostras coletadas no ano em cada ponto.

A concentração média da soma dos 16 HPAs considerados prioritários pela agência ambiental americana (EPA) e a soma dos 38 HPAs quantificados encontram-se na Tabela 6. Há um menor desvio padrão relativo para estes dados em comparação à fração alifática, e menores diferenças entre os valores de médias e medianas.

Tabela 6 - Concentração média, desvio padrão, mediana e faixa de concentração dos HPAs, em ng $\mathrm{m}^{-3}$, da Região Metropolitana do Rio de Janeiro no ano de 2011.

\begin{tabular}{lcccc}
\hline & Média & Desvio Padrão & Mediana & Faixa \\
\hline 16 HPAs EPA & 2,83 & 2,39 & 2,18 & $0,15-15,5$ \\
Soma 38 HPAs & 4,42 & 3,25 & 3,52 & $0,27-19,3$ \\
\hline
\end{tabular}

Alguns exemplos de concentração de HPAs em particulado atmosférico podem ser visualizados na Figura 30. Nesta comparação aplicam-se, mais uma vez, as considerações já discutidas para a fração alifática. Considerações estas como a metodologia de coleta, período amostrado, tamanho da partícula e local de amostragem. Diferente da fração alifática, o período de coleta pode ser decisivo na identificação da composição média das amostras, dadas as diferenças no tempo de meia vida de alguns compostos (Martinis et al., 2002). 


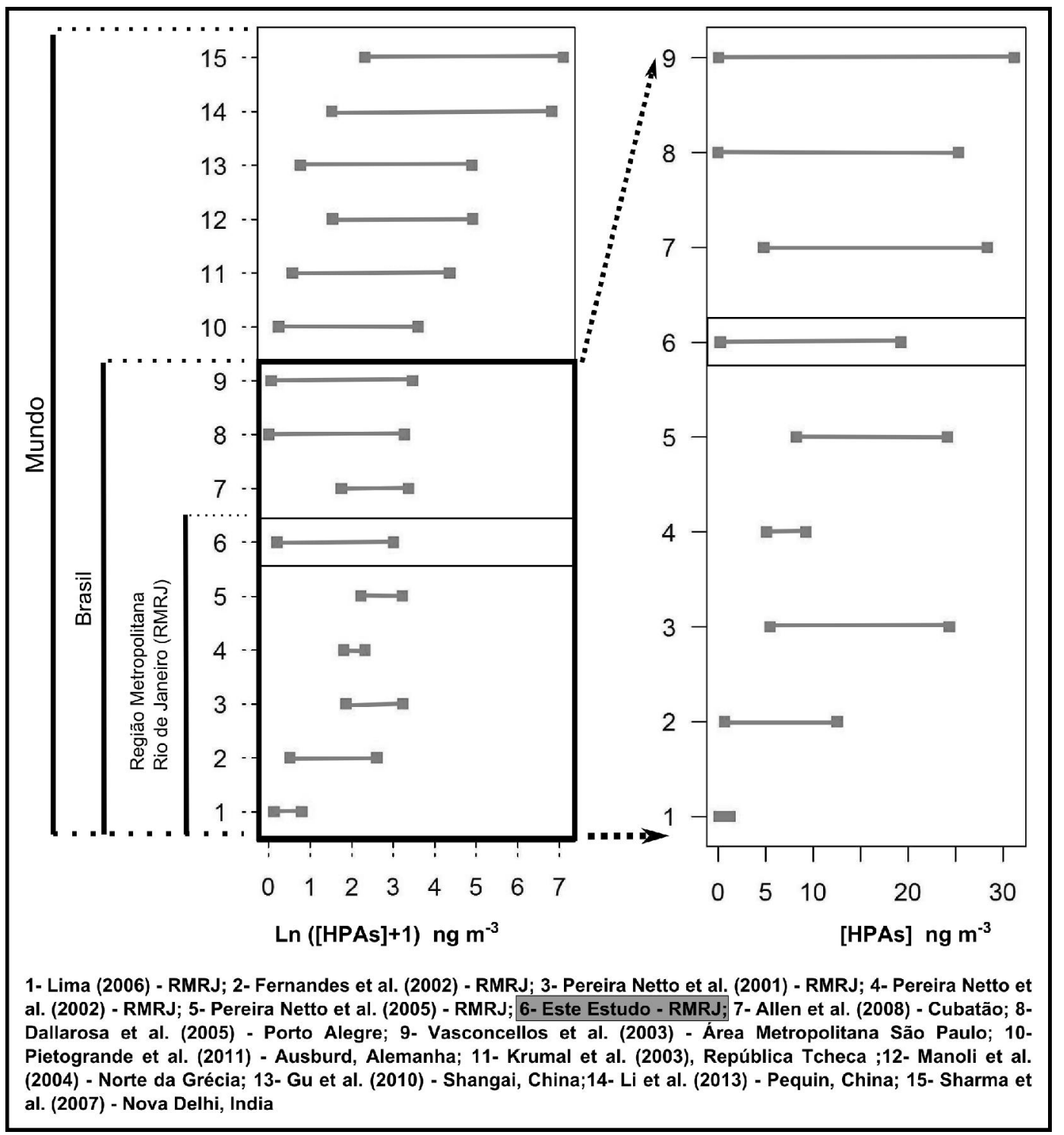

Figura 30 - Comparação da concentração total de hidrocarbonetos policíclicos aromáticos (HPAs) em amostras de material particulado no mundo e no Brasil (Ln ([HPAs]+1) $\mathrm{ng} \mathrm{m}^{-3}$ ) e apenas no Brasil ([HPAs] $\mathrm{ng} \mathrm{m}^{-3}$ ).

A maioria dos estudos na literatura reporta a quantificação de poucos HPAs quando comparada a este trabalho. Em geral quantificam-se os 16 HPAs prioritários, ou menos. Para comparação das concentrações nas estações do Centro e Copacabana isto é especialmente relevante. Nestes dois pontos os 16 HPAs prioritários representam, em média, apenas 45\% (Centro) e 56\% (Copacabana) do total quantificado. Nas demais estações estes percentuais alcançaram um valor médio em torno de $70 \%$.

A variabilidade encontrada por Lima (2006) para a cidade de Niterói foi determinada pela amostragem contínua em um único ponto, no campus da Universidade Federal Fluminense (UFF). Fernandez et al. (2002) coletou apenas 
no período de verão de 1998/1999 desde o Alto da Boa Vista até a Avenida Brasil e apenas em dias de semana.

Pereira Netto et al. (2001) coletaram poucos pontos para comparar as condições nas cidades de Niterói e Rio de Janeiro, e apenas no verão. A comparação entre as cidades baseou-se em coleta no campus da UFF e da FIOCRUZ. Os mesmos autores voltam a coletar apenas na cidade de Niterói, no inverno (Pereira Netto et al., 2002), para comparação sazonal.

Pereira Netto et al. (2005) estudaram a variação diurna e noturna dos HPAs. Por lógica a concentração reportada para o período diurno, onde ocorre a maior emissão de poluentes, supera aquela resultante da integração no período de 24 horas. Machado et al. (2009) coletaram apenas PM 10 entre agosto de 2006 e fevereiro de 2007 na estação rodoviária Prefeito José Carlos Lacerda (Duque de Caxias) e determinou os 16 HPAs obtendo média de $2,63 \mathrm{ng} \mathrm{m}^{-3}$ para 33 amostras. Marques et al. (2009) também coletou $\mathrm{PM}_{10}$, no campus da Fiocruz, obtendo média de $8,99 \mathrm{ng} \mathrm{m}^{-3}$ para os 16 HPAs.

Fernandez et al. (2002) e Lima (2006) associam, para a Região Metropolitana do Rio de Janeiro, o decréscimo da concentração e HPAs ao incentivo do uso do etanol. Vasconcellos et al. (2011) sugerem para a cidade de São Paulo a mesma causa de variação temporal. Abrantes et al. (2009) descrevem emissão de HPAs $92 \%$ em média menor para o etanol comparado à gasolina. Quitério et al. (2007) também sugeriram que mudanças no combustível tenham causado uma melhora na qualidade do ar no Rio de Janeiro ao longo do tempo. Entretanto os mesmos autores ressaltam que as diferenças existentes nos pontos de amostragem e período de cada estudo dificultam tal afirmação.

Avaliações com os objetivos acima também dependem da caracterização detalhada do consumo de combustível de cada localidade. Allen et al. (2008) consideram que, apesar do etanol produzir menores emissões de HPAs, esta informação tem pouco peso em seu trabalho, dadas as características da frota em Cubatão, preferencialmente movida a diesel. Estes autores encontraram faixa de concentração próxima a este estudo.

Destaca-se, mais uma vez, a importância de uma avaliação criteriosa na comparação de dados. O presente estudo inclui um número amostral muito maior do que os acima mencionados e, portanto, aqui estão inseridas concentrações de pico que ocorrem esporadicamente, em especial na estação de Campos Elíseos. Os dados de Allen et al. (2008) apresentam uma ampla faixa de variação com distribuição uniforme dos dados. As concentrações reportadas no presente estudo são baixas com eventos ocasionais de maiores 
concentrações. A simples comparação de faixas entre os dois trabalhos sugere que estas são equivalentes. Criteriosamente conclui-se que não se pode comparar a qualidade do ar no Rio de Janeiro àquela de Cubatão.

As concentrações observadas no presente trabalho são menores do que a média de $10,8 \pm 3,07 \mathrm{ng} \mathrm{m}^{-3}(5,63-17,3)$ para os HPAs reportada em material particulado fino para a cidade de São Paulo (Bourotte et al., 2005). Azevedo et al. (2002) mostram uma faixa de variação de HPAs de 0,14 a 336,17 $\mathrm{ng} \mathrm{m}^{-3}$, com maiores concentrações associadas à queima de cana-de-açúcar. Os dados obtidos pelos autores relacionados a esta atividade são mais elevados do que os reportados no presente estudo para a Região Metropolitana do Rio de Janeiro e do que os de outras localidades brasileiras (Allen et al., 2008; Dallarosa et al., 2005; Vasconcellos et al., 2003) e de algumas no exterior (Pietrogrande et al. 2011; Krumal et al., 2013; Manoli et al., 2004; Gu et al., 2010).

Os dados de concentração de HPAs por estação, assim como foi verificado para a fração alifática, não apresentam distribuição normal. Neste caso, a transformação de Box-Cox tornou possível a diferenciação da concentração das estações utilizando a ferramenta paramétrica ANOVA. Após o teste indicar diferenças entre os pontos utilizou-se o teste de Tukey para obter a diferença honestamente significativa (Figura 31). O teste não demonstrou diferença em apenas 5 combinações dentre as 15 possíveis. São estas: o Centro com São João de Meriti (C-SJ), Niterói com Campos Elíseos (NT-CE) e com Copacabana (NT-CP), Copacabana e Seropédica (CP-SE) e São João de Meriti com Campos Elíseos (SJ-CE). As comparações obtidas são similares às da fração alifática.
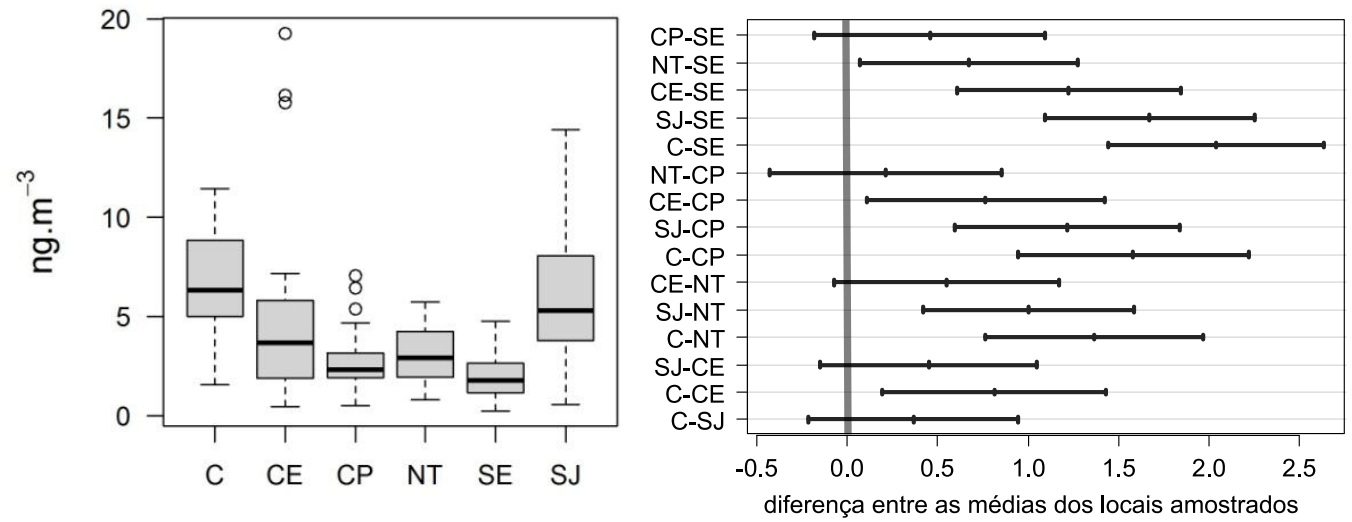

Figura 31 - Concentração de HPAs entre os pontos amostrados de material particulado atmosférico $\left(\mathrm{PM}_{2.5}\right)$ no ano de 2011 e diferença honestamente significativa das médias dos locais amostrados pelo Teste de Tukey. 
Diferenças entre a cidade de Niterói e do Rio de Janeiro já tinham sido reportadas por Lima (2006) e Pereira Netto et al. (2002). Os dados de Copacabana, Niterói e Seropédica são comparáveis aos obtidos por Azevedo et al. (1999) para a Floresta da Tijuca e Quinta da Boa Vista. As diferenças entre as concentrações obtidas por Lima (2006) e as encontradas em Niterói podem ser explicadas pela localização das estações. A estação de coleta em Niterói está localizada na Rua Teixeira Freitas, uma área interna de fluxo intenso de veículos. A estação de coleta de Lima (2006) localiza-se no campus da UFF que, apesar de sofrer influência do fluxo de veículos do centro da cidade de Niterói, se encontra próximo a Baía de Guanabara, onde, portanto, há maior capacidade de dispersão de poluentes.

As diferenças observadas por diversos autores (Azevedo et al. 1999. Pereira Netto et al., 2001; Pereira Netto et al., 2002; Machado et al., 2009; Marques et al., 2009; Quitério et al., 2007) em relação à variabilidade dos contaminantes associada ao fluxo de veículos também aparece refletida nas estações deste estudo.

\section{4 \\ Relação entre a concentração de hidrocarbonetos em amostras de material particulado atmosférico $\left(\mathrm{PM}_{2,5}\right)$ e variáveis complementares.}

A concentração de material particulado e poluentes na atmosfera é influenciada por uma série de fatores neste compartimento dinâmico. Encontramse, por exemplo, registros associando a variação de poluentes a chuvas, temperatura, radiação solar e velocidade dos ventos (Lopes \& Andrade, 1996. Panther et al., 1999; Esen et al., 2008; Trindade et al., 1980; Tham et al., 2008). Somado as condições climáticas e as fontes pontuais e móveis de emissão, alterações ocasionais nas emissões também podem alterar as concentrações na atmosfera (Amador-Muñoz et al., 2011), o que aumenta a complexidade de interpretação deste sistema e dificulta ainda mais sua avaliação. Este subcapítulo busca estabelecer padrões ou tendências que influenciaram a distribuição das concentrações por estação ao longo do ano.

Inicialmente buscou-se estabelecer a relação entre as variáveis ambientais e a quantidade de material particulado atmosférico. Na Figura 32 observa-se a 
variação do material particulado $\left(\mathrm{PM}_{2,5}\right)$ e da pluviosidade para a estação de Campos Elíseos durante o ano de 2011.
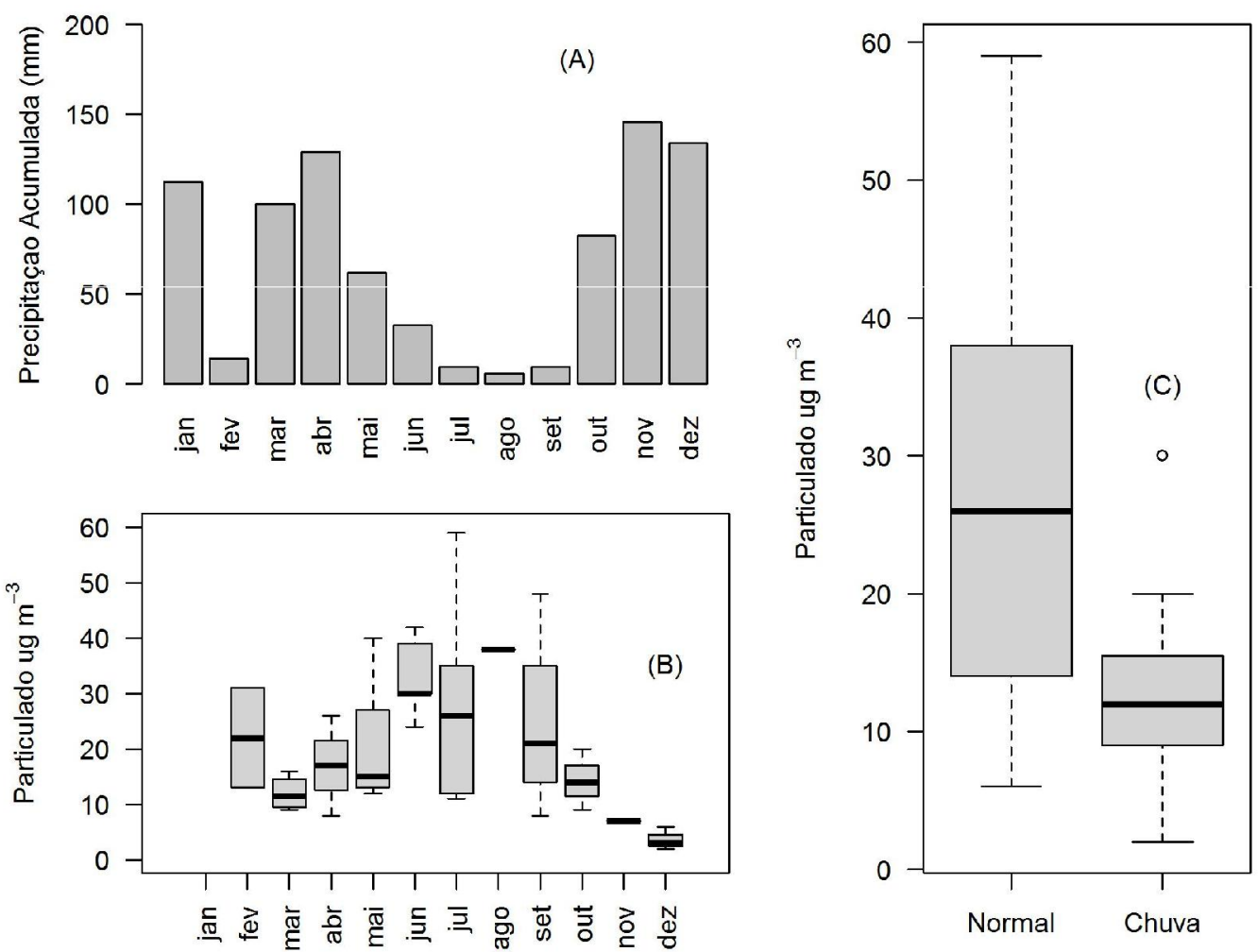

Figura 32 - Variação anual da precipitação acumulada da Estação do Sistema Alerta Rio de Irajá (A), concentração do material particulado para a Estação de Campos Elíseos (B) e box-plot da concentração de material particulado em relação a ocorrência de chuvas considerando o período de 48 horas anterior ao fim da amostragem (C).

A variação sazonal de material particulado associado aos períodos de chuvas é evidente. Entretanto existem particularidades a considerar no tratamento dos dados, como a influência dos eventos de precipitação na concentração de material particulado e o intervalo de amostragem. Os dados de material particulado possuem intervalos maiores entre os registros, além de haver ausência de dados em algumas ocasiões. Os registros de pluviosidade, por outro lado, apresentam maior freqüência durante todo o ano.

Uma das alternativas testadas foi tratar os dados usando médias mensais ou medianas. Entretanto este tipo de avaliação é dificultada pela carência ou total ausência de observações em alguns meses. No caso de Campos Elíseos, retratado na Figura 32, os dados das 5 (cinco) medições de junho teriam o mesmo peso da medição única de agosto e novembro. A comparação dos 
parâmetros por este tipo de abordagem não foi possível em face de descontinuidade e variabilidade observada nos registros.

O efeito da pluviosidade também não pode ser relacionado à concentração de material particulado pelo valor de precipitação acumulada. Os valores elevados de precipitação no final de abril citados no subcapítulo 5.1, por exemplo, não podem ser utilizados para descrever a concentração de material particulado no Centro, com cinco diferentes observações distribuídas regularmente durante o mês. $O$ efeito da sazonalidade sobre os parâmetros observado Figura 32a e Figura 32b ocorre porque a precipitação acumulada normalmente reflete a freqüência mensal de chuvas, a qual influencia na quantidade de material particulado.

Buscou-se então relacionar a pluviosidade acumulada no período de 48 horas anterior ao final da coleta à quantidade de material particulado. As relações descritas neste subcapítulo foram estabelecidas pelo coeficiente de correlação de Spearman. Esta é uma medida que equivale ao coeficiente de correlação de Pearson aplicado a dados ordenados. O coeficiente de correlação de Spearman $\left(r_{\mathrm{s}}\right)$ expressa a intensidade e o sentido da relação monótona que existe entre duas variáveis numéricas. Este coeficiente não exige que a relação seja linear, basta que as duas sequências evoluam no mesmo sentido.

Não há correlação significativa $\left(r_{s}\right)$ entre a precipitação acumulada, considerando-se o período de 48 horas anterior ao fim da coleta, e a concentração de material particulado. Provavelmente porque a precipitação por si só já promove a remoção das partículas na atmosfera. Esta possibilidade é confirmada pela concentração registrada no fim de abril de 2011, durante o evento extremo de precipitação, a qual se assemelha aos valores observados em outros eventos de chuva durante o ano.

Desta forma optou-se por dividir qualitativamente as observações segundo a ocorrência ou não de precipitação, mantendo-se o critério das 48 horas anterior ao fim da coleta (Figura 32c). A avaliação estatística para determinar as diferenças entre as populações de dados, assim como as demais comparações avaliadas neste item, seguiram os mesmos procedimentos descritos no subitem anterior. A única adaptação, nos casos onde se pode utilizar estatística paramétrica, foi a inclusão do teste t para diferenciar as duas distribuições.

Copacabana foi a única estação que não apresentou diferença da concentração de $\mathrm{PM}_{2,5}$ entre períodos normais e de eventos de precipitação. Apesar de não ser estatisticamente significativa observa-se pelos dados que esta variação não deve ser descartada (Figura 33). Entre as possíveis 
explicações pode-se citar o critério adotado para estabelecer os grupos. $\mathrm{Na}$ Figura 32c existe uma observação de maior concentração, considerada outlier, associada à ocorrência de chuva. Uma análise meticulosa dos dados, no entanto, revela que a chuva iniciou-se no dia da coleta às 23 horas. Em Niterói a observação de maior concentração nos dias considerados de chuva teve o início da precipitação registrado às 17:15 horas. Este tipo de observação ocorre em praticamente todas as estações em diferentes horários. Soma-se a isto o fato da maior concentração registrada em Copacabana para os dias de chuva corresponder a um evento de precipitação inferior a $1 \mathrm{~mm}$ ocorrido entre 12 e 13 horas no dia de coleta.

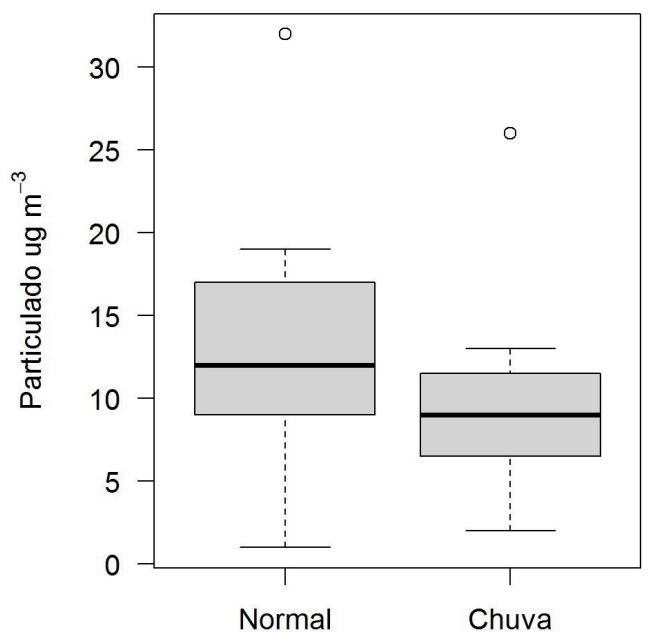

Figura 33 - Box-plot da concentração de material particulado em relação a ocorrência de chuvas considerando o período de 48 horas anterior ao fim da amostragem para Copacabana

Neste ponto destaca-se a importância de monitoramentos contínuos de longo prazo. Um maior número de dados diluiria erros aleatórios, como as considerações sobre o horário e quantidade precipitada, e influenciaria no cálculo pelo maior número de graus de liberdade. Provavelmente a continuidade das análises na estação de Copacabana permitiria estabelecer a diferença estatística entre os eventos.

Optou-se por não reagrupar os grupos ponderando os erros apontados na separação dos mesmos. O ponto crítico em qualquer tratamento de dados é entender os critérios e testes estabelecidos, suas limitações e considerações sobre os resultados. Modificações posteriores aos testes, além de criticáveis, só comprovam as interpretações geradas em uma análise prévia bem efetuada. 
Estudos pretéritos já retratavam qualitativamente a relação entre as concentrações de material particulado e os períodos de maior pluviosidade para o Rio de Janeiro (Trindade et al., 1980; Trindade et al.,1981; Trindade \& Pfeiffer, 1982; Zeri et al.,. 2011). Trindade et al. (1980) reportam que a freqüência de chuva, embora importante na remoção de material particulado, tenha sua influência mascarada pela capacidade de mistura e a velocidade dos ventos. Observa-se para todas as estações um padrão sazonal da quantidade de material particulado em suspensão associado a períodos secos e úmidos. Amador-Muñoz et al. (2011) também encontram variação entre clima seco e úmido para $\mathrm{PM}_{2,5}$ em região do México marcada por clima muito semelhante ao da área de estudo.

Embora se tenha avaliado uma série de parâmetros para descrever a variabilidade de material particulado em suspensão, apenas a chuva demonstrou relação direta com a mesma. Padrão similar a este é observado nas relações com os poluentes atmosféricos e encontram-se descritas no decorrer deste subcapítulo. A relação entre a quantidade de material particulado e a concentração de hidrocarbonetos, estabelecida pelo coeficiente de correlação de Spearman, pode ser visualizada na Tabela 7.

Tabela 7 - Correlação de Spearman $\left(r_{s}\right)$ entre a quantidade de material particulado $\left(\mu \mathrm{g} \mathrm{m}^{-3}\right)$ e os hidrocarbonetos $\left(\mathrm{ng} \mathrm{m}^{-3}\right)$. Valores estatisticamente significantes destacados em negrito e itálico.

\begin{tabular}{|c|c|c|c|c|c|c|}
\hline & $\begin{array}{c}\text { Soma } \\
\text { Alcanos }\end{array}$ & HR & MCNR & $\begin{array}{c}\text { Alifáticos } \\
\text { Totais }\end{array}$ & 16HPAs & 38HPAs \\
\hline Centro & 0,70 & 0,40 & 0,31 & 0,36 & 0,71 & 0,44 \\
\hline $\begin{array}{l}\text { Campos } \\
\text { Elíseos }\end{array}$ & 0,69 & 0,63 & 0,56 & 0,61 & 0,70 & 0,70 \\
\hline Copacabana & $-0,01$ & 0,11 & 0,44 & 0,36 & 0,77 & 0,60 \\
\hline Niterói & 0,54 & 0,31 & 0,28 & 0,32 & 0,71 & 0,70 \\
\hline Seropédica & 0,49 & 0,18 & 0,45 & 0,41 & 0,53 & 0,45 \\
\hline $\begin{array}{l}\text { São João de } \\
\text { Meriti }\end{array}$ & 0,55 & 0,60 & 0,58 & 0,62 & 0,45 & 0,47 \\
\hline
\end{tabular}

Como padrão geral observa-se que a correlação dos parâmetros da fração alifática com o material particulado é baixa, mas significativa. Em estações como São João de Meriti e Campos Elíseos a relação entre os parâmetros é mais relevante. Observa-se para as estações de Campos Elíseos, Centro e São João de Meriti que o valor de $r_{s}$ é influenciado por pontos fora da distribuição, já 
destacados no subcapítulo 5.3, como exemplificado a seguir na Figura 34 para a estação do Centro. A figura mostra a concentração em logaritmo para melhor visualização das relações, diminuindo a variação de escala causada pelos outliers. Como a correlação de Spearman mede relações monótonas seu cálculo não é influenciado pela transformação dos dados, permanecendo inalterado entre as determinações utilizando os dados brutos ou em logaritmo.
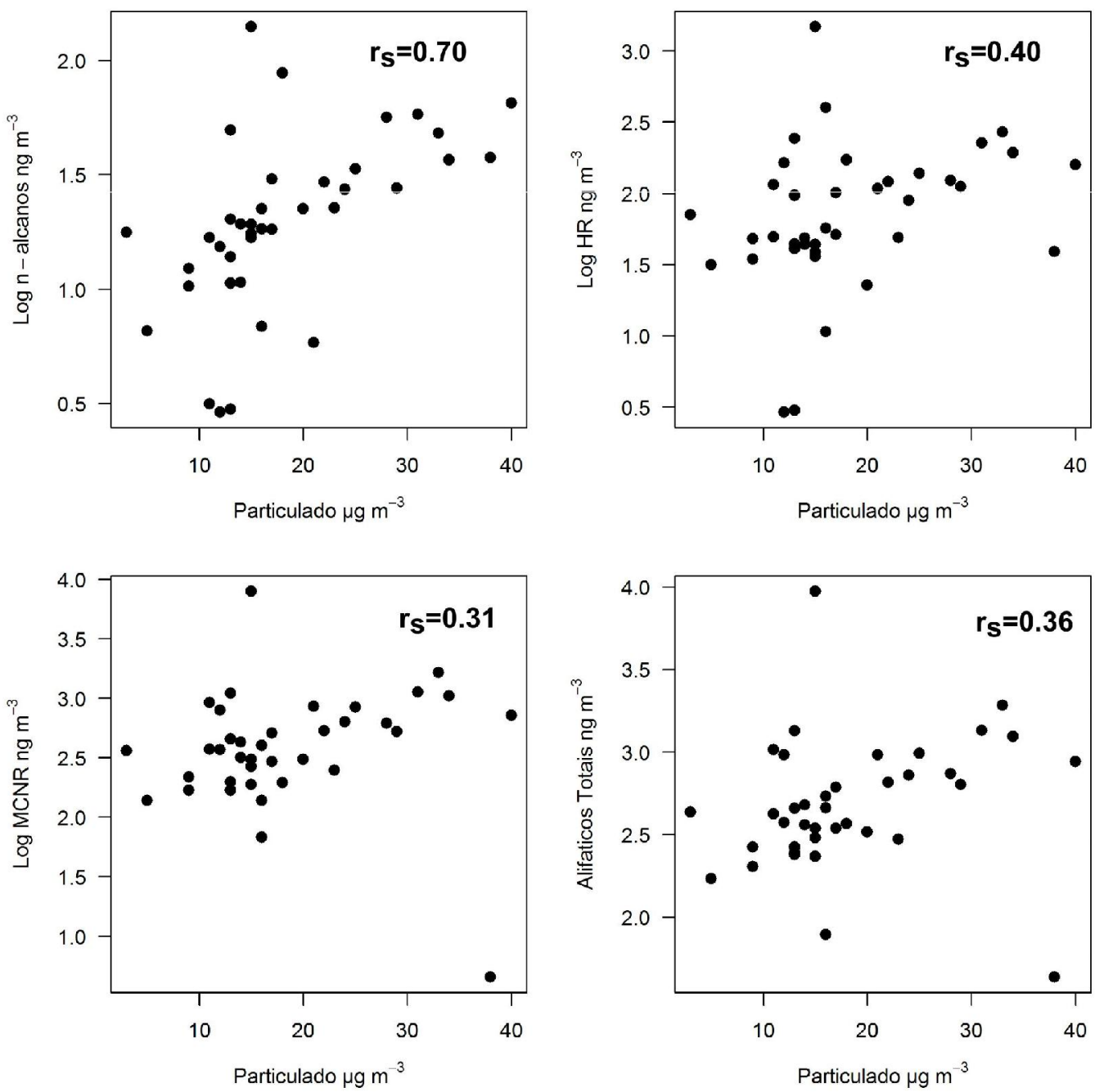

Figura 34 - Relação entre o material particulado fino $\left(\mu \mathrm{g} \mathrm{m}^{-3}\right)$, e a concentração dos parâmetros alifáticos ( $\mathrm{ng} \mathrm{m}^{-3}$ ) para os dados de 2011 da estação do Centro.

$\mathrm{Na}$ Figura 34 observam-se os quatro tipos de interpretações mais prováveis que podem ser formuladas a partir dos dados. Inicialmente temos a correlação significativa e forte para os n-alcanos. No caso dos hidrocarbonetos resolvidos, apesar da correlação $\left(r_{s}\right)$ ser significativa estatisticamente, observase pela dispersão dos dados e baixo valor de $r_{s}$ que a relação entre os parâmetros não deve ser considerada. Nesta estação considerada na figura, as 
concentrações de MCNR e Alifáticos Totais apresentam maior tendência de associação com o material particulado do que a concentração de Hidrocarbonetos Resolvidos (HR), mas o valor da correlação é menor, e sem significância estatística para a MCNR. Nestes dois parâmetros a ocorrência de valores fora da distribuição tem maior influência sobre a correlação quando comparados aos Hidrocarbonetos Resolvidos (HR), onde a relação não é evidente apesar de ser significativamente estatística.

Da mesma forma que populações pequenas de amostras podem ter valores relativamente altos de correlação sem significância estatística, é possível obter-se um padrão inverso para grandes populações de dados. A interpretação dos baixos valores de correlação com $p<0,05$ deve ser analisada com rigor pois, apesar de ser estatisticamente significativa, pode não estar revestida de significado físico (Loureiro \& Gameiro, 2011). Afirmações baseadas apenas na significância estatística com baixos valores de correlação podem ocasionar erros de interpretação (Kraemer et al., 2003). Isto ressalta a importância de avaliar minuciosamente a distribuição de cada parâmetro por estação.

Nas estações de Niterói, Copacabana e Seropédica a dispersão dos dados é muito maior. Provavelmente em função das menores concentrações de hidrocarbonetos ali observadas, a relação com a quantidade de material particulado em suspensão esteja mais sujeita a flutuações decorrentes das variáveis ambientais e dos diferentes tipos de emissões. Lima (2006), que obteve concentrações inferiores às obtidas em Niterói no presente estudo, aponta alterações nas emissões durante o período de amostragem como possível razão para a falta de correlação entre os parâmetros analisados. Esta explicação, entretanto, não se aplica aqui pois há forte correlação significativa naquelas estações com a quantidade de HPAs na atmosfera, especialmente com os 16 HPAs prioritários.

Outra provável explicação para a falta de associação entre os hidrocarbonetos alifáticos e o material particulado, assim como a presença de outliers, é a associação dos compostos segundo suas características químicas. Existem diferenças importantes na distribuição dos hidrocarbonetos alifáticos entre a fase gasosa e o material particulado. $\mathrm{Na}$ fase gasosa há maior abundância de compostos de cadeias curtas e no particulado atmosférico maior percentual relativo de cadeias mais longas (Cautreels \& Cauwenberghe, 1978; Doskey \& Andren, 1986; Cincinelli et al., 2007). Fujitami et al. (2012) demonstraram claramente as diferenças de distribuição entre estas fases em ensaios de emissões para motores a diesel. 
Estes relatos fazem sugerir considerações sobre como a emissão de poluentes é refletida na concentração e distribuição dos parâmetros da fração alifática em particulado atmosférico. Alterações na composição da frota e tipo de combustível influenciam na composição do material particulado e sua concentração. Apenas em regiões onde a movimentação de veículos é intensa e constante, como Campos Elíseos e São João de Meriti, há menores dispersões e encontram-se as maiores correlações envolvendo a fração alifática. Além disto, estas duas estações estão localizadas na área mais industrializada do Rio de Janeiro. Mesmo assim os coeficientes obtidos para estas estações não caracterizam correlações fortes.

$\mathrm{Na}$ Tabela 7 nota-se que para os HPAs existe uma melhor correlação com a quantidade de material particulado do que a obtida para os alifáticos, especialmente considerando os 16 HPAs prioritários. Sabe-se que os HPAs de menor número de anéis dispersos na atmosfera estão particionados entre as fases gasosa e particulada, enquanto aqueles de maior massa molecular ocorrem prioritariamente na fração fina $\left(\mathrm{PM}_{2.5}\right)$ (Baek et al., 1991; Wu et al., 2006; Fang et al., 2006). A distribuição entre o material particulado e a fase de gás depende do tamanho das partículas, do conteúdo de carbono orgânico, da concentração de material particulado no ar e da temperatura ambiente (Tasdemir \& Esen, 2007). Hidrocarbonetos aromáticos relacionados a fontes de combustão são emitidos inicialmente como gases e, com o resfriamento, condensam-se em partículas (Marr et al., 2006).

Abrantes et al. (2004) analisaram emissões veiculares de motores a diesel e reportam, que em concentrações médias, compostos a partir do fluoreno passam a ser mais abundantes na fração particulada. Ré-Poppi e Santiago-Silva (2005) observam o mesmo padrão para amostras de Campo Grande, Mato Grosso do Sul. Tasdemir \& Esen (2007) apontam a maior contribuição de HPAs no material particulado a partir do benzo(a)pireno, mas reportam menores diferenças entre as fases a partir do fluoranteno.

Estudos de emissões veiculares reportam altas concentrações de naftaleno, especialmente para veículos a gasolina (Khalili et al., 1995; Tsai et al., 2012; Mi et al., 1998; Fromme et al., 1998; Abrantes et al., 2009). À exceção do naftaleno, que é obviamente negligenciado pela amostragem neste estudo dada sua partição entre as fases, é importante observar nos estudos citados as diferenças na distribuição dos compostos segundo os combustíveis utilizados.

Khalili et al. (1995) reportam que as principais diferenças observadas nas emissões da gasolina e do diesel encontram-se nos compostos de 2 anéis, pela 
influência do naftaleno, e pela maior emissão de compostos de 6 anéis para veículos a diesel. Resultados similares são reportados por Mi et al. (1998) para em estudo da adição de aditivos na emissão de HPAs em gasolina. Embora haja importantes diferenças a considerar na distribuição das emissões entre os combustíveis, sua variação é menor comparada aos dados encontrados na literatura para os compostos alifáticos (Doskey \& Andren, 1986; Cincinelli et al., 2007; Fujitami et al., 2012; Yao et al. 2013). Marr et al. (1999), por exemplo, reportam relevantes emissões de HPAs de alto peso molecular associada a veículos movidos a gasolina. Uma das hipóteses é que a maior correlação entre os HPAs e o material particulado ocorra devido a menor variação entre a composição das fontes de emissão e, consequentemente, menor influência da partição gás/partícula na concentração das amostras.

Entretanto sugere-se que os valores de correlação encontrados entre os HPAs e o material particulado sejam predominantemente influenciados pela combinação do fenômeno de partição entre as fases gás e particulado e a distribuição relativa dos compostos em cada local. A Tabela 7 mostra maior correlação para os 16 HPAs prioritários (EPA) do que os obtidos em relação ao total de HPAs na estação do Centro do Rio de Janeiro e Copacabana. Como será avaliado exaustivamente no próximo subitem, as estações do Centro e Copacabana apresentam um percentual relativo maior de compostos leves e alquilados, enquanto nas demais estações há majoritariamente HPAs de maior peso molecular. Nestas duas estações as diferenças obtidas entre as relações do material particulado com a concentração total de HPAs e dos 16 HPAs prioritários pode ser explicada pela influência da partição gás/particulado. Para a relação com os 16 HPAs prioritários, menos sujeitos a esta influência, obtemos menores variações. (Figura 35a). Este fenômeno é especialmente marcante nestas estações em eventos de precipitação, como será demonstrado adiante.

Nas estações de Niterói e Campos Elíseos as correlações são praticamente iguais para os dois parâmetros, como exemplificado na Figura 35b. Nestas estações a distribuição é caracterizada por compostos de alta massa molecular, e são minimizadas as influências observadas para o Centro do Rio de Janeiro e em Copacabana. 

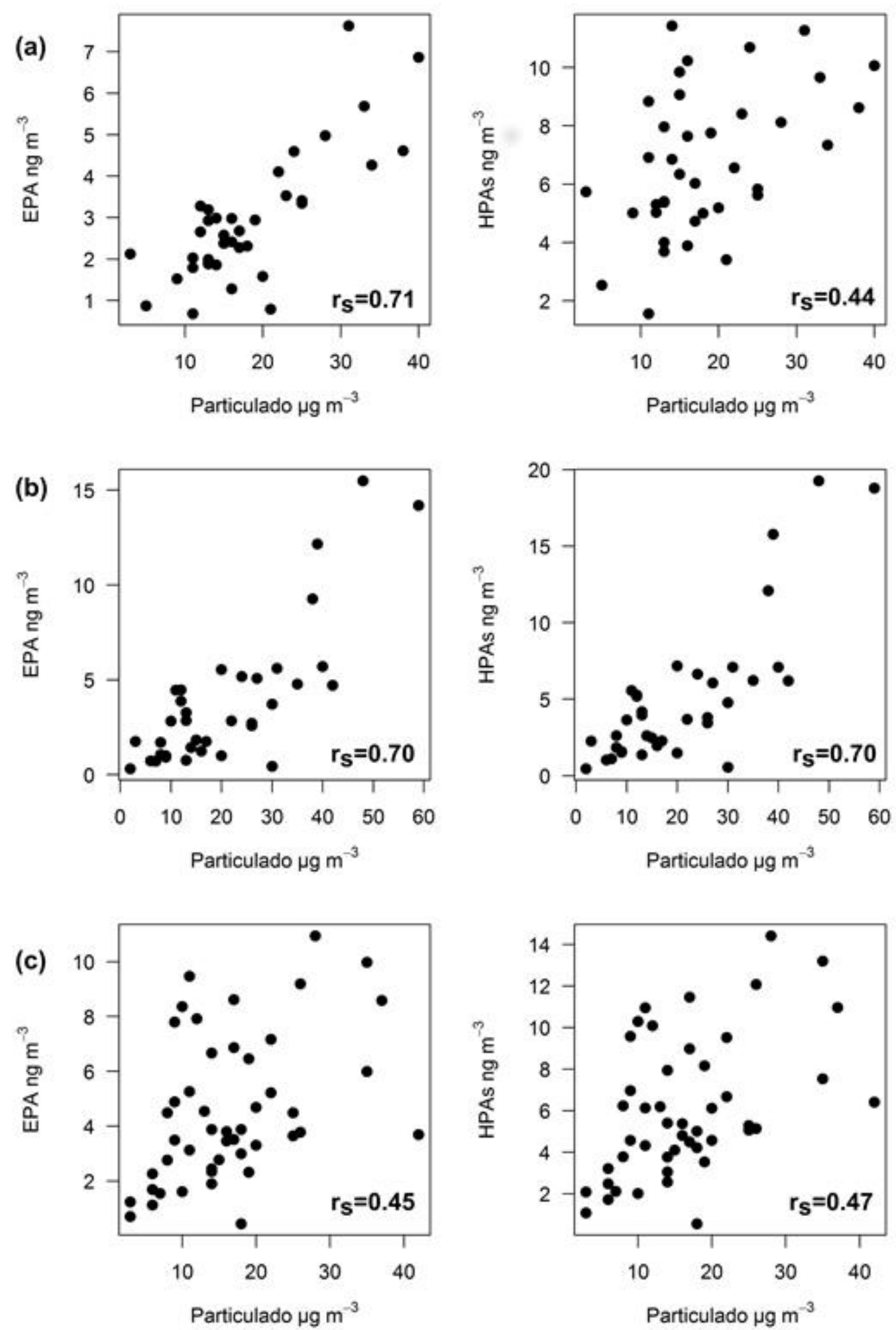

Figura 35 - Relação entre o material particulado atmosférico $\left(\mathrm{PM}_{2,5}\right)$ e a concentração dos 16 HPAs prioritários (EPA) e o total de HPAs Quantificados para as estações do (a) Centro; (b) Campos Elíseos e (c) São João Meriti 
Nas estações de São João de Meriti e Seropédica observa-se que, apesar de serem majoritariamente caracterizadas por compostos de maior massa molecular, as correlações obtidas são consideradas moderadas (Figura 35c). As correlações obtidas se assemelham às da fração alifática. Provavelmente, nestes locais, a diversidade das emissões é o fator mais importante na determinação da relação com o material particulado, uma vez que o padrão de distribuição dos dados é praticamente o mesmo para os 16 HPAs prioritários e o total quantificado. Em Seropédica, em função das baixas concentrações encontradas, deve-se ainda considerar que os dados estão sujeitos a maiores flutuações decorrentes de variáveis ambientais, além dos diferentes tipos de emissões.

Buscou-se também estabelecer a influência de eventos de precipitação na concentração de poluentes. As amostras foram tratadas seguindo o mesmo procedimento adotado para o material particulado. Apesar das expectativas de relação inversa entre os parâmetros, apenas nas estações de Campos Elíseos e Niterói foram detectadas diferenças significativas. Em Campos Elíseos houve diferença significativa segundo a precipitação para concentração de n-alcanos, Hidrocarbonetos Resolvidos (HR), os 16 HPAs prioritários e o total de HPAs. Para Niterói apenas a concentração dos 16 HPAs prioritários apresentou diferença estatística entre eventos.

Para estas duas estações as diferenças encontradas foram acentuadas o suficiente para serem consideradas nos testes estatísticos aplicados. Observase que, assim como para a concentração de HPAs em Campos Elíseos, a estação de São João de Meriti também apresenta diferença entre as situações meteorológicas (Figura 36), mas em menor proporção. Este é o mesmo padrão observado em Copacabana para o material particulado. De maneira geral todas as variáveis analisadas nas estações de estudo apresentam diferenças entre os eventos, mas sem significância estatística.

Esses casos ocorrem dadas as considerações já apresentadas para o material particulado sobre os critérios de agrupamento, número de amostras e significância estatística quando de um período de observação mais longo. Agregam-se à discussão dos poluentes os valores considerados outliers, especialmente nos parâmetros da fração alifática, que prejudicam muito a segregação estatística dos grupos.

Diferente das demais estações, Copacabana não demonstrou qualquer variação na concentração de HPAs com as condições de tempo, seja o total quantificado ou os 16 prioritários. Para a estação do Centro não há diferença 
considerando os 16 HPAs prioritários e as concentrações em dias de chuva para o total de HPAs aparecem superiores àquelas determinadas em períodos sem precipitação (Figura 36).
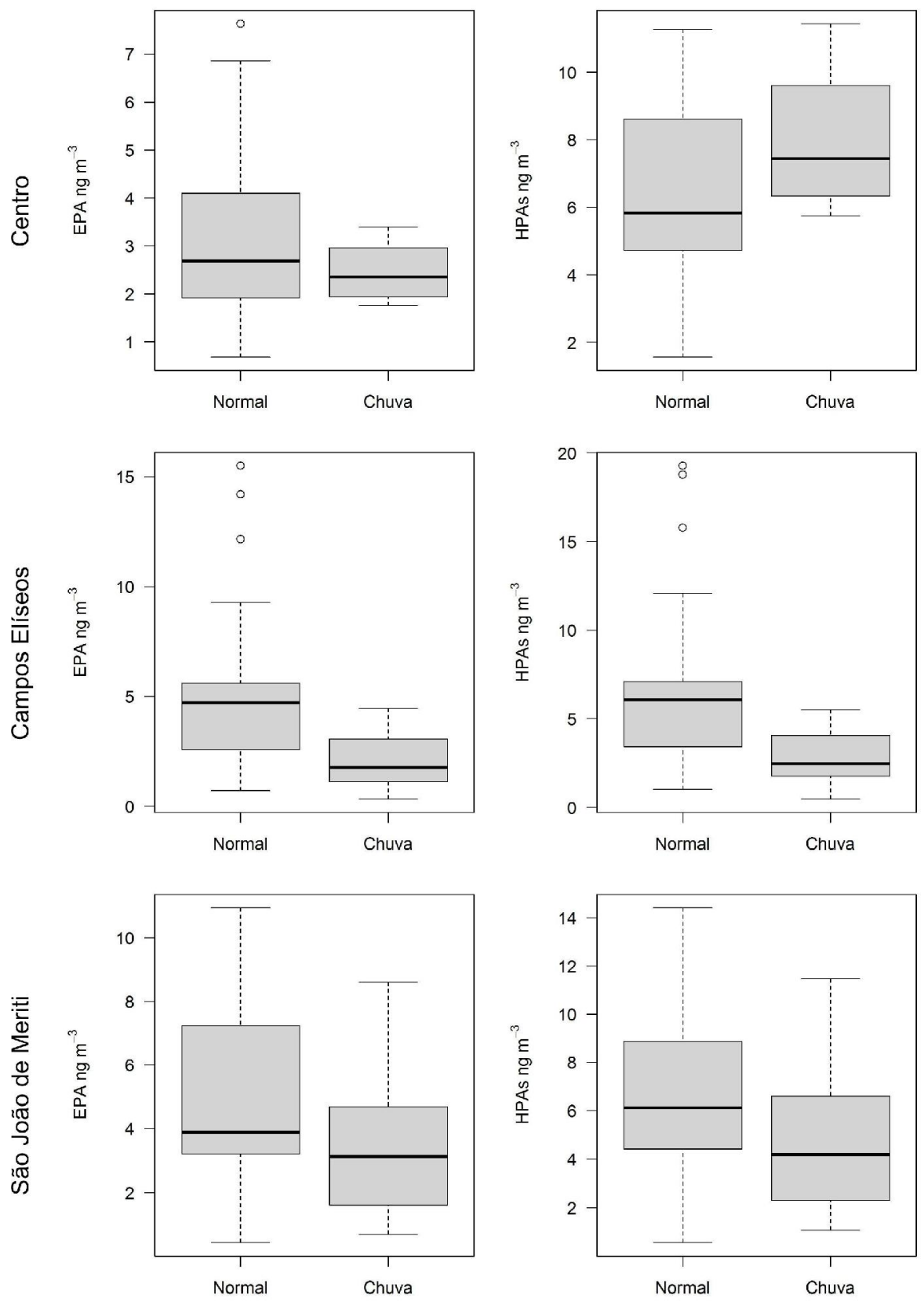

Figura 36 - Concentração dos 16 HPAs prioritários (EPA) e da soma dos 38 HPAs quantificados para períodos sem e com ocorrência de chuva.

Conforme já apresentado, a distribuição de HPAs no Centro e em Copacabana mostra particularidades em relação às demais estações deste estudo. Centro e Copacabana apresentam maior contribuição relativa de compostos leves, principalmente alquilados. Observa-se na Figura 37 a 
diferença entre a distribuição de HPAs na estação do Centro em distintas condições climáticas. Fica evidente que na ocorrência de precipitação a distribuição é marcada pelo aumento da contribuição relativa de compostos leves e alquilados e o decréscimo da contribuição dos compostos com maior massa molecular.
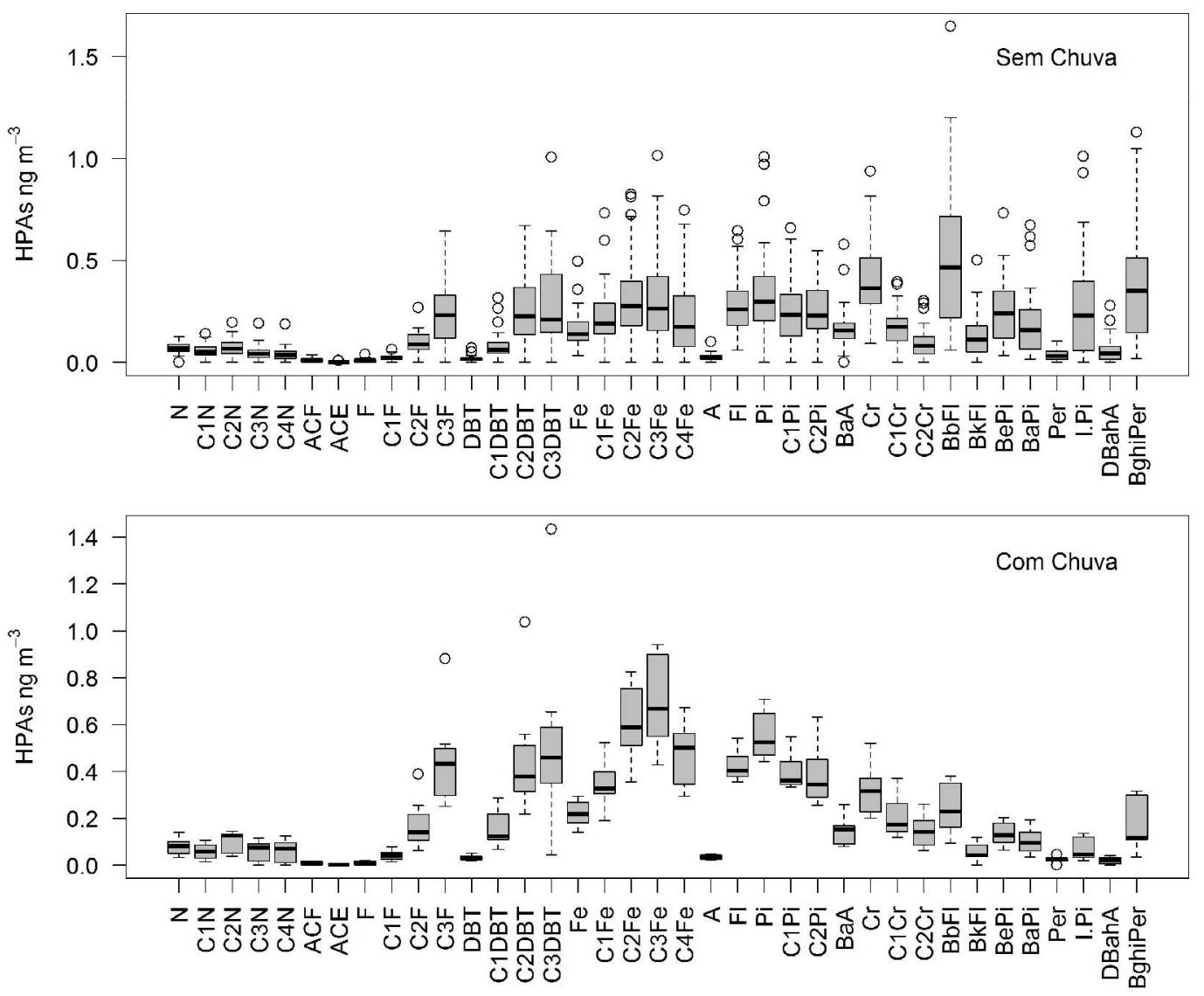

Figura 37 - Distribuição dos HPAs em amostras do Centro do Rio de Janeiro para o ano de 2011 entre dias normais e eventos de precipitação.

O mesmo padrão é observado em todas as estações, mas a modificação da distribuição dos compostos é menos relevante. Apenas as amostras da estação de Copacabana, além do Centro, mostram mudanças acentuadas da tipologia. Isto pelas características únicas destas duas estações em relação às demais. As alterações em Copacabana, entretanto, não são tão intensas quanto às observadas no Centro, onde ocorre a total modificação do padrão de distribuição dos HPAs (Figura 38). Provavelmente as chuvas removem os HPAs de maior peso molecular enquanto os compostos parentais e alquilados de menor peso molecular permaneçam mais disponíveis. Isto ocorre porque o 
processo de remoção úmida de hidrocarbonetos da atmosfera é mais eficiente para os compostos de maior peso molecular (Lopes \& Andrade, 1996; Venkataraman \& Friedlander, 1994).
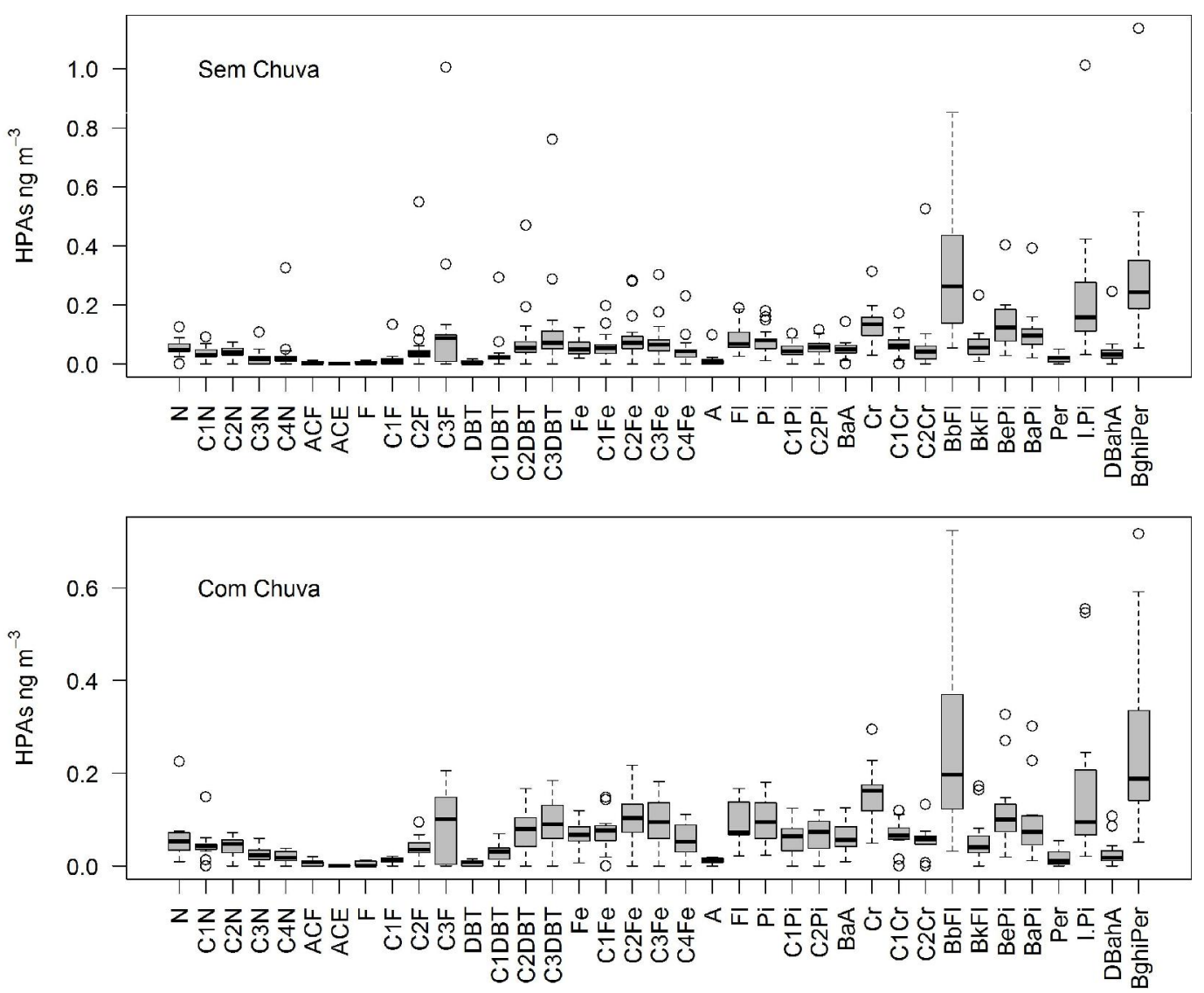

Figura 38 - Distribuição dos HPAs em amostras de Copacabana para o ano de 2011 entre dias normais e eventos de precipitação

A alteração do perfil de hidrocarbonetos aromáticos em eventos de precipitação já foi reportado por Panther et al. (1999) com menores contribuições de HPAs de maior peso molecular em períodos úmidos. A maior variação entre os períodos reportado pelos autores foi para o composto Fluoranteno, já apontado por Brun et al. (1991) em estudo prévios como o mais abundante em água de chuva (superior a 73\%). Allen et al. (2008) associa a variação de compostos leves a dias de chuva na cidade de Cubatão.

Em todas as estações observa-se o padrão sazonal com as maiores concentrações associadas a períodos mais secos. Vários estudos destacam a variabilidade entre a concentração de material particulado e poluentes associados a períodos secos e úmidos em climas tropicais, especialmente na área de estudo (Panther et al., 1999; Vasconcelos et al., 2011; Allen et al., 2008; 
Lopes \& Andrade, 1996; Amador-Muñoz et al., 2011; Trindade et al., 1980; Trindade et al.,1981; Trindade \& Pfeiffer, 1982; Zeri et al.,. 2011; Souza, 2006).

Panther et al. (1999) destacam que apesar de observar as menores concentrações de poluentes (HPAs) na estação seca, não há significante correlação entre o nível de chuvas e os poluentes. Estudo pretéritos de poluentes atmosféricos como os de Quitério et al. (2005) e Pereira Netto et al. (2002) já reportavam a impossibilidade de estabelecer relação entre a concentração de poluentes e os parâmetros sazonais da região. Vasconcellos et al. (2003) também associam qualitativamente as condições de entradas de frentes frias e inversões térmicas à concentração de poluentes em São Paulo, apesar de não encontrarem correlação significativa entre a concentração e o volume de chuvas. Isto corrobora que a maneira mais adequada de avaliar o efeito da chuva seja de forma qualitativa. Um exemplo da variabilidade sazonal pode ser visto na Figura 39 para a concentração de HPAs em São João de Meriti.

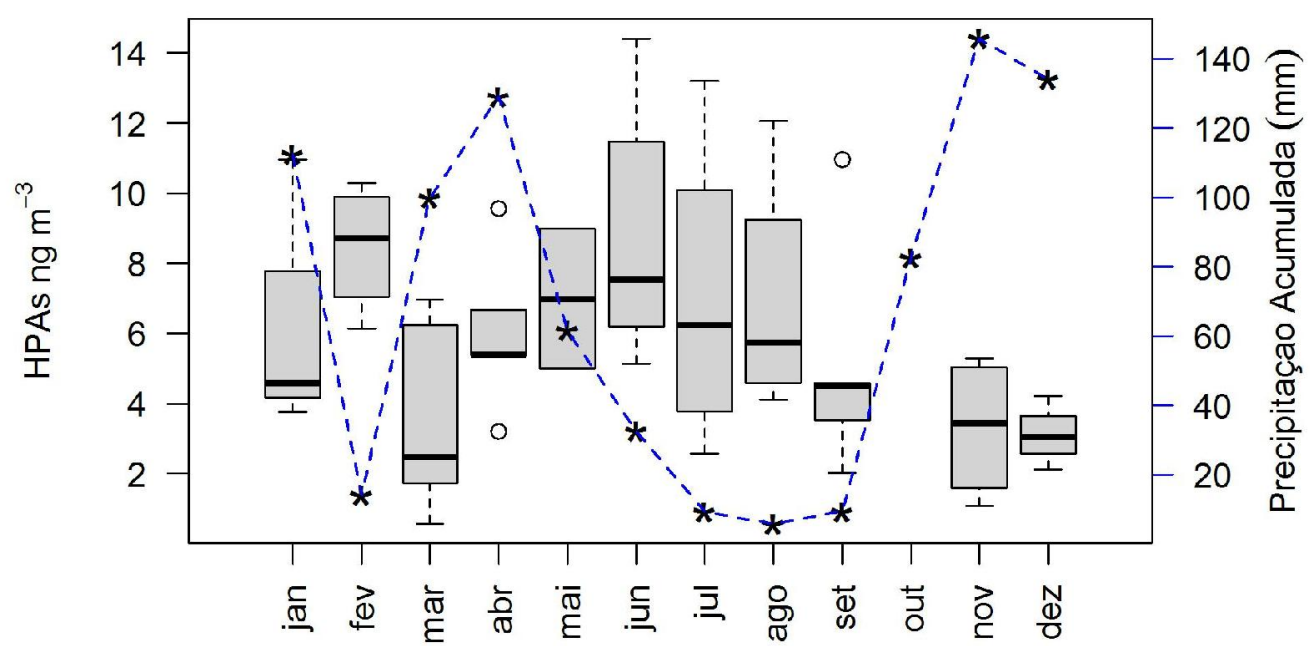

Figura 39 - Box-plot da concentração total de HPAs por mês e precipitação acumulada mensal para o ano de 2011 na estação de São João de Meriti.

Os dados mais destacados talvez sejam os de Sharma et al. (2007) que mostram as diferenças obtidas para os hidrocarbonetos em período seco e as obtidas no período das monções na Índia. Vasconcellos et al. (2011), além dos períodos mais secos, ainda associa as maiores concentrações no inverno a períodos de estagnação em São Paulo. Períodos de estagnação que podem ocorrer na área de estudo justamente no período mais seco, devido à atuação dos sistemas de alta pressão que dominam a região (INEA, 2009). 
Apenas em alguns estudos realizados em ambientes tropicais o uso do solo parece ser mais importante que a precipitação, como em regiões afetadas pelo cultivo da cana-de-açúcar (Andrade et al., 2012; Azevedo et al., 2002; Cristale et al., 2012; Vasconcellos et al., 2010).

Na estação de São João de Meriti e em Campos Elíseos o padrão é claro para todas as variáveis observadas, tanto para os poluentes quanto para a quantidade de particulado $\left(\mathrm{PM}_{2,5}\right)$. Em todas as estações a influência dos valores extremos prejudica a análise da variação sazonal, em diferentes proporções. Em Seropédica, por exemplo, os dados de junho para a fração alifática são muito mais elevados que os observados no restante do ano, mascarando a variabilidade sazonal dos dados. Nesta estação, assim como em Campos Elíseos e São João de Meriti, os HPAs (prioritários e totais) e a concentração de $\mathrm{PM}_{2,5}$ seguiram o padrão de distribuição sazonal, mas com abundâncias diferentes dentre os meses de cada período, seco e chuvoso.

As estações de Copacabana e do Centro, pelas características já descritas, obviamente não apresentam padrão sazonal em relação à concentração do total de HPAs e dos 16 prioritários. Embora em Niterói seja observada a diferença da concentração de HPAs (prioritários e total) em eventos de precipitação esta estação também não apresentou um padrão sazonal característico. A variabilidade das concentrações ao longo dos meses, com diferente número de observações realizadas por mês e em diversas condições de tempo é responsável por este efeito. Nota-se que as concentrações determinadas no período seco (inverno) são as que apresentam a maior variabilidade nas estações coletadas. Este padrão também foi observado por Pereira Netto et al. (2002) indicando que as concentrações podem variar bastante com a estação do ano.

Conforme realizado para o material particulado em suspensão buscou-se descrever a variabilidade dos poluentes por uma série de parâmetros, onde apenas a chuva demonstrou relação direta com o mesmo. Em regiões temperadas os registros de concentração associados a outras variáveis de padrão sazonal são mais evidentes. Nestas regiões, além dos parâmetros ambientais destaca-se 0 aumento das emissões pela necessidade de aquecimento no inverno (Akyüz \& Çabuk, 2008, Manoli et al., 2004; Li et al., 2003; Esen et al., 2008; Xie et al., 2009, Vadar et al., 2008, Guo et al., 2003a).

Esen et al. (2008) encontram maior percentual de HPAs associados a partículas nestes períodos de uso de aquecimento, pelo efeito sinérgico das maiores emissões e menores temperaturas influenciando na partição 
gás/partícula dos compostos mais leves. Fang et al. (2006) também relaciona a concentração à emissões provenientes de aquecimento e maior associação ao material particulado pela baixa temperatura e redução de degradação fotoquímica.

Tham et al. (2008) determinaram forte correlação negativa $\left(r_{s}\right)$ entre a concentração de hidrocarbonetos com a temperatura e a radiação solar no Japão, mas reporta que os dados de ventos e umidade relativa do ar não influenciam a distribuição dos poluentes.

Parâmetros como a temperatura aparecem com menor importância em estudos tropicais. Pereira Netto et al. (2002) já apontavam que, para Niterói, as pequenas flutuações de temperatura não tem efeitos capazes de estabelecer estatisticamente um padrão sazonal. A razão apontada pelo autor e corroborada com os dados deste trabalho é que, embora existam diferenças de temperatura ao longo do ano, não se pode comparar o efeito da baixa amplitude anual de ambientes tropicais à influência da variação de temperatura em climas temperados.

Em Cubatão Allen et al. (2008) reporta a influencia da chuva e variação da temperatura na concentração relativa de compostos mais leves. As observações sobre as chuvas confirmam a discussão já exposta para o Centro do Rio de Janeiro e Copacabana e, embora as considerações sobre a temperatura possam ser aplicadas a este estudo, não se observou sua influência nas estações. Alterações na distribuição de compostos leves causados pela ação da temperatura na partição gás/partícula, capazes de inferir um padrão sazonal são mais comuns em regiões temperadas (Bi et al., 2008; Esen et al., 2008; Tham et al., 2008, Vadar et al., 2008; Guo et al., 2003b). Esen et al. (2008) compararam os valores experimentais da partição gás/particulado $(\mathrm{Kp})$ com os resultados obtidos de dois modelos distintos. Mesmo os autores obtendo bons resultados entre as comparações, os modelos não foram capazes de explicar a variabilidade observada nos valores experimentais de $\mathrm{Kp}$, o que destaca a complexidade de estabelecer a relação deste fenômeno às concentrações obtidas.

Observa-se no Centro do Rio de Janeiro que a precipitação é o fator determinante para a concentração de compostos de menor peso molecular, embora não se possa descartar a influência da temperatura. Apesar da concentração total de HPAs e dos 16 prioritários não apresentar um padrão sazonal claro, o mesmo não ocorre se considerarmos apenas os compostos de 2 e 3 anéis (Figura 40). Este padrão, entretanto, é encontrado apenas nesta 
estação, que apresenta a maior influência de chuvas na distribuição dos HPAs. Mesmo para Copacabana o padrão sazonal exposto não é evidente. Interessante ressaltar que o padrão sazonal no Centro do Rio de Janeiro deixa de ser observado se é considerada a contribuição relativa dos HPAs de menor peso molecular.

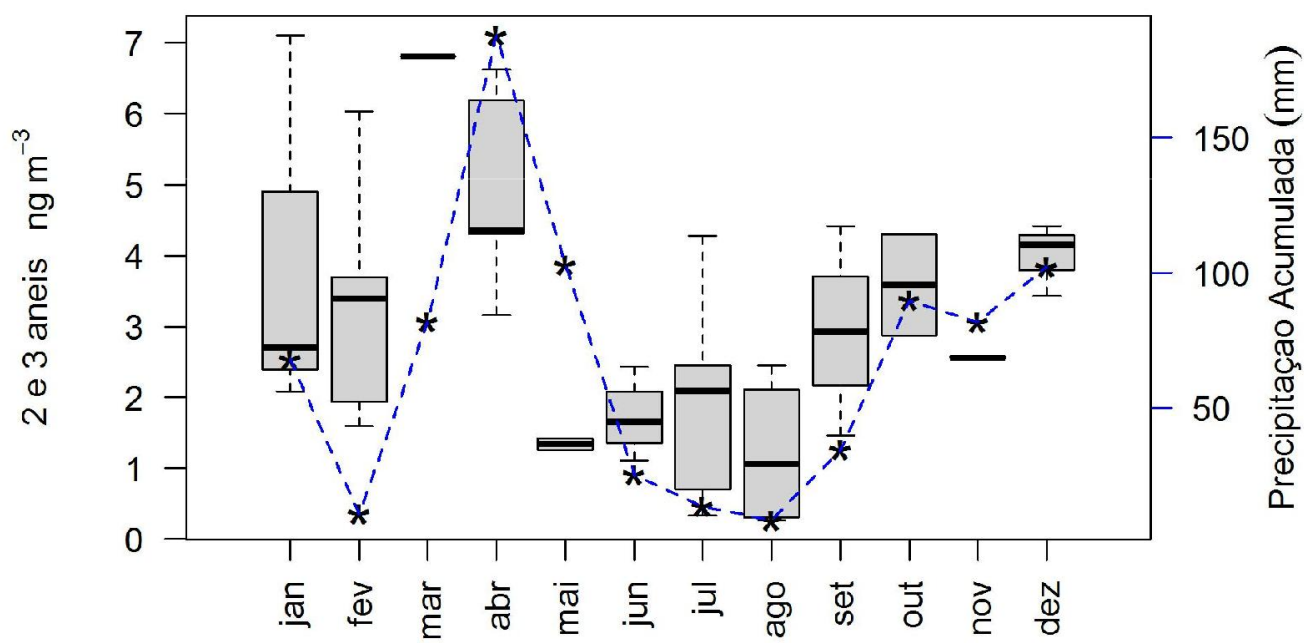

Figura 40 - Box-plot da concentração de HPAs de 2 e 3 anéis por mês e precipitação acumulada mensal para o ano de 2011 na estação do Centro.

A avaliação de cada relação deve ser feita com cuidado. Gu et al. (2010) reporta que a concentração de HPAs é diretamente correlacionada à umidade e inversamente a velocidade dos ventos e temperatura, as quais atuam na partição gás-partícula. Embora o aumento da umidade relativa possa suprimir a adsorção de compostos da fase gás ao particulado (Pankow, 1993) os autores destacam que isto não ocorreu no estudo, pois a umidade também se correlaciona com a temperatura e a velocidade dos ventos. O que ocorreu então foi a correlação mútua dos HPAs e umidade com os demais parâmetros. Mastral et al. (2003) também reporta diferença com a temperatura e correlação positiva com a umidade relativa. Lima (2006) encontrou apenas baixo valor de correlação significativa entre a velocidade de ventos para a quantidade de $\mathrm{PM}_{10}$ na atmosfera de Niterói.

Apesar dos métodos empregados não foi possível estabelecer a influência da radiação solar, direção e intensidade do vento, temperatura e umidade relativa do ar. Um dos problemas observados, e recorrentes em vários estudos, é que se tenta estabelecer a influência das variáveis ambientais parâmetro a parâmetro. Obviamente a concentração final de material particulado ou qualquer 
poluente é resultado do efeito sinérgico de todas as variáveis. Este estudo foi capaz de destacar o efeito da chuva porque evidentemente esta variável tem o maior efeito sobre as concentrações reportadas, o que não sugere que os demais parâmetros deixem de atuar em diferentes proporções.

Em relação à degradação fotoquímica, sabe-se seu efeito não é o mesmo para todos os compostos, especialmente considerando o benzo(a)pireno (Martinis et al., 2002; Panther et al., 1999; Tobiszewski \& Namiesnik., 2012; Vasconcellos et al., 2011; Fernandez et al., 2002). Entretanto não foram encontradas diferenças sazonais associadas à radiação solar, o que sugere que mesmo que este efeito seja relevante para alguns compostos sua influência não é forte o suficiente para impor uma variação sazonal à concentração total reportada. Vasconcellos et al. (2003) também não encontram sinais de degradação fotoquímica para amostragens realizadas em São Paulo.

Embora tenha se tentado prever o valor de concentração para as estações por modelo de regressão múltipla, o mesmo não gerou bons resultados. Um dos problemas a considerar no modelo de regressão, assim como nas tentativas de estabelecer relações simples entre as variáveis é o período de tempo a considerar para a influência de cada variável e como determinar sua influência para as considerações de regressão.

As maiores concentrações são obviamente relacionadas às emissões em períodos diurnos, onde há maior movimento (Pereira Netto et al., 2005; Marr et al. 2006, Ochs et al., 2011). O modelo mais adequado a princípio seria aquele relacionado ao período de emissão. Entretanto os dados de ventos variam em direção e velocidade ao longo do dia e se poderia desconsiderar ventos de diferentes intensidades que atuem fora deste período na dispersão ou carreando material particulado e poluentes. Os dados como temperatura e radiação têm grandes variações no decorrer do dia. Os cálculos de médias diárias ou considerando períodos específicos podem não ser úteis por gerarem valores muito próximos para condições estáveis ou de grandes amplitudes.

Outro problema a considerar é que apesar das curtas distâncias entre as estações cada uma tem características únicas. A própria cidade do Rio de Janeiro apresenta uma variedade de microclimas. O que significa que as considerações sobre a atuação das variáveis em uma determinada estação podem não ser extrapoladas a outra. Ainda ter-se-ia que considerar os valores de entrada de variáveis cujo efeito é mais qualitativo que quantitativo, tal como o da precipitação. Variáveis cuja influência não é linear tem que ser transformadas para entrar no modelo. 
Contribuem ainda para a variabilidade das concentrações na atmosfera o transporte por longas distâncias, como o observado por Vasconcellos et al. (2003) para a cidade de São Paulo, e padrões de comportamento humano nas emissões diárias (Pereira Netto et al., 2005; Marr et al., 2006; Ochs et al., 2011). Tavares et al. (2004) estudou as emissões de diesel na estação central de ônibus de Londrina e percebeu que aos domingos, dias de menor fluxo de veículos, as concentrações eram menores. Tasdemir \& Esen (2007) reportaram aumento de HPAs associado à movimentação de veículos em viagens de férias. Apesar do horário de movimentação de carros ser mais longo Marr et al. (2006) reportam as maiores concentrações as 10 da manhã associadas às condições atmosféricas da Cidade do México. Amador-Muñoz et al. (2011) observaram alterações nas concentrações de $\mathrm{PM}_{2,5}$ e HPAs associados a queima de fogos na noite de Natal.

Todas as variáveis deste estudo foram examinadas meticulosamente, o que exigiu a compilação, organização e interpretação dos dados a cada observação em cada estação estudada. Conforme descrito anteriormente a variação das concentrações depende do efeito sinérgico destas variáveis, que não são independentes e não é necessariamente linear para todas. Ou seja, busca-se estabelecer relações entre as variáveis e as concentrações, mas as próprias variáveis ambientais possuem dependência entre si. O melhor exemplo é a relação entre a radiação solar e a temperatura.

A melhor opção é um estudo a parte de modelagem atmosférica considerando todas as variáveis do modelo, ponderando a influência de cada uma em cada estação. Será necessário obter um maior número de dados ambientais para carregar o modelo de maior abrangência e realizar a interpretação pela lógica inversa à normalmente abordada. Isto significa que os dados analíticos obtidos serviriam para calibrar e corroborar os resultados obtidos pelo modelo. A partir daí entender os ajustes necessários nas considerações e premissas do mesmo. Esta ferramenta, inclusive, seria de grande importância na gestão ambiental direcionando ações efetivas em programas de qualidade do ar. 


\section{5 \\ Distribuição de hidrocarbonetos em particulado atmosférico e sua relação com fontes emissoras}

\subsection{1}

\section{Origem dos hidrocarbonetos alifáticos}

A distribuição de $n$-alcanos entre as estações encontra-se exposta na Figura 41 e na Figura 42. Todas as estações apresentam distribuição similar caracterizada pela maior abundância de n-alcanos de cadeias longas e destaque de compostos ímpares na faixa do $\mathrm{n}-\mathrm{C} 23$ ao $\mathrm{n}-\mathrm{C} 33$, menos evidente nas estações do Centro e Campos Elíseos.

A avaliação do composto mais abundante $\left(C_{\max }\right)$ e a faixa de distribuição são alguns dos indicativos utilizados para inferência de fontes (Mazurek et al., 1989). Em geral distribuições com $C_{\max }$ maiores ou iguais a $n-C 27$ são características de contribuições biogênicas e menores cadeias são associadas a assinaturas petrogênicas. Vários estudos associam o $\mathrm{C}_{\max }$ em n-C29 e n-C31 a contribuição biogênica proveniente de ceras de vegetais superiores (Omar et al., 2007; Bi et al., 2008; Li et al., 2003; Vasconcellos et al., 1998; Mostafa et al., 2009. Simoneit et al., 1991a).

Azevedo et al. (1999) destaca para o Rio de Janeiro a contribuição máxima em C29 nas amostras da Floresta da Tijuca e Quinta da Boa Vista. Para as estações deste estudo destaca-se a contribuição do n-C29 como $\mathrm{C}_{\max }$. Entretanto nas estações do Centro e Campos Elíseos isto é menos evidente e não se observa o predomínio de compostos com número ímpar de carbonos, o que sugere que predomine o aporte antropogênico.

Os mecanismos de emissão biogênica consistem em volatilização dos nalcanos ou oxidação seguida de condensação e adsorção em partículas préexistentes (Andreou \& Rapsomanikis, 2009). Emissões induzidas mecanicamente a partir de detritos vegetais também resultam uma contribuição natural relevante ao material particulado atmosférico (Simoneit \& Mazurek, 1982; Andreou \& Rapsomanikis, 2009). 

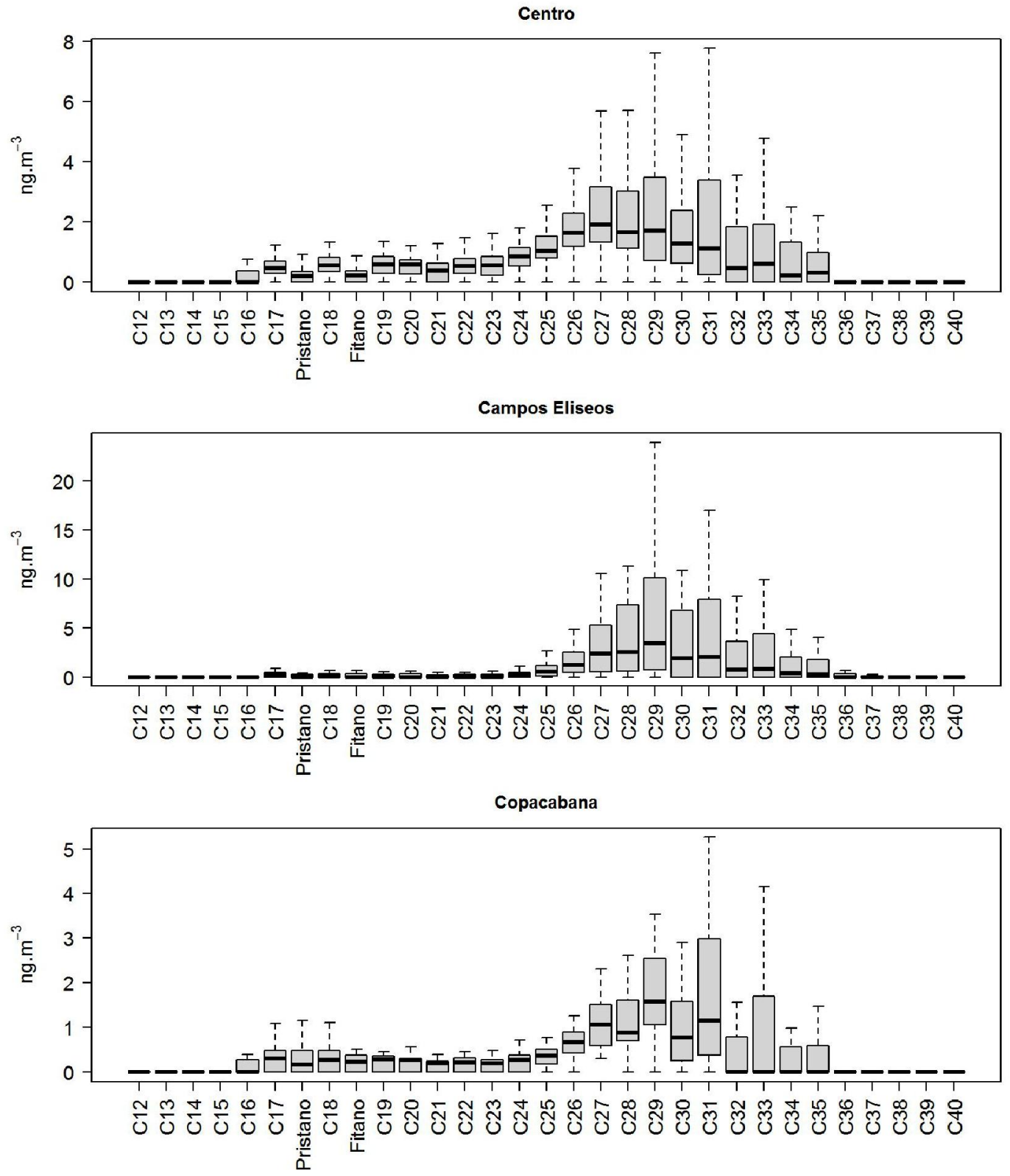

Figura 41 - Box-plot da distribuição de n-alcanos no material particulado atmosférico ( $\left.\mathrm{PM}_{2.5}\right)$, sem outliers, amostrado durante o ano de 2011 nas estações do Centro, Campos Elíseos e Copacabana.

Enquanto a distribuição encontrada na faixa de n-C24 a n-C36 com predominância de ímpares confirma a existência de fontes biogênicas no particulado, a distribuição sem predomínio na faixa abaixo do n-C23 e com a presença de pristano e fitano confirma a queima incompleta de combustível fóssil. (Simoneit, 1984; Cincinelli et al., 2007; Rogge et al., 1993a; Rogge et al., 1993b; Mostafa et al., 2009).

A contribuição de compostos com menor número de átomos de carbono já foi associado por Souza (2006) na cidade de São Paulo a múltiplas emissões 
corroborando o aporte antropogênico. O mesmo padrão de fontes sobrepostas é reportado por outros autores (Bi et al., 2008; Pietrogrande et al. 2011; Yassa et al., 2001; Cheng et al., 2006) e é utilizado para diferenciação de emissões entre diferentes áreas de estudo.
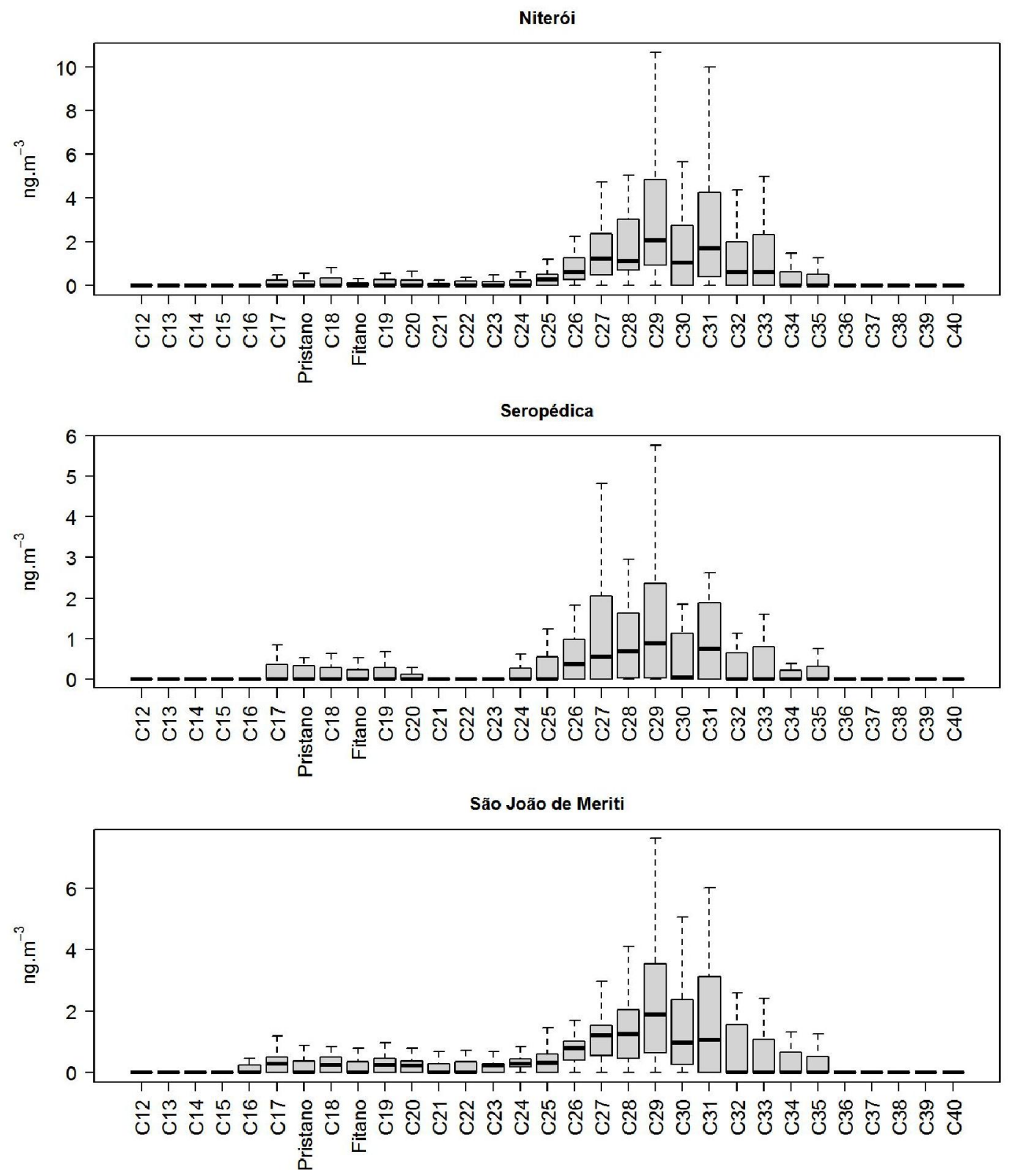

Figura 42 - Box-plot da distribuição de n-alcanos no material particulado atmosférico $\left(\mathrm{PM}_{2.5}\right)$, sem outliers, amostrado durante o ano de 2011 nas estações de Niterói, Seropédica e São João de Meriti.

Nas amostras do Centro e Copacabana pode-se notar a maior contribuição destes compostos de menor peso molecular, inclusive pristano e fitano, em relação às estações de São João de Meriti e Seropédica, onde são menos abundantes e das estações de Campos Elíseos e Niterói, praticamente 
ausentes. Este tipo de distribuição, que caracteriza a emissão de resíduo proveniente de combustível fóssil (Rogge et al., 1993a; Azevedo et al., 2002; Abas \& Simoneit, 1996; Bi et al., 2003), já foi reportada inclusive para áreas afastadas dos grandes centros como a Floresta Amazônica e sudoeste da Austrália (Abas et al., 1995; Simoneit et al., 1991b; Simoneit et al., 1990).

Azevedo et al. (1999) reportam para as amostras do Túnel Rebouças e Cinelândia $C_{\max }$ em C24 e C23, respectivamente. Rogge et al. (1993a) estudou emissões de diferentes veículos e concluiu que os valores de IPC obtidos dependiam do tipo de motor, combustível e condições catalíticas, com $\mathrm{C}_{\max }$ em C25 em todas as amostras de seu estudo. Os autores destacam que compostos de baixo peso molecular são emitidos diretamente como combustível não queimado e que os compostos de maior peso molecular seriam derivados de combustão incompleta e de óleos lubrificantes.

Buscando determinar as diferenças entre as fontes petrogênicas e biogênicas foi calculado o Índice de Preferência de Carbono (IPC), exposto na Figura 43. Valor do IPC superior a 3 é indicativo de contribuição recente de constituintes biológicos, enquanto contaminantes possuem IPC próximos a 1 (Rogge et al., 1993a; Rogge et al., 1993b; Gogou et al., 1996, 1998; Omar et al., 2007; Ladji et al., 2009; Wu et al., 2007). Isto ocorre dado que a combustão incompleta de combustível e as emissões de óleo lubrificante são caracterizadas pela ausência de preferência entre as cadeias com diferentes números de carbono (Simoneit 1984; Abas \& Simoneit, 1996), tal como ocorre no petróleo.

Os IPCs obtidos para as estações, em medianas, foram de 1,07 para o Centro, 1,33 para Campos Elíseos, 1,47 para Copacabana, 1,63 para Niterói, 1,33 para Seropédica e 1,23 para São João de Meriti. As estações são, portanto, caracterizadas pela emissão antropogênica de hidrocarbonetos, apesar das distribuições expostas na Figura 43 demonstrarem que há uma pequena variação deste índice. Mesmo para as estações da Quinta da Boa Vista e Floresta da Tijuca do estudo de Azevedo et al. (1999) realizado no Rio de Janeiro foram reportados valores de 1,57 e 1,96, respectivamente, indicando mais de uma fonte. Os mesmos autores reportaram valores de 1,06 e 1,05 para as amostras do Túnel Rebouças e Cinelândia.

Bi et al. (2008) apesar de reportar $C_{\max }$ característico de contribuição de vegetais encontra valores de IPC entre 1,3 e 1,5, indicando influência antropogênica. O mesmo padrão de respostas conflitantes entre índices é observado neste estudo e reportado por diversos autores para áreas sob 
influência antrópica, corroborando a sobreposição de fontes (Li et al., 2013; Pietrogrande et al. 2011; Xie et al., 2009; Azevedo et al., 2002).

Observam-se menores variações do IPC para as estações do Centro, Campos Elíseos e São João de Meriti. Isto provavelmente ocorre porque estas estações, já caracterizadas como de maior concentração, estão sujeitas à emissão antrópica de hidrocarbonetos constante durante o ano. Estudos realizados em zonas rurais e de florestas observam maior variação deste índice em função da variabilidade nas emissões (Guo et al., 2003a; Gelencser et al., 1998; Vasconcellos et al., 1998; Azevedo et al., 2002).

Não foi observada qualquer alteração correspondente a padrões sazonais. Em zonas temperadas a variabilidade nas emissões é confirmada pela variação do IPC, que é menor no inverno fruto do aumento das emissões antrópicas e menor aporte natural de hidrocarbonetos (Guo et al., 2003b; Xie et al., 2009; Pietogrande et al. 2011; Li et al., 2003; Andreou \& Rapsomanikis, 2009).

Ressalta-se que a variação deste índice (IPC) não decorre apenas da contribuição petrogênica versus natural, dado que a combustão de biomassa vegetal também pode produzir IPC maiores que 3 e distribuições com $C_{\max }$ similares. Oros et al. (2006) reportaram valores de IPC de 2,8 a 11,8 para combustão de gramíneas, com $\mathrm{C}_{\max }$ em C31, C29 e C27. A queima de angiospermas também produz $\mathrm{C}_{\max }$ de $\mathrm{C} 27$ e C29 com valores de IPC entre 2,6 e 6,8 (Oros \& Simoneit., 2001a) enquanto a combustão de coníferas os valores de IPC são menores $\left(0,5\right.$ a 3,1) com $C_{\max }$ variando entre $\mathrm{C} 20$ e C33 (Oros \& Simoneit, 2001b). A queima de carvão, por outro lado, produz $C_{\max }$ que varia de C24 a C30 sem predomínio de compostos ímpares (Oros \& Simoneit, 2000).

Outra forma de determinar a importância relativa de fontes biogênicas e petrogênicas é dada pela estimativa da contribuição de n-alcanos derivados de ceras cuticulares de plantas superiores (Kavouras et al., 1999; Simoneit, 1989; Simoneit et al., 1991a, 1991b; Ladji et al., 2009). Este índice é calculado com base nos compostos de maior peso molecular pela Equação 1, a partir do C23 e, valores negativos encontrados são substituídos por zero. Esta estimativa aparece na literatura identificada como WNA, sigla em inglês para Wax Normal Alkane. Os valores em percentuais para os $\mathrm{n}$-alcanos encontrados nas amostras, em medianas, são: 12,0\% para o Centro; 18,3\% para Campos Elíseos; 20,6\% para Copacabana; 24,9\% para Niterói; 28,7\% para Seropédica e; 17,9\% para São João de Meriti (Figura 43).

$$
\text { WNA } C_{n}=\left[C_{n}\right]-\left[\left(C_{n+1}\right)+\left(C_{n-1}\right)\right] / 2
$$



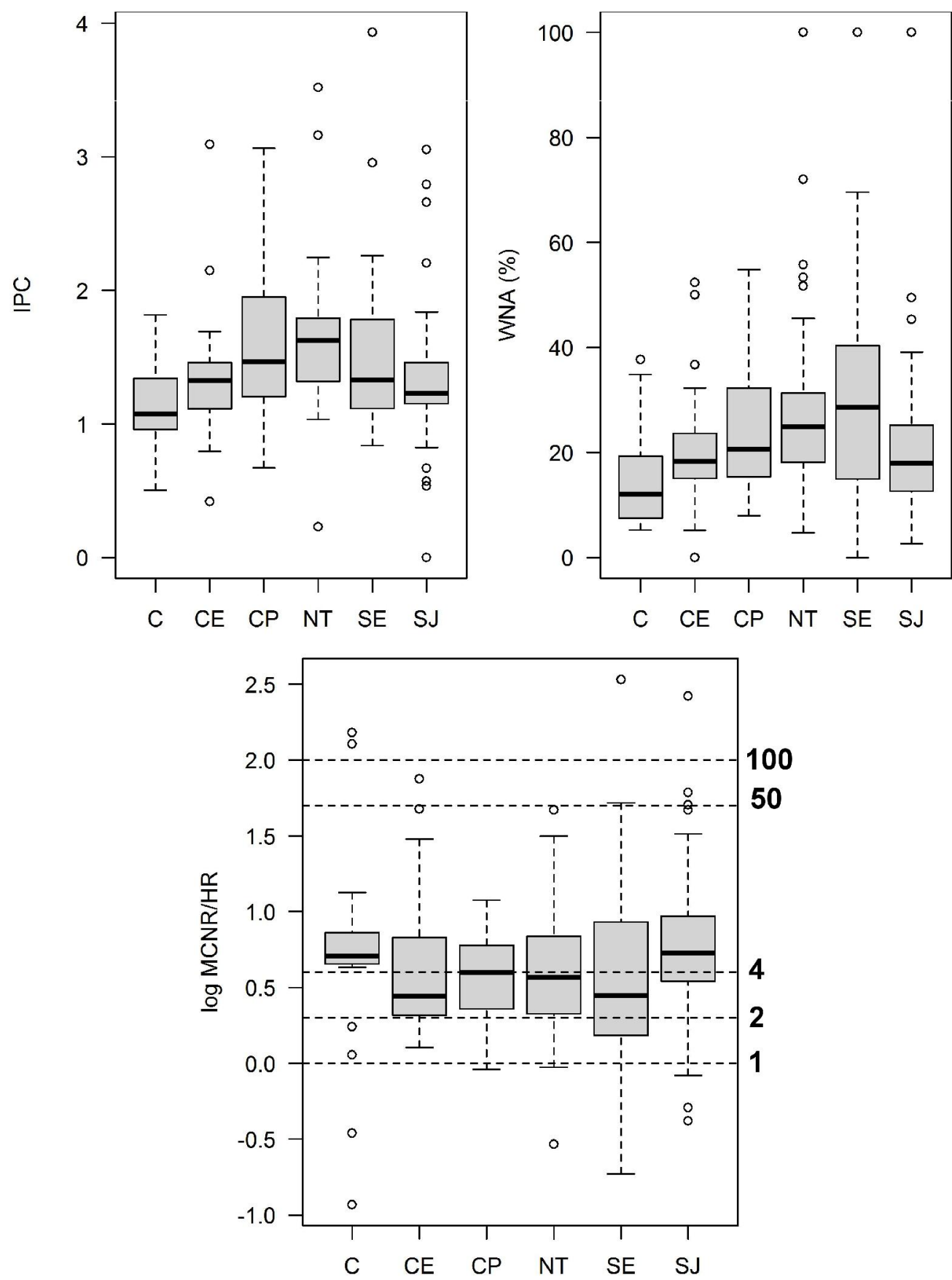

Figura 43 - Resultados dos Índices de Preferência de Carbono, Cálculo da contribuição natural de vegetais superiores (WNA \%) e da razão entre a Mistura Complexa Não Resolvida e os Hidrocarbonetos Resolvidos (MCNR/HR) para as estações de coleta no ano de 2011.

Os resultados deste índice estão na faixa daqueles do estudo de Ladji et al. (2009) para Algeres, Algeria. Bi et al. $(2003,2008)$ reportam uma variação entre $1,05-7,54 \%$ e $9,6-15 \%$ em períodos diferentes para cidade em 
desenvolvimento no sul da China. Mesmo em locais de maior contaminação, como Pequim, são encontrados valores entre 16 e 29,3\% (Li et al., 2003). Nascimento (2006) reporta as diferenças nas emissões biogênicas entre as cidades de São Paulo (8-10\%), Bogotá (6\%) e Buenos Aires (8\%) enquanto Kavouras et al. (2001) reportam o valor de médio de 19,9\% para a cidade de Santiago, Chile. Azevedo et al. (1999) reportam valor de 9,8\% para amostra coletada na Cinelândia, valor próximo a mediana da estação do Centro neste estudo. Os valores reportados nas demais estações condizem com os resultados obtidos aqui, à exceção da amostra do Túnel Rebouças, de 2,5\% (Azevedo et al., 1999), o que se explica pelas condições de coleta nesta área.

Os índices calculados devem ser avaliados com cuidado dado que a partição dos compostos de diferentes massas moleculares entre a fase gás e particulado não é igual. Analisando a distribuição de n-alcanos observa-se a sobreposição de fontes nas estações, mas a concentração de cada faixa de distribuição pode não expressar diretamente à quantidade emitida.

Outra observação importante é que alguns dos valores extremos obtidos para o WNA, como o de $100 \%$, referem-se a amostras que apresentaram nalcanos próximos ao limite de detecção. Estas amostras, apesar de indicarem nalcanos unicamente de origem natural contêm Mistura Complexa Não Resolvida (MCNR), característica de fonte petrogênica. Uma quantidade maior de amostra provavelmente permitiria um calculo mais acurado. Os valores do IPC e do WNA servem de comparação entre as estações, destacando a maior contribuição natural em Seropédica e Niterói. Estes índices também destacam a maior emissão antrópica de hidrocarbonetos nas estações do Centro, Campos Elíseos e São João de Meriti.

A razão $M C N R / H R$ pode ser usada para verificar a magnitude da contribuição de produtos de petróleo para aerossóis atmosféricos. A MCNR consiste majoritariamente de compostos de cadeias lineares ligadas a pontos de ramificação em forma de "T" (Gough \& Rowland, 1990) e sua presença na atmosfera é predominantemente derivada da utilização de combustíveis fósseis cujo componente principal das exaustões de motores a gasolina e diesel é o óleo lubrificante (Simoneit, 1984; Rogge et al., 1993a; Simoneit \& Mazurek, 1982). Rogge et al. (1993b) reportam valores para a razão MCNR/HR de 5,5 para motores de automóveis equipados com catalisador e 9,3 para motores de caminhões movidos a diesel. Em geral utiliza-se o valor de 4 ou superior para esta razão como indicativo de emissão veicular. (Kavouras et al., 2001) 
Emissões derivadas de plantas não exibem MCNR e, portanto a relação pode ser usada para indicar de contaminação petrogênica (Simoneit \& Mazurek, 1982). Emissões atmosféricas proveniente da queima de diferentes tipos de biomassa vegetal emitem pouca MCNR apresentando baixos valores para a razão acima, próximos a 1 (Oros et al., 2006; Oros et al., 2001a; 2001b). Oros et al. (2001b), entretanto, destacam que os baixos valores e a variabilidade não permitem diferenciar os diferentes tipos de combustão de biomassa, apenas destacá-los de fontes petrogênicas. Oros \& Simoneit (2000) reportam valores entre 2,9 e 3,3 para diferentes emissões da queima de carvão.

As medianas de MCNR/HR para as estações foram de 5,08 para o Centro, 2,76 para Campos Elíseos, 3,97 para Copacabana, 3,70 para Niterói, 2,80 para Seropédica e 5,35 para São João de Meriti (Figura 43). Todas as estações apresentam contribuição veicular em diferentes níveis, nas quais se destacam as estações do Centro e São João de Meriti como as de maiores aportes. Esta variação entre locais está coerente com o reportado por Azevedo et al. (1999) para o Rio de Janeiro: valores de 1,9 e 2,1 para a Floresta da Tijuca e Quinta da Boa Vista e 4,4 e 4,6 para a Cinelândia e Túnel Rebouças.

Azevedo et al. (2002) encontrou variações similares entre áreas urbanas e rurais no nordeste do Estado do Rio de Janeiro. Vasconcellos et al. (2010) reportam valores médios para este índice entre 9 e 11 para o material particulado atmosférico da cidade de São Paulo. Os autores sugerem que os valores da razão superiores aos de amostras de Bogotá e Buenos Aires derivam da alteração da razão MCNR/HR na mistura de combustíveis usada no Brasil, ainda segundo os autores carentes de estudos mais detalhados.

Observa-se que existe uma grande variabilidade da MCNR/HR nas estações de estudo, com alguns valores extremamente altos. Conforme demonstrado anteriormente no subcapítulo 5.3 as concentrações reportadas são consideradas baixas comparadas àquelas de outros trabalhos. Não é observada grande variação na concentração de MCNR que justifique os elevados valores obtidos para a razão em algumas amostras. Altos valores resultam da menor concentração de Hidrocarbonetos Resolvidos (HR). Como a MCNR é relativamente inerte na atmosfera e à degradação biológica (Gough \& Rowland, 1990; Killops \& Al-Jubooti, 1990) e é encontrada em todos os tipos de emissões veiculares (Simoneit, 1984; Rogge et al., 1993a; Simoneit \& Mazurek, 1982; Rogge et al., 1993b), sua concentração provavelmente é menos sujeita a variações. As variações distintas da MCNR e de HR resultam no aparecimento 
de valores extremos da razão entre as variáveis, que podem ultrapassar o valor de 100.

Em Seropédica e Campos Elíseos as medianas de MCNR/HR foram inferiores a 3. Em Seropédica, por se tratar de uma zona com características mais rurais, são esperados menores valores desta razão em relação às áreas urbanas, conforme observado na literatura (Omar et al., 2007; Simoneit, 1984; Azevedo et al., 1999, 2002; Li et al., 2003). Em Campos Elíseos os valores provavelmente estão associados à combinação de fontes, já que os resultados obtidos para MCNR/HR são similares aos avaliados em estudos de comprovada sobreposição de aportes (Simoneit, 1984; Bi et al., 2003; Mostafa et al., 2009, Azevedo et al. 2002). Esta estação além da movimentação de veículos é cercada por indústrias e encontra-se na base da Serra do Mar, região com vasta área de floresta.

Entretanto, apesar da localização geográfica e atividades em Campos Elíseos sugerirem mais de uma fonte de hidrocarbonetos, existe um forte indicativo de origem comum nas amostras desta estação. Observa-se na Figura 44 boa correlação $\left(r_{s}=0,91\right)$ entre os Hidrocarbonetos Resolvidos e a Mistura Complexa Não Resolvida, cuja avaliação é utilizada para indicar origem comum (Bouloubassi \& Saliot, 1993). Embora não se possa descartar as contribuições naturais nesta estação os índices descritos neste subcapítulo demonstraram que sua influência é muito reduzida. O que provavelmente ocorre neste local de estudo são emissões constantes e proporcionais durante o ano e, por este motivo, há indicação de fonte comum.

As correlações encontradas para as estações e que aparecem na Figura 44 foram todas significativas pelos critérios deste estudo. Observa-se que a variabilidade encontrada nas diferentes estações surge da maior ou menor influência de observações fora da distribuição, sendo estas menos relevantes para Campo Elíseos $\left(r_{s}=0,91\right)$, seguido das estações de Copacabana $\left(r_{s}=0,71\right)$, Seropédica $\left(r_{s}=0,69\right)$, Centro $\left(r_{s}=0,63\right)$, São João de Meriti $\left(r_{s}=0,56\right)$ e Niterói $\left(r_{s}=0,52\right)$. Embora este tipo de avaliação seja mais aplicada a sedimentos sob poluição crônica os resultados sugerem uma escala decrescente de estabilidade entre as diferentes emissões. Esta observação, principalmente para São João de Meriti, corrobora as discussões realizadas no subcapítulo anterior sobre as possíveis razões para as baixas associações com o material particulado. 

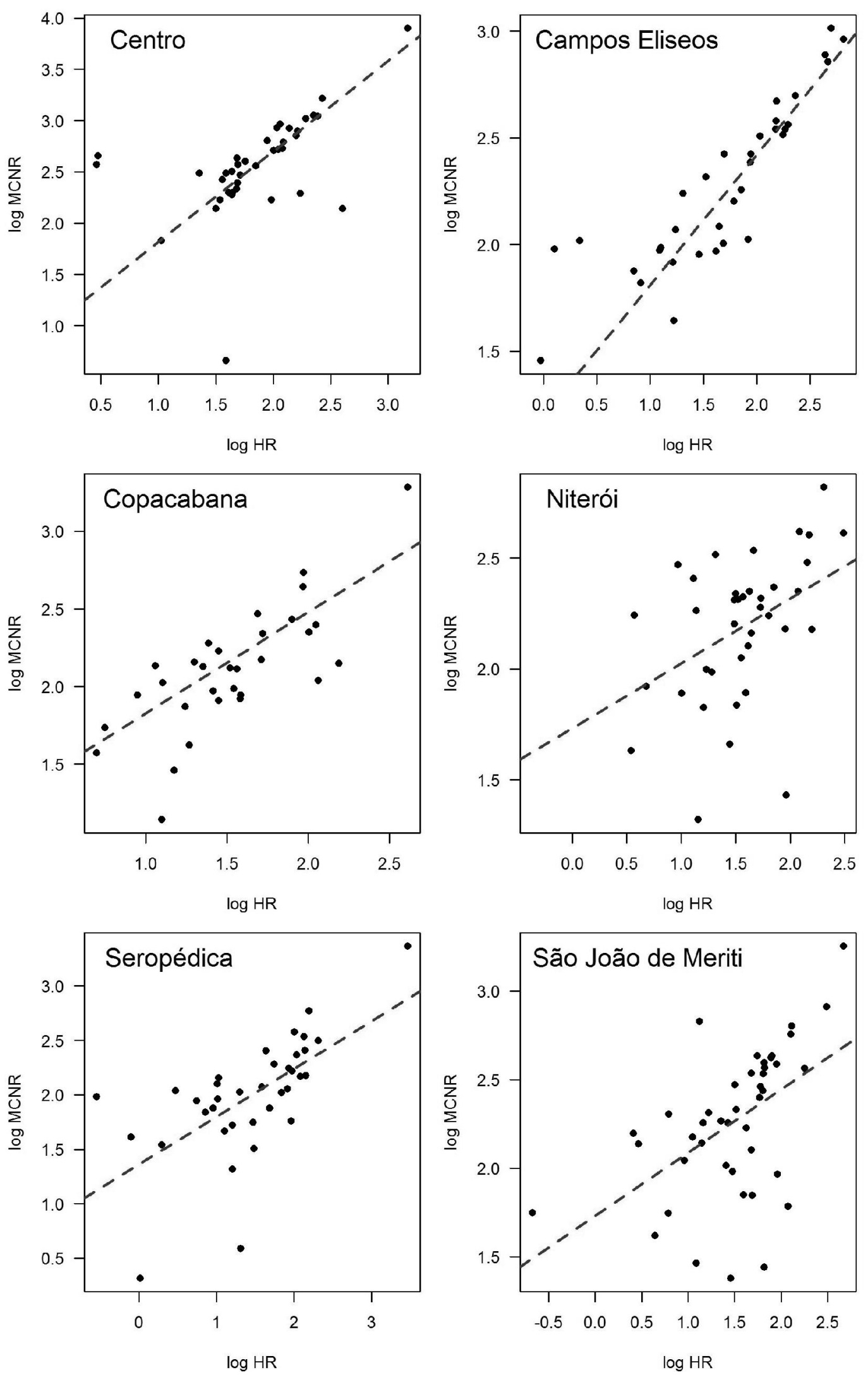

Figura 44 - Gráfico log-log da concentração da concentração de Hidrocarbonetos Resolvidos (HR) e da Mistura Complexa Não Resolvida (MCNR) 
As informações passíveis de serem extraídas a partir das razões acima comentadas sugerem uma forte componente antrópica proveniente de emissões veiculares, caracterizada pela abundância de MCNR. Apesar de sua menor contribuição, a influência natural também é observada e tem maior relevância na área de Seropédica decrescendo gradativamente para as demais estações, chegando a um mínimo no centro da cidade do Rio de Janeiro.

As ferramentas aqui utilizadas não permitem diferenciar com exatidão as contribuições naturais das derivadas de combustão de material vegetal. Ressalta-se também que a frota do Rio e Janeiro é da mais variada com veículos circulando em diversas condições, diferente do que ocorre nas caracterizações de emissões realizadas em ensaios controlados. Esta discrepância entre as condições de coleta e a caracterização das emissões impede que os índices sejam utilizados de maneira taxativa. 


\section{5 .2}

\section{Origem dos hidrocarbonetos aromáticos}

A distribuição dos hidrocarbonetos aromáticos nas estações pode ser verificada na Figura 45 e na Figura 46. Para a maioria das estações a distribuição é caracterizada pela predominância de compostos de massa 252, com destaque para o benzo(b)fluoranteno, e de massa 276. Apenas no Centro, e em menor escala em Copacabana, observa-se uma distribuição mais homogênea com maior concentração de compostos de menor massa molecular.

A tipologia dos HPAs é similar à de outros estudos realizados em Niterói e Rio de Janeiro (Pereira Netto et al., 2002; Pereira Netto et al. 2001), Duque de Caxias (Machado et al., 2009) e Cubatão (Allen et al., 2008). Pereira Netto et al. (2001) também destaca a contribuição de compostos de massa 228, benzo(a)antraceno e criseno, assim como também foi observado por Azevedo et al. (1999) para amostras dos Rio de Janeiro. Daisey et al. (1987) já observava predomínio de massa 276 nas amostras de particulado atmosférico desta área de estudo, mas com distribuição mais uniforme dos demais compostos.

Bourrote et al. (2005) também reportam na fração fina de aerossóis para a Cidade de São Paulo a predominância dos compostos indeno(1,2,3-cd)pireno, benzo(ghi)perileno e benzo(b)fluoranteno. Perfis estes semelhantes aos já reportados para esta cidade por Martinis et al. (2002) e Vasconcellos et al. (2003), Porto Alegre (Dallarosa et al., 2008), e alguns locais no exterior (Manoli et al., 2004; Ladji et al., 2009).

Embora exista semelhança na tipologia encontrada em vários centros urbanos, há variações reportadas na literatura tanto para diferentes locais de estudo quanto para o mesmo local. Em Niterói, Lima (1996) reporta presença de compostos de menor massa molecular, como o fenantreno e o benzo(a)antraceno, em concentrações similares aos compostos usualmente de maior abundância, benzo(b)fluoranteno e benzo(ghi)perileno. Marques et al. (2009), por exemplo, reportam uma tipologia de HPAs mais homogênea a partir do fluoranteno em amostras coletadas no campus da FIOCRUZ, Rio de Janeiro.

Quitério et al. (2007) também reportam maior abundância de fenantreno e antraceno para amostras da Região Metropolitana do Rio de Janeiro, assim como Dallarosa et al. (2005) para amostras coletadas ao sul do Estado do Rio Grande do Sul. Nascimento (2006) reporta para São Paulo a predominância de 
compostos de 5 anéis seguida dos compostos de 4 anéis, enquanto Bourotte et al. (2005) verificaram a predominância de compostos de 6 anéis para esta cidade. Todos estes estudos expressam a variabilidade da tipologia de HPAs dentro de uma mesma região de estudo.
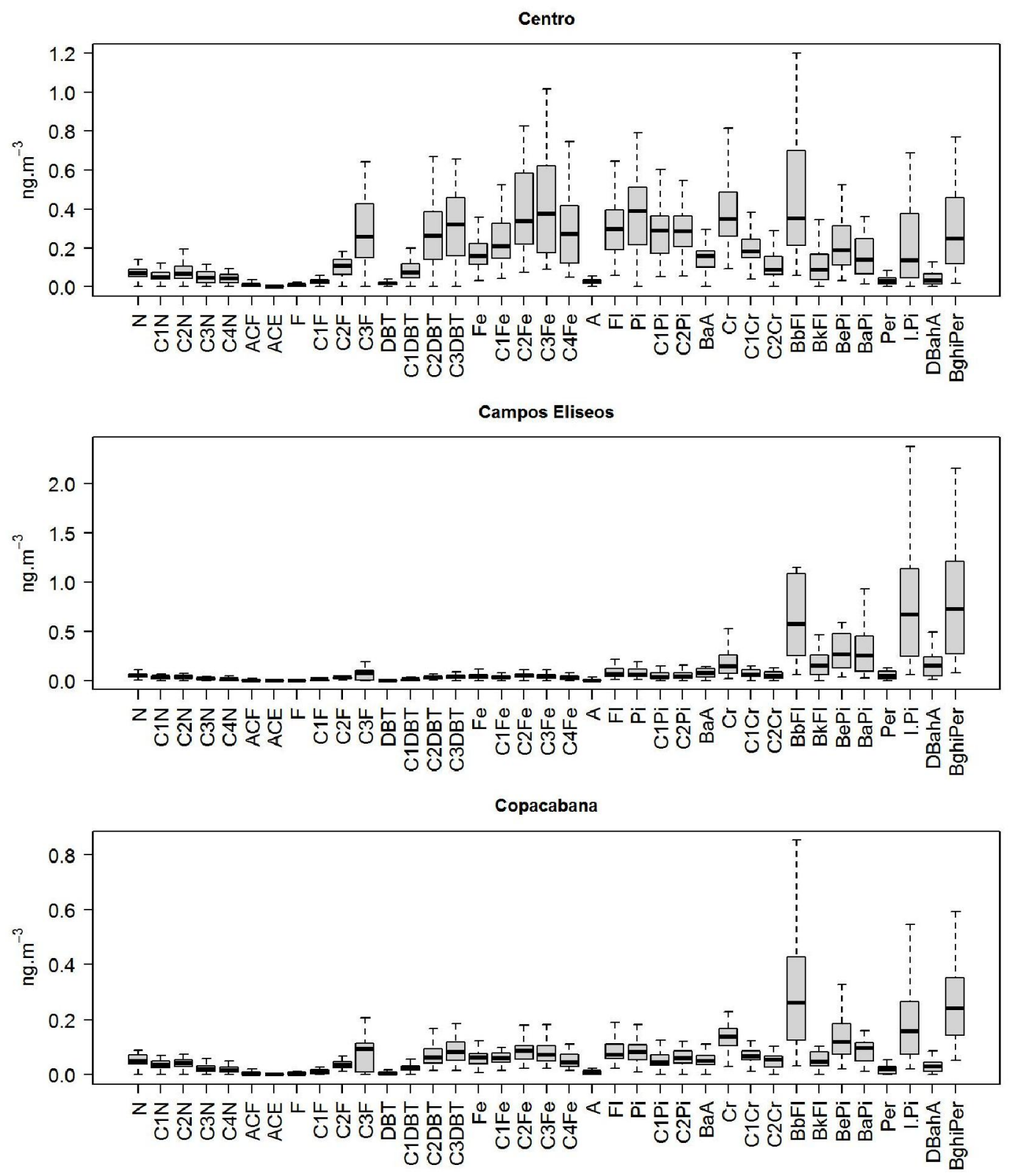

Figura 45 - Box-plot da tipologia de HPAs no material particulado atmosférico $\left(\mathrm{PM}_{2.5}\right)$, eliminados os outliers, amostrado durante o ano de 2011 nas estações do Centro, Campos Elíseos e Copacabana.

Alkurdi et al. (2013) encontram tipologia similar àquela do presente estudo para HPAs de alto peso molecular em ensaios de emissões veiculares, mas reportam maior contribuição de compostos mais leves. Ho et al. (2009) reportam compostos de 4 anéis como os mais abundantes na fase particulada e na fase 
gasosa em amostras provenientes de túneis de Hong Kong, similar à distribuição encontrada por Ré-Poppi e Santiago-Silva (2005) para a atmosfera de Campo Grande, Brasil. Alan et al. (2003) reportam elevadas contribuições de fluoranteno, pireno e fenantreno considerando-os bons indicativos de emissões veiculares para amostras do Reino Unido.
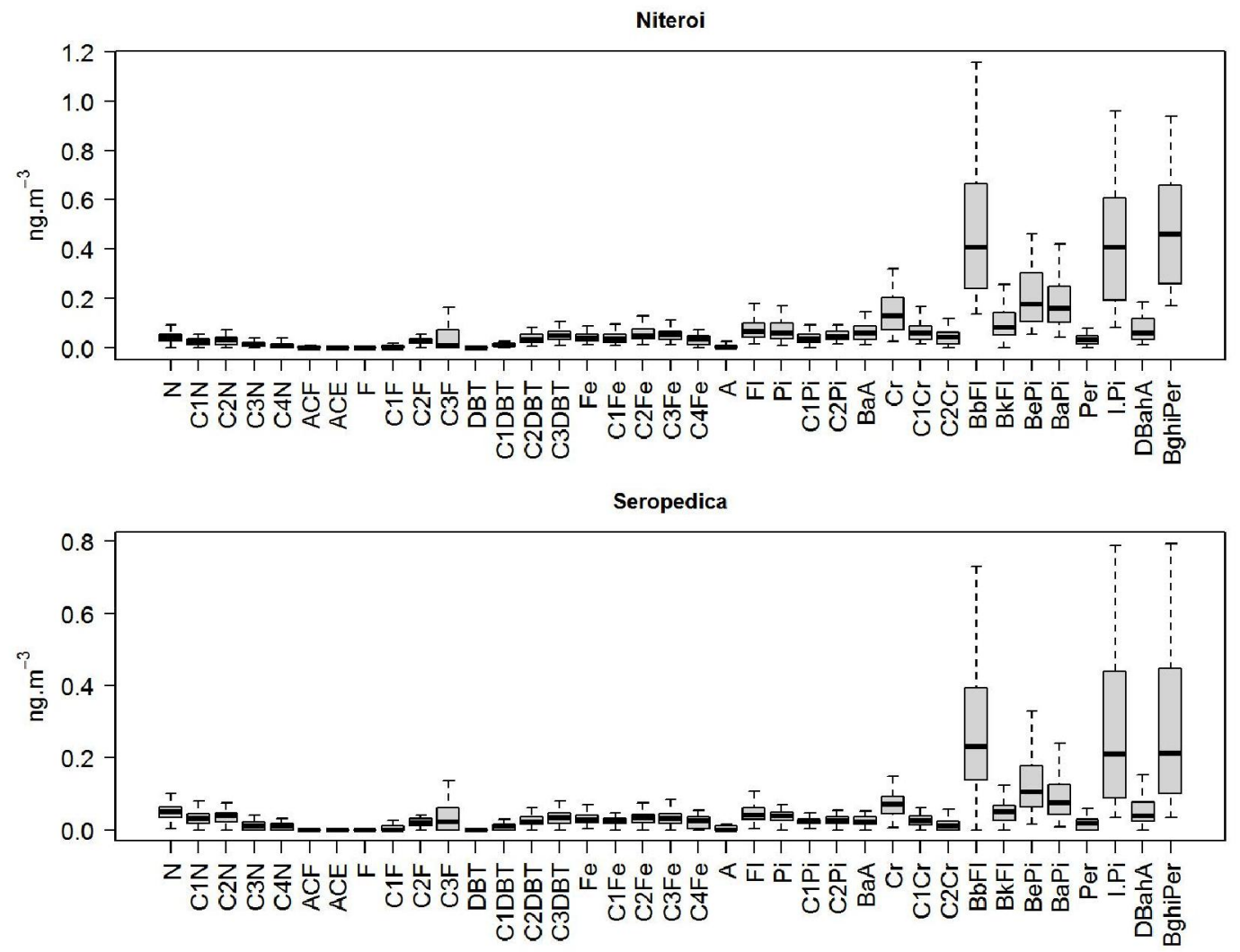

Sao Joao Meriti

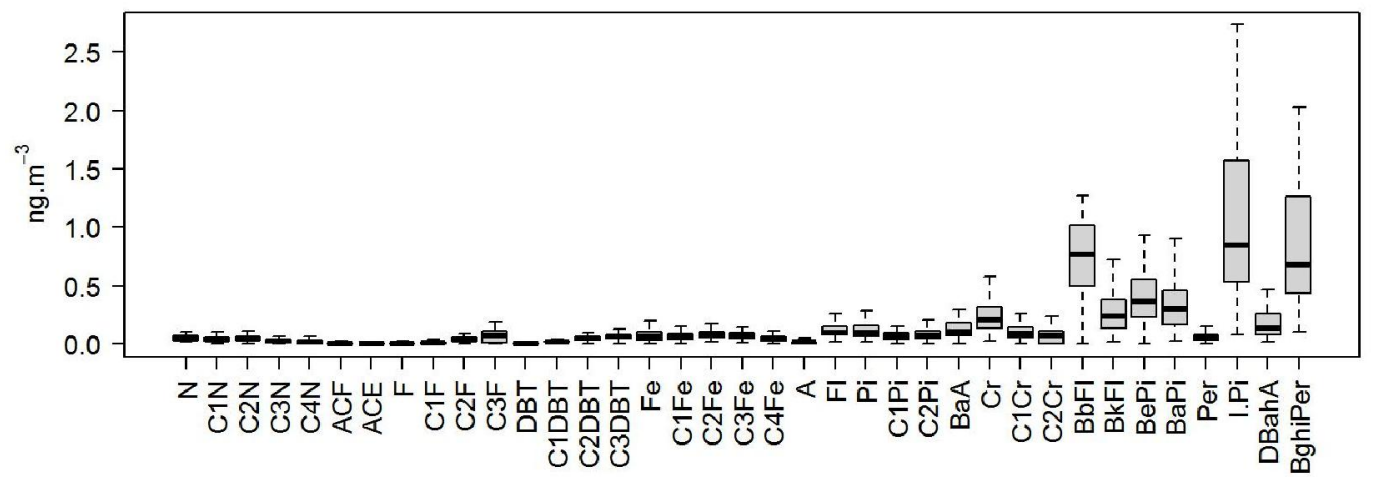

Figura 46 - Box-plot da tipologia de HPAs no material particulado atmosférico $\left(\mathrm{PM}_{2.5}\right)$, eliminados os outliers, amostrado durante o ano de 2011 nas estações de Niterói, Seropédica e São João de Meriti.

A comparação de tipologias de HPAs entre estudos realizados com diferentes tamanhos de partículas não compromete a avaliação de fontes. Apesar da partição de HPA na atmosfera entre as fases gasosa e particulado, a 
proporção relativa dos HPAs, e obviamente a razão entre estes se mantêm estável no material particulado apesar das variações de tamanho de partícula (Tobiszewski \& Namiesnik, 2012). Wang et al. (2010) não reportam diferenças entre as razões de amostras $\mathrm{PM}_{2.5-10}$ e $\mathrm{PM}_{2.5}$. Zhou et al. (2005) também reportam valores estáveis para as razões ao longo de uma gama de tamanhos de partícula. Este mesmo padrão é encontrado por Fang et al. (2006) em Taiwan e Dallarosa et al. (2008) para o Sul do Brasil. Tobiszewski \& Namiesnik (2012) reportam valores estáveis para as razões de HPAs para diferentes tamanhos de partícula, á exceção da razão envolvendo o composto benzo(a)pireno, como será discutido adiante. A mesma estabilidade das razões entre $\mathrm{PM}_{10}$ e PTS foi observado por Machado et al. (2009) para Duque de Caxias. Este comportamento ocorre, basicamente, porque a tipologia dos compostos e a escolha das razões consideram semelhanças químicas.

Embora não sejam reportadas diferenças significantes entre os diferentes tamanhos de aerossóis na literatura o mesmo não ocorre para a fase gasosa, não contemplada neste estudo. Contini et al. (2011) demonstram claramente as diferenças em razões de HPAs considerando as diferentes fases estudadas.

Apesar da tipologia marcante para as diferentes estações, assim como as diferenças entre o Centro e Copacabana e as demais estações, é difícil estabelecer indicativos de fontes apenas através deste tipo de avaliação. Embora a literatura voltada à caracterização de emissões veiculares e de queima de biomassa seja abundante, a variabilidade destas e a sobreposição de tipologias compromete esta abordagem.

Fang et al. (2010) reporta os HPAs fenantreno, fluoranteno, pireno, indeno $(1,2,3,-$-cd)pireno e benzo(ghi)perileno como os mais abundantes e atribui esta feição a fontes mistas de carvão, diesel e gasolina. Combustão de carvão emitem majoritariamente fenantreno e antraceno, principalmente alquilados (Oros \& Simoneit, 2000). O mesmo padrão encontra-se para a queima de biomassa vegetal, associada também a altas emissões de fluoranteno e pireno, enquanto compostos de maior peso molecular são minoritários (Oros \& Simoneit, 2001a, 2001b; Oros et al., 2006). Os autores apontam que estes HPAs emitidos também são encontrados em emissões veiculares (Rogge et al., 1993a; Simoneit, 1989) e portanto não podem ser usados para identificar a combustão de biomassa. A tipologia de fenantrenos e dibenzotiofenos, incluindo seus respectivos compostos alquilados, já foi reportada por Simoneit (1984) como derivada de queima de material vegetal. 
Dyremark et al. (1995) reportam o fluoranteno e o pireno como as principais emissões de carvão vegetal enquanto Barbosa et al. (2006) reportam para emissão fenantreno e antraceno como principais poluentes. Andrade et al. (2012) reportam que na época de queima relacionado ao plantio de cana-deaçúcar as concentrações de fenantreno, fluoreno e pireno se elevam, pois estão associados a material fino (Simoneit, 2002; Santos et al., 2002; Hall et al., 2012). Abrantes et al. (2004) em estudo de emissões de diesel observaram maior contribuição de pireno, fluoranteno e fenantreno semelhantes aos dados de Rogger et al. (1999a) para este mesmo combustível e, ainda reportam importante contribuição de alquilfenantrenos, enquanto a queima de gasolina produz relevantes quantidades de compostos mais pesados como o benzo(ghi)perileno. Borras et al. (2009) reportam que o biodiesel produz emissões com tipologia mais homogênea dos HPAs quando comparada às emissões do diesel comum, mas a concentração total emitida pelos diferentes combustíveis praticamente não varia.

Estudos de diferentes emissões caracterizam o fluoranteno e o pireno como bons marcadores moleculares para emissões do diesel enquanto o benzo(ghi)perileno e o indeno(1,2,3-cd)pireno seriam bons marcadores para gasolina (Ho et al., 2009; Rogge et al., 1993a; Westerholm et al., 1988). Bergvall \& Westerholm (2009) e Riddle et al. (2007) reportam elevadas emissões de benzo(b)fluoranteno, indeno(1,2,3-cd)pireno, benzo(ghi)perileno e benzo(a)pireno de veículos à gasolina. Marr et al. (1998) reportam que significante fração de compostos de baixo peso molecular coletados em particulados da exaustão de motores a diesel provém da queima incompleta de combustível e do óleo lubrificante.

Vasconcellos et al. (2003) associam para a área metropolitana de São Paulo as concentrações de fluoranteno, criseno e pireno à emissões de veículos à gasolina enquanto as concentrações de criseno, pireno e benzo(a)antraceno à emissão de motores a diesel. Quitério et al. (2007) utiliza fluoranteno, pireno, fenantreno e antraceno como indicadores de diesel e os compostos benzo(a)antraceno, benzo(b)fluoranteno, benzo(k)fluoranteno, benzo(ghi)perileno e benzo(a)pireno como indicativos de emissões de gasolina, assim como Guo et al. (2003b) para a atmosfera de Hong Kong. Fromme et al. (1998) entretanto utiliza os compostos benzo(a)pireno, pireno, benzo(a)antraceno e indeno (1,2,3-cd)pireno para descrever a emissão pelo aquecimento a carvão enquanto o benzo(ghi)perileno e o coroneno são utilizados para comprovar emissões veiculares. Ho et al. (2009) utiliza a boa 
correlação entre os compostos fluoranteno e pireno e entre o benzo(ghi)perileno e indeno(1,2,3-cd)pireno para comprovar as emissões de diesel e gasolina, respectivamente, na atmosfera de Hong Kong.

Embora os estudos mostrem tendências parecidas observa-se uma grande variabilidade na tipologia de HPAs entre estes e o uso de diferentes marcadores para identificar uma mesma origem. Abrantes et al. (2004) concluem que devido a grande número de variáveis nos ensaios de emissões veiculares há grandes variações no perfil de emissão de HPAs. Estes autores, por exemplo, citam que as razões de HPAs encontradas para as emissões são inconsistentes com os dados de campo de Martinis et al. (2002), à exceção da razão envolvendo os compostos benzo(a)pireno e benzo(ghi)perileno. Ressalta-se ainda que todos os ensaios de emissões veiculares sejam realizados sob condições controladas e, portanto, não consideram a variação de temperatura ambiente que influencia na partição entre gás e partícula e a variabilidade da frota e seus mais diversos estados de conservação.

Pode-se inferir a principio pelas distribuições encontradas que as amostras do Centro e de Copacabana, principalmente as do Centro, demonstram maior influencia de veículos à diesel se comparadas as demais estações. Estas duas estações são caracterizadas pela maior abundância de compostos de menor peso molecular. As emissões veiculares à gasolina, caracterizada principalmente pelo benzo(ghi)perileno, é marcante em todas as estações, inclusive Centro e Copacabana.

A tipologia de HPAs no Centro também poderia ser oriunda da queima de biomassa vegetal, mas esta avaliação não é compatível com a área de estudo. A observação de perfil de queima de biomassa seria mais esperada para estações rurais, como Seropédica ou em zonas industriais, como Campos Elíseos. Embora os produtos das emissões de queima de biomassa possam ser transportadas por grandes distâncias, como observado para São Paulo por Maritinis et al. (2002) e para Porto Alegre por Dallarosa et al. (2005, 2008), não se observa uma contribuição homogênea entre as estações. As diferenças espaciais na tipologia de HPAs sugerem que a fonte de HPAs de menor peso molecular seja predominantemente local. Emissões de combustível não queimado também podem contribuir para o perfil encontrado no Centro. Estas suposições são apenas uma avaliação preliminar das distribuições, e outras ferramentas devem ser utilizadas para confirmar estas indicações.

Apesar das tipologias encontradas sugerirem a predominância de emissões veiculares relacionadas à utilização de combustível leve, a 
confirmação desta origem não pode se basear somente nesta avaliação simples, dada a variabilidade entre os estudos. A diversidade de fontes pode ser também caracterizada através de razões entre compostos específicos, denominadas diagnóstico. Diversos estudos caracterizaram faixas de valores para a razão entre indeno(1,2,3-cd)pireno e benzo(ghi)perileno, IPi/(IPi+BPe) que indicariam presença de: gasolina se igual a 0,18 ; diesel se igual a 0,37 ; carvão se igual a 0,56 e; vegetação se igual a 0,62 (Grimmer et al., 1983; Ho et al., 2009).

Os valores limítrofes de cada fonte, entretanto, não são um consenso na literatura. Kavouras et al. (2001), por exemplo, utiliza valor entre 0,35 e 0,70 para emissões a diesel nesta razão. Yunker et al. (2002) compila 37 trabalhos diferentes envolvendo petróleo, produtos de petróleo, amostras de combustão e amostras ambientais e delimitaram valores entre 0,2 e 0,5 para combustão de material petrogênico e maior que 0,5 para combustão de madeira, vegetação e carvão (Figura 47).
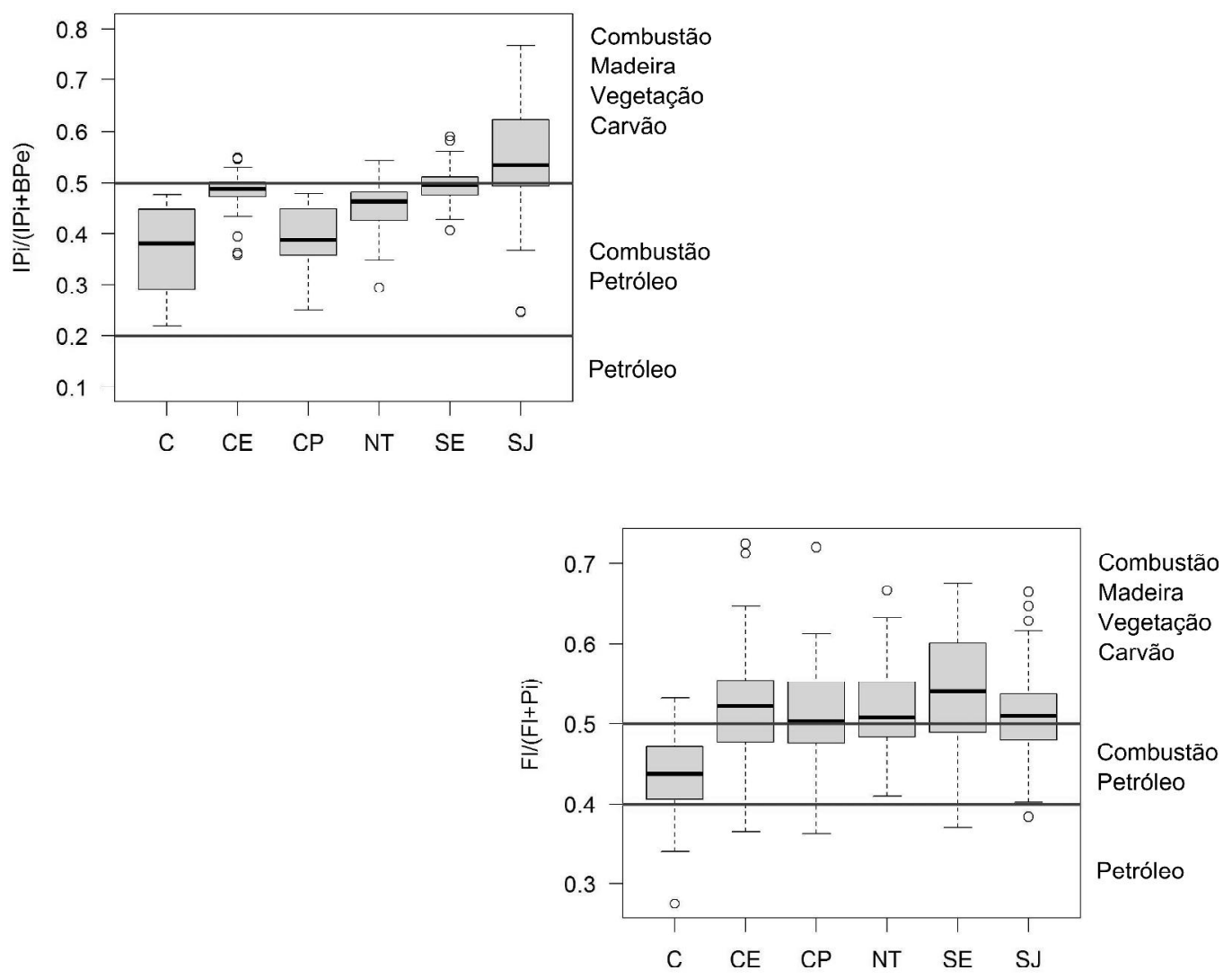

Figura 47 - Box-plot das razões $\mathrm{IPi} /(\mathrm{IPi}+\mathrm{BPe})$ e $\mathrm{Fl} /(\mathrm{Fl}+\mathrm{Pi})$ para o material particulado das estações de coleta.

Embora estes mesmos autores tenham estabelecido para a razão $\mathrm{Fl} /(\mathrm{Fl}+\mathrm{Pi})$ valores entre 0,4 e 0,5 para combustão de petróleo os dados 
encontrados sugerem que os limites estabelecidos por outros estudos (Rogge et al., 1993a; Fang et al., 2004) $>0,5$ para diesel e $<0,5$ para gasolina, sejam de melhor aplicação à comparação dos dados. As amostras de campo, porém, resultam da contribuição de fontes diversas e de emissões de diferentes tipos de frota e portanto torna-se menos exata a especificação de origem através de valores limítrofes de razões estabelecidos para uma determinada fonte.

Assim, a interpretação dos dados deve ser realizada observando o gradiente da influencia de cada fonte entre as estações. Como explicado anteriormente o benzo(ghi)perileno é um traçador de gasolina, cuja maior influência observa-se no Centro e é caracterizada por menores valores da razão $\mathrm{IPi} /(\mathrm{IPi}+\mathrm{BPe})$. Baixos valores desta razão $(<0,4)$ são condizentes com o aporte de veículos à gasolina enquanto valores próximos a 0,5 seriam característicos de emissões de veículos à diesel (Caricchia et al., 1999; Ravindra et al., 2008a), o que condiz com os gradientes dos valores para a razão $\mathrm{Fl} /(\mathrm{Fl}+\mathrm{Pi})$ entre as estações segundo as observações de Rogge et al. (1993a) e Fang et al. (2004) para os diversos combustíveis. O gradiente encontrado sugere maior influência de diesel nas estações de São João de Meriti e Campos Elíseos. Esta avaliação entretanto se opõe ao que é apresentado na discussão da tipologia de HPAs para a estação do Centro o que, além de alerta sobre a capacidade de discriminação das razões, sugere uma maior probabilidade da tipologia de HPAs leves ser fruto de emissão de combustível não queimado.

Da mesma forma, apesar das indicações das duas razões anteriormente apresentadas, as amostras de São João de Meriti e Campos Elíseos não possuem tipologia característica de diesel, conforme já discutido. Isto corrobora que as razões diagnósticas devem ser avaliadas em conjunto com uma avaliação da influencia da sobreposição de aportes entre as estações e usando cautela na definição de predominância. Kuo et al. (2013) reportam valores para razões em um estudo comparativo entre gasolina e diesel que corroboram as observações, usando limites diferentes daqueles estabelecidos por Yunker et al. (2002) e dos dados de Rogge et al. (1993a) e Fang et al. (2004), em algumas ocasiões.

Dallarosa et al. (2005) encontrou valor da razão de $\mathrm{IPi} /(\mathrm{IPi}+\mathrm{BPe})$ de 0,35 para Porto Alegre, condizente com as observações deste estudo para o Centro. A partir dos dados de Azevedo et al. (1999) é possível observar que a razão $\mathrm{IPi} /(\mathrm{IPi}+\mathrm{BPe})$ apresenta valores de 0,32 para a estação da Cinelândia, 0,30 para a Quinta da Boa Vista e 0,72 para a estação na Floresta da Tijuca. Os dados destes autores são assim mais condizentes com os limites pré-estabelecidos na 
literatura para esta razão. Estes autores ainda reportam a razão $\mathrm{Fl} /(\mathrm{Fl}+\mathrm{Pi})$ de 0,40 e 0,34 para o Túnel Rebouças e Cinelândia e 0,45 e 0,52 para a Quinta da Boa Vista e Floresta da Tijuca. A partir dos dados de Lima (2006) observa-se para Niterói valor médio da razão $\mathrm{IPi} /(\mathrm{IPi}+\mathrm{BPe})$ de $0,20 \pm 0,08$ e $\mathrm{Fl} /(\mathrm{FI}+\mathrm{Pi})$ de $0,43 \pm 0,08$.

Machado et al. (2009) reportam para Duque de Caxias valores da razão $\mathrm{Fl} /(\mathrm{Fl}+\mathrm{Pi})$ de 0,37 e 0,36 para $\mathrm{PTS}$ e $\mathrm{PM}_{10}$ e 0,37 para a razão $\mathrm{IPi} /(\mathrm{IPi}+\mathrm{BPe})$ nas duas frações. A área de estudo destes autores encontra-se sob forte influência de veículos movidos a diesel. Estes resultados contestam aqueles obtidos por Allen et al. (2008) que reportam o valor de 0,52 para a razão $\mathrm{Fl} /(\mathrm{Fl}+\mathrm{Pi})$ em área onde a principal fonte de emissão também provém de veículos a diesel. Os dados de Pereira Netto et al. $(2001,2002)$ permitem calcular médias entre 0,42 e 0,47 para a razão $\mathrm{IPi} /(\mathrm{IPi}+\mathrm{BPe})$ e, para a razão $\mathrm{Fl} /(\mathrm{FI}+\mathrm{Pi})$, médias entre 0,46 e 0,43 . Estes estudos consideraram 2 períodos de coleta em Niterói e apenas um na cidade do Rio de Janeiro.

Marques et al. (2009) para amostras coletadas na FIOCRUZ, sob forte influencia da Avenida Brasil, reportam valores de 0,68 para a razão $\mathrm{Fl} /(\mathrm{FI}+\mathrm{Pi})$ em $\mathrm{PM}_{10}$. O valor encontrado pelos autores está de acordo com o estudo de Manoli et al. (2004) para rodovias com elevados fluxos veiculares. Estes autores (Manoli et al., 2004), entretanto, reportam que os valores calculados por eles para emissões à gasolina e diesel foram inferiores ao normalmente reportado na literatura (Sicre et al., 1987; Rogge et al., 1993a). Altos valores da razão $\mathrm{Fl} /(\mathrm{Fl}+\mathrm{Pi})$ também são reportados por Dallarosa et al. (2008) para áreas de tráfego intenso em Porto Alegre.

$\mathrm{Na}$ Figura 48 observa-se a distribuição das razões $\mathrm{BaA} /(\mathrm{BaA}+\mathrm{Cr})$ e $\mathrm{BaPi} /(\mathrm{BaPi}+\mathrm{Cr})$ para o material particulado das estações de coleta. Akyüz \& Çabuk (2010) reportam para a razão $\mathrm{BaA} /(\mathrm{BaA}+\mathrm{Cr})$ valores entre 0,2 e 0,35 para emissão de carvão e maiores que 0,35 para emissões veiculares, de acordo com o proposto por Yunker et al. (2002) para emissões de combustão, valores abaixo de 0,2 seriam característicos de fontes petrogênicas. Para a razão $\mathrm{BaA} /(\mathrm{BaA}+\mathrm{Cr})$, observa-se que grande parte das amostras estão dentro da faixa de valores relativos à mistura de fontes proposta por Yunker et al. (2002), sem variações significativas entre as estações.

Quitério et al. (2007), baseados nas observações de outros trabalhos (Gogou et al., 1996; Khalili et al., 1995; Manoli et al., 2004), reportam média de 0,23 para a razão $\mathrm{BaA} /(\mathrm{BaA}+\mathrm{Cr})$ e consideram este valor típico para emissões de veículos leves registradas em amostras de $\mathrm{PM}_{10}$. Allen et al. (2008) reportam 
o valor da razão $\mathrm{BaA} /(\mathrm{BaA}+\mathrm{Cr})$ de 0,61 para frota predominantemente a diesel. Marques et al. (2009) reportam para o campus da FIOCRUZ valores da razão $\mathrm{BaA} /(\mathrm{BaA}+\mathrm{Cr})$ e $\mathrm{BaPi} /(\mathrm{BaPi}+\mathrm{Cr})$ de 0,35 e 0,42, respectivamente, associados ao alto fluxo de veículos da Avenida Brasil.
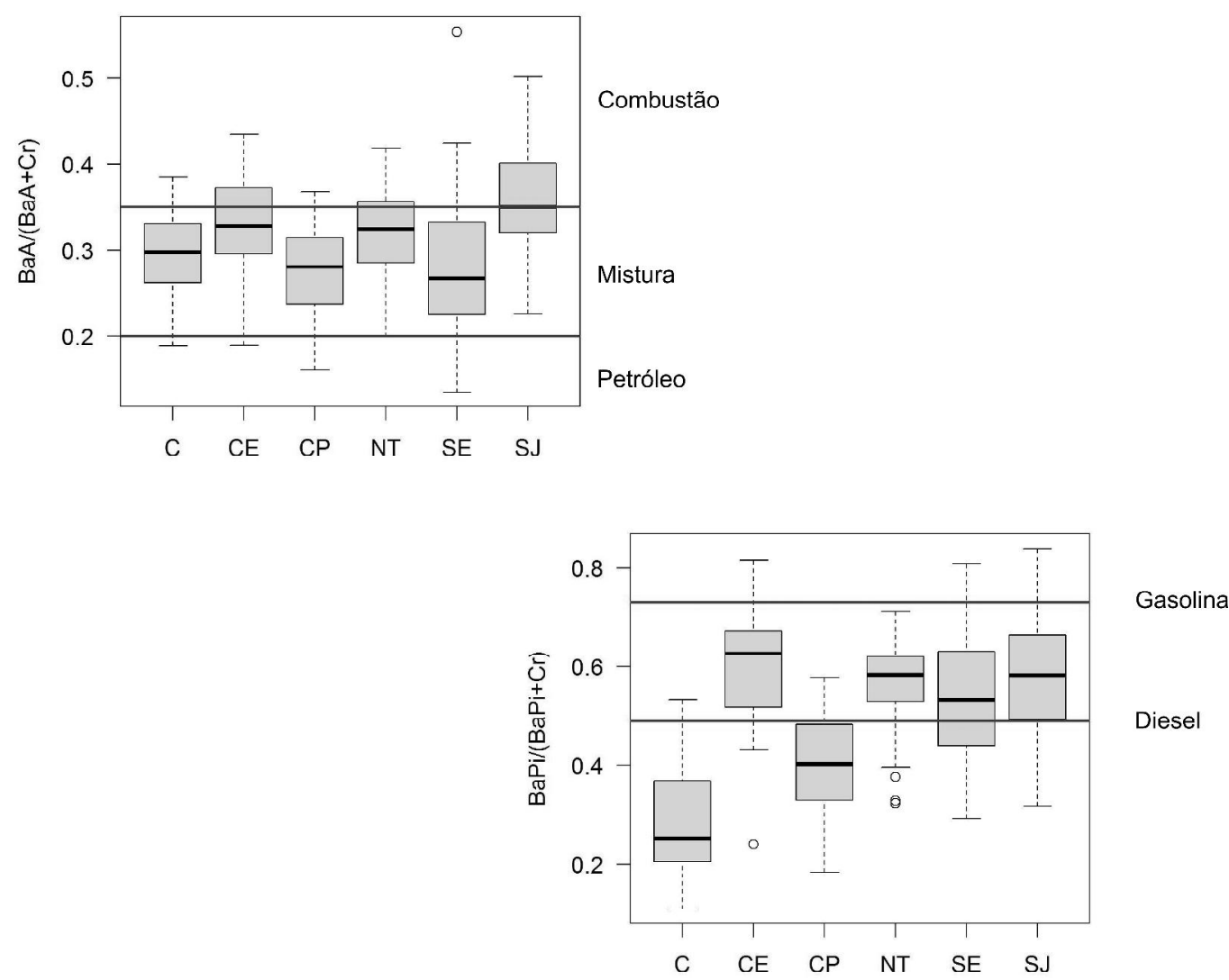

Figura 48 - Box-plot das razões $\mathrm{BaA} /(\mathrm{BaA}+\mathrm{Cr})$ e $\mathrm{BaPi} /(\mathrm{BaPi}+\mathrm{Cr})$ para o material particulado das estações de coleta.

A razão $\mathrm{BaPi} /(\mathrm{BaPi}+\mathrm{Cr})$, por outro lado demonstra diferenças para as estações de Centro e Copacabana. As indicações de fontes de diesel, entretanto, se contrapõem as indicações das razões $\mathrm{IPi} /(\mathrm{IPi}+\mathrm{BPe})$ e $\mathrm{Fl} /(\mathrm{FI}+\mathrm{Pi})$ discutidas anteriormente, o que aumenta a complexidade de interpretação e especificação das fontes predominantes. Khalili et al. (1995) e Guo et al. (2003b) propuseram valor da razão $\mathrm{BaP} /(\mathrm{BaP}+\mathrm{Cr})$ em torno de 0,49 para emissões a diesel e 0,73 para gasolina. Estas indicações não estão de acordo as razões e tipologias discutidas anteriormente.

Azevedo et al. (1999) reportam valores da razão $\mathrm{BaAn} /(\mathrm{BaA}+\mathrm{Cr})$ de 0,47 e 0,15 para amostras do Túnel Rebouças e Cinelândia, respectivamente. Lima (2006) obteve em média para esta razão $\mathrm{BaAn} /(\mathrm{BaA}+\mathrm{Cr}) 0,70 \pm 0,20$ e para a razão $\mathrm{BaP} /(\mathrm{BaP}+\mathrm{Cr}) 0,45 \pm 0,12$. Machado et al. (2009) reportam para Duque de 
Caxias valores médios de 0,39 e 0,40 para a razão $\mathrm{BaA} /(\mathrm{BaA}+\mathrm{Cri})$ em PTS e $\mathrm{PM}_{10}$ e 0,56 e 0,55 para a razão $\mathrm{BaPi} /(\mathrm{BaPi}+\mathrm{Cr})$ em PTS e $\mathrm{PM}_{10}$. Pereira Netto et al. $(2001,2002)$ reportam para Niterói inverno e verão e para verão no Rio de Janeiro valores da razão $\mathrm{BaA} /(\mathrm{BaA}+\mathrm{Cr})$ em torno de 0,3 e para a razão $\mathrm{BaP} /(\mathrm{BaP}+\mathrm{Cr})$ entre 0,32 e 0,60.

$\mathrm{Na}$ Figura 49 são observados os resultados para as razões $\mathrm{BbFl/BkFI} \mathrm{e}$ $\mathrm{BaPi} / \mathrm{BPe}$. Altos valores destas duas razões são indicativos de emissões veiculares (Ravindra et al., 2008a). Pandey et al. (1999) e Park et al. (2002) sugerem para a razão $\mathrm{BbFl} / \mathrm{BkFI}$ valores maiores que 0,5 para diesel e 0,73 para gasolina enquanto para a razão $\mathrm{BaPi} / \mathrm{BPe}$ entre 0,5 e 0,6 seriam provenientes de tráfego veicular.
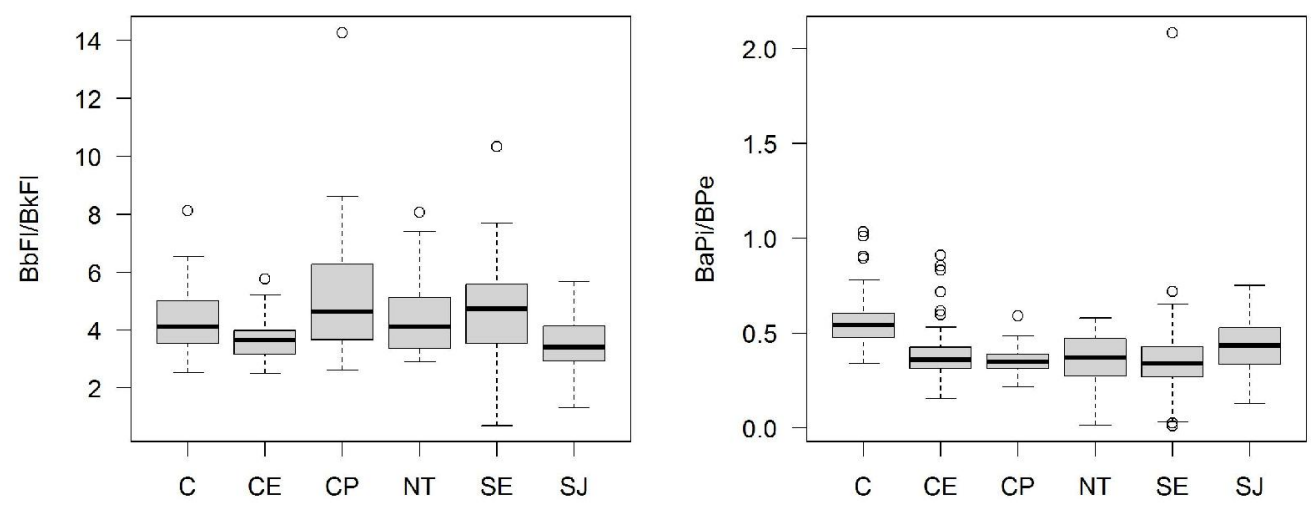

Figura 49 - Box-plot das razões BbFl/BkFl e BaPi/BPe para o material particulado das estações de coleta.

Os valores altos encontrados para a razão $\mathrm{BbFl} / \mathrm{BkFI}$ corroboram as indicações de combustão a gasolina de algumas razões já discutidas. Em contrapartida os valores reportados para $\mathrm{BaPi} / \mathrm{BPe}$ estão em sua maioria abaixo de 0,5. Apesar de não atender as observações de Pandey et al. (1999) e Park et al. (2002) valores abaixo de 0,5 já foram reportados como característicos de rodovias movimentadas (Manoli et al., 2004). Usando-se os dados de Lima (2006) se obtêm 4,11 \pm 1,66 para a razão $\mathrm{BbF} / \mathrm{BkFl}$ e 0,27 $\pm 0,07$ para $\mathrm{BaPi} / \mathrm{BPe}$, enquanto Machado et al. (2009) encontra valores de 0,41 e 0,44 para a razão $\mathrm{BaPi} / \mathrm{BPe}$ em PTS e $\mathrm{PM}_{10}$. Pereira Netto et al. $(2001,2002)$ reportam para Niterói e Rio de Janeiro médias de $\mathrm{BbFl} / \mathrm{BkFI}$ entre 3,9 e 7,8 e $\mathrm{BaPi} / \mathrm{BPe}$ entre 0,24 e 0,68 , demonstrando a variabilidade que estes índices podem apresentar. Amostras próximas a Avenida Brasil (Marques et al., 2009) apresentaram valores da razão $\mathrm{BaPi} / \mathrm{BPe}$ de 0,38 e 0,47 para PTS e $\mathrm{PM}_{10}$, respectivamente. 
Alguns autores (Prahl et al., 1984; Takada et al., 1990; Gogou et al., 1996) sugerem que a razão entre a soma dos nove compostos não alquilados reconhecidos como HPAs derivados de combustão $(\mathrm{FI}, \mathrm{Pi}, \mathrm{BaA}, \mathrm{Cr}, \mathrm{BbFl}, \mathrm{BkFI}$, $\mathrm{BaPi}, \mathrm{IPi}, \mathrm{BPe})$, indicados como CHPAs, sobre a concentração total dos 16 HPAs prioritários (CHPAs / 16HPAs) possa ser usado na identificação de fontes de combustão. Valores desta razão próximos a 1 sugerem que HPAs são originados predominantemente por processos de combustão.

Lima (2006) reporta para essa razão o valor médio de 0,75 e os dados médios de Machado et al. (2009) para estação de ônibus em Duque de Caxias, 0,93 e 0,91 para PTS e $\mathrm{PM}_{10}$, assim como os de Manoli et al. (2004) para a Grécia $(0,92-0,95)$ são mais próximos ao do presente estudo (Figura 50). Marques et al. (2009) reportam variação da razão CHPAs/16HPAs e BaPi/BPe em relação aos dados de Quitério et al. (2007) e Pereira Netto et al. (2002), sugerindo que a desativação da refinaria de Manguinhos tenha modificado o perfil de HPAs na Avenida Brasil. Os três estudos também reforçam a necessidade de maiores estudos quanto ao uso de etanol e gás natural veicular na frota brasileira.

Rogge et al. (1993a) reportaram o valor de 0,41 para essa razão em emissões sem catalisador, 0,51 para emissões de veículos equipados com catalisador e 0,30 para veículos a diesel. Ressalta-se que os altos valores desta razão encontrados não consideram os compostos alquilados, marcadamente presentes em algumas estações.

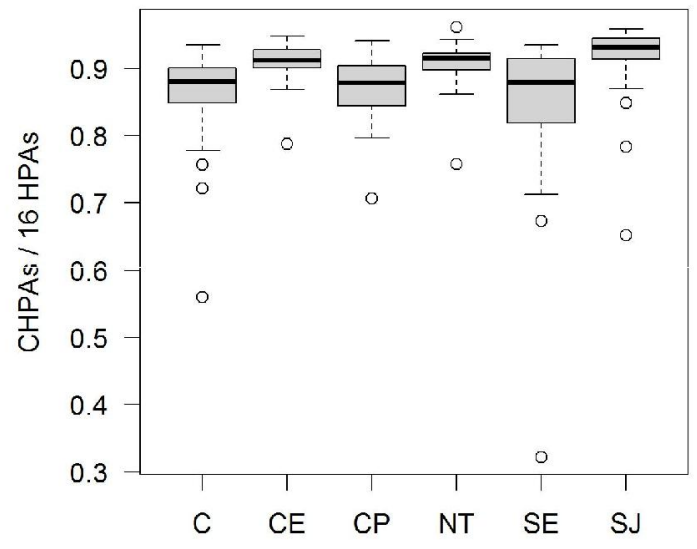

Figura 50 - Box-plot da razão CHPAs / 16 HPAs para o material particulado das estações de coleta.

Esta última razão, assim como as demais razões baseadas em diferentes isômeros (BaPi/BePi, BaPi/(BaPi+Cr), são tratadas com menor relevância ou até 
mesmo desconsiderada em alguns estudos. A diferença na reatividade química, volatilidade e solubilidade dos diversos HPAs podem introduzir erros, por isso são mais estudadas razões que envolvam compostos de mesma massa e com propriedades físico-químicas semelhantes, menos sujeitas a estas variações (Ravindra et al., 2008a,b).

Cabe lembrar que as amostragens estão sujeitas a fatores meteorológicos e a fotodegradação. O tempo de amostragem pode ser de grande influencia em algumas razões, especialmente quando envolvem o benzo(a)pireno, cujo tempo de meia vida é $1,9 \mathrm{~h}$, bem diferente do benzo(ghi)perileno $(4,2 \mathrm{~h})$ (Martinis et al., 2002). É válido considerar que as razões discutidas anteriormente, em especial as que envolvem o composto benzo(a)pireno seriam influenciadas por este fenômeno.

Em função do acima exposto utilizou-se de ferramentas auxiliares para avaliação dos processos de alteração do material uma vez na atmosfera. A razão $\mathrm{BaPi} /(\mathrm{BaPi}+\mathrm{BePi})$ é utilizada para verificar o tempo de exposição do material no ar atmosférico já que ambos compostos são emitidos na atmosfera em quantidades semelhantes. Entretanto, devido à diferença de reatividade entre os compostos, o BaPi é mais reativo, a razão entre estes é utilizada para inferir o tempo de exposição do material atmosférico. Logo, a razão $\mathrm{BaP} /(\mathrm{BaP}+\mathrm{BeP})$ é considerada um marcador de tempo de exposição. Em dias de forte insolação os níveis de $\mathrm{BaPi}$ são reduzidos enquanto o BePi permanece constante (Panther et al., 1999).

Oliveira et al. (2011) observaram que o valor da razão BaPi/BePi decrescia com o aumento do tamanho da partícula amostrada. Assim, valores próximos a 1 estariam relacionados a menor fração $\left(\mathrm{PM}_{0.49}\right)$, o que sugere uma emissão recente. O decréscimo dos valores desta razão estaria associado com fenômenos como volatilização e condensação, ou por ressuspensão de material depositado, produzindo aerossóis ditos envelhecidos em frações maiores. Akyüz \& Çabuk (2010) investigaram como a fotoxidação química afeta as razões diagnóstico de HPAs, especialmente alterações dos valores de $A /(F e+A)$ e $\mathrm{BaPi} / \mathrm{BePi}$, dada a maior suscetibilidade do antraceno e o benzo(a)pireno a este processo. O decaimento preferencial do $\mathrm{BaPi}$ já foi diretamente relacionado com o número de horas com luz solar durante o dia (del Rosario Sienra et al., 2005), e variações diurnas (Alves et al., 2006). Akyüz \& Çabuk (2010) reportam as maiores concentrações de benzo(a)pireno na província de Zonguldak, Turquia, associadas ao período de inverno. 
Para o material particulado da Baía de Guanabara caracterizado na fração $\mathrm{PM}_{2.5}$, não existem evidências de acentuada degradação fotoquímica. As amostras apresentaram relações para a razão $\mathrm{BaPi} /(\mathrm{BaPi}+\mathrm{BePi})$ próximas a 0,5 , com poucas exceções (Figura 51). Estes valores caracterizam emissões recentes condizentes com a fração amostrada.

A razão $A /(\mathrm{Fe}+\mathrm{A})$ influenciada, conforme discutido anteriormente, pelas alterações na concentração do antraceno, apresentou valores acima de 0,1, o que confirma que as alterações químicas dos compostos na atmosfera nesta fração são de curta duração.
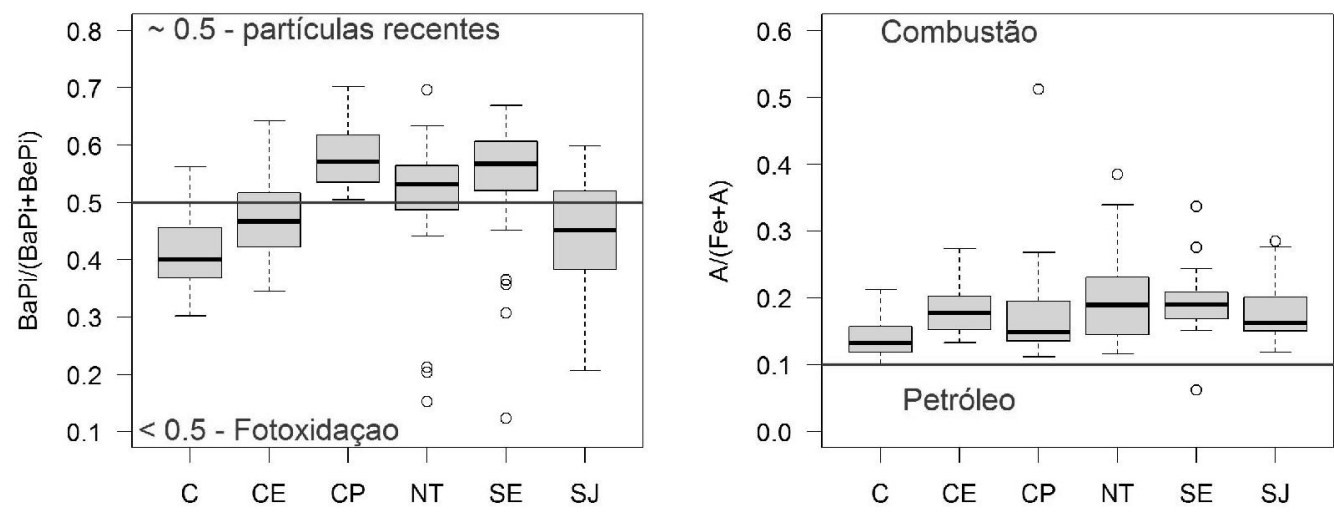

Figura 51 - Box-plot das razões de $\mathrm{BaPi} /(\mathrm{BaPi}+\mathrm{BePi})$ e $\mathrm{A} /(\mathrm{Fe}+\mathrm{A})$ para as diferentes estações amostradas durante o ano de 2011.

A variação dessa razão com o tamanho de partícula é corroborada nos dados de Lima (2006) para $\mathrm{PM}_{10}$. Estes autores reportam um valor médio de $0,21 \pm 0,05$, bem inferior ao encontrado para $\mathrm{PM}_{2,5}$ no presente estudo. Pereira Netto et al. (2005) observam a influência da luz solar na degradação de compostos de 5 anéis em estação da FIOCRUZ, especialmente o BaPi. O estudo destes autores, entretanto seguiu a lógica de comparação de períodos, diurno e noturno, e não integrando um dia inteiro de amostragem como o presente estudo. Estas diferenças entre os tempos e condições de amostragem podem ser responsáveis pela observação de ausência relevante de degradação neste trabalho.

Souza (2006), através dessa razão, sugerem forte degradação fotoquímica em amostras de São Paulo $\left(\mathrm{PM}_{10}\right)$. Para amostras da Amazônia Simoneit et al. (1990) reportam a ausência de benzo(a)pireno derivada da fotoxidação 
(aerossóis antigos). Exemplos de variação sazonal desta razão estão expostos na Figura 52.

A ausência de um padrão sazonal, como ocorre em Campos Elíseos (Figura 52), também ocorre nas estações de Niterói, Copacabana e Seropédica. Em São João de Meriti e no Centro do Rio existe uma tendência que sugere um padrão sazonal daquela razão. Cabe ressaltar que a variação é pequena quando comparada à variação sazonal reportada para estudos em clima temperado (Pietrogrande et al. 2011; Akyüz \& Çabuk 2010; Manoli et al., 2004) e que os dados devem ser avaliados com cuidado. Observa-se na Figura 52 que a mediana do mês de junho para São João de Meriti para a razão $\mathrm{BaPi} /(\mathrm{BaPi}+\mathrm{BePi})$ é menor que a observada para os meses de março e abril. Isto sugere que variações diárias da razão são mais importantes do que as variações sazonais.
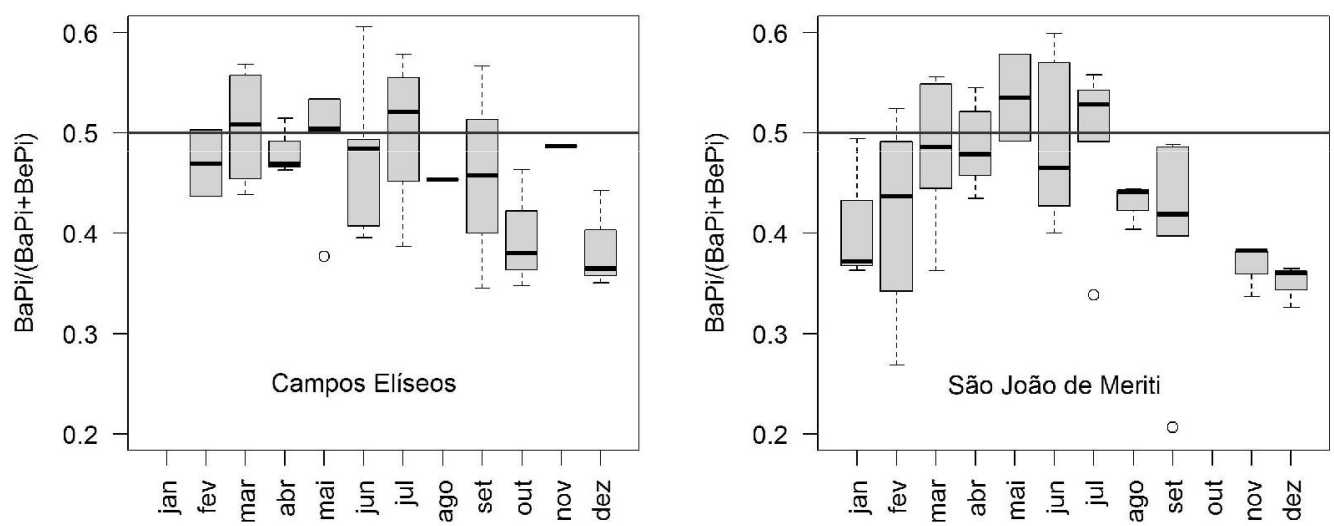

Figura 52 - Variação anual da razão $\mathrm{BaPi} /(\mathrm{BaPi}+\mathrm{BePi})$ para as estações de Campos Elíseos e São João de Meriti.

Pode-se inferir pelos valores da razão $\mathrm{BaPi} /(\mathrm{BaPi}+\mathrm{BePi})$ na Figura 51 que nas estações de São João de Meriti, Centro e Campos Elíseos este fenômeno é bem evidenciado, enquanto nas estações de Niterói, Copacabana e Seropédica os valores são geralmente superiores a 0,5. Este padrão poderia ocorrer pela baixa emissão de poluentes e sua provável dispersão no ambiente o que não permite evidenciar o "envelhecimento" destas partículas. Nas estações de maior emissão, entretanto, seria possível evidenciar o início do processo de "envelhecimento" das partículas.

Não foi observada variação sazonal das razões nas estações deste estudo. Também não ocorre variação em função da precipitação, à exceção das 
razões CHPAs /16 HPAs e do índice pirolítico para o Centro do Rio de Janeiro durante eventos de precipitação. Para estas razões que envolvem compostos de diferentes massas, a variabilidade é resultante da alteração do perfil em dias de precipitação, já demonstrado no subitem 5.4. Não foi observado o fenômeno reportado por Allen et al. (2008) de decréscimo das razões $\mathrm{Fl} / \mathrm{Pi}, \mathrm{BaPi} / \mathrm{BPe}$ e $\mathrm{BaA} / \mathrm{Cr}$ durante o período de maior umidade, resultante da correlação inversa entre as razões e a pressão de vapor e solubilidade.

Uma das formas de avaliar a variabilidade de emissões ou fontes é a relação logarítmica entre os compostos parentais de 3 a 6 anéis e a série de 5 HPAs alquilados (Figura 53). Este tipo de abordagem é amplamente útil em amostras de sedimento (Wagener et al., 2011, 2012), quando o uso de razões diagnósticas não permite uma clara diferenciação de fontes nas amostras. Observa-se que as únicas estações onde a relação entre estes parâmetros é significativa são Campos Elíseos $\left(r_{s}=0,78\right)$ e São João de Meriti $\left(r_{s}=0,65\right)$. O comportamento com os HPAs é bem diferente do observado para a fração alifática (Figura 44). A maior dispersão dos dados, provavelmente, é decorrente da maior influência da partição gás-partícula dos compostos de menor peso molecular e da baixa concentração nas estações de Niterói, Copacabana e Seropédica.

As maiores concentrações em Campos Elíseos e São João de Meriti, associado à distribuição de HPAs de maior peso molecular, refletem-se em uma maior relação entre estas variáveis. No Centro, apesar de apresentar concentrações equivalentes a São João de Meriti, a distribuição dos compostos mais leves e a influência da precipitação acarretam na maior dispersão dos dados. Observa-se que as declividades resultantes para São João de Meriti e Campos Elíseos são muito próximas, sugerindo que estas duas estações estão sob influência de fontes similares de hidrocarbonetos. A aplicação deste tipo de abordagem mostra-se menos eficiente na matriz atmosférica, sendo mais bem aplicada em sedimentos sob poluição crônica.

O uso de razões diagnósticas neste trabalho permite observar a variação da influencia das diferentes emissões nas estações, mas não permite a quantificação dos aportes de cada fonte. Machado et al. (2009) nota que as razões estão dispersas por uma grande faixa e que não é clara a diferença entre emissões de motores a gasolina e a diesel.

Galernau (2008) faz uma análise crítica das razões diagnósticas de fontes e afirma que devido à grande variabilidade reportada para razões diagnósticas em cada tipo de fonte é improvável que uma simples razão ou perfil selecionado 
da literatura seja representativo de uma fonte em uma outra parte do mundo, que emite em diferentes condições.
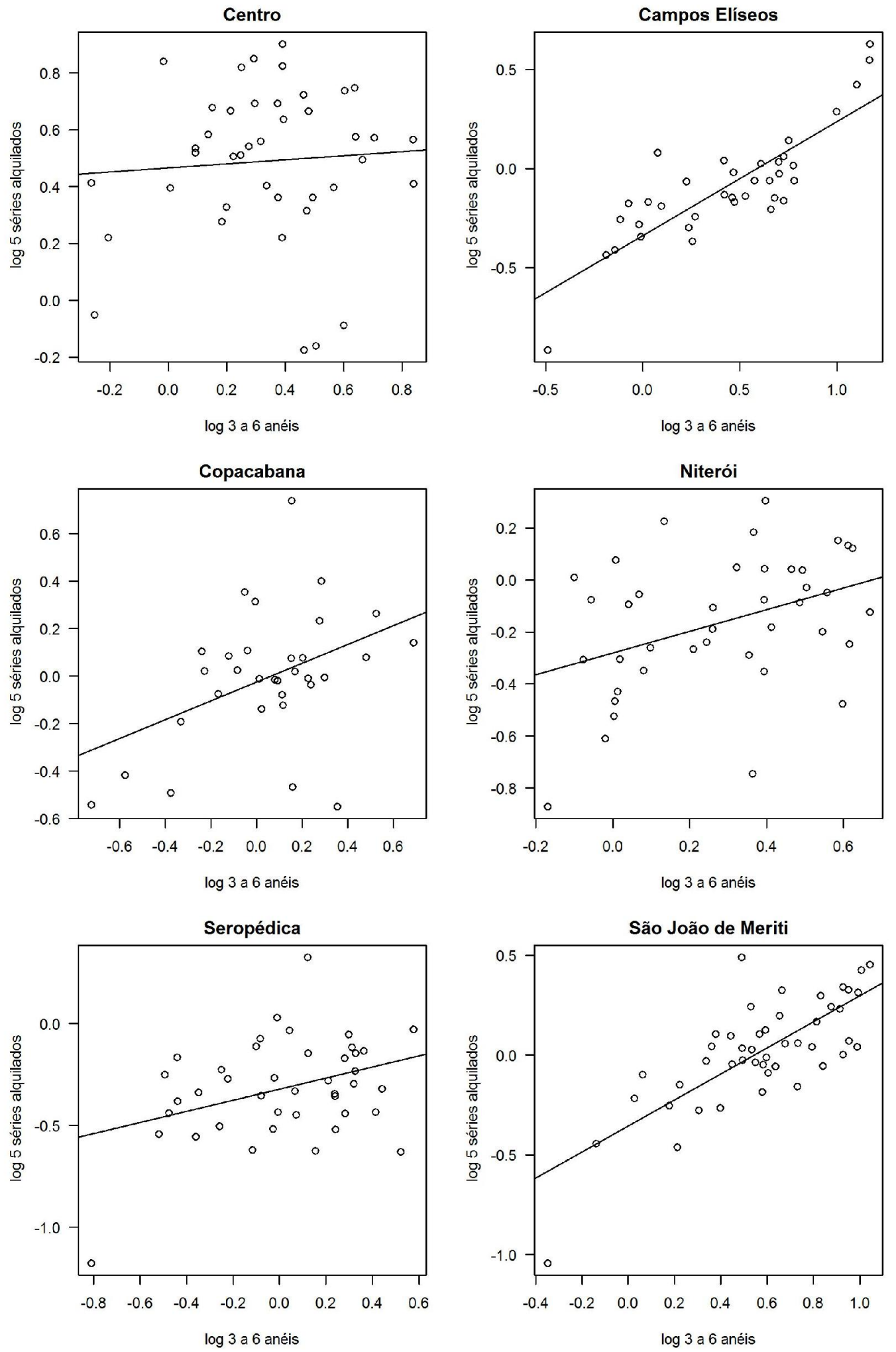

Figura 53 - Gráfico log-log da concentração da concentração de HPAs de 3 a 6 anéis e da soma das 5 séries de HPAs alquilados 
Esta mesma autora (Galernau, 2008) compila dados da literatura com médias da razão $\mathrm{IPi} /(\mathrm{IPi}+\mathrm{BPe})$ para emissões a diesel menores que o limite de 0,2 proposto por Yunker et al. (2002) e razões $\mathrm{Fl} /(\mathrm{Fl}+\mathrm{Pi})$ para emissões a gasolina na faixa esperada para resíduos de combustão de madeira e carvão. Manoli et al. (2004) reportam a dificuldade da avaliação das razões diagnosticas, considerando ainda a reatividade das diferentes espécies de HPAs no ambiente.

Uma das formas alternativas de avaliar a influência dos HPAs nas amostras é pela Análise de Componentes Principais (ACP). A ACP é um método estatístico través do qual um número grande de variáveis independentes é sistematicamente reduzido por combinações lineares a um número menor e conceitualmente mais coerente de grupos de variáveis (Dunteman, 1989).

A concentração de cada variável foi dividida pela concentração total da amostra tornando o perfil relativo de HPAs o objetivo de discriminação nesta análise e, consequentemente, removendo qualquer efeito de concentração. Uma vez que esta análise é realizada sobre a matriz de correlação não há necessidade de centralizar e reduzir os dados, procedimento intrínseco a formulação da matriz. O resultado encontrado para os fatores 1 e 2 explicam $51,4 \%$ da variância total das amostras (Figura 54).
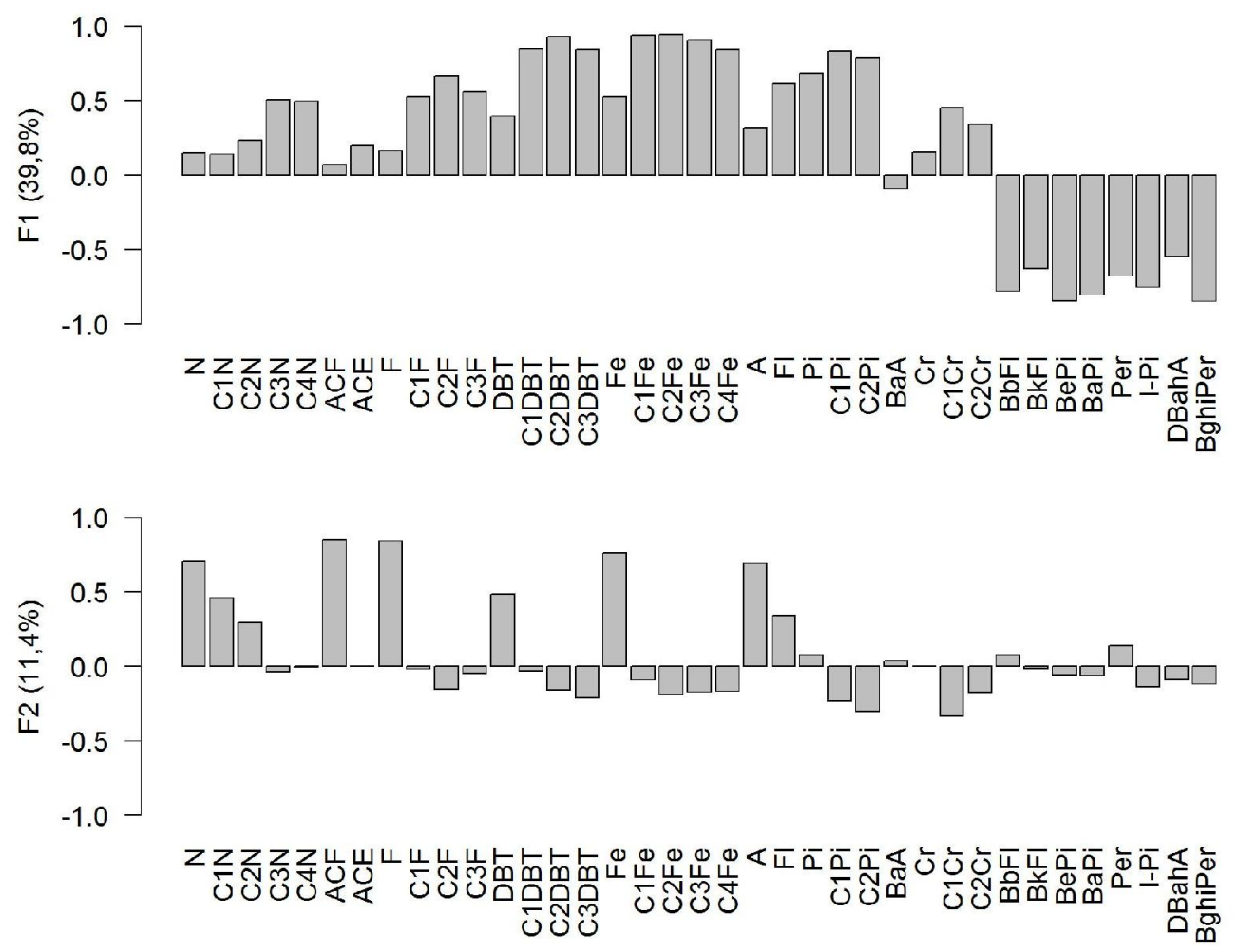

Figura 54 - Distribuição dos Fatores para a ACP realizada com a concentração relativa das amostras de particulado atmosférico da Região Metropolitana do Rio de Janeiro. 
O fator 1 divide basicamente as amostras pelo número de anéis, com valores positivos para compostos de 2 a 4 anéis e negativos para compostos de 5 a 6 anéis. $O$ fator 2 representa a influência de poucos compostos de menor peso molecular observado em algumas amostras. Como já observado para as razões diagnósticas, existe um acoplamento entre as estações de coleta, mas com gradiente que vai do Centro, com maior abundancia de compostos leves, a São João de Meriti e Campos Elíseos, com maior abundancia de compostos pesados (Figura 55).

Esta abordagem apesar de diferenciar as distribuições entre as estações não evidencia claramente os diferentes tipos de emissões veiculares, como observado por outros autores para esta análise (Dallarosa et al., 2005, 2008; Vasconcellos et al., 2003, 2011; Larsen \& Baker, 2003; Li et al., 2012).

Embora seja possível diferenciar qualitativamente a distribuição de HPAs entre as estações, não é possível estimar quantitativamente a sobreposição dos diferentes tipos de emissões, assim como a avaliação das razões diagnóstico. A análise quantitativa destes aportes é primordial para qualquer avaliação (Li et al., 2002) e pode ser obtida pela associação entre a Análise de Componentes Principais e Regressão Múltipla Linear. Este tipo de abordagem iniciou-se com o trabalho de Larsen \& Baker (2003) para amostras de atmosfera urbana, mas tem se difundido para sólidos em suspensão (Sofowote et al., 2008) e sedimentos (Chen et al., 2012; Li et al., 2012; Liu et al., 2009; Zhang et al., 2012; Wang et al., 2009).

O método consiste em uma ACP nos dados de concentração onde, após rotação varimax, são extraídos todos os fatores cujo eigenvalue seja superior a 1. Estes fatores são usados como variáveis independentes para descrever a concentração de HPAs nas amostras. Neste método todas as variáveis, a dependente e as independentes, devem ser normalizadas pela média e desvio padrão antes da análise. No caso das variáveis independentes (fatores) estes já são normalizados pelo principio da ACP. A variável dependente, a concentração total de HPAs, necessita ser normalizada antes da análise. A distribuição de HPAs em cada fator é avaliada e identificada a provável fonte correspondente. Posteriormente o peso de cada fator no modelo de regressão é definido para explicar a concentração total na amostra. 


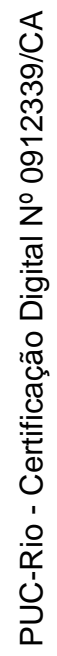

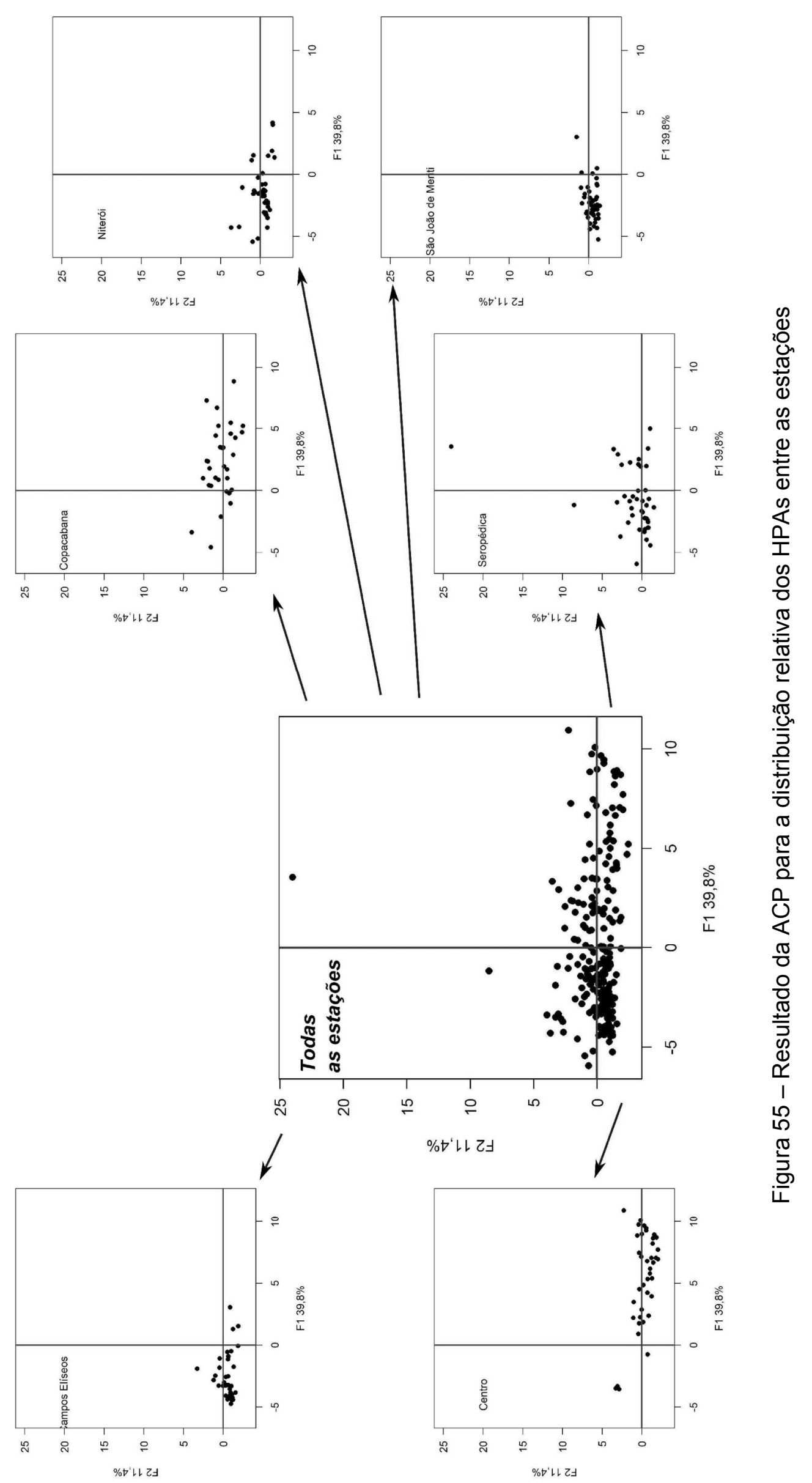


Observa-se na Figura 56 que o Fator 1, responsável por $43,7 \%$ da variância, pode ser identificado como fonte de combustível não queimado.

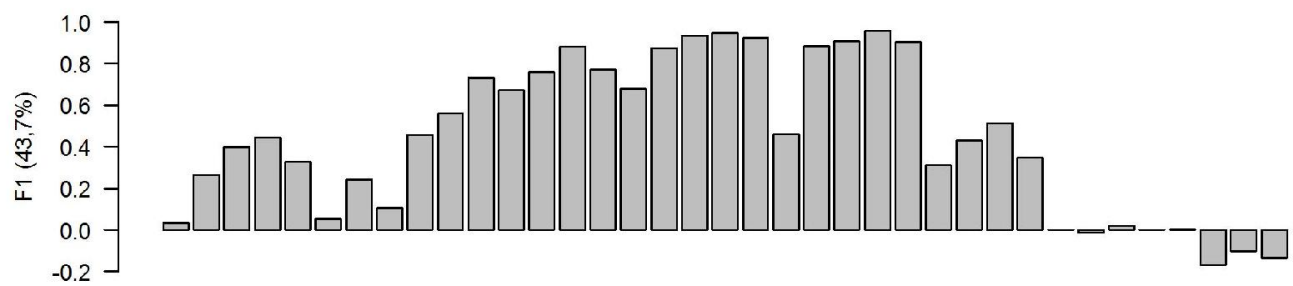

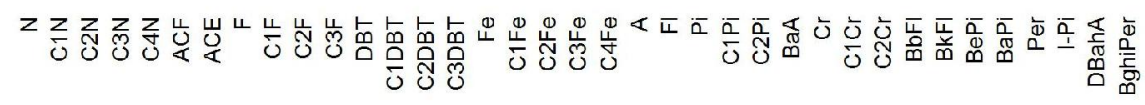

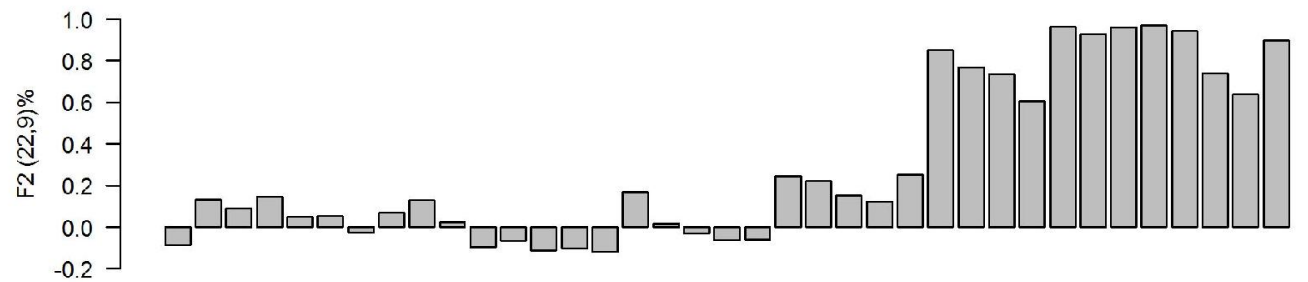

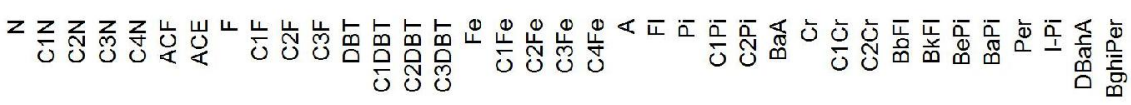
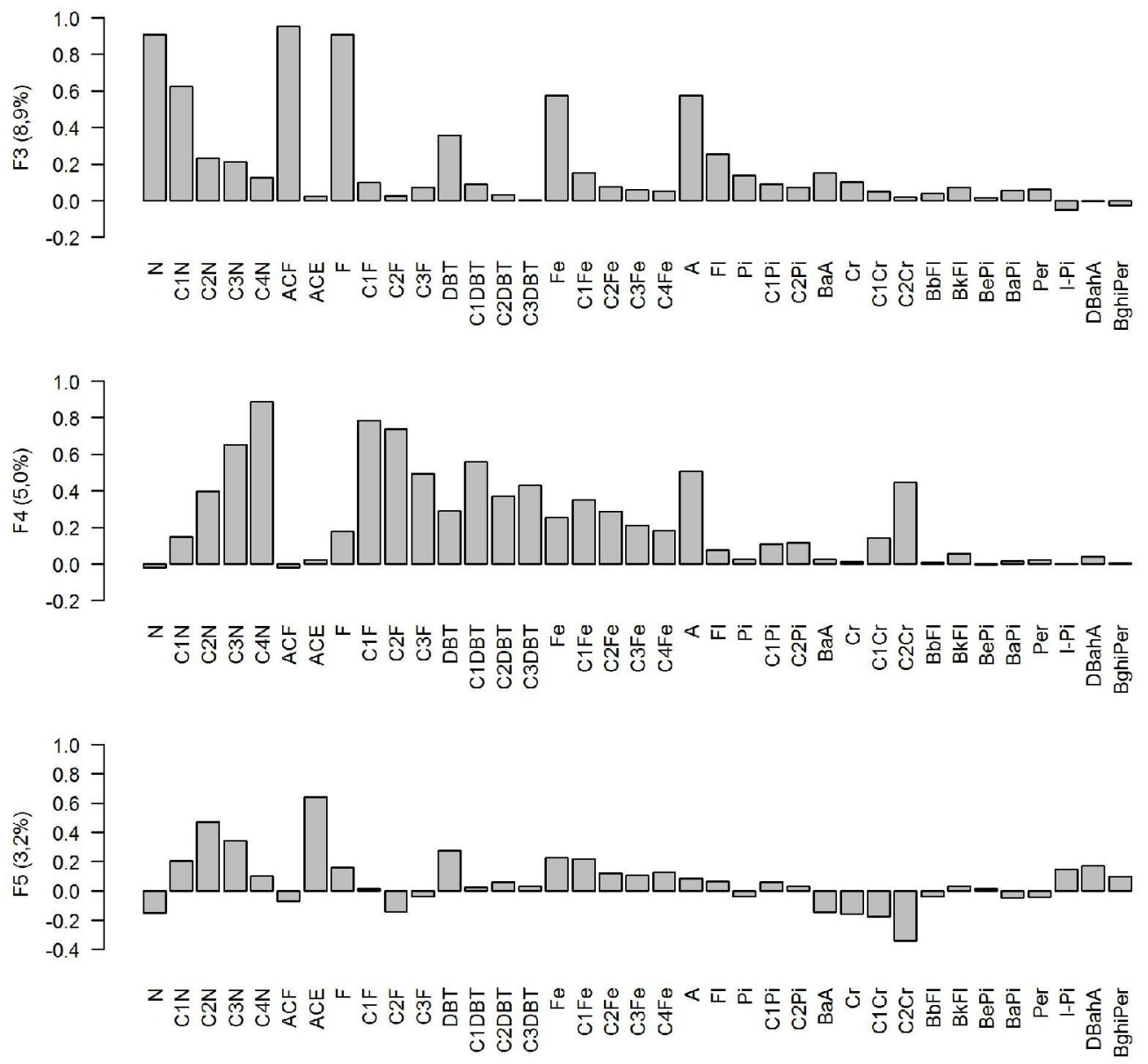

Figura 56 - Loadings dos 5 fatores extraídos da ACP para serem aplicado no Modelo Linear de Regressão Múltipla 
No Fator 3, que explica $8,9 \%$ da variância, observa-se o predomínio de compostos leves, com padrão de distribuição de seus respectivos alquilados típico de combustão, ou seja $\mathrm{C} 0>\mathrm{C} 1>\mathrm{C} 2>\mathrm{C} 3>\mathrm{C} 4$ (Page et al., 1993). Portanto, pode-se afirmar que este fator (F3) corresponde a emissões de compostos mais leves provenientes da queima de combustível.

Nos Fatores 4 e $5(8,2 \%)$ não está associado qualquer perfil característico de fonte, mas a variância explicada pelos mesmos é de apenas $8,2 \%$. O modelo resultante desta avaliação foi bastante satisfatório $\left(R^{2}=0,78, F<0,05\right)$ e, como pode ser observado na Figura 57 , existe boa relação entre a concentração mensurada nos ensaios realizados e a prevista pelo modelo de regressão linear.
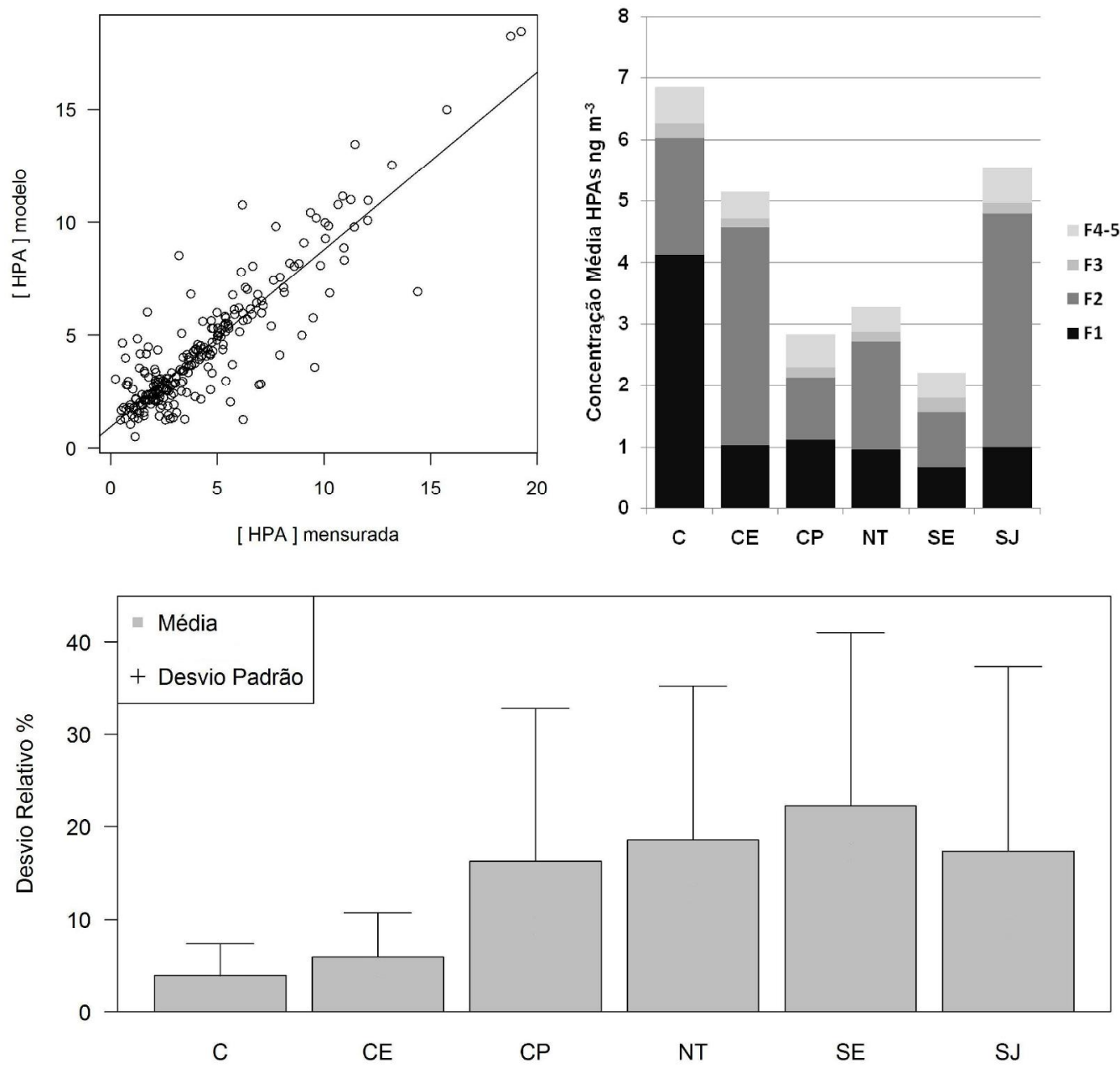

Figura 57 - Gráfico da concentração mensurada versus prevista; Contribuição média de cada fator para a concentração média das estações e desvios relativos da concentração prevista em relação à mensurada para cada estação de amostragem. 
Observa-se que o F1, correspondente a emissões de combustível não queimado, tem maior peso na concentração média das amostras do Centro. Nas amostras de São João de Meriti e de Campos Elíseos esse fator tem menor relevância, pois nestas estações predomina a segunda componente do modelo (F2), correspondente a emissões de HPAs de alto peso molecular através da queima incompleta de combustível. Em todas as estações o peso dos demais fatores é muito menor em relação aos dois primeiros.

Os resultados encontrados permitem corroborar quantitativamente as observações e pressupostos estabelecidos de forma qualitativa pela tipologia de HPAs e as razões diagnóstico de fontes. O desvio relativo da concentração mensurada foi maior para as estações de Copacabana, Niterói, Seropédica e São João de Meriti. Nas três primeiras o maior desvio pode ser explicado por tratarem-se de estações com menores concentrações. O ajuste do método de regressão múltipla linear é realizado para obter-se os menores desvios absolutos que, obviamente, ocorrem na zona de maior concentração.

Os maiores desvios obtidos para São João de Meriti, de concentração equivalente ao Centro, são justamente em algumas amostras de menores concentrações. Embora os resultados obtidos apresentem desvios maiores que os observados para outros estudos que seguiram o mesmo procedimento (Larsen \& Baker, 2003; Sofowote et al., 2008; Chen et al., 2012; Li et al., 2012; Liu et al., 2009; Zhang et al., 2012; Wang et al., 2009) deve-se considerar que para o número de amostras e variabilidade de estações e perfis o modelo pode ser considerado bem ajustado. Embora esta avaliação não permita quantificar os aportes da queima de gasolina e diesel separadamente os resultados são um ganho quantitativo na diferenciação entre as estações.

Além dos HPAs normalmente analisados em estudos atmosféricos outras informações provêm de HPAs analisados com menor freqüência. Na Figura 58 se pode observar a concentração de acefenantrileno, benzo(c)fenantreno, indeno(7,1,2,3-cdef)criseno, dibenzo(a,j)antraceno, pentafeno, benzo(b)criseno, piceno e reteno. Muitos compostos estiveram abaixo do limite de quantificação do método e é evidente o perfil semelhante de distribuição em todas as estações com maior abundancia relativa para o indeno(7,1,2,3-cdef)criseno.

O acefenantrileno é um compostos reportado em menores concentrações que seus respectivos isômeros, fluoranteno e pireno, em poeiras urbanas, túneis, e produtos de combustão de madeira, carvão e combustíveis (Lee et al., 1977 apud Yunker et al., 2002; Grimmer et al., 1983; Wise et al., 1986; Benner et al., 1990; Fine et al., 2001; Schauer et al., 2001). Yunker et al. (2002) compilando os 
dados destes trabalhos reportam para a razão acefenantrileno (Act) sobre os compostos de massa 202 menores que 0.1 para amostras de combustão de diesel e entre 0,15 a 0,24 para combustão de carvão, entre 0,16 e 0,20 para amostras de óleo cru e 0,14 a 0,22 para amostras de combustão de madeira.
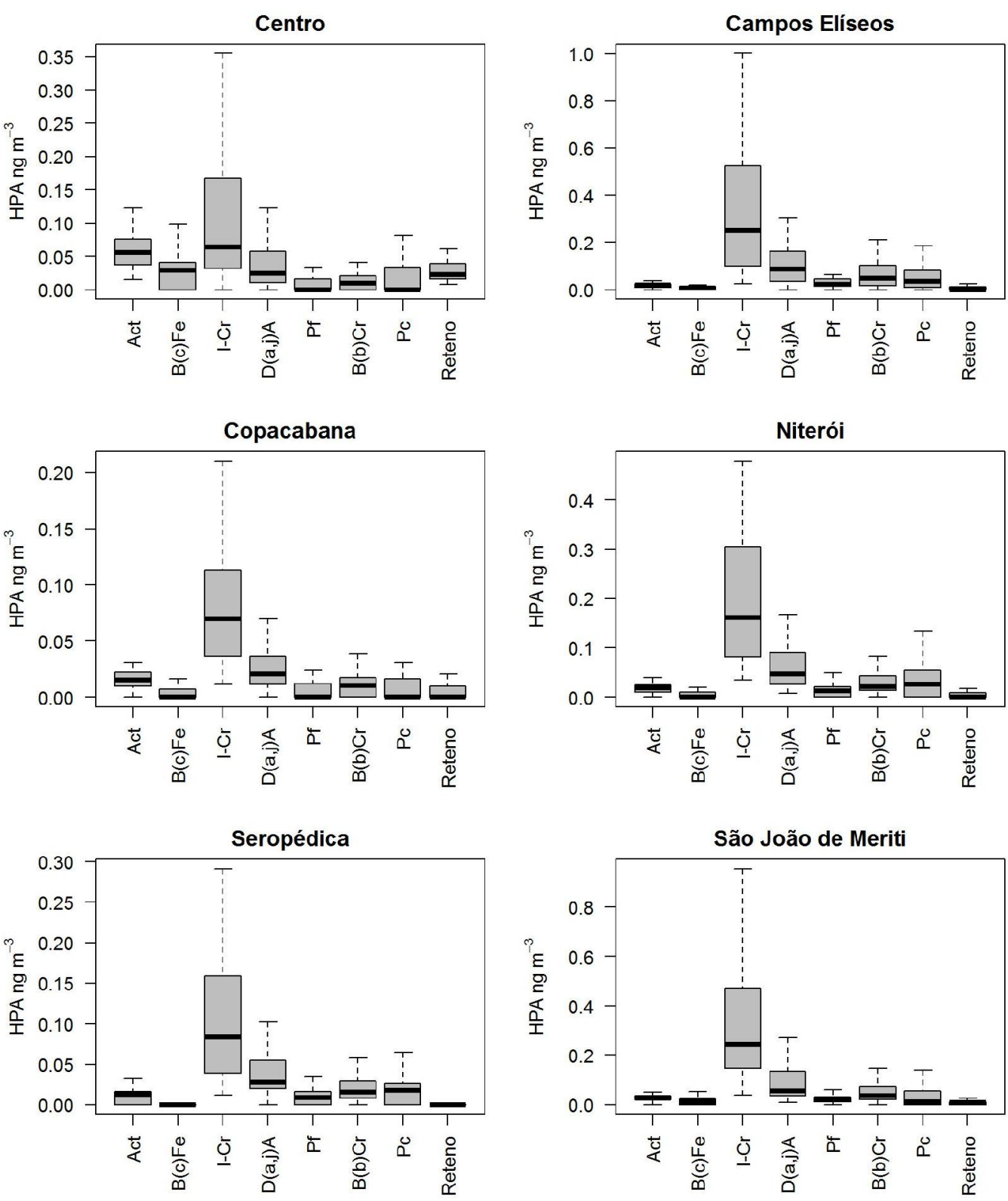

Figura 58 - Resultado dos demais HPAs quantificados para as estações de coleta de material particulado atmosférico $\left(\mathrm{PM}_{2,5}\right)$

Observa-se que os autores reportam faixas sobrepostas para as diferentes emissões, como já comentado para as razões discutidas anteriormente. A mediana dessa razão foi inferior a 0,1 para o Centro e Copacabana, de 0,12 para São João de Meriti e Campos Elíseos e de 0,11 e 0,15 para Niterói e 
Seropédica, respectivamente. Embora não esteja de acordo com a proposta inicial de Yunker et al. (2002), os resultados se comparam aos obtidos por Mazquiarán \& Pinedo (2007), com valores médios próximos de 0,15 para região da Espanha, onde o tráfego veicular também é caracterizado como fonte predominante. A variabilidade dessa razão também pode ser observada nos dados do estudo de Panagiotou \& Levendis (1996), que fornece valores entre 0,11 e 0,30 para queima de PVC, poliestireno e polietileno.

Kavouras et al. (1999), por exemplo, não detectaram acefenantrileno em região do Chile, reconhecidamente sobre influência de emissões veiculares. Oros et al. (2006) não detectam este compostos em combustão de biomassa vegetal à exceção de um tipo de gramínea cuja queima gerou valor de 0,21 para a razão em discussão.

Os próprios autores (Yunker et al., 2002) que propuseram a razão destacam a maior susceptibilidade do acefenantrileno à degradação fotoquímica e sua caracterização em emissões e uso para diagnóstico de fontes é pouco reportada na literatura. Assim como o acefenantrileno, o benzo(c)fenantreno é escasso de maiores estudos. Sua quantificação, embora não seja usada para determinação de fontes, foi realizada dada a sua conhecida toxicidade (Barbosa 2005), constituindo assim mais uma informação de valor para o monitoramento, especialmente de sedimento. Este composto foi quantificado em menos da metade das amostras e sempre em concentrações próximas ao limite de detecção. Sua quantificação é mais frequente em águas e sedimentos como parâmetro de qualidade, embora não esteja listado como HPA prioritário pela US-EPA.

Outros HPAs como o indeno(7,1,2,3-cdef)criseno, dibenzo(a,j)antraceno, pentafeno, benzo(b)criseno e piceno são encontrados em poeiras urbanas e resíduos de combustão de carvão e outros combustíveis (Grimmer et al., 1983; Wise et al., 1986; Rogge et al., 1993a; Bergvall \& Westerholm, 2009). Rogge et al. (1993a) associam benzo(b)criseno e dibenzo(a,h)antraceno a emissões de gasolina, não sendo detectados em emissões a diesel. Nos dados de Bergvall \& Westerholm (2009) é possível verificar que a emissão de piceno e dibenzo(ah)antraceno é praticamente equivalente para os dois combustíveis, gasolina e diesel.

O mesmo perfil com indeno(7,1,2,3-cdef)criseno mais elevado é achado por Bi et al. $(2003,2002)$ para amostras atmosféricas de Guangzhou, China. Ressalta-se que os autores associam as concentrações encontradas às emissões veiculares e não quantificaram 0 acefenantrileno $\quad$ e $\quad$ o 
benzo(c)fenantreno. Gao et al. (2012) apontam a boa correlação entre benzo(ghi)perileno e piceno como indicativa de emissões veiculares e queima de carvão para $\mathrm{PM}_{2,5}$. O piceno, entretanto, foi detectado em apenas $65 \%$ das amostras analisadas.

Yunker et al. (2011), através de regressão linear significativa entre as razões de alguns destes compostos obtidos na literatura para diferentes emissões, estabeleceram os limites descritos na Figura 59. Observa-se que razões estabelecidas estão mais de acordo com as características das emissões e locais de coleta já descritos. Estas razões, entretanto, não são capazes de identificar as emissões relacionadas aos diferentes combustíveis.

A partir dados de Azevedo et al. (1999) é possível observar que a razão $\mathrm{IPi} /(\mathrm{IPi}+\mathrm{BPe})$ indica fontes em aerossóis como petróleo para a amostras da Cinelândia, combustão de petróleo para a Quinta da Boa Vista e combustão de biomassa para a Floresta da Tijuca. Os dados da razão $\mathrm{ICr} /(\mathrm{ICr}+\mathrm{BPe})$ aplicados aos limites propostos por Yunker et al. (2011) para os dados destes autores já fornecem indicações mais próximas a combustão de petróleo para a Cinelândia $(0,31)$ e Quinta da Boa Vista $(0,30)$ e apontam para combustão de biomassa na Floresta da Tijuca $(0,71)$, comprovando maior capacidade na separação de fontes.

Além destes HPAs ainda quantificou-se o reteno. Este composto tem sido reportado na atmosfera predominantemente relacionado à queima de coníferas (Simoneit, 2002; Oros et al., 2001b; Bi et al., 2003). Nascimento (2006) reporta valores deste composto, com média de $0,82 \mathrm{ng} \mathrm{m}^{-3}$, em São Paulo, enquanto Vasconcellos et al. (1998) reporta baixas concentrações para a Floresta Amazônica. Vasconcellos et al. (2010) encontram concentrações elevadas de reteno na atmosfera relacionando-os à queima de biomassa vegetal em locais mais afastados e posterior transporte atmosférico. Azevedo et al. (2002) entretanto reporta reteno para a região de Campos dos Goytacazes e sugere que esteja, provavelmente, associado à queima de madeira (ex. Pinus) nos arredores da cidade, uma vez que a combustão da cana-de-açúcar não emite reteno.

Este composto foi quantificado em apenas $53 \%$ das amostras analisadas. Todas as amostras do Centro contêm este composto acima do limite de quantificação, enquanto em Seropédica apenas 7 amostras apresentaram concentração quantificável. Esperar-se-ia que, caso o reteno fosse proveniente de fonte de combustão e sofresse transporte por longas distâncias, sua distribuição espacial se apresentasse mais homogênea. Como este composto 
também é detectado minoritariamente em emissões veiculares (Khalili et al., 1995; Herrington et al., 2012; Westerholm et al., 1996) é muito mais provável que sua presença esteja diretamente relacionada a este tipo de emissão.
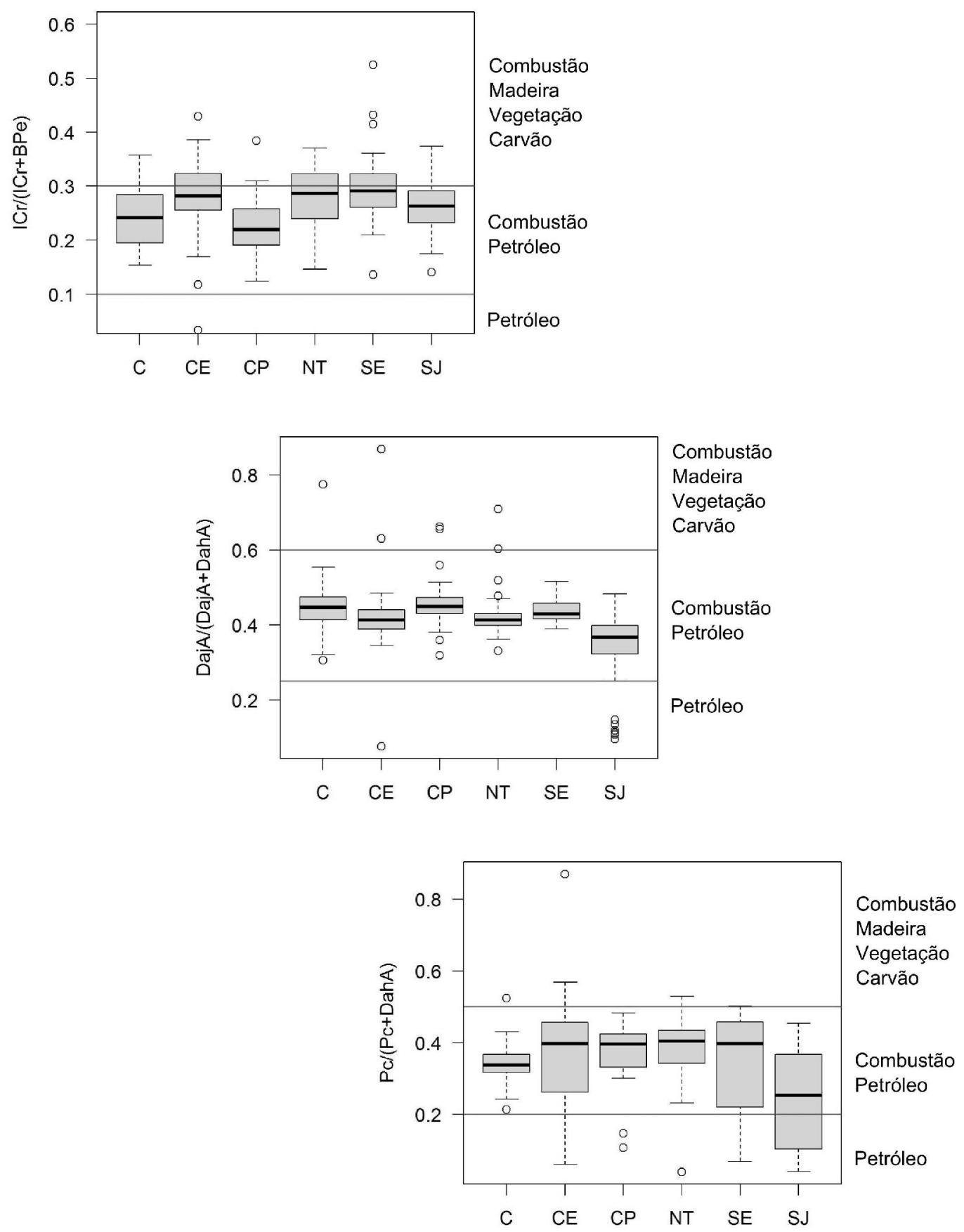

Figura 59 - Razões diagnóstico de fontes baseadas em outros HPAs.

Isto faz com que sua distribuição seja dependente da fonte local, como já discutido anteriormente sobre a possibilidade da presença de resíduos de combustão vegetal nas amostras da estação do Centro. Shen et al. (2012) 
alertam que a queima de carvão pode ser outra fonte de reteno importante, normalmente negligenciada por autores que tratam apenas da combustão de biomassa.

Todas as observações aqui corroboram as avaliações de estudos pretéritos de hidrocarbonetos (Fernandes et al., 2002; Lima, 2006; Quitério et al., 2005; Azevedo et al. 1999; Pereira Netto et al., 2002, 2001; Machado et al., 2009; Dayse et al., 1987; Marques et al., 2009) e de outros poluentes (Souza et al., 2013; Godoy et al., 2009; Carneiro et al., 2008; Mariani \& Mello, 2007) que caracterizam as emissões veiculares como principais componentes na distribuição de poluentes atmosféricos na Região Metropolitana do Rio de Janeiro. A avaliação das razões diagnósticas identifica necessidade de que novos limites, mais adequados às condições reais de campo, sejam estabelecidos ou que sua utilização seja associada principalmente a métodos estatísticos e outros critérios de avaliação.

Existe uma variabilidade temporal e espacial na tipologia de HPAs na Região Metropolitana do Rio de Janeiro. As diferenças encontradas devem-se principalmente ao local de amostragem, mas a mudança na composição da frota e no uso de combustível deve ser levado em consideração. 


\section{6}

\section{Sedimentos}

\subsection{1}

\section{Carbono Orgânico}

A concentração de carbono orgânico por ponto está apresentada na Tabela 8 onde é possível evidenciar a diferença de concentração entre a entrada da baía e o fundo (Figura 60). A concentração varia desde os menores valores na entrada da baía, $0,5 \%$ no $\mathrm{P} 1$, até o valor de $10 \%$ no P4, caminhando para a região mais interna. Os valores encontrados estão de acordo com estudos prévios (Hamacher, 1996; Lima 1996; Carreira et al., 2002) e os dados reportados por Wagener et al. (2012) para quatro campanhas semestrais de monitoramento. Estes autores, além da variabilidade temporal, reportam grande variação de concentração no mesmo ponto ao longo do monitoramento.

Tabela 8 - Concentração de Carbono Orgânico em amostras de sedimento da Baía de Guanabara

\begin{tabular}{cc}
\hline Ponto de Coleta & Carbono Orgânico (\%) \\
\hline P1 & 0,49 \\
P2 & 4,37 \\
P3 & 5,90 \\
P4 & 9,98 \\
P5 & 5,86 \\
P6 & 5,71 \\
P7 & 4,28 \\
P8 & 6,12 \\
P9 & 4,68 \\
P10 & 0,61 \\
P11 & 1,78
\end{tabular}

Todos os pontos deste estudo, à exceção do ponto P7, são os mesmos monitorados por estes autores cuja malha amostral baseou-se em locais de dados pretéritos (Hamacher, 1996; Lima, 1996; Meniconi et al., 2002). As observações corroboram indicações anteriores sobre o acúmulo de matéria 
orgânica em sedimentos nesta baía (Borges et al., 2009; Wagener et al., 2012; Carreira et al., 2002).

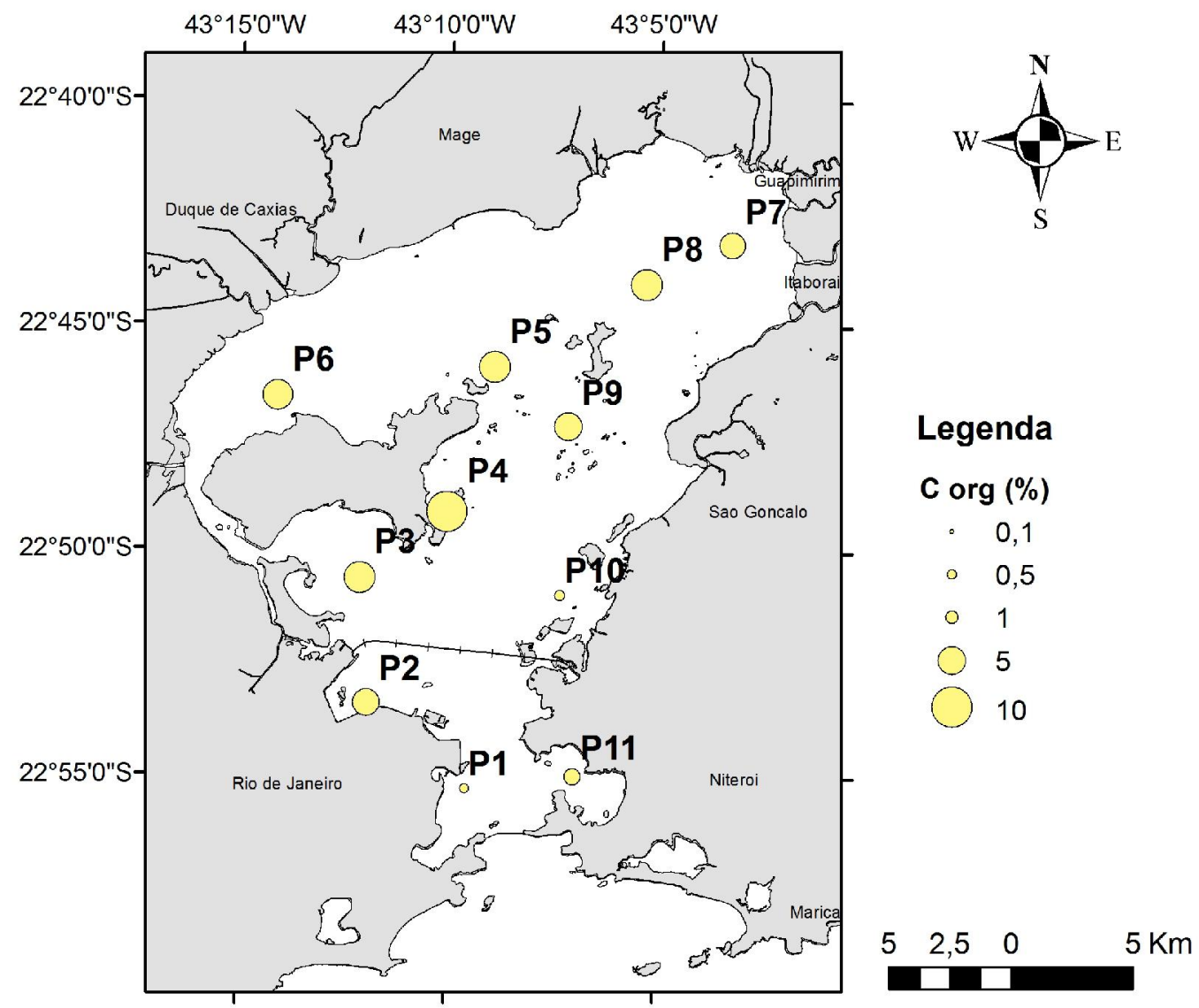

Figura 60 - Distribuição espacial da concentração de Carbono Orgânico (\%) em sedimentos da Baía de Guanabara.

Os dados de granulometria para os sedimentos estudados fornecidos por Bernardes (comunicação pessoal) não se relacionam com a concentração de carbono orgânico ou a concentração dos hidrocarbonetos aromáticos e alifáticos. O mesmo ocorre quando são comparados os dados de carbono orgânico aos de poluentes. Esta ausência de relação entre o carbono orgânico e poluentes já tinha sido observada em estudos anteriores (Hamacher, 1996; Carreira et al., 2004; Wagener et al., 2012). Segundo Wagener et al. (2012) os altos valores reportados para o carbono orgânico são fruto do estado trófico deste sistema e representam apenas uma fração do carbono fixado dado que as taxas de degradação na coluna d'água e nos primeiros centímetros de sedimento são muito intensas (Wagener et al., 1990; Carreira et al., 2002). 


\subsection{2}

\section{Hidrocarbonetos alifáticos}

Os resultados detalhados da análise da fração alifática encontram-se em anexo e a Tabela 9 contém um resumo dos resultados e razões aplicadas aos dados. A recuperação média para o surrogate da fração alifática foi de $108 \pm$ $11 \%$. Os sedimentos deste sistema são altamente contaminados e foi observada coeluição em algumas amostras do primeiro padrão usado para recuperação, o nC30 $\mathrm{d}_{62}$, tendo sido a mesma verificada através do segundo padrão de recuperação adicionado às amostras, o $\mathrm{nC} 16 \mathrm{~d}_{34}$. $\mathrm{A}$ distribuição dos parâmetros da fração alifática encontra-se exposto na Figura 61.

Tabela 9 - Resultados obtidos da fração alifática para amostras de sedimento da Baía de Guanabara

\begin{tabular}{|c|c|c|c|c|c|c|c|c|}
\hline & $\begin{array}{l}n \text {-alc }{ }^{1} \\
\mu g^{-1}\end{array}$ & $\begin{array}{c}\text { HR } \\
\mu \mathbf{g ~ g}^{-1}\end{array}$ & $\begin{array}{l}\text { MCNR } \\
\mu \mathbf{g ~ g}^{-1}\end{array}$ & $\begin{array}{c}\text { MCNR } \\
\text { /HR }\end{array}$ & $\begin{array}{l}\text { nC17I } \\
\text { nC29 }\end{array}$ & $\begin{array}{c}\mathrm{nC17I} \\
\text { Pristano }\end{array}$ & $\begin{array}{l}\mathrm{nC} 18 / \\
\text { Fitano }\end{array}$ & IPC \\
\hline P1 & 1,65 & 5,86 & 40,9 & 7,00 & 0,41 & 0,88 & 1,01 & 1,20 \\
\hline P2 & 12,7 & 60,5 & 1025 & 16,9 & 0,15 & 0,43 & 0,45 & 1,44 \\
\hline P3 & 10,5 & 42,4 & 646 & 15,2 & 0,14 & 1,19 & 0,94 & 1,52 \\
\hline P4 & 4,23 & 13,9 & 172 & 12,3 & 0,30 & 0,80 & 0,76 & 1,71 \\
\hline P5 & 11,1 & 29,5 & 313 & 10,6 & 0,20 & 1,63 & 1,44 & 2,05 \\
\hline P6 & 10,5 & 50,2 & 663 & 13,2 & 0,03 & 0,92 & 0,70 & 2,26 \\
\hline P7 & 12,1 & 26,4 & 47,2 & 1,80 & 0,01 & 0,86 & 0,63 & 4,38 \\
\hline P8 & 13,9 & 19,3 & 109 & 5,60 & 0,02 & 1,93 & 1,00 & 3,68 \\
\hline P9 & 5,58 & 36,7 & 538 & 14,7 & 0,07 & 1,08 & 0,90 & 1,92 \\
\hline P10 & 0,97 & 5,97 & 45,4 & 7,60 & 0,10 & 0,75 & 0,49 & 1,31 \\
\hline P11 & 3,34 & 15,6 & 172 & 11,1 & 0,07 & 0,66 & 0,66 & 1,51 \\
\hline
\end{tabular}

Venkatesan et al. (1980), consideram o valor de $2 \mu \mathrm{g} \mathrm{g}^{-1}$ como nível de background para a soma de n-alcanos em sedimentos, enquanto Bouloubassi \& Saliot (1993) sugerem que este valor pode ser superado em duas ou três vezes quando altos aportes de matéria orgânica terrestres se fazem presentes. As concentrações encontradas para os sedimentos superam este limite $\left(2 \mu \mathrm{g} \mathrm{g}^{-1}\right)$ em quase todas as amostras. Os níveis encontrados para n-alcanos, Hidrocarbonetos Resolvidos (HR) e Mistura Complexa Não Resolvida (MCNR) são de ambientes altamente contaminados e são superiores aos encontrados em sedimentos de Santos e Cananéia (Nishigima et al., 2001), costa do Mar Cáspio (Tolosa et al., 2004) e Baía de Ushuaia (Commendatore et al., 2012). A 
concentração reportada e sua variação é análoga a dados pretéritos desta baía (Meniconi et al., 2002; Meniconi,2007; Wagener et al., 2012).
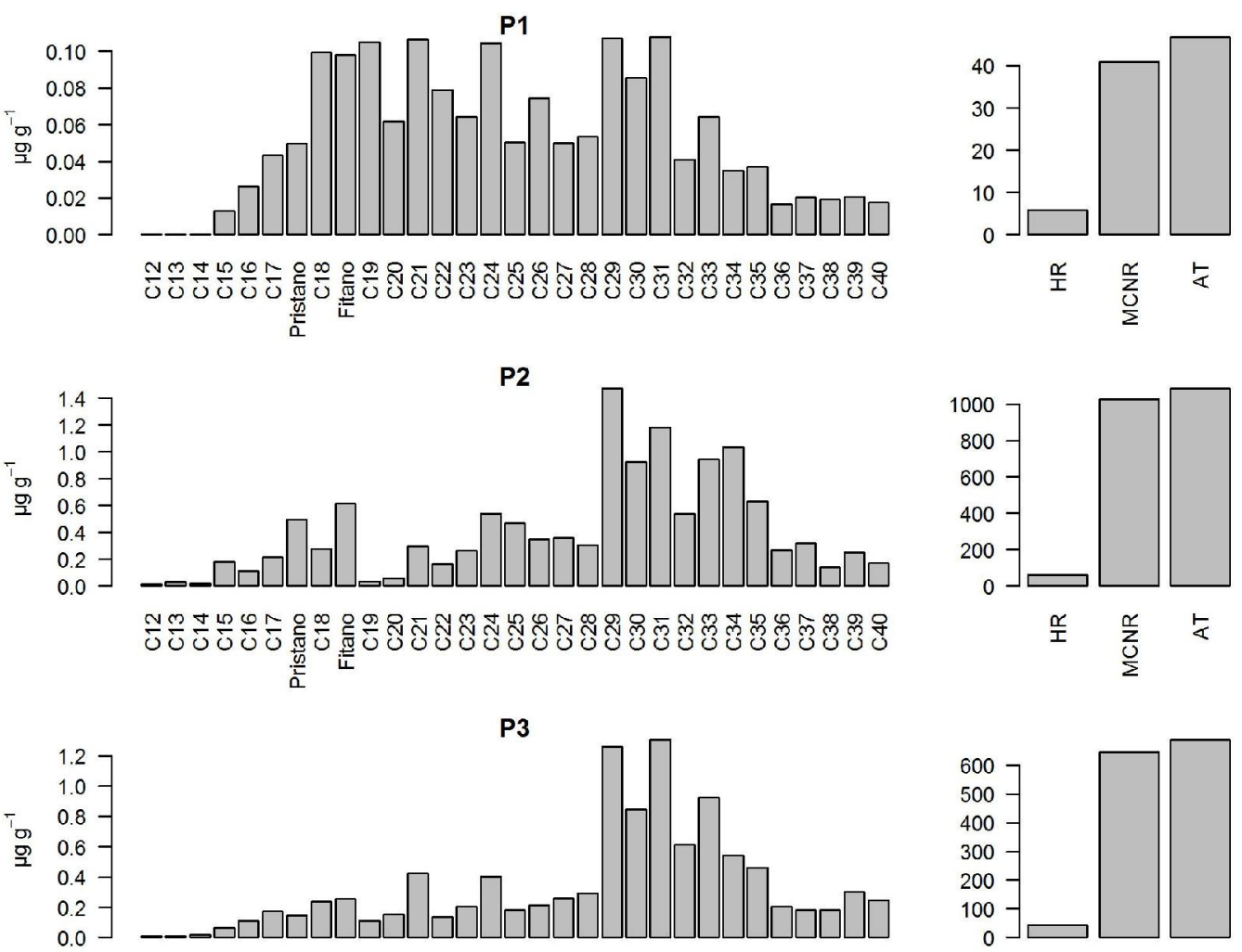

P3
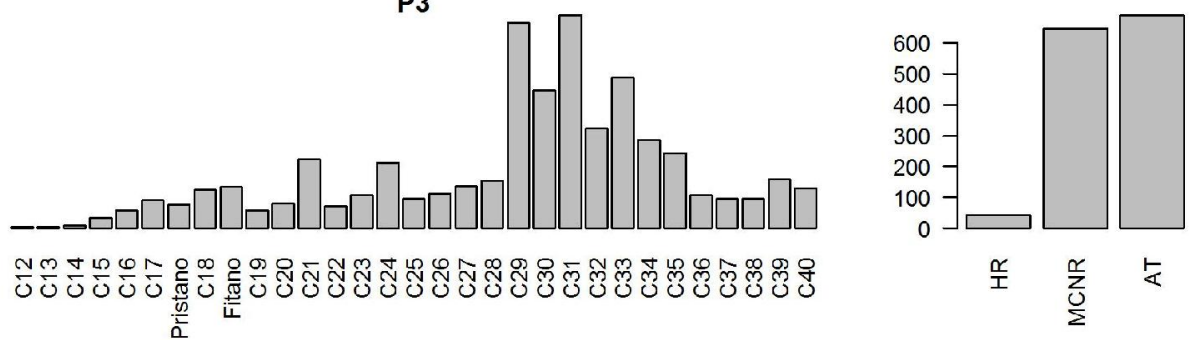

P4
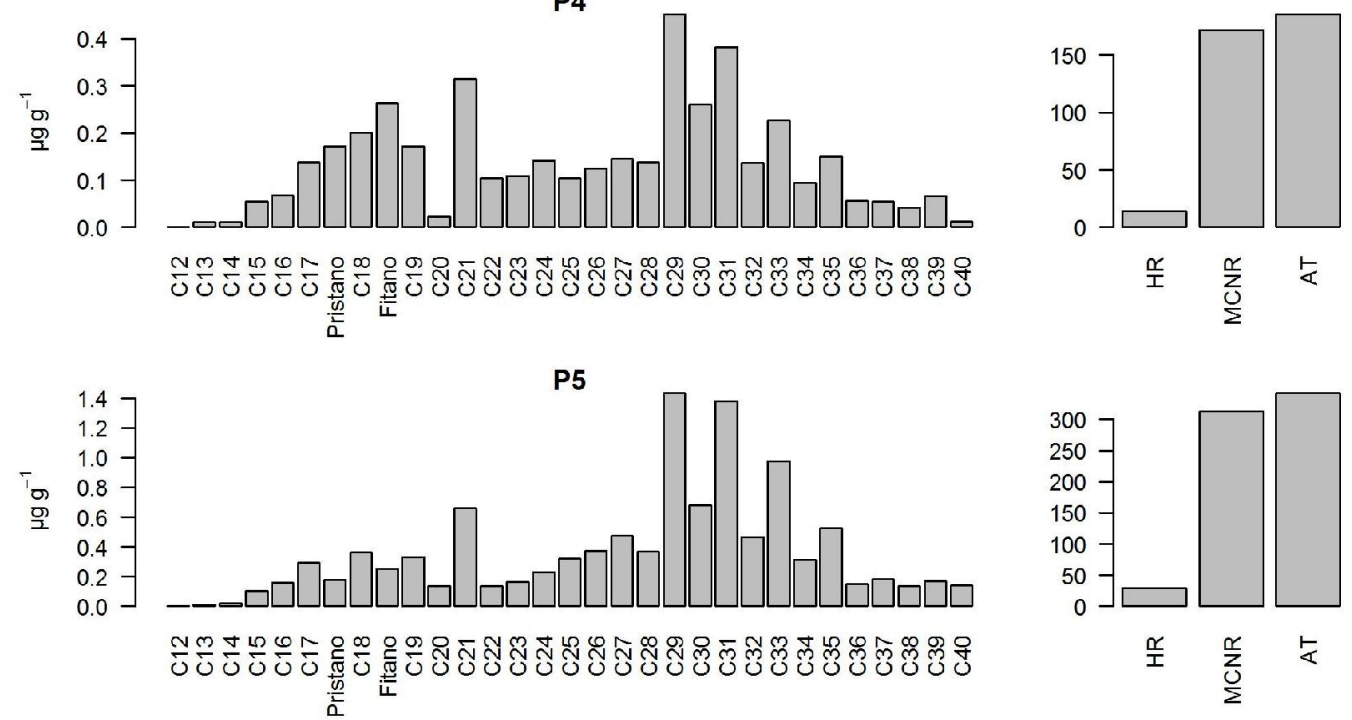

Figura 61 - Distribuição dos n-alcanos, HR, MCNR e Alifáticos Totais (AT) em amostras de sedimento da Baía de Guanabara. 

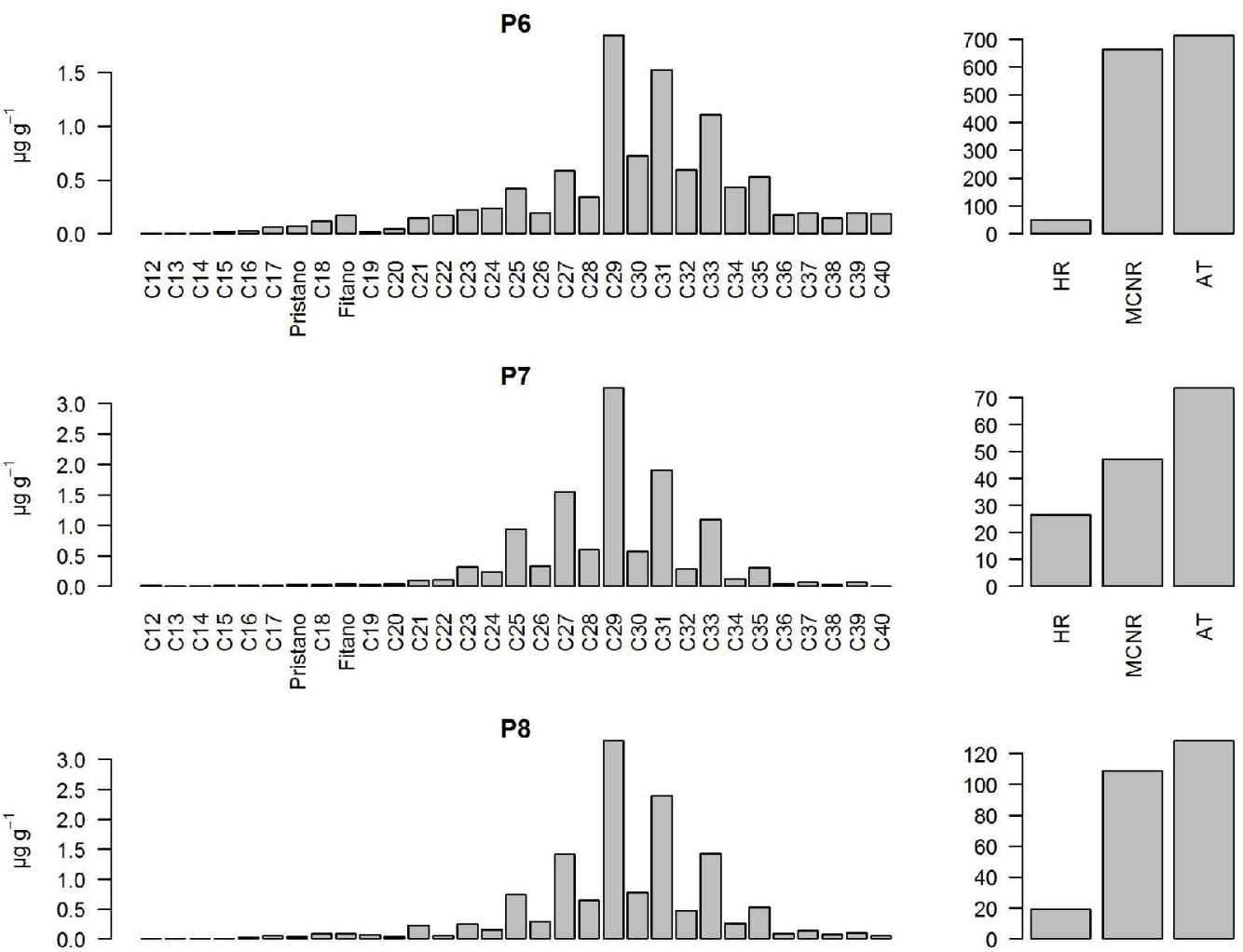

P8

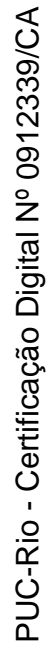
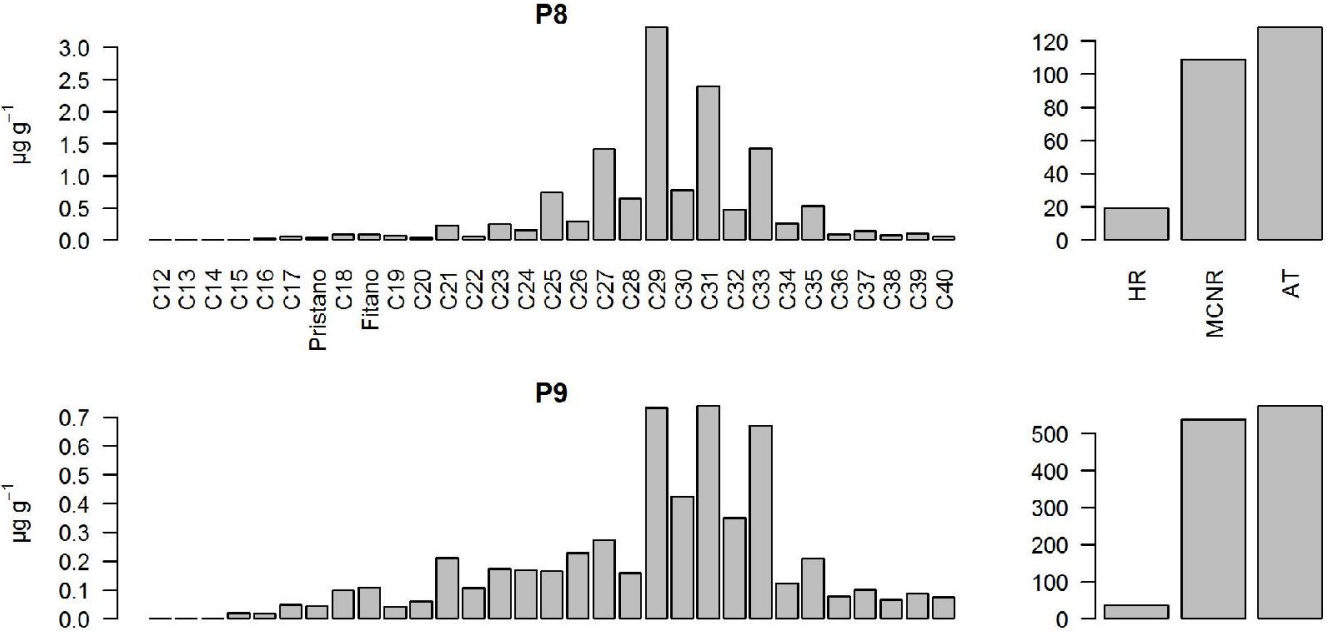

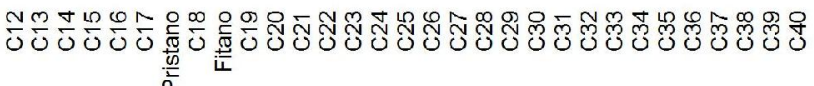
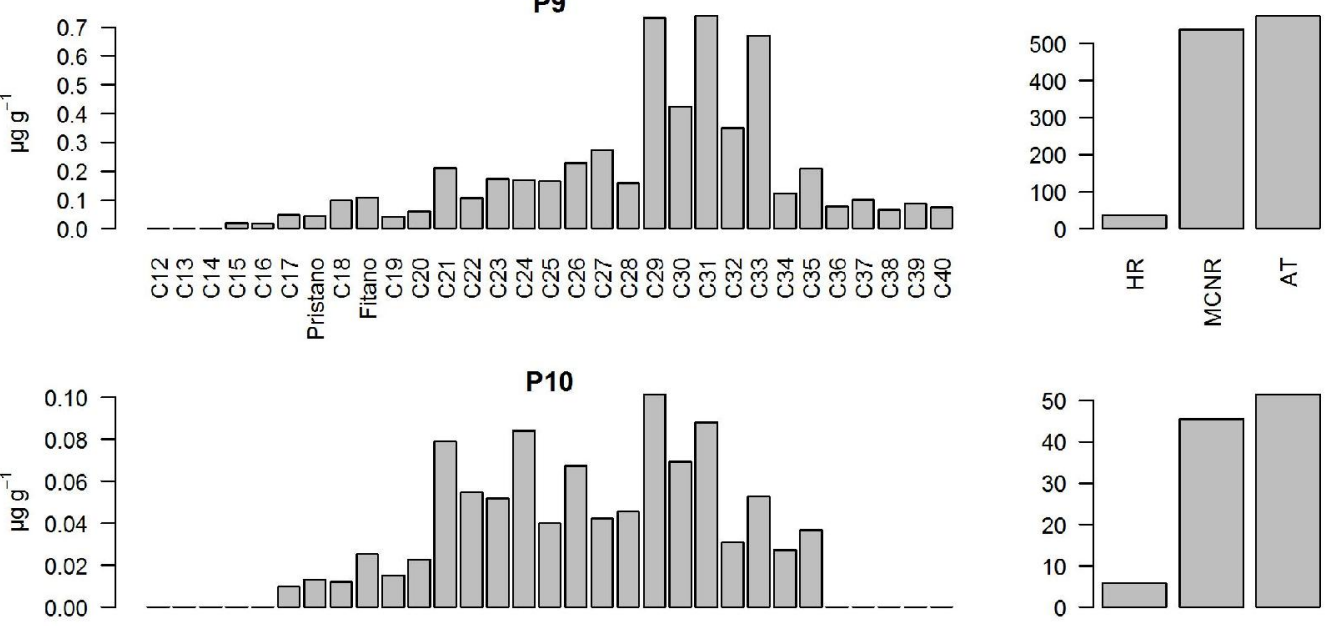

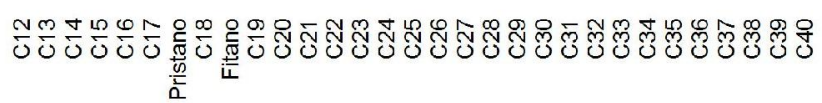
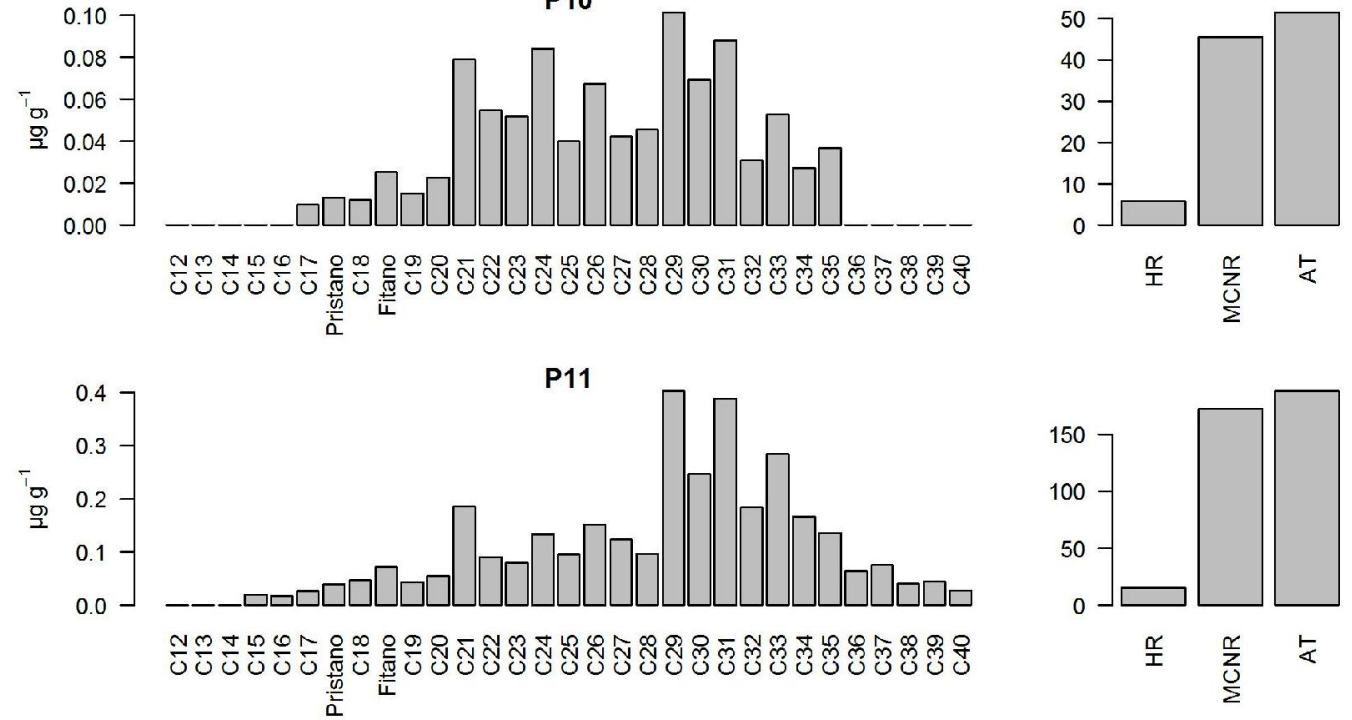

Figura 61 - Distribuição dos n-alcanos, HR, MCNR e Alifáticos Totais (AT) em amostras de sedimento da Baía de Guanabara. (Continuação) 
Razões utilizando compostos saturados são bastante utilizadas para diferenciação de fontes biogênicas e petrogênicas, enquanto os HPAs são mais representativos para fontes petrogênicas e pirolíticas (Colombo et al., 1989). Uma das principais razões usadas como base em compostos saturados é o Índice de Preferência de Carbono (IPC). O limite típico desta razão em sedimentos para indicar contribuição terrígena natural é de 4 ou mais. Entretanto Zanardi et al. (1999), Jaffe et al. (2003) e Bouloubassi \& Saliot (1993) reportam valores inferiores em regiões de confirmado aporte terrígeno. Amostras com valores de IPC próximos a 1 são consideradas contaminadas por hidrocarbonetos petrogênicos (Clark \& Blumer, 1967; Farrigton \& Tripp, 1997; Wang et al., 1999a). Na Figura 62 pode-se ver a variabilidade deste índice nas três matrizes estudadas. Observa-se claramente a baixa dispersão deste índice nas amostras de óleo, os valores predominantemente entre 1 e 1,6 para aerossóis da Região Metropolitana do Rio de Janeiro e na dispersão dos dados de sedimento se observa um gradiente da contribuição terrígena destacada nos dois pontos fora da distribuição, o P8 e o P7, este último em valor superior a 4. Em São Sebastião, por exemplo, Zanardi et al. (1999) reportaram IPC entre 1,2 e 3,2 onde a contribuição terrígena também foi evidenciada.
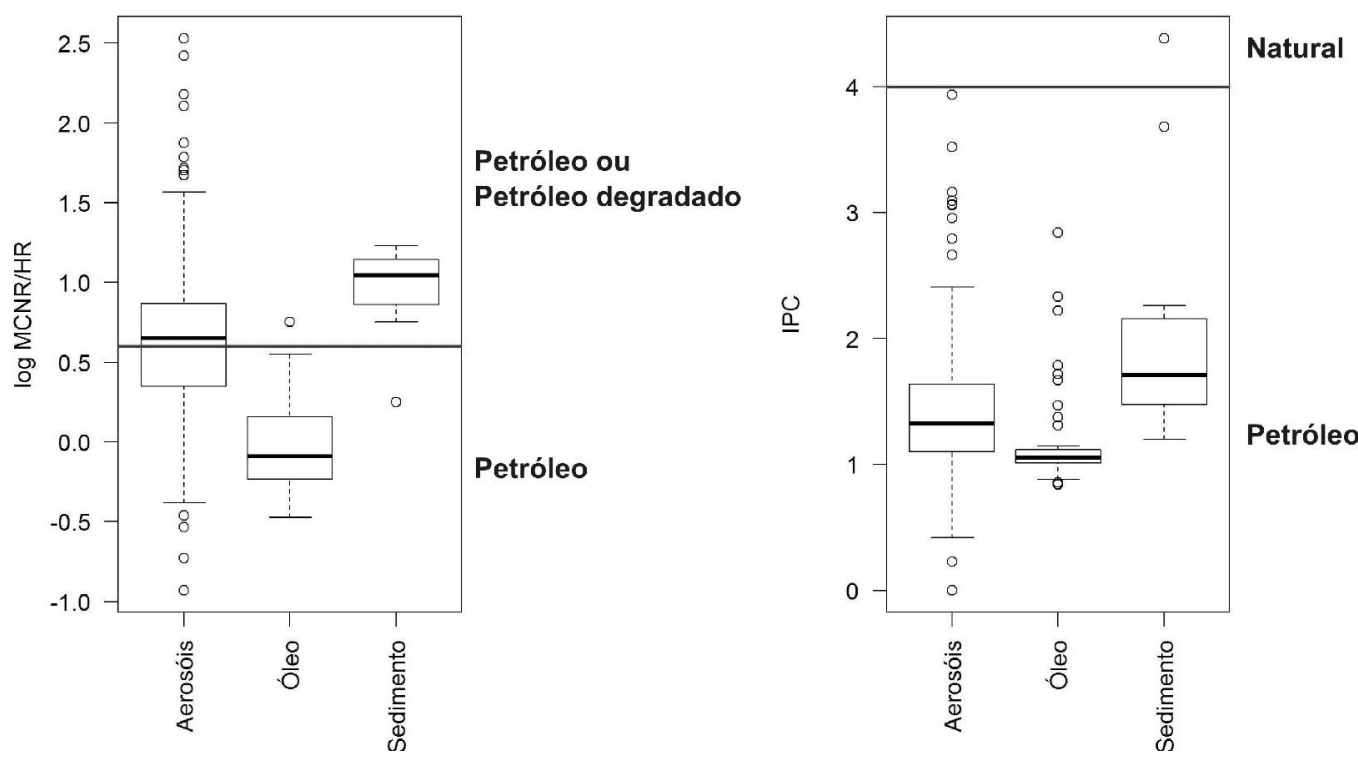

Figura 62 - Comparação entre as matrizes analisadas para a variação em escala logarítima da relação entre MCNR e HR e do índice de Preferência de Carbono (IPC)

Outra feição destacável na Figura 62 é a diferença na distribuição da relação MCNR/HR. A MCNR e sua importância relativa é comumente usada para 
identificar a contaminação por petróleo ou degradação deste material no ambiente (Readman et al., 2002; Wang et al., 1999; Volkman et al., 1992) com, em geral, valores da razão superiores a 4. A presença da MCNR por si só já é considerada marcador de contaminação por petróleo (Volkman et al. 1992; Simoneit, 1986). Embora se considere que a presença desta mistura possa ocorrer naturalmente (Venkatesan \& Kaplan, 1982), esta contribuição em ambientes costeiros é relativamente muito inferior à contribuição petrogênica (White et al., 2013).

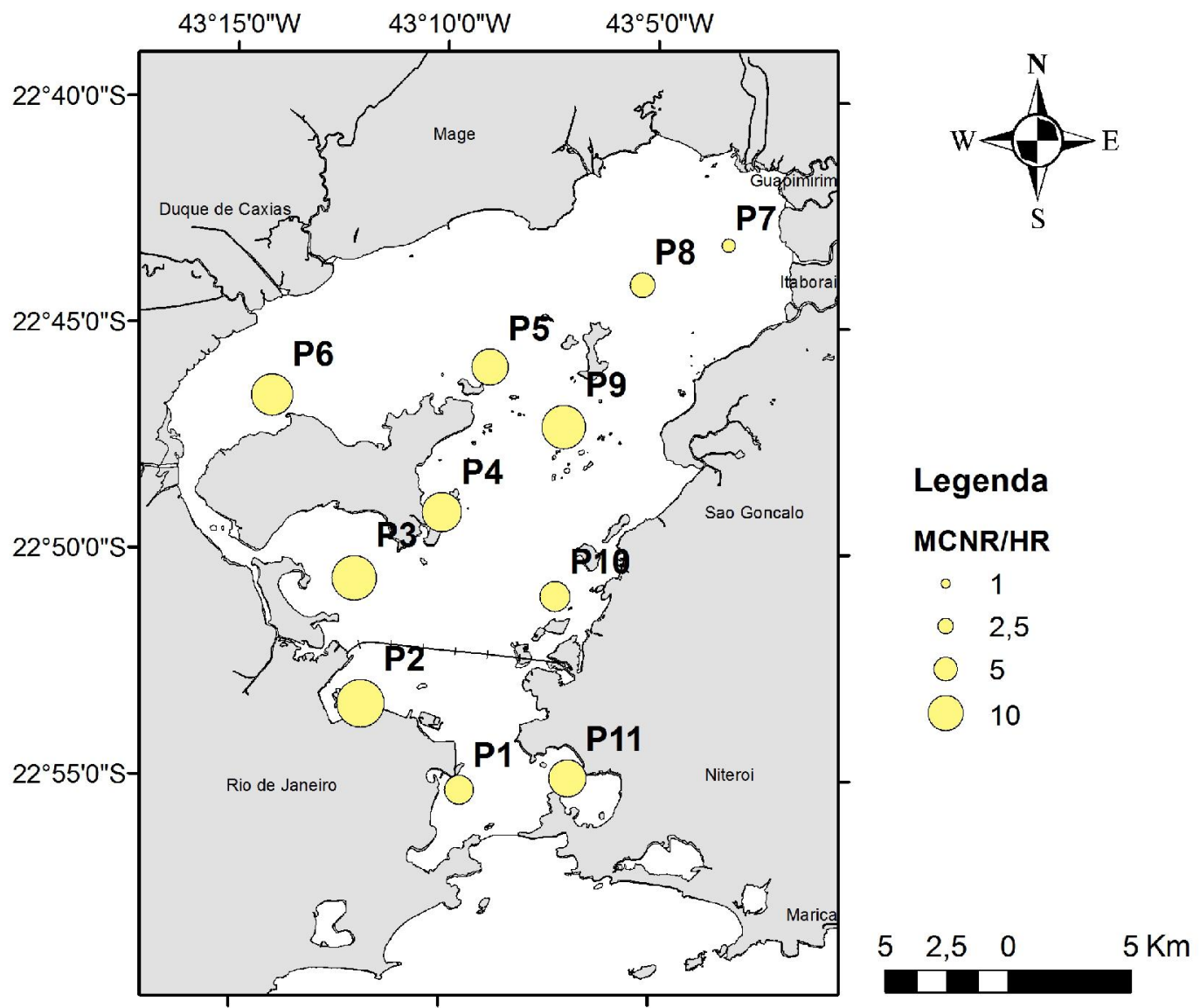

Figura 63 - Variação especial da relação MCNR/HR para as amostras de sedimento da Baía de Guanabara

Apenas a estação 7 mostrou valor abaixo do limite de 4 para esta razão (Simoneit \& Mazurek, 1982; Simoneit, 1984). Para os demais sedimentos esta razão indicou estágio avançado de degradação, especialmente na estação P2 (Figura 63), com menor contribuição relativa dos compostos resolvidos. Os valores reportados são superiores aos obtidos nas demais matrizes (Figura 62), sugerindo um quadro de degradação mais elevado. 
Este processo de degradação também é evidenciado pelos valores das razões nC17/pristano e nC18/fitano abaixo ou menores que 1. Entretanto as interpretações destas razões envolvendo os isoprenóides não são consideradas robustas dada a grande diversidade de fontes para estes compostos (Powell,1988). Por esta razão Wang et al. (2013) sugerem a utilização de biomarcadores e razão isotópica dos n-alcanos individuais como ferramenta de avaliação.

Em geral os trabalhos em sedimentos costumam dividir as fontes em naturais e antropogênicas, quando tratamos de hidrocarbonetos alifáticos. Valores de IPC próximos a 1 e altas concentrações de MCNR são associadas a aporte petrogênico, mas existe uma dissociação que esta característica petrogênica possa ser oriunda de emissões atmosférica, seja por deposição direta ou lixiviamento urbano. Geoquímicos costumam associar estes parâmetros a fontes locais, desconsiderando estes fatores. Este quadro complica ainda mais a avaliação ambiental pois não basta caracterizar aporte petrogênico sem determinar sua origem e, para tal, as ferramentas obtidas a partir da fração alifática não são suficientes.

As amostras P1, P4 e P5 mostraram significante contribuição de compostos mais leves comparadas às demais amostras. Esta contribuição pode ser evidenciada pela maior relação nC17/nC29 exposta na Tabela 9. Como estas estações localizam-se próximo a saídas de esgotos é possível que esta contribuição seja relacionada a blooms de algas. Dada a elevada produtividade primária na baía seria de esperar valores da razão acima elevados, mas os valores bastante inferiores à unidade retratam a intensidade dos processos de degradação na coluna d'água e nos sedimentos, assim como a maior labilidade do alcanos de baixa massa molecular.

A distribuição de hidrocarbonetos alifáticos na Baía de Guanabara, considerando todas as fontes e processos de degradação, sugere poluição petrogênica ubíqua (Figura 64). As únicas exceções são as amostras P7 e P8 cuja contribuição natural de hidrocarbonetos as destaca do restante das amostras. 


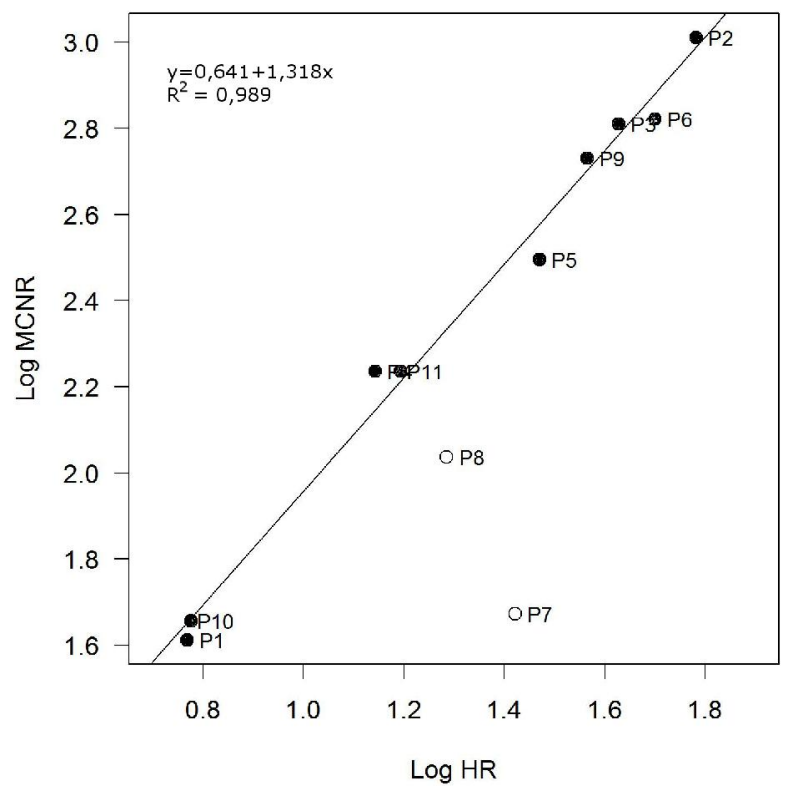

Figura 64 - Gráfico log da relação entre os hidrocarbonetos resolvidos (HR) e a Mistura Complexa Não Resolvida. (P7 e P8 não utilizados no cálculo de regressão). 


\subsection{3}

\section{Hidrocarbonetos aromáticos}

Os resultados detalhados da análise da fração aromática encontram-se em anexo e a Tabela 10 contém um resumo dos resultados e razões aplicadas aos dados. A recuperação média para o padrão subrogado da fração aromática foi de $90 \pm 13 \%$.

Tabela 10 - Resultados obtidos da fração aromática para amostras de sedimento da Baía de Guanabara

\begin{tabular}{|c|c|c|c|c|c|c|c|c|c|c|c|}
\hline & P1 & P2 & P3 & P4 & P5 & P6 & P7 & P8 & P9 & P10 & P11 \\
\hline $\begin{array}{l}16 \text { HPAs } \\
\text { EPA ng g-1 }^{-1}\end{array}$ & 872 & 22409 & 2298 & 1774 & 1425 & 629 & 207 & 597 & 8729 & 1532 & 1906 \\
\hline $\begin{array}{l}\text { Soma } 38 \\
{\text { HPAs } \mathrm{ng} \mathrm{g}^{-1}}\end{array}$ & 11497 & 46199 & 4765 & 2903 & 3062 & 1552 & 424 & 1197 & 16159 & 2234 & 3036 \\
\hline $\begin{array}{l}\text { \% Perl } \\
\text { Isômeros }\end{array}$ & 5,47 & 6,26 & 6,12 & 6,29 & 6,40 & 10,2 & 27,7 & 17,8 & 5,38 & 6,86 & 6,29 \\
\hline $\begin{array}{l}\% 2-3 \\
\text { Anéis }\end{array}$ & 27,6 & 30,4 & 35,5 & 28,6 & 38,4 & 36,3 & 33,8 & 29,6 & 20,3 & 15,9 & 18,1 \\
\hline $\begin{array}{l}\% 4-6 \\
\text { Anéis }\end{array}$ & 72,4 & 69,6 & 64,5 & 71,4 & 61,6 & 63,7 & 66,2 & 70,4 & 79,7 & 84,1 & 81,9 \\
\hline $\begin{array}{l}\% 5-6 \\
\text { Anéis }\end{array}$ & 34,3 & 24,6 & 30,3 & 26,9 & 29,5 & 23,2 & 37,1 & 37 & 39,1 & 38 & 35,9 \\
\hline $\begin{array}{l}\mathrm{An} / \\
(\mathrm{Fe}+\mathrm{An})\end{array}$ & 0,27 & 0,47 & 0,46 & 0,2 & 0,4 & 0,33 & 0,34 & 0,39 & 0,48 & 0,3 & 0,31 \\
\hline $\begin{array}{l}\mathrm{BFI} / \\
(\mathrm{BFI}+\mathrm{BePi})\end{array}$ & 0,74 & 0,73 & 0,74 & 0,76 & 0,75 & 0,74 & 0,76 & 0,75 & 0,77 & 0,75 & 0,75 \\
\hline $\begin{array}{l}\mathrm{FI} / \\
(\mathrm{FI}+\mathrm{Pi})\end{array}$ & 0,54 & 0,43 & 0,44 & 0,54 & 0,51 & 0,44 & 0,55 & 0,49 & 0,42 & 0,53 & 0,5 \\
\hline $\begin{array}{l}\mathrm{BaA} / \\
(\mathrm{BaA}+\mathrm{Cr})\end{array}$ & 0,55 & 0,55 & 0,57 & 0,54 & 0,55 & 0,54 & 0,51 & 0,51 & 0,52 & 0,55 & 0,55 \\
\hline $\begin{array}{l}\mathrm{Co} /(\mathrm{CO}+\mathrm{C} 1) \\
\mathrm{Fe} / \mathrm{An}\end{array}$ & 0,45 & 0,36 & 0,48 & 0,64 & 0,43 & 0,44 & 0,43 & 0,41 & 0,43 & 0,57 & 0,54 \\
\hline $\begin{array}{l}1,7 /(1,7+2,6) \\
\text { DMFe }\end{array}$ & 0,74 & 0,69 & 0,78 & 0,73 & 0,75 & 0,82 & 0,79 & 0,82 & 0,69 & 0,74 & 0,79 \\
\hline $\begin{array}{l}\mathrm{IPi} / \\
(\mathrm{IPi}+\mathrm{BPe})\end{array}$ & 0,55 & 0,52 & 0,55 & 0,58 & 0,58 & 0,54 & 0,59 & 0,58 & 0,54 & 0,60 & 0,56 \\
\hline $\begin{array}{l}\text { Índice } \\
\text { Pirolítico }\end{array}$ & 1,58 & 1,21 & 1,13 & 1,5 & 0,98 & 0,83 & 1,32 & 1,38 & 1,68 & 2,46 & 2,06 \\
\hline
\end{tabular}

A concentração de HPAs em sedimentos da Baía de Guanabara esteve na faixa de estudos anteriores: 1564 - $18438 \mathrm{ng} \mathrm{g}^{-1}$ (Lima, 1996); 554 - $1984 \mathrm{ng} \mathrm{g}^{-1}$ 
(Hamacher, 1996); 91 - 58439 ng g-1 dez dias após o derrame de 18 de janeiro de 2000 (Meniconi et al., 2002); 400 - $52384 \mathrm{ng} \mathrm{g}^{-1}$ em amostras coletadas no ano de 2003 (Meniconi, 2007) e 14 - $153316 \mathrm{ng} \mathrm{g}^{-1}$ em dois anos de programa de monitoramento com coletas semestrais, no período de 2005 a 2007 (Wagener et al., 2012).

As concentrações reportadas são difíceis de comparar dado o fato dos autores terem utilizado diferentes metodologias, determinado diferentes números de compostos e deve-se considerar que apesar da escolha dos pontos baseado em estudos pretéritos a coleta não é exatamente coincidente. O monitoramento de sedimentos nos mesmos locais de amostragem ao longo dos anos (Meniconi et al., 2002; Meniconi, 2007; Wagener et al., 2012) seguindo a mesma metodologia mostram que as concentrações não variam com o tempo e também não variam para um mesmo local de coleta. No presente trabalho as amostras P9 e P2 mostraram concentração marcadamente superior às demais em uma e duas ordens de grandeza, respectivamente. Para a estação P2, próxima ao Porto do Rio de Janeiro, apresentou a concentração mais elevada assim como observado em estudos anteriores (Meniconi et al., 2002, Meniconi, 2007; Wagener et al., 2012).

A estação P9 foi a segunda maior concentração apesar de se encontrar sobre influência do canal central de circulação, cujo valor encontrado de 16159 ng g-1 está dentro da variação história (2000 - 2008) reportada (Meniconi et al., 2002, Meniconi, 2007; Wagener et al., 2012). Cabe ressaltar que esta estação encontra-se próxima ao Terminal da Ilha D'Água, e deve estar sob influência do mesmo. Apesar da coerência com os dados históricos, quando comparada a outros ambientes costeiros a concentração reportada é superior (Wagener et al., 2010; Tolun et al., 2001; Medeiros et al., 2005; Commendatore et al., 2012; Tolosa et al., 2004). A tipologia dos HPAs por estação pode ser visualizada na Figura 65.

Esses estudos prévios mostraram o predomínio de compostos de alto peso molecular (4 a 6 anéis) no perfil de HPAs nos sedimentos. Nas amostras do presente estudo há maior abundância de compostos de 4 anéis: fluoranteno, pireno, criseno e seus alquilados, e benzo(a)antraceno. Yunker et al. (2000) indicam que amostras de sedimentos com predominância de compostos de massas 252 e 202 são típicos de áreas sobre influencia urbano-industrial, especialmente os de massa 202. A mesma avaliação é corroborada por outros autores (Bouloubassi \& Saliot, 1993; Savinov et al., 2000; Simoneit, 1985). 
Várias razões diagnósticas de fontes foram aplicadas aos dados para determinação da origem dos hidrocarbonetos (Tabela 10) nos sedimentos superficiais da Baía de Guanabara. Dentre as razões normalmente utilizadas apenas a relação $\mathrm{CO} /(\mathrm{CO}+\mathrm{C} 1) \mathrm{Fe} / \mathrm{A}$ foi capaz de discriminar as amostras em grupos indicando possível origem petrogênica (Figura 66). Apesar da separação em grupos este índice não define fonte petrogênica unicamente, não sendo possível corroborar este aporte.
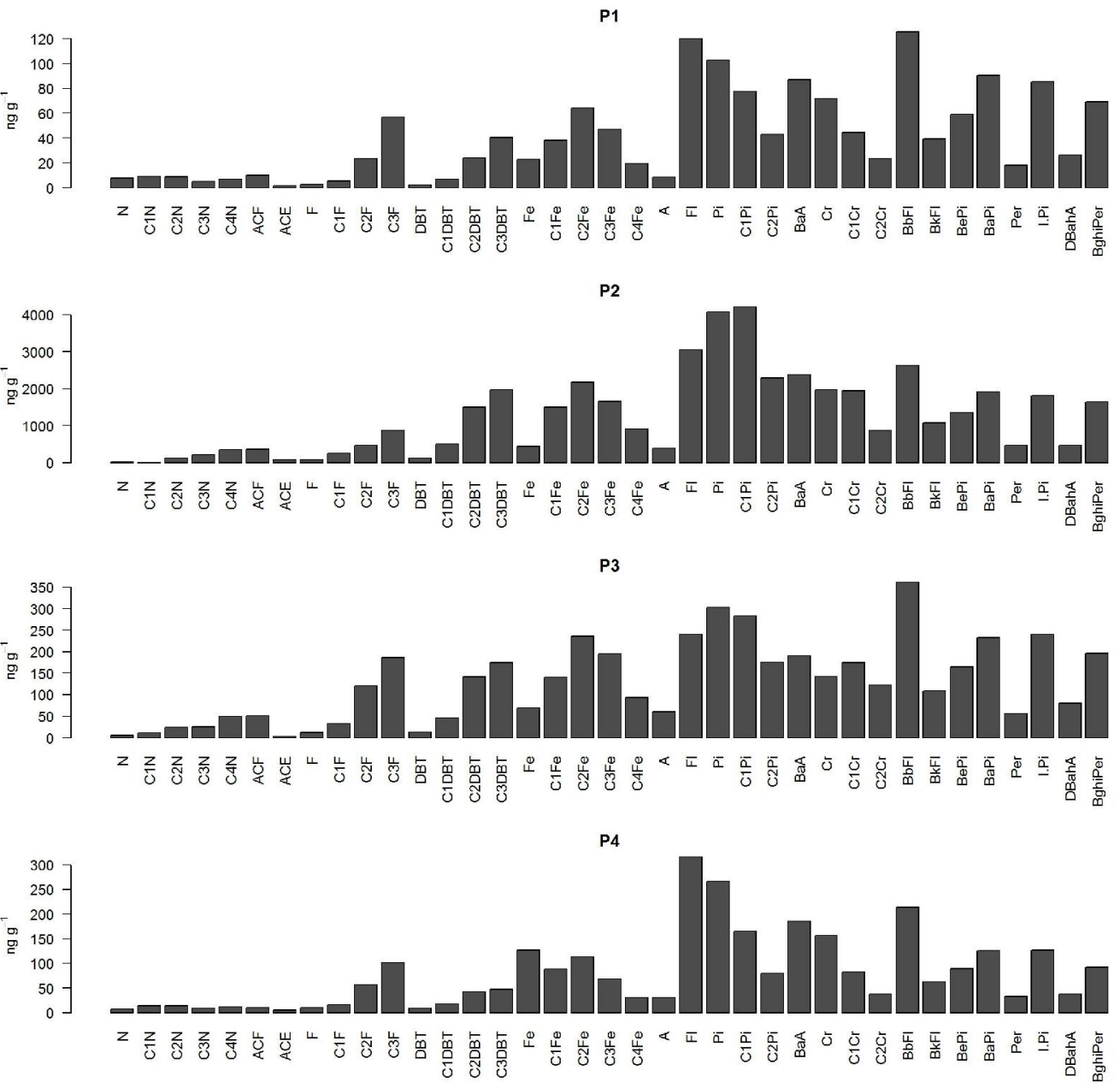

P5

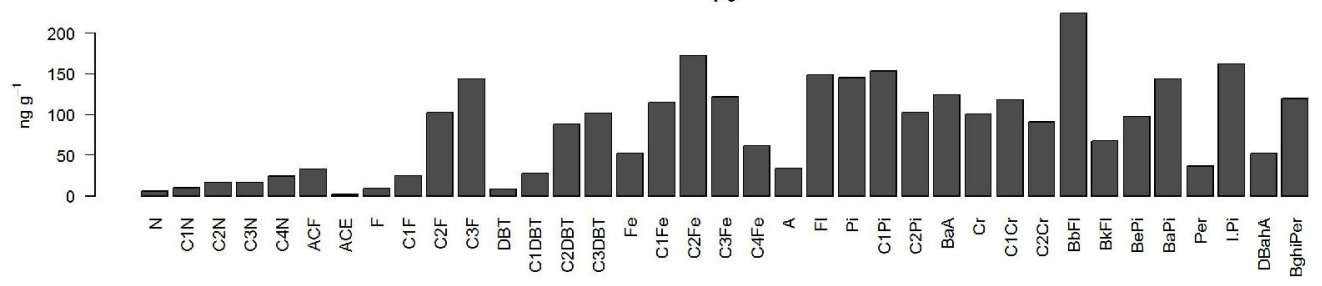

Figura 65 - Distribuição dos HPAs em amostras de sedimento da Baía de Guanabara. 


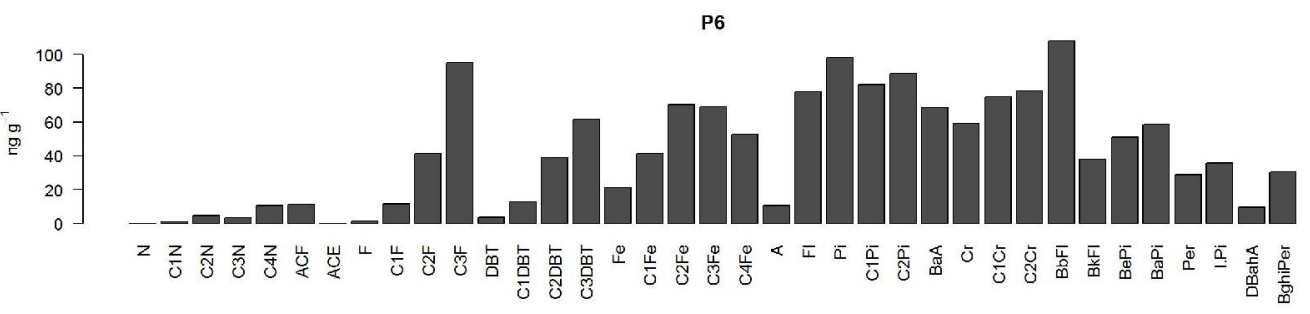

P7

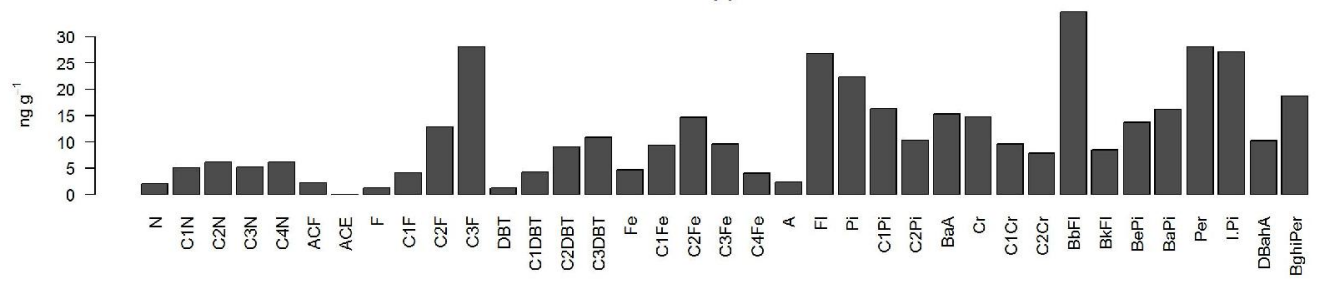

P8

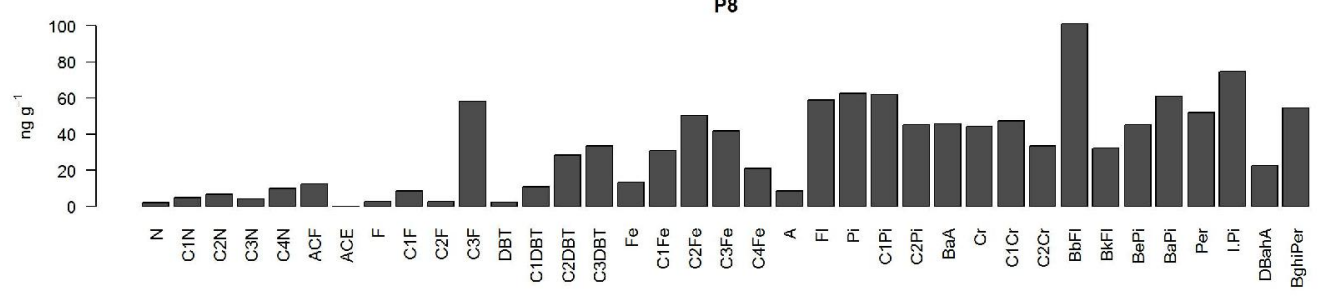

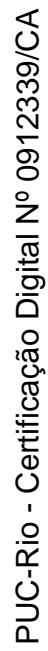
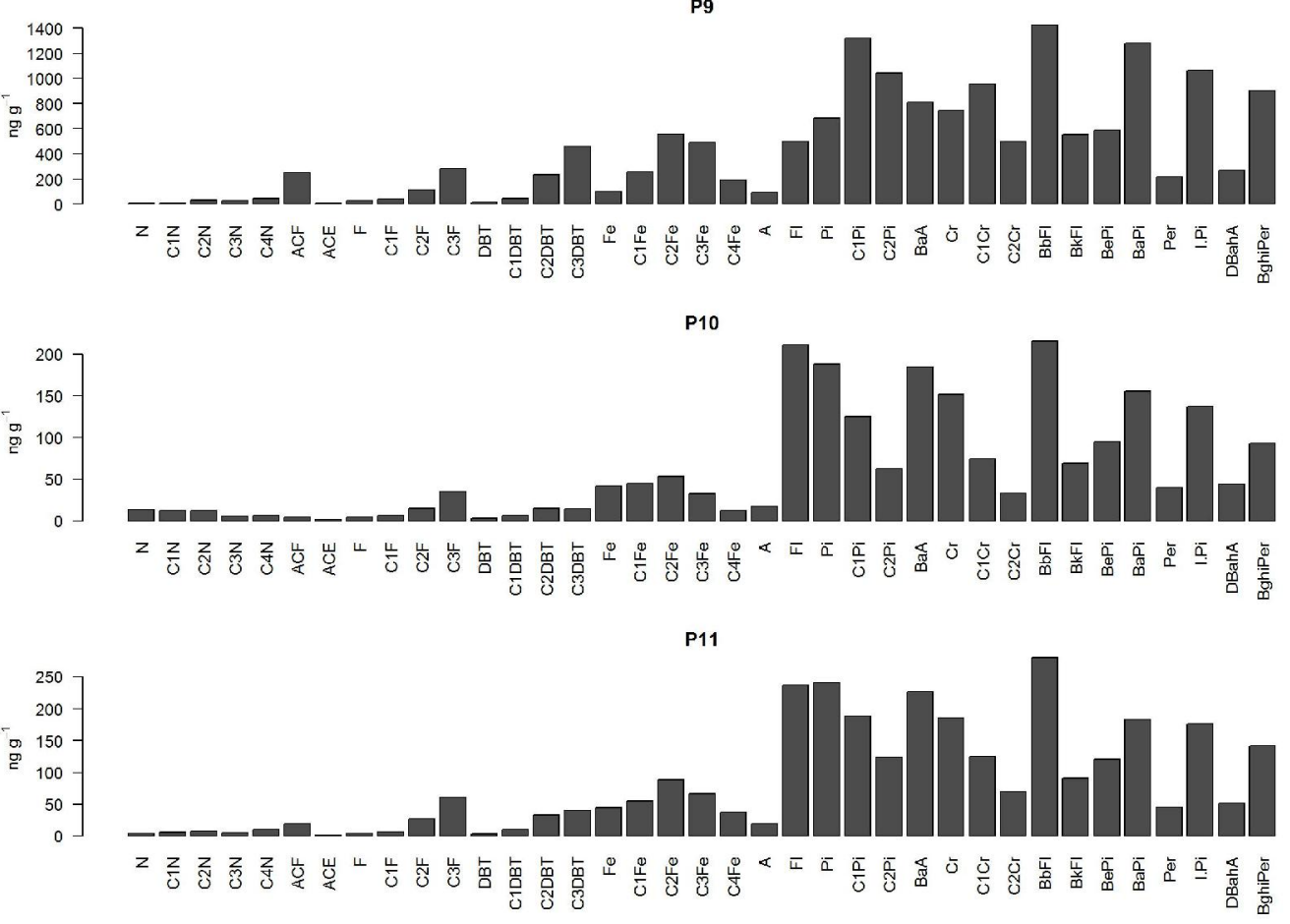

Figura 65 - Distribuição dos HPAs em amostras de sedimento da Baía de Guanabara. (Continuação) 


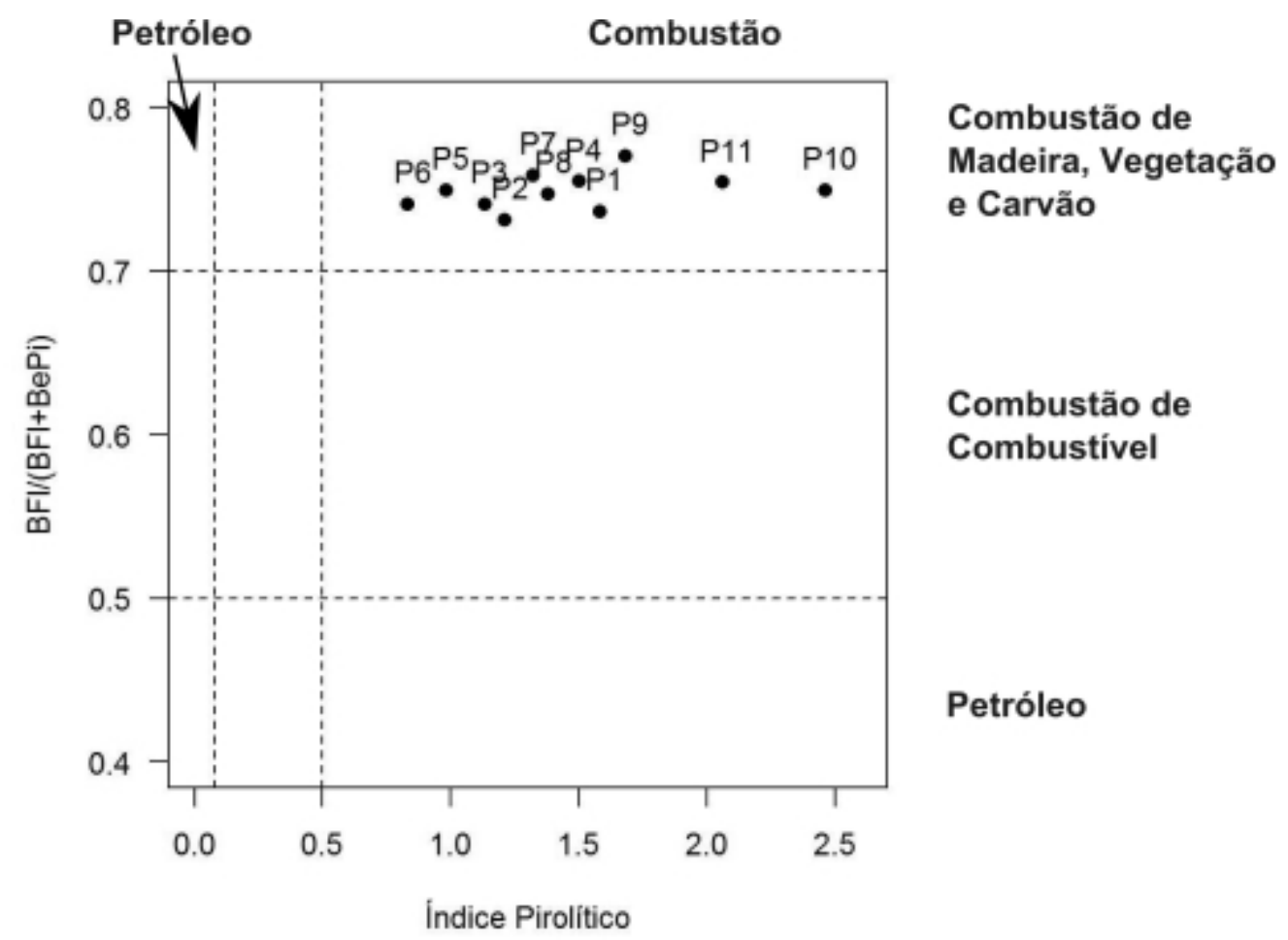

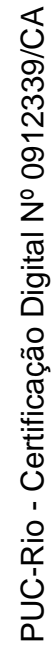

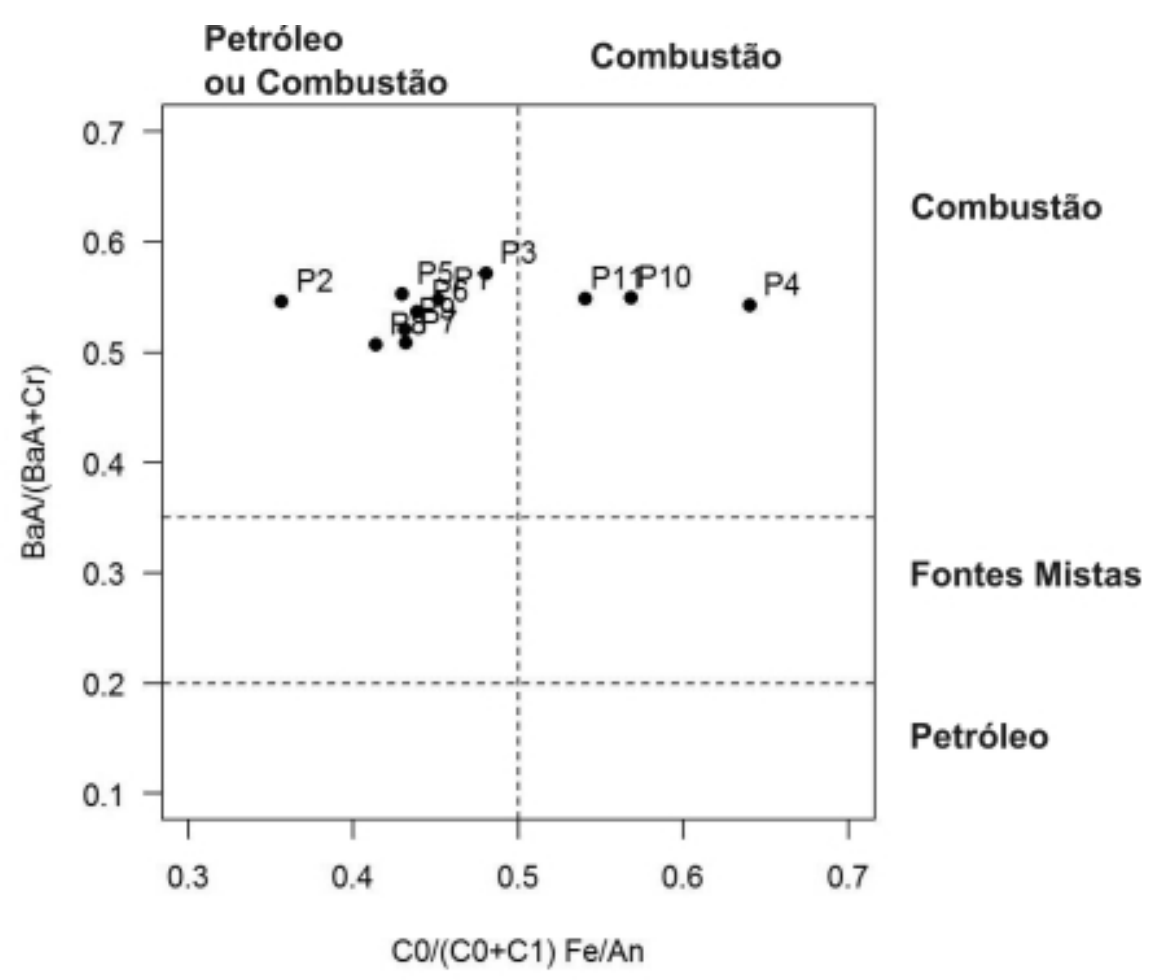

Figura 66 - Gráfico cruzado de razões diagnósticas de fontes aplicadas aos dados de Sedimento da Baía de Guanabara 


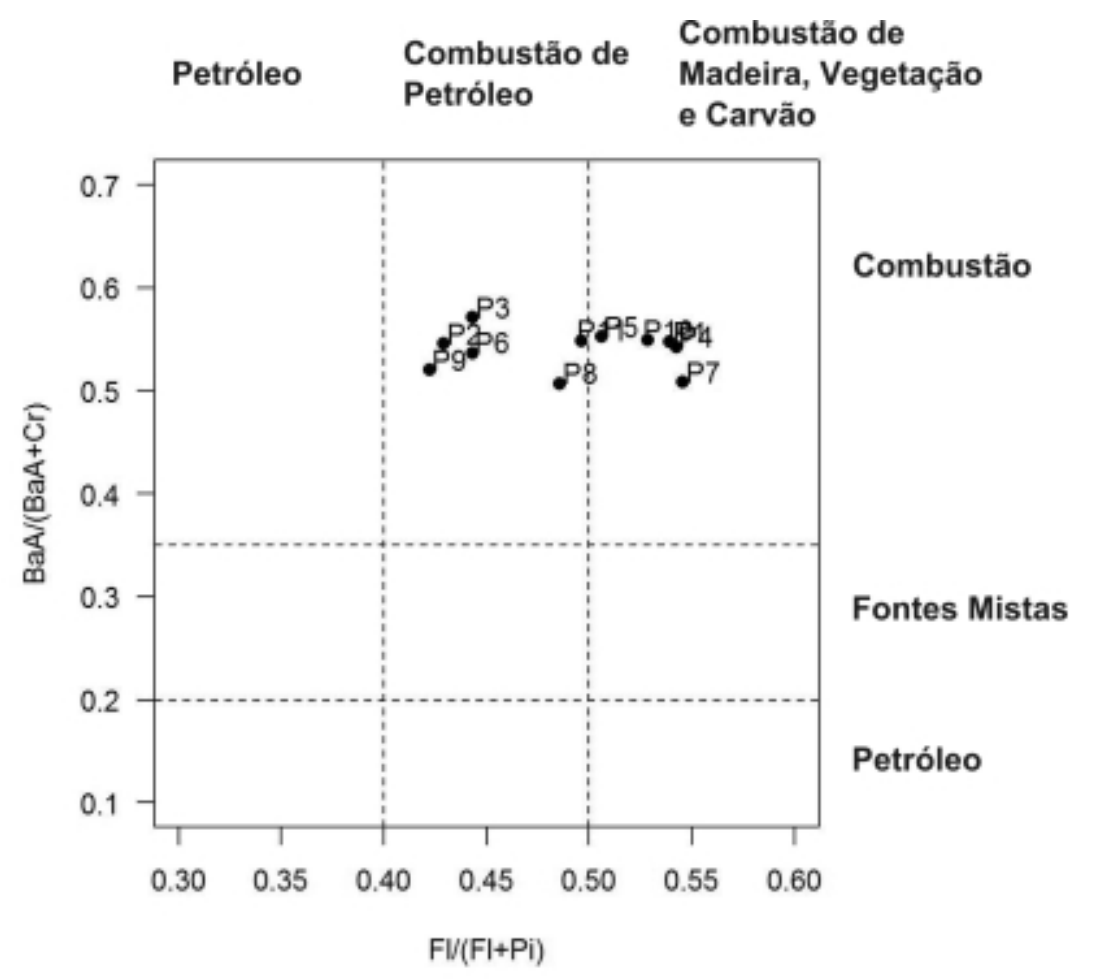

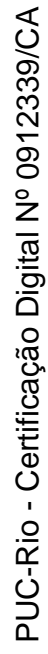

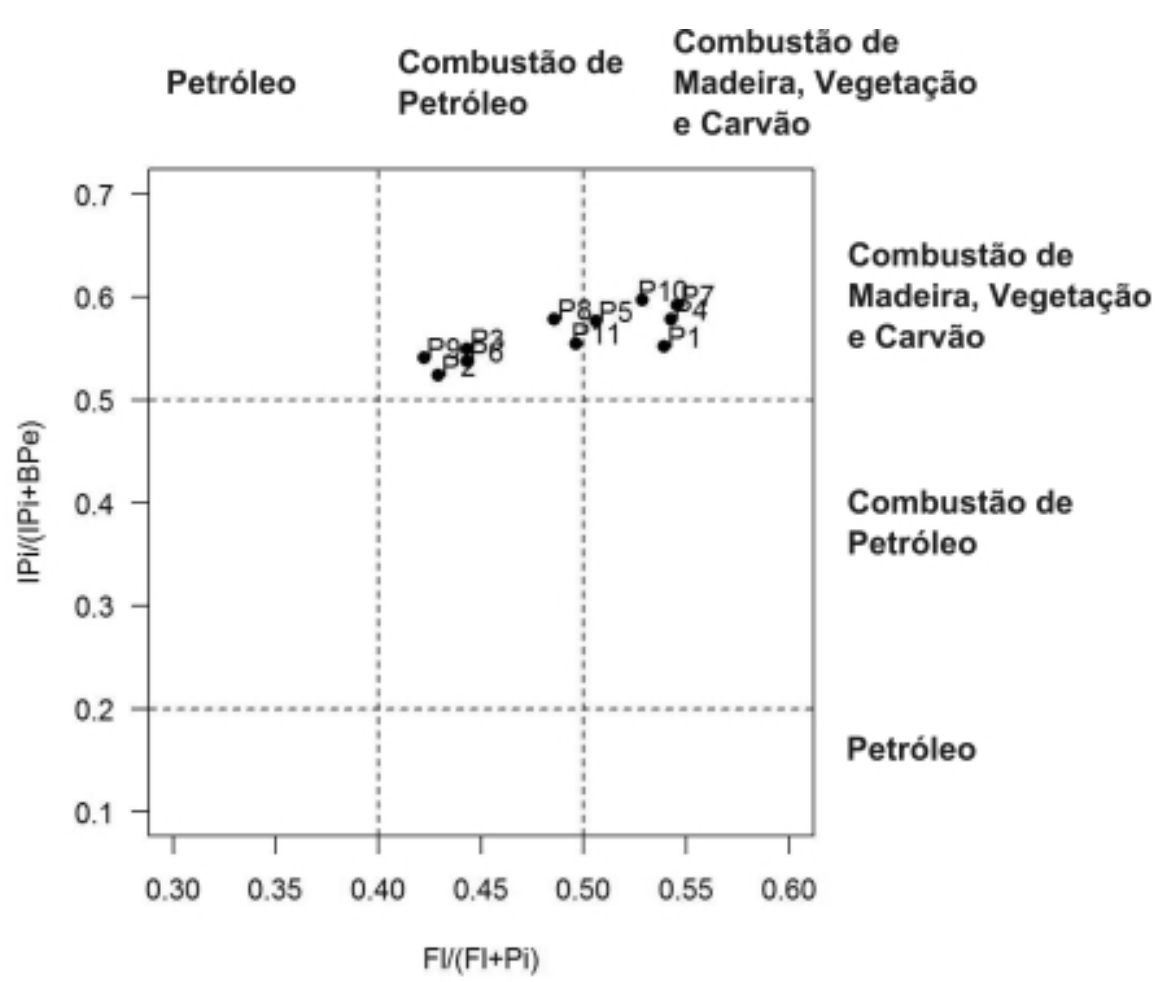

Figura 66 - Gráfico cruzado de razões diagnósticas de fontes aplicadas aos dados de Sedimento da Baía de Guanabara (Continuação) 
Todas as razões mostram contaminação exclusiva por hidrocarbonetos de origem de combustão nas amostras (Figura 66) segundo os critérios normalmente utilizados na literatura (Yunker et al., 2002; Sicre et al., 1987; Baumard et al., 1998; Gschwend \& Hites, 1981; Wang et al., 1999a). Apesar do uso difundido destas razões as mesmas devem ser aplicadas com cautela e associadas a ferramentas estatísticas para avaliação (Wagener et al., 2011). Valores de razões reportadas por Meniconi et al. (2002) para o óleo MF380 de Fe/A $<10$, derramado na Baía de Guanabara, assim como $\mathrm{Fl} / \mathrm{Pi}<1$ para óleo cru colombiano valores considerados de fontes pirolíticas, quando as amostras são conhecidamente petrogênicas. Wang et al. (2001) também reportam Fe/A e $\mathrm{BaA} /(\mathrm{BaA}+\mathrm{Cr})$ em óleo cru com valores considerados provenientes de processos de combustão.

Outro problema no uso de razões diagnósticas de fontes ocorre quando diferentes fontes coexistem (Soclo et al., 2000, Wang et al., 1999). Deve-se considerar é que a sobreposição de fontes nem sempre afeta a razão diagnóstico de fonte na mesma proporção em que os diferentes aportes ocorrem. Analisando a diferença entre os perfis de petróleo e produtos de petróleo e dos aerossóis observa-se que neste último a proporção de compostos de maior massa molecular é muito maior. Compostos de massa molecular 276 estão em níveis praticamente não detectáveis nas amostras de petróleo analisadas e, em aerossóis, são os mais abundantes. Em um aporte equivalente de ambas as fontes, razões envolvendo estes compostos como IPi/(IPi+BPer) seriam pouco afetados pela mistura e provavelmente seguiriam com as mesmas indicações dos aerossóis.

Os resultados obtidos para o índice pirolítico, proposto por Wang et al. (1999a,b), indicaram contribuições de combustão para todas as amostras. Ressalta-se que este índice não considera os efeitos do intemperismo, principalmente a perda de compostos leves e sua aplicabilidade restringe-se mais a derrames recentes.

O gráfico entre a relação da soma das 5 séries de HPAs alquilados (predominantes em óleos) e compostos de 3 a 6 anéis (predominantes em resíduos de combustão) foi mais uma vez aplicado e encontra-se exposto na Figura 67. As indicações desta avaliação sugerem que as amostras provém de mistura equivalente entre as diversas fontes ou de fonte única.

O processo de degradação de HPAs pode também afetar a tipologia original nas amostras e, portanto, a avaliação das fontes. A maioria das amostras apresentam elevada MCNR, que é uma forte evidência de degradação, 
assim como a análise das séries de HPAs alquilados nestas amostras. Observase o padrão típico de degradação , $\mathrm{C} 0<\mathrm{C} 1<\mathrm{C} 2<\mathrm{C} 3$ (Page et al., 1993), para as séries de naftalenos, fluorenos e dibenzotiofenos. A série de fenantrenos, entretanto, apresenta maior concentração de alquilados distribuídos em forma de sino, característico de contribuição petrogênica.

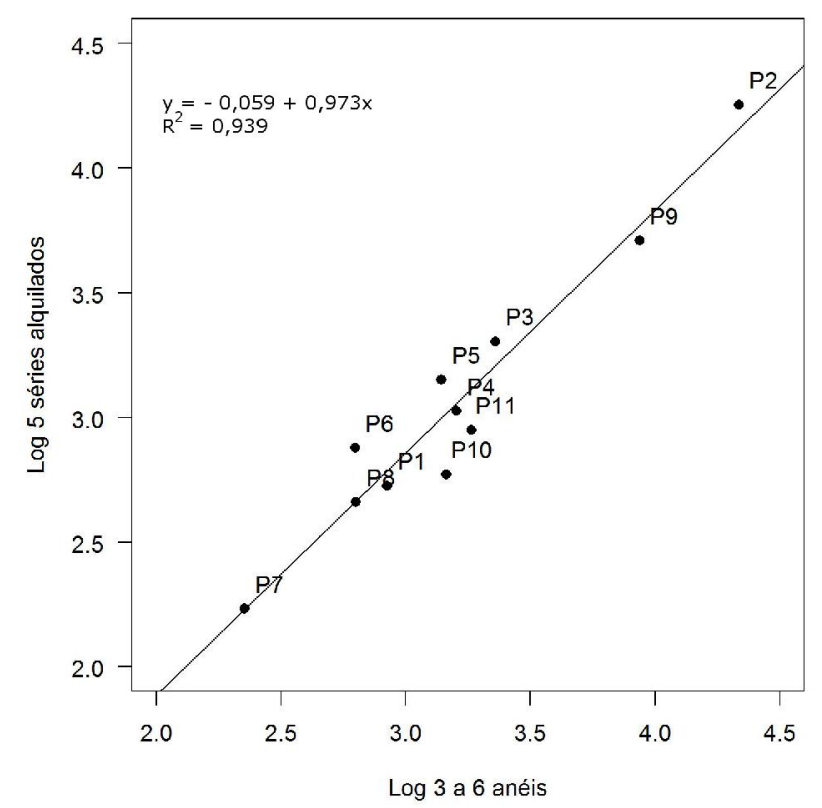

Figura 67 - Gráfico log-log da concentração da concentração de HPAs de 3 a 6 anéis e da soma das 5 séries de HPAs alquilados para amostras de sedimento da Baía de Guanabara.

Uma possível explicação para esta diferença de indicações entre estas séries de HPAs seria a entrada natural de alguns compostos. Esta contribuição natural foi proposta inicialmente por Wakeham et al. (1980a) e Venkatesan \& Kaplan (1982), ainda Colombo et al. (1989) já reportaram problemas em razões diagnóstico de fontes pela influência de alquilfenantrenos derivados de diagênese.

Nas estações P7 e P8 a contribuição natural é evidenciada pela contribuição relativa do perileno em relação aos compostos de mesma massa, sendo de 27,7 e $18,7 \%$ respectivamente. Os precursores naturais deste compostos e condições ideais para sua formação encontram-se sumarizados no trabalho de Venkatesan (1988). Este composto é encontrado associado com material terrígeno e condições de redução (Ainzenshat, 1973; Wakeham, 1977), tendo sido frequentemente associado a sedimentos de rios e estuários (Laflamme \& Hites, 1978; Baumard, 1998; Venkatesan \& Kaplan, 1982). Perileno 
derivado de contribuição natural nas estações $\mathrm{P} 7$ e P8, próximas a área de proteção ambiental colonizada por manguezais, sugerem que a origem diagenética supera a fonte de combustão para este composto.

Embora a maioria dos autores relacione a origem do perileno com a matéria orgânica terrestre, alguns estudos inferem correlações significativas entre sedimentos de diatomáceas e elevadas concentrações de perileno (Hites et al., 1980; Venkatesan, 1988). Wakeham et al. (1979) encontraram altas concentrações de perileno derivada de produção algal, implicando em precursores aquáticos para este composto. Fang et al. (2003) encontraram

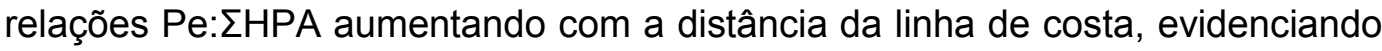
a origem marinha deste composto. Embora a contribuição marinha para a formação do perileno seja uma possibilidade, esta não pode ser observada nas amostras deste estudo, onde predomina a terrestre. Silliman (1998) sugere que a formação deste composto é controlada mais por processos microbiológicos in situ de materiais orgânicos do que a disponibilidade de materiais precursores. $\mathrm{O}$ autor se baseia na ausência de correlações significativas entre a ocorrência de perileno e os indicadores de fontes de matéria orgânica, tanto terrígena como marinha. Silliman (2000), através de análise isotópica, também afirma que o perileno se origina de mais de um precursor, de diferentes processos biológicos, ou de uma combinação destas possibilidades. As indicações de contribuição natural deste composto a partir de precursores terrestres são confirmadas pela distribuição de n-alcanos e IPC reportados para as mesmas.

Assim como para o material particulado atmosférico a aplicação de razões em sedimentos fornece apenas informações qualitativas. Para obter-se uma estimativa quantitativa do aporte das diferentes fontes de hidrocarbonetos foi realizado o mesmo procedimento descrito por Larsen \& Baker (2003) para particulado atmosférico, também aplicado a esta matriz por outros autores (Chen et al., 2012; Li et al., 2012; Liu et al., 2009; Zhang et al., 2012; Wang et al., 2009). Cabe relembrar que a ACP foi realizada sobre a matriz de correlação, não existindo necessidade de padronizar os dados para análise.

Inicialmente observou-se que os dados de concentração não poderiam ser usados como variáveis de entrada na ACP. Apesar de outros estudos considerarem esta metodologia bem ajustada a grandes variações de concentração (Chen et al., 2012; Li et al., 2012; Liu et al., 2009; Zhang et al., 2012) o mesmo não se aplica aos sedimentos deste estudo. Observa-se que o Fator 1 representa quase a totalidade da variância (93\%) e não há discriminação da influência das variáveis, onde todas apresentam valores positivos (Figura 68). 
A explicação gerada pelo modelo de regressão a partir destes dados é que a concentração de hidrocarbonetos depende da concentração destes nas amostras. Além de redundante, esta metodologia não diferencia as fontes de HPAs, seu propósito inicial.

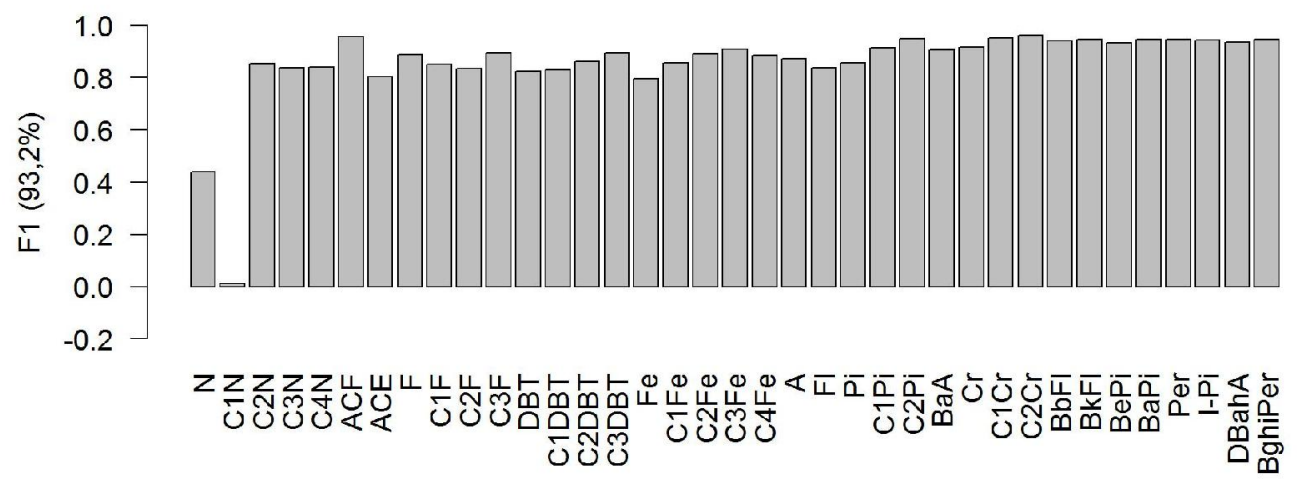

Figura 68 - Factor Loadings resultantes de ACP nos dados de concentração dos sedimentos.

Esse padrão é decorrente da grande amplitude na concentração dos sedimentos, evidenciada na Figura 69. Tal resultado pode ser facilmente compreendido uma vez que a ACP trata de relações lineares entre as variáveis. Apesar da distribuição relativa dos HPAs entre os sedimentos não ser idêntica à concentração de cada HPA (variável) nas amostras, a amostra P2, seguida da amostra P9, estão sempre em concentrações bastante superiores às demais amostras. Isto gera o mesmo efeito observado em relações simples quando poucas amostras de maior concentração tendem a inferir relação entre variáveis.

Apesar da diferentes técnicas aplicadas para normalizar os dados este padrão manteve-se. Desta forma adaptou-se a metodologia utilizando-se a avaliação normalmente aplicada para diferenciação de fontes. Isto significou usar a distribuição relativa dos HPAs, assim como na primeira ACP aplicada aos dados de aerossóis. Nesta análise 5 fatores apresentaram eigenvalues maiores que 1. O Fator 1 teve correlação positiva para os compostos parentais e alquilados associados a contribuição petrogênica e explica $29 \%$ da variância total (Figura 70). A amostra P2 mostrou o escore positivo mais elevado neste fator, o que era esperado dada a proximidade do porto, enquanto a amostra P10 apresentou o escore mais negativo. 

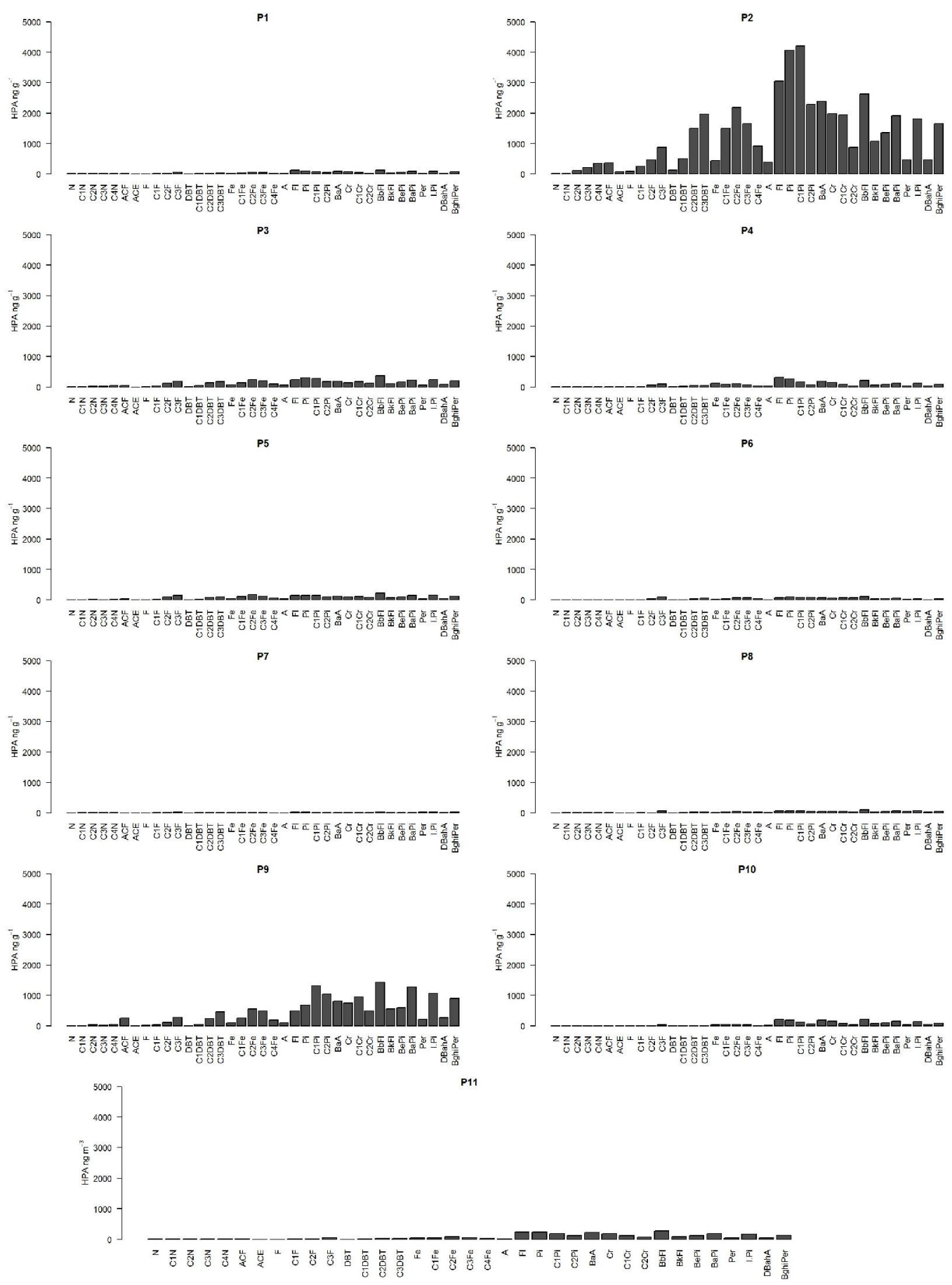

Figura 69 - Distribuição dos HPAs entre as estações de sedimento - Gráficos na mesma escala 

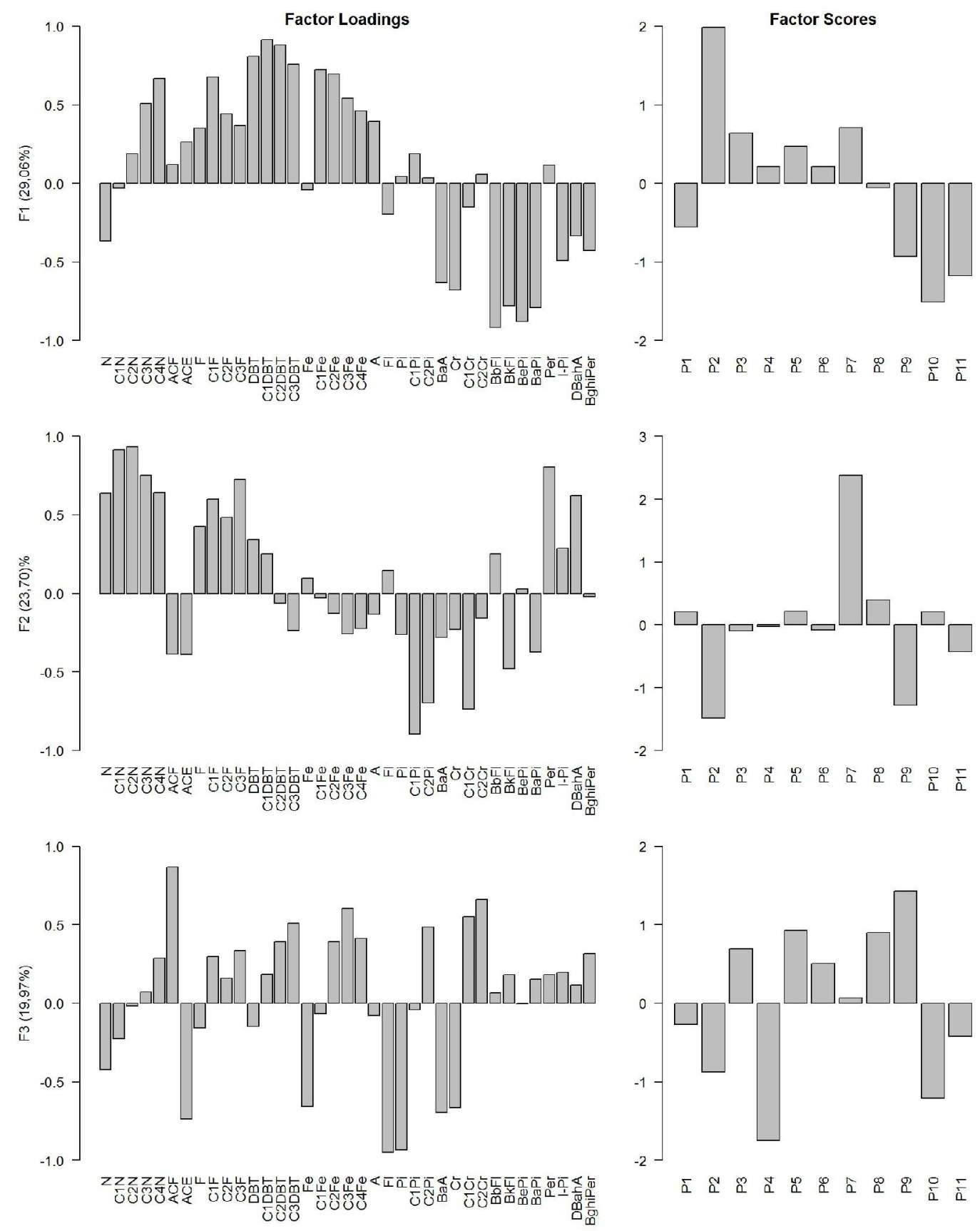

Figura 70 - Distribuição dos Carregamentos e Escores resultantes da ACP com Rotação Varimax nos dados de distribuição relativa.

No fator 2 observam-se valores positivos para o perileno e HPAs de baixo peso molecular, incluindo alquilados, representando $23 \%$ da variância total. Valores positivos neste fator estão associados à diagênese de HPAs e provavelmente a influências petrogênicas como combustível não queimado (Yunker et al., 1996). Corroborando discussões prévias a amostra P7 apresenta o maior score neste segundo fator. O Fator 3, que explica $19 \%$ da variância total, é mais complexo e difícil de descrever dada a complexidade da distribuição das 
variáveis. Existe um padrão de degradação no perfil dos HPAs neste fator, mas não claramente definido. Os demais fatores, F3 e F4, foram considerados como fontes não determinadas pela ausência de padrão na distribuição das variáveis.

A análise hierárquica de agrupamento (Cluster Analyses), baseada na distância euclidiana e no método de Ward, a partir dos mesmos dados reduzidos e centralizados, confirma as suposições de agrupamentos de amostras que pode ser realizada a partir dos resultados da ACP (Figura 71). A análise de agrupamento é um procedimento estatístico multivariado que busca organizar as informações em grupos relativamente homogêneos a partir dos dados (Aldenderfer e Blashifield, 1984).

Estas avaliações estatísticas permitem dividir a baía em três setores segundo a contribuição de hidrocarbonetos: (1) área predominantemente de contribuição petrogênica, constituí as amostras P1, P2, P3, P4, P5, P6 e P8; (2) área predominantemente de hidrocarbonetos oriundos de combustão, constituída pelas amostras P9, P10 e P11 e; (3) área onde a contribuição natural é evidente (P7).

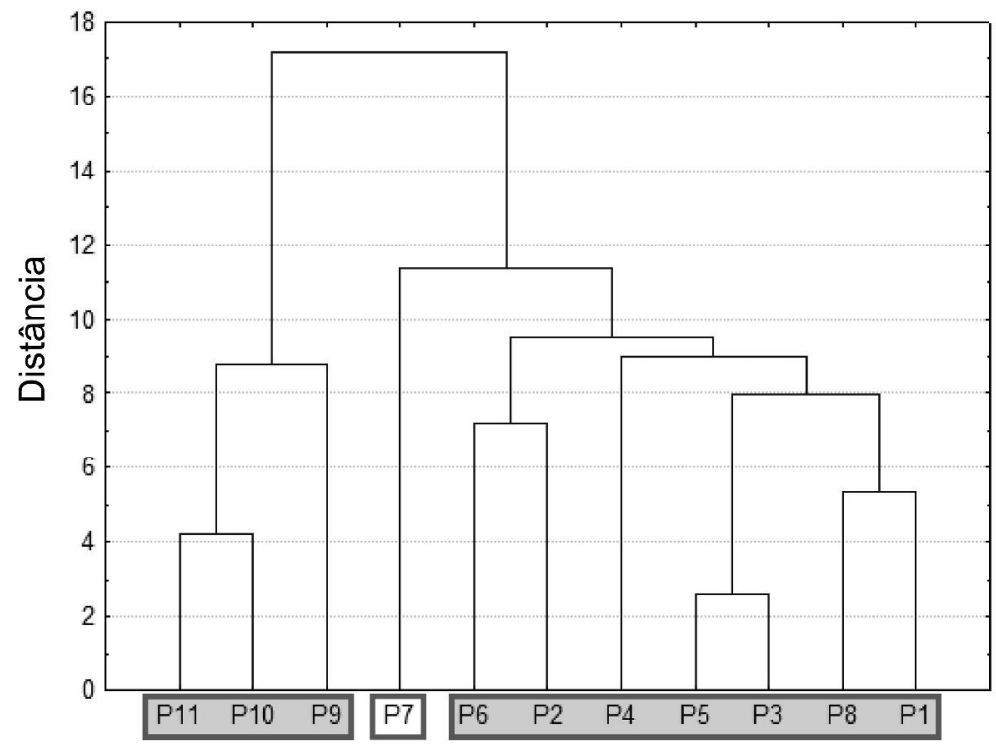

Figura 71 - Resultado da Análise Hierárquica de Agrupamento nos dados de distribuição relativa de HPAs em sedimentos.

O modelo de regressão múltipla linear resultante apresentou-se bem ajustado $\left(R^{2}=0,96, F<0.05\right)$. Entretanto a análise dos respectivos resíduos gera algumas considerações relevantes. O efeito da ampla faixa de concentração se faz presente mais uma vez e as amostras de menor concentração tem desvios superiores, em alguns casos, a $70 \%$ da concentração. $O$ efeito dos ajustes pelos 
menores desvios absolutos, como ocorreu para algumas das amostras de aerossóis, é mais intenso nesta matriz.

O melhor ajuste de concentração encontrado foi utilizar o logaritmo neperiano da concentração total de HPAs como variável dependente. Uma vez que a concentração de HPAs é inserida no modelo sem estar reduzida pela media e pelo desvio padrão a equação do modelo resultante passa a apresentar uma constante (b). Observa-se na Figura 72a e Figura 72b a diferença entre os resultados desta análise depende da normalização da variável dependente. A Figura 72 c e Figura 72 d mostram a contribuição de cada fator e da constante do modelo na concentração. Este procedimento apresentou menores resíduos para as amostras $(2,7 \pm 2,2 \%)$ e praticamente a mesma eficiência do modelo anterior $\left(R^{2}=0.96, F<0.05\right)$.
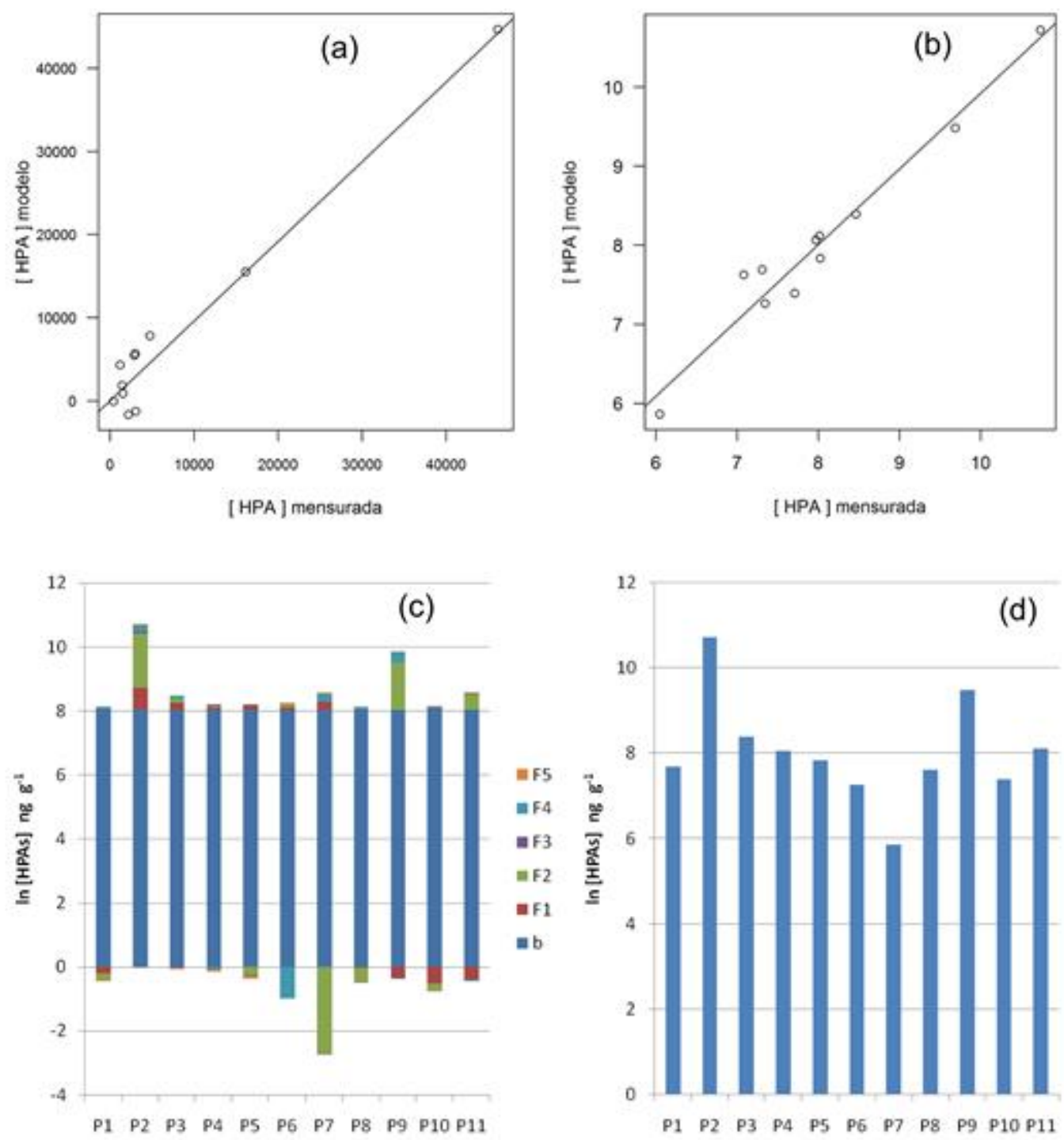

Figura 72 - Resultados obtidos no método de Análise de Componentes Principais associado a Regressão Múltipla Linear (ACP-MLR). 
Apesar de ser matematicamente melhor ajustado que o resultado obtido para os aerossóis nota-se que o valor do coeficiente linear b resultante representa praticamente a totalidade da contribuição deste modelo nas amostras. Este coeficiente não é relacionado com qualquer fonte descrita e pode ser interpretado como um valor médio para a concentração de HPAs, o que leva a avaliações bem diferentes a obtida por outros autores (Chen et al., 2012; Li et al., 2012; Liu et al., 2009; Zhang et al., 2012; Wang et al., 2009).

Neste ponto o entendimento dos procedimentos aplicados e dos resultados obtidos é crucial na avaliação desta baía. Para a ACP, realizada sobre a matriz de correlação, os dados são reduzidos da média e divididos pelo desvio padrão. A Figura 73 apresenta a tipologia média dos HPAs nas amostras da Baía de Guanabara e seu respectivo desvio padrão.

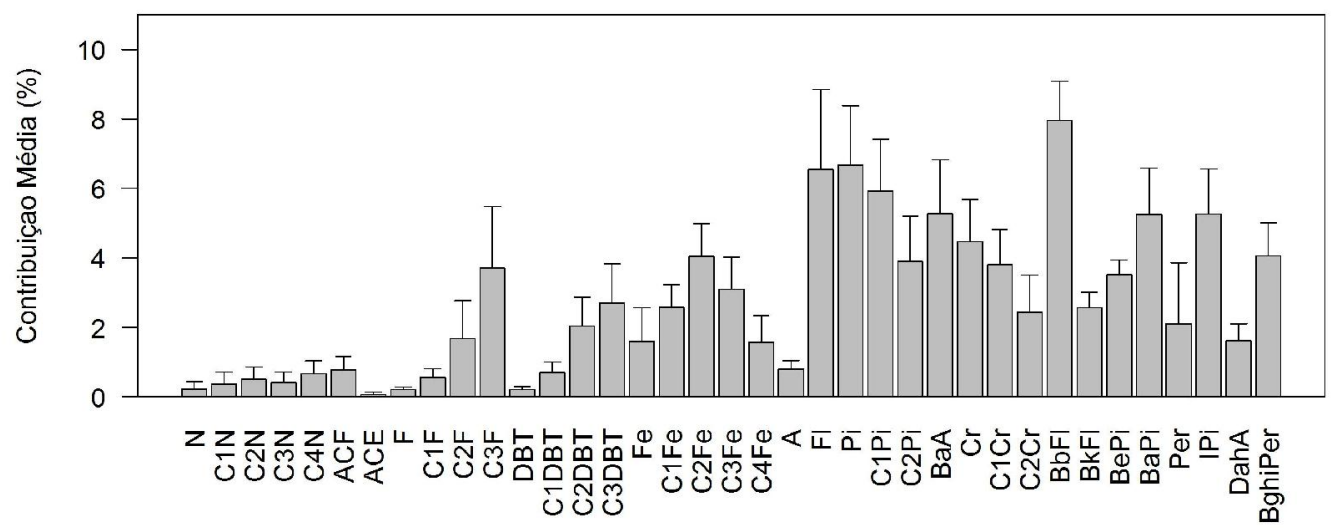

Figura 73 - Contribuição média e desvio-padrão da distribuição relativa das 11 amostras de sedimento da Baía de Guanabara.

Observa-se pela baixa dispersão dos dados que os sedimentos deste ambiente possuem distribuição similar, dominada por compostos de alto peso molecular. Uma forma mais interessante de analisar os dados é considerar que o percentual mínimo, considerando as 11 amostras, varia de $0 \%$ para o naftaleno a $5,7 \%$ para o benzo(k)fluoranteno e soma para os 38 compostos tem o valor de $56 \%$. Isto significa considerar que na comparação dos HPAs entre duas amostras desta baía, as mesmas compartilham pelo menos $56 \%$ de uma tipologia comum.

Este fato é muito importante porque as diferenças obtidas entre as amostras na ACP desconsidera a influência comum a todas, pelo princípio do método. Isto fica mais evidente na indicação da amostra P7 como HPAs de fonte diagenética e de combustível leve (F2 da ACP), contrastante com a informação 
obtida na análise da tipologia dos HPAs (Figura 65). A informação que provém do intercepto b, ou coeficiente linear, é justamente a distribuição comum entre as amostras de sedimento, o que é condizente com avaliações pretéritas (Figura $67)$.

Isto também explica a diferença entre as observações obtidas a partir da ACP e das razões diagnósticas de fontes. Razões de HPAs são fortemente influenciadas por esta componente comum, minimizadas na ACP. Estas duas técnicas produzem informações complementares e sugere-se que sejam usadas em conjunto em avaliações.

Estes resultados levantam a questão de determinar a origem desta distribuição comum. Pela distribuição em toda a baía, com perfis semelhantes desde a entrada até o fundo, é mais provável que a combustão seja a fonte mais relevante dada a sua ampla atuação geográfica. Este padrão, entretanto não corrobora com distribuição geográfica da concentração de HPAs na baía (Figura 74), que deveria ser diretamente relacionada ao acumulo de matéria orgânica e proximidade dos rios que carregam o material lixiviado.

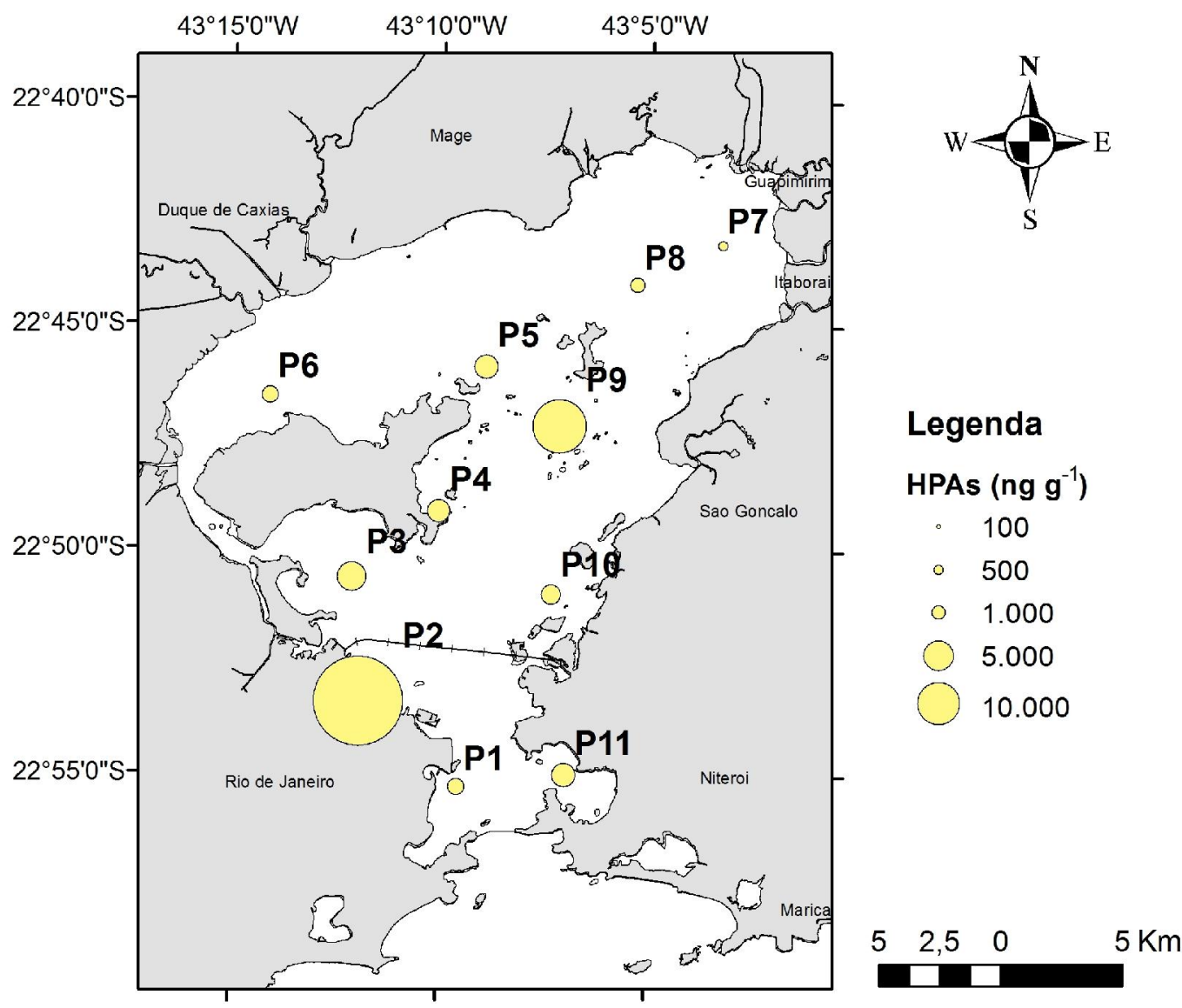

Figura 74 - Distribuição espacial da concentração total de HPAs em sedimentos. 
$\mathrm{O}$ acúmulo de HPAs na baía, principalmente nos pontos $\mathrm{P} 2$ e P9, não corrobora o aporte atmosférico direto e a lixiviação urbana. Nestes casos a contribuição local é a explicação mais plausível para o gradiente de concentração entre a estação P2 próxima ao Porto do Rio de Janeiro, a estação P6 que está em uma área de influência de rios altamente poluídos, a estação P9 próxima ao terminal da llha D’Água e a estação P7 próxima a APA de Guapimirim.

Outra hipótese possível para a tipologia comum de HPAs nas amostras, e talvez mais provável, é que esta seja fruto do elevado estado de degradação do material orgânico nos sedimentos. O padrão de degradação é justamente o responsável pelo enriquecimento de HPAs de maior peso molecular e pelo perfil característico dos compostos alquilados nestas amostras, especialmente em P2.

Os dados de Mauad (comunicação pessoal) que subsidiaram o estudo de Mauad et al. (2012) demonstram maior percentual de compostos de menor peso molecular nos rios que deságuam na Baía de Guanabara em comparação as amostras de aerossóis. Tais dados indicam que desde a emissão de HPAs na atmosfera até sua posterior lixiviação e carreamento existe uma mistura com aporte petrogênico. Estes autores analisaram amostras de água do Rio Suruí, Rio São João de Meriti, Canal do Cunha, Rio Guapimirim, Rio Caceribu e Canal do Mangue.

O período de coleta destes autores foram as últimas semanas dos meses de setembro, outubro, novembro de 2011 e janeiro e março de 2012. Os rios amostrados na região nordeste da Baía de Guanabara apresentam características mais acentuadas de contaminação por hidrocarbonetos alquilados e parentais de menor massa molecular, característicos de origem petrogênica, enquanto na da região noroeste e oeste há maior abundância de hidrocarbonetos característicos de processos de combustão os quais os autores sugerem serem provenientes das emissões atmosféricas desta porção da baía. Entretanto este gradiente espacial de fontes encontrado por Mauad et al. (2012) não pode ser observado para a distribuição dos sedimentos na Baía de Guanabara.

Similar a tipologia de HPAs observada por Mauad et al. (2012) em alguns rios, Ribeiro et al. (2012) reportam para o material carreado nos córregos da Avenida Ary Parreiras e da Rua Sete de Setembro, ambas de Niterói, maior abundância de fenantreno, fluoranteno, pireno e benzo(a)antraceno. Estes autores demonstram claramente a influência da precipitação e posterior 
lixiviamento urbanos na sazonalidade da concentração de HPAs nestes córregos e, consequentemente, posterior aporte a baía.

Os dados obtidos de Silva et al. (2007) para estações de coleta de água e sedimento na porção noroeste da baia, próximo a desembocadura dos principais rios, também mostram a diferença no perfil de distribuição pelo peso molecular entre estes dois compartimentos. Todos estes estudos (Pereira Netto et al., 2006; Ribeiro et al., 2012; Mauad et al., 2012; Silva et al., 2007) são exemplos que demonstram a alteração do perfil de HPAs desde a coluna d'água até sua posterior deposição e acúmulo em sedimentos (Wagener et al., 1990; Carreira et al., 2002).

A diferença entre as razões obtidas entre as matrizes deste estudo pode ser visualizada na Figura 75 . Os sedimentos obviamente estão sujeitos a uma mistura maior de diferentes aportes, mas é interessante notar que para algumas razões o valor encontrado é superior as reportadas para aerossóis. Isto ocorre para o $\mathrm{BaPi} /(\mathrm{BaPi}+\mathrm{BePi}), \quad \mathrm{BaA} /(\mathrm{BaA}+\mathrm{Cr}), \quad \mathrm{BFl} /(\mathrm{BFl}+\mathrm{BePi}), \quad \mathrm{A} /(\mathrm{A}+\mathrm{Fe}) \quad \mathrm{e}$ $\mathrm{IPi} /(\mathrm{IPi}+\mathrm{BPe})$. Nos dados de Pereira Netto et al. (2006) para poeiras urbanas demonstram elevadas razões $\mathrm{Fl} /(\mathrm{FI}+\mathrm{Pi})(>0,6)$ e nos dados de Silva et al. (2007) para sedimentos da porção noroeste da baía observam-se valores de $\mathrm{IP} /(\mathrm{IPi}+\mathrm{BPe})$ maiores que 0,5 e resultados da razão $\mathrm{BaA} /(\mathrm{BaA}+\mathrm{Cr})$ intermediários entre os valores dos aerossóis e sedimentos deste estudo. As indicações de Mauad (comunicação pessoal) contidas no trabalho de Mauad et al. (2012) também indicam para alguns índices, valores enriquecidos em relação aos aerossóis. Observa-se na figura também a baixa aplicabilidade da razão $\mathrm{C} 0 / \mathrm{C} 0+\mathrm{C} 1 \mathrm{Fe} / \mathrm{A}$ e $1,7 /(1,7+2,6) \mathrm{DMFe}$ dadas suas indicações em amostras de petróleo e produtos de petróleo neste estudo comparadas às demais matrizes analisadas.

Assim como neste trabalho, Gogou et al. (1998) comparam razões para análises efetuadas em amostras de aerossóis e sedimentos e observam maiores valores nesta última matriz para os índices $\mathrm{IPi} /(\mathrm{IPi}+\mathrm{BPe})$ e principalmente para o $\mathrm{BaA} /(\mathrm{BaA}+\mathrm{Cr})$. Os autores sugerem que este enriquecimento ocorra devido aos HPAs derivados de combustão serem mais resistentes a alterações durante o processo de transporte e degradação até o acúmulo na coluna d'água. Baseados na diferença entre estas matrizes para razão envolvendo os compostos benzo(a)pireno e benzo(e)pireno, com indicações de degradação para o sedimento, os autores sugerem fontes de combustão associadas a transporte por grandes distâncias. 


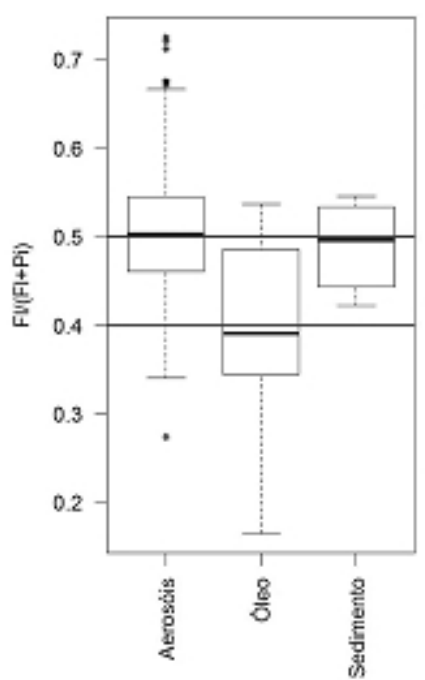

Combustăo de

Madeira, Vegetaçăo
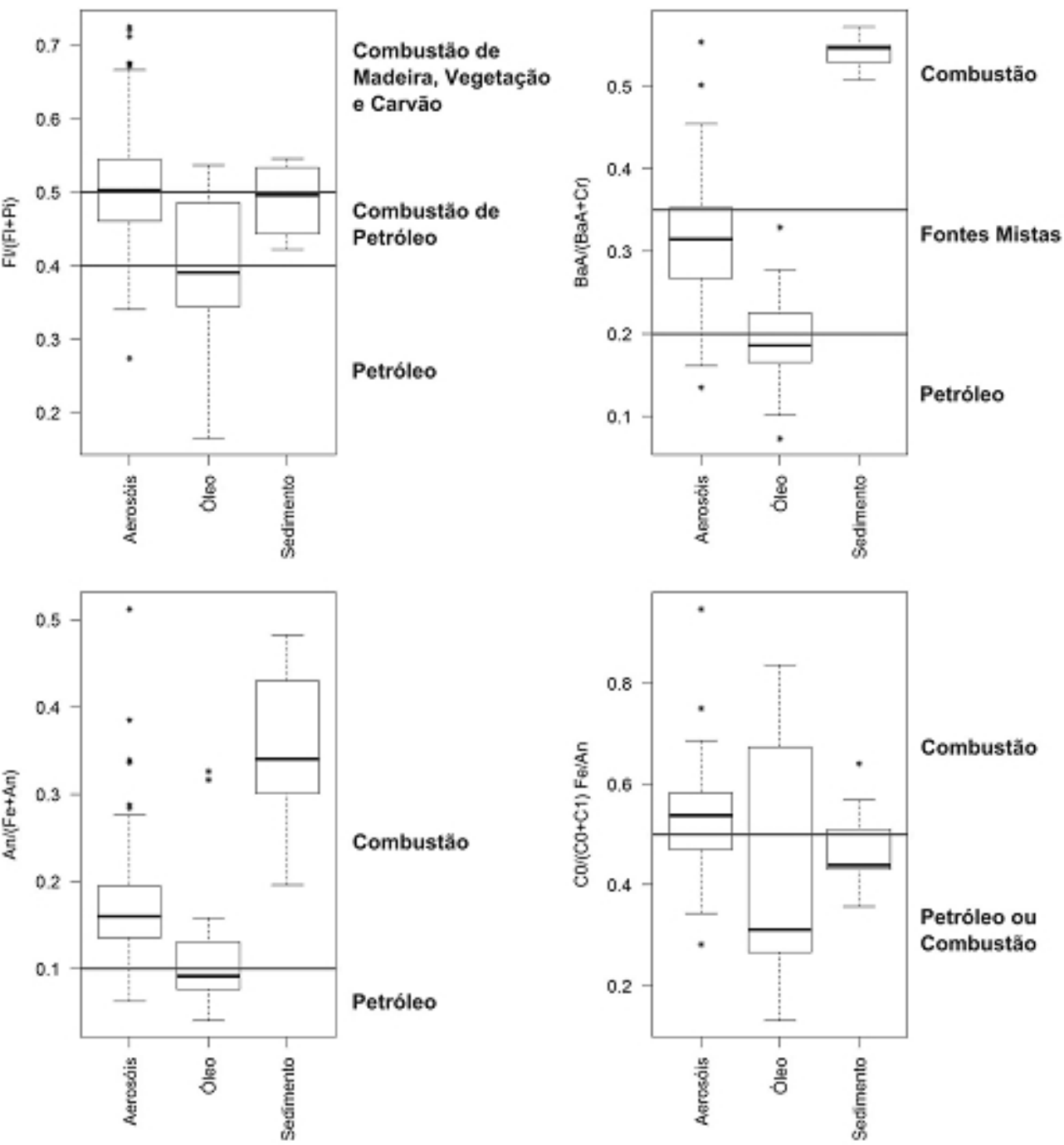

Combustăo de Petróleo

Petróleo

\section{Combustằ}
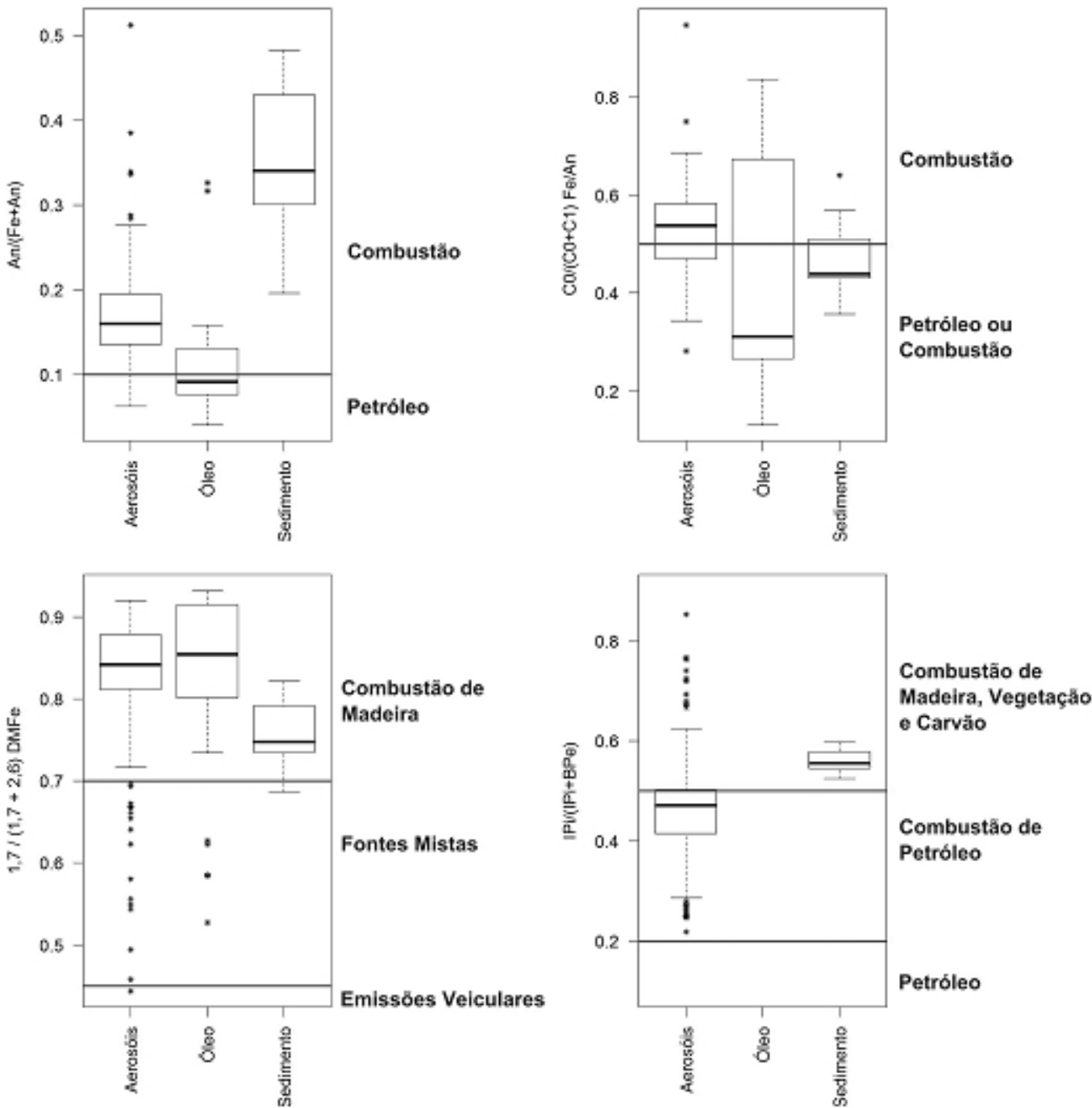

Figura 75 - Razões diagnóstico de fontes aplicadas a diversas matrizes estudadas. 

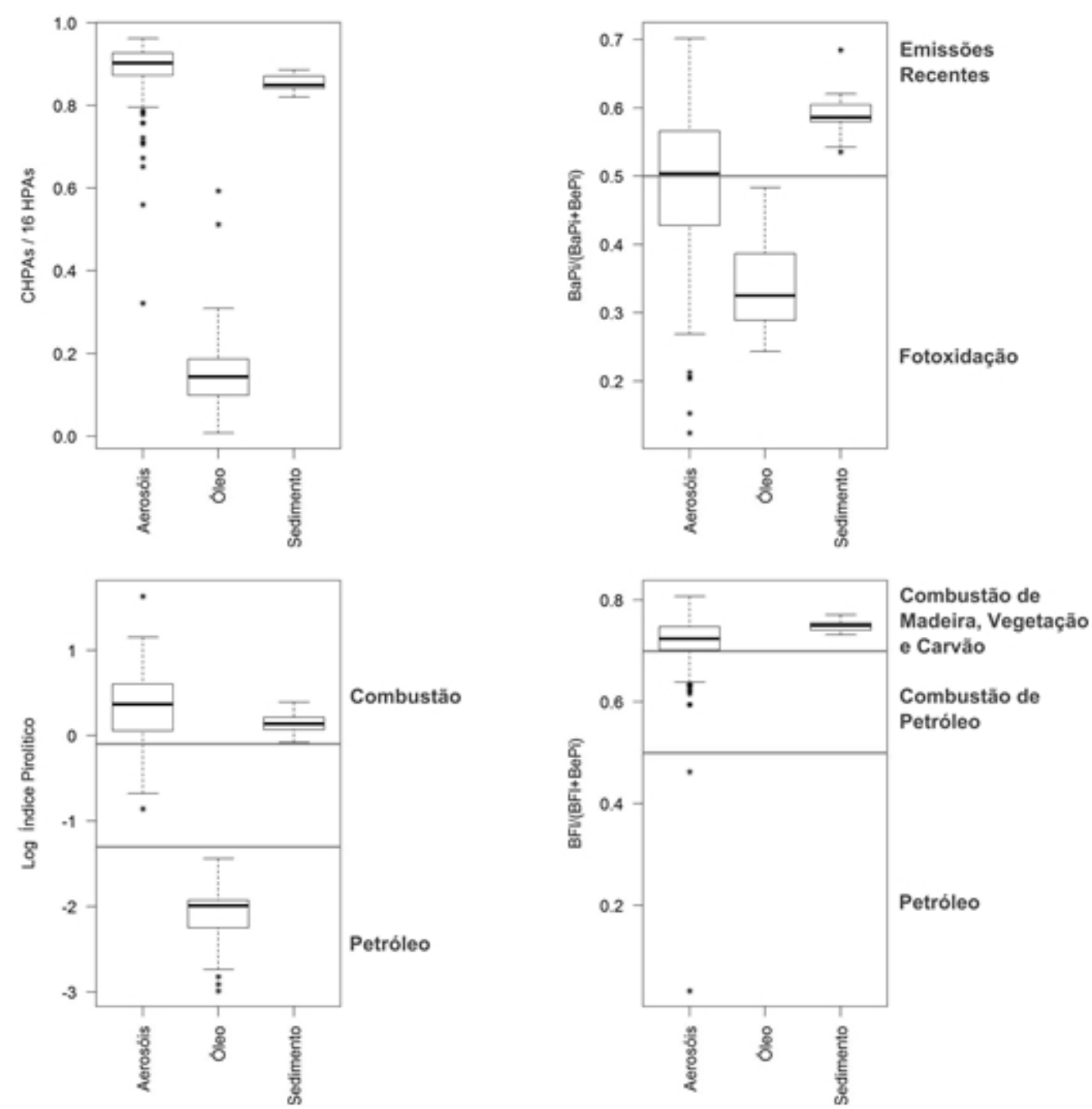

Figura 75 - Razões diagnóstico de fontes aplicadas a diversas matrizes estudadas (Continuação)

Há degradação dos compostos mais lábeis, possivelmente pela grande densidade bacteriana na baía, e há penetração por diferentes vias (rio e deposição atmosférica). O que se percebe nos sedimentos é a combinação destes dois processos. Na atmosfera impera a degradação fotoquímica que parece ser menos eficiente do que a bacteriana.

A comparação das razões $\mathrm{BaPi} /(\mathrm{BaPi}+\mathrm{BePi})$ e $\mathrm{A} /(\mathrm{Fe}+\mathrm{A})$, com valores elevados, corroboram que o material dos sedimentos esteja associado a contribuições recentes e/ou baixa degradação fotoquímica. Cabe ressaltar que assim como algumas razões diagnóstico de fontes não apresentam valores característico de sua respectiva fonte, como já reportado nos dados de amostras de óleo de Meniconi et al. (2002) e Wang et al. (1999a), o mesmo pode ocorrer nesta razão para petróleos e produtos de petróleo brasileiros. Por limitações 
analíticas não foi possível verificar esta razão em todos os produtos de petróleo, o que poderia ser um motivo para maiores valores em sedimentos, associados a fontes petrogênicas.

Razão diagnóstico envolvendo compostos de massa 178 (Fenantreno e Antraceno) tendem a ser menos efetivas na determinação de fontes de HPAs (Yunker et al., 2000; Yunker et al., 2002), pois possuem pequena diferença em estabilidade entre seus isômeros. Desta forma razões envolvendo isômeros com maior diferença em estabilidade seriam mais efetivas, como Fluoranteno e Pireno ou benzo(a)antraceno e criseno.

Compostos de massa 202 (fluoranteno e pireno) tiveram grande eficiência na separação de fontes de hidrocarbonetos em amostras de sedimento da Baía de Guanabara (Meniconi et al., 2003). Fang et al. (2003) reportam a razão envolvendo compostos de massa 228 (benzo(a)antraceno e criseno) como uma das mais importantes na diferenciação de fontes para sedimentos costeiros de Taiwan. Yunker et al. (2002) reportaram grande importância para razão envolvendo compostos de maior peso molecular, como massa 276 (indeno(1,2,3-cd)pireno e benzo(g,h,i)perileno) e 228 (benzo(a)antraceno e criseno), utilizados na diferenciação de fontes em áreas urbanas. Sicre et al. (1987) reportam a razão envolvendo compostos de massa 276 como critério mais útil para distinção entre emissões de automóveis e aquecedores domésticos.

Além dos HPAs normalmente analisados em estudos atmosféricos outras informações provém de HPAs analisados com menor freqüência. Na Figura 76 se pode observar a concentração de acefenantrileno, benzo(c)fenantreno, indeno(7,1,2,3-cdef)criseno, dibenzo(a,j)antraceno, pentafeno, benzo(b)criseno, piceno e reteno. Destaca-se na distribuição dos compostos, a diferença com os dados de aerossóis, onde o indeno(7,1,2,3-cdef)criseno era predominante. Em sedimentos, por outro lado, existe maior abundancia de compostos de massa 278.

A relação média entre os compostos de massa 276 sobre os compostos de massa 278, considerando os HPAs normalmente quantificados é de 12,2 $\pm 4,7$ e 6,0 0 0,9 para aerossóis e sedimentos, respectivamente. Se forem incluídos os demais compostos quantificados esta razão modifica-se para 4,8 $\pm 1,9$ em aerossóis e 1,9 \pm 0,4 em sedimentos. Esta relação é a única com diferença significativa entre a distribuição de massas das amostras de sedimento e de todas as estações de particulado atmosférico. 

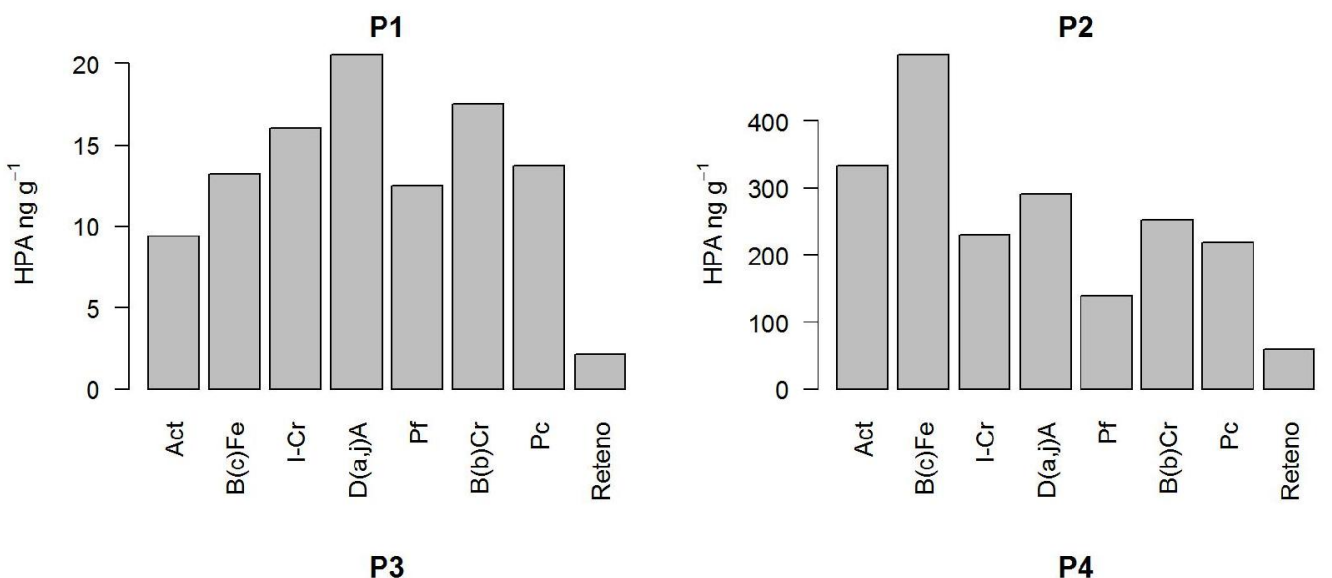

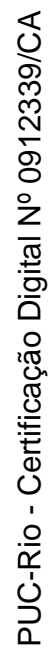
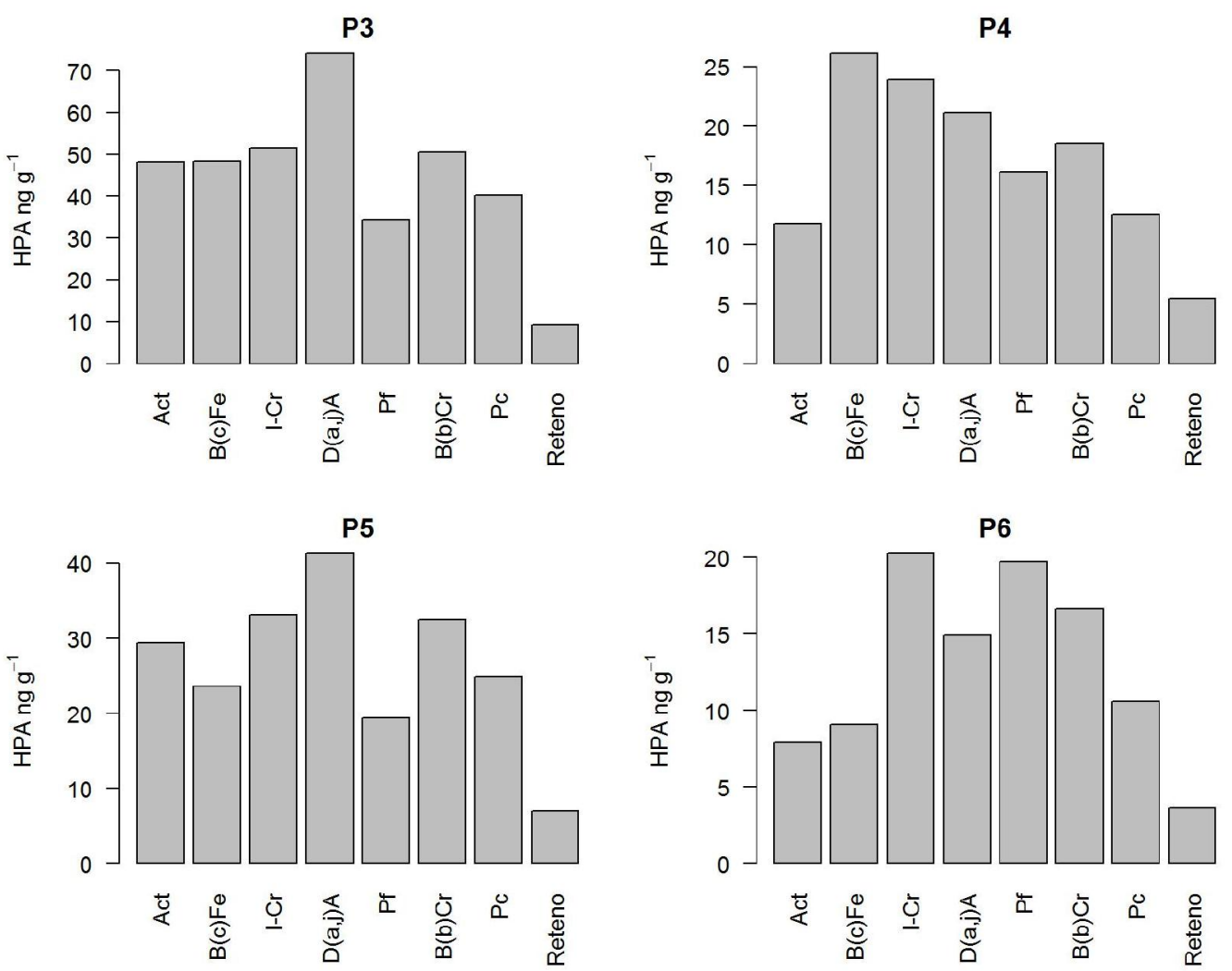

Figura 76 - Resultado dos demais HPAs quantificados para as estações de sedimento da Baía de Guanabara 

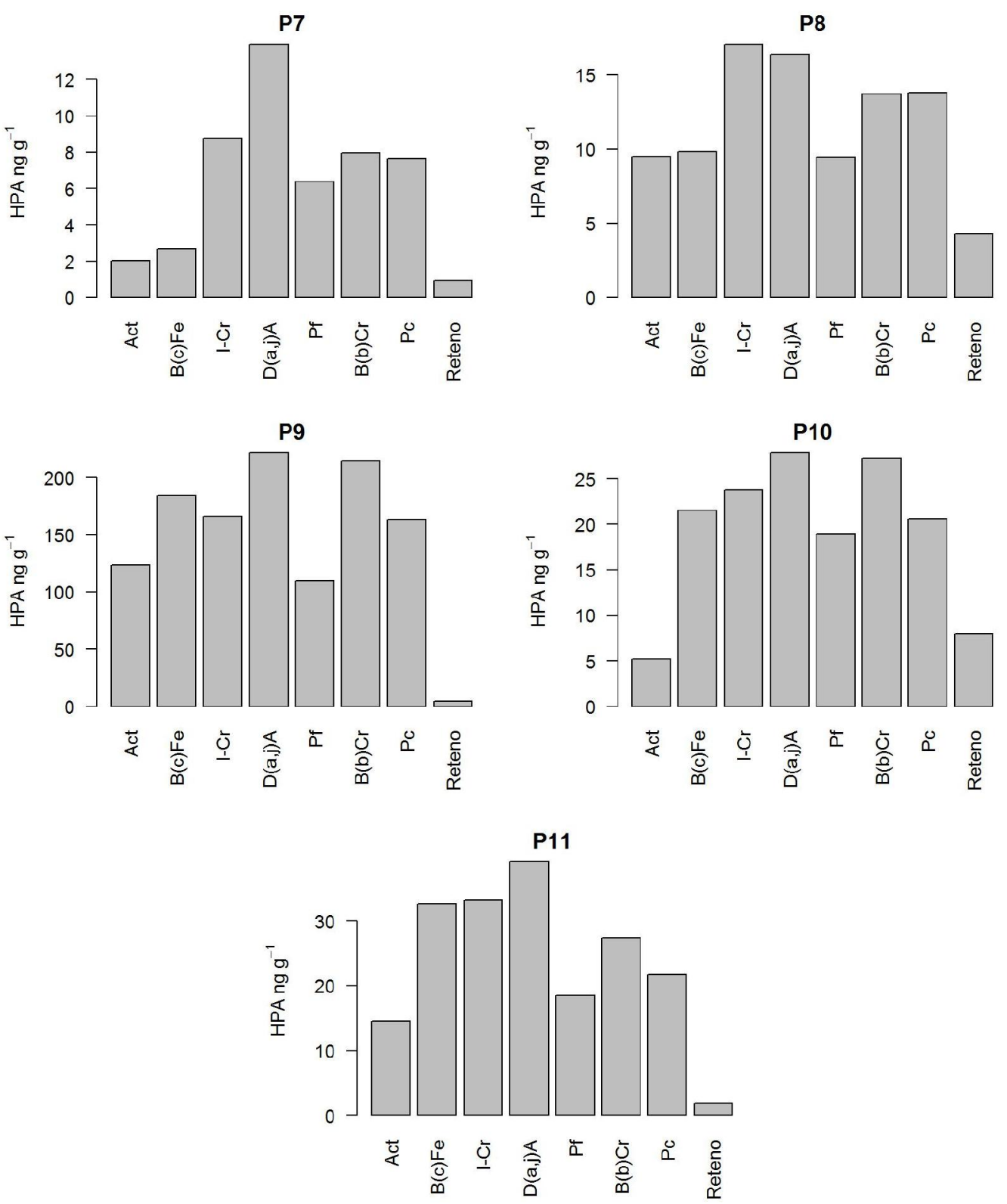

Figura 76 - Resultado dos demais HPAs quantificados para as estações de sedimento da Baía de Guanabara (Continuação)

Quitério et al. (2007) analisa a distribuição de massas entre vários estudos atmosféricos no Brasil e no mundo, inclusive sobre os dados do Rio de Janeiro (Pereira Netto et al., 2001, 2002), São Paulo (Martinis et al., 2002) e Porto Alegre (Dallarosa et al., 2005). Estes autores observam na maioria dos estudos a mesma predominância de massa 276 sobre 278.

Embora Yunker et al. (2000, 2002) e outros autores (Fang et al., 2003; Sicre et al., 1987; Meniconi et al., 2003) avaliem proporções de HPAs de diferentes massas em sedimentos marinhos como indicativos de fontes este tipo 
de avaliação não é robusta o suficiente para corroborar aportes. Em geral este tipo de abordagem é utilizada como avaliação prévia de uma área. Na Figura 77 é possível observar algumas das razões propostas por Yunker et al. (2011) aplicada aos dados de sedimentos e aerossóis.
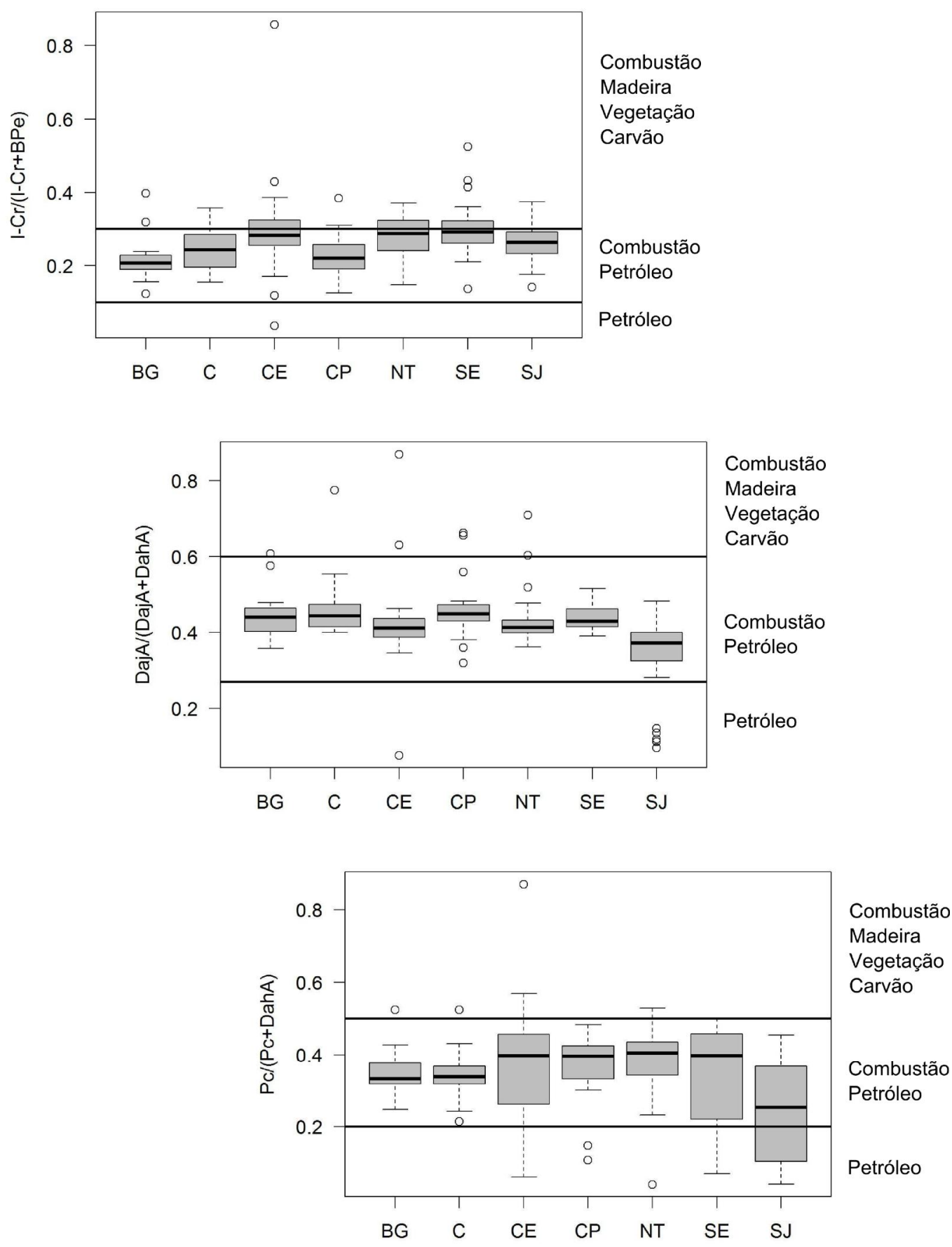

Figura 77 - Comparação das razões diagnóstico de fontes baseadas em outros HPAs para as amostras de aerossóis e sedimentos.

Para todas as razões expostas o ponto P6 apresentou o maior valor, seguido do ponto P7. Estas duas amostras estão localizadas mais próximas a 
desembocaduras dos rios da porção oeste e leste da baía, respectivamente. Cabe ressaltar também que entre os compostos de massa 276 o uso do indeno(7,1,2,3-cdef)criseno no lugar do indeno(1,2,3-cd)pireno mostrou resultados menos discrepantes. Apesar da busca de novos compostos para auxiliar a investigação de fontes existe, a princípio, o mesmo problema de indicação comum de fonte para toda a baía.

As baixas concentrações de reteno reportadas para estas amostras em relação aos demais compostos segue o mesmo padrão do particulado atmosférico, onde a origem através de queima de biomassa não parece provável. Não se deve desconsiderar que a queima de alguns pinos possam produzir este composto, apenas não é observado padrão espacial que reflita esta suposição ou concentração diferenciada entre as amostras.

A solução encontrada para uma avaliação ambiental mais coerente e embasada foi refazer a ACP usando outros critérios. Foram utilizados compostos a partir do fluoranteno e descartados os respectivos alquilados. Cada composto foi dividido pela soma dos compostos de mesma massa. Buscou-se com este procedimento retirar a influência da degradação na abundância dos diferentes pesos moleculares e na distribuição dos alquilados. Apenas o reteno, o benzo(c)fenantreno e o perileno foram retirados desta análise. O primeiro pela pouca abundância e por ser um dos compostos alquilados e o segundo porque, apesar da sua quantificação, é apenas mais um balizador de toxicidade dos sedimentos. O perileno não foi inserido na planilha para retirar a influência natural deste compostos na análise, já comprovada anteriormente, e destacar as diferenças entre a contribuição petrogênica e pirolítica.

Os resultados desta análise encontram-se na Figura 78. Uma das primeiras informações que aparecem nesta análise é a distribuição dos compostos de massa 276 e 278 no Fator 1, que explica 32,6\% da variância total. Para estas massas o isômero mais estável termodinamicamente encontra-se com valor positivo destacado neste fator, assim como o isômero menos estável aparece com valor negativo destacado. A diferença para outros compostos de diferentes massas não é tão acentuada neste fator, o que sugere que alguns índices são mais importantes para um determinado grupo de amostras. Esta abordagem é corroborada por Gao et al. (2012) que conclui que, uma vez que cada categoria de fonte tem um HPA traçador distinto, não se pode extrapolar o mesmo índice para uma área com diferentes aportes. 

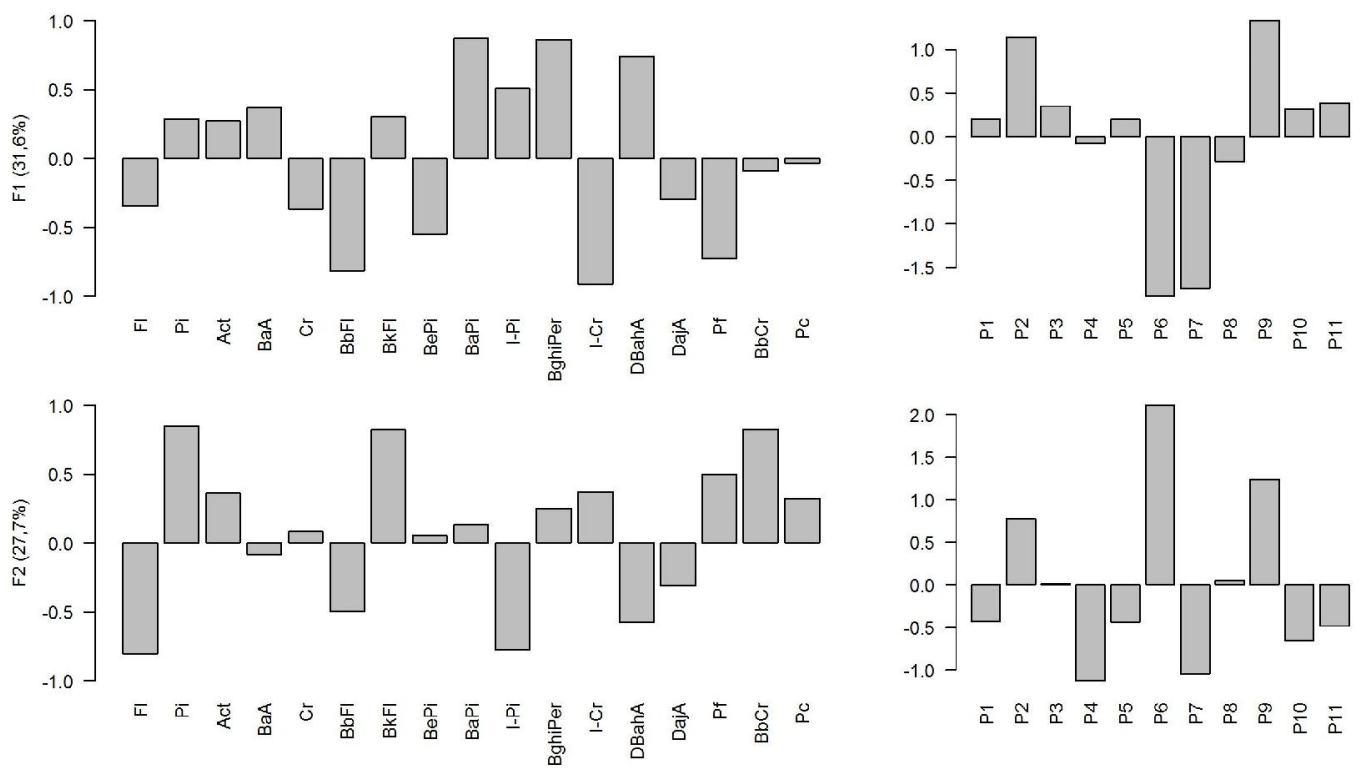

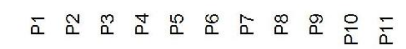
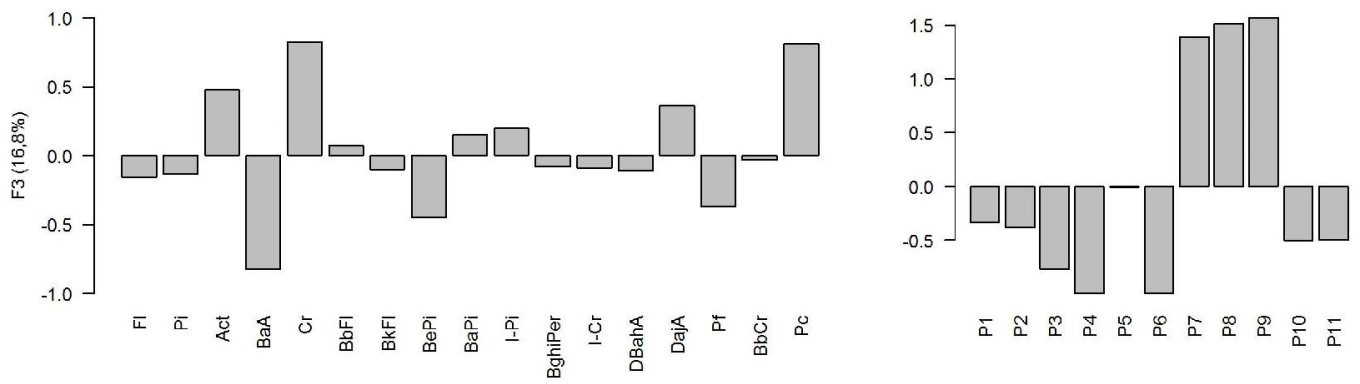

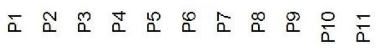
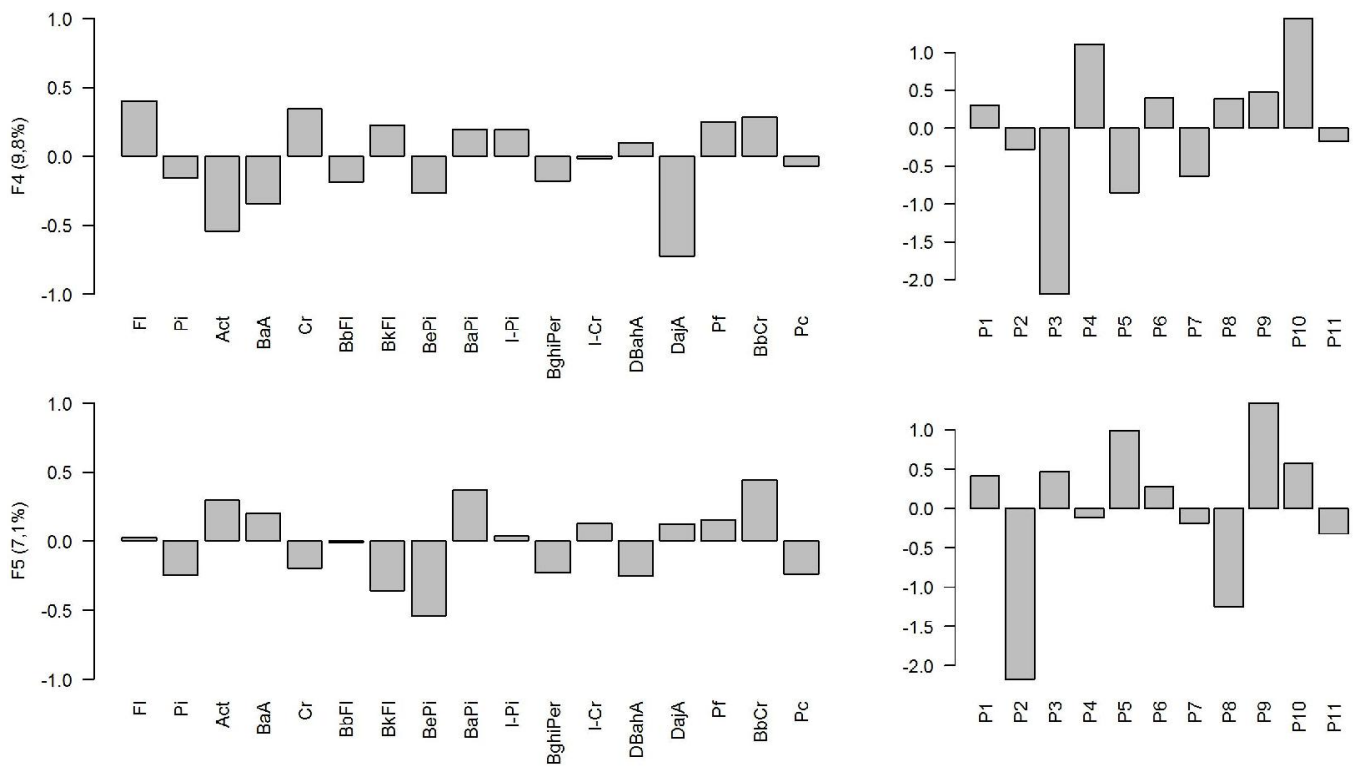

Figura 78 - Distribuição dos Carregamentos e Escores resultantes da ACP com nova normalização dos dados.

Desta forma este fator destaca a contribuição petrogênica principalmente nas amostras P2 e P9, assim como a fonte de combustão para as amostras P6, P7 e menos evidente P8. No Fator 2 a diferença nos valores obtidos para as variáveis de massa 202 (fluoranteno e pireno) e de massa 278 são as mais 
destacáveis. Neste eixo as indicações destas duas massas são contraditórias, uma vez que o isômero mais estável termodinamicamente possui valores positivos neste eixo para massa 202 e, no caso dos compostos de massa 278, ocorre o inverso. Neste fator (F2) foi o benzo(b)criseno traçador de contribuição pirolítica.

A diferença nas indicações é coerente em zonas de aporte misto, com indícios diferentes para as amostras P2, P9 e principalmente P6 com valores positivos e P4 e P7 com valores negativos neste eixo. No Fator 3, que explica $16,8 \%$ da variância, destaca-se a razão $\mathrm{BaA} /(\mathrm{BaA}+\mathrm{Cr})$ pelos valores encontrados nestes isômeros. Neste Fator o composto de massa 278 piceno aparece destacado. As amostras P7, P8 e P9 destacam-se com valores positivos neste eixo.

A partir desta análise destacam-se vários fatos. Inicialmente observa-se que a distribuição dos compostos indeno(1,2,3-cd)pireno e benzo(ghi)perileno tem pouca capacidade discriminatória para separação das amostras, o que corrobora as indicações obtidas neste estudo e de observações pretéritas (Meniconi et al., 2003; Wagener et al., 2012). A baixa capacidade do índice composto dos HPAs benzo(b)fluoranteno e benzo(k)fluoranteno é observada pois ambos sugerem influências diferentes nos eixos, mas são utilizados tanto no numerador quanto no denominador da razão $\mathrm{BFI} /(\mathrm{BFI}+\mathrm{BePi})$.

Existe um ganho real neste tipo de avaliação em relação à normalmente utilizada em estudos de HPAs. Inicialmente pela amostra P9, cuja concentração elevada e gradiente espacial sugeriam degradação de petróleo. $\mathrm{Na}$ análise anterior usando a tipologia relativa dos HPAs esta amostra foi tratada como fonte de combustão predominante e, agora, observa-se o aporte petrogênico.

O aporte dos rios também não era discriminado na abordagem usual. Observa-se pelos Fatores 1, 2 e 3 que a amostra P6 é predominantemente influenciada fonte pirolítica assim como em menor proporção nas amostra P7 e P8, onde existe maior coexistência de diferentes aportes. Existe ainda a diferença entre a zona dos rios da porção noroeste onde se destaca a influência do benzo(b)criseno pelo fator 2, e na margem leste o piceno pelo fator 3. Yunker et al. (2011) sugerem que o piceno seja melhor traçador de queima de biomassa enquanto o benzo(b)criseno estaria mais relacionado as emissões veiculares, principalmente gasolina (Rogge et al., 1993a). Estas diferenças evidenciadas entre a amostra P6 e as amostras P7 e P8 estão de acordo as conclusões de Mauad et al. (2012) sobre o gradiente espacial da contribuição de HPAs nos rios desta baía. 
Utilizando os dados de entrada para a ACP normalizados e reduzidos foi realizada nova Análise Hierárquica de Agrupamento, exposta na Figura 79. A divisão das estações é bem diferente a obtida anteriormente (Figura 71). Agora é possível evidenciar um grupo com maiores características de combustão (P6, $\mathrm{P} 7, \mathrm{P} 8$ ) associado provavelmente ao material transportado pelos rios e amostras com maior contribuição petrogênica (P1-P5, P9-P11). Dentro de cada grupo pode-se inferir dois outros subgrupos. Nas amostras de combustão, P6, P7 e P8, as últimas duas possuem maior mistura com influência petrogênica e destaca-se a concentração de piceno. Embora este composto também influencie o ponto P9, conforme observado no fator 3 , tem menor relevância em relação a influência dos Fatores 1 e 2 nesta amostra. Nas amostras caracterizadas como de origem petrogênica destacam-se as amostras P2 e P9 com características mais marcantes deste aporte, provavelmente oriundas da proximidade de fonte contínua e processos de degradação acentuados.

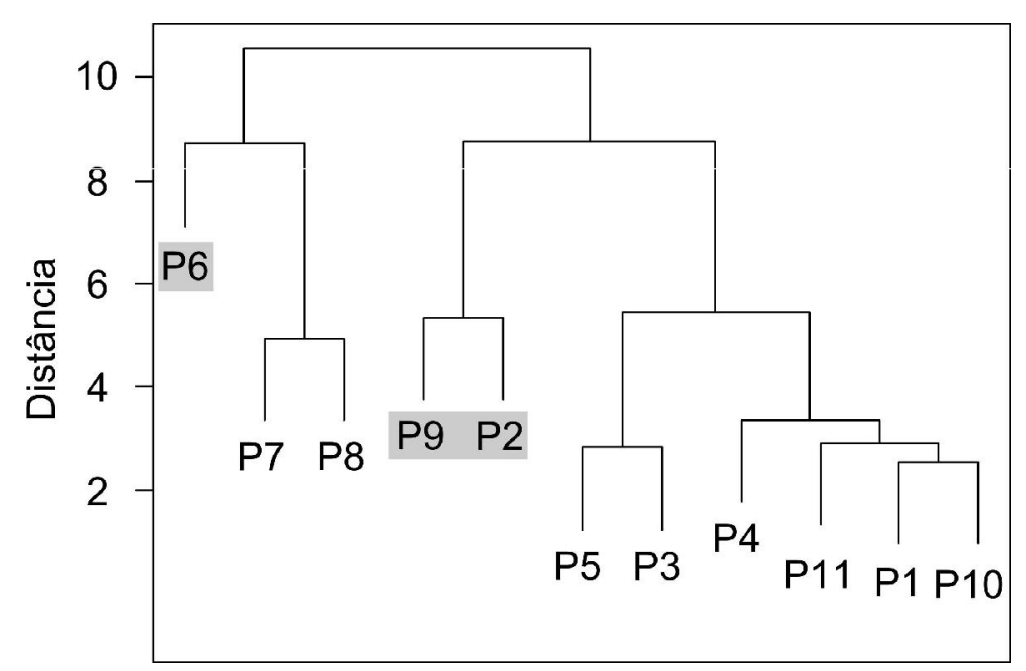

Figura 79 - Resultado da Análise Hierárquica de Agrupamento (AHA) a partir da nova normalização dos dados.

Além da nova luz que os compostos indeno(7,1,2,3-cdef)criseno, benzo(b)criseno e piceno trouxeram a separação das amostras destaca-se também o tratamento prévio a ACP e AHA. A baixa contribuição do acefenantrileno para separação das amostras já foi observada por Yunker et al. (2002) que observam que este composto é mais abundante no material particulado, com baixa eficiência em sedimentos.

Embora estas análises tenham separado com mais critério as fontes existentes nas amostras de sedimento, diminuindo os efeitos de concentração e 
intemperismo, a análise quantitativa de cada aporte ainda não pode ser realizada. As tentativas posteriores esbarraram no mesmo problema gerado pela variação da concentração e similaridade na tipologia.

O fato mais importante a destacar é que, de maneira geral, estudos geoquímicos que aplicam ferramentas estatísticas costumam basear suas interpretações a partir dos resultados destas. O tratamento realizado nos dados deste estudo exemplifica bem que a etapa mais importante é a definição das premissas e sua adequação as análises estatísticas. As três ACP realizadas neste subcapítulo foram efetuadas a partir das observações dos resultados e interpretações ambientais. Cada análise realizada forneceu uma interpretação diferente sobre as amostras. 


\section{6 \\ Conclusões e Considerações}

As amostras de óleo apresentaram resultados compatíveis com os reportados na literatura, mas é necessário estabelecer metodologia específica para a quantificação dos compostos de maior peso molecular e reavaliar as razões correspondentes.

A concentração de hidrocarbonetos na atmosfera é considerada relativamente baixa, mas existe um gradiente de concentração com maiores valores para o Centro, São João de Meriti e Campos Elíseos.

A estação de Seropédica não se mostrou um branco adequado uma vez que Niterói e Copacabana apresentaram concentrações similares, podendo ser descartada como controle em estudos futuros.

O principal fenômeno atmosférico que influenciou na concentração de material particulado e de hidrocarbonetos foi a precipitação, mas sugere-se que um estudo de modelagem seja realizado para melhor averiguação deste e dos demais fenômenos.

A principal fonte de hidrocarbonetos para a atmosfera são as emissões veiculares, principalmente a gasolina, caracterizada pelas maiores concentrações de benzo(ghi)perileno. Embora a queima de gasolina não seja considerado o principal responsável pela geração de material particulado a distribuição dos HPAs nesta fração sugere esta fonte, provavelmente derivada da partição entre as fases gás e particulado das diferentes emissões.

As razões diagnóstico de fontes com indicações mais coerentes em relação à fonte emitida foram aquelas obtidas com HPAs normalmente ignorados em estudos de monitoramento

A concentração de hidrocarbonetos aromáticos e alifáticos em sedimentos mantém no mesmo nível ao longo do tempo na Baía de Guanabara, 
corroborando o forte aporte crônico ao qual está sujeita. Apesar da contribuição natural evidenciada em alguns sedimentos é a fonte antrópica a principal responsável pelos níveis encontrados.

Muitas das razões diagnósticas e seus limites estabelecidos em literatura não correspondem aos valores encontrados nas diferentes matrizes analisadas, existindo também sobreposição de valores entre estas. O uso destas em ambientes sujeitos a fontes múltiplas mostrou-se de pouca eficiência.

A avaliação quantitativa das fontes de HPAs em sedimento demonstrou que os sedimentos da Baía de Guanabara se encontram em um estado elevado de degradação que interfere na quantificação de fontes e avaliação de aportes.

O método mais adequado para avaliação de fontes foi utilizar uma ACP com a proporção relativa dos HPAs em relação aos compostos de mesma massa, sendo retirada a influência da degradação dos alquilados e da variabilidade dos compostos leves. Os compostos adotados neste procedimento estão na faixa de massa 202 a 278 , à exceção do perileno e incluindo os HPAs normalmente não quantificados em estudos ambientais.

Os HPAs normalmente não quantificados em estudos ambientais, especialmente os de massa 278 e 276 mostraram maior capacidade discriminatória de fontes. Os compostos de maior relevância foram o indeno(7,1,2,3-cdef)criseno, benzo(b)criseno e piceno.

Sugere-se que todos os HPAs estudados sejam quantificados nas amostras de rios ao redor da Baía de Guanabara para corroborar as diferenças espaciais encontradas, principalmente em relação ao benzo(b)criseno e piceno. Este estudo já está em andamento no laboratório e é objeto de estudo de tese de doutorado cuja parte dos dados já foi apresentada por Mauad et al. (2012). 


\section{Referências}

ABAS, M. R. B.; SIMONEIT, B. R. T. Composition of Organic Matter of Air Particles from Malaysia: Initial Study. Atmospheric Environment, 30(15). 27792793. 1996.

ABAS, M. R. B. et al. Composition of high molecular weight organic matter in smoke aerosol from biomass combustion in Amazonia. Chemosphere, 30 (5) 995-1015. 1995.

ABDULLAH, A. R.; TAHIR, N. M.; WEI, L. K. Hydrocarbons in seawater and sediment from the west coast of Peninsular Malaysia Bulletin of Environmental Contamination and Toxicology 53: 618-626. 1994

ABRANTES, R.; ASSUNÇÃO, J. V.; PESQUERO, C. R. Emission of polycyclic aromatic hydrocarbons from light-duty diesel vehicles exhaust. Atmospheric Environment, 38: 1631-1640. 2004

ABRANTES, R. et al. Emission of polycyclic aromatic hydrocarbons from gasohol and ethanol vehicles. Atmospheric Environment, 43. 648-654. 2009

AICKIN, M.; GENSLER, H. Adjusting for Multiple Testing When Reporting Research Results:The Bonferroni vs Holm Methods. Public Health Briefs. Vol. 86, No. 5. 726-727. 1996

AITCHISON, J. The Statistical Analysis of Compositional Data. ISBN 1930665-78-4. 416p. 2003.

AIZENSHAT, Z. Perylene and its geochemical significance. Geochimica et Cosmochimica Acta, v.37, p. 559-567. 1973

AKYÜZ, M.; CABUK, H. Particle-associated polycyclic aromatic hydrocarbons in the atmospheric environment of Zonguldak, Turkey. Science of the Total Environment, 405. 62-70. 2008 
ALAN, M. S. et al. Using atmospheric measurements of PAH and quinone compounds at roadside and urban background sites to assess sources and reactivity. Atmospheric Environment, 77. 24-35. 2013

ALDENDERFER, M. S.; BLASHIFIELD, R. K. Cluster Aanalysis. Series: Quantitative Applications in the Social Sciences. Sage Publications. ISBN 08039-2376-7. 88p. 1984

ALKURD, F.; KARABET, F.; DIMASHKI, M. Characterization, concentrations and emission rates of polycyclic aromatic hydrocarbons in the exhaust emissions from in-service vehicles in Damascus. Atmospheric Research, 120. 68-77. 2013

ALLEN, A. G. et al. Atmospheric particulate polycyclic aromatic hydrocarbons from road transport in southeast Brazil. Transportation Research Part D 13. 483-49. 2008

ALVES, C. et al. Atmospheric carbonaceous aerosols over grasslands of central Europe and a Boreal forest. Chemosphere 63, 153-164. 2006

AMADOR, E.S. Baía de Guanabara e Ecossistemas Periféricos: Homem e Natureza. Reproarte Gráfica e Editora Ltda, Rio de Janeiro, 539 pp. 1997

AMADOR-MUÑOZ, O. et al. Organic compounds of $\mathrm{PM}_{2.5}$ in Mexico Valley: Spatial and temporal patterns, behavior and sources. Science of the Total Environment 409, 1453-1465. 2011

ANDRADE, S. J. et al. Contribution of sugar-cane harvesting season to atmospheric contamination by polycyclic aromatic hydrocarbons (PAHs) in Araraquara city, Southeast Brazil. Atmospheric Environment, 44. 2913-2919. 2012

ANDRADE, S. J. et al. Contribution of sugar-cane harvesting season to atmospheric contamination by polycyclic aromatic hydrocarbons (PAHs) in Araraquara city, Southeast Brazil. Atmospheric Environment, 44. 2913-2919. 2010

ANDREOU, G.; RAPSOMANIKIS, S. Origins ofn-alkanes, carbonyl compounds and molecular biomarkers in atmospheric fine and coarse particles of Athens, Greece. Science of the Total Environment, 407. 5750-5760. 2009 
AZEVEDO, D. A.; MOREIRA, L. S.; SIQUEIRA, D. S. Composition of extractable organic matter in aerosols from urban areas of Rio de Janeiro city, Brazil. Atmospheric Environment 33. 4987 - 5001. 1999

AZEVEDO, D. A.; SANTOS, C. Y. M.; AQUINO NETO, F. R. Identification and seasonal variation of atmospheric organic pollutants in Campos dos Goytacazes, Brazil. Atmospheric Environment 36. 2383-2395. 2002

AZEVEDO, L. A; BRÜNING, I. M.R. A.; MOREIRA, I. Hydrocarbon contamination in mussels from Guanabara Bay. Marine Pollution Bulletin, 49 (11-12). 11201122. 2004

AZEVEDO, L. A. C. Determinação de Hidrocarbonetos em Amostras de Água e Mexilhões da Baía de Guanabara. Rio de Janeiro. Dissertação de mestrado. PUC-Rio. 1998

BAEK, S.O. et al. Phase distribution and particle size dependency of polycyclic aromatic hydrocarbons in the urban atmosphere. Chemosphere 22, 503-520. 1991

BARBIÉRE, E. B.; KRONEMBERGER, D. P. Climatologia do litoral sul-sudeste do estado do Rio de Janeiro (um subsídeo a análise ambiental). Cadernos de Geociências. Rio de Janeiro, out./dez, n.12, 57-73. 1994

BARBOSA, J. M. S.; RE'-POPPI, N.; SANTIAGO-SILVA, M. Polycyclic aromatic hydrocarbons from wood pyrolyis in charcoal production furnaces. Environmental Research, 101. 304-311. 2006

BAUMARD, P. et al. Origin and Bioavailability of PAHs in the Mediterranean Sea from Mussel and Sediment Records. Estuarine, Coastal and Shelf Science, 47 (1), 77-90. 1998

BENCE, A.E., KVENVOLDEN, K.A., KENNICUTT, M.C., Organic geochemistry applied to environmental assessment of Prince William Sound, Alaska, after theExxon Valdezoil spill - a review. Org. Geochem. 24, 7-42. 1996

BENNER, B. A.; GORDON, G.E. Mobile Sources ofAtmospheric Polycyclic Aromatic Hydrocarbons: A Roadway Tunnel Study. Environmental Science \& Technology, 23, 1269-1278. 1989 
BENNER, B. B. et al. Polycyclic Aromatic Hydrocarbon Emissions from Combustion of Crude Oil on Water. Environmental Science \& Technology, 24, 1418-1427. 1990

BERGVALL, C; WESTERHOLM, R. Determination of highly carcinogenic dibenzopyrene isomers in particulate emissions from two diesel- and two gasoline-fuelled light-duty vehicles. Atmospheric Environment, 43. 3883-3890. 2009

$\mathrm{BI}, \mathrm{X}$. et al. Extractable organic matter in PM from LiWan district of Guangzhou City, PR China. The Science of the Total Environment, 300. 213-228. 2002

$\mathrm{BI}, \mathrm{X}$. et al. Distribution of particulate- and vapor-phasen-alkanes and polycyclic aromatic hydrocarbons in urban atmosphere of Guangzhou, China. Atmospheric Environment, 37. 289-298. 2003

$\mathrm{BI}$, X. et al. Composition and major sources of organic compounds in urban aerosols. Atmospheric Research, 88. 256-265. 2008

BLUMER, M.; GUILLARD, R. R. L.; CHASE, T. Hydrocarbons of marine Phytoplankton. Marine Biology, 8, 183-189. 1971

BOEHM, P. D.; FARRINGTON, J. W. Aspects of the Polycyclic Aromatic Hydrocarbon Geochemistry of Recent Sediments in the Georges Bank Region. Environmental Science \& Technology, 18 (11), 840-845. 1984

BOEHM, P.D. et al. Application of petroleum hydrocarbon chemical fingerprinting and allocation techniques after the Exxon Valdez oil spill. Mar. Pollut. Bull. 34, 599-613. 1997

BORGES, A. C. et al. Eutropication history of Guanabara Bay (SE Brazil) recorded by phosphorus flux to sediments from a degraded mangrove area. Marine Pollution Bulletin, 58. 1739-1765. 2009

BORRAS, E. et al. Polycyclic aromatic hydrocarbon exhaust emissions from different reformulated diesel fuels and engine operating conditions. Atmospheric Environment, 43. 5944-5952. 2009 
BOULOUBASSI, I.; SALIOT, A. Investigation of anthropogenic and natural organic inputs in estuarine sediments using hydrocarbon markes (NAH, LAB, PAH). Oceanologica Acta, 16 (2), 145-161. 1993

BOUROTTE, C. et al. A wintertime study of PAHs in fine and coarse aerosols in São Paulo city, Brazil. Atmospheric Environment, 39. 3799-3811. 2005

BOX, G. E. P.; COX, D. R. An Analysis of Transformations. Journal of the Royal Statistical Society. Series B (Methodological), Vol. 26, No. 2. 211-252. 1964

BRITO, E. M. S. et al. Characterization of hydrocarbonoclastic bacterial communities from mangrove sediments in Guanabara Bay, Brazil. Research in Microbiology, 157 (8), 752-762. 2006

BRUN, G. L.; HOWELL, G. D.; O’NELL, H. J. Spatial and Temporal Patterns of Organic Contaminants in Wet Precipitation in Atlantic Canada. Environ. Sci. Techn. 25, 1249- 1261.1991

BUDZINSK, $\mathrm{H}$. et al. Evaluation of sediment contamination by polycyclic aromatic hydrocarbons in the Gironde estuary. Marine Chemistry, v. 58, n. 1-2, p.85-97. 1997

CARICCHIA, A.M., CHIAVARINI, S., PESSA, M. Polycyclic aromatic hydrocarbons in the urban atmospheric particulate matter in the city of Naples (Italy). Atmospheric Environment 33, 3731-3738. . 1999

CARNEIRO, M. C. et al. Traffic and catalytic converter - Related atmospheric contamination in the metropolitan region of the city of Rio de Janeiro, Brazil. Chemosphere, 71. 677-684. 2008

CARREIRA, R. S.; WAGENER, A. L. R.; READMAN, J. W. Sterols as markers of sewage contamination in a tropical urban estuary (Guanabara Bay, Brazil): space-time variations. Estuarine, Coastal and Shelf Science, 60. 587-598. 2004

CARREIRA, R. S. et al. Changes in the sedimentary organic carbon pool of a fertilized tropical estuary, Guanabara Bay, Brazil: an elemental, isotopic and molecular marker approach. Marine Chemistry, 79 (3-4), 207-227. 2002 
CARTA NÁUTICA 1501. Baía de Guanabara. DHN/Marinha do Brasil. Escala 1:50.000. Disponível em https://www.mar.mil.br/dhn/chm/cartas/download/cartasbsb/cartas eletronicas In ternet.htm. Acesso em: 12 de março de 2013.

CAUTREELS, W., VAN CAWENBERGHE, K. Experiments on the distribution of organic pollutants between airborne particulate matter and the corresponding gas phase. Atmospheric Environment 12, 1133-1141. 1978

CHEN, H.Y.; TENG, Y. G.; WANG, J. S. Source apportionment of polycyclic aromatic hydrocarbons (PAHs) in surface sediments of the Rizhao coastal area (China) using diagnostic ratios and factor analysis with nonnegative constraints.

Science of the Total Environment, 414. 293-300. 2012

CHENG, Y. et al. Spatial and diurnal distributions ofn-alkanes andn-alkan-2-ones on $\mathrm{PM}_{2.5}$ aerosols in the Lower Fraser Valley, Canada. Atmospheric Environment, 40. 2706-2720. 2006

CHRISTENSEN, J. H. et al. A novel approach for characterization of polycyclic aromatic hydrocarbon (PAH) pollution patterns in sediments from Guanabara Bay, Rio de Janeiro, Brazil. Environmental Pollution, 158. 3290-3297. 2010

CINCINELLI, A. et al. Gas-particle concentration and distribution ofn-alkanes and polycyclic aromatic hydrocarbons in the atmosphere of Prato (Italy). Chemosphere 68. 472-478. 2007

CLARK, R. C.; BLUMER, M. Distribution of $n$-aparafins in marine organisms and sediment. Limnology and Oceanography, 123, 79-87. 1967

COLOMBO, J. C. et al. Determination of Hydrocarbon Sources Using n-Alkane and Polyaromatic Hydrocarbon Distribution Indexes, Case Study: Rio de La Plata Estuary, Argentina. Environ. Sci. Technol, v. 23, p. 888-894. 1989

COMMENDATORE, M. G. et al. Sources and distribution of aliphatic and polyaromatic hydrocarbons in coastal sediments from the Ushuaia Bay (Tierra del Fuego, Patagonia, Argentina). Marine Environmental Research, 74, 20-31. 2012 
CONAMA - Conselho Nacional de Meio Ambiente. Resolução n003 de 28 de julho de 1990. Piblicada no D.O.U. de 22/08/90, Seção I, páginas 15.973 a 15.939 .

CONTINI, D. et al. The direct influence of ship traffic on atmospheric $\mathrm{PM}_{2.5}, \mathrm{PM}_{10}$ and PAH in Venice. Journal of Environmental Management. 92. 2119-2129. 2011

COOPER, J. J.; BRAY, E. E. A postulated role of fatty acids in petroleum formation. Geochimica et Cosmochimica Acta, 27, 1113-1127. 1963

DAISEY, J. M. et al. An Overview of the Rio de Janeiro Aerosol Characterization Study. JAPCA, 37:1, 15-23. 1987

DALLAROSA, J. B. et al. Polycyclic aromatic hydrocarbons in atmospheric particles in the metropolitan area of Porto Alegre, Brazil. Atmospheric Environment 39. 1609-1625. 2005

DALLAROSA, J. B. et al. Study of the chemical elements and polycyclic aromatic hydrocarbons in atmospheric particles of $\mathrm{PM}_{10}$ and $\mathrm{PM}_{2.5}$ in the urban and rural areas of South Brazil. Atmospheric Research, 89. 76-92. 2008

DAVIES, J. M.; TIBBETTS, J. C. The use if In Situ Benthic Chambers to Study the Fate of Oil in Subtidal Sediments. Estuarine Coastal and Shelf Science, v. 24, p.205-223. 1987

DEL ROSARIO SIENRA, M. et al. Polycyclic aromatic hydrocarbons and their molecular diagnostic ratios in urban atmospheric respirable particulate master. Atmospheric Research 75, 267-281. 2005

DOSKEY, P. V.; ANDREN, A. W. Particulate and Vapor phase $\mathrm{n}$-alkanes in the Northern Wiscosin Atmosphere. Atmospheric Environment, 20. 1735-1744. 1986

DOUGLAS, G.S. et al. Environmental stability of selected petroleum hydrocarbon source and weathering ratios. Environ. Sci. Technol. 30, 2332 - 2339. 1996

DUNN, O. J. Confidence Intervals for the Means of Dependent, Normally Distributed Variables, Journal of the American Statistical Association, 54:287, 613-621. 1959 
DUNN, O. J.. Multiple Comparisons among Means, Journal of the American Statistical Association, 56:293, 52-64. 1961

DUNTEMAN, G. H. Principal Component Analysis. London, United Kingdom. ISBN 0-8039-3104-2. 96p. 1989

DYREMARK, A. et al. Polycyclic Aromatic Hydrocarbon (PAH) Emissions from Coal Grilling. Atmospheric Environment. 29. 1553-1558. 1995

EHRHARDT, M. G.; BURNS, K. A.; BICEGO, M. C. Sunblight-induced compositional alterations in the seawater-soluble fraction of a crude oil. Marine Chemistry, v. 37 , p. 53-64, 1992

EPA - 3540. Soxhlet extraction. In: Test method for evaluation solid waste physical/chemical methods. Laboratory manual. Environmental Protection Agency, 1986. v. I-B

EPA - 8270D - Gas chromatography/mass spectrometry for semi volatile organics capillary column technique. In: Test method for evaluation solid waste physical/chemical methods. Laboratory manual. Environmental Protection Agency, 2007

EPA, Method 8015C: Nonhalogenated Organics by Gas Chromatography. Revision 3. February. Environmental Protection Agency, 2007

ESEN, F.; TASDEMIR, Y.; VARDAR, N. Atmospheric concentrations of PAHs, their possible sources and gas-to-particle partitioning at a residential site of Bursa, Turkey. Atmospheric Research, 88. 243-255. 2008

FANG, G-C. et al. Characteristic of polycyclic aromatic hydrocarbon concentrations and source identification for fine and coarse particulates at Taichung Harbor near Taiwan Strait during 2004-2005. Science of the Total Environment, 366. 729-738. 2006

FARIAS, C. O. Avaliação da degradação de óleo em sedimentos de manguezal: Estudo de caso, Baía de Guanabara, RJ. Tese de Doutorado. Departamento de Química. Pontifícia Universidade Católica. PUC-RIO. 301pp. 2006 
FARRINGTON, B. W.; TRIPP, B. W. Hydrocarbon in western North Atlantica surface sediments. Geochimica et Cosmochimica Acta, v. 41, p. 1627-1641. 1997

FEEMA - Fundação Estadual de Engenharia do Meio Ambiente. Qualidade da água da Baía da Guanabara-1990 a1997. Secretaria de Estado de Meio Ambiente, Fundação Estadual de Engenharia do Meio Ambiente, Rio de Janeiro. 1998

FEEMA - Fundação Estadual de Engenharia do Meio Ambiente. Qualidade das Águas do Estado do Rio de Janeiro - 1987-1989 volume IV. Baía da Guanabara e rios constituintes e Baía de Sepetiba e sub-bacias adjacentes. 1991

FERNANDES, M. B. et al. Atmospheric BTX and polyaromatic hydrocarbons in Rio de Janeiro, Brazil. Chemosphere, 47, 417-425. 2002

FILLIPO, A. M. Passagem de Frentes Frias na Baía de Guanabara, RJ - Brasil: Impacto no nível do mar. Dissertação de Mestrado, Departamento de Geoquímica Ambiental, Universidade Federal Fluminense - UFF, Niterói, 79 pp. 1997

FINE, P.M., CASS, G.R., SIMONEIT, B.R. Chemical characterization of fine particle emissions from fireplace combustion of woods grown in the northeastern United States. Environ.Sci.Technol.35,2665-2675. 2001

FROMME, H. et al. Polycyclic aromatic hydrocarbons PAH and diesel engine emission elemental carbon inside a car and a subway train. The Science of the Total Environment, 217. 165-173. 1998

FUJITAMI, Y. et al. Effect of isothermal dilution on emission factors of organic carbon andn-alkanes in the particle and gas phases of diesel exhaust. Atmospheric Environment, 59. 389-397. 2012

GALARNEAU, E. Source specificity and atmospheric processing of airborne PAHs: Implications for source apportionment. Atmospheric Environment, 42, 8139-8149. 2008 
GAO, B. et al. Polycyclic aromatic hydrocarbons in $\mathrm{PM}_{2.5}$ in Guangzhou, southern China: Spatiotemporal patterns and emission sources. Journal of Hazardous Materials, 239. 78-87. 2012

GARRIDES, P. et al. Pyrolitic and petrogenic inputs in recent sediments: a definitive signature through phenanthrene and chysene compound distribution.Polycyclic Aromatic Compounds, v. 7, p. 275-284. 1995

GEO-RIO/DEP/GPE. Relatório Anual de Chuvas 2011. Relatório GEORIO/DEP/GPE - N. ${ }^{\circ}$ 02/2012. 164p. 2012

GESAMP - Group of Expersts on the Scientific Aspects of Marine Pollution. Anthropogenic Influences on Sediment Discharge to the Coastal Zone and Environmental Consequences. UNESCO-IOC, 1993, 67p.

GODOY, J. M. et al. A study of Guanabara Bay sedimentation rates. Journal of Radioanalytical and Nuclear Chemistry, v. 227 (1-2). 157-160. 1998

GODOY, M. L, D. P. et al. Coarse and fine aerosol source apportionment in Rio de Janeiro, Brazil. Atmospheric Environment. 43, 2366-2374. 2009

GOGOU, A. I.; APOSTOLAKI, M.; STEPHANOU, E. G. Determination of organic molecular markers in marine aerosols and sediments: one-step flash chromatography compound class fractionation and capillary gas chromatographic analysis. Journal of Chromatography A, 799. 215-231. 1998

GOGOU, A. et al. Organic aerosols in Eastern Mediterranean: Components source reconciliation by using molecular markers and atmospheric back trajectories. Organic Geochemistry, 25. 79-96. 1996

GOUGH, M. A.; ROWLAND, S. J. Characterization of unresolved complex mixtures in petroleum. Nature, v. 344, p. 648-650, 1990

GRIMMER, G. et al. Determination of polycyclic aromatic compounds emitted from brown-coal-fired residential stoves by gas chromatography/mass spectrometry. Anal. Chem. 55, 892-900. 1983

Gschwend, P. M.; Hites, R. A. Fluxes of polycyclic aromatic hydrocarbons to marine and lacustrine sediments in the northeastern United States. Geochimica et Cosmochimica Acta, 45, 2359-2367. 1981 
GU, Z. et al. Diurnal variations of polycyclic aromatic hydrocarbons associated with $\mathrm{PM}_{2.5}$ in Shanghai, China. Journal of Environmental Sciences, 22(3) 389396. 2010

GUIMARÃES, G. P. Estimativa dos fluxos de amônia óxido nitroso na interface ar-mar da Baía de Guanabara - RJ. Dissertação de Mestrado. Universidade Federal Fluminense. 116pp. 2005

GUO, Z. G. et al. Seasonal variation of solvent extractable organic compounds in the aerosols in Qingdao, China. Atmospheric Environment, 37. 1825-1834. $2003 a$

GUO, H. et al. Particle-associated polycyclic aromatic hydrocarbons in urban air ofHong Kong. Atmospheric Environment, 37. 5307-5317. 2003b

HALL, D. et al. PAHs, carbo nyls, VOCs and $\mathrm{PM}_{2.5}$ emission factors for preharvest burning of Florida sugarcane. Atmospheric Environment, 55.) 164 172. 2012

HAMACHER, C. Determinação de hidrocarbonetos em amostras de água e sedimento da Baía de Guanabara. Dissertação de Mestrado, PUC-Rio, Rio de Janeiro, 105 p. 1996

HERRINGTON, J. S. et al. The effec ts of operating conditions on semivolatile organic compound s emitted from light-duty, gasoline-powered motor vehicles. Atmospheric Environment, 54. 53-59. 2012

HITES, R. A., LAFLAMME, R. E.; WINDSOR, J. G. Polycyclic aromatic hydrocarbons in an anoxic sediment core from the Pettaquamscutt River (Rhode Island, U.S.A.). Geochimica et Cosmochimica Acta, v. 44, p. 873878. 1980

HO, K. F. et al. Emissions of gas- and particle-phase polycyclic aromatic hydrocarbons (PAHs) in the Shing Mun Tunnel, Hong Kong. Atmospheric Environment, 43. 6343-6351. 2009

INEA - Instituto Estadual do Ambiente.Relatório Anual de Qualidade do Ar 2009. 108p. 2009 
JAFFE, R. et al. Organic compounds and trace metals of anthropogenic origin in sediments from Montego Bay,Jamaica: assessment of sources and distribution pathways. Environmental Pollution. 123 (2), 291-299. 2003

JICA. Japan International Cooperation Agency. The study of recuperation of the Guanabara Bay ecosystem. Supporting Report, Tokyo, Kokusai Kogyo Co., Ltd, Vol. 1-4. 1994

KAVOURAS, I. G. et al. Source Apportionment of Urban Particulate Aliphatic and Polynuclear Aromatic Hydrocarbons (PAHs) Using Multivariate Methods. Environ. Sci. Technol.35, 2288-2294. 2001

KAVOURAS, I. G. et al. Measurement of particulate aliphatic and polynuclear aromatic hydrocarbons in Santiago de Chile: source reconciliation and evaluation of sampling artifacts. Atmospheric Environment, 33. 4977-4986. 1999

KHALILI, N. R.; SCHEFF, P. A.; HOLSEN, T. M. PAH Source Fingerprints for Coke Ovens, Diesel and Gasoline Engines Highway Tunnels, and Wood Combustion Emissions. Atmospheric Environment Vol. 29, No. 4, pp. 533542. 1995

KILLOPS, S. D.; AL-JUBOORI, M. A. H. A. Characterisation of the unresolved complex mixture (UCM) in the gas chromatograms of biodegraded petroleums. Org. Geochem, 15 (2). 147-160. 1990

KILLOPS, S. D.; KILLOPS, V. J. An Introduction to Organic Geochemistry. Longman Scientific \& Technical, 1993, 265p.

KJERFVE, B. et al. Oceanographic characteristics of an impacted coastal bay: Baia de Guanabara, Rio de Janeiro, Brazil. Continental Shelf Research, Vol. 17, No. 13 , pp. 1609-1 643. 1997

KRAEMER, $\mathrm{H}$. et al. Measures of Clinical Significance. J Am Acad Child Adolesc Psychiatry, 42(12), 1524-1529. 2003

KRUMAL, K.; MIKUSKA, P.; VECERA, Z. Polycyclic aromatic hydrocarbons and hopanes in PM1 aerosols in urban áreas. Atmospheric Environment 67, 27-37. 2013 
$\mathrm{KUO}, \mathrm{C}-\mathrm{Y}$. et al. Comparison of polycyclic aromatic hydrocarbon emissions on gasoline- and diesel-dominated routes. Environ Monit Assess. 185. 5749 5761. 2013

KUSKAL, W. H.; WALLIS, W. A. Use of Ranks in One-Criterion Variance Analysis. Journal of the American Statistical Association. 260 (47). 584-621. 1952

LADJI, R. et al. Annual variation of particulate organic compounds in PM10in the urban atmosphere of Algiers. Atmospheric Research, 92. 258-269. 2009

LAFLAMME, R. E.; HITES, R. A. The Globaldistribution of polycyclic aromatic hydrocarbons in recent sediments. Geochimica et Cosmochimica Acta, 42,.289-303. 1978

LAKE, J. L. et al. Origins of polycyclic aromatic hydrocarbons in estuarine sediments. Geochimica et Cosmochimica Acta, v. 43, p. 1847-1854. 1979

LARSEN, R. K.; BAKER, J. E. Source Apportionment of Polycyclic Aromatic Hydrocarbons in the Urban Atmosphere: A Comparison of Three Methods. Environmental Science \& Technology, 37, 1873-1881. 2003

LAWS, E. A. Aquatic Pollution: An Introduction Text. 2. ed. New York:Jonn Wiley \& Sons, 611p. 1993

LEE, M.L. et al. Source identification of urban airborne polycyclic aromatic hydrocarbons by gas chromatographic mass spectrometry and high resolution mass spectrometry. Biomed. Mass Spectrom. 4, 182-186. 1977

LEMON, J. Plotrix: a package in the red light district of R. R-News, 6. (4) 8-12. 2006

LI, B. et al. Spatial distribution and source apportionment of PAHs in surficial sediments of the Yangtze Estuary, China. Marine Pollution Bulletin, 64, 636643. 2012

LI, X. et al. Seasonal variation and source apportionment of organic and inorganiccompounds in $\mathrm{PM}_{2.5}$ and $\mathrm{PM}_{10}$ particulates in Beijing, China. Journal of Environmental Sciences, 25(4) 741-750. 2013 
LIMA, A.L.C. Geocronologia de hidrocarbonetos poliaromáticos (PAHs)—estudo de caso: Baía de Guanabara. Dissertação de Mestrado, PUC-Rio, Rio de Janeiro, 106 p. 1996

LIMA, F. M. Hidrocarbonetos Policíclicos Aromáticos em Material Particulado Atmosférico na Região Central de Niterói, RJ. Dissertação de Mestrado. Instituto de Química - UFF. 95p. 2006

LIPIATOU, E; SALIOT, A. Fluxes and transport of Anthropogenic and natural polycyclic aromatic hydrocarbons in the western Mediterranean Sea. Marine Chemistry, v. 32, p. 51-71. 1991

LIU, Y. et al. Source apportionment of polycyclic aromatic hydrocarbons (PAHs) in surface sediments of the Huangpu River, Shanghai, China. Science of the Total Environment, 407, 2931-2938. 2009

LOPES, W. A.; ANDRADE, J. B. Fontes, Formação, Reatividade e Quntificação de Hidrocarbonetos Policíclicos Aromáticos na Atmosfera. Quimica Nova, 19(5). 497-516. 1996

LOUREIRO, L. M J; GAMEIRO, M. G. H. Interpretação crítica dos resultados estatísticos: para lá da significância estatística. Revista de Enfermagem Refrência III, série $n^{\circ} 3,151-161.2011$

MACHADO, M. C. S. et al. Particle-Associated Polycyclic Aromatic Hydrocarbons and their Dry Deposition Fluxes from a Bus-Station in the Rio de Janeiro Metropolitan Area, Brazil. J. Braz. Chem. Soc., Vol. 20, No. 9, 1565-1573. 2009

MANOLI, E.; KOURAS, A.; SAMARA, C. Profile analysis of ambient and source emitted particle-bound polycyclic aromatic hydrocarbons from three sites in northern Greece. Chemosphere 56, 867-878. 2004

MARIANI, R. L.; MELLO, W, Z. PM2.5-10, PM2.5 and associated water-soluble inorganic species at a coastal urban site in the metropolitan region of Rio de Janeiro. Atmospheric Environment, 41. 2887-2892. 2007

MARQUES, L. F. C. S. et al. Particle-Associated Polycyclic Aromatic Hydrocarbons in a Suburban Region of Rio de Janeiro, Brazil, with Industrial and Traffic Emissions. J. Braz. Chem. Soc., Vol. 20, No. 3, 518-529. 2009 
MARR, L. C. et al. Real-Worls Emissions of PAH in the exhaust of California Reformulated Gasoline and Heavy Duty Diesel Fueled Vehicles. J. Aerosol Sci. 29, 73-74. 1998

MARR, L.C. et al. Sources and transformations of particle-bound polycyclic aromatic hydrocarbons in Mexico City. Atmospheric Chemistry and Physics 6, 1733-1745. 2006

MARTINIS, BRUNO S. DE et al. Polycyclic aromatic hydrocarbons in a bioassay-fractionated extract of PM 10 collected in São Paulo, Brazil. Atmospheric. Environment, v. 36, p. 307-314. 2002

MASTRAL, A. M. et al. Spatial and temporal PAH concentrations in Zaragoza, Spain. The Science of the Total Environment, 307. 111-124. 2003

MASSONE, C. G. Caracterização de hidrocarbonetos na região costeira do Rio Paraíba do Sul, Estação de Tratamento de Efluentes de Cabiúnas e Emissário de Ipanema,RJ. Dissertação de Mestrado. Departamento de Geoquímica. Universidade Federal Fluminense. 98p. 2004

MAUAD, C. R. et al. Aporte Fluvial de Hidrocarbonetos Policíclicos Aromáticos (HPA) no Material Particulado em Suspensão para a Baía de Guanabara, Rio de Janeiro, RJ. In: Congresso Brasileiro de Oceanografia. 13 a 16 de novembro de 2012. Rio de Janeiro, RJ. 2012

MAYR, L.M. et al. Hydrobiological characterization of Guanabara Bay. In: Maggon, O.T. \& Neves, C, (eds), Coastlines of Brazil. Am Soc Civil Engen, NY, p 124-139. 1989

MAZQUIARÁN, M. A. B. et al. Organic composition of atmospheric urban aerosol: Variations and sources of aliphatic and polycyclic aromatic hydrocarbons. Atmospheric Research, 85. 288- 299. 2007

MAZUREK, M. A.; CASS, G. R.; SIMONEIT, B. R. T. Interpretation of HighResolution Gas Chromatography and High-Resolution Gas Chromatography I Mass Spectrometry Data Acquired from Atmospheric Organic Aerosol Samples. Aerosol Science and Technology, 10:2, 408-420. 1989 
MEDEIROS, P. M. et al. Natural and anthropogenic hydrocarbon inputs to sediments of Patos Lagoon Estuary, Brazil. Environment International, 31, 7787. 2005

MELLO, W. Z. Precipitation chemistry in the coast of the Metropolitan Region of Rio de Janeiro, Brazil. Environmental Pollution, 114. 235-242. 2001

MENICONI, M. F. G. Hidrocarbonetos policíclicos aromáticos no meio ambiente: Diferenciação de fontes em sedimentos e metabólitos de peixes. Tese de Doutorado, UFRN, Natal. 192p. 2007

MENICONI, M. F. G. et al. Brazilian Oil Spills Chemical Characterization-Case Studies. Environmental Forensics, 3 ( 3-4), 303-321. 2002

$\mathrm{MI}, \mathrm{H}-\mathrm{H}$. et al. Effect of the gasoline additives on PAH emission. Chemosphere, 36 (9). 2031-2041. 1998

MOSTAFÁ, A. R. et al. Source characterization and the environmental impact of urban street dusts from Egypt based on hydrocarbon distributions. Fuel 88. 95104. 2009

NASCIMENTO, K. H. Determinação de Compostos Orgânicos no Aerossol Atmosférico em Sítios da América do Sul. Dissertação de Mestrado. Instituto de Química. Universidade de São Paulo. 139p. 2006

NEFF, J. M. Polycyclic Aromatic Hydrocarbons in the Aquatic Environment - Sourses, Fates and Biological Effects. 1 ed. Londres. Applied Science Publishers, 262p. 1979

NIENCHESKI, L. F.; BAUNGARTEN, M. G. Z. Oceanografia Química: Levantamento bibliográfico e identificação do estado atual do conhecimento. Rio de Janeiro: FEEMAR/MMA/Cirm. 171p. 1999

NISHIGIMA, F. N.; WEBER, R. R.; BICEGO, M. C. Aliphatic and Aromatic Hydrocarbons in Sediments of Santos and Cananéia, SP, Brazil. Marine Pollution Bulletin, 42 (11), 1064-1072. 2001

NRC - National Research Council. Oil in the Sea: Imputs, Fates, and Effects. National Academy Press, 1985. 601p 
OCHS, S. M. et al. Evaluation of $\mathrm{C} 1 \mathrm{eC} 13$ carbonyl compounds by RRLC-UV in the atmosphere of Niterói City, Brazil. Atmospheric Environment, 45. 51835190. 2011

OLIVEIRA, C. et al. Size distribution of polycyclic aromatic hydrocarbons in a roadway tunnel in Lisbon, Portugal. Chemosphere, 83. 1588-1596. 2011

OMAR, N. Y. M. J. et al. Levels and distributions of organic source tracers in air and roadside dust particles of Kuala Lumpur, Malaysia. Environ Geol, 52:14851500. 2007

OROS, D. R. et al. Identification and emission factors of molecular tracers in organic aerosols from biomass burning: Part 3. Grasses. Applied Geochemistry 21. 919-940. 2006

OROS, D. R.; SIMONEIT, B. R. T. Identification and emission rates of molecular tracers in coal smoke particulate matter. Fuel, 79. 515-536. 2000

OROS, D. R.; SIMONEIT, B. R. T. Identification and emission factors of molecular tracers in organic aerosols from biomass burning Part 1. Temperate climate conifers. Applied Geochemistry, 16. 1513 - 1544. 2001a

OROS, D. R.; SIMONEIT, B. R. T. Identification and emission factors of molecular tracers in organic aerosols from biomass burning Part 2. Deciduos trees. Applied Geochemistry, 16. 1545 - 1565. 2001b

PAGE, D. S. et al. Identification of hydrocarbon sources in the benthic sediments of Prince William Sound and the Gulf of Alaska Following the Exxon Valdez oil spill. Exxon Valdez Oil Spill: Fate and Effects in Alaskan Waters. ASTM STP 1219, Peter G. Wells, James N. Butler, James S Hughes, Eds., American Society for Testing and Materials, Philadelphia, 1995. 41-83. 1993

PANDEY, P.K., PATEL, K.S., LENICEK, J. Polycyclic aromatic hydrocarbons: need for assessment of health risks in India? Study of an urban-industrial location in India. Environmental Monitoring and Assessment 59, 287-319. 1999

PANKOW, J. F. A simple box model for the annual cycle of partioning of semivolatile organic compounds between the atmosphere and the Earth's surface. Atmospheric Environment. 27A, 7, 1139-1152. 1993 
PANTHER, B.C., HOOPER, M.A., TAPPER, N.J. A comparison of air particulate matter and associated polycyclic aromatic hydrocarbons in some tropical and temperate urban environments. Atmospheric Environment 33, 4087-4099. 1999

PARK, S.S., KIM, Y.J., KANG, C.H. Atmospheric polycyclic aromatic hydrocarbons in Seoul, Korea. Atmospheric Environment 36, 2917-2924. 2002

PEREIRA NETTO, A. D. et al. Preliminary Comparison of PAH in Total Suspended Particulate Samples Taken at Niterói and Rio de Janeiro Cities, Brazil. Bull. Environ. Contam. Toxicol. 66:36 - 43. 2001

PEREIRA NETTO, A. D. et al. PAHs in Diurnal and Nocturnal Samples of Total Suspended Particulate in a Highly Trafficked Area of Rio de Janeiro City, Brazil. Bull. Environ. Contam. Toxicol. 75:1004-1011. 2005

PEREIRA NETTO, A. D. et al. Identification of Polycyclic Aromatic Hydrocarbons in Street Dust of Niterói City, RJ, Brazil. Bull. Environ. Contam. Toxicol. 68:831- 838. 2002

PETROBRAS - Petróleo Brasileiro S. A. Monitoramento Ambiental da Área de Influência do Emissário de Cabiúnas, Região de Macaé/RJ: Caracterização Pré-operacional e Monitoramento Pós-operacional: Relatório Final. Rio de Janeiro, 276 pp. 2002

PIETROGRANDE, M. C. et al. Seasonal variation and source estimation of organic compounds in urban aerosol of Augsburg, Germany. Environmental Pollution 159, 1861-1868. 2011

POWELL, F. G. Pristane/Phytane ratio as environment indicator. Nature, 333, 604. 1988

PRAHL, F. G.; CARPENTER, R. Polycyclic aromatic hydrocarbon (PAH) - phase associations in Washington coastal sediment. Geochimica et Cosmochimica Acta, 47, 1013-1023. 1983

PRAHL, F.G., CRECELLIUS, E., CARPENTER, R. Polycyclic aromatic hydrocarbons in Washington coastal sediments: an evaluation of atmospheric and riverine routes of introduction. Environ. Sci. Technol. 18, 687-693. 1984 
PRAHL, F.G.; CARENTER, R. The role of zooplankton fecal pellets in the sedimentation of polycuclic aromatic hydrocarbons in Dabob Bay, Washington. Geochimica et Cosmochimica Acta, v. 43, p.1959-1972. 1979

QUARESMA, V. S. Caracterização da dinâmica sedimentar da Baía de Guanabara. RJ. Dissertação de Mestrado. LAGEMAR. Universidade Federal Fluminense, 97pp. 1997

QUITÉRIO, S. L. et al. Polycyclic Aromatic Hydrocarbons and their Molecular Diagnostic Ratios in Airborne Particles (PM10) Collected in Rio de Janeiro, Brazil. Water Air Soil Pollut 179:79-92. 2007

QUITÉRIO, S. L. et al. Evaluation of levels, sources and distribution of airborne trace metals in seven districts of the Baixada Fluminense,Rio de Janeiro, Brazil. Atmospheric Environment, 39, 3503-3512. 2005

$R$ CORE TEAM. R: A language and environment for statistical computing. $R$ Foundation for Statistical Computing, Vienna, Austria. ISBN 3-900051-07-0, URL http://www.R-project.org/. 2012

RAVINDRA, K.; SOKHI, R.; GRIEKEN, R. V. Atmospheric polycyclic aromatic hydrocarbons: Source attribution, emission factors and regulat ion. Atmospheric Environment, 42. 2895 - 2921. 2008a

RAVINDRA, K.; WAUTERS, E.; GRIEKEN, R. V. Variation in particulate PAHs levels and their relation with the transboundary movement of the air masses. Science of the Total Environment, 396. 100-110. 2008b

READMAN, J. et al. Petroleum and PAH contamination of the Black Sea. Marine Pollution Bulletin,44 (1), 48-62. 2002

RÉ-POPPI, N.; SANTIAGO-SILVA, M. Polycyclic aromatic hydrocarbons and other selected organic compounds in ambient air ofCampo Grande City, Brazil. Atmospheric Environment, 39. 2839-2850. 2005

RIBEIRO, A. M. et al. Seasonal variation of polycyclic aromatic hydrocarbons concentrations in urban streams at Niterói City, RJ, Brazil. Marine Pollution Bulletin, 64. 2834-2838. 2012 
RIBEIRO, C.H.A. Uma análise da qualidade de água da Baía de Guanabara entre 1980 e 1993. Dissertação de Mestrado, UFF, Niterói. 136 p. 1996

RIDDLE, S. et al. Large PAHs detected in fine particulate matter emitted from light-duty gasoline vehicles. Atmospheric Environment, 41. 8658 - 8668. 2007

ROGGE, W. F. et al. Sources of Fine Organic Aerosol. 2. Noncatalyst and Catalyst-Equipped Automobiles and Heavy-Duty Diesel Trucks. Environ. Sci. Techno. 27, 636-651. 1993a

ROGGE, W. F. et al. Sources of Fine Organic Aerosol. 4. Particulate Abrasion Products from Leaf Surfaces of Urban Plants. Environ. Sci. Technol. 27, 27002711. $1993 b$

SANTOS, C.Y.M., AZEVEDO, D.A., AQUINO NETO, F.R. Selected organic compounds from biomass burning found in the atmospheric particulate matter over sugarcane plantation areas. Atmospheric Environment 36, 3009-3019. 2002

SAVINOV, V. M. et al. Polycyclic Aromatic Hydrocarbons (PAHs) in Sediments of the White Sea, Russia. Marine Pollution Bulletin, 40 (10), 807-818. 2000

SCHAUER, J. J. et al. Measurement of emissions from air pollution sources 3 . $\mathrm{C}_{1}-\mathrm{C}_{29}$ organic compounds from fireplace combustion of wood. Environ. Sci. Technol. $35,1716-1728.2001$

SHARMA, H.; JAIN, V. K.; KHAN, Z. H. Characterization and source identification of polycyclic aromatic hydrocarbons (PAHs) in the urban environment of Delhi. Chemosphere 66, 302-310. 2007

SHEN, G. et al. Retene Emission from Residential Solid Fuels in China and Evaluation of Retene as a Unique Marker for Soft Wood Combustion. Environmental Science e Technology, 46. 4666-4672. 2012

SICRE, M. A.; MARTY, J. C.; SALIOT, A. Aliphatic and Aromatic Hydrocarbons in Diferrent Sized Aerosols Over The Mediterranean Sea: Ocurrence and Origin. Atmospheric Environment, v. 21, n. 10, p. 2247-2259. 1987 
SILLIMAN, J. E.; MEYERS, P. A.; EADIE, B. J. Perylene: an indicator of alteration processes or precursor materials? Organic Geochemistry, 29. 5-7, 1737- 1744. 1998

SILLIMAN, J. E. et al. A hypothesis for the origin of perylene based on its low abundance in sediments of Green Bay, Wisconsin. Chemical Geology, 177 (34), 309-322. 2001

SILLIMAN, J. E. et al. Insights into the origin of perylene from isotopic analyses of sediments from Saanich Inlet, British Columbia. Organic Geochemistry, 31. 1133-1142. 2000

SILVA, T. F.; AZEVEDO, D. A.; AQUINO NETO, F. R. Distribution of Polycyclic Aromatic Hydrocarbons in Surface Sediments and Waters from Guanabara Bay, Rio de Janeiro, Brazil. J. Braz. Chem. Soc. 18, 628-637. 2007

SIMONEIT, B. R. T. Organic Matter of the Troposphere - III. Characterization and sources of petroleum and pyrogenic residues in aerosols over the western United States. Atmospheric Environment, 18. 51-67. 1984

SIMONEIT, B. R. T. Application of Molecular Marker Analysis to Vehicular Exhaust for Source Reconciliations. International Journal of Environmental Analytical Chemistry,. 22, 203-233. 1985

SIMONEIT, B. R. T. Application of molecular marker analysis to reconcile sources of carbonaceous particulates in tropospheric aerosols. Science of The Total Environment, 36 (1), 61-72. 1986

SIMONEIT, B. R. T. Organic Matter of the Troposphere- V: Application of Molecular Marker Analysis to Biogenic Emissions into the Troposphere for Source Reconciliations. Journal of Atmospheric Chemistry, 8. 251-275. 1989

SIMONEIT, B. R. T. Biomass burning - a review of organic tracers for smoke from incomplete combustion. Applied Geochemistry, 17. 129-162. 2002

SIMONEIT, B. R. T.; CARDOSO, J. N.; ROBINSON, N. An assessment of the origin and composition of high molecular weight organic matter in aerosols over Amazonia. Chemosphere, 21. 1285-1301. 1990 
SIMONEIT, B. R. T.; COX, R. E.; STANDLEY, L. J. Organic matter of the troposphere-IV. Lipids in Harmattan aerosols of Nigeria. Atmos. Environ., 22, 983-1004. 1988

SIMONEIT, B. R. T. et al. Molecular Marker Study of Extractable Organic Matter in Aerosols fromUrban Areas os China. Atmospheric Environment, 25A (10) 2111-2129. 1991a

SIMONEIT, B. R. T. et al. Composition of Organic Matter from the Blue Mountains and Southeast Coast of Australia. Environment International, 17, 405-419. 1991b

SIMONEIT, B. R. T; MAZUREK, M. A. Organic matter of the troposphere-II. Natural background of biogenic lipid matter in aerosols over the rural western united states. Atmospheric Environment, 16 (9), 2139-2159. 1982

SOARES-GOMES, A. et al. Changes and variations of polycyclic aromatic hydrocarbon concentrations in fish, barnacles and crabs following an oil spill in a mangrove of Guanabara Bay, Southeast Brazil. Marine Pollution Bulletin, 60 (8). 1359-1363. 2010

SOCLO, H. H.; GARRIDES, P.; EWALD, M. Origin of Polycyclic Aromatic Hydrocarbons (PAHs) in Coastal Marine Sediments: Case Studies in Cotonou (Benin) and Aquitaine (France) Areas. Marine Pollution Bulletin, 40 (5), 387396. 2000

SOFOWOTE, U.M., MCCARRY, B.E., MARVIN, C.H. Source apportionment of $\mathrm{PAH}$ in Hamilton Harbour suspended sediments: comparison of two factor analysis methods. Environmental Science Technology. 42, 6007-6014. 2008

SOUSA, C. A.; LIRA, M. A.; FERREIRA, R. L. C. Avaliação de testes estatísticos de comparações múltiplas de médias. Rev. Ceres, Viçosa, v. 59, n.3, p. 350354, mai/jun, 2012

SOUZA, C. D. R. et al. Inventory of conventional air pollutants emissions from road transportation for the state of Rio de Janeiro. Energy Policy, 53. 125-135. 2013

SOUZA, D. Z. A Variação Sazonal da Concentração de Hidrocarbonetos Policíclicos Aromáticos em Material Particulado $\mathrm{MP}_{10}$ na Atmosfera de São 
Paulo. Dissertação de Mestrado. Instituto de Pesquisas Energéticas e Nucleares - Universidade de São Paulo. 75p. 2006

STEINHAUER, M. S.; BOEHM, P, D. The Composition and Distribution of Saturated and Aromatic Hydrocarbons in Nearshore Sediments, River Sediments, and Coastal Peat of the Alaskan Beaufort Sea: Implications for Detecting Anthropogenic Hydrocarbons Inputs. Marine Environment Research,v. 33, p. 223-253. 1992

STEINHAUER, M. S.; CERCELIUS, E.; STEINHAUER, W. Temporal and spatial changes in the concentrations of hydrocarbonsand trace metals in the vicinity of an offshore oil-production platform. Marine Environmental Research,v. 37, n. 2, p.129-163. 1994

TAKADA, H.; ONDA, T.; OGURA, O. Determination of Polycyclic Aromatic Hydrocarbons in Urban Street Dusts and Their Source Materials by Capillary Gas Chromatography. Environ. Sci. Technol, 24. 1179-1186. 1990

TASDEMIR, Y., ESEN, F., 2007. Urban air PAHs: concentrations, temporal changes and gas/particle partitioning at a traffic site in Turkey. Atmospheric Research 84, 1-12.

TAVARES, M. et al. Emission of polycyclic aromatic hydrocarbons from diesel engine in a bus station, Londrina, Brazil. Atmospheric Environment, 38. 50395044. 2004

THAM, Y. W. F.; TAKEDA, K.; SAKUGAWA, H. Polycyclic aromatic hydrocarbons (PAHs) associated with atmospheric particles in Higashi Hiroshima, Japan: Influence of meteorological conditions and seasonal variations. Atmospheric Research, 88. 224-233. 2008

TOBISZEWSKI, M.; NAMIESNIK, J. PAH diagnostic ratios for the identification of pollution emission sources. Environmental Pollution, 162. 110-119. 2012

TOLOSA, I. et al. Aliphatic and aromatic hydrocarbons in coastal Caspian Sea sediments. Marine Pollution Bulletin, 48, 44-60. 2004

TOLUN, L. G. et al. The pollution status and the toxicity of surface sediments in Izmit Bay (Marmara Sea), Turkey. Environment International, 26, 163-168. 2001 
TRINDADE, H. A. et al. Meteorological parameters and concentration of total suspended particulates in the urban área of Rio de Janeiro. Atmospheric Environment. 14, 973-978. 1980

TRINDADE, H. A. et al. Atmospheric Concentration of Metals and Total Suspended Particulates in Rio de Janeiro. Environ. Sci. Technol., 15 (1), pp 84-89. 1981

TRINDADE, H. A; PFEIFFER, W. C. Relationship between ambient lead concentration and lead in gasoline in Riode Janeiro. Brazil. SHORT COMUNICATION. Atmospheric Environmet. Vol. 16, 2749-2751. 1982

TSAI, J-H.; CHANG, S-Y.; CHIANG, H-L. Volatile organic compounds from the exhaust of light-duty diesel vehicles. Atmospheric Environment, 61. 499-506. 2012

VADAR, N.; ESEN, F.; TASDEMIR, Y. Seasonal concentrations and partitioning of PAHs in a suburban site of Bursa, Turkey. Environmental Pollution, 155. 298-307. 2008

VALENTIN, J.L. et al. O sistema planctônico da Baía de Guanabara: síntese do conhecimento. In: Silva, S.H.G., Lavrado, H.P. (Ed.), Ecologia de Ambientes Costeiros do Estado do Rio de Janeiro. Oecologia Brasiliensis. PPGE-UFRJ, Rio de Janeiro, 35-59. 1999

VASCONCELLOS, P. C. et al. Determinação dos hidrocarbonetos saturados e policíclicos aromáticos presentes no material particulado da atmosfera amazônica. Quimica Nova, 21(4). 385-393. 1998

VASCONCELLOS, P. C. et al. Comparative study of the atmospheric chemical composition of three South American cities. Atmospheric Environment 45, 5770-5777. 2011

VASCONCELLOS, P. C. et al. Measurements of polycyclic aromatic hydrocarbons in airborne particles from the metropolitan area of São Paulo City, Brazil. Atmospheric Environment 37, 3009-3018. 2003

VASCONCELLOS, P. C. et al. Determination of anthropogenic and biogenic compounds on atmospheric aerosolcollected in urban, biomass burning and 
forest areas in São Paulo, Brazil. Science of the Total Environment 408, 58365844. 2010

VENKATARAMAN, C., FRIEDLANDER, S. Size distributions of polycyclic aromatic hydrocarbons and elemental carbon. 2. Ambient measurement and effects of atmospheric processes. Environmental Science Technology 28, 563572. 1994

VENKATESAN, M. I. Occurrence and PossibleSources of Perylene in Marine Sediments - a Review. Marine Chemistry, 25, 1-27. 1988

VENKATESAN, M. I. et al. Hydrocarbons in age-dated sediments cores from two basins in the Southern California Bight. Geochimica et Cosmochimioca Acta,. 44 (6), 789-802. 1980

VENKATESAN, M. I.; KAPLAN, I. R. Distribution and transport of Hydrocarbons in surface sediments of the Alaskan outer continental shelf. Geochimica et Cosmochimica Acta, v. 46, p. 2135-2149. 1982

VILLAC, M.C., MAYR, L., TENENBAUM, D.R., PARANHOS, R. Sampling strategies proposed to monitor Guanabara Bay, RJ, Brazil. 7th International Symposium on Coastal and Ocean Manage-ment-Coastal Zone 91. 1991

VOLKMAN, J. K.; HOLDSWORTHA, D. G.; NEILLA, G. P.; BAVOR, H. J. Identification of natural, anthropogenic and petroleum hydrocarbons in aquatic sediments. The Science of the Total Environment, v. 112, p. 203-219. 1992

WAGENER, A. DE L.R. Estado atual de conhecimento de algumas característicasquímicas de águas costeiras e estuarinas da região Sul-Sudeste do Brasil, in:Anais do II Simpósio de Ecossistemas da Costa Sul-Sudeste Brasileira, vol I.Academia de Ciências do Estado de São Paulo, São Paulo, pp. 28-39. 1990

WAGENER, A. DE L. R. et al. Evaluation of Tools to Identify Hydrocarbon Sources in Recent and Historical Sediments of a Tropical Bay. Marine Chemistry. 21, 67-79. 2010

WAGENER, A. L. et al. Hydrocarbon composition and distribution in a coastal region under influence of oil production in northeast Brazil. Marine Pollution Bulletin 62 (2011) 1877-1882. 2011 
WAGENER, A. L.R. et al. Hydrocarbons in sediments of a chronically contaminated bay: The challenge of source assignment. Marine Pollution Bulletin, 64. 284-294. 2012

WAKEHAM S. G. Synchronous Fluorescence Spectroscopy and Its Application to Indigenous and Petroleum-Derived Hydrocarbons in Lacustrine Sediments. Environmental Science \& Technology,11, 272-276. 1977

WAKEHAM, S. G.; SCHAFENER, C.; GIGER, W. Polycyclic aromatic hydrocarbons in Recent lake sediments - II. Compounds derived from biogenic precursors during early diagenesis. Geochimica et Cosmochimica Acta, v. 44, p.415-429. 1980a

WAKEHAM, S. G.; SCHAFENER, C.; GIGER, W. Diagenetic polycyclic aromatic hydrocarbons in Recent sediments: Structural information obtained by high performance liquid chromatography. Physics and Chemistry of The Earth, v. 12, p.353-363. $1980 b$

WAKEHAM, S. G.; SCHFENER, C.; GIGER, W. Diagenetic polycyclic aromatic hydrocarbons in Recent sediments: Structural information obtained by high performance liquid chromatography. Physics and Chemistry of The Earth, 12, 353-363. 1980c

WAKEHAM, S. G.; SHAFFNER, C.; GIGER, W. Perylene in sediments from the Nambian Shelf. Geochimica et Cosmochimica Acta, v. 43, p.1141-1144. 1979

WANG, C. et al. Fingerprint and weathering characteristics of crude oils after Dalian oil spill, China. Marine Pollution Bulletin. Artigo no Prelo. 2013

WANG, L. et al. Characterization, ecological risk assessment and source diagnostics of polycyclic aromatic hydrocarbons in water column of the Yellow River Delta, one of the most plenty biodiversity zones in the world. Journal of Hazardous Materials, 169, 460-465. 2009

WANG, Y. et al. PAHs distribution in precipitation at Mount Taishan China. Identification of sources and meteorological influences. Atmospheric Research 95. $1-7.2010$

WANG, Z.; FINGAS, M.; PAGE, D. S. Oil spill identification. Journal of Chromatography A, v. 843, n. 1-2, p. 369-411. 1999a 
WANG, Z. et al. Quantitative Characterization of PAHs in Burn Residue and Soot Samples and Differentation of Pyrogenic PAHs from Petrogenic PAHs - The 1994 Mobile Burn Study. Environ. Sci. Technol 33 (18), pp 3100-3109. 1999b

WANG, Z.; FINGAS, M.; SIGOUIN, L. Characterization and identification of a "mystery" oil spill from Quebec (1999). Journal of Chromatography A, 909 (2), 155-169. 2001

WANG, Z.D., FINGAS, M. Development of oil hydrocarbon fingerprinting and identification techniques. Marine Pollution Bulletin 47. 423-452. 2003

WANG, Z.D. et al. Using systematic and comparative analytical data to identify the source of an unknown oil on contaminated birds. J. Chromatogr. A 775, 251-265. 1997

WESTERHOLM, R.; CHRISTENSEN, A.; ROSÉN, A. Regulated and unregulated exhaust emissions from two three-way catalyst equipped gasoline fuelled vehicles. Atmospheric Environment, 30. 3529-3536. 1996

WESTERHOLM, R.; STENBERG, U.; ALSBERG, T. Some aspects o the distribution of polycyclic aromatic hydrocarbons (PAH) between particles and gas phase from diluted gasoline exhausts generated with the use o dilution tunnel, and its validity rom measurement in ambient air. Atmospheric Environment, 22. 1005-1010. 1998

WHITE, H. K. et al. Unresolved Complex Mixture (UCM) in Coastal Environments Is Derived from Fossil Sources. Environ. Sci. Technol. 47, 726 - 731. 2013

WILKEN, R. D.; MOREIRA, I.; REBELLO. 210Pb and 137Cs fluxes in a sediment core from Guanabara Bay, Brazil. The Ecience of the Total Environment, 58. 195-198. 1986

WISE, S. A. et al. Determination of Polycyclic Aromatic Hydrocarbons in a Coal Tar Standard Reference Material. Anal. Chem. 60, 887-894. 1988

WISE, S.A. et al. Characterization of the polycyclic aromatic hydrocarbons from two standard reference material air particulate samples. Anal. Chem. 58, 30673077. 1986 
WU, S-P. et al. Characterization of TSP-boundn-alkanes and polycyclic aromatic hydrocarbons at rural and urban sites of Tianjin, China. Environmental Pollution, 147. 203-210. 2007

XIE, M. et al. Aliphatic alkanes and polycyclic aromatic hydrocarbons in atmospheric PM10 aerosols from Baoji, China: Implications for coal burning. Atmospheric Research 93. 840-848. 2009

YAO, Y-C. et al. Emissions of gaseous pollutant from motorcycle powered by ethanol-gasoline blend. Applied Energy, 102. 93-100. 2013

YASSA, N. et al. Particulaten-alkanes,n-alkanoic acids and polycyclic aromatic hydrocarbons in the atmosphere of Algiers City Area. Atmospheric Environment, 35. 1843-1851. 2001

YOUNGBLOOD W. W.; BLUMER, M. Polycyclic aromatic hydrocarbons in the environment: homologous series in soilsand recent marine sediments. Geochimica et Cosmochimica Acta, 39, 1303-1314.. 1975

YUNKER, M. B. et al. Assessment of Natural and Anthropogenic Hydrocarbon Inputs Using PAHs as Tracers. The Fraser River Basin and Strait of Georgia 1987-1997. Report DOE FRAP, Vancouver; BC: Environment Canada and Fisheries and Oceans Canada. p. 128. 2000

YUNKER, M. B. et al. Alkane and PAH biomarkers as tracers of terrigenous organic carbon in Arctic Ocean sediments. Organic Geochemistry, 42. 11091146. 2001

YUNKER, M. B. et al. Fraser River basin: a critical appraisal of PAH ratios as indicators of PAH source and composition. Organic Geochemistry, 33, 489515. 2002

YUNKER, M.B. et al. Polycyclic aromatic hydrocarbon composition and potential sources for sediment samples from the Beaufort and Barents Seas. Environmental Science \& Technology. 30, 1310-1320. 1996

ZANARDI, E. et al. Distribution and Origin of Hydrocarbons in Water and Sediment in Sao Sebastiao, SP, Brazil. Marine Pollution Bulletin. 38 (4), 261267. 1999 
ZERI, M.; OLIVEIRA-JUNIOR, J. F.; LYRA, G. B. Spatiotemporal analysis of particulate matter, sulfur dioxide and carbon monoxide concentrations over the city of Rio de Janeiro, Brazil. Meteorol Atmos Phys, 113:139-152. 2011

ZHANG, Y. et al. Potential source contributions and risk assessment of PAHs in sediments from Taihu Lake, China: Comparison of three receptor models. Water Resesearch, 46, 3065-3073. 2012

ZHOU, J. et al. Size distribution of polycyclic aromatic hydrocarbons in urban and suburban sites of Beijing, China. Chemosphere 61, 792-799. 2005 
Anexos

Gráficos de intensidade e direção do vento 

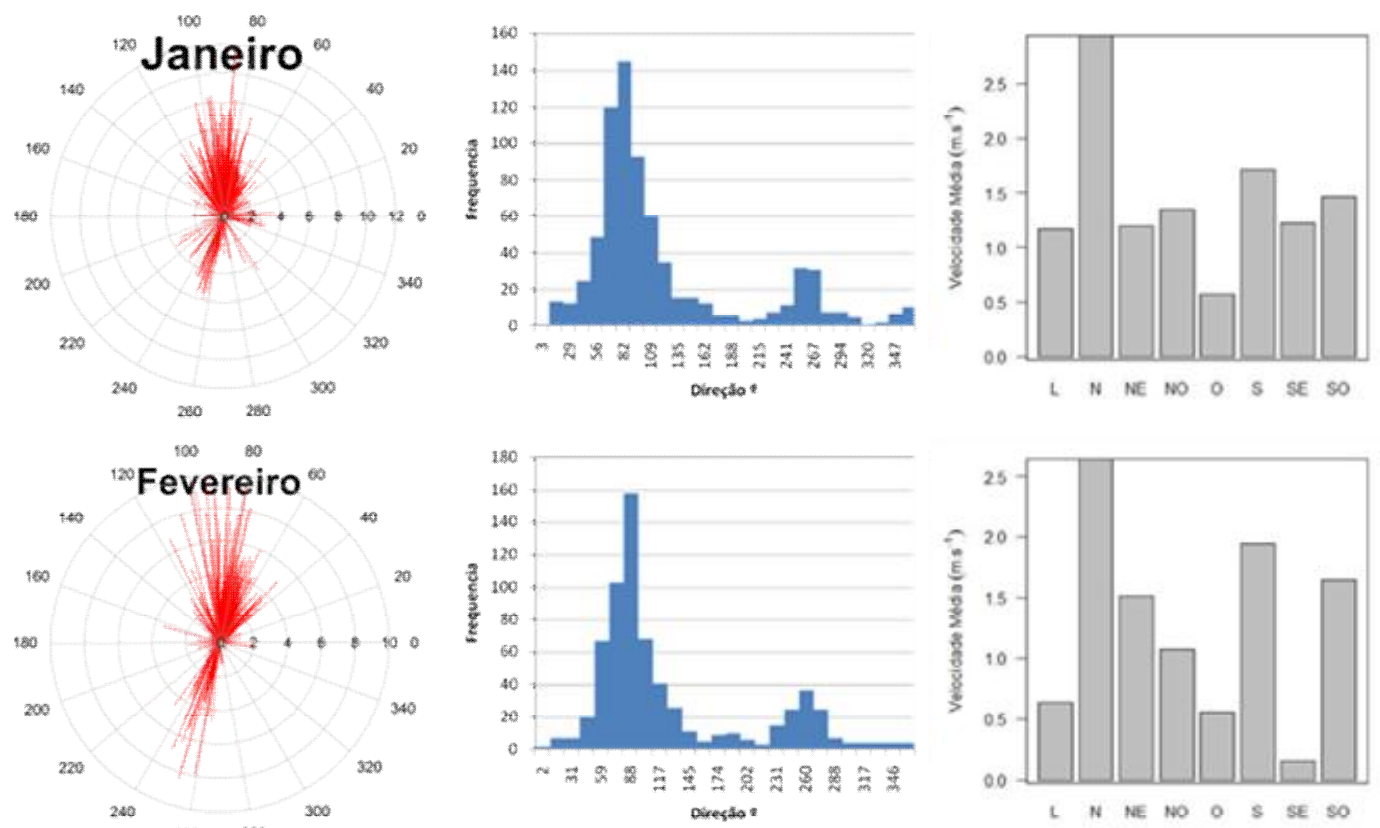

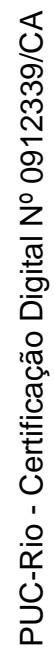
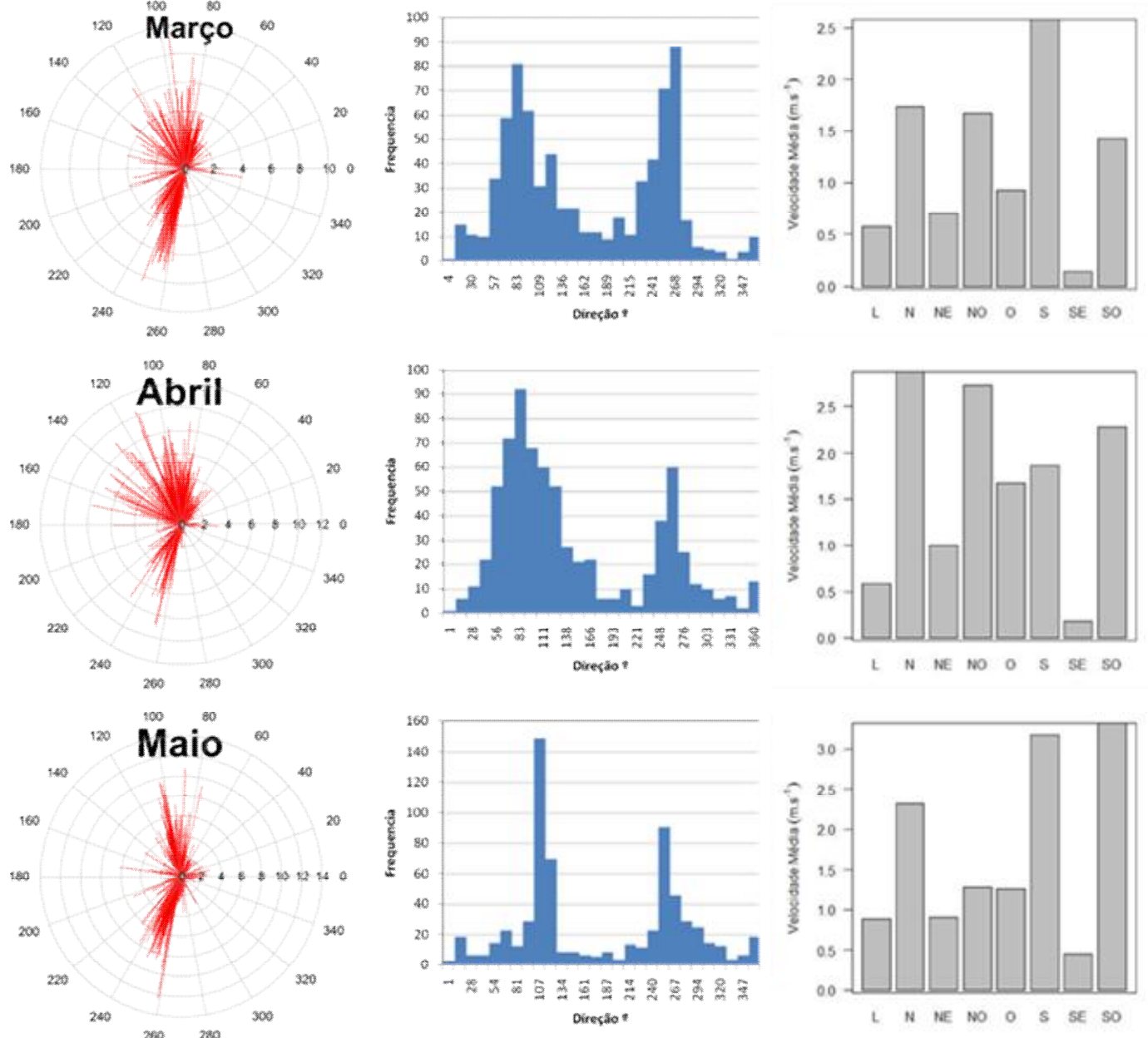

Dados de direção e intensidade $\left(\mathrm{m} \mathrm{s}^{-1}\right)$ dos ventos para a estação do INMET de Copacabana 

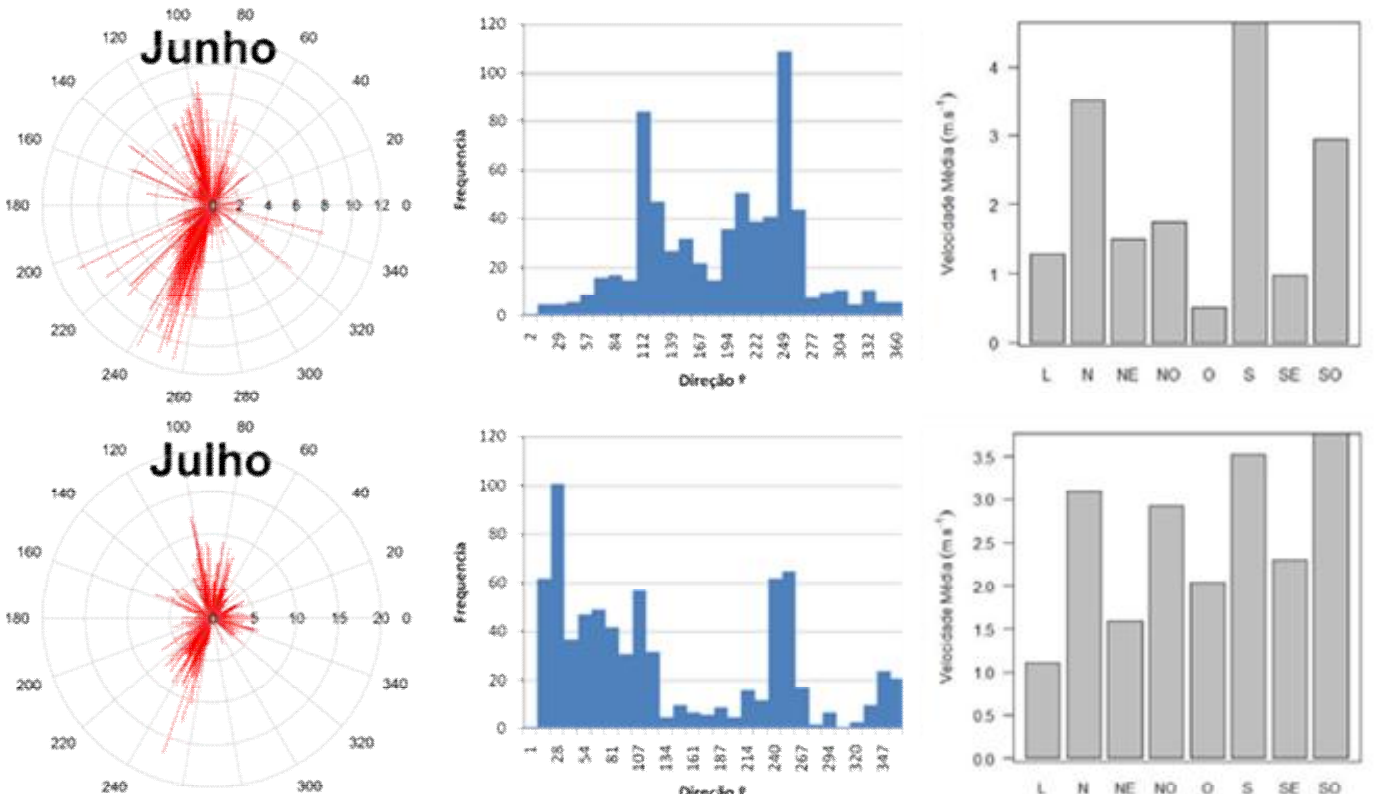

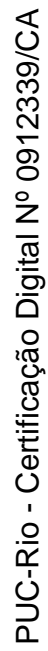
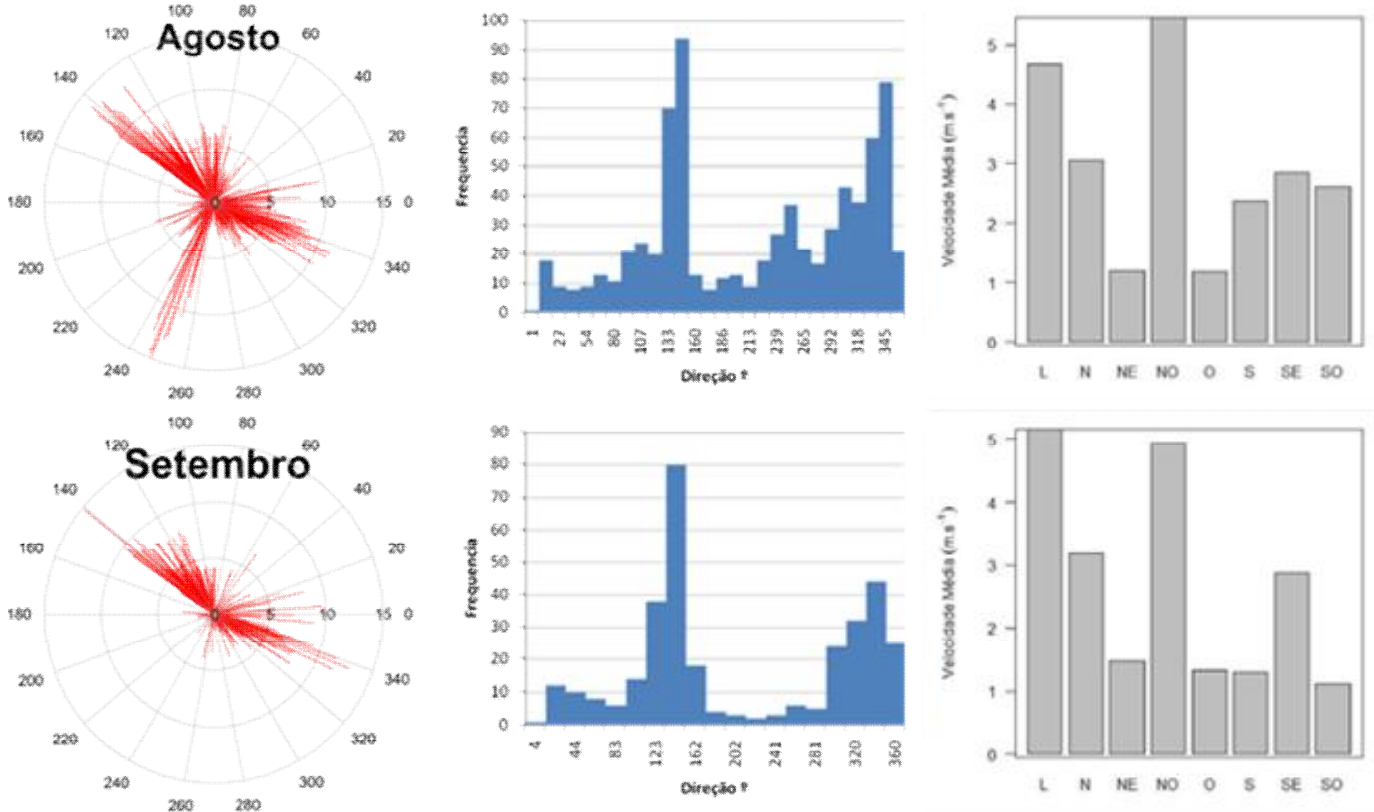

Dados de direção e intensidade $\left(\mathrm{m} \mathrm{s}^{-1}\right)$ dos ventos para a estação do INMET de Copacabana 

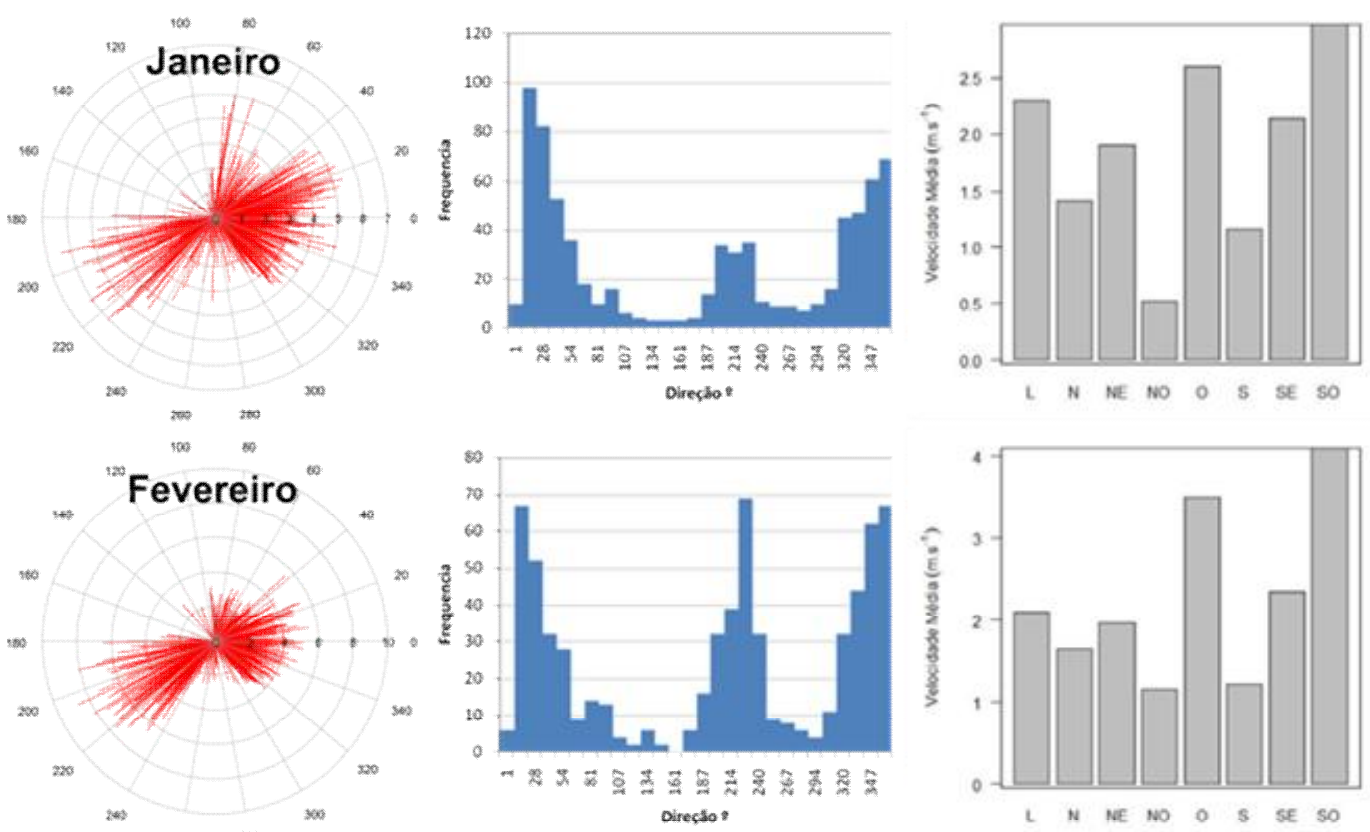

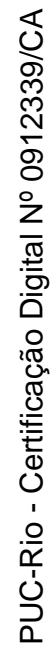
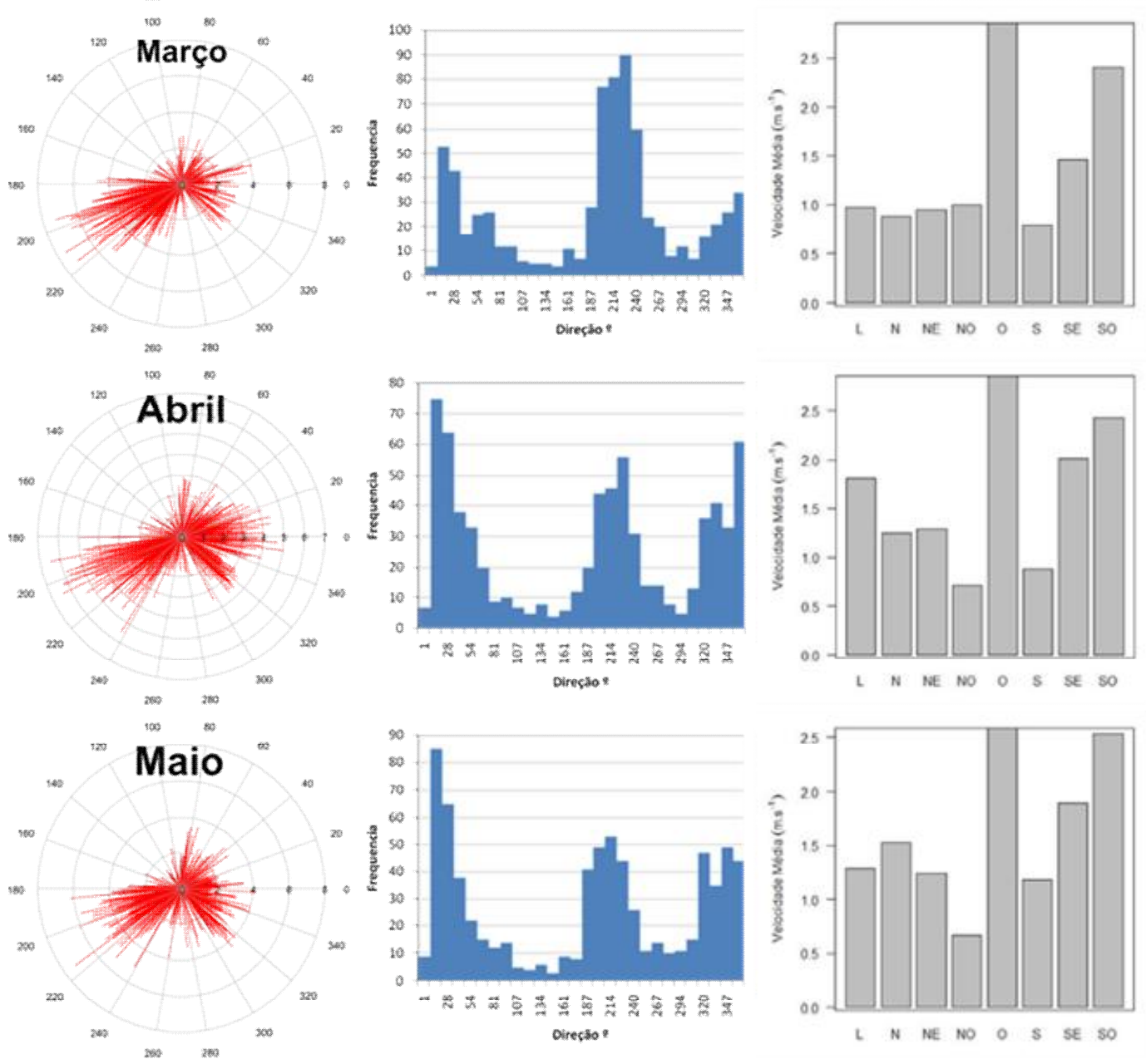

Dados de direção e intensidade $\left(\mathrm{m} \mathrm{s}^{-1}\right)$ dos ventos para a estação do INMET de Seropédica. 

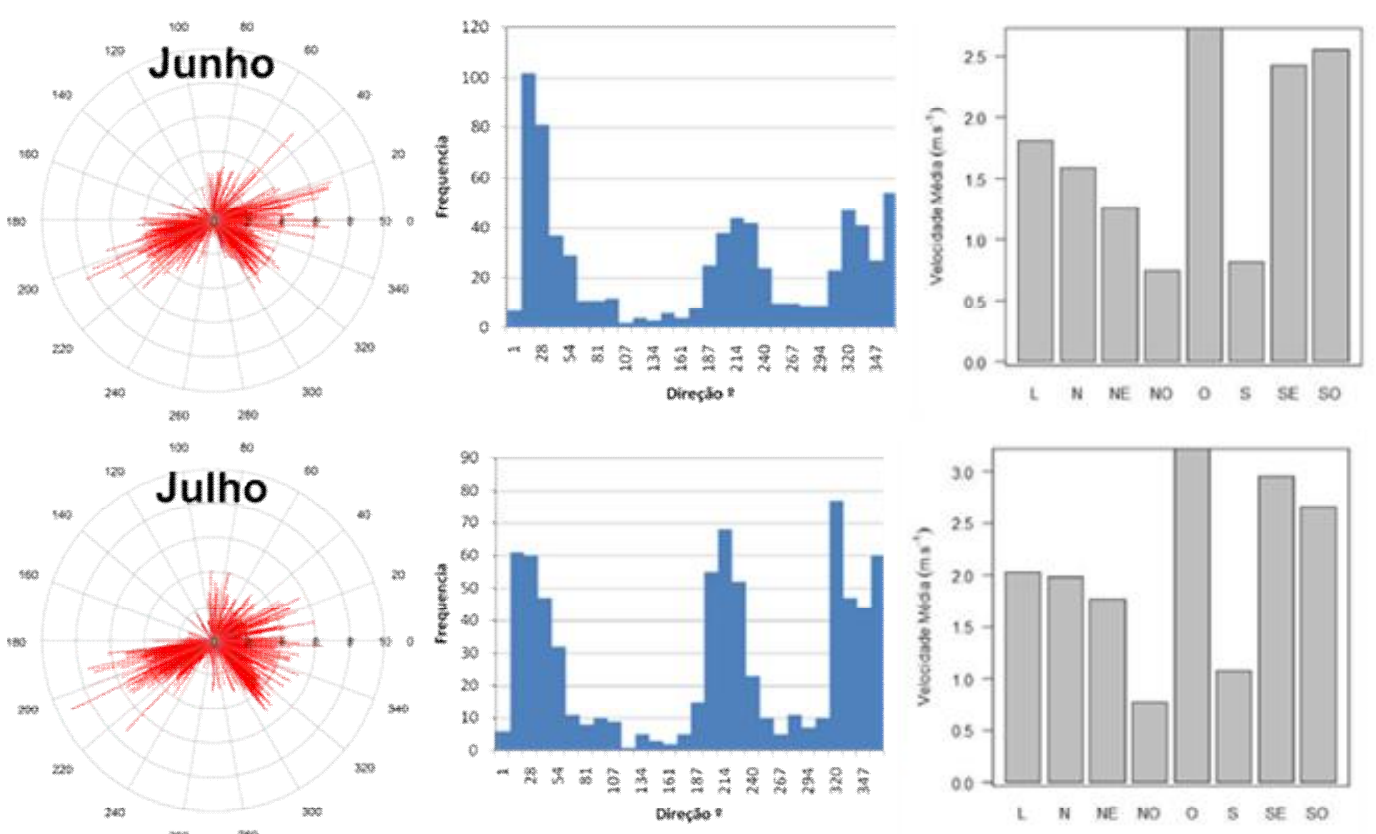

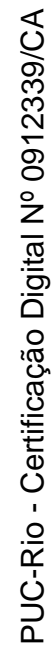
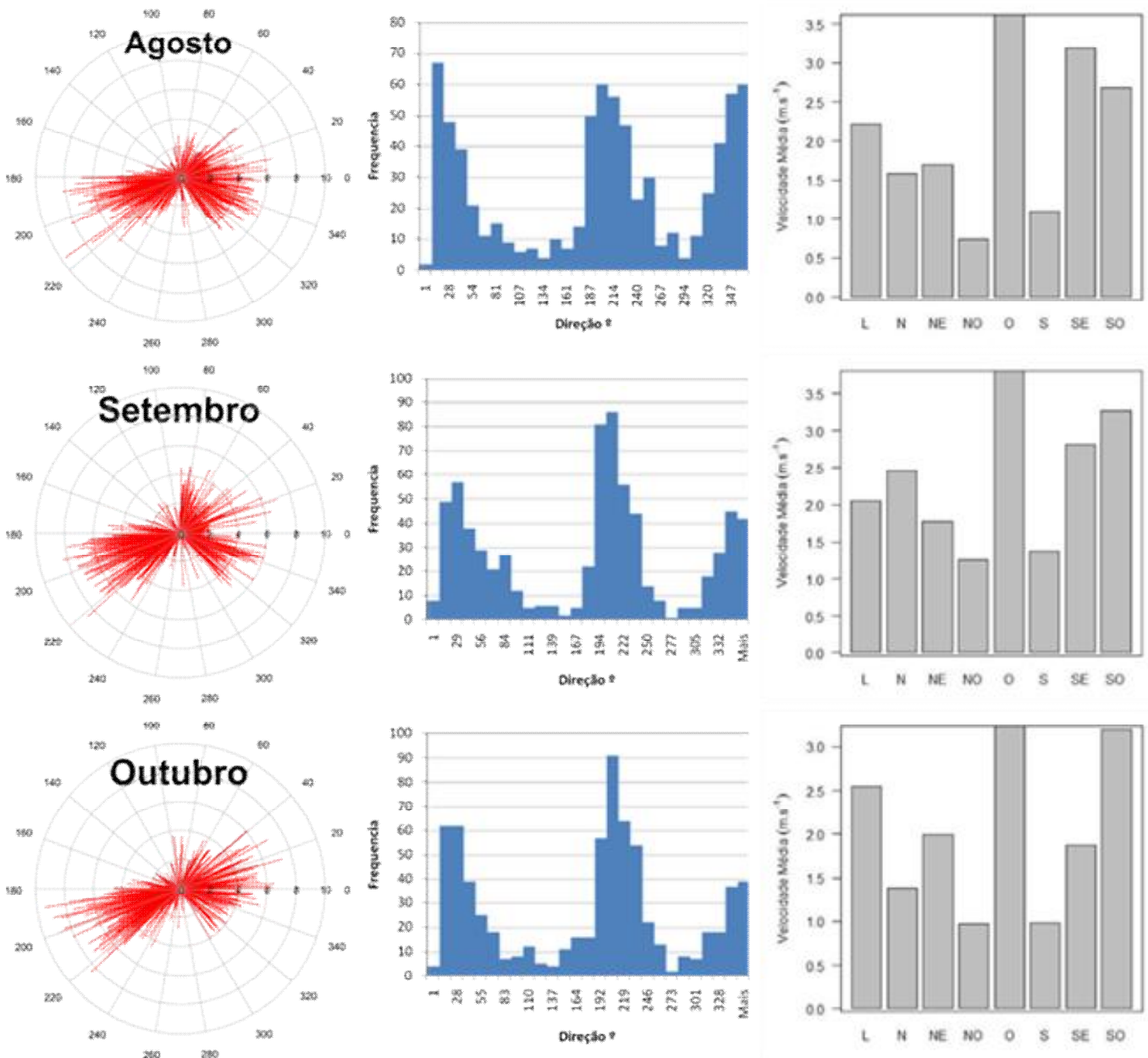

Dados de direção e intensidade $\left(\mathrm{m} \mathrm{s}^{-1}\right)$ dos ventos para a estação do INMET de Seropédica. 

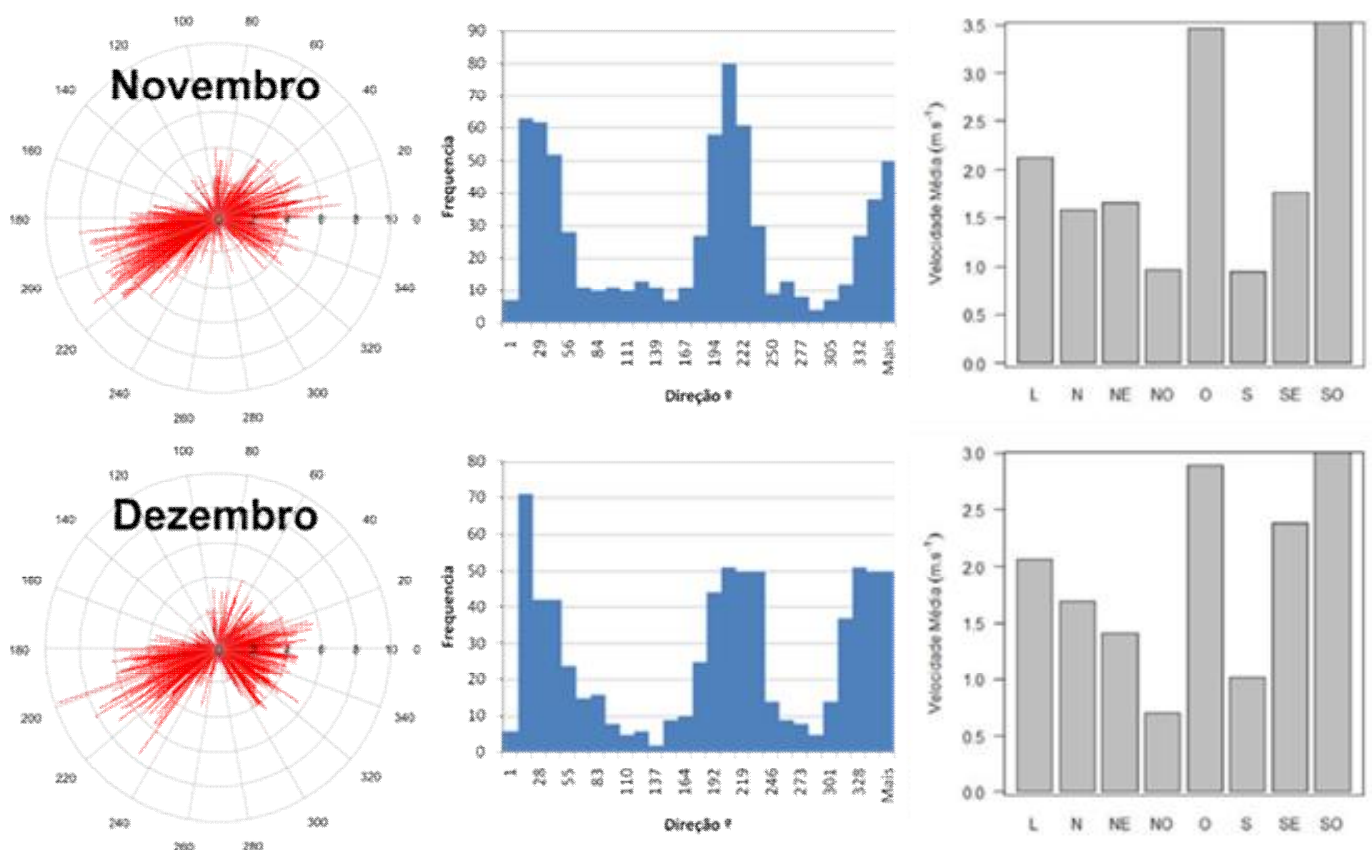

Dados de direção e intensidade $\left(\mathrm{m} \mathrm{s}^{-1}\right)$ dos ventos para a estação do INMET de Seropédica. 

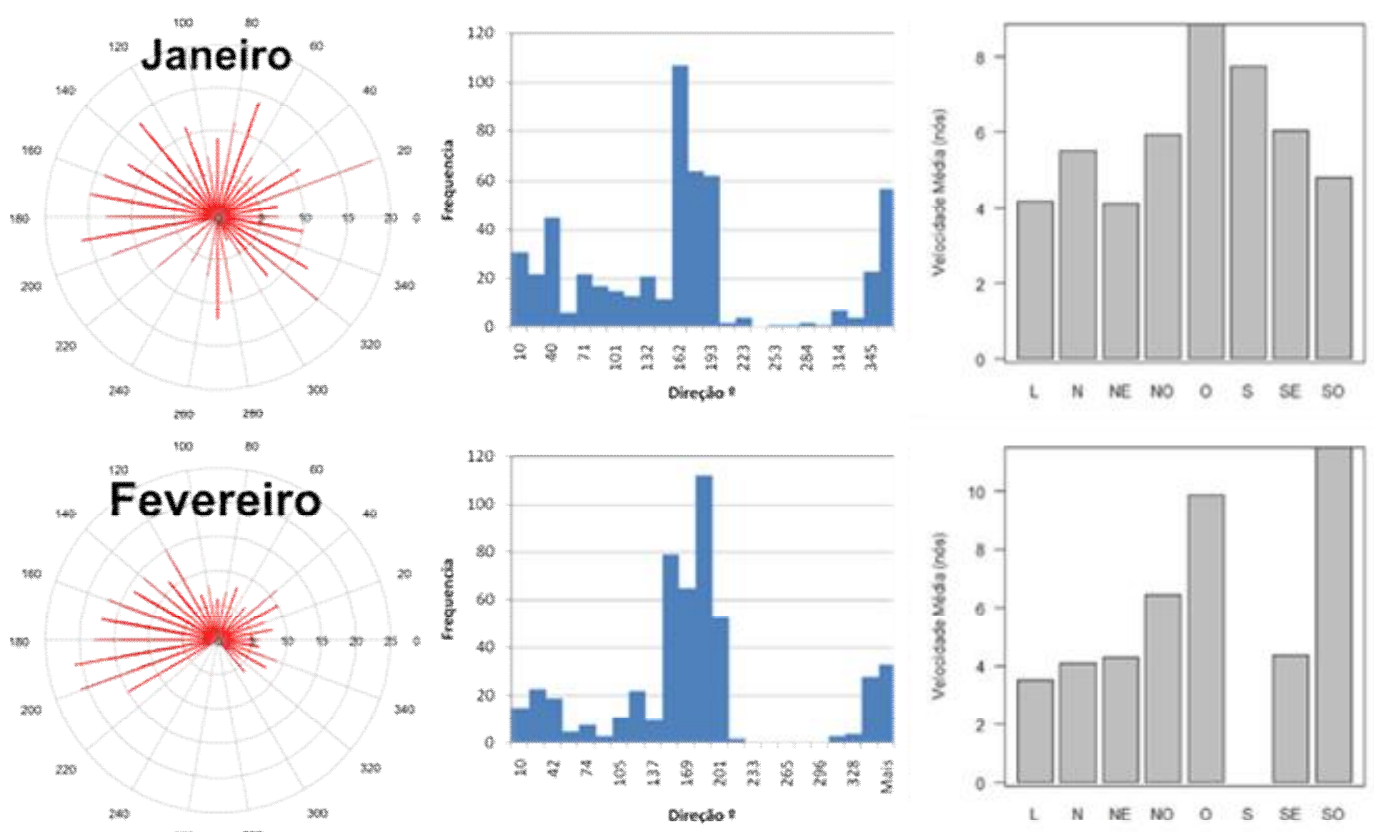

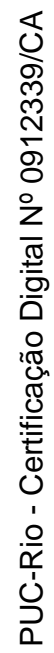
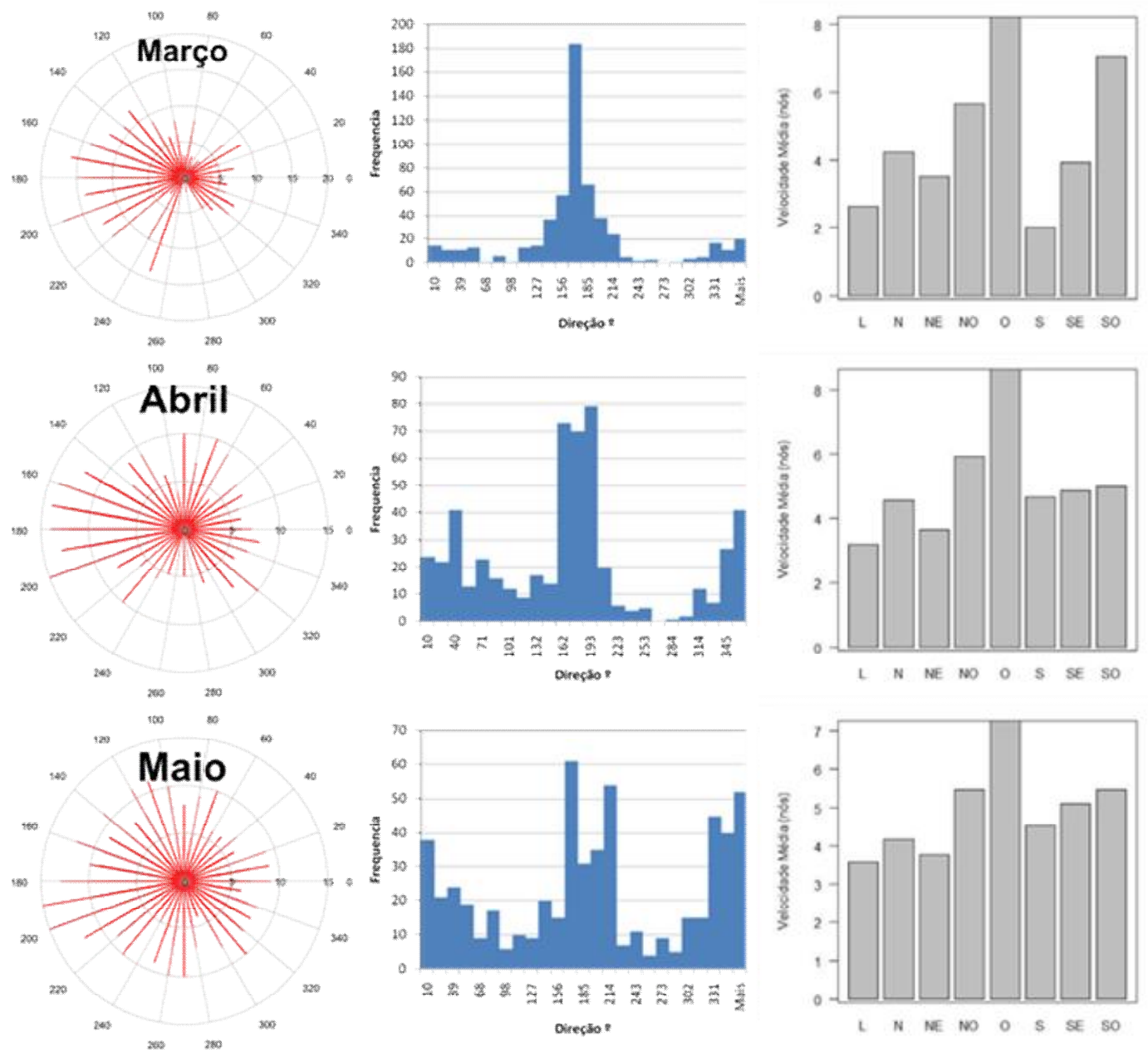

Dados de direção e intensidade (nós) dos ventos para a estação do Aeroporto Santos Dumont. 

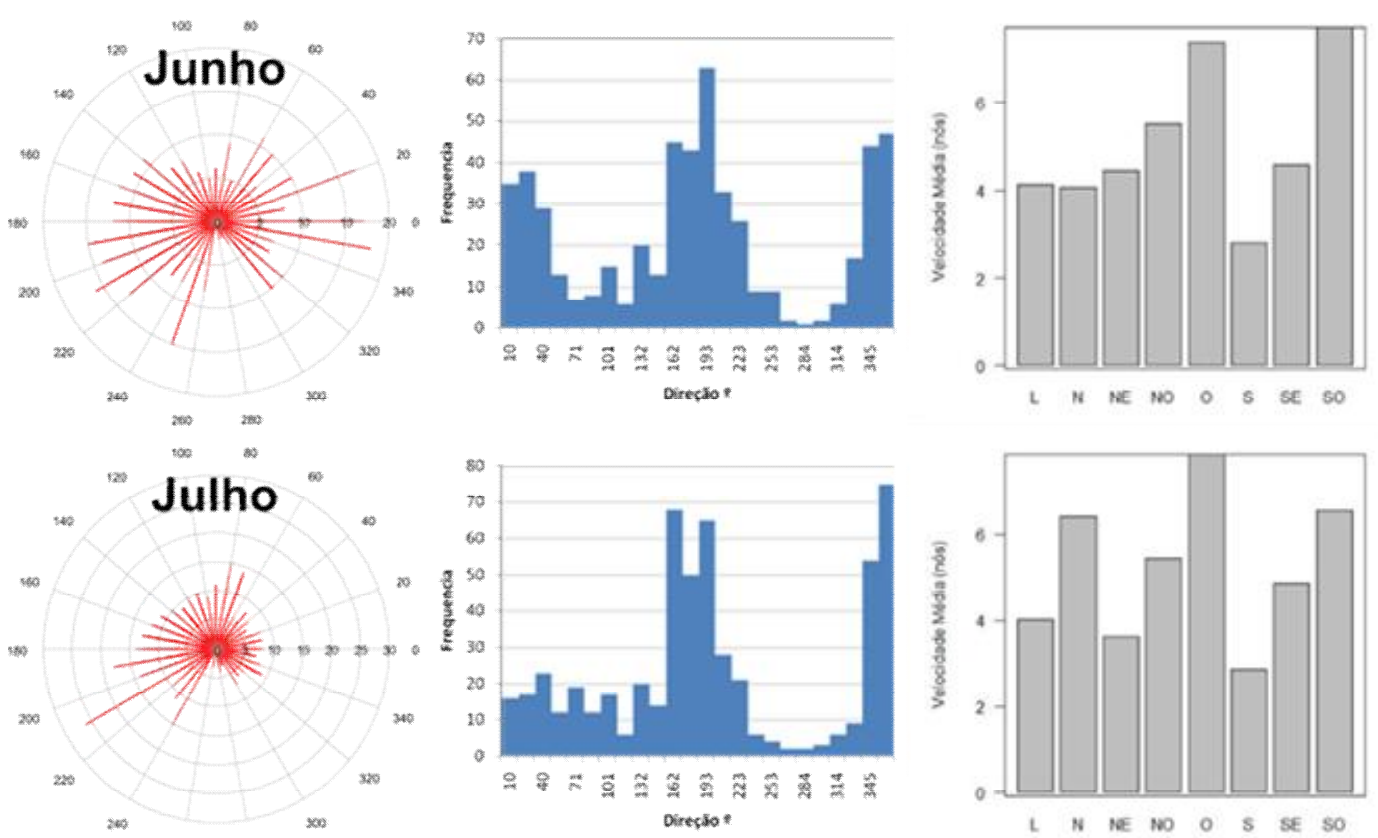

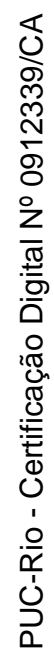
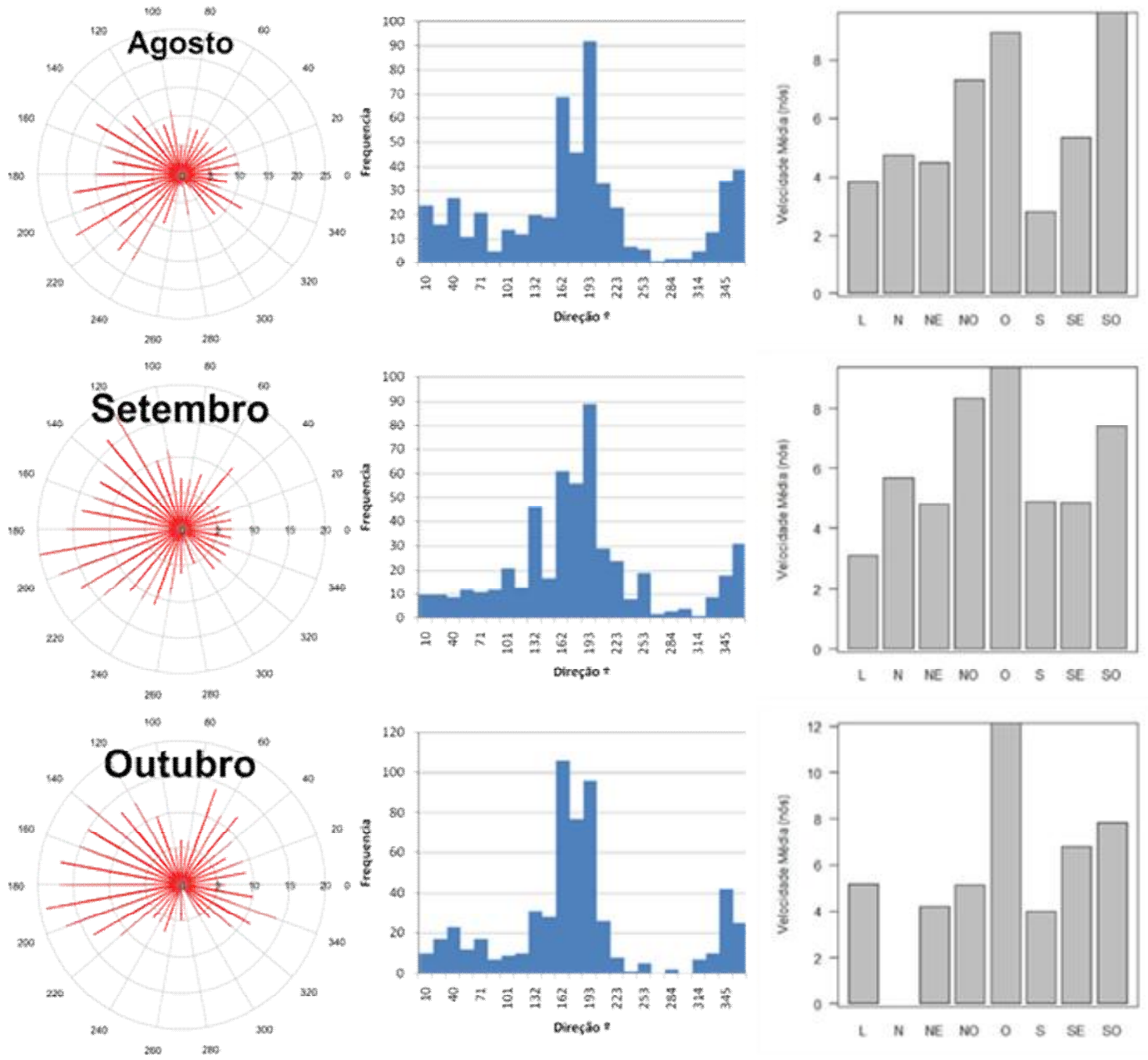

Dados de direção e intensidade (nós) dos ventos para a estação do Aeroporto Santos Dumont. 

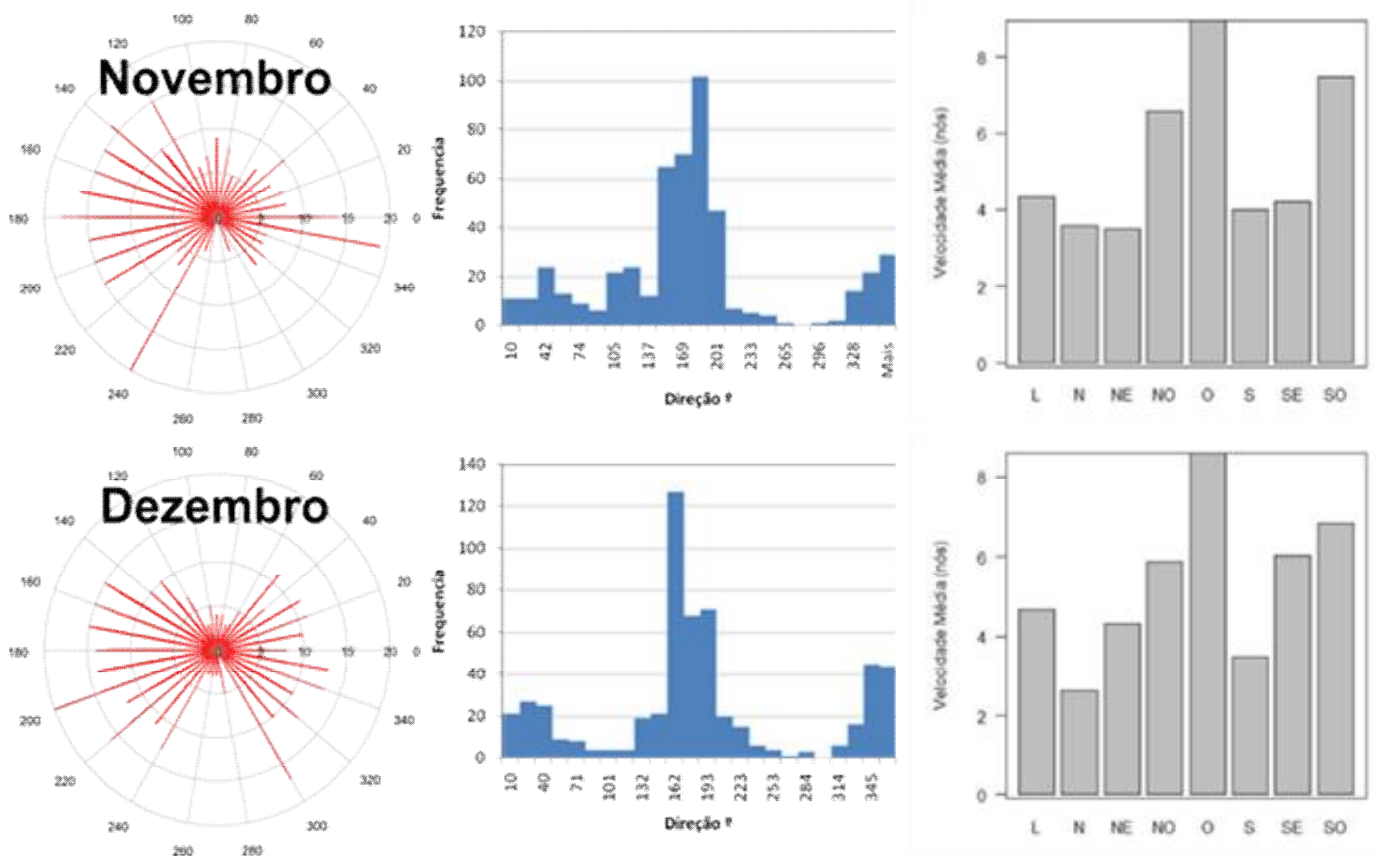

Dados de direção e intensidade (nós) dos ventos para a estação do Aeroporto Santos Dumont. 

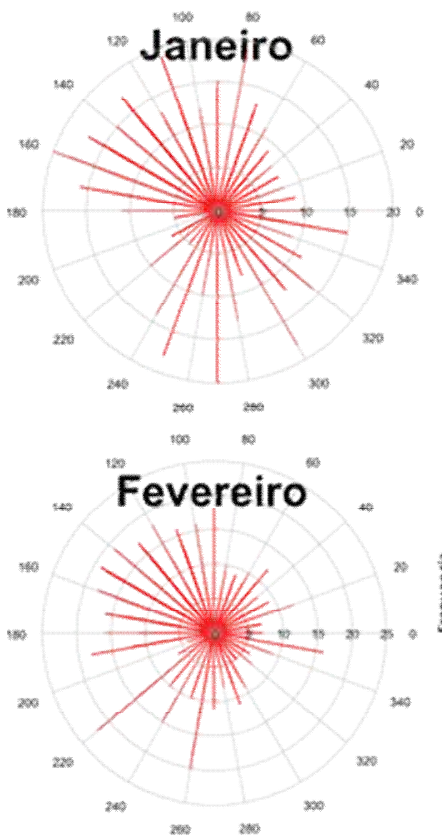

100

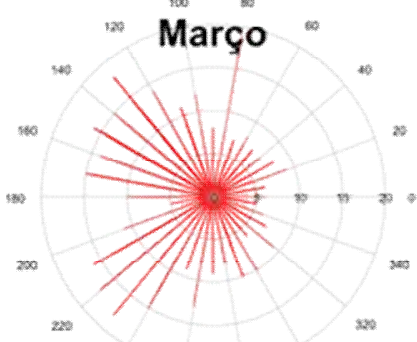

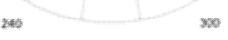

Abril

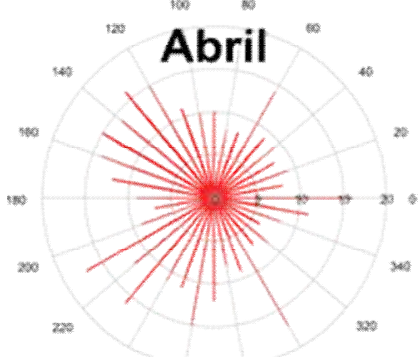

(4)

\section{Maio}
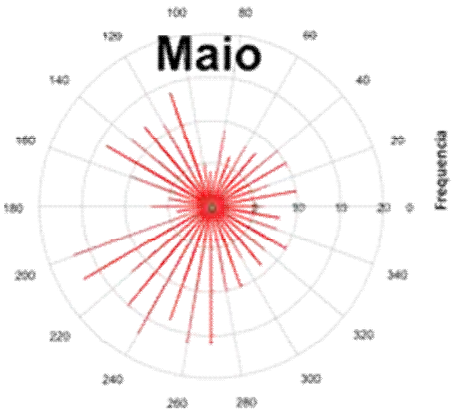
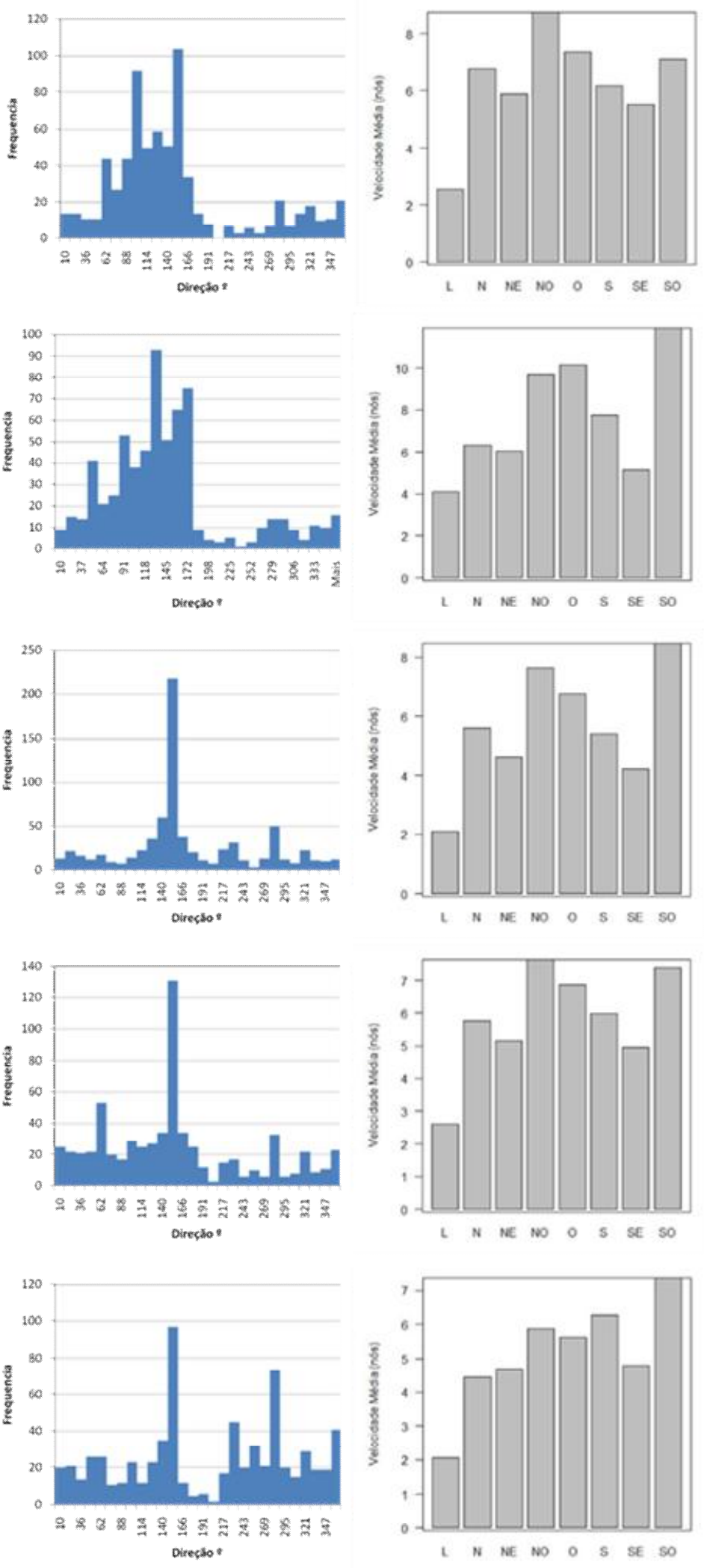

Dados de direção e intensidade (nós) dos ventos para a estação do Aeroporto Internacional Antonio Carlos Jobim (Galeão). 

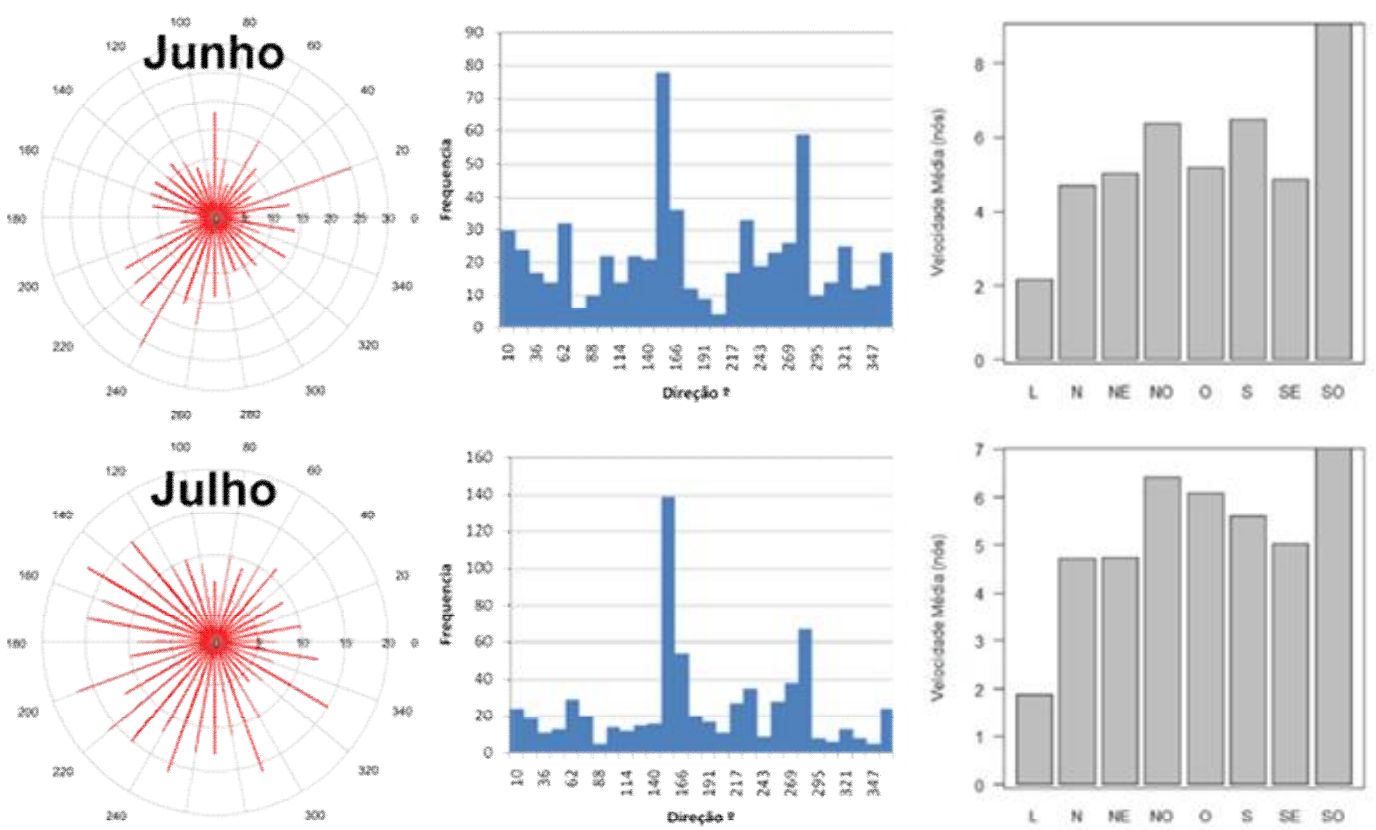

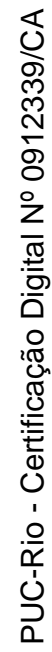
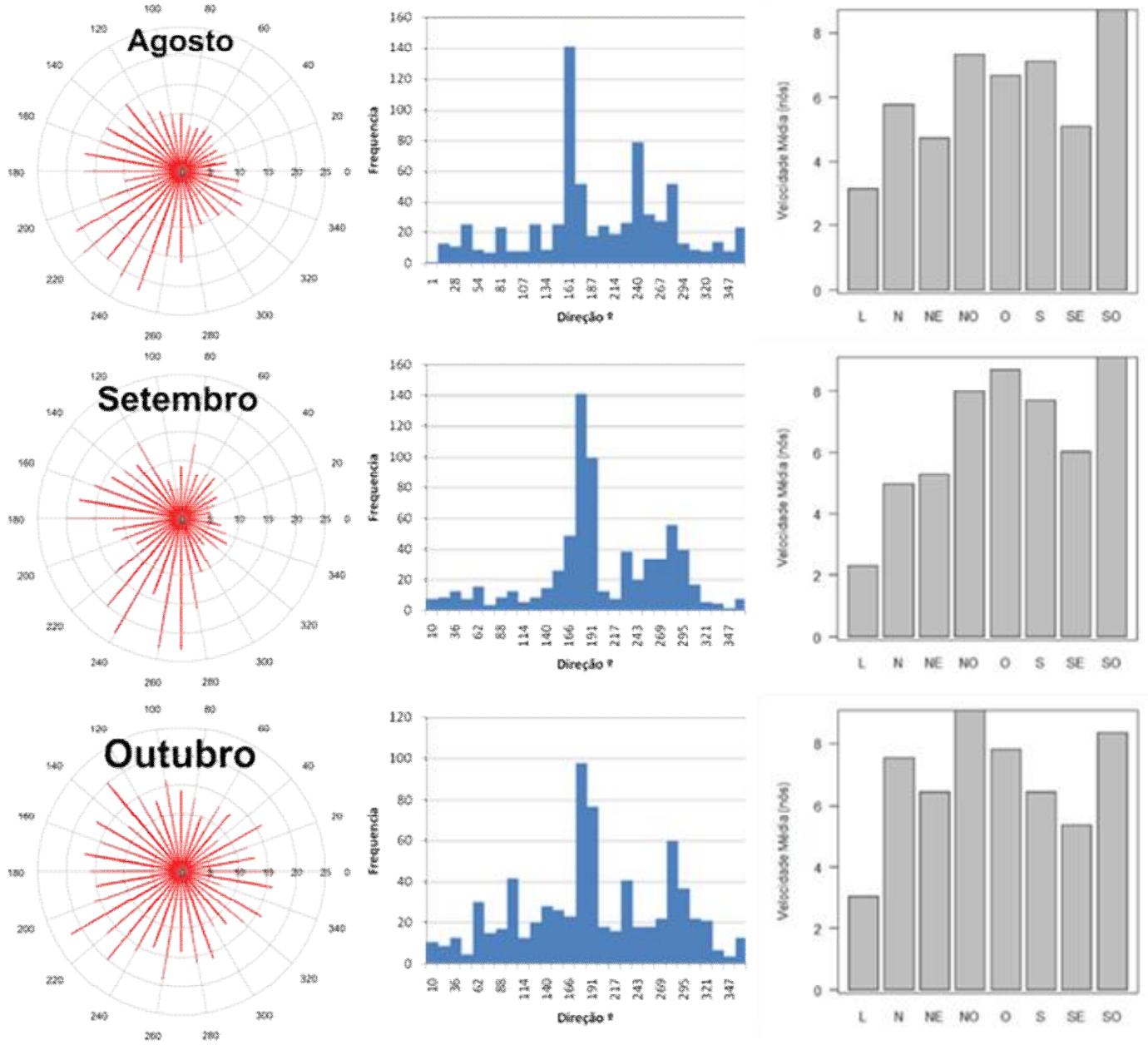

Dados de direção e intensidade (nós) dos ventos para a estação do Aeroporto Internacional Antonio Carlos Jobim (Galeão). 

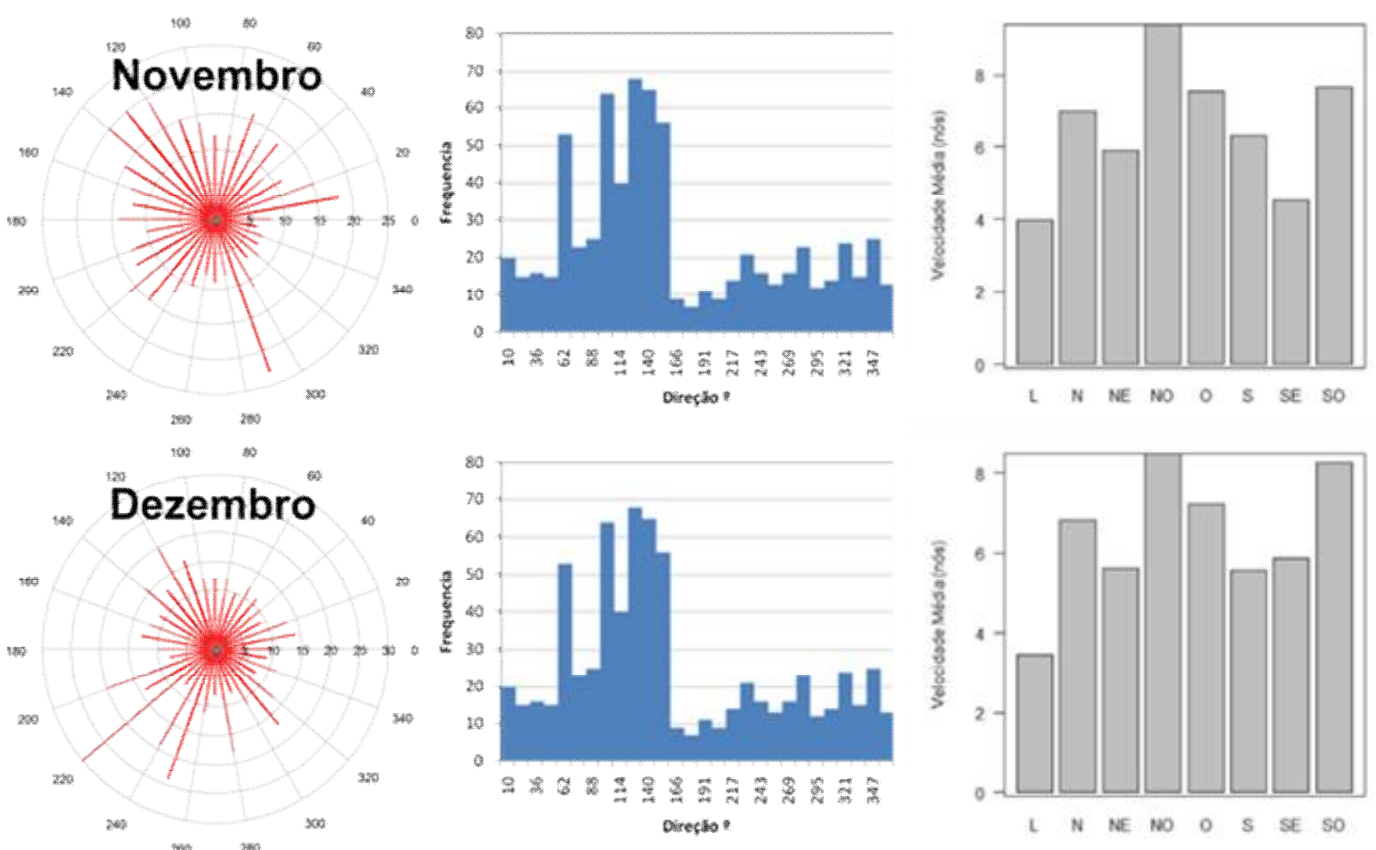

Dados de direção e intensidade (nós) dos ventos para a estação do Aeroporto Internacional Antonio Carlos Jobim (Galeão). 
Dados de precipitação e temperatura das estações do Sistema Alerta Rio e do INMET 


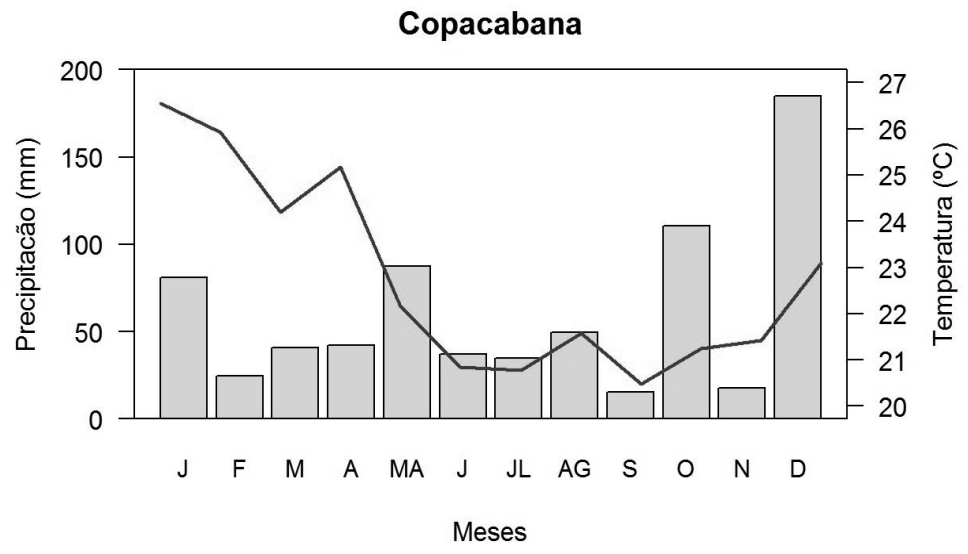

Variação da precipitação acumulada $(\mathrm{mm})$ e da média da temperatura do ar para o ano de 2011 na estação do INMET de Copacabana

São Cristovão

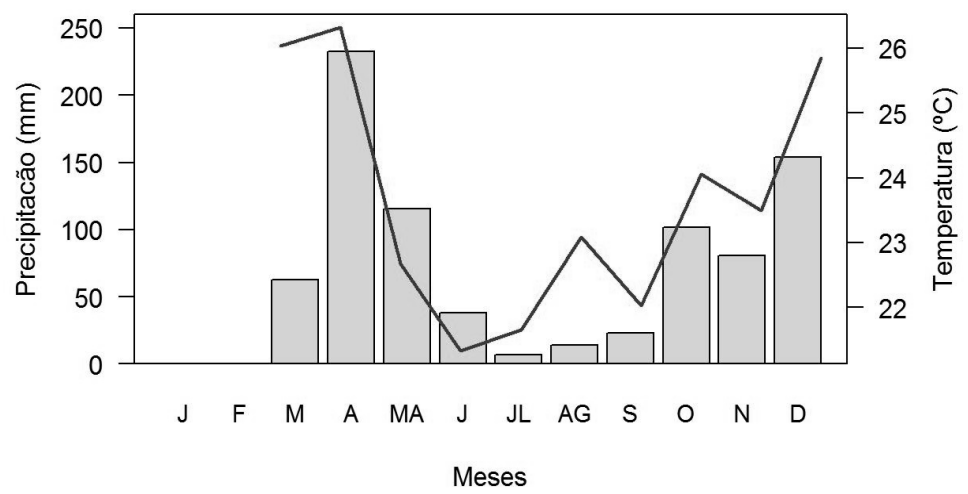

Variação da precipitação acumulada $(\mathrm{mm})$ e da média da temperatura do ar para o ano de 2011 na estação do Sistema Alerta Rio de São Cristovão.

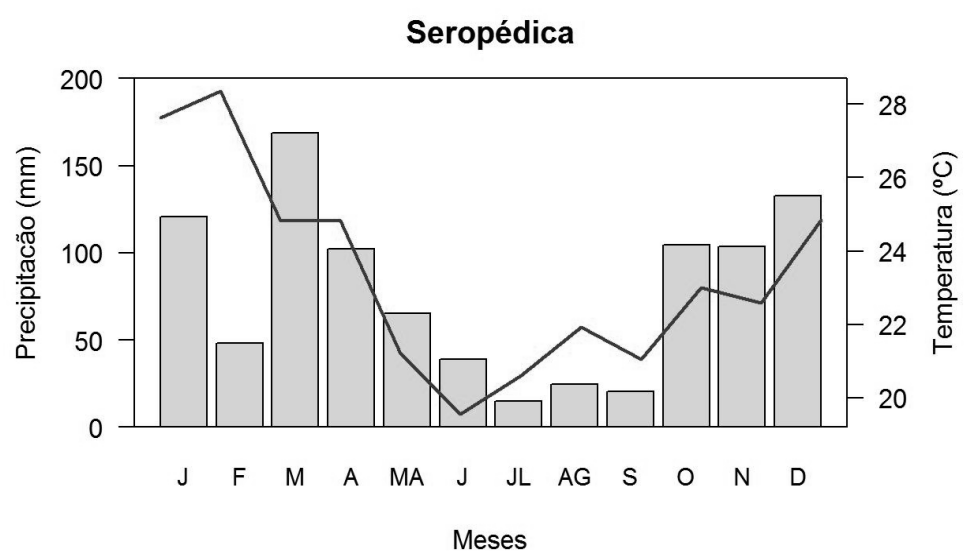

Variação da precipitação acumulada $(\mathrm{mm})$ e da média da temperatura do ar para o ano de 2011 na estação do INMET de Seropédica 


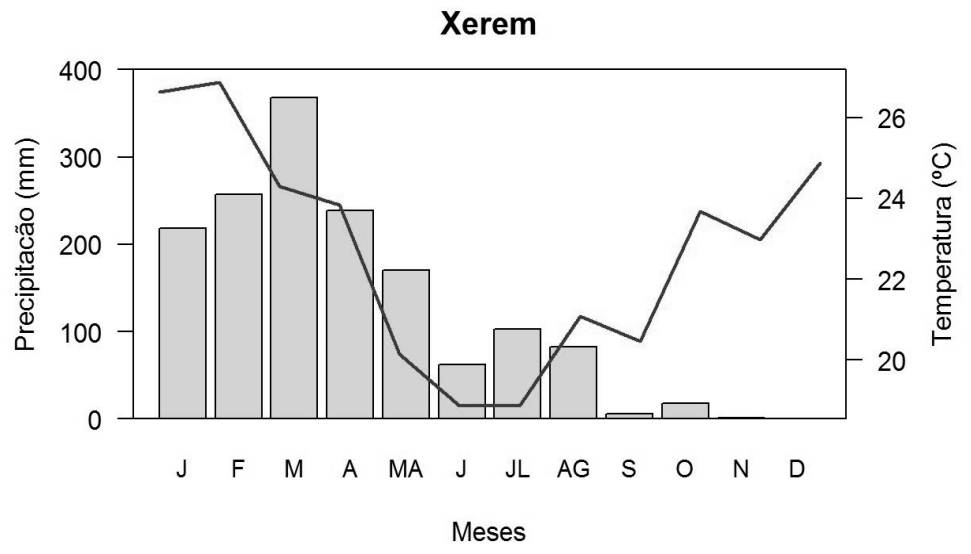

Variação da precipitação acumulada $(\mathrm{mm})$ e da média da temperatura do ar para o ano de 2011 na estação do INMET de Xerém - Dados de dezembro para a estação de Xerém não coletados para chuvas e falhas na amostragem desde agosto acentuando-se para o fim de ano

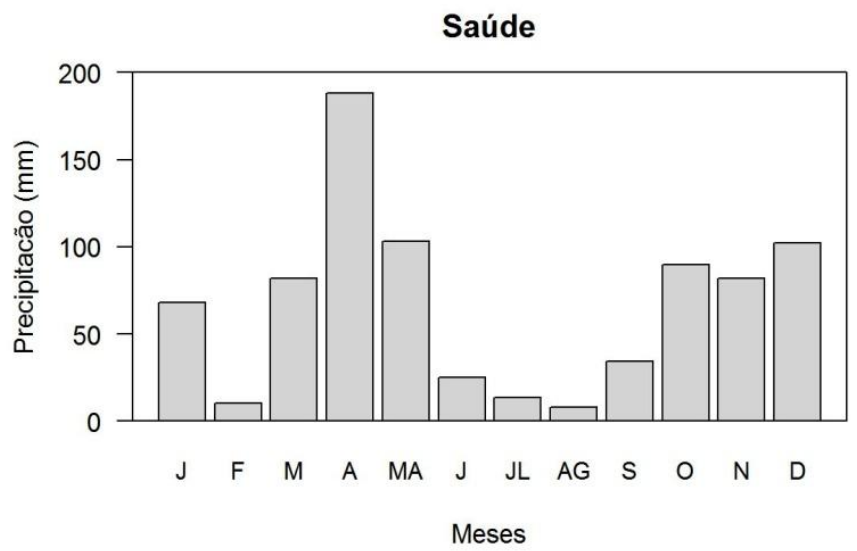

Variação da precipitação acumulada $(\mathrm{mm})$ para o ano de 2011 na estação do Sistema Alerta Rio de Saúde.

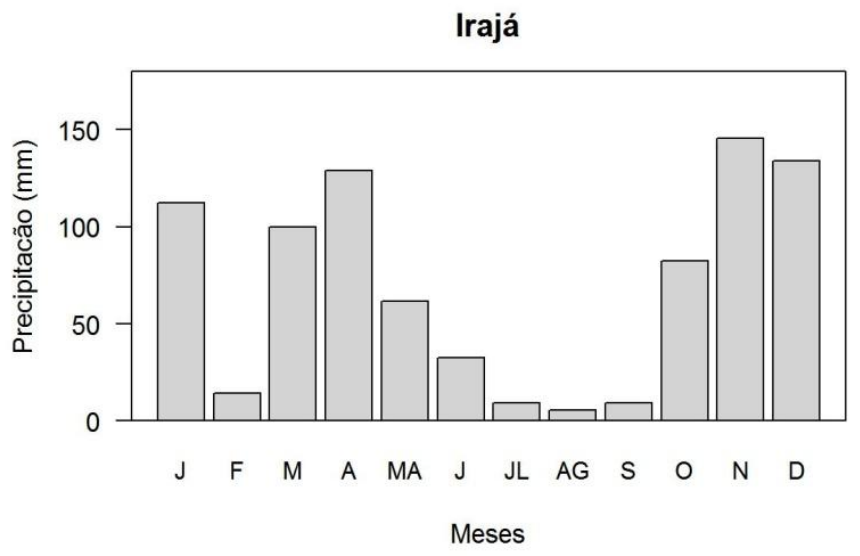

Variação da precipitação acumulada $(\mathrm{mm})$ para o ano de 2011 na estação do Sistema Alerta Rio de Irajá. 


\section{Vila Militar}

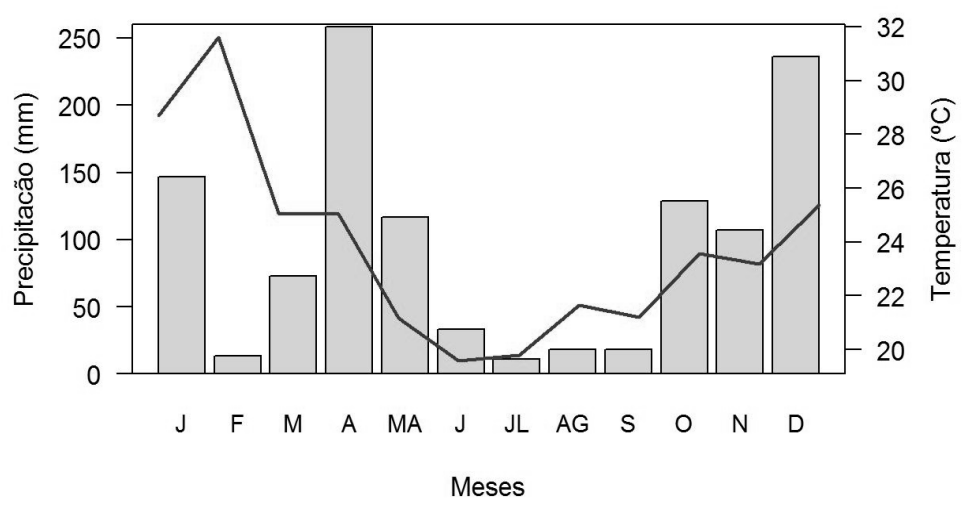

Variação da precipitação acumulada $(\mathrm{mm})$ e da média da temperatura do ar para o ano de 2011 na estação do INMET da Vila Militar. 
8 - Anexos

224

DADOS DE ALIFÁtICOS EM AMOSTRAS MATERIAL PARTICULADO ATMOSFÉRICO

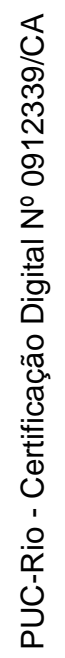


Resultado de hidrocarbonetos alifáticos, em $\mathrm{ng} \mathrm{m}^{-3}$, para as amostras de material particulado atmosférico ( $\left(\mathrm{PM}_{2,5}\right)$ coletadas no ano de 2011

\begin{tabular}{|c|c|c|c|c|c|c|c|c|c|}
\hline Código & C8 & C14 & C26 & C32 & C44 & C50 & C56 & $\mathrm{C} 92$ & C98 \\
\hline Data & 8-jan & 14-jan & 26-jan & 1-fev & 13-fev & 19-fev & 25-fev & 2-abr & 8-abr \\
\hline C12 & nd & nd & nd & nd & nd & nd & nd & nd & nd \\
\hline C13 & nd & nd & nd & nd & nd & nd & nd & nd & nd \\
\hline C14 & nd & nd & nd & nd & nd & nd & nd & nd & nd \\
\hline C15 & nd & nd & nd & nd & nd & nd & nd & 0,20 & 0,24 \\
\hline C16 & nd & 0,24 & nd & nd & nd & 0,26 & nd & nd & 0,23 \\
\hline C17 & nd & 0,29 & nd & 0,27 & 0,24 & 0,31 & nd & 0,38 & 0,32 \\
\hline Pristano & nd & 0,21 & nd & 0,31 & 0,25 & 0,28 & nd & 0,49 & 0,63 \\
\hline C18 & nd & 0,61 & nd & 0,48 & 0,37 & 0,47 & 0,51 & 0,66 & 0,78 \\
\hline Fitano & nd & 0,35 & nd & 0,22 & 0,23 & 0,27 & nd & 0,40 & 0,45 \\
\hline C19 & 0,19 & 0,76 & 0,31 & 0,60 & 0,39 & 0,43 & 0,60 & 0,67 & 1,09 \\
\hline $\mathrm{C} 20$ & 0,27 & 0,73 & 0,43 & 0,66 & 0,35 & 0,45 & 0,70 & 0,64 & 1,08 \\
\hline $\mathrm{C} 21$ & 0,22 & 0,65 & 0,36 & 0,52 & 0,32 & 0,32 & 0,65 & 0,50 & 0,75 \\
\hline $\mathrm{C} 22$ & 0,31 & 0,77 & 0,41 & 0,55 & 0,35 & 0,35 & 0,80 & 0,61 & 0,94 \\
\hline $\mathrm{C} 23$ & 0,39 & 0,85 & 0,45 & 0,56 & 0,37 & 0,41 & 0,92 & 0,67 & 0,79 \\
\hline $\mathrm{C} 24$ & 0,49 & 0,99 & 0,65 & 0,94 & 0,64 & 0,55 & 1,51 & 0,86 & 1,14 \\
\hline $\mathrm{C} 25$ & 0,61 & 1,18 & 0,75 & 0,94 & 0,88 & 0,99 & 2,13 & 1,06 & 1,24 \\
\hline $\mathrm{C} 26$ & 0,73 & 1,50 & 1,16 & 1,51 & 3,27 & 2,73 & 2,16 & 1,57 & 2,00 \\
\hline $\mathrm{C} 27$ & 0,93 & 1,33 & 1,24 & 2,08 & 8,97 & 5,69 & 2,82 & 1,35 & 1,83 \\
\hline C28 & 0,87 & 0,55 & 1,42 & 2,43 & 12,72 & 6,92 & 2,85 & 1,26 & 1,82 \\
\hline C29 & 1,23 & 0,25 & 1,69 & 3,31 & 19,10 & 10,33 & 3,46 & 1,49 & 2,30 \\
\hline C30 & 0,64 & nd & 1,14 & 2,31 & 13,56 & 7,32 & 2,18 & 0,99 & 1,22 \\
\hline C31 & nd & nd & 0,61 & 2,73 & 13,67 & 6,63 & 1,19 & 0,95 & 0,58 \\
\hline C32 & nd & nd & nd & 0,85 & 5,31 & 2,36 & nd & nd & nd \\
\hline C33 & nd & nd & nd & 1,47 & 6,01 & 2,66 & nd & nd & nd \\
\hline C34 & nd & nd & nd & nd & 1,01 & nd & nd & nd & nd \\
\hline C35 & nd & nd & nd & 0,46 & 0,62 & 0,30 & nd & nd & nd \\
\hline C36 & nd & nd & nd & nd & nd & nd & nd & nd & nd \\
\hline C37 & nd & nd & nd & nd & nd & nd & nd & nd & nd \\
\hline C38 & nd & nd & nd & nd & nd & nd & nd & nd & nd \\
\hline C39 & nd & nd & nd & nd & nd & nd & nd & nd & nd \\
\hline C40 & nd & nd & nd & nd & nd & nd & nd & nd & nd \\
\hline n-alcanos & 6,88 & 10,70 & 10,62 & 22,69 & 88,15 & 49,48 & 22,48 & 13,85 & 18,34 \\
\hline HR & 10,67 & 43,80 & 41,11 & 48,95 & 171,79 & 96,62 & 400,09 & 44,26 & 57,11 \\
\hline $\begin{array}{l}\text { MCNR } \\
\text { Alifáticos }\end{array}$ & 67,5 & 318,2 & 198,0 & 246,9 & 195,3 & 168,6 & 138,5 & 198,2 & 399,4 \\
\hline Totais & 78,2 & 362,0 & 239,1 & 295,8 & 367,1 & 265,2 & 538,6 & 242,5 & 456,5 \\
\hline $\operatorname{Rec}(\%)$ & 64 & 63 & 64 & 57 & 65 & 69 & 101 & 144 & 57 \\
\hline
\end{tabular}


Resultado de hidrocarbonetos alifáticos, em $\mathrm{ng} \mathrm{m}^{-3}$, para as amostras de material particulado atmosférico $\left(\mathrm{PM}_{2,5}\right)$ coletadas no ano de 2011

\begin{tabular}{|c|c|c|c|c|c|c|c|c|c|}
\hline Código & C104 & C110 & C116 & C122 & C128 & C152 & C164 & C170 & C182 \\
\hline Data & 14-abr & 20-abr & 26-abr & 2-mai & 8-mai & 1-jun & 13-jun & 19-jun & 1-jul \\
\hline C12 & nd & nd & nd & nd & nd & nd & nd & nd & nd \\
\hline C13 & nd & nd & nd & nd & nd & 0,19 & nd & nd & nd \\
\hline C14 & 0,65 & nd & nd & nd & nd & nd & nd & nd & nd \\
\hline C15 & 0,76 & nd & nd & nd & nd & nd & nd & nd & nd \\
\hline C16 & nd & 0,40 & 0,44 & nd & nd & nd & nd & nd & nd \\
\hline C17 & nd & 0,67 & 0,65 & 0,26 & 0,42 & 0,42 & 0,60 & 0,45 & 0,57 \\
\hline Pristano & 0,54 & 0,34 & 0,33 & nd & nd & nd & nd & nd & nd \\
\hline C18 & 0,21 & 1,08 & 0,98 & nd & 0,25 & 0,31 & 0,52 & 0,42 & 0,60 \\
\hline Fitano & 0,98 & 0,41 & 0,45 & nd & nd & nd & nd & nd & nd \\
\hline C19 & 0,79 & 1,35 & 1,20 & nd & nd & 0,23 & 0,45 & 0,35 & 0,57 \\
\hline $\mathrm{C} 20$ & 0,72 & 1,21 & 1,17 & nd & nd & 0,23 & 0,48 & 0,35 & 0,43 \\
\hline $\mathrm{C} 21$ & 0,90 & 0,92 & 0,99 & nd & nd & nd & 0,27 & nd & 0,25 \\
\hline $\mathrm{C} 22$ & 0,71 & 0,99 & 1,18 & 0,30 & nd & 0,22 & 0,51 & 0,24 & 0,40 \\
\hline $\mathrm{C} 23$ & nd & 0,92 & 1,14 & 0,24 & nd & 0,23 & 0,66 & 0,31 & 0,42 \\
\hline $\mathrm{C} 24$ & 1,00 & 1,13 & 1,50 & 0,52 & 0,34 & 0,41 & 1,07 & 0,66 & 0,71 \\
\hline C25 & 1,54 & 1,10 & 1,65 & 0,41 & 0,36 & 0,71 & 1,58 & 1,21 & 0,93 \\
\hline C26 & 2,43 & 1,66 & 2,00 & 0,70 & 0,54 & 0,92 & 2,60 & 2,47 & 1,48 \\
\hline $\mathrm{C} 27$ & 3,35 & 1,55 & 1,93 & 0,46 & 0,39 & 1,57 & 3,62 & 4,05 & 2,54 \\
\hline C28 & 5,31 & 1,34 & 1,45 & nd & nd & 1,48 & 4,60 & 5,04 & 3,12 \\
\hline C29 & 0,50 & 1,52 & 1,72 & nd & nd & 1,96 & 4,39 & 8,01 & 4,71 \\
\hline C30 & 6,98 & 0,96 & 0,91 & nd & nd & 1,42 & 4,89 & 6,14 & 3,28 \\
\hline C31 & 2,36 & 0,70 & 0,25 & nd & 0,28 & 2,29 & 5,00 & 9,36 & 5,47 \\
\hline C32 & 4,80 & nd & nd & nd & nd & 1,29 & 3,54 & 5,09 & 2,53 \\
\hline C33 & 1,52 & nd & nd & nd & nd & 1,89 & 4,79 & 7,58 & 4,11 \\
\hline C34 & 1,76 & nd & nd & nd & 0,40 & 1,49 & 3,48 & 3,64 & 2,41 \\
\hline C35 & 0,59 & nd & nd & nd & nd & 0,98 & 3,12 & 4,11 & 2,20 \\
\hline C36 & 0,35 & nd & nd & nd & nd & nd & 1,14 & 2,18 & nd \\
\hline C37 & 0,26 & nd & nd & nd & nd & nd & 0,40 & 1,86 & nd \\
\hline C38 & nd & nd & nd & nd & nd & nd & 0,37 & 1,55 & nd \\
\hline C39 & nd & nd & nd & nd & nd & nd & nd & nd & nd \\
\hline C40 & nd & nd & nd & nd & nd & nd & nd & nd & nd \\
\hline n-alcanos & 37,48 & 17,53 & 19,16 & 2,90 & 2,99 & 18,26 & 48,05 & 65,06 & 36,74 \\
\hline HR & 39,00 & 36,20 & 38,85 & 2,91 & 2,99 & 51,54 & 268,75 & 158,63 & 192,84 \\
\hline $\begin{array}{l}\text { MCNR } \\
\text { Alitaticos }\end{array}$ & 4,57 & 266,0 & 305,1 & 370,9 & 452,5 & 293,1 & 1646,3 & 715,7 & 1046,8 \\
\hline Totais & 43,6 & 302,2 & 343,9 & 373,8 & 455,5 & 344,7 & 1915,1 & 874,3 & 1239,7 \\
\hline$\overline{\operatorname{Rec}(\%)}$ & 60 & 66 & 68 & 77 & 85 & 91 & 102 & 108 & 101 \\
\hline
\end{tabular}


Resultado de hidrocarbonetos alifáticos, em $\mathrm{ng} \mathrm{m}^{-3}$, para as amostras de material particulado atmosférico $\left(\mathrm{PM}_{2,5}\right)$ coletadas no ano de 2011

\begin{tabular}{|c|c|c|c|c|c|c|c|c|c|}
\hline Código & C188 & C194 & $\mathrm{C} 200$ & C206 & C212 & C218 & $\mathrm{C} 230$ & $\mathrm{C} 236$ & C242 \\
\hline Data & 7-jul & 13-jul & 19-jul & 25-jul & 31-jul & 6-ago & 18-ago & 24-ago & 30 -ago \\
\hline C12 & nd & nd & nd & nd & nd & nd & nd & nd & $\mathrm{nd}$ \\
\hline C13 & nd & nd & nd & nd & nd & nd & nd & nd & nd \\
\hline C14 & nd & nd & nd & nd & nd & nd & nd & nd & nd \\
\hline C15 & nd & nd & nd & nd & nd & nd & nd & nd & nd \\
\hline C16 & nd & 0,38 & nd & nd & nd & 0,32 & 0,68 & nd & nd \\
\hline C17 & 0,79 & 1,24 & 0,72 & 0,95 & 0,44 & 0,91 & 1,35 & 0,47 & 0,62 \\
\hline Pristano & nd & 0,38 & nd & nd & nd & 0,21 & 0,40 & nd & nd \\
\hline C18 & 0,55 & 1,33 & 0,56 & 1,12 & nd & 0,68 & 1,18 & 0,31 & 0,34 \\
\hline Fitano & nd & 0,37 & nd & nd & nd & nd & 0,32 & nd & nd \\
\hline C19 & nd & 1,06 & 0,26 & 0,86 & nd & 0,45 & 0,96 & nd & 0,30 \\
\hline $\mathrm{C} 20$ & nd & 0,78 & nd & 0,66 & nd & 0,28 & 0,88 & nd & 0,21 \\
\hline $\mathrm{C} 21$ & nd & 0,53 & nd & 0,49 & nd & nd & 0,58 & nd & nd \\
\hline $\mathrm{C} 22$ & nd & 0,71 & nd & 0,82 & nd & 0,30 & 0,74 & nd & nd \\
\hline $\mathrm{C} 23$ & nd & 1,04 & nd & 0,97 & nd & 0,34 & 0,88 & 0,24 & 0,22 \\
\hline $\mathrm{C} 24$ & 0,42 & 1,65 & 0,41 & 1,81 & nd & 0,56 & 1,27 & 0,59 & 0,45 \\
\hline $\mathrm{C} 25$ & 0,95 & 2,57 & 0,73 & 2,16 & nd & 0,68 & 2,04 & 1,01 & 1,04 \\
\hline $\mathrm{C} 26$ & 1,22 & 4,10 & 0,90 & 1,84 & 0,67 & 1,18 & 2,69 & 1,82 & 1,90 \\
\hline C27 & 2,10 & 6,24 & 1,24 & 1,76 & 1,06 & 1,78 & 4,39 & 2,27 & 3,42 \\
\hline $\mathrm{C} 28$ & 1,88 & 6,33 & 0,78 & 1,37 & 0,69 & 2,04 & 4,73 & 2,51 & 3,56 \\
\hline C29 & 1,68 & 9,27 & nd & nd & nd & 3,66 & 7,60 & 2,49 & 5,32 \\
\hline C30 & 0,53 & 1,55 & 0,23 & 0,81 & nd & 2,35 & 4,50 & 2,35 & 3,27 \\
\hline C31 & 3,26 & 7,77 & nd & 0,41 & nd & 4,03 & 7,38 & 2,55 & 5,84 \\
\hline C32 & 0,85 & 3,26 & nd & nd & nd & 1,91 & 3,17 & 1,30 & 1,81 \\
\hline C33 & 0,62 & 4,65 & nd & nd & nd & 4,16 & 5,52 & 0,88 & 2,35 \\
\hline C34 & nd & 2,42 & nd & 0,23 & 0,30 & 1,66 & 2,44 & 0,84 & 1,66 \\
\hline C35 & 0,51 & 1,27 & nd & 0,57 & nd & 2,01 & 2,89 & 0,57 & 1,24 \\
\hline C36 & nd & nd & nd & nd & nd & nd & 0,39 & nd & nd \\
\hline C37 & nd & nd & nd & nd & nd & nd & nd & nd & nd \\
\hline C38 & nd & nd & nd & nd & nd & nd & nd & nd & nd \\
\hline C39 & nd & nd & nd & nd & nd & nd & nd & nd & nd \\
\hline C40 & nd & nd & $\mathrm{nd}$ & nd & nd & nd & nd & nd & nd \\
\hline n-alcanos & 15,35 & 58,13 & 5,83 & 16,82 & 3,15 & 29,30 & 56,27 & 20,21 & 33,55 \\
\hline HR & 163,49 & 225,35 & 108,12 & 115,07 & 49,45 & 120,17 & 123,01 & 243,33 & 138,17 \\
\hline $\begin{array}{l}\text { MCNR } \\
\text { Alitaticos }\end{array}$ & 793,9 & 1123,2 & 852,4 & 918,8 & 371,7 & 533,6 & 615,5 & 1099,6 & 841,1 \\
\hline Totais & 957,4 & 1348,5 & 960,5 & 1033,9 & 421,2 & 653,8 & 738,5 & 1342,9 & 979,3 \\
\hline $\operatorname{Rec}(\%)$ & 91 & 99 & 78 & 111 & 105 & 108 & 106 & 96 & 88 \\
\hline
\end{tabular}


Resultado de hidrocarbonetos alifáticos, em $\mathrm{ng} \mathrm{m}^{-3}$, para as amostras de material particulado atmosférico $\left(\mathrm{PM}_{2,5}\right)$ coletadas no ano de 2011

\begin{tabular}{|c|c|c|c|c|c|c|c|c|c|}
\hline Código & C248 & C 254 & C 260 & $\mathrm{C} 272$ & C284 & C290 & C314 & C333 & C350 \\
\hline Data & 5-set & 11-set & 17-set & 29-set & 11-out & 17-out & 10-nov & 29-nov & 16-dez \\
\hline $\mathrm{C} 12$ & nd & nd & nd & nd & nd & nd & nd & nd & nd \\
\hline C13 & nd & nd & nd & nd & nd & nd & nd & nd & nd \\
\hline C14 & nd & nd & nd & nd & nd & nd & nd & nd & 3,62 \\
\hline C15 & nd & nd & nd & 0,48 & nd & nd & nd & nd & 4,54 \\
\hline C16 & 0,78 & 0,64 & 0,45 & 1,02 & nd & 0,51 & 0,39 & nd & 4,19 \\
\hline C17 & 1,24 & 0,59 & 0,37 & 1,02 & 0,28 & 0,80 & 0,64 & 0,33 & 4,99 \\
\hline Pristano & 0,92 & 0,64 & 0,67 & 1,03 & 0,23 & 0,35 & 0,37 & nd & 0,86 \\
\hline C18 & 1,77 & 0,71 & 0,67 & 0,96 & 0,40 & 0,98 & 0,73 & 0,43 & 7,84 \\
\hline Fitano & 0,88 & 0,44 & 0,43 & 0,64 & nd & 0,29 & 0,35 & 0,25 & 2,30 \\
\hline C19 & 1,87 & 0,62 & 0,73 & 0,87 & 0,54 & 0,96 & 0,76 & 0,47 & 11,92 \\
\hline $\mathrm{C} 20$ & 1,87 & 0,54 & 0,58 & 0,84 & 0,61 & 0,82 & 0,71 & 0,45 & 15,27 \\
\hline $\mathrm{C} 21$ & 1,29 & 0,26 & 0,37 & 0,68 & 0,46 & 0,61 & 0,58 & 0,39 & 11,97 \\
\hline $\mathrm{C} 22$ & 1,49 & 0,30 & 0,50 & 0,83 & 0,62 & 0,86 & 0,69 & 0,62 & 7,82 \\
\hline $\mathrm{C} 23$ & 1,62 & 0,24 & 0,45 & 0,71 & 0,57 & 0,85 & 0,62 & 0,66 & 5,26 \\
\hline $\mathrm{C} 24$ & 2,11 & 0,43 & 0,82 & 1,20 & 0,79 & 1,27 & 0,86 & 1,16 & 9,38 \\
\hline $\mathrm{C} 25$ & 2,71 & 0,52 & 1,03 & 1,74 & 1,02 & 1,46 & 0,95 & 1,51 & 15,52 \\
\hline C26 & 3,78 & 0,86 & 1,54 & 2,89 & 1,37 & 1,65 & 1,32 & 1,94 & 9,36 \\
\hline C27 & 3,23 & 0,64 & 1,32 & 3,10 & 2,06 & 1,67 & 1,50 & 1,92 & 4,61 \\
\hline C28 & 1,67 & 0,23 & 0,81 & 2,94 & 2,01 & 1,47 & 1,62 & 1,66 & 5,70 \\
\hline C29 & 0,95 & nd & 0,65 & 3,51 & 2,33 & 1,25 & 1,82 & 1,45 & 3,36 \\
\hline C30 & 0,93 & nd & nd & 2,42 & 1,52 & 1,09 & 1,28 & 1,31 & 3,95 \\
\hline C31 & nd & nd & nd & 3,01 & 2,65 & 1,09 & 1,04 & 1,12 & 3,52 \\
\hline C32 & nd & nd & nd & 0,47 & 1,05 & 0,54 & 0,29 & 0,54 & 1,87 \\
\hline C33 & nd & nd & nd & 1,59 & 1,97 & 0,70 & 0,26 & 0,81 & 0,82 \\
\hline C34 & nd & nd & nd & nd & 0,71 & 0,35 & 0,25 & 0,31 & 2,50 \\
\hline C35 & nd & nd & nd & nd & 1,04 & 0,28 & 0,52 & 0,62 & 1,51 \\
\hline C36 & nd & nd & nd & nd & 0,29 & nd & nd & nd & 0,48 \\
\hline C37 & nd & nd & nd & nd & 0,24 & nd & nd & nd & 0,37 \\
\hline C38 & nd & nd & nd & nd & nd & nd & nd & nd & nd \\
\hline C39 & nd & nd & nd & nd & nd & nd & nd & nd & nd \\
\hline C40 & nd & nd & nd & nd & nd & nd & nd & nd & nd \\
\hline n-alcanos & 27,29 & 6,57 & 10,29 & 30,29 & 22,55 & 19,24 & 16,83 & 17,71 & 140,35 \\
\hline HR & 89,15 & 31,61 & 34,51 & 100,87 & 22,78 & 48,61 & 43,80 & 70,83 & 1477,95 \\
\hline $\begin{array}{l}\text { MCNR } \\
\text { Alifaticos }\end{array}$ & 635,2 & 138,5 & 167,8 & 511,0 & 304,8 & 428,3 & 188,1 & 361,4 & 7935,3 \\
\hline Totais & 724,4 & 170,1 & 202,3 & 611,8 & 327,6 & 476,9 & 231,9 & 432,2 & 9413,3 \\
\hline $\operatorname{Rec}(\%)$ & 59 & 79 & 86 & 78 & 81 & 79 & 55 & 57 & 50 \\
\hline
\end{tabular}


Resultado de hidrocarbonetos alifáticos, em $\mathrm{ng} \mathrm{m}^{-3}$, para as amostras de material particulado atmosférico $\left(\mathrm{PM}_{2,5}\right)$ coletadas no ano de 2011

\begin{tabular}{lcc}
\hline Código & C356 & C362 \\
\hline Data & 22-dez & 28-dez \\
\hline C12 & nd & nd \\
C13 & nd & nd \\
C14 & nd & nd \\
C15 & nd & nd \\
C16 & 0,25 & 0,24 \\
C17 & 0,56 & 0,58 \\
Pristano & 0,25 & nd \\
C18 & 0,87 & 0,77 \\
Fitano & 0,34 & nd \\
C19 & 1,13 & 0,75 \\
C20 & 1,15 & 0,62 \\
C21 & 0,98 & 0,47 \\
C22 & 1,05 & 0,74 \\
C23 & 0,91 & 0,71 \\
C24 & 1,04 & 1,10 \\
C25 & 1,16 & 1,17 \\
C26 & 1,85 & 1,21 \\
C27 & 2,39 & 0,98 \\
C28 & 2,36 & 0,98 \\
C29 & 2,34 & 0,79 \\
C30 & 1,97 & 0,62 \\
C31 & 2,56 & 0,26 \\
C32 & 1,12 & nd \\
C33 & 1,80 & nd \\
C34 & 1,16 & nd \\
C35 & 0,99 & 0,31 \\
C36 & nd & nd \\
C37 & nd & nd \\
C38 & nd & nd \\
C39 & nd & nd \\
C40 & nd & nd \\
\hline n-alcanos & 27,63 & 12,30 \\
HR & 111,26 & 48,00 \\
MCNR & 522,6 & 216,9 \\
Alitaticos & 633,8 & 264,9 \\
Totais & 69 & 63 \\
\hline Rec (\%) & & \\
\hline &
\end{tabular}


Resultado de hidrocarbonetos alifáticos, em $\mathrm{ng} \mathrm{m}^{-3}$, para as amostras de material particulado atmosférico $\left(\mathrm{PM}_{2,5}\right)$ coletadas no ano de 2011

\begin{tabular}{|c|c|c|c|c|c|c|c|c|c|}
\hline Código & CE 50 & CE 56 & CE 62 & CE 68 & CE 74 & CE 80 & CE 92 & CE 104 & CE 116 \\
\hline Data & 19-fev & 25-fev & 3-mar & 9-mar & 15-mar & 21-mar & $2-a b r$ & 14-abr & 26-abr \\
\hline C12 & nd & nd & nd & nd & nd & nd & nd & nd & nd \\
\hline C13 & nd & nd & nd & nd & nd & nd & nd & nd & nd \\
\hline C14 & nd & nd & nd & nd & nd & nd & nd & nd & 0,11 \\
\hline C15 & nd & nd & 0,20 & nd & nd & 0,09 & nd & nd & nd \\
\hline C16 & nd & nd & nd & 0,28 & 0,31 & nd & nd & 2,55 & 0,37 \\
\hline C17 & nd & nd & 0,53 & 0,42 & nd & 0,44 & 0,27 & nd & 0,88 \\
\hline Pristano & nd & nd & nd & nd & 0,73 & 0,11 & nd & 0,38 & 0,66 \\
\hline C18 & nd & nd & 0,17 & nd & 0,39 & 0,17 & nd & 0,15 & 0,57 \\
\hline Fitano & nd & nd & 0,48 & 0,31 & 0,46 & 0,42 & 0,24 & 0,55 & 0,90 \\
\hline C19 & nd & nd & 0,23 & nd & 0,42 & 0,30 & 0,19 & 0,39 & 0,70 \\
\hline $\mathrm{C} 20$ & nd & nd & 0,17 & 0,25 & 0,45 & 0,23 & 0,25 & 0,40 & 0,80 \\
\hline $\mathrm{C} 21$ & nd & nd & 0,15 & nd & 0,23 & 0,22 & 0,17 & 0,37 & 0,36 \\
\hline $\mathrm{C} 22$ & nd & nd & 0,17 & nd & 0,21 & 0,23 & 0,18 & 0,33 & 0,41 \\
\hline $\mathrm{C} 23$ & nd & nd & 0,20 & nd & 0,17 & 0,15 & nd & 0,29 & 0,37 \\
\hline $\mathrm{C} 24$ & nd & 0,29 & 0,47 & nd & 0,17 & 0,24 & 0,24 & 0,35 & 0,69 \\
\hline $\mathrm{C} 25$ & 0,47 & 0,49 & 0,80 & nd & 0,32 & 0,23 & 0,24 & 0,35 & 0,61 \\
\hline C26 & 1,93 & 1,62 & 0,75 & nd & 0,58 & 0,57 & 0,39 & 0,52 & 0,79 \\
\hline $\mathrm{C} 27$ & 5,30 & 4,20 & 0,54 & nd & 0,83 & 0,74 & 0,48 & 0,40 & 0,55 \\
\hline C28 & 7,85 & 5,04 & 0,61 & nd & 1,47 & 1,24 & 0,56 & nd & 0,43 \\
\hline C29 & 13,18 & 5,03 & 0,94 & nd & 2,50 & 2,19 & 0,19 & nd & 0,21 \\
\hline C30 & 10,38 & nd & 0,80 & nd & 2,38 & 2,00 & nd & nd & nd \\
\hline C31 & 12,67 & nd & 1,05 & nd & 2,96 & 3,00 & nd & nd & nd \\
\hline C32 & 5,15 & nd & 0,18 & nd & 0,73 & 1,52 & nd & nd & nd \\
\hline C33 & 9,89 & nd & 0,20 & nd & nd & 1,72 & nd & nd & nd \\
\hline C34 & 1,92 & nd & nd & nd & nd & 0,32 & nd & nd & nd \\
\hline C35 & 4,52 & nd & nd & nd & nd & nd & nd & nd & nd \\
\hline C36 & nd & nd & nd & nd & nd & nd & nd & nd & nd \\
\hline C37 & nd & nd & nd & nd & nd & nd & nd & nd & nd \\
\hline C38 & nd & nd & nd & nd & nd & nd & nd & nd & nd \\
\hline C39 & nd & nd & nd & nd & nd & nd & nd & nd & nd \\
\hline C40 & nd & nd & nd & nd & nd & nd & nd & nd & nd \\
\hline n-alcanos & 73,25 & 16,67 & 8,16 & 0,95 & 14,12 & 15,59 & 3,17 & 6,10 & 7,86 \\
\hline HR & 48,43 & 16,68 & 8,21 & 1,27 & 61,04 & 16,41 & 12,62 & 7,04 & 17,33 \\
\hline $\begin{array}{l}\text { MCNR } \\
\text { AlItaticos }\end{array}$ & 101,0 & 44,0 & 66,1 & 95,4 & 159,7 & 82,5 & 96,7 & 75,1 & 117,2 \\
\hline Totais & 149,4 & 60,7 & 73,4 & 96,7 & 220,7 & 96,0 & 109,3 & 82,1 & 134,5 \\
\hline $\operatorname{Rec}(\%)$ & 79 & 101 & 97 & 82 & 79 & 75 & 70 & 65 & 60 \\
\hline
\end{tabular}


Resultado de hidrocarbonetos alifáticos, em $\mathrm{ng} \mathrm{m}^{-3}$, para as amostras de material particulado atmosférico $\left(\mathrm{PM}_{2,5}\right)$ coletadas no ano de 2011

\begin{tabular}{|c|c|c|c|c|c|c|c|c|c|}
\hline Código & CE 122 & CE 128 & CE 134 & CE 140 & CE 146 & CE 152 & CE 158 & CE 164 & CE 170 \\
\hline Data & 2-mai & 8-mai & 14-mai & 20-mai & 26-mai & 1-jun & 7-jun & 13-jun & 19-jun \\
\hline C12 & nd & nd & nd & nd & nd & nd & nd & nd & nd \\
\hline C13 & nd & nd & nd & nd & nd & nd & nd & nd & nd \\
\hline C14 & nd & nd & nd & nd & nd & nd & nd & nd & nd \\
\hline C15 & nd & nd & nd & nd & nd & nd & nd & nd & nd \\
\hline C16 & nd & nd & nd & nd & nd & nd & nd & nd & nd \\
\hline C17 & nd & 0,32 & 0,49 & nd & nd & 0,20 & nd & 0,36 & nd \\
\hline Pristano & nd & nd & nd & nd & nd & 0,29 & nd & nd & 0,25 \\
\hline C18 & nd & 0,29 & nd & nd & nd & 0,20 & nd & 0,25 & nd \\
\hline Fitano & nd & nd & 0,21 & nd & nd & 0,20 & nd & nd & 0,22 \\
\hline C19 & nd & nd & nd & nd & nd & 0,20 & nd & nd & 0,21 \\
\hline $\mathrm{C} 20$ & nd & nd & nd & nd & nd & nd & nd & nd & 0,32 \\
\hline $\mathrm{C} 21$ & nd & nd & nd & nd & nd & nd & nd & nd & 0,24 \\
\hline $\mathrm{C} 22$ & nd & nd & nd & nd & 0,19 & nd & nd & nd & 0,35 \\
\hline $\mathrm{C} 23$ & nd & nd & nd & nd & 0,25 & 0,22 & nd & 0,25 & 0,27 \\
\hline $\mathrm{C} 24$ & nd & 0,45 & nd & nd & 0,66 & 0,35 & nd & 1,06 & 0,42 \\
\hline $\mathrm{C} 25$ & nd & 1,27 & nd & nd & 1,18 & 0,57 & 0,27 & 2,41 & 0,60 \\
\hline $\mathrm{C} 26$ & 0,45 & 3,25 & 0,45 & 0,49 & 3,08 & 1,49 & 1,23 & 6,61 & 1,39 \\
\hline $\mathrm{C} 27$ & 0,45 & 5,74 & 0,36 & 0,92 & 5,26 & 2,52 & 2,86 & 14,79 & 2,57 \\
\hline C28 & 0,67 & 7,89 & 0,39 & 1,32 & 7,04 & 3,37 & 3,72 & 18,31 & 3,25 \\
\hline C29 & 0,63 & 9,88 & nd & 2,02 & 10,33 & 5,28 & 7,16 & 23,91 & 5,87 \\
\hline C30 & nd & 0,59 & nd & 0,81 & 8,77 & 4,37 & 4,88 & 20,62 & 3,90 \\
\hline C31 & nd & 0,80 & nd & 2,10 & 12,27 & 6,23 & 8,52 & 26,75 & 7,35 \\
\hline C32 & nd & nd & nd & 1,71 & 7,59 & 3,66 & 3,57 & 17,22 & 3,57 \\
\hline C33 & nd & nd & nd & 1,77 & 9,94 & 4,04 & 4,40 & 17,61 & 5,75 \\
\hline C34 & nd & 0,38 & nd & 1,27 & 4,68 & 1,86 & 0,88 & 7,20 & 2,65 \\
\hline C35 & nd & 0,43 & nd & 1,53 & 4,07 & 1,53 & 0,39 & 3,89 & 3,10 \\
\hline C36 & nd & nd & nd & 0,58 & 1,30 & 0,36 & nd & nd & 1,64 \\
\hline C37 & nd & nd & nd & 0,23 & 0,30 & nd & nd & 1,64 & 1,50 \\
\hline C38 & nd & nd & nd & nd & nd & nd & nd & nd & 1,50 \\
\hline C39 & nd & nd & nd & nd & nd & nd & nd & 1,47 & 1,17 \\
\hline C40 & nd & nd & nd & nd & nd & nd & nd & nd & 0,98 \\
\hline n-alcanos & 2,20 & 31,29 & 1,68 & 14,76 & 76,91 & 36,46 & 37,88 & 164,37 & 48,58 \\
\hline HR & 2,20 & 88,36 & 49,73 & 71,49 & 195,23 & 107,00 & 153,73 & 466,20 & 86,72 \\
\hline $\begin{array}{l}\text { MCNR } \\
\text { Alitaticos }\end{array}$ & 104,31 & 265,9 & 265,5 & 180,1 & 365,4 & 321,6 & 468,8 & 720,1 & 242,7 \\
\hline Totais & 106,5 & 354,2 & 315,2 & 251,6 & 560,7 & 428,6 & 622,5 & 1186,3 & 329,5 \\
\hline$\overline{\operatorname{Rec}(\%)}$ & 106 & 62 & 100 & 95 & 90 & 77 & 97 & 112 & 73 \\
\hline
\end{tabular}


Resultado de hidrocarbonetos alifáticos, em $\mathrm{ng} \mathrm{m}^{-3}$, para as amostras de material particulado atmosférico $\left(\mathrm{PM}_{2,5}\right)$ coletadas no ano de 2011

\begin{tabular}{|c|c|c|c|c|c|c|c|c|c|}
\hline Código & CE 176 & CE 182 & CE 188 & CE 194 & CE 200 & CE 206 & CE 242 & CE 248 & CE 254 \\
\hline Data & 25-jun & 1-jul & 7-jul & 13-jul & 19-jul & 25-jul & 30 -ago & 5-set & 11-set \\
\hline C12 & nd & $\mathrm{nd}$ & nd & nd & nd & nd & nd & nd & nd \\
\hline C13 & nd & nd & nd & nd & nd & nd & nd & nd & nd \\
\hline C14 & nd & nd & nd & nd & nd & nd & nd & nd & nd \\
\hline C15 & nd & nd & nd & nd & nd & 4,41 & nd & nd & nd \\
\hline C16 & nd & nd & nd & nd & nd & nd & nd & 0,27 & nd \\
\hline C17 & nd & 0,41 & 0,69 & 0,67 & 0,37 & 0,36 & 0,45 & 0,34 & 0,28 \\
\hline Pristano & nd & nd & nd & nd & nd & nd & nd & 0,97 & 0,42 \\
\hline C18 & nd & 0,30 & 0,26 & 0,64 & nd & nd & 0,32 & 0,46 & 0,53 \\
\hline Fitano & nd & nd & nd & nd & nd & nd & nd & 0,65 & 0,36 \\
\hline C19 & nd & nd & nd & 0,46 & nd & nd & nd & 0,51 & 0,76 \\
\hline $\mathrm{C} 20$ & 0,31 & nd & nd & 0,26 & nd & nd & nd & 0,56 & 2,69 \\
\hline $\mathrm{C} 21$ & nd & nd & nd & nd & nd & nd & nd & 0,33 & 2,30 \\
\hline $\mathrm{C} 22$ & nd & nd & nd & 0,29 & nd & nd & nd & 0,49 & 1,35 \\
\hline $\mathrm{C} 23$ & 0,24 & nd & nd & 0,38 & nd & nd & nd & 0,72 & 3,15 \\
\hline $\mathrm{C} 24$ & 0,43 & 0,37 & nd & 1,05 & nd & nd & 0,40 & 1,54 & 4,11 \\
\hline C25 & 1,37 & 1,19 & nd & 2,64 & 0,24 & 0,50 & 2,02 & 5,56 & 8,70 \\
\hline $\mathrm{C} 26$ & 3,52 & 3,82 & 0,37 & 11,83 & 1,21 & 2,00 & 4,87 & 12,05 & 14,04 \\
\hline C27 & 6,13 & 6,92 & 0,67 & 18,06 & 2,77 & 2,98 & 10,51 & 19,45 & 21,91 \\
\hline C28 & 7,61 & 8,62 & 1,02 & 20,36 & 3,02 & 2,63 & 11,30 & 21,29 & 25,64 \\
\hline $\mathrm{C} 29$ & 13,00 & 12,77 & 1,57 & 31,06 & 3,73 & 1,26 & 20,13 & 31,49 & 32,06 \\
\hline C30 & 10,06 & 9,89 & 1,38 & 20,65 & 0,75 & 2,47 & 10,90 & 10,26 & 28,86 \\
\hline C31 & 14,48 & 13,25 & 2,04 & 26,54 & nd & nd & 17,00 & 2,61 & 31,30 \\
\hline C32 & 8,25 & 5,81 & 1,09 & 14,94 & nd & nd & 7,99 & 0,95 & 27,39 \\
\hline C33 & 11,73 & 4,41 & 0,77 & 16,80 & nd & nd & 11,47 & 2,42 & 25,83 \\
\hline C34 & 4,87 & 0,75 & 1,67 & 4,54 & nd & 2,42 & 3,43 & 0,30 & 20,29 \\
\hline C35 & 5,05 & nd & 0,27 & 2,63 & 0,25 & 0,22 & 1,61 & 2,46 & 17,94 \\
\hline C36 & 1,86 & nd & nd & nd & nd & nd & nd & 0,63 & 13,14 \\
\hline C37 & 0,99 & nd & nd & nd & nd & nd & nd & nd & 12,11 \\
\hline C38 & 0,55 & nd & nd & nd & nd & nd & nd & 0,72 & 8,86 \\
\hline C39 & 0,20 & nd & nd & nd & nd & 0,92 & nd & nd & 9,07 \\
\hline C40 & nd & nd & nd & nd & nd & nd & nd & nd & 6,00 \\
\hline n-alcanos & 90,65 & 68,49 & 11,81 & 173,82 & 12,35 & 20,17 & 102,40 & 115,43 & 318,30 \\
\hline HR & 230,08 & 149,89 & 175,17 & 648,39 & 33,29 & 152,27 & 439,16 & 185,36 & 498,68 \\
\hline $\begin{array}{l}\text { MCNR } \\
\text { Alitaticos }\end{array}$ & 499,4 & 347,2 & 327,0 & 915,1 & 207,0 & 379,6 & 773,4 & 347,2 & 1031,6 \\
\hline Totais & 729,5 & 497,1 & 502,2 & 1563,5 & 240,3 & 531,9 & 1212,6 & 532,6 & 1530,2 \\
\hline $\operatorname{Rec}(\%)$ & 112 & 103 & 95 & 98 & 73 & 60 & 91 & 54 & 109 \\
\hline
\end{tabular}


Resultado de hidrocarbonetos alifáticos, em $\mathrm{ng} \mathrm{m}^{-3}$, para as amostras de material particulado atmosférico $\left(\mathrm{PM}_{2,5}\right)$ coletadas no ano de 2011

\begin{tabular}{|c|c|c|c|c|c|c|c|c|c|}
\hline Código & CE 266 & CE 272 & CE 284 & CE 290 & CE 296 & CE 308 & CE 338 & CE 344 & CE 350 \\
\hline Data & 23-set & 29-set & 11-out & 17-out & 23-out & 4-nov & 4-dez & 10-dez & 16-dez \\
\hline C12 & nd & nd & nd & nd & nd & nd & nd & nd & nd \\
\hline C13 & nd & nd & nd & nd & nd & nd & nd & nd & nd \\
\hline C14 & nd & nd & nd & nd & nd & nd & nd & nd & nd \\
\hline C15 & nd & nd & nd & nd & 0,77 & nd & nd & 0,41 & nd \\
\hline C16 & nd & 0,35 & nd & nd & nd & nd & nd & nd & nd \\
\hline C17 & 0,57 & 0,75 & 0,23 & nd & nd & nd & 0,30 & nd & nd \\
\hline Pristano & 0,21 & 0,25 & 0,25 & nd & nd & nd & 0,27 & nd & nd \\
\hline C18 & 0,18 & 0,36 & 0,29 & nd & nd & nd & 0,25 & nd & nd \\
\hline Fitano & 0,31 & 0,48 & 0,21 & nd & nd & nd & nd & nd & nd \\
\hline C19 & 0,34 & 0,49 & 0,25 & nd & nd & nd & 0,23 & nd & nd \\
\hline C2O & 0,33 & 0,36 & 0,60 & nd & nd & nd & nd & nd & nd \\
\hline $\mathrm{C} 21$ & 0,21 & 0,26 & 0,49 & nd & nd & nd & nd & nd & nd \\
\hline $\mathrm{C} 22$ & 0,28 & 0,29 & 0,75 & nd & nd & nd & nd & nd & nd \\
\hline $\mathrm{C} 23$ & 0,21 & 0,23 & 0,57 & nd & nd & nd & nd & nd & nd \\
\hline C24 & 0,36 & 0,42 & 0,96 & nd & nd & nd & 0,26 & nd & nd \\
\hline C25 & 0,60 & 0,61 & 1,11 & nd & nd & nd & 0,35 & nd & 0,54 \\
\hline C26 & 1,44 & 1,75 & 1,61 & nd & 0,41 & nd & 0,41 & nd & 0,95 \\
\hline $\mathrm{C} 27$ & 2,74 & 3,02 & 2,24 & nd & 0,53 & nd & 0,49 & 0,28 & 1,60 \\
\hline C28 & 3,13 & 3,71 & 2,45 & 0,28 & 0,66 & 0,30 & 0,55 & 0,39 & 2,20 \\
\hline C29 & 5,26 & 5,45 & 4,05 & 0,47 & 0,94 & 0,63 & 0,88 & 0,50 & 3,18 \\
\hline C30 & 2,54 & 1,76 & 2,32 & nd & 1,69 & nd & 0,72 & nd & 2,72 \\
\hline C31 & 2,01 & nd & 4,35 & nd & 1,07 & nd & 1,15 & 0,64 & 3,80 \\
\hline C32 & nd & nd & 1,89 & nd & 0,76 & nd & 0,62 & 0,31 & 2,88 \\
\hline C33 & nd & nd & 3,73 & nd & 0,82 & nd & 0,90 & 0,32 & 2,95 \\
\hline C34 & nd & nd & 0,99 & nd & 0,36 & nd & 0,47 & nd & 2,10 \\
\hline C35 & nd & nd & 1,31 & nd & 0,52 & nd & 0,56 & nd & 1,95 \\
\hline C36 & nd & nd & 0,60 & nd & 0,26 & nd & 0,32 & nd & 1,45 \\
\hline C37 & nd & nd & 0,57 & nd & nd & nd & 0,28 & nd & 1,24 \\
\hline C38 & nd & nd & 0,48 & nd & nd & nd & 0,26 & nd & 0,76 \\
\hline C39 & nd & nd & 0,24 & nd & 0,34 & nd & nd & nd & nd \\
\hline C40 & 0,22 & nd & 0,44 & nd & nd & nd & 0,26 & nd & 0,44 \\
\hline n-alcanos & 20,44 & 19,80 & 32,53 & 0,75 & 9,13 & 0,93 & 9,27 & 2,85 & 28,74 \\
\hline HR & 41,52 & 44,49 & 83,08 & 0,79 & 28,87 & 0,95 & 23,40 & 12,32 & 20,29 \\
\hline $\begin{array}{l}\text { MCNR } \\
\text { Alifáticos }\end{array}$ & 92,7 & 121,2 & 105,9 & nd & 89,6 & 28,6 & nd & 93,7 & 173,6 \\
\hline Totais & 134,2 & 165,7 & 189,0 & 0,7 & 118,5 & 29,5 & 23,4 & 106,0 & 193,8 \\
\hline $\operatorname{Rec}(\%)$ & 68 & 45 & 74 & 74 & 65 & 61 & 60 & 75 & 78 \\
\hline
\end{tabular}


Resultado de hidrocarbonetos alifáticos, em $\mathrm{ng} \mathrm{m}^{-3}$, para as amostras de material particulado atmosférico $\left(\mathrm{PM}_{2,5}\right)$ coletadas no ano de 2011

\begin{tabular}{|c|c|c|c|c|c|c|c|c|c|}
\hline Código & CP8 & CP14 & CP20 & CP26 & CP38 & CP44 & CP56 & CP92 & CP98 \\
\hline Data & 8-jan & 14-jan & 20-jan & 26-jan & 7-fev & 13-fev & 25-fev & 2-abr & 8-abr \\
\hline C12 & nd & nd & nd & nd & nd & nd & nd & nd & nd \\
\hline C13 & nd & nd & nd & nd & nd & nd & nd & 0,16 & nd \\
\hline C14 & nd & nd & nd & nd & nd & nd & nd & nd & nd \\
\hline C15 & nd & nd & nd & nd & nd & nd & nd & 2,85 & nd \\
\hline C16 & nd & nd & nd & nd & 0,13 & 0,40 & nd & nd & 0,25 \\
\hline C17 & nd & nd & nd & nd & nd & 0,38 & nd & nd & 0,25 \\
\hline Pristano & nd & nd & nd & 0,53 & 0,27 & 0,50 & nd & 0,17 & 0,65 \\
\hline C18 & nd & nd & nd & nd & 0,24 & 0,48 & 0,19 & 0,23 & 0,44 \\
\hline Fitano & nd & nd & nd & nd & 0,30 & 0,39 & nd & 0,22 & 0,41 \\
\hline C19 & nd & nd & nd & nd & 0,31 & 0,35 & 0,18 & 0,22 & 0,45 \\
\hline $\mathrm{C} 20$ & nd & 0,19 & 0,30 & nd & 0,32 & 0,30 & nd & 0,18 & 0,40 \\
\hline $\mathrm{C} 21$ & nd & nd & 0,32 & nd & 0,24 & nd & nd & 0,19 & 0,26 \\
\hline $\mathrm{C} 22$ & nd & 0,18 & 0,38 & nd & 0,30 & nd & 0,18 & 0,19 & 0,28 \\
\hline $\mathrm{C} 23$ & nd & 0,21 & 0,49 & 0,23 & 0,28 & nd & 0,21 & 0,19 & 0,27 \\
\hline $\mathrm{C} 24$ & nd & 0,26 & 0,52 & 0,31 & 0,30 & 0,26 & 0,29 & nd & 0,33 \\
\hline $\mathrm{C} 25$ & 0,20 & 0,29 & 0,55 & 0,45 & 0,41 & 0,38 & 0,36 & 0,16 & 0,40 \\
\hline $\mathrm{C} 26$ & 0,29 & 0,37 & 0,53 & 0,66 & 0,81 & 1,93 & 0,90 & 0,47 & 0,66 \\
\hline $\mathrm{C} 27$ & 0,31 & 0,45 & 0,52 & 0,76 & 1,19 & 7,01 & 1,78 & 0,55 & 0,93 \\
\hline C28 & 0,33 & 0,52 & 0,49 & 0,85 & 0,60 & 11,03 & 2,08 & 0,77 & 1,10 \\
\hline C29 & 0,51 & 0,97 & 0,78 & 1,32 & nd & 18,42 & 3,23 & 1,20 & 1,75 \\
\hline C30 & 0,20 & 0,57 & 0,39 & 0,84 & nd & 13,33 & 1,83 & 1,30 & 1,00 \\
\hline C31 & nd & 0,94 & 0,21 & 1,15 & nd & 15,75 & 1,26 & 0,82 & 1,08 \\
\hline C32 & nd & nd & nd & nd & nd & 5,80 & nd & 0,28 & nd \\
\hline C33 & nd & nd & nd & 0,45 & nd & 7,41 & nd & nd & nd \\
\hline C34 & nd & nd & nd & nd & nd & 0,98 & nd & 0,93 & nd \\
\hline C35 & nd & nd & nd & nd & nd & 0,91 & nd & nd & nd \\
\hline C36 & nd & nd & nd & nd & nd & nd & nd & nd & nd \\
\hline C37 & nd & nd & nd & nd & nd & nd & nd & nd & nd \\
\hline C38 & nd & nd & nd & nd & nd & nd & nd & nd & nd \\
\hline C39 & nd & nd & nd & nd & nd & nd & nd & 0,56 & nd \\
\hline C40 & nd & nd & nd & nd & nd & nd & nd & nd & nd \\
\hline n-alcanos & 1,84 & 4,95 & 5,48 & 7,03 & 5,13 & 85,11 & 12,50 & 11,27 & 9,86 \\
\hline HR & 14,91 & 4,96 & 5,57 & 18,48 & 11,46 & 115,36 & 26,05 & 36,51 & 34,75 \\
\hline $\begin{array}{l}\text { MCNR } \\
\text { Alifáticos }\end{array}$ & 28,7 & 37,4 & 54,3 & 42,0 & 136,2 & 109,2 & 93,7 & 129,3 & 96,6 \\
\hline Totais & 43,6 & 42,3 & 59,8 & 60,5 & 147,7 & 224,6 & 119,8 & 165,8 & 131,4 \\
\hline $\operatorname{Rec}(\%)$ & 68 & 72 & 59 & 79 & 66 & 80 & 66 & 75 & 73 \\
\hline
\end{tabular}


Resultado de hidrocarbonetos alifáticos, em $\mathrm{ng} \mathrm{m}^{-3}$, para as amostras de material particulado atmosférico $\left(\mathrm{PM}_{2,5}\right)$ coletadas no ano de 2011

\begin{tabular}{|c|c|c|c|c|c|c|c|c|c|}
\hline Código & CP104 & CP110 & CP116 & CP194 & CP200 & CP206 & CP212 & CP218 & CP224 \\
\hline Data & 14-abr & $20-a b r$ & 26-abr & 13-jul & 19-jul & 25-jul & 31-jul & 6-ago & 12-ago \\
\hline C12 & nd & nd & nd & nd & nd & nd & nd & nd & nd \\
\hline C13 & nd & nd & nd & nd & nd & nd & nd & nd & nd \\
\hline C14 & nd & nd & nd & nd & nd & nd & nd & nd & nd \\
\hline C15 & nd & 0,24 & 0,16 & nd & nd & nd & nd & nd & 0,19 \\
\hline C16 & nd & nd & nd & nd & nd & nd & nd & nd & 0,32 \\
\hline C17 & 0,25 & 0,14 & nd & 0,75 & 0,47 & nd & 0,45 & 0,23 & 0,66 \\
\hline Pristano & nd & 0,77 & 0,50 & nd & nd & nd & nd & nd & 0,48 \\
\hline C18 & nd & 0,29 & 0,23 & 0,60 & 0,28 & nd & nd & nd & 0,63 \\
\hline Fitano & 0,32 & 0,33 & 0,29 & nd & nd & nd & nd & nd & 0,40 \\
\hline C19 & 0,35 & 0,33 & 0,29 & 0,38 & nd & nd & nd & nd & 0,44 \\
\hline $\mathrm{C} 20$ & 0,41 & 0,28 & 0,30 & 0,26 & nd & nd & nd & nd & 0,28 \\
\hline $\mathrm{C} 21$ & 0,36 & 0,23 & 0,31 & nd & nd & nd & nd & nd & 0,21 \\
\hline $\mathrm{C} 22$ & 0,38 & 0,23 & 0,36 & nd & nd & nd & nd & nd & 0,23 \\
\hline $\mathrm{C} 23$ & 0,31 & 0,15 & 0,23 & nd & nd & nd & nd & nd & 0,19 \\
\hline $\mathrm{C} 24$ & 0,42 & 0,16 & 0,38 & 0,37 & nd & nd & nd & nd & 0,20 \\
\hline $\mathrm{C} 25$ & 0,44 & 0,20 & 0,36 & 0,65 & nd & nd & nd & nd & 0,29 \\
\hline $\mathrm{C} 26$ & 0,77 & 0,50 & 0,81 & 2,59 & nd & nd & nd & 0,66 & 0,84 \\
\hline $\mathrm{C} 27$ & 1,42 & 0,78 & 0,88 & 4,36 & 0,63 & 0,45 & 0,39 & 1,19 & 1,17 \\
\hline $\mathrm{C} 28$ & 1,75 & 0,88 & 0,79 & 4,57 & 0,67 & 0,34 & 0,72 & 1,31 & 1,13 \\
\hline $\mathrm{C} 29$ & 2,02 & 1,58 & 1,15 & 8,61 & 1,50 & 0,70 & 1,50 & 2,99 & 1,73 \\
\hline C30 & 0,53 & 0,93 & 0,48 & 5,32 & 0,27 & 0,23 & 0,64 & 1,95 & 0,69 \\
\hline C31 & nd & 2,51 & 0,84 & 11,17 & 2,43 & 1,12 & 2,16 & 5,26 & 0,49 \\
\hline C32 & nd & 0,21 & nd & 4,55 & 0,51 & 0,22 & 0,65 & 1,56 & nd \\
\hline C33 & nd & 1,06 & nd & 7,47 & 0,30 & nd & 1,12 & 3,85 & nd \\
\hline C34 & nd & nd & nd & 2,45 & nd & 0,21 & 0,53 & 0,58 & 0,18 \\
\hline C35 & nd & nd & nd & 1,47 & nd & nd & 0,51 & 0,78 & nd \\
\hline C36 & nd & nd & nd & nd & nd & nd & nd & nd & nd \\
\hline C37 & nd & nd & nd & nd & nd & nd & nd & nd & nd \\
\hline C38 & nd & nd & nd & nd & nd & nd & nd & nd & nd \\
\hline C39 & nd & nd & nd & nd & nd & nd & nd & nd & nd \\
\hline C40 & nd & nd & nd & nd & nd & nd & nd & nd & nd \\
\hline n-alcanos & 9,42 & 10,71 & 7,56 & 55,58 & 7,05 & 3,27 & 8,66 & 20,36 & 9,86 \\
\hline HR & 24,32 & 17,46 & 8,88 & 94,07 & 101,69 & 154,51 & 38,29 & 93,23 & 52,64 \\
\hline $\begin{array}{l}\text { MCNR } \\
\text { Alitaticos }\end{array}$ & 190,39 & 74,3 & 87,9 & 540,8 & 223,0 & 140,8 & 83,2 & 438,8 & 218,5 \\
\hline Totais & 214,7 & 81,7 & 91,8 & 634,8 & 324,7 & 295,4 & 121,5 & 532,1 & 271,1 \\
\hline $\operatorname{Rec}(\%)$ & 101 & 74 & 66 & 114 & 84 & 58 & 76 & 92 & 55 \\
\hline
\end{tabular}


Resultado de hidrocarbonetos alifáticos, em $\mathrm{ng} \mathrm{m}^{-3}$, para as amostras de material particulado atmosférico $\left(\mathrm{PM}_{2,5}\right)$ coletadas no ano de 2011

\begin{tabular}{|c|c|c|c|c|c|c|c|c|c|}
\hline Código & CP230 & CP236 & CP242 & CP248 & CP254 & CP260 & CP266 & CP272 & CP284 \\
\hline Data & 18-ago & 24-ago & 30 -ago & 5-set & 11-set & 17-set & 23-set & 29-set & 11-out \\
\hline C12 & nd & nd & nd & nd & nd & nd & nd & nd & nd \\
\hline C13 & nd & nd & nd & nd & nd & nd & nd & nd & nd \\
\hline C14 & nd & nd & nd & nd & nd & nd & nd & nd & nd \\
\hline C15 & nd & nd & 0,27 & nd & 0,33 & nd & nd & nd & nd \\
\hline C16 & nd & nd & 0,28 & 0,29 & nd & 0,26 & 0,35 & 0,93 & 0,23 \\
\hline C17 & 0,50 & 0,89 & 0,63 & 0,38 & nd & 0,33 & 0,77 & 1,09 & 0,31 \\
\hline Pristano & nd & nd & 0,64 & 0,33 & 0,17 & 0,69 & nd & 1,15 & 0,26 \\
\hline C18 & 0,30 & 0,56 & 0,53 & 0,31 & nd & 0,39 & 0,21 & 1,11 & 0,30 \\
\hline Fitano & nd & nd & 0,51 & 0,26 & nd & 0,31 & 0,40 & 1,91 & 0,22 \\
\hline C19 & nd & nd & 0,41 & 0,38 & 0,14 & 0,34 & 0,26 & 25,50 & 0,35 \\
\hline $\mathrm{C} 20$ & nd & nd & 0,25 & 0,38 & 0,22 & 0,29 & 0,32 & 18,64 & 0,29 \\
\hline $\mathrm{C} 21$ & nd & nd & 0,22 & 0,24 & 0,19 & nd & 0,21 & 0,35 & 0,24 \\
\hline $\mathrm{C} 22$ & nd & nd & 0,27 & 0,33 & 0,21 & 0,17 & 0,28 & 0,46 & 0,36 \\
\hline $\mathrm{C} 23$ & nd & nd & 0,25 & 0,29 & 0,20 & nd & 0,27 & 0,36 & 0,29 \\
\hline $\mathrm{C} 24$ & nd & nd & 0,29 & 0,42 & 0,23 & nd & 0,40 & 0,28 & 0,38 \\
\hline C25 & nd & nd & 0,51 & 0,53 & 0,28 & nd & 0,57 & 0,77 & 0,40 \\
\hline $\mathrm{C} 26$ & 0,43 & 0,62 & 1,26 & 0,90 & 0,38 & 0,34 & 1,02 & 0,89 & 0,79 \\
\hline $\mathrm{C} 27$ & 0,94 & 1,08 & 2,31 & 1,27 & 0,53 & 0,30 & 1,62 & 3,82 & 1,18 \\
\hline $\mathrm{C} 28$ & 0,74 & 0,74 & 2,32 & 0,18 & 0,79 & nd & 1,48 & 20,75 & 0,98 \\
\hline C29 & 1,30 & 0,44 & 5,65 & nd & 1,46 & nd & 1,91 & 10,48 & 1,95 \\
\hline C30 & 0,17 & nd & 1,95 & nd & 0,96 & nd & nd & 5,95 & 0,93 \\
\hline C31 & 0,28 & 1,92 & 4,12 & nd & 1,68 & nd & nd & 0,84 & 2,80 \\
\hline C32 & nd & nd & 0,52 & nd & 0,53 & nd & nd & nd & 0,93 \\
\hline C33 & nd & nd & nd & nd & 1,56 & nd & nd & nd & 1,85 \\
\hline C34 & 0,19 & nd & nd & nd & nd & nd & nd & nd & 0,64 \\
\hline C35 & nd & nd & nd & nd & 0,37 & nd & nd & nd & 0,67 \\
\hline C36 & nd & nd & nd & nd & nd & nd & nd & nd & 0,22 \\
\hline C37 & nd & nd & nd & nd & nd & nd & nd & 0,83 & nd \\
\hline C38 & nd & nd & nd & nd & nd & nd & nd & nd & nd \\
\hline C39 & nd & nd & nd & nd & nd & nd & nd & nd & nd \\
\hline C40 & nd & nd & nd & nd & nd & nd & nd & nd & nd \\
\hline n-alcanos & 4,85 & 6,23 & 22,03 & 5,91 & 10,06 & 2,42 & 9,67 & 93,05 & 16,07 \\
\hline HR & 12,70 & 48,88 & 79,64 & 19,87 & 12,56 & 38,42 & 32,98 & 411,19 & 22,51 \\
\hline $\begin{array}{l}\text { MCNR } \\
\text { Alitaticos }\end{array}$ & 105,9 & 293,7 & 270,9 & 144,0 & 13,9 & 88,2 & 131,1 & 1920,3 & 134,0 \\
\hline Totais & 118,6 & 342,6 & 350,5 & 163,9 & 26,4 & 126,6 & 164,0 & 2331,5 & 156,5 \\
\hline $\operatorname{Rec}(\%)$ & 74 & 85 & 96 & 65 & 53 & 94 & 74 & 93 & 75 \\
\hline
\end{tabular}


Resultado de hidrocarbonetos alifáticos, em $\mathrm{ng} \mathrm{m}^{-3}$, para as amostras de material particulado atmosférico $\left(\mathrm{PM}_{2,5}\right)$ coletadas no ano de 2011

\begin{tabular}{|c|c|c|c|c|}
\hline Código & CP290 & CP314 & CP326 & CP344 \\
\hline Data & 17-out & 10-nov & 22-nov & 10-dez \\
\hline C12 & nd & nd & nd & nd \\
\hline C13 & nd & nd & nd & nd \\
\hline C14 & nd & nd & nd & nd \\
\hline C15 & nd & 0,76 & nd & nd \\
\hline C16 & 0,29 & 0,26 & 0,30 & nd \\
\hline C17 & 0,46 & 0,48 & 0,53 & nd \\
\hline Pristano & 0,36 & 0,42 & 0,38 & nd \\
\hline C18 & 0,52 & 0,49 & 0,52 & nd \\
\hline Fitano & 0,51 & 0,38 & 0,38 & nd \\
\hline C19 & 0,35 & 0,41 & 0,40 & nd \\
\hline $\mathrm{C} 20$ & 0,56 & 0,30 & 0,36 & nd \\
\hline C21 & 0,39 & nd & 0,29 & nd \\
\hline $\mathrm{C} 22$ & 0,41 & 0,29 & 0,36 & nd \\
\hline $\mathrm{C} 23$ & 0,45 & nd & 0,31 & nd \\
\hline $\mathrm{C} 24$ & 0,72 & 0,30 & 0,43 & nd \\
\hline $\mathrm{C} 25$ & 1,54 & 0,31 & 0,52 & 0,56 \\
\hline C26 & 2,88 & 0,42 & 0,74 & 1,15 \\
\hline $\mathrm{C} 27$ & 5,06 & 1,06 & 1,03 & 2,06 \\
\hline $\mathrm{C} 28$ & 5,99 & 1,11 & 1,19 & 2,61 \\
\hline C29 & 7,36 & 2,10 & 2,01 & 3,54 \\
\hline C30 & 6,02 & 0,78 & 1,33 & 2,90 \\
\hline C31 & 6,98 & 3,19 & 3,17 & 3,97 \\
\hline C32 & 4,41 & 0,97 & 0,96 & 2,75 \\
\hline C33 & 4,16 & 2,14 & 1,96 & 2,64 \\
\hline C34 & 2,63 & 0,27 & 0,96 & 1,69 \\
\hline C35 & 2,26 & 0,74 & 0,85 & 1,50 \\
\hline C36 & 1,41 & nd & nd & 0,92 \\
\hline C37 & 1,17 & nd & nd & 0,75 \\
\hline C38 & 0,83 & nd & nd & 0,55 \\
\hline C39 & 0,52 & nd & nd & nd \\
\hline $\mathrm{C} 40$ & 0,59 & nd & nd & nd \\
\hline n-alcanos & 57,98 & 16,39 & 18,24 & 27,56 \\
\hline HR & 111,91 & 51,42 & 28,14 & 28,01 \\
\hline $\begin{array}{l}\text { MCNR } \\
\text { Alitaticos }\end{array}$ & 248,6 & 148,1 & 169,5 & 81,0 \\
\hline Totais & 360,5 & 199,6 & 197,6 & 107,0 \\
\hline $\operatorname{Rec}(\%)$ & 68 & 59 & 68 & 74 \\
\hline
\end{tabular}


Resultado de hidrocarbonetos alifáticos, em $\mathrm{ng} \mathrm{m}^{-3}$, para as amostras de material particulado atmosférico $\left(\mathrm{PM}_{2,5}\right)$ coletadas no ano de 2011

\begin{tabular}{|c|c|c|c|c|c|c|c|c|c|}
\hline Código & NT 20 & NT 26 & NT 32 & NT 38 & NT 44 & NT 50 & NT 56 & NT 92 & NT 98 \\
\hline Data & 20-jan & 26-jan & 1-fev & 7-fev & 13-fev & 19-fev & 25-fev & 2-abr & 8-abr \\
\hline C12 & nd & nd & nd & nd & nd & nd & nd & nd & nd \\
\hline C13 & nd & nd & nd & nd & nd & nd & nd & nd & nd \\
\hline C14 & nd & nd & nd & nd & nd & nd & nd & nd & nd \\
\hline C15 & nd & nd & nd & 2,41 & nd & nd & nd & nd & nd \\
\hline C16 & nd & nd & nd & nd & nd & nd & nd & nd & nd \\
\hline C17 & nd & nd & nd & nd & nd & nd & nd & nd & nd \\
\hline Pristano & nd & nd & 0,28 & nd & nd & 0,16 & nd & 0,33 & 0,25 \\
\hline C18 & nd & nd & 0,18 & 0,28 & nd & 0,12 & nd & 0,34 & nd \\
\hline Fitano & nd & nd & nd & nd & nd & 0,11 & nd & 0,27 & nd \\
\hline C19 & nd & nd & 0,25 & 0,30 & nd & nd & nd & 0,33 & 0,30 \\
\hline $\mathrm{C} 20$ & nd & nd & 0,24 & 0,41 & 0,36 & nd & nd & 0,27 & 0,33 \\
\hline $\mathrm{C} 21$ & nd & nd & nd & 0,46 & 0,28 & nd & nd & nd & 0,21 \\
\hline $\mathrm{C} 22$ & nd & nd & nd & 0,54 & 0,33 & 0,21 & nd & nd & 0,21 \\
\hline $\mathrm{C} 23$ & nd & nd & 0,19 & 0,67 & 0,42 & 0,49 & nd & nd & 0,20 \\
\hline C24 & nd & nd & 0,26 & 1,04 & 0,66 & 1,08 & 0,19 & nd & nd \\
\hline C25 & 0,26 & nd & 0,38 & 1,08 & 1,22 & 1,70 & 0,28 & nd & 0,22 \\
\hline C26 & 0,38 & nd & 0,67 & 1,50 & 2,99 & 3,09 & 0,60 & nd & 0,41 \\
\hline C27 & 0,55 & nd & 1,59 & 2,28 & 8,16 & 6,58 & 0,77 & 0,30 & 0,66 \\
\hline C28 & 0,87 & 0,81 & 2,42 & 2,83 & 12,51 & 8,95 & 0,54 & 0,59 & 0,96 \\
\hline C29 & 2,07 & 0,19 & 4,63 & 5,05 & 19,99 & 13,41 & 0,33 & 0,96 & 2,07 \\
\hline C30 & 1,51 & nd & 3,01 & 2,96 & 14,28 & 10,32 & nd & 0,64 & 1,03 \\
\hline C31 & 2,28 & nd & 4,92 & 4,51 & 14,63 & 10,34 & nd & 0,43 & 1,54 \\
\hline C32 & 0,66 & nd & 2,01 & 1,77 & 5,58 & 4,37 & nd & nd & 0,27 \\
\hline C33 & 1,18 & nd & 3,09 & 2,78 & 6,46 & 4,99 & nd & nd & 0,57 \\
\hline C34 & nd & nd & 0,82 & 0,42 & nd & 0,98 & nd & nd & nd \\
\hline C35 & nd & nd & 1,16 & nd & nd & 0,89 & nd & nd & nd \\
\hline C36 & nd & nd & nd & nd & nd & nd & nd & nd & nd \\
\hline C37 & nd & nd & nd & nd & nd & nd & nd & nd & nd \\
\hline C38 & nd & nd & nd & nd & nd & nd & nd & nd & nd \\
\hline C39 & nd & nd & nd & nd & nd & nd & nd & nd & nd \\
\hline C40 & nd & nd & nd & nd & nd & nd & nd & nd & nd \\
\hline n-alcanos & 9,76 & 0,99 & 25,82 & 31,31 & 87,88 & 67,51 & 2,71 & 3,87 & 8,98 \\
\hline HR & 32,40 & 14,36 & 39,26 & 118,48 & 159,11 & 91,86 & 3,48 & 4,80 & 10,11 \\
\hline $\begin{array}{l}\text { MCNR } \\
\text { Alifáticos }\end{array}$ & 68,6 & 20,9 & 77,9 & 223,9 & 150,3 & 26,9 & 42,7 & 83,5 & 77,7 \\
\hline Totais & 101,0 & 35,3 & 117,1 & 342,4 & 309,4 & 118,8 & 46,2 & 88,3 & 87,8 \\
\hline $\operatorname{Rec}(\%)$ & 74 & 75 & 57 & 64 & 63 & 70 & 84 & 70 & 82 \\
\hline
\end{tabular}


Resultado de hidrocarbonetos alifáticos, em $\mathrm{ng} \mathrm{m}^{-3}$, para as amostras de material particulado atmosférico $\left(\mathrm{PM}_{2,5}\right)$ coletadas no ano de 2011

\begin{tabular}{|c|c|c|c|c|c|c|c|c|c|}
\hline Código & NT 104 & NT 110 & NT 116 & NT 122 & NT 128 & NT 134 & NT 140 & NT 146 & NT 152 \\
\hline Data & 14-abr & $20-a b r$ & 26-abr & 2-mai & 8-mai & 14-mai & 20-mai & 26-mai & 1-jun \\
\hline C12 & nd & nd & nd & nd & nd & nd & nd & nd & nd \\
\hline C13 & nd & nd & nd & nd & nd & nd & nd & nd & nd \\
\hline C14 & nd & nd & nd & nd & nd & nd & nd & nd & nd \\
\hline C15 & nd & nd & nd & nd & nd & nd & nd & nd & nd \\
\hline C16 & nd & nd & nd & nd & nd & nd & nd & nd & nd \\
\hline C17 & 0,24 & 0,22 & nd & nd & nd & 0,21 & 0,31 & 0,30 & 0,10 \\
\hline Pristano & 0,21 & 0,35 & nd & nd & nd & nd & nd & nd & nd \\
\hline C18 & 0,39 & 0,43 & nd & nd & nd & nd & nd & nd & nd \\
\hline Fitano & 0,24 & 0,26 & nd & nd & nd & nd & nd & nd & nd \\
\hline C19 & 0,50 & 0,41 & nd & nd & nd & nd & nd & nd & nd \\
\hline $\mathrm{C} 20$ & 0,45 & 0,26 & nd & nd & nd & nd & nd & nd & nd \\
\hline $\mathrm{C} 21$ & 0,29 & nd & nd & nd & nd & nd & nd & nd & nd \\
\hline $\mathrm{C} 22$ & 0,32 & nd & nd & nd & nd & nd & nd & nd & nd \\
\hline $\mathrm{C} 23$ & 0,30 & nd & nd & nd & nd & nd & nd & nd & nd \\
\hline $\mathrm{C} 24$ & 0,45 & nd & nd & nd & nd & nd & nd & 0,22 & nd \\
\hline C25 & 0,62 & 0,30 & nd & nd & nd & nd & 1,38 & 0,50 & 0,07 \\
\hline C26 & 1,06 & 0,72 & nd & nd & 0,26 & nd & 0,39 & 1,66 & 0,21 \\
\hline C27 & 2,14 & 1,19 & 0,32 & nd & 0,71 & 0,22 & 1,93 & 3,53 & 0,46 \\
\hline C28 & 3,26 & 1,43 & 0,52 & nd & 0,89 & 0,23 & 0,96 & 4,76 & 0,60 \\
\hline C29 & 7,67 & 2,64 & 0,56 & nd & 0,80 & 0,25 & 3,41 & 7,47 & 0,93 \\
\hline C30 & 4,39 & 1,59 & 0,38 & nd & nd & nd & 1,19 & 5,69 & 0,76 \\
\hline C31 & 8,22 & 2,55 & 0,65 & nd & 0,77 & 0,60 & 2,43 & 8,00 & 1,14 \\
\hline C32 & 3,16 & 0,69 & 0,40 & nd & nd & 0,69 & 0,57 & 3,33 & 0,53 \\
\hline C33 & 4,71 & 1,37 & 0,44 & nd & nd & 0,73 & nd & 1,54 & 0,65 \\
\hline C34 & 1,65 & nd & nd & nd & nd & 0,83 & nd & nd & 0,21 \\
\hline C35 & 1,89 & nd & nd & nd & 0,30 & 0,72 & 0,35 & nd & 0,17 \\
\hline C36 & 0,67 & nd & nd & nd & nd & 0,24 & nd & nd & nd \\
\hline C37 & 0,40 & nd & nd & nd & nd & 0,19 & nd & nd & nd \\
\hline C38 & 0,25 & nd & nd & nd & nd & 0,22 & nd & nd & nd \\
\hline C39 & 0,29 & nd & nd & nd & nd & nd & nd & nd & nd \\
\hline C40 & nd & nd & nd & nd & nd & nd & nd & nd & nd \\
\hline n-alcanos & 43,30 & 13,81 & 3,26 & nd & 3,72 & 5,14 & 12,93 & 37,00 & 5,83 \\
\hline HR & 143,16 & 16,08 & 20,63 & nd & 3,72 & 19,19 & 12,93 & 37,00 & 44,17 \\
\hline $\begin{array}{l}\text { MCNR } \\
\text { Alitaticos }\end{array}$ & 302,55 & 67,0 & 326,7 & 88,7 & 174,7 & 96,4 & 255,5 & 211,1 & 145,2 \\
\hline Totais & 445,7 & 83,1 & 347,3 & 88,7 & 178,4 & 115,6 & 268,4 & 248,1 & 189,4 \\
\hline $\operatorname{Rec}(\%)$ & 76 & 71 & 72 & 59 & 57 & 85 & 80 & 72 & 101 \\
\hline
\end{tabular}


Resultado de hidrocarbonetos alifáticos, em $\mathrm{ng} \mathrm{m}^{-3}$, para as amostras de material particulado atmosférico $\left(\mathrm{PM}_{2,5}\right)$ coletadas no ano de 2011

\begin{tabular}{|c|c|c|c|c|c|c|c|c|c|}
\hline Código & NT 158 & NT 164 & NT 176 & NT 182 & NT 188 & NT 206 & NT 212 & NT 218 & NT 224 \\
\hline Data & 7-jun & 13-jun & 25-jun & 1-jul & 7-jul & 25-jul & 31-jul & 6-ago & 12-ago \\
\hline C12 & nd & nd & nd & nd & nd & nd & nd & nd & $\mathrm{nd}$ \\
\hline C13 & nd & nd & nd & nd & nd & nd & nd & nd & nd \\
\hline C14 & nd & nd & nd & nd & nd & nd & nd & nd & nd \\
\hline C15 & nd & nd & nd & 0,93 & nd & nd & nd & nd & 0,37 \\
\hline C16 & nd & nd & nd & nd & nd & nd & nd & nd & 0,41 \\
\hline C17 & 0,24 & 0,09 & nd & 0,50 & nd & nd & 0,72 & 0,42 & 0,76 \\
\hline Pristano & nd & nd & nd & nd & nd & nd & nd & nd & 0,69 \\
\hline C18 & nd & 0,05 & nd & 0,29 & nd & nd & 0,37 & 0,34 & 0,69 \\
\hline Fitano & nd & nd & nd & nd & nd & nd & nd & nd & 0,60 \\
\hline C19 & nd & nd & nd & nd & nd & nd & nd & 0,23 & 0,49 \\
\hline $\mathrm{C} 20$ & nd & nd & nd & nd & nd & nd & nd & nd & 0,32 \\
\hline $\mathrm{C} 21$ & nd & nd & nd & nd & nd & nd & nd & nd & 0,26 \\
\hline $\mathrm{C} 22$ & nd & nd & nd & nd & nd & nd & nd & nd & 0,26 \\
\hline $\mathrm{C} 23$ & nd & 0,05 & nd & nd & nd & nd & nd & nd & 0,21 \\
\hline $\mathrm{C} 24$ & nd & 0,15 & nd & nd & nd & nd & nd & 0,26 & 0,21 \\
\hline C25 & nd & 0,28 & nd & 0,37 & nd & nd & nd & 0,47 & 0,87 \\
\hline $\mathrm{C} 26$ & 0,38 & 1,48 & nd & 1,36 & nd & nd & 0,58 & 1,13 & 1,93 \\
\hline $\mathrm{C} 27$ & 0,86 & 2,53 & nd & 2,81 & 0,45 & 0,39 & 1,32 & 2,48 & 2,99 \\
\hline $\mathrm{C} 28$ & 1,15 & 3,21 & nd & 3,26 & 0,64 & 0,53 & 1,50 & 3,32 & 3,57 \\
\hline C29 & 2,84 & 4,28 & nd & 6,11 & 1,12 & 1,12 & 2,97 & 7,64 & 8,03 \\
\hline C30 & 1,39 & 3,47 & nd & 2,55 & nd & nd & 1,66 & 4,39 & 1,96 \\
\hline C31 & 3,66 & 3,31 & 0,22 & 7,30 & 1,83 & nd & 3,21 & 10,18 & 1,07 \\
\hline C32 & 1,21 & 2,54 & nd & 2,15 & 0,55 & nd & 1,10 & 3,48 & nd \\
\hline C33 & 2,23 & 2,05 & 0,21 & 2,28 & 0,42 & nd & 0,37 & 6,31 & nd \\
\hline C34 & 0,43 & 0,81 & nd & 0,49 & nd & 0,25 & nd & 1,43 & nd \\
\hline C35 & 0,34 & 0,39 & nd & 0,45 & 0,36 & nd & nd & 0,71 & nd \\
\hline C36 & nd & nd & nd & nd & nd & nd & nd & nd & nd \\
\hline C37 & nd & nd & nd & nd & nd & nd & nd & nd & nd \\
\hline C38 & nd & nd & nd & nd & nd & nd & nd & nd & nd \\
\hline C39 & nd & nd & nd & nd & nd & nd & nd & nd & nd \\
\hline C40 & nd & nd & $\mathrm{nd}$ & nd & nd & nd & nd & nd & nd \\
\hline n-alcanos & 14,74 & 24,69 & 0,43 & 30,84 & 5,38 & 2,29 & 13,81 & 42,77 & 24,39 \\
\hline HR & 35,76 & 89,84 & 0,43 & 203,16 & 31,83 & 13,80 & 53,50 & 121,82 & 70,63 \\
\hline $\begin{array}{l}\text { MCNR } \\
\text { Alitaticos }\end{array}$ & 112,1 & 151,3 & nd & 659,6 & 218,7 & 182,9 & 189,1 & 415,3 & 233,4 \\
\hline Totais & 147,9 & 241,1 & 0,4 & 862,8 & 250,5 & 196,7 & 242,6 & 537,1 & 304,1 \\
\hline $\operatorname{Rec}(\%)$ & 101 & 113 & 107 & 82 & 82 & 98 & 75 & 104 & 52 \\
\hline
\end{tabular}


Resultado de hidrocarbonetos alifáticos, em $\mathrm{ng} \mathrm{m}^{-3}$, para as amostras de material particulado atmosférico $\left(\mathrm{PM}_{2,5}\right)$ coletadas no ano de 2011

\begin{tabular}{|c|c|c|c|c|c|c|c|c|c|}
\hline Código & NT 230 & NT 236 & NT 242 & NT 248 & NT 254 & NT 260 & NT 266 & NT 272 & NT 284 \\
\hline Data & 18-ago & 24-ago & 30 -ago & 5-set & 11-set & 17-set & 23-set & 29-set & 11-out \\
\hline C12 & nd & nd & nd & nd & nd & nd & nd & nd & nd \\
\hline C13 & nd & nd & nd & nd & nd & nd & nd & nd & nd \\
\hline C14 & nd & nd & nd & nd & nd & nd & nd & nd & nd \\
\hline C15 & 0,47 & nd & 0,39 & nd & nd & 0,19 & 0,18 & nd & nd \\
\hline C16 & 0,66 & nd & nd & 0,26 & nd & nd & nd & nd & nd \\
\hline C17 & 1,21 & 0,24 & 1,08 & 0,21 & nd & 0,19 & nd & nd & nd \\
\hline Pristano & 0,89 & 0,21 & 0,40 & 0,57 & nd & 0,19 & nd & nd & nd \\
\hline C18 & 1,06 & 0,26 & 0,85 & 0,46 & nd & 0,18 & 0,16 & nd & nd \\
\hline Fitano & 0,68 & 0,18 & nd & 0,38 & nd & 0,20 & nd & nd & nd \\
\hline C19 & 0,77 & 0,26 & 0,39 & 0,56 & nd & 0,19 & 0,27 & nd & nd \\
\hline $\mathrm{C} 20$ & 0,47 & nd & nd & 0,55 & nd & nd & 0,26 & nd & nd \\
\hline $\mathrm{C} 21$ & 0,37 & nd & nd & 0,35 & nd & nd & 0,23 & nd & nd \\
\hline $\mathrm{C} 22$ & 0,39 & nd & nd & 0,36 & 0,20 & nd & 0,28 & nd & nd \\
\hline C23 & 0,40 & nd & nd & 0,36 & 0,19 & nd & 0,25 & nd & nd \\
\hline $\mathrm{C} 24$ & 0,51 & 0,19 & nd & 0,64 & 0,21 & nd & 0,27 & nd & nd \\
\hline $\mathrm{C} 25$ & 1,13 & 0,35 & 0,51 & 1,21 & 0,27 & nd & 0,42 & 0,20 & 0,24 \\
\hline C26 & 2,81 & 0,95 & 1,10 & 2,25 & 0,57 & 0,50 & 1,20 & 0,82 & 0,76 \\
\hline $\mathrm{C} 27$ & 4,74 & 1,57 & 2,20 & 3,38 & 0,56 & 0,62 & 2,00 & 1,96 & 1,56 \\
\hline C28 & 5,07 & 1,87 & 1,07 & 1,56 & 0,89 & 0,77 & 2,34 & 1,58 & 1,58 \\
\hline C29 & 10,67 & 3,64 & nd & 0,32 & 0,92 & 1,47 & 3,83 & 2,08 & 2,65 \\
\hline C30 & 5,55 & 2,35 & nd & nd & nd & 0,46 & 1,10 & 0,38 & 1,32 \\
\hline C31 & 9,98 & 3,98 & 0,33 & nd & nd & 0,42 & 0,42 & 0,30 & 2,68 \\
\hline C32 & 2,72 & 2,04 & nd & nd & nd & nd & 0,24 & nd & 1,04 \\
\hline C33 & 2,41 & 2,52 & nd & nd & nd & nd & nd & nd & 2,45 \\
\hline C34 & nd & 1,49 & nd & nd & nd & nd & nd & nd & 0,65 \\
\hline C35 & nd & 1,28 & 0,34 & nd & nd & nd & nd & 0,17 & 1,25 \\
\hline C36 & nd & 0,65 & nd & nd & nd & nd & nd & nd & 0,30 \\
\hline C37 & nd & 0,48 & nd & nd & nd & nd & nd & nd & 0,32 \\
\hline C38 & nd & 0,28 & nd & nd & nd & nd & nd & nd & 0,27 \\
\hline C39 & nd & nd & nd & nd & nd & nd & nd & nd & nd \\
\hline C40 & nd & 0,18 & nd & nd & nd & nd & nd & nd & nd \\
\hline n-alcanos & 51,40 & 24,59 & 8,25 & 12,48 & 3,82 & 4,98 & 13,46 & 7,50 & 17,06 \\
\hline HR & 148,77 & 30,82 & 46,27 & 42,29 & 63,62 & 41,29 & 33,32 & 30,80 & 17,06 \\
\hline $\begin{array}{l}\text { MCNR } \\
\text { Alifáticos }\end{array}$ & 401,9 & 159,3 & 341,2 & 224,1 & 173,9 & 126,9 & 205,7 & 204,3 & 99,2 \\
\hline Totais & 550,7 & 190,1 & 387,5 & 266,4 & 237,5 & 168,2 & 239,0 & 235,1 & 116,3 \\
\hline $\operatorname{Rec}(\%)$ & 103 & 71 & 140 & 80 & 75 & 72 & 44 & 67 & 55 \\
\hline
\end{tabular}


Resultado de hidrocarbonetos alifáticos, em $\mathrm{ng} \mathrm{m}^{-3}$, para as amostras de material particulado atmosférico $\left(\mathrm{PM}_{2,5}\right)$ coletadas no ano de 2011

\begin{tabular}{|c|c|c|c|c|}
\hline Código & NT 290 & NT 326 & NT 350 & NT 356 \\
\hline Data & 17-out & 22-nov & 16-dez & 22-dez \\
\hline C12 & nd & nd & nd & nd \\
\hline C13 & nd & nd & nd & nd \\
\hline C14 & nd & nd & nd & nd \\
\hline C15 & nd & nd & nd & nd \\
\hline C16 & nd & nd & nd & nd \\
\hline C17 & nd & nd & 0,31 & 0,31 \\
\hline Pristano & nd & nd & 0,25 & 0,34 \\
\hline C18 & nd & nd & 0,40 & 0,53 \\
\hline Fitano & nd & nd & 0,33 & 0,91 \\
\hline C19 & nd & nd & 0,39 & 0,29 \\
\hline $\mathrm{C} 20$ & nd & nd & 0,36 & 0,65 \\
\hline $\mathrm{C} 21$ & nd & nd & 0,27 & 0,60 \\
\hline $\mathrm{C} 22$ & nd & nd & 0,29 & 0,59 \\
\hline $\mathrm{C} 23$ & nd & nd & 0,27 & 0,76 \\
\hline $\mathrm{C} 24$ & nd & nd & 0,38 & 1,29 \\
\hline $\mathrm{C} 25$ & nd & nd & 0,53 & 2,99 \\
\hline $\mathrm{C} 26$ & 0,42 & 0,31 & 0,64 & 5,39 \\
\hline $\mathrm{C} 27$ & 0,83 & 0,42 & 1,03 & 10,27 \\
\hline $\mathrm{C} 28$ & 0,93 & 0,58 & 0,90 & 13,98 \\
\hline C29 & 1,09 & 1,51 & 0,97 & 19,71 \\
\hline C30 & 0,74 & 0,93 & 0,65 & 19,92 \\
\hline C31 & 1,55 & 1,87 & 0,63 & 23,39 \\
\hline C32 & 0,86 & 0,78 & nd & 19,69 \\
\hline C33 & 1,43 & 1,16 & nd & 18,56 \\
\hline C34 & 0,62 & 0,65 & 0,31 & 14,17 \\
\hline C35 & 0,89 & 0,63 & nd & 12,54 \\
\hline C36 & nd & 0,37 & nd & 9,76 \\
\hline C37 & nd & 0,31 & nd & 7,84 \\
\hline C38 & nd & 0,30 & nd & 5,68 \\
\hline C39 & nd & 0,30 & nd & 5,01 \\
\hline C40 & nd & 0,29 & nd & 4,17 \\
\hline n-alcanos & 9,37 & 10,41 & 8,33 & 198,08 \\
\hline HR & 9,37 & 27,89 & 53,96 & 308,66 \\
\hline $\begin{array}{l}\text { MCNR } \\
\text { Alitaticos }\end{array}$ & 294,7 & 45,8 & 208,1 & 409,6 \\
\hline Totais & 304,1 & 73,7 & 262,1 & 718,3 \\
\hline $\operatorname{Rec}(\%)$ & 76 & 52 & 80 & 75 \\
\hline
\end{tabular}


Resultado de hidrocarbonetos alifáticos, em $\mathrm{ng} \mathrm{m}^{-3}$, para as amostras de material particulado atmosférico $\left(\mathrm{PM}_{2,5}\right)$ coletadas no ano de 2011

\begin{tabular}{|c|c|c|c|c|c|c|c|c|c|}
\hline Código & SE 8 & SE 12 & SE 14 & SE 18 & SE 20 & SE 26 & SE 29 & SE 34 & SE 38 \\
\hline Data & 8-jan & 12-jan & 14-jan & 18-jan & 20-jan & 26-jan & 29-jan & 3-fev & 7-fev \\
\hline C12 & nd & nd & nd & nd & nd & nd & nd & nd & 0,45 \\
\hline C13 & nd & nd & nd & nd & nd & nd & nd & nd & 0,50 \\
\hline C14 & nd & nd & nd & nd & nd & nd & nd & nd & 0,51 \\
\hline C15 & nd & nd & nd & nd & nd & nd & nd & nd & 0,36 \\
\hline C16 & nd & nd & nd & nd & nd & nd & nd & nd & 0,51 \\
\hline C17 & nd & nd & nd & nd & nd & nd & nd & nd & 0,82 \\
\hline Pristano & nd & nd & nd & nd & nd & nd & nd & nd & 0,39 \\
\hline C18 & nd & nd & nd & nd & nd & nd & nd & nd & 0,82 \\
\hline Fitano & nd & nd & nd & nd & nd & nd & nd & 0,21 & 0,47 \\
\hline C19 & nd & nd & nd & nd & nd & nd & nd & nd & 0,65 \\
\hline $\mathrm{C} 20$ & nd & nd & nd & nd & nd & nd & nd & nd & 0,61 \\
\hline $\mathrm{C} 21$ & nd & nd & nd & nd & nd & nd & nd & nd & 0,50 \\
\hline $\mathrm{C} 22$ & nd & nd & nd & nd & nd & nd & nd & nd & 0,57 \\
\hline $\mathrm{C} 23$ & nd & nd & nd & nd & nd & nd & nd & nd & 0,48 \\
\hline C24 & nd & nd & nd & 0,24 & nd & nd & nd & nd & 0,60 \\
\hline C25 & nd & nd & nd & 0,27 & nd & nd & nd & nd & 0,56 \\
\hline C26 & nd & nd & nd & 0,35 & nd & 0,32 & 0,29 & 0,27 & 0,77 \\
\hline $\mathrm{C} 27$ & nd & nd & nd & 0,37 & nd & 0,36 & 0,51 & 0,33 & 0,55 \\
\hline C28 & nd & nd & nd & 0,53 & nd & 0,60 & 0,45 & 0,61 & 0,20 \\
\hline C29 & nd & 0,28 & nd & 1,21 & nd & 1,21 & 0,30 & 1,35 & nd \\
\hline C30 & nd & nd & nd & 0,74 & nd & 0,76 & nd & 1,11 & nd \\
\hline C31 & 1,97 & 0,35 & nd & 0,87 & 0,73 & 1,06 & nd & 1,77 & nd \\
\hline C32 & nd & 0,16 & nd & nd & nd & nd & nd & 0,88 & nd \\
\hline C33 & nd & nd & nd & 0,36 & 0,95 & 0,73 & nd & 0,84 & nd \\
\hline C34 & nd & nd & nd & nd & nd & nd & nd & 0,22 & nd \\
\hline C35 & nd & nd & nd & nd & 1,36 & nd & nd & nd & nd \\
\hline C36 & nd & nd & nd & nd & nd & nd & nd & nd & nd \\
\hline C37 & nd & nd & nd & nd & nd & nd & nd & nd & nd \\
\hline C38 & nd & nd & nd & nd & nd & nd & nd & nd & nd \\
\hline C39 & nd & nd & nd & nd & nd & nd & nd & nd & nd \\
\hline C40 & nd & nd & nd & nd & nd & nd & nd & nd & nd \\
\hline n-alcanos & 1,97 & 0,78 & nd & 4,93 & 3,05 & 5,04 & 1,55 & 7,37 & 9,46 \\
\hline HR & 1,97 & 0,78 & nd & 16,10 & 4,39 & 30,71 & 10,19 & 9,02 & 10,45 \\
\hline $\begin{array}{l}\text { MCNR } \\
\text { Alifáticos }\end{array}$ & 34,6 & 41,0 & 43,2 & 20,8 & nd & 32,0 & 126,2 & 75,5 & 91,6 \\
\hline Totais & 36,6 & 41,8 & 43,2 & 36,9 & 4,4 & 62,7 & 136,4 & 84,5 & 98,0 \\
\hline $\operatorname{Rec}(\%)$ & 83 & 65 & 124 & 74 & 56 & 65 & 68 & 70 & 49 \\
\hline
\end{tabular}


Resultado de hidrocarbonetos alifáticos, em $\mathrm{ng} \mathrm{m}^{-3}$, para as amostras de material particulado atmosférico $\left(\mathrm{PM}_{2,5}\right)$ coletadas no ano de 2011

\begin{tabular}{|c|c|c|c|c|c|c|c|c|c|}
\hline Código & SE 40 & SE 44 & SE 50 & SE 56 & SE 62 & SE 68 & SE 74 & SE 80 & SE 86 \\
\hline Data & 9-fev & 13-fev & 19-fev & 25-fev & 3-mar & 9-mar & 15-mar & 21-mar & 27-mar \\
\hline C12 & nd & 0,48 & nd & 0,46 & nd & nd & nd & nd & nd \\
\hline C13 & nd & 0,50 & nd & 0,47 & 0,22 & nd & nd & nd & nd \\
\hline C14 & nd & 0,52 & nd & 0,48 & nd & nd & nd & nd & nd \\
\hline C15 & nd & 0,41 & nd & 0,37 & nd & nd & nd & nd & nd \\
\hline C16 & nd & 0,60 & nd & 0,52 & nd & nd & nd & nd & nd \\
\hline C17 & nd & 0,97 & nd & 0,82 & nd & nd & nd & nd & nd \\
\hline Pristano & nd & 0,52 & 0,23 & 0,41 & nd & 0,43 & 0,34 & 0,29 & 0,33 \\
\hline C18 & nd & 0,89 & 0,21 & 0,77 & nd & nd & nd & nd & 0,29 \\
\hline Fitano & nd & 0,52 & 0,20 & 0,45 & nd & nd & nd & nd & 0,28 \\
\hline C19 & nd & 0,67 & nd & 0,60 & nd & nd & nd & nd & 0,37 \\
\hline $\mathrm{C} 20$ & nd & 0,63 & nd & 0,58 & nd & nd & nd & nd & 0,32 \\
\hline $\mathrm{C} 21$ & nd & 0,47 & nd & 0,47 & nd & nd & nd & nd & nd \\
\hline $\mathrm{C} 22$ & nd & 0,53 & nd & 0,55 & nd & nd & nd & nd & nd \\
\hline $\mathrm{C} 23$ & nd & 0,53 & nd & 0,50 & 0,26 & nd & nd & nd & nd \\
\hline $\mathrm{C} 24$ & nd & 0,91 & 0,25 & 0,61 & 0,34 & nd & nd & nd & nd \\
\hline $\mathrm{C} 25$ & nd & 1,68 & 0,57 & 0,84 & nd & nd & nd & nd & nd \\
\hline $\mathrm{C} 26$ & 0,81 & 3,89 & 1,51 & 1,82 & nd & nd & nd & nd & 0,23 \\
\hline $\mathrm{C} 27$ & 2,09 & 7,19 & 2,75 & 4,23 & nd & nd & nd & nd & 0,54 \\
\hline C28 & 1,81 & 9,56 & 1,44 & 5,71 & nd & 0,24 & nd & 0,28 & 0,75 \\
\hline $\mathrm{C} 29$ & 0,83 & 13,73 & nd & 8,76 & nd & 0,25 & 0,48 & 0,32 & 1,61 \\
\hline C30 & nd & 11,00 & nd & 6,45 & nd & nd & nd & nd & 0,88 \\
\hline C31 & nd & 13,30 & nd & 6,62 & nd & nd & nd & nd & 1,01 \\
\hline C32 & nd & 6,56 & nd & 0,93 & nd & nd & nd & nd & nd \\
\hline C33 & nd & 5,92 & nd & nd & nd & nd & nd & nd & 0,52 \\
\hline C34 & nd & 1,29 & nd & nd & nd & nd & nd & nd & nd \\
\hline C35 & nd & nd & nd & nd & nd & nd & nd & nd & nd \\
\hline C36 & nd & nd & nd & nd & 0,82 & nd & nd & nd & nd \\
\hline C37 & nd & nd & nd & nd & 86,51 & nd & nd & nd & nd \\
\hline C38 & nd & nd & nd & nd & 261,39 & nd & nd & nd & nd \\
\hline C39 & nd & nd & nd & nd & 347,91 & nd & nd & nd & nd \\
\hline C40 & nd & nd & nd & nd & nd & nd & nd & nd & nd \\
\hline n-alcanos & 5,54 & 82,21 & 6,74 & 42,56 & 697,45 & 0,49 & 0,48 & 0,60 & 6,51 \\
\hline HR & 5,54 & 143,08 & 7,17 & 69,20 & 86,51 & 94,28 & 138,29 & 156,48 & 134,44 \\
\hline $\begin{array}{l}\text { MCNR } \\
\text { Alitaticos }\end{array}$ & 88,22 & 150,8 & 69,2 & 105,2 & 174,9 & 166,0 & 255,0 & 587,1 & 342,2 \\
\hline Totais & 93,8 & 293,8 & 76,3 & 174,4 & 261,4 & 260,3 & 393,3 & 743,5 & 476,7 \\
\hline$\overline{\operatorname{Rec}(\%)}$ & 62 & 88 & 87 & 88 & 58 & 65 & 91 & 74 & 66 \\
\hline
\end{tabular}


Resultado de hidrocarbonetos alifáticos, em $\mathrm{ng} \mathrm{m}^{-3}$, para as amostras de material particulado atmosférico $\left(\mathrm{PM}_{2,5}\right)$ coletadas no ano de 2011

\begin{tabular}{|c|c|c|c|c|c|c|c|c|c|}
\hline Código & SE 92 & SE 98 & SE 104 & SE 152 & SE 164 & SE 182 & SE 188 & SE 200 & SE 206 \\
\hline Data & $2-a b r$ & $8-a b r$ & 14-abr & 1-jun & 13-jun & 1-jul & 7-jul & 19-jul & 25-jul \\
\hline C12 & nd & nd & nd & nd & nd & nd & $\mathrm{nd}$ & nd & nd \\
\hline C13 & nd & nd & nd & nd & nd & nd & nd & nd & nd \\
\hline C14 & nd & nd & nd & nd & nd & nd & nd & nd & nd \\
\hline C15 & nd & nd & nd & nd & nd & nd & nd & nd & nd \\
\hline C16 & nd & nd & nd & nd & nd & nd & nd & nd & nd \\
\hline C17 & nd & nd & nd & 0,27 & 0,31 & 0,28 & 0,25 & nd & 0,38 \\
\hline Pristano & nd & nd & nd & nd & nd & nd & nd & nd & nd \\
\hline C18 & nd & nd & nd & nd & nd & nd & nd & nd & nd \\
\hline Fitano & nd & nd & nd & nd & nd & nd & nd & nd & nd \\
\hline C19 & nd & 0,02 & 0,21 & nd & nd & nd & nd & nd & nd \\
\hline $\mathrm{C} 20$ & 0,22 & nd & 0,28 & nd & nd & nd & nd & nd & nd \\
\hline $\mathrm{C} 21$ & 0,23 & nd & 0,20 & nd & nd & nd & nd & nd & nd \\
\hline $\mathrm{C} 22$ & 0,25 & nd & 0,20 & nd & nd & nd & nd & nd & nd \\
\hline $\mathrm{C} 23$ & 0,23 & nd & nd & nd & nd & nd & nd & nd & nd \\
\hline $\mathrm{C} 24$ & 0,36 & nd & nd & 0,26 & 0,25 & nd & nd & nd & nd \\
\hline $\mathrm{C} 25$ & 0,47 & 0,02 & nd & 0,65 & 0,98 & nd & nd & nd & nd \\
\hline $\mathrm{C} 26$ & 0,76 & 0,03 & 0,29 & 1,57 & 2,70 & nd & nd & 0,41 & 0,54 \\
\hline C27 & 0,77 & 0,05 & 0,49 & 2,53 & 3,98 & nd & nd & 0,98 & 1,30 \\
\hline $\mathrm{C} 28$ & 0,90 & 0,06 & 0,80 & 2,83 & 4,81 & nd & 0,31 & 1,15 & 1,53 \\
\hline C29 & 0,69 & 0,07 & 1,58 & 4,05 & 7,40 & nd & 0,54 & 2,27 & 2,95 \\
\hline C30 & 0,79 & 0,07 & 1,13 & 2,82 & 5,07 & nd & 0,22 & 1,14 & 1,46 \\
\hline C31 & 0,64 & 0,07 & 1,62 & 5,36 & 6,14 & nd & 1,22 & 2,62 & 2,54 \\
\hline C32 & 0,51 & 0,04 & 0,51 & 2,44 & 3,56 & nd & 0,32 & 1,13 & 0,76 \\
\hline C33 & 0,44 & 0,02 & 1,17 & 5,72 & 3,23 & nd & 0,22 & 1,58 & 0,29 \\
\hline C34 & 0,36 & 0,03 & nd & 1,88 & 0,70 & nd & 0,37 & 0,78 & nd \\
\hline C35 & 0,32 & 0,02 & nd & 3,05 & 0,68 & nd & 0,29 & 0,75 & nd \\
\hline C36 & 0,25 & nd & nd & 0,55 & $\mathrm{nd}$ & nd & nd & nd & nd \\
\hline C37 & 0,26 & nd & nd & 0,45 & nd & nd & nd & nd & nd \\
\hline C38 & nd & nd & nd & nd & nd & nd & nd & nd & nd \\
\hline C39 & 0,22 & nd & nd & nd & nd & nd & nd & nd & nd \\
\hline C40 & 0,21 & nd & nd & nd & nd & nd & nd & nd & nd \\
\hline n-alcanos & 8,88 & 0,49 & 8,48 & 34,42 & 39,80 & 0,28 & 3,75 & 12,79 & 11,75 \\
\hline HR & 26,76 & 1,03 & 29,57 & 38,56 & 2935 & 0,28 & 19,87 & 55,34 & 108,12 \\
\hline $\begin{array}{l}\text { MCNR } \\
\text { Alitaticos }\end{array}$ & nd & 2,1 & 56,0 & 118,1 & 2312,2 & 96,0 & 105,5 & 191,4 & 233,1 \\
\hline Totais & 26,8 & 3,1 & 85,5 & 156,6 & 5247,0 & 96,2 & 125,3 & 246,8 & 341,3 \\
\hline $\operatorname{Rec}(\%)$ & 73 & 72 & 85 & 98 & 106 & 95 & 90 & 96 & 83 \\
\hline
\end{tabular}


Resultado de hidrocarbonetos alifáticos, em $\mathrm{ng} \mathrm{m}^{-3}$, para as amostras de material particulado atmosférico $\left(\mathrm{PM}_{2,5}\right)$ coletadas no ano de 2011

\begin{tabular}{|c|c|c|c|c|c|c|c|c|c|}
\hline Código & SE 212 & SE 218 & SE 224 & SE 230 & SE 236 & SE 242 & SE 254 & SE 260 & SE 266 \\
\hline Data & 31-jul & 6-ago & 12-ago & 18-ago & 24-ago & 30 -ago & 11-set & 17-set & 23-set \\
\hline C12 & nd & nd & nd & nd & nd & nd & nd & nd & nd \\
\hline C13 & nd & 0,34 & nd & nd & nd & nd & 0,12 & nd & nd \\
\hline C14 & nd & nd & nd & nd & nd & nd & 0,14 & nd & nd \\
\hline C15 & nd & nd & nd & nd & nd & 0,29 & 0,28 & nd & nd \\
\hline C16 & nd & nd & nd & nd & nd & 0,68 & 0,95 & 0,32 & 0,33 \\
\hline C17 & 0,53 & 0,29 & 0,89 & nd & 0,69 & 1,57 & 0,85 & 0,41 & 0,33 \\
\hline Pristano & nd & 0,32 & 0,41 & nd & nd & 1,03 & 1,00 & 0,39 & 0,45 \\
\hline C18 & 0,26 & 0,22 & 0,62 & nd & 0,44 & 1,59 & 1,04 & 0,29 & 0,29 \\
\hline Fitano & nd & 0,27 & 0,23 & nd & nd & 1,17 & 0,60 & 0,38 & 0,46 \\
\hline C19 & nd & 0,28 & 0,26 & nd & nd & 1,64 & 0,59 & 0,33 & 0,38 \\
\hline C2O & nd & nd & nd & nd & nd & 1,64 & 0,94 & 0,27 & 0,34 \\
\hline $\mathrm{C} 21$ & nd & nd & nd & nd & nd & 1,98 & 0,29 & nd & nd \\
\hline $\mathrm{C} 22$ & nd & nd & nd & nd & nd & 2,76 & 0,84 & nd & nd \\
\hline C23 & nd & nd & nd & nd & nd & 3,11 & 0,38 & nd & nd \\
\hline C24 & nd & 0,24 & nd & nd & nd & 3,24 & 1,24 & 0,28 & 0,33 \\
\hline C25 & nd & nd & 0,97 & 0,55 & nd & 3,17 & 1,23 & 0,34 & 0,51 \\
\hline C26 & 1,10 & 0,73 & 3,28 & 1,37 & 0,32 & 3,28 & 2,66 & 0,58 & 0,85 \\
\hline C27 & 2,83 & 1,09 & 4,82 & 2,00 & 0,29 & 3,97 & 3,15 & 0,73 & 1,57 \\
\hline C28 & 2,96 & 1,45 & 2,65 & 0,96 & nd & 2,88 & 4,60 & 0,41 & 1,57 \\
\hline C29 & 6,68 & 2,84 & 2,20 & 0,71 & nd & 5,36 & 5,77 & nd & 2,06 \\
\hline C30 & 3,14 & 0,70 & nd & nd & nd & 1,11 & 5,86 & nd & nd \\
\hline C31 & 8,63 & 1,76 & nd & 0,88 & nd & 0,75 & 6,94 & nd & nd \\
\hline C32 & 2,77 & nd & nd & nd & nd & 0,26 & 6,23 & nd & nd \\
\hline C33 & 6,16 & nd & nd & 0,48 & nd & nd & 6,24 & nd & nd \\
\hline C34 & 1,64 & nd & 0,20 & nd & nd & nd & 5,38 & nd & nd \\
\hline C35 & 2,04 & 1,84 & 0,36 & nd & nd & nd & 5,13 & nd & nd \\
\hline C36 & nd & nd & nd & nd & nd & nd & 4,19 & nd & nd \\
\hline C37 & nd & nd & nd & nd & nd & nd & 3,82 & nd & nd \\
\hline C38 & nd & nd & nd & nd & nd & nd & 2,82 & nd & nd \\
\hline C39 & nd & 1,44 & nd & nd & nd & nd & 3,19 & nd & nd \\
\hline C40 & nd & nd & nd & nd & nd & nd & 1,85 & nd & nd \\
\hline n-alcanos & 38,74 & 13,24 & 16,26 & 6,95 & 1,75 & 39,29 & 76,70 & 3,96 & 8,56 \\
\hline HR & 205,16 & 82,32 & 43,55 & 10,70 & 2,95 & 100,80 & 121,24 & 15,98 & 12,75 \\
\hline $\begin{array}{l}\text { MCNR } \\
\text { Alifáticos }\end{array}$ & 313,1 & 113,5 & 253,9 & 143,2 & 108,7 & 378,2 & 146,7 & 52,5 & 46,5 \\
\hline Totais & 518,2 & 195,8 & 297,5 & 153,9 & 111,6 & 479,0 & 268,0 & 68,4 & 59,2 \\
\hline $\operatorname{Rec}(\%)$ & 98 & 65 & 46 & 58 & 77 & 53 & 114 & 88 & 84 \\
\hline
\end{tabular}


Resultado de hidrocarbonetos alifáticos, em $\mathrm{ng} \mathrm{m}^{-3}$, para as amostras de material particulado atmosférico $\left(\mathrm{PM}_{2,5}\right)$ coletadas no ano de 2011

\begin{tabular}{|c|c|c|c|c|}
\hline Código & SE 320 & SE 350 & SE 356 & SE 362 \\
\hline Data & 16-nov & 16-dez & 22-dez & 28-dez \\
\hline C12 & nd & nd & nd & nd \\
\hline C13 & nd & nd & nd & nd \\
\hline C14 & nd & nd & nd & nd \\
\hline C15 & nd & nd & nd & nd \\
\hline C16 & nd & nd & nd & nd \\
\hline C17 & nd & nd & nd & nd \\
\hline Pristano & nd & nd & nd & nd \\
\hline C18 & nd & nd & nd & nd \\
\hline Fitano & nd & nd & nd & nd \\
\hline C19 & 0,28 & nd & nd & nd \\
\hline $\mathrm{C} 20$ & nd & nd & nd & nd \\
\hline $\mathrm{C} 21$ & nd & nd & nd & nd \\
\hline $\mathrm{C} 22$ & nd & nd & nd & nd \\
\hline $\mathrm{C} 23$ & nd & nd & nd & nd \\
\hline $\mathrm{C} 24$ & nd & nd & nd & nd \\
\hline $\mathrm{C} 25$ & nd & 0,39 & nd & 0,52 \\
\hline $\mathrm{C} 26$ & nd & 0,70 & 0,37 & nd \\
\hline $\mathrm{C} 27$ & nd & 1,37 & 0,82 & 0,50 \\
\hline $\mathrm{C} 28$ & nd & 1,67 & 0,73 & nd \\
\hline $\mathrm{C} 29$ & nd & 2,46 & 1,49 & 0,91 \\
\hline $\mathrm{C} 30$ & nd & 1,84 & 0,69 & nd \\
\hline C31 & 0,32 & 2,49 & 1,06 & 0,52 \\
\hline $\mathrm{C} 32$ & nd & 1,67 & nd & nd \\
\hline $\mathrm{C} 33$ & nd & 1,60 & nd & nd \\
\hline C34 & nd & 1,02 & nd & nd \\
\hline C35 & nd & 0,87 & nd & nd \\
\hline C36 & nd & 0,63 & nd & nd \\
\hline $\mathrm{C} 37$ & nd & 0,46 & nd & nd \\
\hline C38 & nd & 0,32 & nd & nd \\
\hline C39 & nd & nd & nd & nd \\
\hline C40 & nd & 0,23 & nd & nd \\
\hline n-alcanos & 0,61 & 17,71 & 5,16 & 2,44 \\
\hline HR & 20,69 & 92,46 & 48,51 & 17,52 \\
\hline $\begin{array}{l}\text { MCNR } \\
\text { Alitaticos }\end{array}$ & 3,9 & 57,4 & 75,1 & nd \\
\hline Totais & 24,6 & 149,9 & 123,6 & 17,5 \\
\hline $\operatorname{Rec}(\%)$ & 61 & 67 & 58 & 69 \\
\hline
\end{tabular}


Resultado de hidrocarbonetos alifáticos, em $\mathrm{ng} \mathrm{m}^{-3}$, para as amostras de material particulado atmosférico $\left(\mathrm{PM}_{2,5}\right)$ coletadas no ano de 2011

\begin{tabular}{|c|c|c|c|c|c|c|c|c|c|}
\hline Código & SJ 14 & SJ 20 & SJ 26 & SJ 32 & SJ 38 & SJ 44 & SJ 56 & SJ 62 & SJ 68 \\
\hline Data & 14-jan & 20-jan & 26-jan & 1-fev & 7-fev & 13-fev & 25-fev & 3-mar & 9-mar \\
\hline$\overline{C 12}$ & 0,49 & nd & nd & nd & 0,44 & 0,45 & nd & nd & nd \\
\hline C13 & 0,53 & nd & nd & nd & 0,49 & 0,52 & nd & nd & nd \\
\hline C14 & 0,53 & nd & nd & nd & 0,50 & 0,52 & nd & 0,11 & nd \\
\hline C15 & 0,35 & nd & nd & nd & 0,40 & 0,40 & nd & 0,21 & nd \\
\hline C16 & 0,47 & nd & nd & 0,26 & 0,61 & 0,60 & nd & nd & nd \\
\hline C17 & 0,67 & nd & nd & 0,36 & 0,86 & 0,90 & nd & 0,27 & nd \\
\hline Pristano & nd & nd & nd & 0,39 & 0,38 & 0,44 & 0,23 & 0,64 & nd \\
\hline C18 & 0,59 & nd & nd & 0,48 & 0,79 & 0,83 & 0,28 & 0,45 & nd \\
\hline Fitano & 0,24 & nd & 0,20 & 0,36 & 0,39 & 0,44 & nd & 0,37 & nd \\
\hline C19 & 0,45 & nd & 0,23 & 0,45 & 0,61 & 0,59 & 0,30 & 0,46 & nd \\
\hline $\mathrm{C2O}$ & 0,48 & nd & 0,37 & 0,35 & 0,62 & 0,50 & 0,29 & 0,41 & nd \\
\hline $\mathrm{C} 21$ & 0,48 & nd & 0,44 & 0,21 & 0,52 & 0,44 & nd & 0,29 & nd \\
\hline $\mathrm{C} 22$ & 0,53 & 0,19 & 0,45 & 0,23 & 0,58 & 0,51 & 0,23 & 0,36 & nd \\
\hline $\mathrm{C} 23$ & 0,53 & 0,29 & 0,77 & 0,22 & 0,51 & 0,49 & 0,23 & 0,24 & nd \\
\hline $\mathrm{C} 24$ & 0,62 & 0,43 & 1,19 & 0,23 & 0,60 & 0,59 & 0,29 & 0,25 & nd \\
\hline $\mathrm{C} 25$ & 0,63 & 0,74 & 0,89 & 0,33 & 0,61 & 0,59 & 0,30 & 0,30 & nd \\
\hline C26 & 0,68 & 1,00 & 1,12 & 0,78 & 0,86 & 0,97 & 0,52 & 0,57 & nd \\
\hline $\mathrm{C} 27$ & 0,58 & 1,06 & 0,41 & 1,50 & 1,27 & 2,00 & 0,25 & 0,63 & nd \\
\hline $\mathrm{C} 28$ & 0,29 & 0,97 & 0,44 & 2,39 & 1,71 & 3,38 & nd & 0,93 & nd \\
\hline $\mathrm{C} 29$ & nd & 1,23 & nd & 3,87 & 2,55 & 6,10 & nd & 1,23 & 0,44 \\
\hline C30 & nd & 0,72 & nd & 3,17 & 1,87 & 4,51 & nd & 0,98 & 0,26 \\
\hline C31 & nd & 0,49 & nd & 4,31 & 2,83 & 6,01 & nd & 1,11 & 0,72 \\
\hline C32 & nd & nd & nd & 2,19 & 0,67 & 1,55 & nd & nd & 0,38 \\
\hline C33 & nd & nd & nd & 2,73 & 0,46 & 1,35 & nd & nd & 0,18 \\
\hline C34 & nd & nd & nd & 1,07 & nd & nd & nd & nd & 0,20 \\
\hline C35 & nd & nd & nd & 0,83 & nd & nd & nd & nd & 0,20 \\
\hline C36 & nd & nd & 6,51 & 0,26 & nd & nd & nd & nd & nd \\
\hline C37 & nd & nd & 66,00 & nd & nd & nd & nd & nd & nd \\
\hline C38 & nd & nd & 93,50 & nd & nd & nd & nd & nd & nd \\
\hline C39 & nd & nd & 159,50 & nd & nd & nd & nd & nd & nd \\
\hline C40 & nd & nd & nd & nd & $\mathrm{nd}$ & nd & $\mathrm{nd}$ & nd & nd \\
\hline n-alcanos & 8,90 & 7,13 & 331,83 & 26,23 & 20,34 & 33,79 & 2,69 & 8,80 & 2,39 \\
\hline HR & 9,15 & 49,28 & 66,00 & 119,06 & 42,55 & 48,16 & 2,91 & 22,58 & 16,61 \\
\hline $\begin{array}{l}\text { MCNR } \\
\text { Alifáticos }\end{array}$ & 110,4 & 70,0 & 27,5 & 60,8 & 168,6 & 126,9 & 136,6 & 184,8 & 205,1 \\
\hline Totais & 119,5 & 119,3 & 93,5 & 179,8 & 211,2 & 175,0 & 139,5 & 207,4 & 221,8 \\
\hline $\operatorname{Rec}(\%)$ & 71 & 68 & 67 & 85 & 83 & 71 & 78 & 70 & 62 \\
\hline
\end{tabular}


Resultado de hidrocarbonetos alifáticos, em $\mathrm{ng} \mathrm{m}^{-3}$, para as amostras de material particulado atmosférico $\left(\mathrm{PM}_{2,5}\right)$ coletadas no ano de 2011

\begin{tabular}{|c|c|c|c|c|c|c|c|c|c|}
\hline Código & SJ 74 & SJ 80 & SJ 86 & SJ 92 & SJ 98 & SJ 104 & SJ 110 & SJ 116 & SJ 140 \\
\hline Data & 15-mar & 21-mar & 27-mar & 2-abr & 8-abr & 14-abr & $20-a b r$ & 26-abr & 20-mai \\
\hline C12 & nd & nd & nd & nd & nd & nd & nd & nd & nd \\
\hline C13 & nd & nd & nd & nd & nd & nd & nd & nd & nd \\
\hline C14 & nd & nd & nd & 0,10 & nd & nd & nd & nd & nd \\
\hline C15 & nd & 0,26 & nd & nd & nd & nd & 0,21 & nd & nd \\
\hline C16 & 0,23 & nd & nd & 0,42 & 0,37 & nd & nd & nd & nd \\
\hline C17 & 0,33 & 0,40 & nd & 0,28 & 0,33 & nd & 0,15 & nd & 0,51 \\
\hline Pristano & nd & 0,78 & nd & 0,78 & 0,65 & nd & 0,64 & nd & nd \\
\hline C18 & nd & 0,63 & nd & 0,31 & 0,67 & nd & 0,39 & nd & 0,20 \\
\hline Fitano & 0,22 & 0,58 & nd & 0,36 & 0,71 & 0,20 & 0,48 & nd & nd \\
\hline C19 & nd & 0,56 & nd & 0,35 & 0,85 & 0,23 & 0,51 & nd & 0,20 \\
\hline $\mathrm{C} 20$ & 0,23 & 0,57 & nd & 0,30 & 0,80 & 0,34 & 0,34 & nd & 0,22 \\
\hline $\mathrm{C} 21$ & 0,19 & 0,33 & nd & 0,21 & 0,67 & 0,26 & 0,43 & nd & nd \\
\hline $\mathrm{C} 22$ & nd & 0,45 & nd & 0,25 & 0,73 & 0,35 & 0,39 & nd & 0,20 \\
\hline $\mathrm{C} 23$ & nd & 0,28 & nd & 0,19 & 0,68 & 0,22 & 0,28 & nd & 0,26 \\
\hline $\mathrm{C} 24$ & 0,22 & 0,37 & nd & 0,30 & 0,92 & 0,34 & 0,33 & nd & 0,46 \\
\hline C25 & nd & 0,30 & nd & 0,31 & 1,37 & 0,40 & 0,31 & nd & 0,58 \\
\hline C26 & 0,23 & 0,85 & nd & 0,52 & 2,12 & nd & 0,61 & 0,21 & 0,98 \\
\hline $\mathrm{C} 27$ & nd & 0,97 & 0,25 & 0,66 & 2,51 & 0,24 & 0,75 & nd & 1,23 \\
\hline C28 & nd & 1,39 & 0,71 & 0,72 & 3,04 & nd & 1,01 & nd & 1,27 \\
\hline C29 & nd & 2,12 & 1,59 & 0,41 & 4,24 & nd & 1,69 & nd & 0,63 \\
\hline C30 & nd & 1,63 & 1,34 & nd & 3,23 & nd & 1,21 & nd & 3,05 \\
\hline C31 & nd & 2,19 & 3,12 & nd & 3,11 & nd & 1,74 & nd & 0,59 \\
\hline C32 & nd & 0,40 & 1,62 & nd & 0,98 & nd & 0,20 & nd & nd \\
\hline C33 & nd & nd & 2,04 & nd & 0,64 & nd & 0,33 & nd & nd \\
\hline C34 & nd & nd & 1,21 & nd & 0,58 & nd & nd & nd & 2,31 \\
\hline C35 & nd & nd & 1,25 & nd & 0,63 & nd & nd & nd & 0,64 \\
\hline C36 & nd & nd & 0,25 & nd & nd & nd & nd & nd & nd \\
\hline C37 & nd & nd & nd & nd & nd & nd & nd & nd & nd \\
\hline C38 & nd & nd & nd & nd & nd & nd & nd & nd & nd \\
\hline C39 & nd & nd & nd & nd & nd & nd & nd & nd & nd \\
\hline C40 & nd & nd & nd & nd & nd & nd & nd & nd & nd \\
\hline n-alcanos & 1,43 & 13,68 & 13,38 & 5,34 & 28,47 & 2,37 & 10,88 & 0,21 & 13,32 \\
\hline HR & 4,42 & 14,13 & 14,52 & 64,30 & 78,33 & 2,58 & 25,79 & 0,21 & 13,32 \\
\hline $\begin{array}{l}\text { MCNR } \\
\text { Alitaticos }\end{array}$ & 41,57 & 138,5 & 180,2 & 341,5 & 420,1 & 157,1 & 103,6 & 55,9 & 675,2 \\
\hline Totais & 46,0 & 142,6 & 194,7 & 405,8 & 498,4 & 159,7 & 129,4 & 56,2 & 688,5 \\
\hline$\overline{\operatorname{Rec}(\%)}$ & 52 & 100 & 96 & 58 & 64 & 70 & 82 & 85 & 91 \\
\hline
\end{tabular}


Resultado de hidrocarbonetos alifáticos, em $\mathrm{ng} \mathrm{m}^{-3}$, para as amostras de material particulado atmosférico $\left(\mathrm{PM}_{2,5}\right)$ coletadas no ano de 2011

\begin{tabular}{|c|c|c|c|c|c|c|c|c|c|}
\hline Código & SJ 146 & SJ 152 & SJ 158 & SJ 164 & SJ 170 & SJ 176 & SJ 182 & SJ 188 & SJ 194 \\
\hline Data & 26-mai & 1-jun & 7-jun & 13-jun & 19-jun & 25-jun & 1-jul & 7-jul & 13-jul \\
\hline C12 & nd & nd & nd & nd & nd & nd & nd & $\mathrm{nd}$ & nd \\
\hline C13 & nd & nd & nd & nd & nd & nd & nd & nd & nd \\
\hline C14 & nd & nd & nd & nd & nd & nd & nd & nd & nd \\
\hline C15 & nd & nd & nd & 0,82 & nd & nd & nd & nd & nd \\
\hline C16 & nd & nd & nd & nd & nd & nd & 0,25 & nd & nd \\
\hline C17 & 0,34 & 0,22 & 0,32 & 0,48 & 0,23 & 0,24 & 0,74 & 0,38 & 0,71 \\
\hline Pristano & nd & nd & nd & nd & nd & nd & 0,21 & nd & nd \\
\hline C18 & 0,26 & nd & nd & 0,26 & nd & nd & 0,47 & 0,25 & 0,64 \\
\hline Fitano & nd & nd & nd & nd & nd & nd & nd & nd & nd \\
\hline C19 & nd & nd & nd & nd & nd & nd & 0,23 & nd & 0,42 \\
\hline $\mathrm{C} 20$ & nd & nd & nd & nd & nd & nd & nd & nd & nd \\
\hline $\mathrm{C} 21$ & nd & nd & nd & nd & nd & nd & nd & nd & nd \\
\hline $\mathrm{C} 22$ & nd & nd & nd & nd & nd & nd & nd & nd & nd \\
\hline $\mathrm{C} 23$ & nd & nd & nd & 0,35 & nd & nd & nd & nd & 0,23 \\
\hline $\mathrm{C} 24$ & 0,46 & 0,21 & 0,25 & 0,51 & 0,34 & nd & 0,23 & nd & 0,43 \\
\hline C25 & nd & 0,24 & 0,35 & 1,52 & 0,49 & 0,21 & 0,25 & nd & 0,78 \\
\hline $\mathrm{C} 26$ & 1,49 & 0,55 & 0,85 & 3,22 & 1,10 & 0,85 & 0,91 & 0,40 & 3,25 \\
\hline $\mathrm{C} 27$ & 3,14 & 1,41 & 1,54 & 5,88 & 1,87 & 1,44 & 1,38 & 0,80 & 6,53 \\
\hline $\mathrm{C} 28$ & 3,86 & 1,88 & 2,14 & 7,65 & 2,51 & 2,05 & 1,96 & 1,26 & 8,12 \\
\hline C29 & 6,73 & 2,79 & 3,88 & 7,03 & 4,25 & 3,54 & 3,38 & 2,00 & 8,73 \\
\hline C30 & 4,79 & 2,06 & 3,00 & 9,51 & 3,03 & 2,48 & 2,37 & 1,02 & 9,31 \\
\hline C31 & 8,42 & 3,16 & 4,36 & 10,61 & 5,73 & 4,14 & 4,21 & 1,05 & 11,60 \\
\hline C32 & 4,45 & 1,69 & 2,09 & 7,46 & 2,60 & 2,27 & 1,62 & nd & 7,01 \\
\hline C33 & 5,03 & 1,72 & 2,42 & 8,81 & 3,10 & 3,37 & 1,08 & nd & 7,18 \\
\hline C34 & 3,33 & 1,75 & nd & 5,31 & 1,32 & 2,05 & 0,45 & 0,30 & 3,20 \\
\hline C35 & 2,69 & 0,94 & nd & 5,85 & 0,91 & 2,25 & nd & 0,34 & 1,83 \\
\hline C36 & 1,63 & 0,44 & nd & 3,55 & nd & 0,73 & nd & nd & nd \\
\hline C37 & 0,98 & nd & nd & 2,55 & nd & 0,59 & nd & nd & nd \\
\hline C38 & 0,52 & nd & nd & 1,96 & nd & 0,28 & nd & nd & nd \\
\hline C39 & nd & nd & nd & 0,90 & nd & nd & nd & nd & nd \\
\hline C40 & nd & nd & nd & nd & nd & nd & nd & nd & nd \\
\hline n-alcanos & 48,11 & 19,06 & 21,19 & 84,22 & 27,49 & 26,50 & 19,53 & 7,80 & 69,97 \\
\hline HR & 179,83 & 64,03 & 79,57 & 470,77 & 130,11 & 79,71 & 66,24 & 47,95 & 308,38 \\
\hline $\begin{array}{l}\text { MCNR } \\
\text { Alitaticos }\end{array}$ & 366,3 & 274,0 & 424,2 & 1792,9 & 634,7 & 430,5 & 392,7 & 343,6 & 817,6 \\
\hline Totais & 546,2 & 338,0 & 503,7 & 2263,7 & 764,8 & 510,2 & 458,9 & 391,5 & 1126,0 \\
\hline $\operatorname{Rec}(\%)$ & 92 & 93 & 98 & 98 & 92 & 87 & 115 & 87 & 97 \\
\hline
\end{tabular}


Resultado de hidrocarbonetos alifáticos, em $\mathrm{ng} \mathrm{m}^{-3}$, para as amostras de material particulado atmosférico $\left(\mathrm{PM}_{2,5}\right)$ coletadas no ano de 2011

\begin{tabular}{|c|c|c|c|c|c|c|c|c|c|}
\hline Código & SJ 200 & SJ 212 & SJ 218 & SJ 230 & SJ 236 & SJ 242 & SJ 248 & SJ 254 & SJ 260 \\
\hline Data & 19-jul & 31-jul & 6-ago & 18-ago & 24-ago & 30 -ago & 5-set & 11-set & 17-set \\
\hline C12 & nd & nd & nd & nd & nd & nd & nd & nd & nd \\
\hline C13 & nd & nd & nd & nd & nd & nd & nd & nd & nd \\
\hline C14 & nd & nd & nd & nd & nd & nd & nd & nd & nd \\
\hline C15 & nd & nd & nd & nd & 0,36 & 0,59 & nd & nd & nd \\
\hline C16 & nd & nd & 0,58 & nd & 0,59 & 0,88 & 0,44 & nd & nd \\
\hline C17 & 0,24 & 0,41 & 1,19 & 0,78 & 0,98 & 1,44 & 0,63 & nd & nd \\
\hline Pristano & nd & nd & 0,37 & nd & 0,74 & 0,87 & 0,67 & nd & nd \\
\hline C18 & nd & nd & 0,82 & 0,50 & 0,84 & 1,32 & 0,67 & nd & 0,24 \\
\hline Fitano & nd & nd & 0,19 & nd & 0,60 & 0,80 & 0,59 & 0,34 & nd \\
\hline C19 & nd & nd & 0,53 & nd & 0,61 & 0,96 & 0,59 & 0,24 & 0,26 \\
\hline $\mathrm{C} 20$ & nd & nd & 0,37 & nd & 0,36 & 0,64 & 0,44 & 0,23 & 0,18 \\
\hline $\mathrm{C} 21$ & nd & nd & 0,19 & nd & 0,28 & 0,55 & 0,37 & nd & nd \\
\hline C22 & nd & nd & 0,37 & nd & 0,29 & 0,59 & 0,45 & nd & 0,19 \\
\hline $\mathrm{C} 23$ & nd & nd & 0,35 & nd & 0,25 & 0,44 & 0,48 & nd & 0,18 \\
\hline $\mathrm{C} 24$ & nd & nd & 0,51 & 0,20 & 0,24 & 0,44 & 0,83 & nd & 0,18 \\
\hline $\mathrm{C} 25$ & nd & nd & 0,63 & 0,40 & 0,30 & 0,52 & 1,45 & nd & 0,18 \\
\hline C26 & 0,49 & nd & 1,05 & 1,30 & 0,99 & 1,29 & 2,25 & 0,26 & 0,37 \\
\hline C27 & 1,25 & 0,56 & 1,81 & 1,63 & 1,11 & 1,92 & 2,97 & 0,34 & 0,55 \\
\hline C28 & 1,44 & 0,32 & 2,00 & 1,23 & 1,40 & 2,13 & 3,49 & 0,45 & 0,78 \\
\hline $\mathrm{C} 29$ & 1,97 & nd & 2,80 & 0,97 & 2,05 & 3,80 & 4,09 & 0,69 & 0,63 \\
\hline C30 & 0,50 & nd & 0,74 & nd & 0,88 & 1,55 & 1,60 & nd & 0,53 \\
\hline C31 & 0,85 & nd & 0,29 & 0,59 & 0,73 & 1,08 & nd & nd & 0,75 \\
\hline C32 & nd & nd & nd & nd & 0,27 & nd & nd & nd & nd \\
\hline C33 & nd & nd & nd & nd & 0,40 & nd & nd & nd & nd \\
\hline C34 & 0,26 & nd & 0,30 & nd & 0,22 & 0,39 & nd & nd & nd \\
\hline C35 & 0,47 & nd & nd & 0,30 & nd & nd & nd & nd & 0,32 \\
\hline C36 & nd & nd & nd & nd & nd & nd & nd & nd & nd \\
\hline C37 & nd & nd & nd & nd & nd & nd & nd & nd & nd \\
\hline C38 & nd & nd & nd & nd & nd & nd & nd & nd & nd \\
\hline C39 & nd & nd & nd & nd & nd & nd & nd & nd & nd \\
\hline C40 & nd & nd & nd & nd & nd & nd & nd & nd & nd \\
\hline n-alcanos & 7,45 & 1,29 & 14,52 & 7,89 & 13,13 & 20,53 & 20,75 & 2,21 & 5,34 \\
\hline HR & 55,60 & 6,19 & 127,20 & 31,91 & 60,58 & 89,43 & 66,83 & 6,13 & 33,13 \\
\hline $\begin{array}{l}\text { MCNR } \\
\text { Alifáticos }\end{array}$ & 430,6 & 201,6 & 568,6 & 295,7 & 289,3 & 387,8 & 369,0 & 55,6 & 214,2 \\
\hline Totais & 486,2 & 207,8 & 695,8 & 327,6 & 349,9 & 477,2 & 435,8 & 61,7 & 247,3 \\
\hline $\operatorname{Rec}(\%)$ & 82 & 87 & 75 & 73 & 90 & 67 & 61 & 49 & 100 \\
\hline
\end{tabular}


Resultado de hidrocarbonetos alifáticos, em $\mathrm{ng} \mathrm{m}^{-3}$, para as amostras de material particulado atmosférico $\left(\mathrm{PM}_{2,5}\right)$ coletadas no ano de 2011

\begin{tabular}{|c|c|c|c|c|c|c|c|c|}
\hline Código & SJ 266 & SJ 272 & SJ 314 & SJ 320 & SJ 326 & SJ 338 & SJ 344 & SJ 356 \\
\hline Data & 23-set & 29-set & 10-nov & 16-nov & 22-nov & 4-dez & 10-dez & 22-dez \\
\hline C12 & nd & nd & $\mathrm{nd}$ & $\mathrm{nd}$ & $\mathrm{nd}$ & nd & $\mathrm{nd}$ & nd \\
\hline C13 & nd & nd & nd & nd & nd & nd & nd & nd \\
\hline C14 & nd & nd & nd & nd & nd & nd & nd & nd \\
\hline C15 & nd & nd & 0,27 & nd & nd & nd & nd & nd \\
\hline C16 & nd & nd & nd & nd & nd & nd & nd & nd \\
\hline C17 & 0,73 & nd & nd & nd & 0,28 & nd & nd & nd \\
\hline Pristano & nd & nd & nd & nd & 0,26 & nd & nd & nd \\
\hline C18 & 0,64 & nd & nd & nd & 0,32 & nd & nd & 0,29 \\
\hline Fitano & nd & 0,35 & nd & nd & 0,37 & nd & 0,23 & 0,34 \\
\hline C19 & 0,32 & 0,36 & 0,29 & nd & 0,34 & nd & nd & 0,31 \\
\hline $\mathrm{C} 20$ & nd & 0,43 & 0,26 & nd & 0,36 & nd & nd & 0,45 \\
\hline $\mathrm{C} 21$ & nd & 0,35 & nd & nd & 0,27 & nd & nd & 0,37 \\
\hline C22 & nd & 0,35 & nd & nd & 0,31 & nd & nd & 0,40 \\
\hline $\mathrm{C} 23$ & nd & 0,38 & nd & nd & 0,25 & nd & 0,24 & 0,39 \\
\hline C24 & 0,23 & 0,38 & nd & nd & 0,35 & nd & 0,30 & 0,52 \\
\hline $\mathrm{C25}$ & 0,21 & 0,46 & nd & nd & 0,41 & nd & 0,90 & 0,78 \\
\hline $\mathrm{C} 26$ & 0,73 & 0,85 & nd & nd & 0,60 & 0,27 & 0,46 & 0,95 \\
\hline $\mathrm{C} 27$ & 1,48 & 1,21 & 0,30 & nd & 0,73 & 0,35 & 1,22 & 1,35 \\
\hline $\mathrm{C} 28$ & 1,65 & 1,24 & 0,40 & 0,30 & 0,88 & 0,45 & 0,77 & 1,57 \\
\hline $\mathrm{C} 29$ & 1,99 & 1,86 & 0,56 & 1,51 & 1,11 & 0,52 & 1,88 & 2,47 \\
\hline C30 & 0,76 & 0,65 & 0,50 & 0,83 & 0,96 & nd & 0,40 & 1,61 \\
\hline C31 & 1,24 & nd & 0,38 & 2,65 & 1,24 & nd & 0,89 & 1,55 \\
\hline C32 & nd & nd & nd & 0,63 & 0,70 & nd & nd & 0,51 \\
\hline C33 & nd & nd & nd & 0,74 & 0,92 & nd & nd & nd \\
\hline C34 & 0,71 & nd & nd & nd & 0,65 & nd & nd & 0,32 \\
\hline C35 & 0,49 & nd & nd & nd & 0,52 & nd & nd & 0,23 \\
\hline C36 & nd & nd & nd & nd & 0,29 & nd & nd & nd \\
\hline C37 & nd & nd & nd & nd & 0,25 & nd & nd & nd \\
\hline C38 & nd & nd & nd & nd & nd & nd & nd & nd \\
\hline C39 & nd & nd & nd & nd & nd & nd & nd & nd \\
\hline C40 & nd & nd & nd & nd & nd & nd & nd & nd \\
\hline n-alcanos & 11,17 & 8,53 & 2,95 & 6,66 & 11,77 & 1,58 & 7,05 & 14,09 \\
\hline HR & 11,17 & 26,87 & 92,21 & 12,25 & 30,16 & 28,66 & 39,39 & 58,71 \\
\hline $\begin{array}{l}\text { MCNR } \\
\text { Alitaticos }\end{array}$ & 149,9 & 180,7 & 92,3 & 29,1 & 95,8 & 23,8 & 70,7 & 250,1 \\
\hline Totais & 161,0 & 207,6 & 184,5 & 41,3 & 126,0 & 52,4 & 110,1 & 308,8 \\
\hline $\operatorname{Rec}(\%)$ & 87 & 54 & 54 & 72 & 62 & 73 & 51 & 89 \\
\hline
\end{tabular}


DADOS DE ALIFÁTICOS EM AMOSTRAS DE ÓLEO 
Resultado de hidrocarbonetos alifáticos, em $\mathrm{mg} \mathrm{g}^{-1}$, para as amostras de petróleo e produtos de petróleo

\begin{tabular}{|c|c|c|c|c|c|c|c|c|c|}
\hline Código & A & A & AA & $\mathrm{AA}$ & B & $\mathrm{B}$ & BB & BB & $\mathrm{C}$ \\
\hline C12 & nd & nd & 5,282 & 4,546 & 4,636 & 4,628 & nd & nd & 3,673 \\
\hline C13 & 0,255 & 0,234 & 5,762 & 4,935 & 4,468 & 4,440 & nd & nd & 4,048 \\
\hline C14 & 0,237 & nd & 5,837 & 4,963 & 4,190 & 4,169 & nd & nd & 4,625 \\
\hline C15 & nd & nd & 7,965 & 6,833 & 4,382 & 4,423 & nd & nd & 3,793 \\
\hline C16 & nd & nd & 6,634 & 5,639 & 3,432 & 3,290 & nd & nd & 3,023 \\
\hline C17 & nd & nd & 7,308 & 6,190 & 2,872 & 2,629 & nd & nd & 2,419 \\
\hline Pristano & nd & nd & 4,423 & 3,801 & 3,830 & 3,530 & nd & nd & 2,882 \\
\hline C18 & nd & nd & 5,181 & 4,394 & 2,172 & 2,008 & nd & nd & 1,961 \\
\hline Fitano & 0,255 & nd & 6,537 & 5,620 & 2,220 & 2,056 & nd & nd & 1,941 \\
\hline C19 & nd & nd & 4,872 & 4,125 & 1,764 & 1,719 & nd & nd & 1,524 \\
\hline $\mathrm{C} 20$ & nd & nd & 4,441 & 3,741 & 1,534 & 1,378 & nd & nd & 1,327 \\
\hline C21 & nd & nd & 4,449 & 3,727 & 1,337 & 1,242 & nd & nd & 1,228 \\
\hline $\mathrm{C} 22$ & nd & nd & 4,551 & 3,778 & 1,318 & 1,255 & nd & nd & 1,259 \\
\hline C23 & nd & nd & 4,855 & 4,074 & 1,438 & 1,242 & nd & nd & 1,400 \\
\hline C24 & nd & nd & 4,749 & 3,986 & 1,390 & 1,172 & nd & nd & 1,384 \\
\hline $\mathrm{C25}$ & nd & 0,512 & 4,837 & 4,111 & 1,409 & 1,299 & nd & nd & 1,332 \\
\hline C26 & nd & nd & 4,031 & 3,394 & 1,275 & 1,225 & nd & nd & 1,181 \\
\hline $\mathrm{C} 27$ & nd & nd & 4,070 & 3,440 & 1,242 & 1,234 & nd & nd & 1,217 \\
\hline C28 & nd & nd & 3,256 & 2,759 & 1,127 & 1,172 & nd & nd & 1,082 \\
\hline C29 & nd & nd & 3,115 & 2,597 & 1,457 & 1,374 & nd & nd & 1,103 \\
\hline C30 & 0,318 & 0,320 & 2,282 & 1,917 & 0,916 & 1,041 & nd & nd & 0,952 \\
\hline C31 & 0,237 & nd & 2,000 & 1,704 & 0,801 & 0,652 & nd & nd & 0,895 \\
\hline C32 & nd & nd & 1,379 & 1,144 & 0,547 & 0,538 & nd & nd & 0,593 \\
\hline C33 & nd & nd & 0,815 & 0,671 & 0,407 & 0,249 & nd & nd & 0,458 \\
\hline C34 & nd & nd & 0,718 & 0,574 & 0,345 & 0,551 & nd & nd & 0,338 \\
\hline C35 & nd & nd & 0,890 & 0,736 & nd & nd & nd & nd & 0,271 \\
\hline C36 & nd & nd & 0,317 & 0,231 & nd & nd & nd & nd & nd \\
\hline C37 & nd & nd & 0,322 & nd & nd & nd & nd & nd & nd \\
\hline C38 & nd & nd & nd & nd & nd & nd & nd & nd & nd \\
\hline C39 & nd & nd & nd & nd & nd & nd & nd & nd & nd \\
\hline $\mathrm{C} 40$ & nd & nd & nd & nd & nd & nd & nd & nd & nd \\
\hline n-alcanos & 1,30 & 1,07 & 110,88 & 93,63 & 50,51 & 48,52 & nd & nd & 45,91 \\
\hline HR & 38,1 & 32,6 & 226,5 & 169,3 & 144,4 & 118,5 & 19,1 & 64,0 & 126,3 \\
\hline MCNR & 23,7 & 22,1 & 164,9 & 185,3 & 140,6 & 115,1 & 108,5 & 161,0 & 73,9 \\
\hline $\begin{array}{l}\text { Alifáticos } \\
\text { Totais } \\
\end{array}$ & 61,7 & 54,8 & 391,4 & 354,6 & 285,0 & 233,6 & 127,6 & 225,0 & 200,2 \\
\hline
\end{tabular}


Resultado de hidrocarbonetos alifáticos, em $\mathrm{mg} \mathrm{g}^{-1}$, para as amostras de petróleo e produtos de petróleo

\begin{tabular}{|c|c|c|c|c|c|c|c|c|c|}
\hline Código & C & $\mathrm{CC}$ & $\mathrm{CC}$ & D & D & DD & DD & $E$ & $E$ \\
\hline C12 & 3,958 & 15,552 & 15,212 & 7,034 & 7,380 & 8,435 & 7,628 & 2,184 & 2,097 \\
\hline C13 & 4,090 & 11,694 & 11,398 & 6,910 & 7,240 & 8,605 & 7,810 & 1,705 & 1,639 \\
\hline C14 & 4,946 & 8,403 & 8,050 & 6,459 & 6,781 & 8,816 & 7,988 & 0,576 & 0,535 \\
\hline C15 & 4,051 & 7,040 & 6,789 & 6,672 & 6,739 & 0,355 & 0,301 & 0,433 & 0,419 \\
\hline C16 & 3,294 & 4,593 & 4,384 & 5,810 & 6,058 & 8,476 & 7,596 & nd & nd \\
\hline C17 & 2,719 & 2,742 & 2,594 & 5,604 & 5,821 & 8,033 & 7,299 & nd & nd \\
\hline Pristano & 3,181 & 2,456 & 2,401 & 3,373 & 3,441 & 4,047 & 3,691 & 4,581 & 4,470 \\
\hline C18 & 2,070 & 1,637 & 1,546 & 4,899 & 5,041 & 6,730 & 6,191 & nd & nd \\
\hline Fitano & 2,026 & 1,065 & 1,044 & 2,847 & 2,899 & 3,095 & 2,755 & 2,493 & 2,483 \\
\hline C19 & 1,657 & 1,024 & 0,952 & 4,451 & 4,608 & 6,035 & 5,511 & nd & nd \\
\hline $\mathrm{C} 20$ & 1,377 & 0,629 & 0,589 & 4,522 & 4,684 & 5,819 & 5,269 & nd & nd \\
\hline C21 & 1,318 & 0,383 & 0,368 & 4,534 & 4,800 & 5,149 & 4,694 & nd & nd \\
\hline $\mathrm{C} 22$ & 1,362 & 0,302 & 0,262 & 4,556 & 4,740 & 4,737 & 4,507 & nd & nd \\
\hline $\mathrm{C} 23$ & 1,318 & 0,230 & nd & 4,646 & 5,064 & 4,660 & 4,443 & nd & nd \\
\hline $\mathrm{C} 24$ & 1,332 & nd & nd & 4,433 & 4,703 & 4,459 & 4,024 & nd & nd \\
\hline C25 & 1,382 & nd & nd & 4,463 & 4,672 & 3,980 & 3,577 & nd & nd \\
\hline C26 & 1,264 & nd & nd & 3,843 & 4,104 & 3,532 & 3,111 & nd & nd \\
\hline $\mathrm{C} 27$ & 1,313 & nd & nd & 3,690 & 3,878 & 2,842 & 2,582 & nd & nd \\
\hline C28 & 1,185 & nd & nd & 3,019 & 3,268 & 2,508 & 2,272 & nd & nd \\
\hline $\mathrm{C} 29$ & 1,175 & nd & nd & 2,784 & 2,963 & 2,075 & 1,898 & 0,493 & 0,486 \\
\hline C30 & 1,008 & nd & nd & 2,149 & 2,380 & 1,514 & 1,382 & nd & nd \\
\hline C31 & 0,949 & nd & nd & 1,653 & 1,916 & 1,045 & 0,949 & nd & nd \\
\hline C32 & 0,708 & nd & nd & 1,116 & 1,299 & 0,711 & 0,648 & nd & nd \\
\hline C33 & 0,482 & nd & nd & 0,858 & 1,020 & 0,525 & 0,470 & nd & nd \\
\hline C34 & 0,393 & nd & nd & 0,634 & 0,821 & 0,448 & 0,452 & 0,387 & 0,442 \\
\hline C35 & 0,261 & nd & nd & 0,578 & 0,610 & 0,268 & nd & nd & nd \\
\hline C36 & nd & nd & nd & 0,265 & 0,313 & nd & nd & nd & nd \\
\hline C37 & nd & nd & nd & 0,216 & 0,256 & nd & nd & nd & nd \\
\hline C38 & nd & nd & nd & nd & nd & nd & nd & nd & nd \\
\hline C39 & nd & nd & nd & nd & 0,211 & nd & nd & nd & nd \\
\hline C40 & nd & nd & nd & nd & $\mathrm{nd}$ & nd & nd & nd & nd \\
\hline n-alcanos & 48,82 & 57,75 & 55,59 & 102,02 & 107,71 & 106,90 & 97,05 & 12,85 & 12,57 \\
\hline HR & 117,4 & 155,3 & 139,7 & 200,8 & 183,5 & 303,0 & 307,2 & 105,4 & 116,7 \\
\hline MCNR & 70,6 & 124,7 & 113,6 & 126,6 & 136,6 & 135,8 & 107,5 & 116,5 & 153,8 \\
\hline $\begin{array}{l}\text { Alifáticos } \\
\text { Totais }\end{array}$ & 188,0 & 280,0 & 253,3 & 327,5 & 320,1 & 438,7 & 414,7 & 221,9 & 270,5 \\
\hline
\end{tabular}


Resultado de hidrocarbonetos alifáticos, em $\mathrm{mg} \mathrm{g}^{-1}$, para as amostras de petróleo e produtos de petróleo

\begin{tabular}{|c|c|c|c|c|c|c|c|c|c|}
\hline Código & $\mathrm{EE}$ & $\mathrm{EE}$ & $\mathrm{F}$ & $\mathrm{F}$ & $\mathrm{FF}$ & $\mathrm{FF}$ & G & G & $\mathrm{H}$ \\
\hline C12 & nd & 0,220 & 4,302 & 4,596 & 3,626 & 3,429 & 2,492 & 2,542 & 1,462 \\
\hline C13 & nd & nd & 4,067 & 4,429 & 3,805 & 3,607 & 2,707 & 2,735 & 1,401 \\
\hline C14 & nd & nd & 3,858 & 4,158 & 3,765 & 3,538 & 3,470 & nd & 0,564 \\
\hline C15 & nd & nd & 4,241 & 4,573 & 4,096 & 3,883 & 2,492 & 2,458 & 0,500 \\
\hline C16 & nd & nd & 3,225 & 3,472 & 3,133 & 2,999 & 2,025 & 2,055 & nd \\
\hline C17 & nd & nd & 2,640 & 2,845 & 2,525 & 2,357 & 1,838 & 1,870 & nd \\
\hline Pristano & nd & nd & 3,619 & 3,865 & 3,491 & 3,335 & 2,569 & 2,640 & 4,820 \\
\hline C18 & nd & nd & 2,223 & 2,415 & 1,911 & 1,793 & 1,473 & 1,356 & nd \\
\hline Fitano & nd & nd & 2,773 & 2,986 & 2,041 & 1,927 & 1,518 & 1,565 & 2,655 \\
\hline C19 & nd & nd & 1,946 & 2,092 & 1,513 & 1,418 & 1,185 & 1,265 & nd \\
\hline $\mathrm{C2O}$ & nd & nd & 1,829 & 1,966 & 1,294 & 1,275 & 1,035 & 1,063 & nd \\
\hline C21 & nd & nd & 1,574 & 1,721 & 1,235 & 1,151 & 0,929 & 0,968 & nd \\
\hline $\mathrm{C} 22$ & nd & nd & 1,662 & 1,799 & 1,316 & 1,206 & 1,039 & 1,130 & nd \\
\hline $\mathrm{C} 23$ & nd & nd & 1,525 & 1,651 & 0,962 & 0,934 & 1,100 & 1,352 & nd \\
\hline C24 & nd & nd & 1,684 & 1,810 & 1,594 & 1,487 & 1,104 & 1,166 & nd \\
\hline C25 & nd & nd & 1,870 & 2,025 & 1,419 & 1,374 & 1,136 & 1,190 & nd \\
\hline C26 & nd & nd & 1,491 & 1,591 & 1,155 & 1,038 & 1,075 & 1,142 & nd \\
\hline $\mathrm{C} 27$ & nd & nd & 1,244 & 1,358 & 1,101 & 1,028 & 1,120 & 1,150 & nd \\
\hline C28 & nd & nd & 1,074 & 1,165 & 1,092 & 1,028 & 0,950 & 1,016 & nd \\
\hline C29 & 0,548 & 0,490 & 0,971 & 1,046 & 1,513 & 1,443 & 0,990 & 1,004 & 0,550 \\
\hline C30 & nd & 0,593 & 0,986 & 1,050 & 1,003 & 0,944 & 0,897 & 0,901 & 0,236 \\
\hline C31 & nd & 0,207 & 0,747 & 0,827 & 0,927 & 0,904 & 0,812 & 0,814 & nd \\
\hline C32 & 0,608 & 0,556 & 0,603 & 0,627 & 0,568 & 0,543 & 0,528 & 0,518 & nd \\
\hline C33 & 2,489 & 2,241 & 0,531 & 0,582 & 0,474 & 0,445 & 0,386 & 0,411 & nd \\
\hline C34 & 0,553 & 0,506 & 0,486 & 0,679 & 0,255 & 0,282 & 0,369 & 0,269 & 0,412 \\
\hline C35 & nd & nd & 0,406 & 0,456 & nd & 0,277 & 0,219 & 0,206 & nd \\
\hline C36 & nd & nd & nd & 0,200 & nd & nd & nd & nd & nd \\
\hline C37 & 0,261 & nd & 0,209 & 0,245 & nd & nd & nd & nd & nd \\
\hline C38 & nd & nd & nd & 0,185 & nd & nd & nd & nd & nd \\
\hline C39 & nd & nd & nd & nd & nd & nd & nd & nd & nd \\
\hline C40 & nd & nd & nd & nd & nd & nd & nd & nd & nd \\
\hline n-alcanos & 4,46 & 4,81 & 51,79 & 56,41 & 45,81 & 43,64 & 35,46 & 32,79 & 12,60 \\
\hline HR & 58,5 & 58,9 & 107,8 & 138,8 & 88,3 & 92,6 & 74,6 & 79,7 & 119,2 \\
\hline MCNR & 136,9 & 136,3 & 108,7 & 122,5 & 173,0 & 183,3 & 36,6 & 40,1 & 144,8 \\
\hline $\begin{array}{l}\text { Alifáticos } \\
\text { Totais }\end{array}$ & 195,4 & 195,2 & 216,5 & 261,3 & 261,3 & 275,8 & 111,2 & 119,9 & 263,9 \\
\hline
\end{tabular}


Resultado de hidrocarbonetos alifáticos, em $\mathrm{mg} \mathrm{g}^{-1}$, para as amostras de petróleo e produtos de petróleo

\begin{tabular}{|c|c|c|c|c|c|c|c|c|c|}
\hline Código & $\mathrm{H}$ & 1 & 1 & $\mathrm{~J}$ & $\mathrm{~J}$ & $\mathrm{~K}$ & $\mathrm{~K}$ & $\mathrm{~L}$ & $\mathrm{~L}$ \\
\hline C12 & 1,455 & 0,768 & 0,262 & 13,141 & 13,172 & 1,274 & 1,276 & 1,134 & 1,336 \\
\hline C13 & 1,348 & 0,307 & 0,412 & 13,243 & 12,973 & 0,232 & 1,880 & 1,893 & 2,384 \\
\hline C14 & 0,573 & nd & nd & 12,681 & 12,573 & 2,371 & 2,246 & 2,426 & 3,226 \\
\hline C15 & 0,545 & 0,525 & 0,290 & 12,676 & 12,496 & 2,264 & 2,392 & 6,435 & 3,771 \\
\hline C16 & nd & nd & nd & 11,627 & 11,299 & 1,518 & 1,446 & 2,300 & 3,208 \\
\hline C17 & nd & nd & nd & 11,162 & 10,777 & 0,999 & 0,915 & 2,046 & 2,742 \\
\hline Pristano & 4,933 & nd & nd & 3,589 & 3,604 & 4,194 & 3,934 & 3,418 & 4,558 \\
\hline C18 & nd & nd & nd & 10,124 & 9,701 & 0,759 & 0,659 & 1,377 & 1,983 \\
\hline Fitano & 2,702 & 0,358 & nd & 2,405 & 2,407 & 2,393 & 2,264 & 2,389 & 3,245 \\
\hline C19 & nd & nd & nd & 10,276 & 9,846 & 0,407 & 0,375 & 1,287 & 1,895 \\
\hline $\mathrm{C} 20$ & nd & nd & nd & 9,832 & 9,252 & 0,300 & 0,270 & 1,092 & 1,532 \\
\hline $\mathrm{C} 21$ & nd & nd & nd & 10,670 & 9,790 & 0,227 & nd & 0,823 & 1,192 \\
\hline $\mathrm{C} 22$ & nd & nd & nd & 11,011 & 9,741 & nd & nd & 0,802 & 1,080 \\
\hline $\mathrm{C} 23$ & nd & 0,354 & nd & 12,330 & 10,570 & 0,257 & nd & 0,775 & 1,085 \\
\hline $\mathrm{C} 24$ & nd & nd & nd & 11,897 & 9,883 & 0,270 & nd & 0,807 & 1,150 \\
\hline $\mathrm{C} 25$ & nd & nd & nd & 13,211 & 10,712 & 0,292 & 0,302 & 0,960 & 1,192 \\
\hline C26 & nd & nd & nd & 11,611 & 8,940 & nd & nd & 0,765 & 0,978 \\
\hline $\mathrm{C} 27$ & nd & nd & nd & 12,773 & 9,713 & nd & 0,229 & 0,738 & 0,885 \\
\hline C28 & nd & nd & nd & 11,432 & 8,511 & nd & nd & 0,807 & 0,899 \\
\hline C29 & 0,584 & 1,583 & nd & 11,038 & 8,115 & 0,729 & 0,668 & 0,939 & 0,805 \\
\hline C30 & nd & 0,734 & 0,674 & 8,827 & 6,521 & 0,399 & 0,380 & 0,796 & 0,750 \\
\hline C31 & nd & nd & nd & 7,211 & 5,303 & nd & nd & 0,723 & 0,694 \\
\hline C32 & nd & nd & nd & 5,346 & 3,968 & nd & nd & 0,543 & 0,470 \\
\hline C33 & nd & nd & nd & 4,211 & 3,167 & 0,223 & nd & 0,501 & 0,442 \\
\hline C34 & 0,444 & 0,239 & nd & 3,059 & 2,371 & 0,395 & 0,384 & 0,443 & 0,447 \\
\hline C35 & nd & nd & nd & 2,562 & 2,095 & nd & nd & 0,359 & 0,447 \\
\hline C36 & nd & nd & nd & 2,919 & 1,278 & nd & nd & nd & nd \\
\hline C37 & nd & nd & nd & 1,432 & 1,222 & nd & nd & nd & nd \\
\hline C38 & nd & nd & nd & 1,146 & 0,947 & nd & nd & nd & nd \\
\hline C39 & nd & nd & nd & 1,086 & 0,943 & nd & nd & nd & nd \\
\hline C40 & nd & nd & nd & 0,800 & 0,684 & nd & nd & nd & nd \\
\hline n-alcanos & 12,58 & 4,87 & 1,64 & 255,33 & 222,57 & 19,50 & 19,62 & 36,58 & 42,39 \\
\hline HR & 108,0 & 64,6 & 60,7 & 336,2 & 259,5 & 89,5 & 87,5 & 118,9 & 109,0 \\
\hline MCNR & 153,5 & 135,7 & 135,9 & 161,1 & 157,2 & 128,9 & 126,4 & 75,7 & 95,6 \\
\hline $\begin{array}{l}\text { Alifáticos } \\
\text { Totais }\end{array}$ & 261,4 & 200,3 & 196,6 & 497,3 & 416,7 & 218,3 & 213,9 & 194,6 & 204,6 \\
\hline
\end{tabular}


Resultado de hidrocarbonetos alifáticos, em $\mathrm{mg} \mathrm{g}^{-1}$, para as amostras de petróleo e produtos de petróleo

\begin{tabular}{|c|c|c|c|c|c|c|c|c|c|}
\hline Código & $\mathrm{M}$ & $M$ & $\mathrm{~N}$ & $\mathrm{~N}$ & 0 & $\mathrm{O}$ & $\mathrm{P}$ & $P$ & $\mathrm{Q}$ \\
\hline C12 & 2,740 & 3,190 & 5,107 & 8,581 & 13,206 & 11,196 & 8,231 & 8,031 & 2,063 \\
\hline C13 & 3,118 & 3,839 & 5,181 & 8,260 & 12,306 & 10,488 & 8,168 & 8,031 & 3,238 \\
\hline C14 & 3,198 & 3,669 & 13,196 & 21,394 & 11,072 & 9,442 & 7,995 & 7,834 & 2,487 \\
\hline C15 & 3,401 & 4,015 & 7,319 & 13,041 & 11,433 & 9,933 & 7,139 & 7,027 & 3,005 \\
\hline C16 & 2,596 & 3,267 & 4,202 & 7,285 & 9,672 & 8,229 & 6,038 & 5,956 & 2,190 \\
\hline C17 & 2,084 & 2,310 & 3,497 & 5,701 & 8,517 & 7,242 & 5,076 & 4,976 & 2,000 \\
\hline Pristano & 2,265 & 2,354 & 2,848 & 4,540 & 6,206 & 5,104 & 3,222 & 3,228 & 1,963 \\
\hline C18 & 1,567 & 1,760 & 2,880 & 4,633 & 6,900 & 5,863 & 4,340 & 4,241 & 1,741 \\
\hline Fitano & 1,429 & 1,529 & 1,953 & 2,990 & 4,400 & 3,729 & 1,876 & 1,806 & 1,799 \\
\hline C19 & 1,242 & 1,513 & 2,305 & 3,780 & 7,039 & 5,217 & 3,703 & 3,545 & 1,529 \\
\hline $\mathrm{C} 20$ & 1,002 & 1,106 & 2,217 & 3,404 & 5,644 & 4,833 & 3,529 & 3,545 & 1,349 \\
\hline $\mathrm{C} 21$ & 0,975 & 1,023 & 1,957 & 3,205 & 4,839 & 4,158 & 3,302 & 3,497 & 1,122 \\
\hline $\mathrm{C} 22$ & 0,933 & 1,023 & 1,934 & 3,438 & 4,428 & 3,908 & 3,320 & 3,492 & 1,217 \\
\hline $\mathrm{C} 23$ & 1,007 & 1,293 & 2,087 & 3,176 & 4,339 & 3,679 & 3,681 & 3,660 & 1,212 \\
\hline $\mathrm{C} 24$ & 0,949 & 1,144 & 2,022 & 3,171 & 3,989 & 3,204 & 3,316 & 3,132 & 1,122 \\
\hline $\mathrm{C} 25$ & 0,933 & 1,067 & 2,147 & 3,180 & 3,483 & 2,892 & 3,311 & 3,184 & 1,132 \\
\hline $\mathrm{C} 26$ & 0,869 & 1,051 & 1,943 & 3,003 & 2,900 & 2,396 & 2,928 & 2,839 & 1,079 \\
\hline $\mathrm{C} 27$ & 0,848 & 1,089 & 1,892 & 2,897 & 2,317 & 1,867 & 2,865 & 2,810 & 0,947 \\
\hline $\mathrm{C} 28$ & 0,837 & 1,177 & 1,753 & 2,576 & 1,961 & 1,629 & 2,473 & 2,382 & 0,905 \\
\hline C29 & 1,109 & 1,480 & 1,614 & 2,331 & 1,783 & 1,429 & 2,286 & 2,142 & 0,852 \\
\hline C30 & 0,805 & 1,150 & 1,262 & 1,841 & 1,500 & 1,271 & 1,725 & 1,623 & 0,783 \\
\hline C31 & 0,597 & 0,693 & 1,030 & 1,546 & 1,383 & 1,125 & 1,502 & 1,460 & 0,444 \\
\hline C32 & 0,432 & 0,600 & 0,724 & 1,085 & 0,983 & 0,800 & 1,029 & 0,913 & 0,354 \\
\hline C33 & 0,309 & 0,418 & 0,506 & 0,815 & 0,922 & 0,788 & 0,829 & 0,687 & 0,291 \\
\hline C34 & nd & 0,347 & 0,366 & 0,785 & 0,906 & 0,692 & 0,441 & 0,480 & nd \\
\hline C35 & nd & nd & 0,288 & 0,456 & 0,472 & 0,450 & 0,272 & nd & 0,402 \\
\hline C36 & nd & nd & nd & nd & 0,317 & 0,263 & nd & nd & nd \\
\hline C37 & nd & nd & nd & nd & nd & 0,242 & nd & nd & nd \\
\hline C38 & nd & nd & nd & nd & nd & nd & nd & nd & nd \\
\hline C39 & nd & nd & nd & nd & nd & 0,213 & nd & nd & nd \\
\hline $\mathrm{C} 40$ & nd & nd & nd & nd & nd & nd & nd & nd & nd \\
\hline n-alcanos & 35,25 & 42,11 & 72,23 & 117,11 & 132,92 & 112,28 & 92,60 & 90,52 & 35,23 \\
\hline HR & 88,8 & 94,6 & 173,5 & 238,8 & 308,9 & 306,6 & 170,5 & 172,1 & 109,0 \\
\hline MCNR & 140,6 & 151,2 & 75,3 & 153,5 & 128,1 & 103,3 & 77,3 & 68,0 & 136,2 \\
\hline $\begin{array}{c}\text { Alifáticos } \\
\text { Totais }\end{array}$ & 229,4 & 245,8 & 248,8 & 392,3 & 437,0 & 409,9 & 247,7 & 240,1 & 245,2 \\
\hline
\end{tabular}


Resultado de hidrocarbonetos alifáticos, em $\mathrm{mg} \mathrm{g}^{-1}$, para as amostras de petróleo e produtos de petróleo

\begin{tabular}{|c|c|c|c|c|c|c|c|c|c|}
\hline Código & $\mathrm{Q}$ & $\mathrm{R}$ & $\mathrm{R}$ & $S$ & $\mathrm{~S}$ & $T$ & $T$ & U & U \\
\hline C12 & 1,984 & 5,820 & 6,321 & 11,343 & 12,293 & 5,166 & 5,881 & 1,451 & 1,409 \\
\hline C13 & 3,172 & 5,788 & 6,220 & 11,243 & 12,306 & 5,034 & 5,535 & 1,572 & 1,519 \\
\hline C14 & 2,432 & 6,232 & 6,547 & 10,898 & 12,306 & 4,596 & 5,111 & 1,647 & 1,457 \\
\hline C15 & 2,977 & 5,448 & 5,638 & 11,375 & 12,390 & 4,709 & 5,204 & 2,177 & 2,029 \\
\hline C16 & 2,159 & 4,560 & 4,733 & 10,803 & 11,851 & 4,036 & 4,504 & 2,022 & 1,822 \\
\hline C17 & 1,980 & 4,076 & 4,253 & 10,113 & 11,138 & 3,454 & 3,934 & 2,022 & 1,678 \\
\hline Pristano & 1,917 & 2,872 & 2,958 & 3,172 & 3,432 & 3,912 & 4,527 & 3,403 & 2,918 \\
\hline C18 & 1,719 & 3,284 & 3,442 & 9,142 & 10,080 & 2,838 & 3,111 & 1,902 & 1,688 \\
\hline Fitano & 1,769 & 1,940 & 2,046 & 2,123 & 2,306 & 2,846 & 3,265 & 1,867 & 1,654 \\
\hline C19 & 1,528 & 2,904 & 3,029 & 9,369 & 10,371 & 2,343 & 2,650 & 1,797 & 1,596 \\
\hline $\mathrm{C2O}$ & 1,364 & 2,728 & 2,770 & 8,966 & 9,878 & 2,434 & 2,708 & 1,947 & 1,712 \\
\hline C21 & 1,118 & 2,512 & 2,564 & 9,673 & 10,750 & 2,139 & 2,327 & 2,082 & 1,909 \\
\hline $\mathrm{C} 22$ & 1,200 & 2,544 & 2,763 & 9,923 & 10,957 & 1,984 & 2,248 & 2,112 & 2,048 \\
\hline $\mathrm{C} 23$ & 1,200 & 2,764 & 2,872 & 11,075 & 12,142 & 1,965 & 2,186 & 2,462 & 2,115 \\
\hline $\mathrm{C} 24$ & 1,072 & 2,844 & 2,782 & 10,526 & 11,518 & 2,052 & 2,327 & 2,377 & 2,351 \\
\hline C25 & 1,095 & 2,596 & 2,639 & 11,511 & 12,597 & 1,837 & 2,190 & 2,442 & 2,413 \\
\hline C26 & 1,267 & 2,552 & 2,575 & 9,914 & 11,096 & 1,602 & 1,774 & 2,052 & 1,918 \\
\hline $\mathrm{C} 27$ & 0,955 & 2,500 & 2,361 & 10,717 & 11,745 & 1,175 & 1,319 & 1,887 & 1,875 \\
\hline C28 & 0,869 & 2,368 & 2,185 & 9,410 & 10,245 & 1,168 & 1,279 & 1,557 & 1,519 \\
\hline C29 & 0,830 & 2,208 & 1,926 & 9,043 & 9,810 & 1,054 & 1,164 & 1,707 & 1,673 \\
\hline C30 & 0,678 & 1,784 & 1,753 & 7,182 & 7,736 & 0,922 & 1,058 & 1,216 & 1,202 \\
\hline C31 & 0,444 & 1,508 & 1,096 & 5,808 & 6,277 & 0,854 & 0,982 & 1,101 & 1,072 \\
\hline C32 & 0,394 & 1,080 & 0,739 & 4,301 & 4,625 & 0,635 & 0,686 & 0,616 & 0,615 \\
\hline C33 & 0,405 & 0,852 & 0,556 & 3,421 & 3,668 & 0,578 & 0,642 & 0,586 & 0,438 \\
\hline C34 & 0,226 & 0,588 & 0,432 & 2,477 & 2,643 & 0,624 & 0,646 & 0,305 & 0,284 \\
\hline C35 & 0,401 & 0,432 & 0,229 & 2,105 & 2,264 & 0,397 & 0,363 & nd & 0,313 \\
\hline C36 & nd & 0,224 & nd & 1,307 & 1,370 & nd & nd & nd & nd \\
\hline C37 & nd & nd & nd & 1,248 & 1,261 & nd & nd & nd & nd \\
\hline C38 & nd & nd & nd & 0,971 & 0,919 & nd & nd & nd & nd \\
\hline C39 & nd & nd & nd & 0,926 & 0,974 & nd & nd & nd & nd \\
\hline C40 & nd & nd & nd & 0,681 & 0,645 & nd & nd & nd & nd \\
\hline n-alcanos & 35,16 & 75,01 & 75,43 & 220,77 & 241,59 & 60,36 & 67,62 & 44,31 & 41,23 \\
\hline HR & 101,0 & 159,5 & 149,7 & 301,1 & 340,0 & 216,8 & 191,8 & 112,0 & 101,4 \\
\hline MCNR & 132,4 & 88,4 & 86,2 & 159,1 & 157,1 & 147,0 & 135,3 & 192,3 & 191,1 \\
\hline $\begin{array}{l}\text { Alifáticos } \\
\text { Totais }\end{array}$ & 233,4 & 247,9 & 235,9 & 460,2 & 497,0 & 363,9 & 327,1 & 304,3 & 292,5 \\
\hline
\end{tabular}


Resultado de hidrocarbonetos alifáticos, em $\mathrm{mg} \mathrm{g}^{-1}$, para as amostras de petróleo e produtos de petróleo

\begin{tabular}{|c|c|c|c|c|c|c|c|c|}
\hline Código & $\mathrm{V}$ & $\mathrm{V}$ & W & W & $Y$ & $Y$ & Z & Z \\
\hline C12 & nd & nd & 2,443 & 2,167 & 8,610 & 8,659 & 5,190 & 4,765 \\
\hline C13 & nd & nd & 3,137 & 2,833 & 8,160 & 8,108 & 5,123 & 4,666 \\
\hline C14 & nd & nd & 2,671 & 2,414 & 7,772 & 7,645 & 4,714 & 4,460 \\
\hline C15 & nd & nd & 3,157 & 2,902 & 7,735 & 7,897 & 0,190 & 4,325 \\
\hline C16 & nd & nd & 2,463 & 2,205 & 6,807 & 6,781 & 3,818 & 3,542 \\
\hline C17 & nd & nd & 2,359 & 2,121 & 6,198 & 6,203 & 3,439 & 3,159 \\
\hline Pristano & nd & nd & 2,532 & 2,219 & 3,888 & 3,962 & 3,532 & 3,336 \\
\hline C18 & nd & nd & 1,952 & 1,772 & 5,253 & 5,230 & 2,595 & 2,393 \\
\hline Fitano & nd & nd & 1,972 & 1,716 & 2,841 & 2,741 & 2,190 & 2,026 \\
\hline C19 & nd & nd & 1,670 & 1,493 & 4,428 & 4,504 & 2,338 & 2,133 \\
\hline $\mathrm{C} 20$ & nd & nd & 1,318 & 1,358 & 4,509 & 4,435 & 2,108 & 1,993 \\
\hline C21 & nd & nd & 1,383 & 1,265 & 3,904 & 3,889 & 2,026 & 1,878 \\
\hline $\mathrm{C} 22$ & nd & nd & 1,249 & 1,205 & 3,896 & 3,838 & 2,212 & 2,059 \\
\hline $\mathrm{C} 23$ & nd & nd & 1,313 & 1,177 & 3,418 & 3,531 & 2,097 & 1,985 \\
\hline $\mathrm{C} 24$ & nd & nd & 1,363 & 1,423 & 3,316 & 3,393 & 2,390 & 2,179 \\
\hline $\mathrm{C} 25$ & nd & nd & 1,333 & 1,205 & 3,013 & 3,012 & 2,212 & 2,076 \\
\hline $\mathrm{C} 26$ & nd & nd & 1,140 & 1,065 & 2,604 & 2,580 & 2,164 & 2,018 \\
\hline $\mathrm{C} 27$ & nd & nd & 0,877 & 0,847 & 2,110 & 2,121 & 2,011 & 1,857 \\
\hline $\mathrm{C} 28$ & nd & nd & 0,961 & 0,870 & 1,881 & 1,887 & 1,978 & 1,800 \\
\hline C29 & nd & nd & 0,897 & 0,828 & 1,733 & 1,699 & 2,316 & 2,117 \\
\hline C30 & nd & nd & 0,565 & 0,619 & 1,582 & 1,607 & 1,442 & 1,347 \\
\hline C31 & nd & nd & 0,575 & 0,586 & 1,316 & 1,304 & 1,126 & 1,075 \\
\hline C32 & nd & nd & 0,411 & 0,377 & 1,038 & 1,019 & 0,743 & 0,680 \\
\hline C33 & nd & nd & 0,337 & 0,298 & 0,834 & 0,849 & 0,580 & 0,552 \\
\hline C34 & nd & nd & 0,263 & 0,312 & 0,883 & 0,799 & 0,584 & 0,478 \\
\hline C35 & nd & nd & 0,733 & 0,386 & 0,572 & 0,574 & 0,353 & 0,338 \\
\hline C36 & nd & nd & nd & nd & 0,278 & 0,271 & nd & nd \\
\hline C37 & nd & nd & nd & nd & 0,237 & nd & nd & nd \\
\hline C38 & nd & nd & nd & nd & nd & nd & nd & nd \\
\hline C39 & nd & nd & nd & nd & nd & nd & nd & nd \\
\hline C40 & nd & nd & nd & nd & nd & nd & nd & nd \\
\hline n-alcanos & nd & $\mathrm{nd}$ & 39,07 & 35,66 & 98,82 & 98,54 & 59,47 & 59,24 \\
\hline HR & 34,4 & 58,4 & 155,9 & 163,7 & 220,1 & 196,7 & 190,3 & 199,1 \\
\hline MCNR & 122,3 & 148,1 & 193,3 & 193,1 & 146,9 & 147,7 & 99,6 & 123,4 \\
\hline $\begin{array}{l}\text { Alifáticos } \\
\text { Totais }\end{array}$ & 156,8 & 206,5 & 349,2 & 356,8 & 366,9 & 344,4 & 289,9 & 322,5 \\
\hline
\end{tabular}


8 - Anexos

261

DADOS DE ALIFÁTICOS EM AMOSTRAS SEDIMENTO

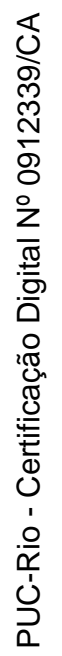


Resultado de hidrocarbonetos alifáticos, em $\mu \mathrm{g} \mathrm{g}^{-1}$, para as amostras sedimento coletadas na Baia de Guanabara.

\begin{tabular}{|c|c|c|c|c|c|c|}
\hline Código & P1 & P2 & P3 & P4 & P5 & P6 \\
\hline C12 & nd & 0,014 & 0,010 & nd & nd & nd \\
\hline C13 & nd & 0,029 & 0,011 & 0,011 & 0,011 & nd \\
\hline C14 & nd & 0,022 & 0,018 & 0,011 & 0,019 & nd \\
\hline C15 & 0,013 & 0,184 & 0,065 & 0,054 & 0,103 & 0,021 \\
\hline C16 & 0,026 & 0,112 & 0,111 & 0,067 & 0,160 & 0,025 \\
\hline C17 & 0,043 & 0,215 & 0,173 & 0,138 & 0,293 & 0,060 \\
\hline Pristano & 0,049 & 0,497 & 0,145 & 0,172 & 0,180 & 0,066 \\
\hline C18 & 0,099 & 0,280 & 0,238 & 0,201 & 0,366 & 0,119 \\
\hline Fitano & 0,098 & 0,616 & 0,254 & 0,264 & 0,254 & 0,170 \\
\hline C19 & 0,105 & 0,034 & 0,110 & 0,172 & 0,332 & 0,017 \\
\hline $\mathrm{C2O}$ & 0,062 & 0,058 & 0,153 & 0,023 & 0,138 & 0,044 \\
\hline C21 & 0,107 & 0,295 & 0,422 & 0,315 & 0,661 & 0,143 \\
\hline C22 & 0,079 & 0,166 & 0,138 & 0,105 & 0,136 & 0,171 \\
\hline $\mathrm{C} 23$ & 0,064 & 0,263 & 0,206 & 0,108 & 0,166 & 0,223 \\
\hline $\mathrm{C} 24$ & 0,104 & 0,541 & 0,403 & 0,140 & 0,227 & 0,237 \\
\hline C25 & 0,050 & 0,467 & 0,182 & 0,105 & 0,323 & 0,418 \\
\hline $\mathrm{C} 26$ & 0,074 & 0,347 & 0,214 & 0,125 & 0,373 & 0,195 \\
\hline $\mathrm{C} 27$ & 0,050 & 0,360 & 0,259 & 0,145 & 0,477 & 0,589 \\
\hline $\mathrm{C} 28$ & 0,053 & 0,305 & 0,294 & 0,138 & 0,370 & 0,344 \\
\hline $\mathrm{C} 29$ & 0,107 & 1,472 & 1,261 & 0,452 & 1,435 & 1,844 \\
\hline C30 & 0,085 & 0,925 & 0,844 & 0,260 & 0,679 & 0,726 \\
\hline C31 & 0,108 & 1,180 & 1,305 & 0,383 & 1,380 & 1,524 \\
\hline C32 & 0,041 & 0,542 & 0,613 & 0,137 & 0,465 & 0,593 \\
\hline $\mathrm{C} 33$ & 0,064 & 0,946 & 0,927 & 0,228 & 0,977 & 1,107 \\
\hline C34 & 0,035 & 1,037 & 0,542 & 0,095 & 0,315 & 0,434 \\
\hline C35 & 0,037 & 0,629 & 0,462 & 0,149 & 0,525 & 0,526 \\
\hline C36 & 0,017 & 0,267 & 0,205 & 0,057 & 0,148 & 0,177 \\
\hline $\mathrm{C} 37$ & 0,020 & 0,320 & 0,185 & 0,054 & 0,182 & 0,195 \\
\hline C38 & 0,019 & 0,142 & 0,183 & 0,041 & 0,136 & 0,147 \\
\hline C39 & 0,021 & 0,252 & 0,303 & 0,066 & 0,170 & 0,193 \\
\hline C40 & 0,018 & 0,172 & 0,247 & 0,012 & 0,143 & 0,187 \\
\hline n-alcanos & 1,65 & 12,69 & 10,48 & 4,23 & 11,14 & 10,50 \\
\hline HR & 5,9 & 60,5 & 42,4 & 13,9 & 29,5 & 50,2 \\
\hline MCNR & 40,9 & 1025,3 & 645,6 & 171,5 & 312,8 & 663,4 \\
\hline $\begin{array}{c}\text { Alifáticos } \\
\text { Totais }\end{array}$ & 46,8 & 1085,8 & 688,0 & 185,5 & 342,3 & 713,6 \\
\hline
\end{tabular}


Resultado de hidrocarbonetos alifáticos, em $\mu \mathrm{g} \mathrm{g}^{-1}$, para as amostras sedimento coletadas na Baia de Guanabara.

\begin{tabular}{|c|c|c|c|c|c|}
\hline Código & P7 & P8 & P9 & P10 & P11 \\
\hline C12 & 0,012 & nd & nd & nd & nd \\
\hline C13 & nd & nd & nd & nd & nd \\
\hline C14 & nd & nd & nd & nd & nd \\
\hline C15 & 0,015 & nd & 0,021 & nd & 0,020 \\
\hline C16 & 0,015 & 0,023 & 0,019 & nd & 0,017 \\
\hline C17 & 0,019 & 0,062 & 0,048 & 0,010 & 0,026 \\
\hline Pristano & 0,022 & 0,032 & 0,044 & 0,013 & 0,040 \\
\hline C18 & 0,022 & 0,092 & 0,099 & 0,012 & 0,048 \\
\hline Fitano & 0,034 & 0,092 & 0,110 & 0,025 & 0,073 \\
\hline C19 & 0,022 & 0,072 & 0,041 & 0,015 & 0,044 \\
\hline $\mathrm{C} 20$ & 0,036 & 0,041 & 0,060 & 0,023 & 0,055 \\
\hline $\mathrm{C} 21$ & 0,097 & 0,229 & 0,212 & 0,079 & 0,185 \\
\hline $\mathrm{C} 22$ & 0,111 & 0,059 & 0,107 & 0,055 & 0,090 \\
\hline $\mathrm{C} 23$ & 0,321 & 0,246 & 0,172 & 0,052 & 0,080 \\
\hline $\mathrm{C} 24$ & 0,237 & 0,153 & 0,167 & 0,084 & 0,133 \\
\hline $\mathrm{C} 25$ & 0,936 & 0,744 & 0,165 & 0,040 & 0,096 \\
\hline C26 & 0,329 & 0,291 & 0,227 & 0,067 & 0,151 \\
\hline $\mathrm{C} 27$ & 1,551 & 1,417 & 0,273 & 0,042 & 0,124 \\
\hline $\mathrm{C} 28$ & 0,604 & 0,649 & 0,159 & 0,046 & 0,096 \\
\hline $\mathrm{C} 29$ & 3,254 & 3,314 & 0,732 & 0,101 & 0,402 \\
\hline C30 & 0,574 & 0,777 & 0,424 & 0,069 & 0,246 \\
\hline C31 & 1,908 & 2,398 & 0,739 & 0,088 & 0,388 \\
\hline C32 & 0,292 & 0,480 & 0,351 & 0,031 & 0,184 \\
\hline C33 & 1,100 & 1,430 & 0,670 & 0,053 & 0,284 \\
\hline C34 & 0,123 & 0,264 & 0,123 & 0,027 & 0,166 \\
\hline C35 & 0,312 & 0,531 & 0,210 & 0,037 & 0,136 \\
\hline C36 & 0,034 & 0,094 & 0,078 & nd & 0,064 \\
\hline C37 & 0,062 & 0,146 & 0,101 & nd & 0,076 \\
\hline C38 & 0,029 & 0,078 & 0,065 & nd & 0,040 \\
\hline C39 & 0,067 & 0,104 & 0,087 & nd & 0,045 \\
\hline C40 & nd & 0,059 & 0,076 & nd & 0,028 \\
\hline n-alcanos & 12,14 & 13,88 & 5,58 & 0,97 & 3,34 \\
\hline HR & 26,4 & 19,3 & 36,7 & 6,0 & 15,6 \\
\hline MCNR & 47,2 & 109,0 & 538,1 & 45,4 & 172,4 \\
\hline $\begin{array}{l}\text { Alifáticos } \\
\text { Totais }\end{array}$ & 73,6 & 128,3 & 574,8 & 51,4 & 188,0 \\
\hline
\end{tabular}


DADOS DE HPAS EM AMOSTRAS MATERIAL PARTICULADO ATMOSFÉRICO 
Resultado de hidrocarbonetos aromáticos, em $\mathrm{ng} \mathrm{m}^{-3}$, para as amostras de material particulado atmosférico ( $\left.\mathrm{PM}_{2,5}\right)$ coletadas no ano de 2011

\begin{tabular}{|c|c|c|c|c|c|c|c|c|c|}
\hline Código & C8 & C14 & $\mathrm{C} 26$ & C32 & C38 & C44 & C50 & C56 & $\mathrm{C} 80$ \\
\hline Data Início & 8-jan & 14-jan & 26-jan & 1-fev & 7-fev & 13-fev & 19-fev & 25-fev & 21-mar \\
\hline $\mathbf{N}$ & 0,054 & 0,081 & 0,051 & 0,075 & nd & 0,063 & 0,068 & 0,089 & 0,119 \\
\hline $\mathrm{C} 1 \mathrm{~N}$ & 0,032 & 0,013 & 0,033 & 0,010 & 0,069 & nd & 0,037 & 0,072 & 0,140 \\
\hline $\mathrm{C} 2 \mathrm{~N}$ & 0,039 & 0,129 & 0,041 & 0,090 & 0,114 & 0,083 & 0,050 & 0,088 & 0,195 \\
\hline C3N & 0,012 & 0,091 & 0,016 & 0,089 & 0,108 & 0,051 & 0,019 & 0,034 & 0,191 \\
\hline $\mathrm{C} 4 \mathrm{~N}$ & 0,013 & 0,095 & 0,015 & 0,076 & 0,081 & 0,056 & 0,017 & 0,031 & 0,188 \\
\hline ACF & nd & 0,011 & nd & 0,012 & 0,022 & nd & 0,008 & 0,010 & 0,026 \\
\hline ACE & nd & nd & nd & nd & 0,010 & nd & nd & nd & nd \\
\hline $\mathbf{F}$ & nd & 0,009 & nd & 0,012 & 0,023 & nd & nd & nd & 0,039 \\
\hline C1F & 0,011 & 0,043 & 0,015 & 0,048 & 0,043 & 0,031 & 0,017 & 0,027 & nd \\
\hline $\mathrm{C} 2 \mathrm{~F}$ & 0,067 & 0,254 & 0,076 & 0,152 & nd & 0,123 & 0,068 & 0,140 & 0,045 \\
\hline C3F & 0,199 & 0,460 & 0,238 & 0,319 & 0,468 & 0,172 & 0,180 & 0,564 & 0,643 \\
\hline DBT & 0,011 & 0,040 & 0,012 & 0,023 & 0,035 & 0,018 & 0,010 & 0,027 & 0,072 \\
\hline C1DBT & 0,062 & 0,285 & 0,073 & 0,109 & nd & 0,069 & 0,047 & 0,198 & 0,316 \\
\hline C2DBT & 0,225 & 1,038 & 0,284 & 0,387 & 0,384 & 0,234 & 0,136 & 0,670 & 0,589 \\
\hline C3DBT & 0,347 & 1,434 & 0,453 & 0,457 & 0,433 & 0,285 & 0,208 & 1,007 & 0,606 \\
\hline $\mathrm{Fe}$ & 0,081 & 0,265 & 0,122 & 0,199 & 0,258 & 0,118 & 0,108 & 0,187 & 0,495 \\
\hline C1Fe & 0,126 & 0,462 & 0,190 & 0,296 & 0,323 & 0,147 & 0,115 & 0,373 & 0,733 \\
\hline $\mathrm{C} 2 \mathrm{Fe}$ & 0,219 & 0,825 & 0,335 & 0,460 & 0,453 & 0,221 & 0,172 & 0,724 & 0,812 \\
\hline $\mathrm{C} 3 \mathrm{Fe}$ & 0,263 & 0,941 & 0,413 & 0,374 & 0,497 & 0,175 & 0,178 & 1,014 & 0,817 \\
\hline $\mathrm{C} 4 \mathrm{Fe}$ & 0,312 & 0,583 & 0,326 & 0,174 & 0,341 & 0,077 & 0,140 & 0,746 & 0,678 \\
\hline A & 0,010 & 0,045 & 0,014 & 0,032 & 0,038 & 0,018 & 0,012 & 0,024 & 0,101 \\
\hline FI & 0,160 & 0,395 & 0,284 & 0,270 & 0,339 & 0,118 & 0,148 & 0,645 & 0,513 \\
\hline $\mathbf{P i}$ & 0,201 & 0,618 & 0,364 & 0,403 & 0,492 & 0,174 & 0,171 & 1,009 & nd \\
\hline C1Pi & 0,160 & 0,475 & 0,265 & 0,336 & 0,431 & 0,123 & 0,124 & 0,605 & 0,472 \\
\hline $\mathrm{C} 2 \mathrm{Pi}$ & 0,216 & 0,529 & 0,262 & 0,414 & 0,513 & 0,166 & 0,165 & 0,476 & 0,481 \\
\hline $\mathrm{BaA}$ & 0,082 & 0,150 & 0,125 & 0,168 & 0,165 & 0,077 & 0,133 & 0,155 & 0,117 \\
\hline $\mathrm{Cr}$ & 0,238 & 0,395 & 0,331 & 0,601 & 0,468 & 0,261 & 0,312 & 0,389 & 0,244 \\
\hline $\mathrm{C} 1 \mathrm{Cr}$ & 0,130 & 0,305 & 0,150 & 0,383 & 0,236 & 0,182 & 0,166 & 0,215 & nd \\
\hline $\mathrm{C} 2 \mathrm{Cr}$ & 0,049 & 0,216 & 0,035 & 0,303 & nd & 0,173 & 0,080 & 0,089 & nd \\
\hline $\mathrm{BbFI}$ & 0,165 & 0,380 & 0,272 & 0,664 & 0,443 & 0,463 & 0,297 & 0,198 & 0,060 \\
\hline BkFI & 0,036 & 0,047 & 0,056 & 0,115 & 0,102 & 0,072 & 0,068 & 0,041 & 0,013 \\
\hline $\mathrm{BePi}$ & 0,093 & 0,201 & 0,157 & 0,336 & 0,258 & 0,270 & 0,163 & 0,123 & 0,050 \\
\hline $\mathrm{BaPi}$ & 0,061 & 0,139 & 0,100 & 0,201 & 0,158 & 0,153 & 0,123 & 0,066 & 0,029 \\
\hline Per & 0,014 & 0,022 & 0,029 & 0,049 & 0,028 & 0,029 & 0,025 & 0,021 & 0,014 \\
\hline I-Pi & 0,050 & 0,121 & 0,073 & 0,306 & 0,147 & 0,346 & 0,153 & 0,041 & nd \\
\hline DBahA & 0,013 & 0,040 & 0,018 & 0,070 & 0,039 & 0,047 & 0,034 & 0,017 & 0,009 \\
\hline BghiPer & 0,132 & 0,292 & 0,180 & 0,398 & 0,239 & 0,402 & 0,246 & 0,110 & 0,029 \\
\hline 16 HPA & 1,28 & 2,99 & 1,99 & 3,53 & 2,94 & 2,31 & 1,88 & 2,98 & 1,80 \\
\hline$\Sigma$ HPA & 3,88 & 11,43 & 5,41 & 8,41 & 7,76 & 5,00 & 4,00 & 10,23 & 8,84 \\
\hline \%p-terfenil & 60 & 102 & 82 & 102 & 79 & 114 & 82 & 105 & 62 \\
\hline $2,6+3,5$ 2MFe & 0,021 & 0,099 & 0,040 & 0,034 & 0,074 & 0,017 & 0,015 & 0,084 & 0,523 \\
\hline 1,7 2MFe & 0,199 & 0,631 & 0,318 & 0,342 & 0,435 & 0,153 & 0,159 & 0,853 & 0,865 \\
\hline $1,52 \mathrm{MFe}$ & nd & 0,460 & nd & 0,262 & nd & 0,144 & nd & nd & 0,601 \\
\hline Acef & 0,018 & 0,092 & 0,038 & 0,070 & 0,067 & 0,025 & 0,023 & 0,099 & 0,145 \\
\hline $\mathrm{BeFe}$ & nd & nd & nd & nd & 0,035 & nd & nd & nd & 0,039 \\
\hline $\mathrm{I}-\mathrm{Cr}$ & 0,036 & 0,063 & 0,035 & 0,175 & 0,066 & 0,224 & 0,082 & 0,028 & nd \\
\hline DajA & 0,012 & 0,025 & 0,016 & 0,057 & 0,017 & 0,163 & 0,042 & 0,015 & nd \\
\hline Pf & nd & nd & nd & 0,010 & nd & 0,010 & nd & nd & nd \\
\hline $\mathrm{BbCr}$ & nd & nd & nd & 0,016 & nd & 0,016 & 0,009 & nd & nd \\
\hline Pc & nd & nd & nd & 0,033 & nd & 0,052 & 0,013 & nd & nd \\
\hline
\end{tabular}


Resultado de hidrocarbonetos aromáticos, em $\mathrm{ng} \mathrm{m}^{-3}$, para as amostras de material particulado atmosférico (PM 2,5) coletadas no ano de 2011

\begin{tabular}{|c|c|c|c|c|c|c|c|c|c|}
\hline Código & C92 & C98 & C104 & C110 & C116 & C122 & C128 & C152 & C164 \\
\hline Data Início & 2-abr & $8-a b r$ & 14-abr & $20-a b r$ & $26-a b r$ & 2-mai & 8-mai & 1-jun & 13-jun \\
\hline $\mathbf{N}$ & 0,108 & 0,046 & 0,098 & 0,113 & 0,139 & 0,040 & 0,069 & 0,071 & 0,127 \\
\hline $\mathrm{C} 1 \mathrm{~N}$ & 0,107 & 0,039 & 0,075 & 0,085 & 0,102 & 0,038 & 0,071 & 0,075 & 0,124 \\
\hline $\mathrm{C} 2 \mathrm{~N}$ & 0,145 & 0,061 & 0,103 & 0,146 & 0,134 & nd & nd & 0,016 & 0,150 \\
\hline C3N & 0,087 & 0,030 & 0,049 & 0,084 & 0,085 & 0,023 & 0,046 & 0,010 & 0,098 \\
\hline $\mathrm{C} 4 \mathrm{~N}$ & 0,085 & 0,030 & 0,042 & 0,089 & 0,124 & 0,019 & 0,036 & 0,008 & 0,067 \\
\hline ACF & 0,017 & 0,008 & 0,015 & 0,015 & 0,015 & nd & nd & nd & 0,021 \\
\hline ACE & nd & nd & nd & 0,007 & nd & nd & nd & nd & nd \\
\hline $\mathbf{F}$ & 0,019 & nd & 0,011 & 0,024 & 0,016 & nd & nd & 0,011 & 0,019 \\
\hline C1F & 0,049 & 0,029 & 0,029 & 0,062 & 0,078 & 0,011 & 0,020 & nd & 0,041 \\
\hline $\mathrm{C} 2 \mathrm{~F}$ & 0,165 & 0,155 & 0,107 & 0,268 & 0,388 & 0,056 & 0,067 & nd & 0,136 \\
\hline $\mathrm{C} 3 \mathrm{~F}$ & 0,400 & 0,429 & 0,352 & 0,575 & 0,881 & 0,151 & 0,119 & 0,034 & 0,011 \\
\hline DBT & 0,035 & 0,020 & 0,019 & 0,052 & 0,051 & nd & 0,010 & nd & 0,016 \\
\hline C1DBT & 0,152 & 0,147 & 0,091 & 0,264 & 0,286 & 0,037 & 0,051 & 0,046 & 0,048 \\
\hline C2DBT & 0,354 & 0,464 & 0,261 & 0,627 & 0,559 & 0,136 & 0,139 & nd & 0,152 \\
\hline C3DBT & 0,441 & 0,643 & 0,297 & 0,626 & 0,654 & 0,172 & 0,160 & nd & 0,186 \\
\hline $\mathrm{Fe}$ & 0,271 & 0,190 & 0,206 & 0,357 & 0,294 & 0,074 & 0,106 & 0,108 & 0,195 \\
\hline $\mathrm{C} 1 \mathrm{Fe}$ & 0,334 & 0,334 & 0,290 & 0,599 & 0,523 & 0,119 & 0,141 & 0,144 & 0,201 \\
\hline $\mathrm{C} 2 \mathrm{Fe}$ & 0,506 & 0,619 & 0,395 & 0,826 & 0,819 & 0,179 & 0,180 & 0,274 & 0,295 \\
\hline $\mathrm{C} 3 \mathrm{Fe}$ & 0,605 & 0,643 & 0,412 & 0,794 & 0,893 & 0,144 & 0,140 & 0,164 & 0,292 \\
\hline $\mathrm{C} 4 \mathrm{Fe}$ & 0,393 & 0,439 & 0,273 & 0,530 & 0,541 & 0,052 & 0,051 & 0,133 & 0,214 \\
\hline A & 0,037 & 0,029 & 0,032 & 0,047 & 0,046 & 0,012 & 0,015 & 0,016 & 0,039 \\
\hline FI & 0,398 & 0,385 & 0,374 & 0,394 & 0,486 & 0,235 & 0,181 & 0,112 & 0,315 \\
\hline $\mathbf{P i}$ & 0,509 & 0,587 & 0,406 & 0,522 & 0,676 & 0,248 & 0,206 & 0,296 & 0,345 \\
\hline C1Pi & 0,347 & 0,410 & 0,235 & 0,379 & 0,407 & 0,123 & 0,126 & 0,287 & 0,314 \\
\hline $\mathrm{C} 2 \mathrm{Pi}$ & 0,309 & 0,333 & 0,230 & 0,286 & 0,373 & 0,129 & 0,141 & 0,325 & 0,524 \\
\hline $\mathrm{BaA}$ & 0,172 & 0,156 & 0,184 & 0,118 & 0,151 & 0,135 & 0,143 & 0,192 & 0,454 \\
\hline $\mathrm{Cr}$ & 0,346 & 0,357 & 0,404 & 0,244 & 0,297 & 0,579 & 0,332 & 0,334 & 0,815 \\
\hline $\mathrm{C} 1 \mathrm{Cr}$ & 0,177 & 0,168 & 0,207 & 0,149 & 0,168 & 0,158 & 0,107 & 0,202 & 0,394 \\
\hline $\mathrm{C} 2 \mathrm{Cr}$ & 0,158 & 0,082 & 0,049 & 0,105 & 0,063 & 0,082 & 0,043 & 0,029 & 0,158 \\
\hline $\mathrm{BbFI}$ & 0,349 & 0,272 & 0,958 & 0,292 & 0,180 & 0,700 & 0,219 & 0,536 & 1,043 \\
\hline BkFI & 0,087 & 0,059 & 0,232 & nd & 0,036 & 0,171 & 0,067 & 0,144 & 0,319 \\
\hline $\mathrm{BePi}$ & 0,158 & 0,140 & 0,422 & 0,118 & 0,125 & 0,379 & 0,105 & 0,280 & 0,444 \\
\hline $\mathrm{BaPi}$ & 0,138 & 0,086 & 0,332 & 0,066 & 0,082 & 0,171 & 0,084 & 0,210 & 0,572 \\
\hline Per & 0,025 & 0,014 & 0,062 & 0,028 & 0,017 & 0,014 & 0,010 & 0,017 & 0,100 \\
\hline I-Pi & 0,135 & 0,057 & 0,545 & 0,042 & 0,038 & 0,375 & 0,189 & 0,252 & 0,571 \\
\hline DBahA & 0,033 & 0,024 & 0,120 & 0,014 & nd & 0,092 & 0,062 & 0,044 & 0,117 \\
\hline BghiPer & 0,305 & 0,159 & 0,696 & 0,120 & 0,111 & 0,448 & 0,246 & 0,350 & 0,735 \\
\hline 16 HPA & 2,93 & 2,41 & 4,61 & 2,38 & 2,57 & 3,28 & 1,92 & 2,68 & 5,69 \\
\hline$\Sigma$ HPA & 7,96 & 7,64 & 8,61 & 9,07 & 9,84 & 5,30 & 3,68 & 4,72 & 9,65 \\
\hline \%p-terfenil & 214 & 82 & 68 & 95 & 100 & 112 & 99 & 98 & 81 \\
\hline $2,6+3,52 \mathrm{MFe}$ & 0,074 & 0,093 & 0,088 & 0,088 & 0,201 & 0,041 & 0,040 & 0,009 & 0,036 \\
\hline $1,72 \mathrm{MFe}$ & 0,493 & 0,657 & 0,432 & 0,543 & 0,883 & 0,176 & 0,182 & 0,070 & 0,188 \\
\hline 1,5 $2 \mathrm{MFe}$ & nd & nd & nd & 0,401 & nd & 0,134 & 0,148 & 0,074 & 0,108 \\
\hline Acef & 0,072 & 0,075 & 0,068 & 0,072 & 0,102 & 0,037 & 0,038 & 0,017 & 0,083 \\
\hline $\mathrm{BeFe}$ & 0,046 & nd & nd & 0,041 & nd & 0,029 & 0,036 & nd & 0,061 \\
\hline $\mathrm{I}-\mathrm{Cr}$ & 0,066 & 0,048 & 0,317 & 0,029 & 0,020 & 0,147 & 0,109 & 0,064 & 0,232 \\
\hline DajA & 0,024 & 0,011 & 0,096 & nd & nd & 0,061 & 0,043 & nd & 0,082 \\
\hline Pf & nd & nd & 0,018 & nd & nd & nd & 0,020 & nd & 0,016 \\
\hline $\mathrm{BbCr}$ & 0,011 & nd & 0,029 & nd & nd & nd & 0,020 & nd & 0,041 \\
\hline Pc & 0,011 & nd & 0,068 & nd & nd & nd & nd & nd & 0,062 \\
\hline
\end{tabular}


Resultado de hidrocarbonetos aromáticos, em $\mathrm{ng} \mathrm{m}^{-3}$, para as amostras de material particulado atmosférico (PM 2,5) coletadas no ano de 2011

\begin{tabular}{|c|c|c|c|c|c|c|c|c|c|}
\hline Código & C170 & C176 & C182 & C188 & C194 & C200 & C206 & C212 & C218 \\
\hline Data Início & 19-jun & 25-jun & 1-jul & 7-jul & 13-jul & 19-jul & 25-jul & 31-jul & 6-ago \\
\hline $\mathbf{N}$ & 0,049 & 0,090 & 0,032 & 0,083 & 0,096 & 0,080 & 0,091 & 0,067 & 0,080 \\
\hline C1N & 0,043 & 0,082 & 0,046 & 0,069 & 0,110 & 0,055 & 0,069 & 0,045 & 0,092 \\
\hline $\mathrm{C} 2 \mathrm{~N}$ & 0,069 & 0,110 & 0,048 & 0,106 & nd & 0,101 & 0,132 & 0,054 & nd \\
\hline $\mathrm{C} 3 \mathrm{~N}$ & 0,059 & 0,077 & nd & 0,042 & 0,065 & 0,045 & 0,061 & 0,023 & 0,059 \\
\hline $\mathrm{C} 4 \mathrm{~N}$ & 0,057 & 0,062 & nd & 0,048 & 0,053 & 0,041 & 0,052 & 0,021 & 0,055 \\
\hline ACF & nd & 0,013 & 0,014 & 0,013 & 0,028 & 0,010 & 0,014 & nd & 0,019 \\
\hline ACE & nd & nd & nd & nd & nd & nd & nd & nd & nd \\
\hline $\mathbf{F}$ & nd & 0,011 & 0,010 & 0,015 & 0,018 & 0,013 & 0,016 & 0,009 & 0,016 \\
\hline C1F & 0,024 & 0,032 & nd & 0,027 & 0,035 & 0,022 & 0,034 & 0,013 & 0,036 \\
\hline $\mathrm{C} 2 \mathrm{~F}$ & 0,125 & 0,098 & nd & 0,063 & 0,140 & 0,065 & 0,111 & 0,022 & 0,110 \\
\hline C3F & nd & 0,014 & nd & 0,121 & 0,258 & 0,168 & 0,257 & 0,010 & 0,231 \\
\hline DBT & 0,009 & 0,011 & 0,015 & 0,018 & 0,018 & 0,015 & 0,025 & nd & 0,012 \\
\hline C1DBT & 0,041 & 0,044 & nd & 0,059 & 0,053 & 0,070 & 0,126 & 0,017 & 0,047 \\
\hline C2DBT & 0,114 & 0,118 & nd & 0,141 & 0,138 & 0,245 & 0,402 & 0,047 & 0,143 \\
\hline C3DBT & 0,145 & 0,149 & nd & 0,167 & 0,157 & 0,319 & 0,524 & 0,061 & 0,160 \\
\hline $\mathrm{Fe}$ & 0,156 & 0,153 & 0,129 & 0,135 & 0,290 & 0,098 & 0,204 & 0,033 & 0,139 \\
\hline C1Fe & 0,162 & 0,153 & nd & 0,142 & 0,236 & 0,155 & 0,321 & 0,041 & 0,148 \\
\hline $\mathrm{C} 2 \mathrm{Fe}$ & 0,227 & 0,218 & nd & 0,194 & 0,267 & 0,293 & 0,581 & 0,075 & 0,181 \\
\hline $\mathrm{C} 3 \mathrm{Fe}$ & 0,172 & 0,150 & nd & 0,197 & 0,234 & 0,361 & 0,715 & 0,091 & 0,156 \\
\hline $\mathrm{C} 4 \mathrm{Fe}$ & 0,101 & 0,121 & nd & 0,164 & 0,089 & 0,276 & 0,510 & 0,071 & 0,062 \\
\hline A & 0,033 & 0,021 & 0,035 & 0,030 & 0,055 & 0,017 & 0,038 & nd & 0,027 \\
\hline FI & 0,350 & 0,191 & 0,256 & 0,220 & 0,481 & 0,171 & 0,440 & 0,059 & 0,283 \\
\hline $\mathbf{P i}$ & 0,385 & 0,254 & 0,295 & 0,217 & 0,565 & 0,186 & 0,477 & 0,052 & 0,248 \\
\hline C1Pi & 0,232 & 0,190 & nd & 0,170 & 0,334 & 0,140 & 0,364 & 0,054 & 0,165 \\
\hline $\mathrm{C} 2 \mathrm{Pi}$ & 0,347 & 0,218 & nd & 0,175 & 0,358 & 0,131 & 0,272 & 0,056 & 0,210 \\
\hline $\mathrm{BaA}$ & 0,294 & 0,134 & 0,284 & 0,180 & 0,579 & nd & 0,094 & nd & 0,239 \\
\hline $\mathrm{Cr}$ & 0,590 & 0,364 & 0,538 & 0,288 & 0,937 & 0,093 & 0,201 & 0,100 & 0,514 \\
\hline $\mathrm{C} 1 \mathrm{Cr}$ & 0,300 & 0,174 & nd & 0,138 & 0,326 & 0,041 & 0,119 & 0,046 & 0,181 \\
\hline $\mathrm{C} 2 \mathrm{Cr}$ & 0,130 & 0,074 & nd & 0,086 & 0,161 & 0,033 & 0,089 & 0,044 & 0,071 \\
\hline $\mathrm{BbFI}$ & 1,648 & 0,714 & 0,955 & 0,486 & 1,200 & 0,071 & 0,237 & 0,186 & 0,718 \\
\hline BkFI & 0,502 & 0,202 & 0,169 & 0,111 & 0,345 & nd & nd & 0,028 & 0,197 \\
\hline $\mathrm{BePi}$ & 0,732 & 0,361 & 0,349 & 0,190 & 0,526 & 0,033 & 0,096 & 0,072 & 0,295 \\
\hline $\mathrm{BaPi}$ & 0,673 & 0,252 & 0,311 & 0,217 & 0,616 & 0,016 & 0,058 & 0,031 & 0,275 \\
\hline Per & 0,105 & 0,034 & 0,080 & 0,054 & 0,084 & 0,009 & 0,026 & 0,012 & 0,036 \\
\hline I-Pi & 0,930 & 0,399 & 0,537 & 0,229 & 1,010 & 0,013 & 0,036 & 0,046 & 0,558 \\
\hline DBahA & 0,206 & 0,077 & 0,086 & 0,033 & 0,278 & nd & 0,011 & 0,013 & 0,128 \\
\hline BghiPer & 1,048 & 0,465 & 0,618 & 0,399 & 1,130 & 0,018 & 0,106 & 0,059 & 0,662 \\
\hline 16 HPA & 6,86 & 3,34 & 4,27 & 2,65 & 7,63 & 0,79 & 2,02 & 0,68 & 4,10 \\
\hline$\Sigma$ HPA & 10,06 & 5,83 & 4,81 & 5,02 & 11,27 & 3,41 & 6,91 & 1,56 & 6,56 \\
\hline \%p-terfenil & 84 & 85 & 87 & 74 & 110 & 66 & 89 & 72 & 104 \\
\hline $2,6+3,52 \mathrm{MFe}$ & 0,029 & 0,025 & 0,029 & 0,018 & 0,068 & 0,025 & 0,053 & nd & 0,048 \\
\hline 1,7 2MFe & 0,130 & 0,112 & 0,205 & 0,122 & 0,300 & 0,160 & 0,452 & 0,031 & 0,183 \\
\hline $1,52 \mathrm{MFe}$ & 0,086 & 0,077 & 0,147 & 0,072 & 0,190 & 0,114 & 0,260 & 0,031 & 0,132 \\
\hline Acef & 0,054 & 0,039 & 0,059 & 0,060 & 0,116 & 0,024 & 0,043 & 0,016 & 0,060 \\
\hline $\mathrm{BeFe}$ & 0,035 & 0,023 & 0,056 & 0,041 & 0,098 & 0,011 & 0,040 & nd & 0,051 \\
\hline $\mathrm{I}-\mathrm{Cr}$ & 0,355 & 0,163 & 0,254 & 0,111 & 0,462 & 0,007 & 0,026 & 0,026 & 0,233 \\
\hline DajA & 0,182 & 0,054 & 0,057 & 0,027 & 0,222 & 0,005 & 0,009 & 0,011 & 0,105 \\
\hline Pf & 0,034 & 0,009 & 0,015 & nd & nd & nd & nd & nd & 0,033 \\
\hline $\mathrm{BbCr}$ & 0,068 & 0,025 & 0,030 & 0,013 & 0,102 & nd & nd & nd & 0,057 \\
\hline Pc & 0,120 & 0,053 & 0,040 & 0,015 & 0,183 & $\mathrm{nd}$ & nd & nd & 0,035 \\
\hline
\end{tabular}


Resultado de hidrocarbonetos aromáticos, em $\mathrm{ng} \mathrm{m}^{-3}$, para as amostras de material particulado atmosférico (PM 2,5) coletadas no ano de 2011

\begin{tabular}{|c|c|c|c|c|c|c|c|c|c|}
\hline Código & $\mathrm{C} 230$ & $\mathrm{C} 236$ & $\mathrm{C} 242$ & C248 & C254 & $\mathrm{C} 260$ & C272 & C284 & C290 \\
\hline Data Início & 18-ago & 24-ago & 30 -ago & 5 -set & 11-set & 17-set & 29-set & 11-out & 17-out \\
\hline $\mathbf{N}$ & 0,101 & 0,038 & 0,045 & 0,057 & 0,065 & 0,056 & 0,058 & 0,063 & 0,081 \\
\hline C1N & 0,114 & 0,044 & 0,049 & 0,032 & 0,029 & 0,009 & 0,027 & 0,044 & 0,068 \\
\hline $\mathrm{C} 2 \mathrm{~N}$ & nd & 0,044 & 0,068 & 0,071 & 0,058 & 0,048 & 0,064 & 0,066 & 0,121 \\
\hline C3N & 0,093 & nd & nd & 0,052 & 0,040 & 0,042 & 0,041 & 0,051 & 0,116 \\
\hline $\mathrm{C} 4 \mathrm{~N}$ & 0,079 & nd & nd & 0,053 & 0,033 & 0,034 & 0,028 & 0,048 & 0,095 \\
\hline ACF & 0,037 & 0,012 & 0,016 & 0,013 & nd & nd & 0,016 & nd & 0,010 \\
\hline ACE & nd & nd & nd & nd & nd & nd & nd & nd & nd \\
\hline $\mathbf{F}$ & 0,020 & 0,009 & 0,011 & 0,011 & 0,007 & nd & 0,012 & nd & 0,013 \\
\hline C1F & 0,051 & nd & nd & 0,032 & 0,020 & 0,023 & 0,033 & 0,022 & 0,058 \\
\hline $\mathrm{C} 2 \mathrm{~F}$ & 0,141 & nd & nd & 0,169 & 0,068 & 0,086 & 0,112 & 0,111 & 0,180 \\
\hline C3F & 0,268 & nd & nd & 0,491 & 0,141 & 0,278 & 0,241 & 0,329 & 0,518 \\
\hline DBT & 0,021 & 0,009 & 0,011 & 0,021 & 0,013 & 0,017 & 0,022 & 0,010 & 0,022 \\
\hline C1DBT & 0,084 & nd & nd & 0,128 & 0,059 & 0,097 & 0,103 & 0,075 & 0,102 \\
\hline C2DBT & 0,199 & nd & nd & 0,401 & 0,126 & 0,367 & 0,281 & 0,260 & 0,275 \\
\hline C3DBT & 0,209 & nd & nd & 0,465 & 0,134 & 0,474 & 0,342 & 0,348 & 0,368 \\
\hline $\mathrm{Fe}$ & 0,237 & 0,082 & 0,119 & 0,248 & 0,108 & 0,114 & 0,183 & 0,100 & 0,210 \\
\hline C1Fe & 0,225 & nd & nd & 0,390 & 0,136 & 0,212 & 0,238 & 0,209 & 0,328 \\
\hline $\mathrm{C} 2 \mathrm{Fe}$ & 0,267 & nd & nd & 0,662 & 0,168 & 0,396 & 0,364 & 0,397 & 0,593 \\
\hline $\mathrm{C} 3 \mathrm{Fe}$ & 0,196 & nd & nd & 0,658 & 0,147 & 0,421 & 0,421 & 0,376 & 0,620 \\
\hline $\mathrm{C} 4 \mathrm{Fe}$ & 0,062 & nd & nd & 0,429 & 0,099 & 0,299 & 0,259 & 0,350 & 0,490 \\
\hline A & 0,047 & 0,020 & 0,023 & 0,035 & 0,012 & 0,016 & 0,024 & 0,014 & 0,035 \\
\hline FI & 0,343 & 0,159 & 0,184 & 0,570 & 0,111 & 0,259 & 0,225 & 0,213 & 0,361 \\
\hline $\mathbf{P i}$ & 0,442 & 0,188 & 0,195 & 0,972 & 0,214 & 0,420 & 0,391 & 0,254 & 0,442 \\
\hline C1Pi & 0,183 & nd & nd & 0,660 & 0,129 & 0,261 & 0,309 & 0,230 & 0,334 \\
\hline $\mathrm{C} 2 \mathrm{Pi}$ & 0,184 & nd & nd & 0,546 & 0,118 & 0,204 & 0,354 & 0,286 & 0,324 \\
\hline $\mathrm{BaA}$ & 0,164 & 0,248 & 0,179 & 0,262 & 0,032 & 0,061 & 0,102 & 0,083 & 0,085 \\
\hline $\mathrm{Cr}$ & 0,459 & 0,442 & 0,387 & 0,619 & 0,117 & 0,197 & 0,347 & 0,291 & 0,239 \\
\hline $\mathrm{C} 1 \mathrm{Cr}$ & 0,182 & nd & nd & 0,288 & 0,054 & 0,075 & 0,177 & 0,192 & 0,158 \\
\hline $\mathrm{C} 2 \mathrm{Cr}$ & 0,120 & nd & nd & 0,191 & 0,041 & 0,062 & 0,126 & 0,088 & 0,125 \\
\hline $\mathrm{BbFI}$ & 0,894 & 0,700 & 0,814 & 0,639 & 0,081 & 0,178 & 0,333 & 0,214 & 0,145 \\
\hline BkFI & 0,247 & 0,117 & 0,144 & 0,179 & 0,013 & 0,030 & 0,089 & 0,052 & 0,036 \\
\hline $\mathrm{BePi}$ & 0,421 & 0,240 & 0,293 & 0,312 & 0,051 & 0,075 & 0,185 & 0,112 & 0,097 \\
\hline $\mathrm{BaPi}$ & 0,363 & 0,259 & 0,246 & 0,249 & 0,024 & 0,041 & 0,123 & 0,065 & 0,062 \\
\hline Per & 0,047 & 0,063 & 0,060 & 0,042 & nd & 0,012 & 0,025 & nd & nd \\
\hline I-Pi & 0,688 & 0,398 & 0,469 & 0,289 & 0,024 & 0,048 & 0,122 & 0,071 & 0,031 \\
\hline DBahA & 0,163 & 0,058 & 0,067 & 0,048 & nd & 0,012 & 0,011 & 0,014 & nd \\
\hline BghiPer & 0,770 & 0,459 & 0,513 & 0,405 & 0,060 & 0,087 & 0,238 & 0,147 & 0,110 \\
\hline 16 HPA & 4,97 & 3,19 & 3,41 & 4,59 & 0,87 & 1,52 & 2,27 & 1,58 & 1,86 \\
\hline$\Sigma$ HPA & 8,12 & 3,59 & 3,89 & 10,68 & 2,53 & 5,01 & 6,03 & 5,18 & 6,85 \\
\hline \%p-terfenil & 113 & 87 & 85 & 94 & 112 & 96 & 96 & 70 & 68 \\
\hline $2,6+3,52 \mathrm{MFe}$ & 0,072 & 0,014 & 0,023 & 0,072 & 0,017 & 0,036 & 0,034 & 0,043 & 0,073 \\
\hline $1,72 \mathrm{MFe}$ & 0,267 & 0,125 & 0,137 & 0,538 & 0,121 & 0,317 & 0,324 & 0,238 & 0,388 \\
\hline $1,52 \mathrm{MFe}$ & 0,189 & 0,091 & 0,124 & nd & nd & nd & nd & 0,153 & 0,271 \\
\hline Acef & 0,069 & 0,046 & 0,036 & 0,122 & 0,016 & 0,023 & 0,044 & 0,036 & 0,038 \\
\hline $\mathrm{BeFe}$ & 0,039 & 0,048 & 0,031 & 0,096 & 0,010 & 0,027 & 0,039 & 0,015 & 0,019 \\
\hline $\mathrm{I}-\mathrm{Cr}$ & 0,299 & 0,167 & 0,212 & 0,153 & 0,015 & 0,036 & 0,056 & 0,032 & 0,021 \\
\hline DajA & 0,122 & 0,040 & 0,048 & 0,049 & nd & nd & 0,014 & nd & 0,007 \\
\hline Pf & 0,042 & 0,010 & 0,011 & nd & nd & nd & nd & nd & nd \\
\hline $\mathrm{BbCr}$ & 0,053 & 0,020 & 0,022 & 0,012 & nd & nd & nd & nd & nd \\
\hline Pc & 0,081 & 0,019 & 0,033 & nd & nd & nd & nd & nd & nd \\
\hline
\end{tabular}


Resultado de hidrocarbonetos aromáticos, em $\mathrm{ng} \mathrm{m}^{-3}$, para as amostras de material particulado atmosférico (PM 2,5) coletadas no ano de 2011

\begin{tabular}{|c|c|c|c|c|c|}
\hline Código & C314 & C333 & C350 & C356 & C362 \\
\hline Data Início & 10-nov & 29-nov & 16-dez & 22-dez & 28-dez \\
\hline $\mathbf{N}$ & 0,089 & 0,041 & 0,058 & 0,095 & 0,033 \\
\hline C1N & 0,073 & 0,045 & 0,045 & 0,088 & 0,015 \\
\hline $\mathrm{C} 2 \mathrm{~N}$ & 0,081 & 0,060 & 0,041 & 0,096 & 0,037 \\
\hline $\mathrm{C} 3 \mathrm{~N}$ & 0,021 & 0,014 & nd & 0,026 & 0,023 \\
\hline $\mathrm{C} 4 \mathrm{~N}$ & nd & nd & nd & 0,015 & 0,021 \\
\hline ACF & 0,013 & nd & nd & 0,016 & nd \\
\hline ACE & nd & nd & nd & nd & nd \\
\hline $\mathbf{F}$ & nd & nd & nd & nd & nd \\
\hline C1F & 0,017 & 0,014 & 0,018 & 0,030 & 0,035 \\
\hline $\mathrm{C} 2 \mathrm{~F}$ & 0,073 & 0,062 & 0,104 & 0,157 & 0,113 \\
\hline C3F & 0,265 & 0,251 & 0,479 & 0,577 & 0,337 \\
\hline DBT & 0,024 & 0,021 & 0,019 & 0,029 & 0,029 \\
\hline C1DBT & 0,084 & 0,067 & 0,116 & 0,143 & 0,118 \\
\hline C2DBT & 0,270 & 0,217 & 0,460 & 0,526 & 0,353 \\
\hline C3DBT & 0,359 & 0,334 & 0,043 & 0,046 & 0,478 \\
\hline $\mathrm{Fe}$ & 0,153 & 0,139 & 0,158 & 0,267 & 0,222 \\
\hline $\mathrm{C} 1 \mathrm{Fe}$ & 0,199 & 0,189 & 0,325 & 0,434 & 0,290 \\
\hline $\mathrm{C} 2 \mathrm{Fe}$ & 0,328 & 0,356 & 0,688 & 0,717 & 0,513 \\
\hline $\mathrm{C} 3 \mathrm{Fe}$ & 0,323 & 0,429 & 0,906 & 0,710 & 0,493 \\
\hline $\mathrm{C} 4 \mathrm{Fe}$ & 0,176 & 0,294 & 0,672 & 0,416 & 0,296 \\
\hline A & 0,020 & 0,022 & 0,023 & 0,033 & 0,030 \\
\hline FI & 0,296 & 0,355 & 0,541 & 0,605 & 0,406 \\
\hline $\mathbf{P i}$ & 0,399 & 0,462 & 0,708 & 0,792 & 0,538 \\
\hline C1Pi & 0,298 & 0,358 & 0,549 & 0,486 & 0,341 \\
\hline $\mathrm{C} 2 \mathrm{Pi}$ & 0,344 & 0,364 & 0,633 & 0,477 & 0,256 \\
\hline $\mathrm{BaA}$ & 0,162 & 0,164 & 0,258 & 0,256 & 0,079 \\
\hline $\mathrm{Cr}$ & 0,486 & 0,331 & 0,521 & 0,634 & 0,216 \\
\hline $\mathrm{C} 1 \mathrm{Cr}$ & 0,311 & 0,223 & 0,371 & 0,327 & 0,128 \\
\hline $\mathrm{C} 2 \mathrm{Cr}$ & 0,290 & 0,162 & 0,260 & 0,264 & 0,084 \\
\hline $\mathrm{BbFI}$ & 0,396 & 0,222 & 0,351 & 0,776 & 0,092 \\
\hline BkFI & 0,136 & 0,084 & 0,118 & 0,231 & 0,036 \\
\hline $\mathrm{BePi}$ & 0,198 & 0,129 & 0,203 & 0,372 & 0,064 \\
\hline $\mathrm{BaPi}$ & 0,120 & 0,108 & 0,192 & 0,262 & 0,035 \\
\hline Per & 0,032 & 0,027 & 0,044 & 0,059 & 0,019 \\
\hline I-Pi & 0,095 & 0,050 & 0,119 & 0,335 & 0,018 \\
\hline DBahA & 0,033 & 0,024 & 0,034 & 0,064 & 0,018 \\
\hline BghiPer & 0,175 & 0,119 & 0,317 & 0,539 & 0,034 \\
\hline 16 HPA & 2,57 & 2,12 & 3,40 & 4,90 & 1,76 \\
\hline$\Sigma$ HPA & 6,34 & 5,74 & 9,37 & 10,90 & 5,80 \\
\hline \%p-terfenil & 79 & 67 & 82 & 89 & 84 \\
\hline $2,6+3,52 \mathrm{MFe}$ & 0,089 & 0,095 & 0,165 & 0,190 & 0,146 \\
\hline 1,7 2MFe & 0,351 & 0,429 & 0,728 & 0,749 & 0,530 \\
\hline $1,52 \mathrm{MFe}$ & 0,209 & 0,244 & 0,470 & 0,501 & 0,372 \\
\hline Acef & 0,053 & 0,080 & 0,102 & 0,107 & 0,056 \\
\hline $\mathrm{BeFe}$ & 0,030 & 0,024 & 0,050 & 0,051 & 0,015 \\
\hline $\mathrm{I}-\mathrm{Cr}$ & 0,057 & 0,031 & 0,058 & 0,163 & 0,014 \\
\hline DajA & 0,024 & 0,022 & 0,031 & 0,062 & 0,017 \\
\hline Pf & 0,017 & 0,017 & 0,018 & 0,023 & 0,016 \\
\hline $\mathrm{BbCr}$ & 0,017 & nd & 0,021 & 0,024 & 0,017 \\
\hline Pc & nd & 0,018 & 0,018 & 0,036 & nd \\
\hline
\end{tabular}


Resultado de hidrocarbonetos aromáticos, em $\mathrm{ng} \mathrm{m}^{-3}$, para as amostras de material particulado atmosférico (PM 2,5) coletadas no ano de 2011

\begin{tabular}{|c|c|c|c|c|c|c|c|c|c|}
\hline Código & CE50 & CE56 & CE62 & CE68 & CE74 & CE80 & CE92 & CE104 & CE116 \\
\hline Data Início & 11-mar & 21-mar & 9-jan & 20-jan & 3-abr & $9-a b r$ & 1-mai & 9-mai & 1-ago \\
\hline $\mathbf{N}$ & 0,058 & 0,038 & 0,046 & 0,054 & 0,031 & 0,057 & 0,032 & 0,086 & 0,047 \\
\hline C1N & 0,039 & nd & 0,034 & 0,026 & nd & 0,044 & 0,015 & 0,063 & 0,012 \\
\hline $\mathrm{C} 2 \mathrm{~N}$ & 0,057 & 0,052 & 0,041 & 0,038 & 0,033 & 0,050 & 0,025 & 0,070 & 0,034 \\
\hline $\mathrm{C} 3 \mathrm{~N}$ & 0,022 & 0,039 & 0,019 & 0,014 & 0,017 & 0,023 & 0,009 & 0,029 & 0,018 \\
\hline C4N & 0,016 & 0,047 & 0,013 & 0,010 & 0,013 & 0,017 & nd & 0,024 & 0,013 \\
\hline ACF & 0,009 & nd & 0,009 & nd & nd & nd & nd & 0,010 & nd \\
\hline ACE & nd & nd & nd & nd & nd & nd & nd & nd & nd \\
\hline $\mathbf{F}$ & 0,010 & nd & nd & nd & nd & nd & nd & nd & nd \\
\hline C1F & 0,013 & 0,016 & 0,011 & nd & 0,011 & 0,011 & nd & 0,015 & 0,010 \\
\hline $\mathrm{C} 2 \mathrm{~F}$ & 0,035 & 0,016 & 0,031 & 0,017 & 0,025 & 0,035 & 0,013 & 0,034 & 0,030 \\
\hline C3F & 0,011 & 0,065 & 0,109 & 0,092 & 0,121 & 0,126 & 0,060 & 0,105 & 0,115 \\
\hline DBT & 0,010 & nd & nd & nd & nd & nd & nd & nd & nd \\
\hline C1DBT & 0,017 & nd & 0,011 & nd & 0,014 & 0,012 & nd & 0,015 & 0,019 \\
\hline C2DBT & 0,041 & 0,031 & 0,020 & 0,017 & 0,032 & 0,033 & 0,015 & 0,035 & 0,041 \\
\hline C3DBT & 0,057 & 0,053 & 0,021 & 0,021 & 0,036 & 0,042 & 0,022 & 0,043 & 0,049 \\
\hline $\mathrm{Fe}$ & 0,062 & nd & 0,061 & 0,024 & 0,036 & 0,050 & 0,018 & 0,078 & 0,045 \\
\hline C1Fe & 0,048 & 0,014 & 0,039 & 0,018 & 0,038 & 0,043 & 0,017 & 0,053 & 0,046 \\
\hline $\mathrm{C} 2 \mathrm{Fe}$ & 0,073 & 0,029 & 0,041 & 0,026 & 0,048 & 0,055 & 0,027 & 0,067 & 0,057 \\
\hline $\mathrm{C} 3 \mathrm{Fe}$ & 0,084 & 0,034 & 0,034 & 0,022 & 0,041 & 0,055 & 0,025 & 0,057 & 0,051 \\
\hline $\mathrm{C} 4 \mathrm{Fe}$ & 0,054 & 0,035 & 0,026 & 0,018 & 0,028 & 0,030 & 0,015 & 0,034 & 0,032 \\
\hline A & 0,014 & nd & 0,009 & nd & nd & 0,009 & nd & 0,014 & 0,007 \\
\hline FI & 0,061 & 0,011 & 0,050 & 0,020 & 0,032 & 0,056 & 0,036 & 0,104 & 0,040 \\
\hline $\mathbf{P i}$ & 0,047 & 0,014 & 0,049 & 0,019 & 0,046 & 0,053 & 0,033 & 0,095 & 0,060 \\
\hline C1Pi & 0,034 & 0,025 & 0,025 & 0,015 & 0,033 & 0,034 & 0,020 & 0,050 & 0,037 \\
\hline $\mathrm{C} 2 \mathrm{Pi}$ & 0,051 & 0,020 & 0,022 & 0,019 & 0,027 & 0,035 & 0,022 & 0,046 & 0,043 \\
\hline $\mathrm{BaA}$ & 0,083 & 0,011 & 0,051 & 0,027 & 0,025 & 0,064 & 0,034 & 0,073 & 0,076 \\
\hline $\mathrm{Cr}$ & 0,125 & 0,026 & 0,077 & 0,053 & 0,068 & 0,108 & 0,066 & 0,164 & 0,139 \\
\hline $\mathrm{C} 1 \mathrm{Cr}$ & 0,086 & 0,031 & 0,035 & 0,036 & 0,030 & 0,066 & 0,030 & 0,060 & 0,056 \\
\hline $\mathrm{C} 2 \mathrm{Cr}$ & 0,115 & 0,027 & 0,047 & 0,037 & 0,026 & 0,099 & 0,038 & 0,066 & 0,045 \\
\hline $\mathrm{BbFI}$ & 1,153 & 0,111 & 0,408 & 0,199 & 0,301 & 0,526 & 0,292 & 0,487 & 0,371 \\
\hline BkFI & 0,251 & nd & 0,123 & 0,047 & 0,061 & 0,140 & 0,077 & 0,120 & 0,096 \\
\hline $\mathrm{BePi}$ & 0,498 & 0,070 & 0,203 & 0,092 & 0,135 & 0,239 & 0,138 & 0,205 & 0,178 \\
\hline $\mathrm{BaPi}$ & 0,503 & 0,054 & 0,267 & 0,081 & 0,106 & 0,288 & 0,119 & 0,182 & 0,189 \\
\hline Per & 0,125 & nd & 0,043 & nd & 0,016 & 0,048 & 0,020 & 0,029 & 0,032 \\
\hline I-Pi & 1,580 & 0,228 & 0,704 & 0,193 & 0,225 & 0,633 & 0,445 & 0,565 & 0,279 \\
\hline DBahA & 0,345 & 0,033 & 0,091 & 0,053 & 0,053 & 0,146 & 0,118 & 0,167 & 0,041 \\
\hline BghiPer & 1,297 & 0,232 & 0,876 & 0,226 & 0,245 & 0,722 & 0,486 & 0,562 & 0,305 \\
\hline 16 HPA & 5,60 & 0,76 & 2,82 & 1,00 & 1,23 & 2,85 & 1,76 & 2,71 & 1,69 \\
\hline$\Sigma$ HPA & 7,09 & 1,36 & 3,65 & 1,51 & 1,95 & 3,95 & 2,27 & 3,81 & 2,61 \\
\hline \%p-terfenil & 117 & 90 & 101 & 68 & 96 & 105 & 72 & 87 & 99 \\
\hline $2,6+3,5$ 2MFe & nd & nd & nd & nd & nd & nd & nd & nd & nd \\
\hline $1,72 \mathrm{MFe}$ & 0,030 & nd & 0,031 & 0,016 & 0,031 & 0,046 & 0,022 & 0,059 & 0,040 \\
\hline 1,5 $2 \mathrm{MFe}$ & 0,042 & nd & nd & nd & nd & nd & nd & nd & nd \\
\hline Acef & 0,022 & nd & 0,013 & nd & 0,008 & 0,016 & 0,010 & 0,021 & 0,010 \\
\hline $\mathrm{BeFe}$ & nd & nd & 0,005 & nd & nd & 0,007 & nd & 0,011 & nd \\
\hline $\mathrm{I}-\mathrm{Cr}$ & 0,751 & 0,175 & 0,203 & 0,084 & 0,099 & 0,249 & 0,191 & 0,241 & 0,102 \\
\hline DajA & 0,243 & 0,056 & 0,069 & 0,036 & 0,035 & 0,087 & 0,071 & 0,088 & 0,035 \\
\hline Pf & 0,064 & 0,013 & 0,025 & 0,016 & 0,007 & 0,022 & 0,015 & 0,021 & 0,007 \\
\hline $\mathrm{BbCr}$ & 0,145 & 0,015 & 0,051 & 0,027 & 0,020 & 0,053 & 0,033 & 0,040 & 0,016 \\
\hline Pc & 0,291 & 0,012 & 0,045 & 0,030 & nd & 0,065 & 0,012 & 0,060 & nd \\
\hline
\end{tabular}


Resultado de hidrocarbonetos aromáticos, em $\mathrm{ng} \mathrm{m}^{-3}$, para as amostras de material particulado atmosférico (PM 2,5) coletadas no ano de 2011

\begin{tabular}{|c|c|c|c|c|c|c|c|c|c|}
\hline Código & CE122 & CE128 & CE134 & CE140 & CE146 & CE152 & CE158 & CE164 & CE170 \\
\hline Data Início & 21-ago & 12-set & 23-set & 12-out & 26-out & 27-out & 8-nov & 27-nov & 28-nov \\
\hline $\mathbf{N}$ & 0,045 & 0,042 & 0,070 & 0,029 & 0,030 & 0,090 & 0,064 & 0,094 & 0,066 \\
\hline $\mathrm{C} 1 \mathrm{~N}$ & 0,036 & 0,036 & 0,059 & 0,025 & 0,013 & 0,057 & 0,044 & 0,064 & 0,037 \\
\hline $\mathrm{C} 2 \mathrm{~N}$ & nd & nd & nd & 0,026 & 0,027 & nd & 0,043 & 0,071 & 0,041 \\
\hline C3N & 0,016 & 0,017 & 0,026 & nd & nd & 0,021 & 0,034 & 0,047 & 0,029 \\
\hline C4N & 0,013 & 0,014 & 0,019 & nd & nd & 0,016 & nd & 0,039 & 0,024 \\
\hline ACF & nd & nd & 0,009 & 0,008 & nd & 0,017 & nd & 0,012 & nd \\
\hline ACE & nd & nd & nd & nd & nd & nd & nd & nd & nd \\
\hline $\mathbf{F}$ & nd & nd & nd & nd & nd & 0,009 & nd & nd & nd \\
\hline C1F & nd & 0,008 & 0,011 & nd & nd & 0,010 & nd & 0,016 & 0,008 \\
\hline $\mathrm{C} 2 \mathrm{~F}$ & 0,037 & 0,027 & 0,028 & 0,022 & 0,026 & 0,043 & 0,034 & 0,048 & 0,028 \\
\hline C3F & 0,068 & 0,048 & 0,056 & 0,096 & nd & 0,078 & nd & nd & nd \\
\hline DBT & nd & nd & nd & 0,009 & nd & nd & nd & nd & nd \\
\hline C1DBT & 0,009 & 0,009 & 0,008 & 0,011 & 0,010 & 0,012 & nd & 0,016 & nd \\
\hline C2DBT & 0,023 & 0,021 & 0,020 & 0,019 & 0,033 & 0,031 & 0,024 & 0,043 & 0,026 \\
\hline C3DBT & 0,031 & 0,021 & 0,023 & 0,034 & 0,047 & 0,038 & 0,045 & 0,055 & 0,042 \\
\hline $\mathrm{Fe}$ & 0,038 & 0,045 & 0,043 & 0,054 & 0,044 & 0,087 & 0,042 & 0,091 & 0,059 \\
\hline $\mathrm{C} 1 \mathrm{Fe}$ & 0,035 & 0,031 & 0,031 & 0,021 & 0,048 & 0,057 & 0,032 & 0,073 & 0,042 \\
\hline $\mathrm{C} 2 \mathrm{Fe}$ & 0,040 & 0,027 & 0,031 & 0,022 & 0,078 & 0,067 & 0,062 & 0,103 & 0,057 \\
\hline $\mathrm{C} 3 \mathrm{Fe}$ & 0,029 & 0,021 & 0,025 & 0,015 & 0,061 & 0,057 & 0,053 & 0,091 & 0,044 \\
\hline $\mathrm{C} 4 \mathrm{Fe}$ & 0,011 & 0,008 & nd & nd & 0,030 & 0,027 & 0,031 & 0,067 & nd \\
\hline A & nd & 0,008 & 0,008 & 0,010 & nd & 0,017 & nd & 0,020 & nd \\
\hline FI & 0,096 & 0,081 & 0,062 & 0,092 & 0,127 & 0,153 & 0,097 & 0,141 & 0,218 \\
\hline $\mathbf{P i}$ & 0,080 & 0,063 & 0,056 & 0,050 & 0,142 & 0,164 & 0,116 & 0,168 & 0,157 \\
\hline C1Pi & 0,038 & 0,031 & 0,034 & 0,022 & 0,097 & 0,085 & 0,082 & 0,149 & 0,077 \\
\hline $\mathrm{C} 2 \mathrm{Pi}$ & 0,038 & 0,041 & 0,032 & 0,020 & 0,110 & 0,089 & 0,087 & 0,329 & 0,067 \\
\hline $\mathrm{BaA}$ & 0,070 & 0,088 & 0,085 & 0,076 & 0,128 & 0,127 & 0,121 & 0,474 & 0,087 \\
\hline $\mathrm{Cr}$ & 0,224 & 0,153 & 0,110 & 0,128 & 0,279 & 0,283 & 0,227 & 0,853 & 0,271 \\
\hline $\mathrm{C} 1 \mathrm{Cr}$ & 0,049 & 0,087 & 0,043 & 0,037 & 0,110 & 0,094 & 0,089 & 0,567 & 0,069 \\
\hline $\mathrm{C} 2 \mathrm{Cr}$ & 0,022 & 0,075 & 0,019 & 0,023 & 0,031 & 0,077 & 0,044 & 0,308 & 0,026 \\
\hline $\mathrm{BbFI}$ & 0,690 & 0,628 & 0,509 & 0,380 & 1,108 & 0,997 & 0,835 & 2,750 & 0,700 \\
\hline BkFI & 0,193 & 0,180 & 0,169 & 0,124 & 0,336 & 0,339 & 0,264 & 0,869 & 0,207 \\
\hline $\mathrm{BePi}$ & 0,386 & 0,395 & 0,270 & 0,190 & 0,575 & 0,526 & 0,427 & 1,201 & 0,386 \\
\hline $\mathrm{BaPi}$ & 0,233 & 0,401 & 0,485 & 0,217 & 0,577 & 0,494 & 0,416 & 1,844 & 0,265 \\
\hline Per & 0,026 & 0,071 & 0,067 & 0,042 & 0,093 & 0,081 & 0,088 & 0,338 & 0,043 \\
\hline I-Pi & 0,702 & 1,439 & 1,280 & 0,306 & 1,288 & 1,063 & 0,945 & 2,121 & 0,767 \\
\hline DBahA & 0,164 & 0,489 & 0,319 & 0,058 & 0,247 & 0,166 & 0,181 & 0,554 & 0,147 \\
\hline BghiPer & 0,731 & 1,459 & 1,257 & 0,302 & 1,390 & 1,169 & 0,998 & 2,161 & 0,775 \\
\hline 16 HPA & 3,27 & 5,08 & 4,46 & 1,84 & 5,70 & 5,18 & 4,31 & 12,15 & 3,72 \\
\hline$\Sigma$ HPA & 4,17 & 6,06 & 5,26 & 2,47 & 7,09 & 6,64 & 5,53 & 15,78 & 4,77 \\
\hline \%p-terfenil & 120 & 111 & 114 & 52 & 66 & 115 & 74 & 94 & 83 \\
\hline $2,6+3,52 \mathrm{MFe}$ & nd & nd & nd & 0,020 & nd & 0,008 & nd & 0,009 & nd \\
\hline 1,7 2MFe & 0,042 & 0,030 & 0,030 & 0,025 & 0,038 & 0,049 & 0,003 & 0,059 & 0,023 \\
\hline 1,5 2MFe & 0,031 & 0,023 & 0,021 & nd & 0,025 & nd & 0,002 & 0,032 & 0,022 \\
\hline Acef & 0,022 & 0,023 & 0,023 & 0,024 & 0,024 & 0,029 & 0,002 & 0,036 & 0,021 \\
\hline $\mathrm{BeFe}$ & 0,012 & 0,014 & 0,011 & nd & 0,016 & 0,018 & 0,001 & 0,049 & 0,015 \\
\hline $\mathrm{I}-\mathrm{Cr}$ & 0,274 & 0,675 & 0,529 & 0,111 & 0,493 & 0,382 & 0,036 & 0,827 & 0,290 \\
\hline DajA & 0,120 & 0,303 & 0,247 & 0,044 & 0,184 & 0,127 & 0,015 & 0,464 & 0,099 \\
\hline Pf & 0,045 & 0,152 & 0,119 & 0,020 & 0,041 & 0,032 & 0,002 & 0,132 & 0,019 \\
\hline $\mathrm{BbCr}$ & 0,044 & 0,210 & 0,202 & 0,032 & 0,103 & 0,072 & 0,006 & 0,314 & 0,051 \\
\hline Pc & 0,034 & 0,065 & nd & 0,051 & 0,176 & 0,114 & 0,012 & 0,412 & 0,156 \\
\hline
\end{tabular}


Resultado de hidrocarbonetos aromáticos, em $\mathrm{ng} \mathrm{m}^{-3}$, para as amostras de material particulado atmosférico (PM 2,5) coletadas no ano de 2011

\begin{tabular}{|c|c|c|c|c|c|c|c|c|c|}
\hline Código & CE176 & CE182 & CE188 & CE194 & CE200 & CE206 & CE242 & CE248 & CE254 \\
\hline Data Início & 17-dez & 30-dez & 11-jan & 15-jan & 5-fev & 5-mar & 29-mar & $16-a b r$ & 22-jun \\
\hline $\mathbf{N}$ & 0,031 & 0,035 & 0,080 & 0,044 & 0,057 & 0,019 & 0,045 & 0,035 & 0,033 \\
\hline $\mathrm{C} 1 \mathrm{~N}$ & 0,013 & 0,037 & 0,048 & 0,044 & 0,037 & 0,010 & 0,038 & 0,027 & 0,009 \\
\hline $\mathrm{C} 2 \mathrm{~N}$ & 0,024 & 0,034 & 0,072 & 0,051 & 0,050 & 0,023 & 0,044 & 0,036 & 0,014 \\
\hline C3N & 0,020 & 0,017 & 0,023 & 0,031 & 0,020 & nd & 0,022 & 0,024 & nd \\
\hline $\mathrm{C} 4 \mathrm{~N}$ & nd & 0,021 & 0,028 & 0,025 & 0,015 & nd & 0,017 & 0,021 & nd \\
\hline ACF & nd & 0,011 & 0,014 & 0,017 & 0,010 & nd & 0,014 & 0,008 & nd \\
\hline ACE & nd & nd & nd & nd & nd & nd & nd & nd & nd \\
\hline $\mathbf{F}$ & nd & nd & 0,012 & 0,014 & 0,011 & nd & 0,009 & 0,007 & nd \\
\hline C1F & nd & 0,011 & 0,015 & 0,020 & 0,013 & 0,010 & 0,018 & 0,012 & nd \\
\hline $\mathrm{C} 2 \mathrm{~F}$ & 0,025 & 0,030 & 0,026 & 0,038 & 0,023 & 0,021 & 0,035 & 0,030 & 0,023 \\
\hline C3F & nd & 0,072 & nd & 0,099 & 0,010 & 0,010 & 0,083 & 0,104 & 0,187 \\
\hline DBT & nd & nd & 0,012 & 0,012 & nd & nd & 0,008 & 0,007 & nd \\
\hline C1DBT & nd & 0,017 & 0,019 & 0,031 & 0,013 & 0,011 & 0,016 & 0,018 & nd \\
\hline C2DBT & 0,033 & 0,043 & 0,039 & 0,065 & 0,022 & 0,022 & 0,040 & 0,058 & 0,012 \\
\hline C3DBT & 0,066 & 0,049 & 0,038 & 0,081 & 0,027 & 0,023 & 0,048 & 0,075 & 0,022 \\
\hline $\mathrm{Fe}$ & 0,022 & 0,060 & 0,070 & 0,113 & 0,054 & 0,031 & 0,086 & 0,084 & 0,010 \\
\hline $\mathrm{C} 1 \mathrm{Fe}$ & 0,033 & 0,049 & 0,044 & 0,081 & 0,035 & 0,028 & 0,066 & 0,051 & 0,018 \\
\hline $\mathrm{C} 2 \mathrm{Fe}$ & 0,066 & 0,061 & 0,058 & 0,109 & 0,055 & 0,050 & 0,100 & 0,075 & 0,070 \\
\hline $\mathrm{C} 3 \mathrm{Fe}$ & 0,060 & 0,064 & 0,058 & 0,107 & 0,050 & 0,045 & 0,077 & 0,091 & 0,074 \\
\hline $\mathrm{C} 4 \mathrm{Fe}$ & 0,053 & 0,055 & 0,041 & 0,138 & 0,033 & 0,043 & 0,067 & 0,075 & 0,082 \\
\hline A & nd & 0,020 & 0,018 & 0,029 & 0,014 & 0,012 & 0,025 & 0,018 & nd \\
\hline FI & 0,085 & 0,123 & 0,074 & 0,210 & 0,099 & 0,061 & 0,169 & 0,142 & 0,027 \\
\hline $\mathbf{P i}$ & 0,099 & 0,112 & 0,059 & 0,193 & 0,070 & 0,051 & 0,148 & 0,118 & 0,028 \\
\hline C1Pi & 0,080 & 0,061 & 0,034 & 0,176 & 0,038 & 0,036 & 0,102 & 0,090 & 0,036 \\
\hline $\mathrm{C} 2 \mathrm{Pi}$ & 0,155 & 0,068 & 0,041 & 0,351 & 0,028 & 0,042 & 0,116 & 0,184 & 0,050 \\
\hline $\mathrm{BaA}$ & 0,121 & 0,143 & 0,107 & 0,861 & 0,054 & 0,130 & 0,405 & 1,096 & 0,027 \\
\hline $\mathrm{Cr}$ & 0,288 & 0,226 & 0,157 & 1,149 & 0,141 & 0,172 & 0,528 & 2,310 & 0,054 \\
\hline $\mathrm{C} 1 \mathrm{Cr}$ & 0,151 & 0,126 & 0,108 & 0,839 & 0,042 & 0,100 & 0,349 & 0,591 & 0,028 \\
\hline $\mathrm{C} 2 \mathrm{Cr}$ & 0,056 & 0,073 & 0,110 & 0,449 & 0,031 & 0,091 & 0,244 & 0,512 & 0,039 \\
\hline $\mathrm{BbFI}$ & 1,121 & 1,078 & 0,862 & 3,743 & 0,676 & 1,094 & 2,402 & 3,618 & 0,174 \\
\hline BkFI & 0,315 & 0,187 & 0,236 & 0,780 & 0,135 & 0,247 & 0,461 & 0,976 & 0,046 \\
\hline $\mathrm{BePi}$ & 0,591 & 0,456 & 0,389 & 1,408 & 0,271 & 0,443 & 1,119 & 1,346 & 0,090 \\
\hline $\mathrm{BaPi}$ & 0,388 & 0,376 & 0,422 & 1,930 & 0,171 & 0,553 & 0,929 & 1,758 & 0,048 \\
\hline Per & 0,069 & 0,095 & 0,098 & 0,428 & 0,048 & 0,096 & 0,206 & 0,349 & 0,008 \\
\hline I-Pi & 1,004 & 1,092 & 0,776 & 2,380 & 0,490 & 0,955 & 1,826 & 2,560 & 0,260 \\
\hline DBahA & 0,211 & 0,227 & 0,122 & 0,618 & 0,100 & 0,205 & 0,476 & 0,644 & 0,047 \\
\hline BghiPer & 1,015 & 1,085 & 0,868 & 2,115 & 0,491 & 0,926 & 1,750 & 2,117 & 0,308 \\
\hline 16 HPA & 4,70 & 4,78 & 3,88 & 14,20 & 2,57 & 4,46 & 9,27 & 15,49 & 1,06 \\
\hline$\Sigma$ HPA & 6,20 & 6,22 & 5,18 & 18,78 & 3,43 & 5,56 & 12,08 & 19,27 & 1,83 \\
\hline \%p-terfenil & 76 & 71 & 76 & 102 & 85 & 83 & 100 & 74 & 63 \\
\hline $2,6+3,52 \mathrm{MFe}$ & nd & 0,009 & nd & 0,013 & nd & nd & 0,108 & nd & nd \\
\hline $1,72 \mathrm{MFe}$ & 0,038 & 0,049 & 0,023 & 0,093 & 0,022 & 0,017 & 0,710 & 0,062 & 0,010 \\
\hline 1,5 2MFe & 0,026 & 0,045 & 0,026 & 0,061 & 0,022 & 0,021 & 0,867 & nd & nd \\
\hline Acef & 0,019 & 0,033 & 0,025 & 0,059 & 0,024 & 0,024 & 0,425 & 0,039 & 0,010 \\
\hline $\mathrm{BeFe}$ & 0,011 & 0,019 & nd & 0,107 & nd & 0,012 & 0,475 & 0,062 & nd \\
\hline $\mathrm{I}-\mathrm{Cr}$ & 0,407 & 0,614 & 0,361 & 1,330 & 0,250 & 0,543 & 10,508 & 1,001 & 0,156 \\
\hline DajA & 0,140 & 0,146 & 0,085 & 0,492 & 0,067 & 0,140 & 3,176 & 0,407 & 0,037 \\
\hline Pf & 0,037 & 0,039 & 0,028 & 0,144 & 0,018 & 0,047 & 0,867 & 0,170 & 0,021 \\
\hline $\mathrm{BbCr}$ & 0,072 & 0,085 & 0,059 & 0,343 & 0,035 & 0,114 & 2,055 & 0,307 & 0,014 \\
\hline Pc & 0,185 & 0,095 & 0,046 & 0,408 & nd & nd & 3,211 & 0,067 & 0,008 \\
\hline
\end{tabular}


Resultado de hidrocarbonetos aromáticos, em $\mathrm{ng} \mathrm{m}^{-3}$, para as amostras de material particulado atmosférico (PM 2,5) coletadas no ano de 2011

\begin{tabular}{|c|c|c|c|c|c|c|c|c|c|}
\hline Código & CE266 & CE272 & CE284 & CE290 & CE296 & CE308 & CE338 & CE344 & CE350 \\
\hline Data Início & 8 -jul & 13-jul & 5-ago & 14-set & 16-set & 16-dez & 31-dez & 17-fev & 3-mar \\
\hline $\mathbf{N}$ & 0,096 & 0,040 & 0,045 & 0,055 & 0,083 & 0,030 & 0,097 & 0,105 & 0,005 \\
\hline C1N & 0,045 & 0,019 & 0,021 & 0,026 & 0,055 & 0,038 & 0,053 & 0,059 & 0,002 \\
\hline $\mathrm{C} 2 \mathrm{~N}$ & 0,072 & 0,029 & 0,034 & 0,051 & nd & 0,042 & 0,034 & nd & nd \\
\hline C3N & 0,031 & 0,016 & 0,026 & 0,031 & 0,027 & nd & nd & 0,015 & 0,001 \\
\hline C4N & 0,022 & 0,012 & 0,022 & nd & 0,013 & nd & nd & nd & nd \\
\hline ACF & nd & nd & nd & nd & nd & nd & nd & nd & nd \\
\hline ACE & nd & nd & nd & nd & nd & nd & nd & nd & nd \\
\hline $\mathbf{F}$ & nd & nd & nd & nd & nd & nd & nd & nd & nd \\
\hline C1F & 0,018 & nd & nd & 0,010 & nd & nd & nd & nd & nd \\
\hline $\mathrm{C} 2 \mathrm{~F}$ & 0,040 & 0,021 & 0,031 & 0,029 & 0,043 & 0,011 & 0,012 & 0,038 & 0,005 \\
\hline C3F & 0,134 & 0,083 & nd & nd & 0,112 & 0,092 & 0,087 & nd & 0,014 \\
\hline DBT & nd & nd & nd & nd & nd & nd & 0,010 & nd & nd \\
\hline C1DBT & nd & nd & nd & 0,011 & 0,024 & 0,013 & 0,010 & nd & 0,002 \\
\hline C2DBT & 0,039 & 0,021 & 0,022 & 0,032 & 0,083 & 0,024 & 0,015 & 0,020 & 0,007 \\
\hline C3DBT & 0,049 & 0,029 & nd & 0,050 & 0,084 & 0,023 & nd & 0,022 & 0,009 \\
\hline $\mathrm{Fe}$ & 0,086 & 0,036 & 0,020 & 0,021 & 0,051 & 0,013 & 0,019 & 0,028 & 0,005 \\
\hline C1Fe & 0,060 & 0,026 & 0,024 & 0,031 & 0,066 & 0,011 & nd & nd & 0,006 \\
\hline $\mathrm{C} 2 \mathrm{Fe}$ & 0,073 & 0,036 & 0,045 & 0,054 & 0,101 & 0,014 & nd & 0,029 & 0,011 \\
\hline $\mathrm{C} 3 \mathrm{Fe}$ & 0,060 & 0,033 & 0,037 & 0,044 & 0,072 & 0,011 & nd & 0,015 & 0,012 \\
\hline $\mathrm{C} 4 \mathrm{Fe}$ & 0,037 & 0,019 & 0,028 & 0,050 & 0,033 & nd & nd & nd & 0,007 \\
\hline A & nd & nd & nd & nd & nd & nd & nd & nd & nd \\
\hline FI & 0,168 & 0,057 & 0,040 & 0,028 & 0,115 & 0,034 & 0,031 & 0,027 & 0,010 \\
\hline $\mathbf{P i}$ & 0,138 & 0,046 & 0,030 & 0,026 & 0,154 & 0,013 & 0,012 & 0,046 & 0,010 \\
\hline C1Pi & 0,069 & 0,024 & 0,021 & 0,026 & 0,104 & nd & nd & 0,015 & 0,006 \\
\hline $\mathrm{C} 2 \mathrm{Pi}$ & 0,057 & 0,025 & 0,029 & 0,043 & 0,114 & nd & nd & 0,022 & 0,007 \\
\hline $\mathrm{BaA}$ & 0,125 & 0,052 & 0,016 & 0,032 & 0,089 & nd & nd & 0,027 & 0,009 \\
\hline $\mathrm{Cr}$ & 0,284 & 0,122 & 0,067 & 0,088 & 0,241 & 0,029 & 0,031 & 0,099 & 0,019 \\
\hline $\mathrm{C} 1 \mathrm{Cr}$ & 0,114 & 0,050 & 0,019 & 0,067 & 0,062 & 0,017 & nd & 0,044 & 0,008 \\
\hline $\mathrm{C} 2 \mathrm{Cr}$ & 0,126 & 0,083 & 0,012 & 0,018 & 0,049 & 0,017 & nd & 0,032 & 0,007 \\
\hline $\mathrm{BbFI}$ & 1,152 & 0,633 & 0,206 & 0,178 & 0,169 & 0,121 & 0,111 & 0,292 & 0,061 \\
\hline BkFI & 0,293 & 0,162 & 0,054 & 0,053 & 0,057 & 0,048 & 0,036 & 0,097 & 0,023 \\
\hline $\mathrm{BePi}$ & 0,495 & 0,264 & 0,105 & 0,087 & 0,124 & 0,059 & 0,050 & 0,176 & 0,031 \\
\hline $\mathrm{BaPi}$ & 0,413 & 0,225 & 0,056 & 0,076 & 0,076 & 0,056 & 0,027 & 0,101 & 0,025 \\
\hline Per & 0,090 & 0,055 & 0,008 & nd & 0,016 & 0,018 & 0,013 & 0,021 & 0,004 \\
\hline I-Pi & 1,178 & 0,629 & 0,205 & 0,134 & 0,137 & 0,153 & 0,171 & 0,321 & 0,061 \\
\hline DBahA & 0,329 & 0,213 & 0,033 & 0,023 & 0,014 & 0,047 & 0,039 & 0,040 & 0,010 \\
\hline BghiPer & 1,269 & 0,624 & 0,222 & 0,206 & 0,241 & 0,169 & 0,157 & 0,573 & 0,079 \\
\hline 16 HPA & 5,53 & 2,84 & 0,99 & 0,92 & 1,43 & 0,71 & 0,73 & 1,76 & 0,32 \\
\hline$\Sigma$ HPA & 7,16 & 3,69 & 1,48 & 1,58 & 2,61 & 1,11 & 1,01 & 2,26 & 0,46 \\
\hline \%p-terfenil & 77 & 73 & 70 & 75 & 107 & 65 & 95 & 68 & 85 \\
\hline $2,6+3,52 \mathrm{MFe}$ & nd & nd & nd & nd & 0,010 & 0,020 & 0,018 & nd & nd \\
\hline 1,7 2MFe & 0,052 & 0,028 & 0,020 & 0,025 & 0,069 & 0,016 & nd & 0,019 & 0,007 \\
\hline 1,5 2MFe & nd & nd & 0,024 & 0,021 & nd & nd & nd & 0,022 & nd \\
\hline Acef & 0,034 & 0,014 & 0,005 & 0,005 & 0,015 & 0,020 & 0,018 & nd & 0,002 \\
\hline $\mathrm{BeFe}$ & 0,020 & 0,008 & nd & nd & 0,015 & nd & nd & nd & nd \\
\hline $\mathrm{I}-\mathrm{Cr}$ & 0,523 & 0,303 & 0,081 & 0,042 & 0,032 & 0,066 & 0,053 & 0,123 & 0,025 \\
\hline DajA & 0,180 & 0,112 & 0,028 & 0,021 & nd & 0,034 & 0,033 & 0,033 & 0,006 \\
\hline Pf & 0,047 & 0,024 & nd & nd & nd & 0,021 & 0,018 & 0,012 & nd \\
\hline $\mathrm{BbCr}$ & 0,101 & 0,060 & 0,009 & nd & nd & 0,027 & 0,021 & 0,015 & 0,004 \\
\hline Pc & nd & 0,014 & 0,034 & 0,030 & nd & 0,036 & 0,039 & 0,027 & 0,008 \\
\hline
\end{tabular}


Resultado de hidrocarbonetos aromáticos, em $\mathrm{ng} \mathrm{m}^{-3}$, para as amostras de material particulado atmosférico (PM 2,5) coletadas no ano de 2011

\begin{tabular}{|c|c|c|c|c|c|c|c|c|c|}
\hline Código & CP8 & CP14 & CP20 & CP26 & CP38 & CP44 & CP50 & CP56 & CP92 \\
\hline Data Início & 8-jan & 14-jan & 20-jan & 26-jan & 7-fev & 13-fev & 19-fev & $25-\mathrm{fev}$ & 2-abr \\
\hline $\mathbf{N}$ & 0,069 & 0,074 & 0,045 & 0,048 & 0,050 & 0,048 & 0,073 & 0,046 & 0,042 \\
\hline $\mathrm{C} 1 \mathrm{~N}$ & 0,048 & 0,050 & 0,025 & 0,025 & 0,008 & 0,007 & 0,054 & nd & 0,039 \\
\hline $\mathrm{C} 2 \mathrm{~N}$ & 0,053 & 0,046 & 0,035 & 0,027 & 0,063 & 0,053 & 0,043 & 0,033 & 0,033 \\
\hline C3N & 0,013 & 0,016 & 0,016 & nd & 0,050 & 0,036 & 0,011 & 0,024 & nd \\
\hline $\mathrm{C} 4 \mathrm{~N}$ & 0,010 & 0,012 & 0,045 & nd & 0,049 & 0,042 & 0,012 & 0,022 & nd \\
\hline ACF & nd & nd & nd & nd & nd & nd & nd & nd & 0,009 \\
\hline ACE & nd & nd & nd & nd & nd & nd & nd & nd & nd \\
\hline $\mathbf{F}$ & nd & nd & nd & nd & nd & nd & nd & nd & 0,008 \\
\hline C1F & nd & 0,013 & 0,020 & nd & 0,026 & 0,021 & nd & 0,010 & nd \\
\hline $\mathrm{C} 2 \mathrm{~F}$ & 0,032 & 0,058 & 0,112 & 0,027 & 0,083 & 0,062 & 0,039 & 0,043 & nd \\
\hline C3F & 0,098 & 0,205 & 0,338 & 0,093 & 0,115 & 0,098 & nd & 0,081 & nd \\
\hline DBT & nd & 0,008 & 0,011 & nd & nd & 0,009 & nd & nd & 0,007 \\
\hline C1DBT & 0,023 & 0,038 & 0,075 & 0,008 & 0,038 & 0,026 & 0,016 & 0,029 & nd \\
\hline C2DBT & 0,059 & 0,120 & 0,194 & 0,030 & 0,128 & 0,076 & 0,040 & 0,101 & nd \\
\hline C3DBT & 0,112 & 0,160 & 0,288 & 0,071 & 0,148 & 0,062 & 0,102 & 0,133 & nd \\
\hline $\mathrm{Fe}$ & 0,047 & 0,079 & 0,074 & 0,024 & 0,080 & 0,073 & 0,035 & 0,030 & 0,050 \\
\hline $\mathrm{C} 1 \mathrm{Fe}$ & 0,049 & 0,092 & 0,138 & 0,027 & 0,099 & 0,062 & 0,036 & 0,048 & nd \\
\hline $\mathrm{C} 2 \mathrm{Fe}$ & 0,066 & 0,136 & 0,279 & 0,051 & 0,163 & 0,083 & 0,052 & 0,087 & nd \\
\hline $\mathrm{C} 3 \mathrm{Fe}$ & 0,066 & 0,148 & 0,303 & 0,051 & 0,127 & 0,058 & 0,057 & 0,079 & nd \\
\hline $\mathrm{C} 4 \mathrm{Fe}$ & 0,043 & 0,111 & 0,231 & 0,043 & 0,073 & 0,044 & 0,035 & 0,047 & nd \\
\hline A & nd & 0,010 & nd & nd & 0,013 & 0,012 & nd & nd & 0,013 \\
\hline FI & 0,055 & 0,133 & 0,187 & 0,046 & 0,108 & 0,062 & 0,061 & 0,040 & 0,072 \\
\hline $\mathbf{P i}$ & 0,066 & 0,139 & 0,148 & 0,052 & 0,110 & 0,061 & 0,047 & 0,043 & 0,085 \\
\hline C1Pi & 0,039 & 0,090 & 0,104 & 0,038 & 0,087 & 0,044 & 0,033 & 0,039 & nd \\
\hline $\mathrm{C} 2 \mathrm{Pi}$ & 0,051 & 0,120 & 0,116 & 0,049 & 0,104 & 0,044 & 0,046 & 0,066 & nd \\
\hline $\mathrm{BaA}$ & 0,041 & 0,126 & 0,051 & 0,050 & 0,072 & 0,032 & 0,037 & 0,046 & 0,090 \\
\hline $\mathrm{Cr}$ & 0,116 & 0,295 & 0,197 & 0,120 & 0,187 & 0,083 & 0,082 & 0,096 & 0,162 \\
\hline $\mathrm{C} 1 \mathrm{Cr}$ & 0,069 & 0,120 & 0,076 & 0,059 & 0,121 & 0,054 & 0,052 & 0,082 & nd \\
\hline $\mathrm{C} 2 \mathrm{Cr}$ & nd & 0,054 & 0,017 & 0,024 & 0,103 & 0,053 & 0,016 & 0,060 & nd \\
\hline $\mathrm{BbFI}$ & 0,205 & 0,724 & 0,446 & 0,210 & 0,436 & 0,273 & 0,227 & 0,115 & 0,330 \\
\hline BkFI & 0,038 & 0,173 & 0,101 & 0,043 & 0,051 & 0,033 & 0,054 & 0,008 & 0,044 \\
\hline $\mathrm{BePi}$ & 0,112 & 0,327 & 0,195 & 0,110 & 0,181 & 0,128 & 0,119 & 0,062 & 0,119 \\
\hline $\mathrm{BaPi}$ & 0,084 & 0,302 & 0,104 & 0,096 & 0,112 & 0,098 & 0,111 & 0,050 & 0,102 \\
\hline Per & 0,017 & 0,055 & 0,024 & 0,022 & 0,019 & 0,017 & 0,024 & nd & 0,031 \\
\hline I-Pi & 0,145 & 0,554 & 0,277 & 0,157 & 0,290 & 0,318 & 0,244 & 0,075 & 0,169 \\
\hline DBahA & 0,022 & 0,086 & 0,046 & 0,029 & 0,069 & 0,055 & 0,032 & 0,014 & 0,023 \\
\hline BghiPer & 0,243 & 0,717 & 0,344 & 0,241 & 0,432 & 0,382 & 0,350 & 0,139 & 0,355 \\
\hline 16 HPA & 1,13 & 3,41 & 2,02 & 1,11 & 2,01 & 1,53 & 1,35 & 0,70 & 1,55 \\
\hline$\Sigma$ HPA & 2,09 & 5,39 & 4,66 & 1,87 & 3,79 & 2,60 & 2,14 & 1,75 & 1,78 \\
\hline \%p-terfenil & 98 & 273 & 123 & 83 & 100 & 110 & 127 & 86 & 100 \\
\hline $2,6+3,52 \mathrm{MFe}$ & nd & 0,021 & 0,023 & nd & 0,017 & 0,008 & 0,008 & nd & 0,012 \\
\hline 1,7 2MFe & 0,058 & 0,111 & 0,258 & 0,041 & 0,116 & 0,050 & 0,037 & 0,062 & 0,085 \\
\hline 1,5 2MFe & nd & nd & nd & nd & 0,105 & 0,034 & 0,012 & 0,039 & 0,062 \\
\hline Acef & nd & 0,022 & 0,025 & nd & 0,022 & 0,010 & 0,007 & 0,009 & 0,019 \\
\hline $\mathrm{BeFe}$ & nd & nd & nd & nd & nd & nd & nd & nd & 0,010 \\
\hline $\mathrm{I}-\mathrm{Cr}$ & 0,068 & 0,210 & 0,111 & 0,053 & 0,193 & 0,239 & 0,086 & 0,037 & 0,075 \\
\hline DajA & 0,019 & 0,070 & 0,041 & 0,016 & 0,051 & 0,109 & 0,061 & 0,017 & 0,014 \\
\hline Pf & nd & 0,021 & 0,015 & 0,008 & 0,010 & 0,014 & 0,010 & nd & nd \\
\hline $\mathrm{BbCr}$ & 0,008 & 0,027 & 0,012 & 0,009 & 0,019 & 0,018 & 0,011 & 0,006 & 0,008 \\
\hline Pc & 0,015 & 0,051 & 0,030 & 0,013 & 0,008 & nd & 0,030 & nd & nd \\
\hline
\end{tabular}


Resultado de hidrocarbonetos aromáticos, em $\mathrm{ng} \mathrm{m}^{-3}$, para as amostras de material particulado atmosférico (PM 2,5) coletadas no ano de 2011.

\begin{tabular}{|c|c|c|c|c|c|c|c|c|c|}
\hline Código & CP98 & CP104 & CP110 & CP116 & CP194 & CP200 & CP206 & CP212 & CP218 \\
\hline Data Início & $8-a b r$ & 14-abr & $20-a b r$ & 26-abr & 13-jul & 19-jul & 25-jul & 31-jul & 6-ago \\
\hline $\mathbf{N}$ & 0,071 & 0,025 & 0,062 & 0,076 & 0,089 & 0,072 & 0,025 & 0,031 & 0,035 \\
\hline C1N & 0,043 & 0,013 & 0,034 & 0,060 & 0,092 & 0,053 & 0,019 & 0,024 & 0,036 \\
\hline $\mathrm{C} 2 \mathrm{~N}$ & 0,048 & 0,024 & 0,039 & 0,072 & nd & 0,074 & 0,025 & 0,031 & 0,031 \\
\hline C3N & 0,022 & 0,012 & 0,016 & 0,036 & 0,035 & 0,027 & nd & nd & nd \\
\hline C4N & 0,017 & 0,011 & 0,013 & 0,034 & 0,025 & 0,025 & nd & 0,010 & nd \\
\hline ACF & 0,008 & nd & nd & 0,008 & 0,013 & 0,011 & nd & nd & 0,009 \\
\hline ACE & nd & nd & nd & nd & nd & nd & nd & nd & nd \\
\hline $\mathbf{F}$ & nd & nd & 0,007 & 0,009 & 0,010 & 0,012 & nd & 0,009 & nd \\
\hline C1F & 0,012 & 0,008 & 0,010 & 0,019 & 0,017 & 0,015 & nd & 0,010 & nd \\
\hline $\mathrm{C} 2 \mathrm{~F}$ & 0,042 & 0,033 & 0,035 & 0,067 & 0,045 & 0,034 & 0,017 & 0,015 & nd \\
\hline C3F & 0,110 & 0,107 & 0,098 & 0,200 & 0,092 & 0,012 & nd & 0,008 & nd \\
\hline DBT & 0,008 & nd & nd & 0,016 & nd & 0,012 & nd & nd & nd \\
\hline C1DBT & 0,034 & 0,017 & 0,029 & 0,069 & 0,021 & 0,030 & 0,011 & 0,008 & nd \\
\hline C2DBT & 0,086 & 0,050 & 0,070 & 0,167 & 0,045 & 0,072 & 0,027 & 0,013 & nd \\
\hline C3DBT & 0,091 & 0,064 & 0,083 & 0,185 & 0,054 & 0,084 & 0,033 & 0,015 & nd \\
\hline $\mathrm{Fe}$ & 0,067 & 0,063 & 0,056 & 0,110 & 0,124 & 0,074 & 0,021 & 0,019 & 0,040 \\
\hline $\mathrm{C} 1 \mathrm{Fe}$ & 0,077 & 0,066 & 0,054 & 0,143 & 0,079 & 0,066 & 0,024 & 0,014 & nd \\
\hline $\mathrm{C} 2 \mathrm{Fe}$ & 0,104 & 0,093 & 0,071 & 0,179 & 0,067 & 0,107 & 0,039 & 0,021 & nd \\
\hline $\mathrm{C} 3 \mathrm{Fe}$ & 0,094 & 0,095 & 0,071 & 0,176 & 0,059 & 0,108 & 0,046 & 0,021 & nd \\
\hline $\mathrm{C} 4 \mathrm{Fe}$ & 0,057 & 0,050 & 0,036 & 0,109 & 0,020 & 0,073 & 0,025 & 0,016 & nd \\
\hline A & 0,010 & 0,011 & 0,009 & 0,016 & 0,022 & 0,016 & 0,008 & nd & 0,012 \\
\hline FI & 0,072 & 0,143 & 0,056 & 0,144 & 0,189 & 0,108 & 0,028 & 0,027 & 0,093 \\
\hline $\mathbf{P i}$ & 0,108 & 0,134 & 0,057 & 0,145 & 0,180 & 0,076 & 0,017 & 0,011 & 0,079 \\
\hline C1Pi & 0,064 & 0,072 & 0,039 & 0,103 & 0,083 & 0,043 & 0,013 & nd & nd \\
\hline $\mathrm{C} 2 \mathrm{Pi}$ & 0,073 & 0,080 & 0,056 & 0,112 & 0,088 & 0,057 & 0,020 & nd & nd \\
\hline $\mathrm{BaA}$ & 0,038 & 0,110 & 0,056 & 0,080 & 0,143 & 0,050 & 0,012 & nd & 0,066 \\
\hline $\mathrm{Cr}$ & 0,131 & 0,228 & 0,134 & 0,172 & 0,313 & 0,140 & 0,037 & 0,029 & 0,142 \\
\hline $\mathrm{C} 1 \mathrm{Cr}$ & 0,061 & 0,111 & 0,069 & 0,088 & 0,122 & 0,058 & 0,019 & 0,012 & nd \\
\hline $\mathrm{C} 2 \mathrm{Cr}$ & 0,046 & 0,133 & 0,072 & 0,075 & 0,075 & 0,041 & 0,015 & 0,013 & nd \\
\hline $\mathrm{BbFI}$ & 0,178 & 0,682 & 0,139 & 0,122 & 0,852 & 0,420 & 0,054 & 0,127 & 0,548 \\
\hline BkFI & 0,027 & 0,164 & 0,038 & 0,037 & 0,233 & 0,076 & 0,010 & 0,020 & 0,081 \\
\hline $\mathrm{BePi}$ & 0,081 & 0,270 & 0,078 & 0,075 & 0,403 & 0,132 & 0,028 & 0,056 & 0,194 \\
\hline $\mathrm{BaPi}$ & 0,044 & 0,227 & 0,068 & 0,073 & 0,392 & 0,089 & 0,021 & 0,024 & 0,160 \\
\hline Per & 0,010 & 0,038 & 0,007 & 0,010 & 0,050 & 0,020 & nd & nd & 0,036 \\
\hline I-Pi & 0,061 & 0,546 & 0,112 & 0,073 & 1,011 & 0,179 & 0,032 & 0,069 & 0,424 \\
\hline DBahA & 0,011 & 0,107 & 0,019 & 0,016 & 0,245 & 0,027 & nd & 0,012 & 0,042 \\
\hline BghiPer & 0,106 & 0,592 & 0,188 & 0,188 & 1,137 & 0,214 & 0,054 & 0,075 & 0,515 \\
\hline 16 HPA & 0,93 & 3,03 & 1,00 & 1,27 & 4,95 & 1,57 & 0,32 & 0,45 & 2,24 \\
\hline$\Sigma$ HPA & 2,11 & 4,38 & 1,98 & 3,27 & 6,43 & 2,71 & 0,68 & 0,74 & 2,54 \\
\hline \%p-terfenil & 108 & 78 & 90 & 94 & 121 & 82 & 62 & 65 & 102 \\
\hline $2,6+3,5$ 2MFe & 0,011 & nd & nd & 0,018 & 0,013 & 0,010 & nd & nd & nd \\
\hline $1,72 \mathrm{MFe}$ & 0,085 & 0,099 & 0,065 & 0,177 & 0,080 & 0,047 & 0,016 & nd & 0,044 \\
\hline 1,5 $2 \mathrm{MFe}$ & nd & nd & nd & nd & 0,055 & 0,037 & 0,025 & nd & 0,045 \\
\hline Acef & 0,013 & 0,031 & 0,010 & 0,025 & 0,043 & 0,023 & 0,013 & 0,013 & 0,021 \\
\hline $\mathrm{BeFe}$ & nd & 0,017 & 0,007 & 0,015 & 0,028 & nd & nd & nd & 0,009 \\
\hline $\mathrm{I}-\mathrm{Cr}$ & 0,028 & 0,230 & 0,046 & 0,044 & 0,468 & 0,082 & 0,015 & 0,025 & 0,151 \\
\hline DajA & 0,012 & 0,093 & 0,018 & nd & 0,205 & 0,022 & 0,005 & 0,011 & 0,034 \\
\hline Pf & nd & 0,024 & 0,009 & nd & 0,060 & nd & nd & nd & 0,008 \\
\hline $\mathrm{BbCr}$ & nd & 0,039 & 0,011 & 0,009 & 0,110 & 0,012 & nd & nd & 0,018 \\
\hline Pc & nd & nd & 0,010 & nd & 0,183 & 0,018 & nd & nd & 0,025 \\
\hline
\end{tabular}


Resultado de hidrocarbonetos aromáticos, em $\mathrm{ng} \mathrm{m}^{-3}$, para as amostras de material particulado atmosférico (PM 2,5) coletadas no ano de 2011.

\begin{tabular}{|c|c|c|c|c|c|c|c|c|c|}
\hline Código & CP224 & CP230 & CP236 & CP242 & CP248 & CP254 & CP260 & CP266 & CP272 \\
\hline Data Início & 12-ago & 18-ago & 24-ago & 30 -ago & 5-set & 11-set & 17-set & 23-set & 29-set \\
\hline $\mathbf{N}$ & 0,025 & 0,042 & 0,043 & 0,027 & 0,067 & 0,010 & 0,076 & 0,053 & 0,049 \\
\hline $\mathrm{C} 1 \mathrm{~N}$ & 0,032 & 0,036 & 0,042 & 0,026 & 0,031 & nd & 0,033 & 0,039 & 0,030 \\
\hline $\mathrm{C} 2 \mathrm{~N}$ & 0,060 & 0,051 & 0,066 & 0,053 & 0,042 & nd & 0,034 & 0,047 & 0,052 \\
\hline C3N & 0,034 & 0,024 & 0,031 & 0,029 & 0,020 & nd & 0,014 & 0,022 & 0,108 \\
\hline $\mathrm{C} 4 \mathrm{~N}$ & 0,025 & 0,024 & 0,030 & 0,022 & 0,014 & nd & 0,010 & 0,018 & 0,325 \\
\hline ACF & 0,009 & 0,009 & 0,012 & 0,009 & 0,009 & nd & nd & nd & nd \\
\hline ACE & nd & nd & nd & nd & nd & nd & nd & nd & nd \\
\hline $\mathbf{F}$ & 0,011 & 0,010 & 0,012 & 0,012 & nd & nd & nd & nd & 0,010 \\
\hline C1F & 0,014 & 0,018 & 0,019 & 0,017 & 0,011 & nd & 0,007 & 0,010 & 0,134 \\
\hline $\mathrm{C} 2 \mathrm{~F}$ & 0,032 & 0,029 & 0,041 & 0,035 & 0,025 & 0,012 & 0,018 & 0,026 & 0,549 \\
\hline C3F & 0,007 & nd & 0,014 & nd & 0,088 & nd & 0,059 & 0,101 & 1,005 \\
\hline DBT & 0,009 & 0,010 & 0,013 & 0,009 & 0,008 & nd & nd & nd & 0,017 \\
\hline C1DBT & 0,030 & 0,022 & 0,040 & 0,022 & 0,015 & nd & 0,018 & 0,013 & 0,293 \\
\hline C2DBT & 0,058 & 0,046 & 0,087 & 0,053 & 0,037 & 0,024 & 0,042 & 0,034 & 0,470 \\
\hline C3DBT & 0,067 & 0,052 & 0,089 & 0,052 & 0,049 & 0,053 & 0,048 & 0,035 & 0,762 \\
\hline $\mathrm{Fe}$ & 0,075 & 0,069 & 0,091 & 0,096 & 0,068 & 0,007 & 0,032 & 0,048 & 0,093 \\
\hline $\mathrm{C} 1 \mathrm{Fe}$ & 0,064 & 0,057 & 0,081 & 0,073 & 0,056 & 0,019 & 0,032 & 0,044 & 0,198 \\
\hline $\mathrm{C} 2 \mathrm{Fe}$ & 0,089 & 0,083 & 0,105 & 0,094 & 0,077 & 0,043 & 0,042 & 0,056 & 0,283 \\
\hline $\mathrm{C} 3 \mathrm{Fe}$ & 0,070 & 0,070 & 0,100 & 0,081 & 0,064 & 0,034 & 0,037 & 0,047 & 0,176 \\
\hline $\mathrm{C} 4 \mathrm{Fe}$ & 0,035 & 0,042 & 0,052 & 0,042 & 0,045 & 0,014 & 0,023 & 0,025 & 0,099 \\
\hline A & 0,018 & 0,014 & 0,017 & 0,017 & 0,010 & nd & nd & 0,008 & 0,098 \\
\hline FI & 0,065 & 0,117 & 0,071 & 0,114 & 0,101 & 0,022 & 0,026 & 0,064 & 0,065 \\
\hline $\mathbf{P i}$ & 0,056 & 0,080 & 0,054 & 0,090 & 0,160 & 0,023 & 0,045 & 0,064 & 0,081 \\
\hline C1Pi & 0,032 & 0,033 & 0,035 & 0,043 & 0,073 & 0,015 & 0,027 & 0,034 & 0,060 \\
\hline $\mathrm{C} 2 \mathrm{Pi}$ & 0,038 & 0,027 & 0,046 & 0,041 & 0,059 & 0,019 & 0,033 & 0,039 & 0,083 \\
\hline $\mathrm{BaA}$ & 0,048 & nd & 0,056 & 0,049 & 0,043 & 0,009 & 0,017 & 0,037 & 0,072 \\
\hline $\mathrm{Cr}$ & 0,099 & 0,160 & 0,126 & 0,127 & 0,156 & 0,049 & 0,069 & 0,112 & 0,124 \\
\hline $\mathrm{C} 1 \mathrm{Cr}$ & 0,065 & 0,047 & 0,063 & 0,064 & 0,061 & 0,015 & 0,029 & 0,055 & 0,171 \\
\hline $\mathrm{C} 2 \mathrm{Cr}$ & 0,065 & 0,028 & 0,048 & 0,053 & 0,049 & 0,007 & 0,022 & 0,057 & 0,526 \\
\hline $\mathrm{BbFI}$ & 0,308 & 0,523 & 0,411 & 0,519 & 0,368 & 0,032 & 0,112 & 0,124 & 0,315 \\
\hline BkFI & nd & 0,088 & 0,082 & 0,103 & 0,083 & nd & 0,018 & 0,030 & 0,103 \\
\hline $\mathrm{BePi}$ & 0,117 & 0,200 & 0,147 & 0,195 & 0,185 & 0,019 & 0,058 & 0,069 & 0,116 \\
\hline $\mathrm{BaPi}$ & 0,107 & 0,094 & 0,110 & 0,127 & 0,120 & 0,011 & 0,033 & 0,045 & 0,088 \\
\hline Per & 0,030 & 0,025 & 0,030 & 0,035 & 0,021 & nd & nd & nd & 0,036 \\
\hline I-Pi & 0,159 & 0,253 & 0,245 & 0,312 & 0,222 & 0,021 & 0,055 & 0,074 & 0,148 \\
\hline DBahA & 0,023 & 0,032 & 0,043 & 0,048 & 0,031 & nd & 0,011 & 0,018 & 0,065 \\
\hline BghiPer & 0,262 & 0,299 & 0,316 & 0,371 & 0,332 & 0,051 & 0,092 & 0,146 & 0,237 \\
\hline 16 HPA & 1,27 & 1,79 & 1,69 & 2,02 & 1,77 & 0,24 & 0,58 & 0,82 & 1,55 \\
\hline$\Sigma$ HPA & 2,24 & 2,72 & 2,87 & 3,06 & 2,80 & 0,51 & 1,17 & 1,59 & 7,04 \\
\hline \%p-terfenil & 83 & 86 & 85 & 96 & 81 & 81 & 114 & 78 & 101 \\
\hline $2,6+3,52 \mathrm{MFe}$ & 0,012 & 0,008 & 0,010 & 0,009 & nd & nd & nd & nd & 0,025 \\
\hline $1,72 \mathrm{MFe}$ & 0,035 & 0,038 & 0,053 & 0,042 & 0,045 & 0,029 & 0,027 & 0,046 & 0,254 \\
\hline 1,5 2MFe & 0,036 & 0,042 & 0,043 & 0,057 & nd & nd & nd & nd & 0,044 \\
\hline Acef & 0,017 & 0,020 & 0,022 & 0,023 & 0,018 & nd & nd & 0,011 & 0,011 \\
\hline $\mathrm{BeFe}$ & nd & nd & nd & 0,008 & 0,010 & nd & nd & nd & nd \\
\hline $\mathrm{I}-\mathrm{Cr}$ & 0,071 & 0,093 & 0,116 & 0,135 & 0,098 & 0,011 & 0,016 & 0,046 & 0,090 \\
\hline DajA & 0,020 & 0,024 & 0,029 & 0,039 & 0,024 & nd & nd & 0,013 & 0,031 \\
\hline Pf & nd & nd & 0,010 & 0,009 & nd & nd & nd & nd & 0,024 \\
\hline $\mathrm{BbCr}$ & 0,012 & 0,010 & 0,018 & 0,017 & nd & nd & nd & 0,008 & 0,017 \\
\hline Pc & nd & nd & nd & 0,008 & nd & nd & nd & nd & nd \\
\hline
\end{tabular}


Resultado de hidrocarbonetos aromáticos, em $\mathrm{ng} \mathrm{m}^{-3}$, para as amostras de material particulado atmosférico (PM 2,5) coletadas no ano de 2011.

\begin{tabular}{|c|c|c|c|c|c|}
\hline Código & CP284 & CP290 & CP314 & CP326 & CP344 \\
\hline Data Início & 11-out & 17-out & 10-nov & 22-nov & 10-dez \\
\hline $\mathbf{N}$ & 0,065 & 0,225 & nd & 0,047 & 0,126 \\
\hline $\mathrm{C} 1 \mathrm{~N}$ & 0,043 & 0,149 & nd & 0,055 & 0,069 \\
\hline $\mathrm{C} 2 \mathrm{~N}$ & 0,053 & nd & nd & 0,058 & nd \\
\hline C3N & 0,036 & 0,059 & nd & nd & 0,020 \\
\hline $\mathrm{C} 4 \mathrm{~N}$ & 0,033 & 0,039 & nd & nd & 0,014 \\
\hline ACF & nd & 0,020 & nd & 0,010 & nd \\
\hline ACE & nd & nd & nd & nd & nd \\
\hline $\mathbf{F}$ & nd & 0,013 & nd & nd & nd \\
\hline C1F & 0,014 & 0,021 & nd & nd & nd \\
\hline $\mathrm{C} 2 \mathrm{~F}$ & 0,034 & 0,095 & 0,023 & 0,024 & 0,048 \\
\hline $\mathrm{C} 3 \mathrm{~F}$ & nd & 0,186 & 0,134 & 0,083 & 0,128 \\
\hline DBT & nd & 0,013 & 0,011 & 0,012 & nd \\
\hline C1DBT & 0,025 & 0,055 & 0,021 & 0,021 & 0,030 \\
\hline C2DBT & 0,080 & 0,160 & 0,062 & 0,050 & 0,112 \\
\hline C3DBT & 0,102 & 0,180 & 0,078 & 0,064 & 0,122 \\
\hline $\mathrm{Fe}$ & 0,058 & 0,120 & 0,038 & 0,049 & 0,043 \\
\hline $\mathrm{C} 1 \mathrm{Fe}$ & 0,077 & 0,148 & 0,043 & 0,046 & 0,057 \\
\hline $\mathrm{C} 2 \mathrm{Fe}$ & 0,132 & 0,218 & 0,059 & 0,058 & 0,106 \\
\hline $\mathrm{C} 3 \mathrm{Fe}$ & 0,125 & 0,182 & 0,046 & 0,043 & 0,105 \\
\hline $\mathrm{C} 4 \mathrm{Fe}$ & 0,093 & 0,084 & 0,023 & 0,019 & 0,057 \\
\hline A & nd & 0,018 & 0,011 & 0,011 & nd \\
\hline FI & 0,104 & 0,167 & 0,102 & 0,085 & 0,067 \\
\hline $\mathbf{P i}$ & 0,095 & 0,181 & 0,084 & 0,082 & 0,085 \\
\hline C1Pi & 0,063 & 0,125 & 0,048 & 0,046 & 0,073 \\
\hline $\mathrm{C} 2 \mathrm{Pi}$ & 0,076 & 0,114 & 0,070 & 0,064 & 0,089 \\
\hline $\mathrm{BaA}$ & 0,045 & 0,055 & 0,062 & 0,072 & 0,039 \\
\hline $\mathrm{Cr}$ & 0,172 & 0,178 & 0,159 & 0,163 & 0,145 \\
\hline $\mathrm{C} 1 \mathrm{Cr}$ & 0,078 & 0,075 & 0,083 & 0,090 & 0,053 \\
\hline $\mathrm{C} 2 \mathrm{Cr}$ & 0,063 & 0,060 & 0,057 & 0,077 & 0,037 \\
\hline $\mathrm{BbFI}$ & 0,197 & 0,104 & 0,258 & 0,263 & 0,090 \\
\hline BkFI & 0,049 & 0,040 & 0,078 & 0,082 & 0,032 \\
\hline $\mathrm{BePi}$ & 0,100 & 0,074 & 0,122 & 0,127 & 0,058 \\
\hline $\mathrm{BaPi}$ & 0,053 & 0,046 & 0,118 & 0,124 & 0,036 \\
\hline Per & 0,009 & nd & 0,028 & 0,024 & nd \\
\hline I-Pi & 0,095 & 0,046 & 0,156 & 0,113 & 0,050 \\
\hline DBahA & 0,011 & nd & 0,030 & 0,033 & nd \\
\hline BghiPer & 0,158 & 0,137 & 0,243 & 0,210 & 0,118 \\
\hline 16 HPA & 1,10 & 1,35 & 1,34 & 1,34 & 0,83 \\
\hline$\Sigma$ HPA & 2,34 & 3,39 & 2,25 & 2,31 & 2,01 \\
\hline \%p-terfenil & 78 & 94 & 57 & 63 & 88 \\
\hline $2,6+3,5$ 2MFe & 0,012 & 0,016 & 0,033 & 0,030 & nd \\
\hline 1,7 2MFe & 0,079 & 0,153 & 0,064 & 0,069 & 0,062 \\
\hline $1,52 \mathrm{MFe}$ & 0,058 & nd & 0,042 & 0,036 & nd \\
\hline Acef & 0,014 & 0,013 & 0,030 & 0,027 & nd \\
\hline $\mathrm{BeFe}$ & nd & 0,010 & nd & nd & nd \\
\hline $\mathrm{I}-\mathrm{Cr}$ & 0,036 & 0,020 & 0,063 & 0,050 & 0,021 \\
\hline DajA & 0,007 & nd & 0,028 & 0,025 & nd \\
\hline Pf & nd & nd & 0,018 & 0,017 & nd \\
\hline $\mathrm{BbCr}$ & nd & nd & 0,021 & 0,019 & nd \\
\hline Pc & 0,008 & nd & 0,025 & 0,023 & nd \\
\hline
\end{tabular}


Resultado de hidrocarbonetos aromáticos, em $\mathrm{ng} \mathrm{m}^{-3}$, para as amostras de material particulado atmosférico (PM 2,5) coletadas no ano de 2011

\begin{tabular}{|c|c|c|c|c|c|c|c|c|c|}
\hline Código & NT20 & NT26 & NT32 & NT38 & NT44 & NT50 & NT56 & NT92 & NT98 \\
\hline Data Início & 20-jan & 26-jan & 1-fev & 7-fev & 13-fev & 19-fev & 25-fev & 2-abr & $8-a b r$ \\
\hline $\mathbf{N}$ & 0,039 & 0,043 & 0,028 & 0,041 & 0,098 & 0,053 & 0,039 & 0,093 & 0,053 \\
\hline C1N & 0,018 & 0,014 & 0,011 & nd & 0,013 & 0,039 & nd & 0,059 & 0,030 \\
\hline $\mathrm{C} 2 \mathrm{~N}$ & 0,025 & 0,022 & 0,029 & 0,040 & 0,025 & 0,033 & 0,037 & 0,056 & 0,032 \\
\hline $\mathrm{C} 3 \mathrm{~N}$ & nd & nd & 0,012 & 0,037 & nd & 0,009 & 0,028 & 0,019 & nd \\
\hline C4N & nd & nd & 0,011 & 0,059 & nd & 0,009 & 0,034 & nd & nd \\
\hline ACF & nd & nd & nd & nd & nd & nd & nd & nd & nd \\
\hline ACE & nd & nd & nd & nd & nd & nd & nd & nd & nd \\
\hline $\mathbf{F}$ & nd & nd & nd & nd & nd & nd & nd & nd & nd \\
\hline C1F & nd & nd & 0,011 & 0,021 & nd & nd & 0,011 & 0,009 & nd \\
\hline $\mathrm{C} 2 \mathrm{~F}$ & 0,023 & 0,012 & 0,031 & 0,110 & 0,022 & 0,024 & 0,054 & 0,049 & 0,026 \\
\hline C3F & nd & nd & 0,094 & 0,270 & nd & nd & 0,073 & 0,164 & nd \\
\hline DBT & nd & nd & nd & 0,009 & nd & nd & nd & nd & nd \\
\hline C1DBT & 0,009 & nd & 0,013 & 0,043 & nd & 0,008 & 0,017 & 0,024 & 0,015 \\
\hline C2DBT & 0,030 & 0,016 & 0,035 & 0,158 & 0,039 & 0,022 & 0,066 & 0,056 & 0,043 \\
\hline C3DBT & 0,073 & 0,056 & 0,066 & 0,208 & 0,129 & 0,051 & 0,079 & 0,071 & 0,060 \\
\hline $\mathrm{Fe}$ & 0,048 & 0,020 & 0,091 & 0,061 & 0,035 & 0,034 & 0,032 & 0,048 & 0,043 \\
\hline C1Fe & 0,033 & 0,016 & 0,056 & 0,099 & 0,026 & 0,028 & 0,043 & 0,052 & 0,042 \\
\hline $\mathrm{C} 2 \mathrm{Fe}$ & 0,047 & 0,021 & 0,064 & 0,246 & 0,045 & 0,030 & 0,067 & 0,067 & 0,055 \\
\hline $\mathrm{C} 3 \mathrm{Fe}$ & 0,047 & 0,026 & 0,067 & 0,196 & 0,059 & 0,029 & 0,055 & 0,058 & 0,059 \\
\hline $\mathrm{C} 4 \mathrm{Fe}$ & 0,034 & 0,022 & 0,051 & 0,149 & 0,056 & 0,029 & 0,036 & 0,035 & 0,042 \\
\hline A & nd & nd & 0,013 & 0,010 & nd & nd & nd & nd & nd \\
\hline FI & 0,097 & 0,025 & 0,141 & 0,104 & 0,077 & 0,041 & 0,034 & 0,064 & 0,083 \\
\hline $\mathbf{P i}$ & 0,093 & 0,028 & 0,128 & 0,083 & 0,059 & 0,043 & 0,035 & 0,074 & 0,083 \\
\hline C1Pi & 0,046 & 0,019 & 0,069 & 0,096 & 0,033 & 0,031 & 0,032 & 0,048 & 0,049 \\
\hline $\mathrm{C} 2 \mathrm{Pi}$ & 0,042 & 0,022 & 0,067 & 0,082 & 0,041 & 0,035 & 0,046 & 0,069 & 0,063 \\
\hline $\mathrm{BaA}$ & 0,039 & 0,016 & 0,077 & 0,065 & 0,024 & 0,030 & 0,043 & 0,070 & 0,085 \\
\hline $\mathrm{Cr}$ & 0,111 & 0,051 & 0,179 & 0,128 & 0,079 & 0,071 & 0,076 & 0,155 & 0,177 \\
\hline $\mathrm{C} 1 \mathrm{Cr}$ & 0,039 & 0,025 & 0,062 & 0,072 & 0,021 & 0,033 & 0,062 & 0,081 & 0,063 \\
\hline $\mathrm{C} 2 \mathrm{Cr}$ & nd & nd & 0,028 & 0,066 & nd & 0,013 & 0,072 & 0,020 & 0,014 \\
\hline $\mathrm{BbFI}$ & 0,313 & 0,184 & 0,523 & 0,539 & 0,229 & 0,351 & 0,276 & 0,426 & 1,156 \\
\hline BkFI & 0,063 & 0,036 & 0,138 & 0,083 & 0,055 & 0,085 & 0,034 & 0,103 & 0,256 \\
\hline $\mathrm{BePi}$ & 0,153 & 0,090 & 0,266 & 0,247 & 0,142 & 0,187 & 0,111 & 0,216 & 0,462 \\
\hline $\mathrm{BaPi}$ & 0,106 & 0,084 & 0,208 & 0,180 & 0,121 & 0,162 & 0,110 & 0,185 & 0,407 \\
\hline Per & 0,017 & 0,014 & 0,051 & 0,044 & 0,034 & 0,038 & 0,018 & 0,031 & 0,066 \\
\hline I-Pi & 0,378 & 0,233 & 0,712 & 0,512 & 0,504 & 0,585 & 0,213 & 0,372 & 0,958 \\
\hline DBahA & 0,065 & 0,041 & 0,110 & 0,136 & 0,064 & 0,131 & 0,027 & 0,042 & 0,297 \\
\hline BghiPer & 0,428 & 0,261 & 0,818 & 0,490 & 0,509 & 0,609 & 0,268 & 0,517 & 0,802 \\
\hline 16 HPA & 1,78 & 1,02 & 3,16 & 2,43 & 1,85 & 2,19 & 1,19 & 2,15 & 4,40 \\
\hline$\Sigma$ HPA & 2,42 & 1,39 & 4,26 & 4,69 & 2,54 & 2,84 & 2,13 & 3,34 & 5,52 \\
\hline \%p-terfenil & 97 & 89 & 90 & 59 & 131 & 58 & 94 & 91 & 78 \\
\hline $2,6+3,52 \mathrm{MFe}$ & nd & nd & nd & 0,014 & nd & nd & nd & nd & nd \\
\hline $1,72 \mathrm{MFe}$ & 0,038 & 0,016 & 0,064 & 0,160 & 0,035 & 0,020 & 0,049 & 0,050 & 0,046 \\
\hline 1,5 $2 \mathrm{MFe}$ & nd & nd & nd & 0,100 & nd & 0,042 & 0,033 & nd & 0,018 \\
\hline Acef & 0,015 & nd & 0,027 & 0,022 & 0,010 & 0,008 & 0,009 & 0,013 & 0,020 \\
\hline $\mathrm{BeFe}$ & nd & nd & nd & nd & nd & nd & nd & nd & nd \\
\hline $\mathrm{I}-\mathrm{Cr}$ & 0,177 & 0,112 & 0,358 & 0,289 & 0,158 & 0,319 & 0,142 & 0,122 & 0,470 \\
\hline DajA & 0,046 & 0,034 & 0,077 & 0,104 & 0,156 & 0,115 & 0,041 & 0,045 & 0,168 \\
\hline Pf & 0,011 & nd & 0,020 & 0,020 & 0,012 & 0,018 & 0,010 & nd & 0,033 \\
\hline $\mathrm{BbCr}$ & 0,019 & 0,017 & 0,039 & 0,047 & 0,019 & 0,033 & 0,016 & 0,014 & 0,074 \\
\hline Pc & 0,049 & 0,030 & 0,086 & 0,117 & 0,062 & 0,077 & 0,009 & 0,027 & 0,142 \\
\hline
\end{tabular}


Resultado de hidrocarbonetos aromáticos, em $\mathrm{ng} \mathrm{m}^{-3}$, para as amostras de material particulado atmosférico (PM 2,5) coletadas no ano de 2011

\begin{tabular}{|c|c|c|c|c|c|c|c|c|c|}
\hline Código & NT104 & NT110 & NT116 & NT122 & NT128 & NT134 & NT140 & NT146 & NT152 \\
\hline Data Início & 14-abr & $20-a b r$ & 26-abr & 2-mai & 8-mai & 14-mai & 20-mai & 26-mai & 1-jun \\
\hline $\mathbf{N}$ & 0,053 & 0,074 & 0,065 & $\mathrm{nd}$ & 0,044 & 0,029 & 0,054 & 0,046 & 0,025 \\
\hline C1N & 0,032 & 0,045 & 0,028 & nd & 0,039 & 0,012 & 0,041 & 0,025 & 0,019 \\
\hline $\mathrm{C} 2 \mathrm{~N}$ & 0,039 & 0,074 & 0,052 & nd & nd & 0,020 & nd & nd & 0,018 \\
\hline $\mathrm{C} 3 \mathrm{~N}$ & 0,011 & 0,027 & 0,040 & 0,011 & 0,015 & 0,013 & 0,017 & 0,016 & 0,011 \\
\hline C4N & 0,010 & 0,020 & nd & 0,010 & 0,010 & nd & 0,015 & 0,014 & 0,008 \\
\hline ACF & nd & 0,011 & nd & nd & nd & nd & nd & nd & nd \\
\hline ACE & nd & nd & nd & nd & nd & nd & nd & nd & nd \\
\hline $\mathbf{F}$ & nd & 0,011 & nd & nd & nd & nd & nd & nd & nd \\
\hline C1F & nd & 0,015 & 0,020 & nd & nd & nd & nd & nd & nd \\
\hline $\mathrm{C} 2 \mathrm{~F}$ & 0,058 & 0,037 & 0,072 & 0,028 & 0,027 & 0,025 & 0,034 & 0,035 & 0,012 \\
\hline C3F & 0,012 & 0,014 & 0,015 & 0,066 & 0,053 & nd & 0,088 & nd & nd \\
\hline DBT & nd & 0,009 & nd & nd & nd & nd & nd & nd & nd \\
\hline C1DBT & 0,025 & 0,023 & 0,045 & 0,013 & nd & nd & 0,012 & 0,010 & 0,004 \\
\hline C2DBT & 0,074 & 0,060 & 0,128 & 0,031 & 0,014 & 0,014 & 0,034 & 0,025 & 0,014 \\
\hline C3DBT & 0,091 & 0,067 & 0,192 & 0,039 & 0,014 & 0,023 & 0,038 & 0,026 & 0,025 \\
\hline $\mathrm{Fe}$ & 0,110 & 0,056 & 0,079 & 0,033 & 0,034 & 0,015 & 0,043 & 0,056 & 0,023 \\
\hline C1Fe & 0,103 & 0,057 & 0,107 & 0,036 & 0,025 & 0,016 & 0,040 & 0,042 & 0,020 \\
\hline $\mathrm{C} 2 \mathrm{Fe}$ & 0,122 & 0,095 & 0,163 & 0,039 & 0,027 & 0,026 & 0,045 & 0,044 & 0,032 \\
\hline $\mathrm{C} 3 \mathrm{Fe}$ & 0,113 & 0,102 & 0,130 & 0,032 & 0,019 & 0,024 & 0,042 & 0,036 & 0,026 \\
\hline $\mathrm{C} 4 \mathrm{Fe}$ & 0,061 & 0,061 & 0,070 & 0,012 & nd & 0,012 & 0,015 & 0,010 & 0,012 \\
\hline A & 0,014 & 0,014 & 0,012 & nd & nd & nd & nd & 0,010 & 0,004 \\
\hline FI & 0,191 & 0,054 & 0,084 & 0,082 & 0,063 & 0,026 & 0,074 & 0,133 & 0,036 \\
\hline $\mathbf{P i}$ & 0,204 & 0,045 & 0,122 & 0,070 & 0,061 & 0,027 & 0,072 & 0,117 & 0,038 \\
\hline C1Pi & 0,104 & 0,036 & 0,111 & 0,038 & 0,032 & 0,021 & 0,043 & 0,049 & 0,029 \\
\hline $\mathrm{C} 2 \mathrm{Pi}$ & 0,095 & 0,041 & 0,195 & 0,043 & 0,030 & 0,023 & 0,055 & 0,046 & 0,044 \\
\hline $\mathrm{BaA}$ & 0,111 & 0,093 & 0,122 & 0,060 & 0,049 & 0,023 & 0,128 & 0,077 & 0,043 \\
\hline $\mathrm{Cr}$ & 0,261 & 0,132 & 0,275 & 0,232 & 0,078 & 0,044 & 0,199 & 0,167 & 0,078 \\
\hline $\mathrm{C} 1 \mathrm{Cr}$ & 0,102 & 0,066 & 0,150 & 0,054 & 0,029 & 0,027 & 0,085 & 0,054 & 0,038 \\
\hline $\mathrm{C} 2 \mathrm{Cr}$ & 0,050 & 0,060 & 0,052 & 0,023 & 0,016 & nd & 0,038 & 0,028 & 0,008 \\
\hline $\mathrm{BbFI}$ & 0,779 & 0,622 & 0,259 & 0,645 & 0,270 & 0,155 & 0,420 & 0,570 & 0,218 \\
\hline BkFI & 0,189 & 0,136 & 0,068 & 0,160 & 0,084 & 0,048 & 0,130 & 0,143 & 0,073 \\
\hline $\mathrm{BePi}$ & 0,402 & 0,228 & 0,136 & 0,321 & 0,139 & 0,089 & 0,187 & 0,288 & 0,102 \\
\hline $\mathrm{BaPi}$ & 0,307 & 0,247 & 0,134 & 0,140 & 0,159 & 0,106 & 0,237 & 0,232 & 0,112 \\
\hline Per & 0,054 & 0,063 & 0,013 & 0,012 & 0,023 & 0,015 & 0,037 & 0,034 & 0,017 \\
\hline I-Pi & 0,868 & 0,463 & 0,135 & 0,481 & 0,701 & 0,199 & 0,489 & 0,826 & 0,162 \\
\hline DBahA & 0,140 & 0,071 & 0,021 & 0,109 & 0,189 & 0,035 & 0,121 & 0,254 & 0,029 \\
\hline BghiPer & 0,938 & 0,434 & 0,253 & 0,501 & 0,732 & 0,284 & 0,577 & 0,826 & 0,195 \\
\hline 16 HPA & 4,16 & 2,46 & 1,63 & 2,51 & 2,46 & 0,99 & 2,54 & 3,46 & 1,04 \\
\hline$\Sigma$ HPA & 5,72 & 3,66 & 3,35 & 3,32 & 2,98 & 1,35 & 3,41 & 4,24 & 1,47 \\
\hline \%p-terfenil & 90 & 100 & 101 & 112 & 115 & 123 & 106 & 120 & 96 \\
\hline $2,6+3,5$ 2MFe & 0,010 & nd & 0,017 & 0,009 & nd & nd & nd & nd & 0,003 \\
\hline 1,7 2MFe & 0,097 & 0,042 & 0,080 & 0,042 & 0,024 & 0,015 & 0,047 & 0,047 & 0,016 \\
\hline 1,5 $2 \mathrm{MFe}$ & nd & 0,059 & 0,055 & 0,032 & 0,018 & 0,010 & 0,039 & 0,033 & 0,011 \\
\hline Acef & 0,032 & 0,025 & 0,022 & 0,019 & 0,020 & nd & 0,024 & 0,033 & 0,010 \\
\hline $\mathrm{BeFe}$ & nd & nd & 0,009 & 0,011 & 0,009 & nd & 0,014 & 0,018 & 0,003 \\
\hline $\mathrm{I}-\mathrm{Cr}$ & 0,422 & 0,212 & 0,053 & 0,165 & 0,347 & 0,072 & 0,193 & 0,479 & 0,060 \\
\hline DajA & 0,099 & 0,051 & 0,015 & 0,073 & 0,118 & 0,021 & 0,100 & 0,159 & 0,018 \\
\hline Pf & 0,018 & 0,014 & nd & 0,028 & 0,049 & nd & 0,042 & 0,057 & 0,005 \\
\hline $\mathrm{BbCr}$ & 0,039 & 0,028 & nd & 0,037 & 0,084 & 0,015 & 0,055 & 0,090 & 0,011 \\
\hline Pc & 0,095 & 0,046 & nd & nd & nd & 0,027 & 0,041 & 0,134 & 0,020 \\
\hline
\end{tabular}


Resultado de hidrocarbonetos aromáticos, em $\mathrm{ng} \mathrm{m}^{-3}$, para as amostras de material particulado atmosférico (PM 2,5) coletadas no ano de 2011

\begin{tabular}{|c|c|c|c|c|c|c|c|c|c|}
\hline Código & NT158 & NT164 & NT176 & NT182 & NT188 & NT206 & NT212 & NT218 & NT224 \\
\hline Data Início & 7-jun & 13-jun & 25-jun & 1-jul & 7-jul & 25-jul & 31-jul & 6-ago & 12-ago \\
\hline $\mathbf{N}$ & 0,061 & 0,016 & 0,055 & 0,038 & 0,049 & 0,020 & 0,027 & 0,019 & 0,045 \\
\hline $\mathrm{C} 1 \mathrm{~N}$ & 0,041 & 0,011 & 0,028 & 0,038 & 0,033 & 0,019 & 0,023 & 0,027 & 0,042 \\
\hline $\mathrm{C} 2 \mathrm{~N}$ & 0,037 & 0,011 & 0,038 & 0,066 & 0,044 & 0,012 & 0,036 & 0,033 & 0,075 \\
\hline C3N & 0,022 & 0,006 & 0,030 & 0,027 & 0,015 & 0,014 & 0,014 & nd & 0,034 \\
\hline $\mathrm{C} 4 \mathrm{~N}$ & 0,019 & 0,006 & nd & 0,022 & 0,020 & 0,017 & 0,019 & nd & 0,042 \\
\hline ACF & nd & 0,002 & nd & 0,012 & nd & nd & 0,009 & 0,011 & 0,012 \\
\hline ACE & nd & nd & nd & nd & nd & nd & nd & nd & nd \\
\hline $\mathbf{F}$ & nd & nd & nd & 0,014 & 0,010 & 0,008 & 0,011 & 0,008 & 0,012 \\
\hline C1F & nd & 0,002 & nd & 0,017 & 0,011 & 0,009 & 0,010 & nd & 0,021 \\
\hline $\mathrm{C} 2 \mathrm{~F}$ & 0,028 & 0,008 & 0,026 & 0,038 & 0,022 & 0,022 & 0,024 & nd & 0,044 \\
\hline C3F & nd & nd & nd & 0,076 & 0,010 & 0,011 & nd & nd & 0,009 \\
\hline DBT & nd & nd & nd & 0,012 & nd & nd & nd & nd & 0,010 \\
\hline C1DBT & nd & nd & 0,010 & 0,025 & 0,014 & 0,012 & 0,012 & nd & 0,022 \\
\hline C2DBT & 0,021 & 0,007 & 0,034 & 0,054 & 0,037 & 0,024 & 0,021 & nd & 0,042 \\
\hline C3DBT & 0,030 & 0,011 & 0,052 & 0,067 & 0,043 & 0,031 & 0,024 & nd & 0,048 \\
\hline $\mathrm{Fe}$ & 0,031 & 0,013 & 0,050 & 0,107 & 0,029 & 0,018 & 0,040 & 0,057 & 0,083 \\
\hline $\mathrm{C} 1 \mathrm{Fe}$ & 0,027 & 0,011 & 0,045 & 0,087 & 0,030 & 0,019 & 0,025 & nd & 0,060 \\
\hline $\mathrm{C} 2 \mathrm{Fe}$ & 0,039 & 0,014 & 0,059 & 0,103 & 0,048 & 0,029 & 0,030 & nd & 0,065 \\
\hline $\mathrm{C} 3 \mathrm{Fe}$ & 0,041 & 0,013 & 0,048 & 0,107 & 0,058 & 0,054 & 0,029 & nd & 0,069 \\
\hline $\mathrm{C} 4 \mathrm{Fe}$ & 0,015 & 0,008 & 0,058 & 0,076 & 0,046 & 0,042 & 0,021 & nd & 0,045 \\
\hline A & nd & 0,002 & 0,011 & 0,026 & 0,010 & nd & 0,013 & 0,013 & 0,021 \\
\hline FI & 0,055 & 0,021 & 0,093 & 0,142 & 0,045 & 0,025 & 0,046 & 0,121 & 0,072 \\
\hline $\mathbf{P i}$ & 0,063 & 0,025 & 0,107 & 0,120 & 0,035 & 0,012 & 0,029 & 0,105 & 0,056 \\
\hline C1Pi & 0,041 & 0,020 & 0,092 & 0,077 & 0,032 & 0,015 & 0,015 & nd & 0,040 \\
\hline $\mathrm{C} 2 \mathrm{Pi}$ & 0,050 & 0,028 & 0,144 & 0,067 & 0,042 & 0,023 & 0,016 & nd & 0,046 \\
\hline $\mathrm{BaA}$ & 0,041 & 0,030 & 0,105 & 0,143 & 0,075 & 0,036 & 0,014 & 0,111 & 0,084 \\
\hline $\mathrm{Cr}$ & 0,092 & 0,056 & 0,211 & 0,225 & 0,150 & 0,065 & 0,045 & 0,190 & 0,117 \\
\hline $\mathrm{C} 1 \mathrm{Cr}$ & 0,033 & 0,033 & 0,105 & 0,128 & 0,061 & 0,039 & 0,017 & nd & 0,095 \\
\hline $\mathrm{C} 2 \mathrm{Cr}$ & 0,013 & 0,019 & 0,047 & 0,090 & 0,055 & 0,030 & 0,022 & nd & 0,123 \\
\hline $\mathrm{BbFI}$ & 0,251 & 0,173 & 0,686 & 0,968 & 0,501 & 0,273 & 0,286 & 0,854 & 0,713 \\
\hline BkFI & 0,074 & 0,055 & 0,181 & 0,212 & 0,085 & nd & 0,048 & 0,166 & 0,146 \\
\hline $\mathrm{BePi}$ & 0,125 & 0,091 & 0,402 & 0,378 & 0,170 & 0,079 & 0,120 & 0,389 & 0,276 \\
\hline $\mathrm{BaPi}$ & 0,108 & 0,110 & 0,323 & 0,333 & 0,172 & 0,070 & 0,071 & 0,362 & 0,289 \\
\hline Per & 0,013 & 0,022 & 0,049 & 0,067 & 0,043 & 0,022 & 0,024 & 0,073 & 0,072 \\
\hline I-Pi & 0,221 & 0,172 & 0,714 & 0,632 & 0,268 & 0,126 & 0,227 & 0,755 & 0,509 \\
\hline DBahA & 0,037 & 0,040 & 0,137 & 0,110 & 0,043 & 0,022 & 0,040 & 0,127 & 0,108 \\
\hline BghiPer & 0,263 & 0,212 & 0,796 & 0,709 & 0,377 & 0,172 & 0,278 & 0,869 & 0,555 \\
\hline 16 HPA & 1,30 & 0,93 & 3,47 & 3,79 & 1,85 & 0,85 & 1,18 & 3,77 & 2,82 \\
\hline$\Sigma$ HPA & 1,89 & 1,25 & 4,74 & 5,41 & 2,68 & 1,37 & 1,68 & 4,29 & 4,10 \\
\hline \%p-terfenil & 94 & 99 & 75 & 76 & 57 & 73 & 92 & 101 & 91 \\
\hline $2,6+3,52 \mathrm{MFe}$ & nd & nd & nd & 0,012 & nd & nd & nd & 0,008 & nd \\
\hline $1,72 \mathrm{MFe}$ & 0,019 & 0,007 & 0,030 & 0,059 & 0,021 & 0,010 & 0,010 & 0,040 & 0,029 \\
\hline 1,5 2MFe & 0,014 & 0,005 & 0,021 & 0,045 & 0,019 & 0,025 & 0,017 & 0,051 & 0,015 \\
\hline Acef & 0,012 & 0,005 & 0,022 & 0,040 & 0,019 & 0,014 & 0,017 & 0,026 & 0,027 \\
\hline $\mathrm{BeFe}$ & nd & 0,003 & 0,011 & 0,020 & nd & nd & nd & 0,015 & 0,008 \\
\hline $\mathrm{I}-\mathrm{Cr}$ & 0,075 & 0,068 & 0,290 & 0,348 & 0,121 & 0,060 & 0,106 & 0,417 & 0,282 \\
\hline DajA & 0,027 & 0,028 & 0,094 & 0,077 & 0,031 & 0,014 & 0,029 & 0,088 & 0,063 \\
\hline Pf & nd & 0,009 & 0,028 & 0,021 & 0,012 & nd & nd & 0,024 & 0,024 \\
\hline $\mathrm{BbCr}$ & 0,012 & 0,013 & 0,049 & 0,042 & 0,021 & 0,011 & 0,014 & 0,056 & 0,063 \\
\hline Pc & 0,024 & 0,034 & 0,120 & 0,040 & 0,022 & nd & nd & 0,038 & nd \\
\hline
\end{tabular}


Resultado de hidrocarbonetos aromáticos, em $\mathrm{ng} \mathrm{m}^{-3}$, para as amostras de material particulado atmosférico (PM 2,5) coletadas no ano de 2011

\begin{tabular}{|c|c|c|c|c|c|c|c|c|c|}
\hline Código & NT230 & NT236 & NT242 & NT248 & NT254 & NT260 & NT266 & NT272 & NT284 \\
\hline Data Início & 18-ago & 24-ago & 30-ago & 5-set & 11-set & 17-set & 23-set & 29-set & 11-out \\
\hline $\mathbf{N}$ & 0,035 & 0,052 & nd & 0,050 & 0,043 & 0,037 & $\mathrm{nd}$ & 0,039 & 0,060 \\
\hline C1N & 0,053 & 0,030 & 0,008 & 0,011 & 0,029 & 0,029 & nd & 0,023 & 0,037 \\
\hline $\mathrm{C} 2 \mathrm{~N}$ & 0,061 & nd & 0,010 & 0,032 & 0,042 & 0,025 & 0,011 & 0,026 & 0,044 \\
\hline C3N & nd & 0,010 & nd & 0,017 & 0,014 & nd & nd & 0,008 & 0,030 \\
\hline C4N & nd & nd & nd & 0,013 & 0,012 & nd & nd & nd & nd \\
\hline ACF & 0,019 & nd & 0,008 & 0,007 & nd & 0,008 & 0,007 & nd & nd \\
\hline ACE & nd & nd & nd & nd & nd & nd & nd & nd & nd \\
\hline $\mathbf{F}$ & 0,014 & nd & 0,009 & nd & nd & nd & nd & nd & nd \\
\hline C1F & nd & nd & 0,021 & 0,011 & nd & nd & nd & 0,006 & 0,011 \\
\hline $\mathrm{C} 2 \mathrm{~F}$ & nd & nd & 0,041 & 0,030 & 0,013 & nd & nd & 0,012 & 0,042 \\
\hline C3F & nd & 0,071 & nd & 0,091 & 0,008 & nd & nd & 0,009 & nd \\
\hline DBT & 0,010 & nd & 0,009 & nd & nd & nd & nd & nd & nd \\
\hline C1DBT & nd & 0,011 & 0,022 & 0,019 & 0,009 & nd & nd & 0,010 & 0,012 \\
\hline C2DBT & nd & 0,034 & 0,053 & 0,058 & 0,032 & nd & nd & 0,028 & 0,036 \\
\hline C3DBT & nd & 0,039 & 0,061 & 0,068 & 0,035 & nd & nd & 0,041 & 0,065 \\
\hline $\mathrm{Fe}$ & 0,123 & 0,040 & 0,071 & 0,074 & 0,013 & 0,015 & 0,013 & 0,017 & 0,031 \\
\hline C1Fe & nd & 0,033 & 0,075 & 0,067 & 0,017 & nd & nd & 0,023 & 0,036 \\
\hline $\mathrm{C} 2 \mathrm{Fe}$ & $\mathrm{nd}$ & 0,052 & 0,130 & 0,082 & 0,037 & nd & nd & 0,040 & 0,073 \\
\hline $\mathrm{C} 3 \mathrm{Fe}$ & nd & 0,044 & 0,105 & 0,074 & 0,052 & nd & nd & 0,053 & 0,065 \\
\hline $\mathrm{C} 4 \mathrm{Fe}$ & nd & nd & 0,061 & 0,045 & 0,037 & nd & nd & 0,041 & 0,062 \\
\hline A & 0,028 & nd & 0,017 & 0,012 & nd & 0,009 & 0,007 & 0,007 & nd \\
\hline FI & 0,181 & 0,072 & 0,111 & 0,143 & 0,025 & 0,017 & 0,076 & 0,044 & 0,058 \\
\hline $\mathbf{P i}$ & 0,171 & 0,084 & 0,099 & 0,172 & 0,014 & 0,011 & 0,080 & 0,035 & 0,061 \\
\hline C1Pi & nd & 0,045 & 0,063 & 0,092 & 0,013 & nd & nd & 0,021 & 0,037 \\
\hline $\mathrm{C} 2 \mathrm{Pi}$ & nd & 0,050 & 0,059 & 0,086 & 0,018 & nd & nd & 0,024 & 0,049 \\
\hline $\mathrm{BaA}$ & 0,129 & 0,090 & 0,081 & 0,148 & 0,020 & 0,014 & 0,082 & 0,044 & 0,024 \\
\hline $\mathrm{Cr}$ & 0,273 & 0,236 & 0,207 & 0,278 & 0,041 & 0,028 & 0,155 & 0,073 & 0,098 \\
\hline $\mathrm{C} 1 \mathrm{Cr}$ & nd & 0,087 & 0,106 & 0,126 & 0,027 & nd & nd & 0,046 & 0,044 \\
\hline $\mathrm{C} 2 \mathrm{Cr}$ & nd & 0,082 & 0,105 & 0,212 & 0,033 & nd & nd & 0,049 & 0,061 \\
\hline $\mathrm{BbFI}$ & 0,993 & 0,793 & 0,947 & 0,889 & 0,287 & 0,146 & 0,563 & 0,398 & 0,231 \\
\hline BkFI & 0,135 & 0,229 & nd & 0,234 & 0,050 & 0,020 & 0,095 & 0,080 & 0,069 \\
\hline $\mathrm{BePi}$ & 0,414 & 0,364 & 0,378 & 0,398 & 0,099 & 0,056 & 0,208 & 0,152 & 0,108 \\
\hline $\mathrm{BaPi}$ & 0,302 & 0,269 & 0,253 & 0,422 & 0,057 & 0,045 & 0,178 & 0,132 & 0,064 \\
\hline Per & 0,067 & 0,044 & 0,067 & 0,081 & 0,021 & 0,012 & 0,032 & 0,034 & nd \\
\hline I-Pi & 0,745 & 0,468 & 0,468 & 0,680 & 0,189 & 0,137 & 0,436 & 0,314 & 0,187 \\
\hline DBahA & 0,122 & 0,084 & 0,096 & 0,169 & 0,036 & 0,019 & 0,058 & 0,051 & 0,025 \\
\hline BghiPer & 0,817 & 0,568 & 0,585 & 0,728 & 0,246 & 0,182 & 0,489 & 0,329 & 0,270 \\
\hline 16 HPA & 4,09 & 2,98 & 2,95 & 4,01 & 1,02 & 0,69 & 2,24 & 1,56 & 1,18 \\
\hline$\Sigma$ HPA & 4,69 & 3,98 & 4,32 & 5,62 & 1,57 & 0,81 & 2,49 & 2,21 & 1,99 \\
\hline \%p-terfenil & 9 & 100 & 91 & 93 & 93 & 97 & 83 & 91 & 73 \\
\hline $2,6+3,52 \mathrm{MFe}$ & 0,012 & nd & 0,023 & nd & nd & nd & 0,007 & nd & nd \\
\hline 1,7 2MFe & 0,063 & 0,028 & 0,051 & 0,058 & 0,016 & 0,012 & 0,038 & 0,017 & 0,036 \\
\hline 1,5 2MFe & 0,067 & 0,035 & 0,079 & nd & 0,028 & 0,034 & 0,039 & 0,031 & 0,026 \\
\hline Acef & 0,039 & 0,018 & 0,026 & 0,039 & 0,015 & 0,010 & 0,022 & 0,017 & 0,010 \\
\hline $\mathrm{BeFe}$ & 0,020 & nd & 0,016 & 0,027 & nd & nd & 0,013 & nd & nd \\
\hline $\mathrm{I}-\mathrm{Cr}$ & 0,371 & 0,258 & 0,256 & 0,358 & 0,096 & 0,063 & 0,203 & 0,148 & 0,084 \\
\hline DajA & 0,078 & 0,060 & 0,064 & 0,126 & 0,025 & 0,013 & 0,049 & 0,038 & 0,018 \\
\hline Pf & 0,022 & 0,017 & 0,015 & 0,033 & 0,008 & nd & 0,012 & 0,012 & nd \\
\hline $\mathrm{BbCr}$ & 0,046 & 0,036 & 0,029 & 0,060 & 0,013 & 0,008 & 0,021 & 0,024 & nd \\
\hline Pc & 0,076 & 0,061 & nd & 0,007 & nd & nd & nd & nd & 0,028 \\
\hline
\end{tabular}


Resultado de hidrocarbonetos aromáticos, em $\mathrm{ng} \mathrm{m}^{-3}$, para as amostras de material particulado atmosférico (PM 2,5) coletadas no ano de 2011

\begin{tabular}{|c|c|c|c|c|}
\hline Código & NT290 & NT326 & NT350 & NT356 \\
\hline Data Início & 17-out & 22-nov & 16-dez & 22-dez \\
\hline $\mathbf{N}$ & 0,061 & 0,068 & 0,107 & 0,207 \\
\hline $\mathrm{C} 1 \mathrm{~N}$ & 0,038 & 0,059 & 0,079 & 0,130 \\
\hline $\mathrm{C} 2 \mathrm{~N}$ & 0,046 & 0,050 & 0,064 & nd \\
\hline C3N & 0,024 & nd & nd & 0,027 \\
\hline $\mathrm{C} 4 \mathrm{~N}$ & 0,026 & nd & nd & 0,020 \\
\hline ACF & nd & nd & 0,012 & 0,012 \\
\hline ACE & nd & nd & nd & nd \\
\hline $\mathbf{F}$ & nd & nd & nd & nd \\
\hline C1F & 0,012 & nd & nd & nd \\
\hline $\mathrm{C} 2 \mathrm{~F}$ & 0,042 & 0,029 & 0,024 & nd \\
\hline C3F & nd & 0,129 & 0,132 & 0,131 \\
\hline DBT & nd & 0,011 & 0,011 & nd \\
\hline C1DBT & 0,020 & 0,023 & 0,029 & 0,017 \\
\hline C2DBT & 0,072 & 0,060 & 0,084 & 0,061 \\
\hline C3DBT & 0,120 & 0,067 & 0,107 & 0,065 \\
\hline $\mathrm{Fe}$ & 0,035 & 0,031 & 0,053 & 0,047 \\
\hline $\mathrm{C} 1 \mathrm{Fe}$ & 0,055 & 0,029 & 0,058 & 0,055 \\
\hline $\mathrm{C} 2 \mathrm{Fe}$ & 0,098 & 0,042 & 0,086 & 0,084 \\
\hline $\mathrm{C} 3 \mathrm{Fe}$ & 0,099 & 0,030 & 0,069 & 0,068 \\
\hline $\mathrm{C} 4 \mathrm{Fe}$ & nd & 0,015 & 0,043 & 0,050 \\
\hline A & nd & 0,009 & 0,013 & nd \\
\hline FI & 0,056 & 0,051 & 0,117 & 0,045 \\
\hline $\mathbf{P i}$ & 0,059 & 0,041 & 0,114 & 0,047 \\
\hline C1Pi & 0,060 & 0,022 & nd & 0,039 \\
\hline $\mathrm{C} 2 \mathrm{Pi}$ & 0,086 & 0,035 & 0,125 & 0,041 \\
\hline $\mathrm{BaA}$ & 0,057 & 0,037 & 0,209 & 0,030 \\
\hline $\mathrm{Cr}$ & 0,139 & 0,101 & 0,322 & 0,075 \\
\hline $\mathrm{C} 1 \mathrm{Cr}$ & 0,083 & 0,054 & 0,167 & 0,062 \\
\hline $\mathrm{C} 2 \mathrm{Cr}$ & 0,052 & 0,042 & 0,091 & 0,093 \\
\hline $\mathrm{BbFI}$ & 0,137 & 0,180 & 0,489 & 0,194 \\
\hline BkFI & 0,041 & 0,058 & 0,169 & 0,064 \\
\hline $\mathrm{BePi}$ & 0,073 & 0,101 & 0,228 & 0,110 \\
\hline $\mathrm{BaPi}$ & 0,066 & 0,085 & 0,237 & 0,073 \\
\hline Per & nd & 0,018 & 0,040 & 0,012 \\
\hline I-Pi & 0,086 & 0,099 & 0,232 & 0,152 \\
\hline DBahA & 0,014 & 0,025 & 0,040 & 0,031 \\
\hline BghiPer & 0,205 & 0,175 & 0,423 & 0,249 \\
\hline 16 HPA & 0,96 & 0,96 & 2,54 & 1,23 \\
\hline$\Sigma$ HPA & 1,96 & 1,77 & 3,97 & 2,29 \\
\hline \%p-terfenil & 71 & 68 & 80 & 87 \\
\hline $2,6+3,5$ 2MFe & nd & 0,025 & 0,037 & 0,012 \\
\hline 1,7 2MFe & 0,050 & 0,047 & 0,094 & 0,049 \\
\hline $1,52 \mathrm{MFe}$ & 0,036 & 0,022 & 0,051 & nd \\
\hline Acef & 0,009 & 0,021 & 0,039 & nd \\
\hline $\mathrm{BeFe}$ & nd & nd & nd & nd \\
\hline $\mathrm{I}-\mathrm{Cr}$ & 0,035 & 0,043 & 0,091 & 0,080 \\
\hline DajA & 0,007 & 0,023 & 0,034 & 0,021 \\
\hline Pf & nd & 0,017 & 0,019 & nd \\
\hline $\mathrm{BbCr}$ & nd & 0,018 & 0,022 & 0,016 \\
\hline $\mathrm{Pc}$ & nd & 0,020 & nd & 0,021 \\
\hline
\end{tabular}


Resultado de hidrocarbonetos aromáticos, em $\mathrm{ng} \mathrm{m}^{-3}$, para as amostras de material particulado atmosférico (PM 2,5) coletadas no ano de 2011

\begin{tabular}{|c|c|c|c|c|c|c|c|c|c|}
\hline Código & SJ14 & SJ20 & SJ26 & SJ32 & SJ38 & SJ44 & SJ56 & SJ62 & SJ68 \\
\hline Data Início & 14-jan & 20-jan & 26-jan & 1-fev & 7-fev & 13-fev & 25-fev & 3-mar & 9-mar \\
\hline $\mathbf{N}$ & 0,028 & 0,087 & 0,092 & 0,072 & 0,044 & 0,047 & 0,028 & 0,070 & 0,051 \\
\hline C1N & 0,012 & 0,054 & 0,067 & 0,053 & 0,035 & 0,030 & nd & 0,063 & 0,029 \\
\hline $\mathrm{C} 2 \mathrm{~N}$ & 0,021 & 0,090 & 0,070 & 0,065 & 0,048 & 0,038 & 0,060 & 0,080 & 0,035 \\
\hline $\mathrm{C} 3 \mathrm{~N}$ & nd & 0,033 & 0,026 & 0,027 & 0,016 & 0,012 & 0,034 & 0,039 & 0,029 \\
\hline C4N & nd & 0,027 & 0,019 & 0,037 & 0,012 & 0,009 & 0,050 & 0,029 & nd \\
\hline ACF & nd & 0,009 & 0,008 & 0,009 & nd & nd & nd & 0,012 & nd \\
\hline ACE & nd & nd & nd & nd & nd & nd & nd & nd & nd \\
\hline $\mathbf{F}$ & nd & 0,012 & nd & 0,009 & nd & nd & nd & 0,010 & nd \\
\hline C1F & nd & 0,022 & 0,014 & 0,024 & 0,010 & 0,009 & 0,014 & 0,018 & 0,010 \\
\hline $\mathrm{C} 2 \mathrm{~F}$ & 0,026 & 0,055 & 0,051 & 0,064 & 0,033 & 0,028 & 0,058 & 0,052 & 0,039 \\
\hline C3F & 0,108 & 0,009 & 0,163 & 0,187 & 0,008 & 0,084 & 0,088 & 0,151 & nd \\
\hline DBT & nd & 0,012 & nd & 0,010 & nd & nd & nd & 0,011 & nd \\
\hline C1DBT & 0,013 & 0,027 & 0,020 & 0,023 & 0,016 & 0,013 & 0,024 & 0,029 & 0,012 \\
\hline C2DBT & 0,044 & 0,061 & 0,049 & 0,060 & 0,052 & 0,038 & 0,073 & 0,072 & 0,035 \\
\hline C3DBT & 0,115 & 0,081 & 0,076 & 0,128 & 0,102 & 0,086 & 0,099 & 0,080 & 0,055 \\
\hline $\mathrm{Fe}$ & 0,024 & 0,076 & 0,071 & 0,137 & 0,066 & 0,037 & 0,059 & 0,128 & 0,038 \\
\hline C1Fe & 0,036 & 0,070 & 0,058 & 0,109 & 0,054 & 0,027 & 0,066 & 0,116 & 0,048 \\
\hline $\mathrm{C} 2 \mathrm{Fe}$ & 0,062 & 0,095 & 0,063 & 0,121 & 0,084 & 0,044 & 0,096 & 0,123 & 0,067 \\
\hline $\mathrm{C} 3 \mathrm{Fe}$ & 0,070 & 0,109 & 0,058 & 0,093 & 0,068 & 0,040 & 0,078 & 0,109 & 0,052 \\
\hline $\mathrm{C} 4 \mathrm{Fe}$ & 0,055 & 0,067 & 0,051 & 0,075 & nd & 0,030 & 0,055 & 0,069 & 0,021 \\
\hline A & nd & 0,014 & 0,014 & 0,019 & 0,009 & nd & 0,015 & 0,022 & nd \\
\hline FI & 0,077 & 0,078 & 0,102 & 0,213 & 0,120 & 0,049 & 0,087 & 0,163 & 0,039 \\
\hline $\mathbf{P i}$ & 0,075 & 0,065 & 0,088 & 0,237 & 0,120 & 0,055 & 0,100 & 0,150 & 0,049 \\
\hline C1Pi & 0,046 & 0,048 & 0,042 & 0,115 & 0,060 & 0,030 & 0,069 & 0,093 & 0,039 \\
\hline $\mathrm{C} 2 \mathrm{Pi}$ & 0,066 & 0,052 & 0,045 & 0,127 & 0,059 & 0,034 & 0,052 & 0,124 & 0,068 \\
\hline $\mathrm{BaA}$ & 0,096 & 0,073 & 0,065 & 0,134 & 0,082 & 0,029 & 0,110 & 0,382 & 0,063 \\
\hline $\mathrm{Cr}$ & 0,207 & 0,139 & 0,111 & 0,297 & 0,183 & 0,082 & 0,139 & 0,514 & 0,121 \\
\hline $\mathrm{C} 1 \mathrm{Cr}$ & 0,076 & 0,067 & 0,040 & 0,153 & 0,054 & 0,029 & 0,065 & 0,175 & 0,057 \\
\hline $\mathrm{C} 2 \mathrm{Cr}$ & 0,021 & 0,080 & nd & nd & nd & 0,015 & 0,092 & 0,181 & 0,013 \\
\hline $\mathrm{BbFI}$ & 0,607 & 0,606 & 0,804 & 0,994 & 0,817 & 0,376 & 1,242 & 0,854 & 0,290 \\
\hline BkFI & 0,149 & 0,129 & 0,255 & 0,392 & 0,218 & 0,108 & 0,290 & 0,232 & 0,093 \\
\hline $\mathrm{BePi}$ & 0,287 & 0,234 & 0,486 & 0,813 & 0,507 & 0,249 & 0,657 & 0,366 & 0,172 \\
\hline $\mathrm{BaPi}$ & 0,164 & 0,139 & 0,474 & 0,299 & 0,361 & 0,210 & 0,724 & 0,444 & 0,138 \\
\hline Per & 0,031 & 0,022 & 0,092 & 0,060 & 0,058 & 0,038 & 0,199 & 0,088 & 0,016 \\
\hline I-Pi & 1,337 & 0,526 & 5,096 & 0,524 & 3,197 & 2,736 & 2,728 & 0,879 & 0,435 \\
\hline DBahA & 0,091 & 0,076 & 0,351 & 2,245 & 0,202 & 0,164 & 0,329 & 0,112 & 0,050 \\
\hline BghiPer & 0,631 & 0,413 & 1,935 & 1,584 & 1,246 & 1,363 & 2,506 & 0,918 & 0,324 \\
\hline 16 HPA & 3,48 & 2,44 & 9,46 & 7,17 & 6,67 & 5,25 & 8,36 & 4,89 & 1,69 \\
\hline$\Sigma$ HPA & 4,57 & 3,76 & 10,95 & 9,51 & 7,94 & 6,14 & 10,29 & 6,96 & 2,49 \\
\hline \%p-terfenil & 105 & 101 & 93 & 149 & 113 & 120 & 101 & 92 & 109 \\
\hline $2,6+3,5$ 2MFe & 0,009 & 0,012 & nd & 0,017 & 0,008 & nd & 0,009 & 0,012 & nd \\
\hline 1,7 2MFe & 0,048 & 0,052 & 0,050 & 0,095 & 0,054 & 0,031 & 0,052 & 0,115 & 0,030 \\
\hline 1,5 $2 \mathrm{MFe}$ & nd & 0,043 & nd & nd & nd & 0,014 & 0,031 & nd & 0,023 \\
\hline Acef & 0,012 & 0,022 & 0,013 & 0,045 & 0,019 & 0,007 & 0,027 & 0,036 & nd \\
\hline $\mathrm{BeFe}$ & nd & nd & nd & nd & nd & nd & nd & 0,036 & nd \\
\hline $\mathrm{I}-\mathrm{Cr}$ & 0,204 & 0,160 & 0,651 & 0,635 & 0,468 & 0,497 & 1,335 & 0,195 & 0,080 \\
\hline DajA & 0,037 & 0,035 & 0,220 & 0,237 & 0,115 & 0,110 & 0,308 & 0,053 & 0,019 \\
\hline Pf & nd & 0,013 & 0,042 & nd & 0,030 & 0,031 & 0,062 & 0,015 & 0,009 \\
\hline $\mathrm{BbCr}$ & 0,019 & 0,022 & 0,074 & 0,163 & 0,058 & 0,041 & 0,198 & 0,029 & 0,016 \\
\hline Pc & nd & 0,044 & 0,141 & 0,555 & 0,009 & 0,010 & 0,029 & 0,011 & 0,025 \\
\hline
\end{tabular}


Resultado de hidrocarbonetos aromáticos, em $\mathrm{ng} \mathrm{m}^{-3}$, para as amostras de material particulado atmosférico (PM 2,5) coletadas no ano de 2011

\begin{tabular}{|c|c|c|c|c|c|c|c|c|c|}
\hline Código & SJ74 & SJ80 & SJ86 & SJ92 & SJ98 & SJ104 & SJ110 & SJ116 & SJ140 \\
\hline Data Início & 15-mar & 21-mar & 27-mar & $2-a b r$ & 8-abr & 14-abr & $20-a b r$ & 26-abr & 20-mai \\
\hline $\mathbf{N}$ & 0,038 & 0,054 & 0,013 & 0,069 & 0,035 & 0,017 & 0,016 & 0,041 & 0,056 \\
\hline C1N & 0,018 & 0,047 & nd & 0,052 & 0,009 & nd & 0,007 & 0,031 & 0,062 \\
\hline $\mathrm{C} 2 \mathrm{~N}$ & 0,030 & 0,063 & 0,010 & 0,066 & 0,038 & 0,013 & 0,016 & 0,038 & nd \\
\hline $\mathrm{C} 3 \mathrm{~N}$ & 0,012 & 0,027 & 0,008 & 0,034 & 0,023 & 0,007 & 0,008 & 0,017 & 0,040 \\
\hline C4N & 0,009 & 0,020 & nd & 0,027 & 0,020 & 0,008 & 0,006 & 0,013 & 0,030 \\
\hline ACF & nd & nd & nd & 0,013 & 0,009 & nd & nd & nd & 0,014 \\
\hline ACE & nd & nd & nd & nd & nd & nd & nd & nd & nd \\
\hline $\mathbf{F}$ & nd & nd & nd & 0,008 & nd & nd & nd & nd & nd \\
\hline C1F & nd & 0,012 & nd & 0,020 & 0,016 & 0,007 & nd & nd & 0,018 \\
\hline $\mathrm{C} 2 \mathrm{~F}$ & 0,018 & 0,039 & nd & 0,046 & 0,054 & 0,028 & 0,021 & 0,025 & 0,068 \\
\hline C3F & 0,066 & 0,124 & nd & 0,106 & 0,166 & 0,088 & 0,137 & 0,073 & 0,155 \\
\hline DBT & nd & nd & nd & nd & 0,007 & nd & nd & nd & nd \\
\hline C1DBT & 0,009 & 0,023 & nd & 0,021 & 0,025 & 0,009 & 0,009 & 0,011 & 0,021 \\
\hline C2DBT & 0,024 & 0,061 & nd & 0,049 & 0,068 & 0,031 & 0,034 & 0,032 & 0,056 \\
\hline C3DBT & 0,038 & 0,078 & 0,016 & 0,057 & 0,090 & 0,047 & 0,057 & 0,048 & 0,070 \\
\hline $\mathrm{Fe}$ & 0,023 & 0,070 & nd & 0,094 & 0,109 & 0,052 & 0,029 & 0,035 & 0,127 \\
\hline C1Fe & 0,024 & 0,066 & nd & 0,079 & 0,118 & 0,049 & 0,038 & 0,035 & 0,112 \\
\hline $\mathrm{C} 2 \mathrm{Fe}$ & 0,035 & 0,093 & 0,013 & 0,094 & 0,161 & 0,076 & 0,065 & 0,051 & 0,107 \\
\hline $\mathrm{C} 3 \mathrm{Fe}$ & 0,034 & 0,086 & 0,009 & 0,069 & 0,137 & 0,088 & 0,074 & 0,055 & 0,078 \\
\hline $\mathrm{C} 4 \mathrm{Fe}$ & 0,025 & 0,052 & nd & 0,045 & 0,082 & 0,042 & 0,042 & 0,037 & 0,025 \\
\hline A & nd & 0,013 & nd & 0,016 & 0,018 & 0,009 & nd & nd & 0,033 \\
\hline FI & 0,029 & 0,096 & 0,012 & 0,097 & 0,156 & 0,129 & 0,094 & 0,061 & 0,231 \\
\hline $\mathbf{P i}$ & 0,031 & 0,092 & 0,016 & 0,144 & 0,219 & 0,121 & 0,078 & 0,054 & 0,211 \\
\hline C1Pi & 0,021 & 0,063 & 0,011 & 0,077 & 0,120 & 0,067 & 0,047 & 0,041 & 0,115 \\
\hline $\mathrm{C} 2 \mathrm{Pi}$ & 0,030 & 0,080 & 0,011 & 0,073 & 0,119 & 0,069 & 0,057 & 0,064 & 0,115 \\
\hline $\mathrm{BaA}$ & 0,058 & 0,224 & nd & 0,106 & 0,186 & 0,124 & 0,159 & 0,139 & 0,451 \\
\hline $\mathrm{Cr}$ & 0,108 & 0,345 & 0,021 & 0,210 & 0,326 & 0,256 & 0,216 & 0,239 & 0,577 \\
\hline $\mathrm{C} 1 \mathrm{Cr}$ & 0,048 & 0,153 & nd & 0,102 & 0,154 & 0,093 & 0,093 & 0,082 & 0,241 \\
\hline $\mathrm{C} 2 \mathrm{Cr}$ & 0,048 & 0,162 & nd & 0,091 & 0,109 & 0,236 & 0,134 & 0,070 & 0,138 \\
\hline $\mathrm{BbFI}$ & 0,216 & 0,990 & 0,065 & 0,618 & 0,706 & 1,039 & 1,794 & 0,476 & 1,215 \\
\hline BkFI & 0,055 & 0,240 & 0,014 & 0,191 & 0,202 & 0,253 & 0,508 & 0,123 & 0,455 \\
\hline $\mathrm{BePi}$ & 0,095 & 0,412 & 0,042 & 0,376 & 0,338 & 0,429 & 0,760 & 0,194 & 0,567 \\
\hline $\mathrm{BaPi}$ & 0,090 & 0,515 & 0,024 & 0,289 & 0,311 & 0,361 & 0,826 & 0,232 & 0,777 \\
\hline Per & 0,016 & 0,079 & nd & 0,031 & 0,058 & 0,073 & 0,173 & 0,035 & 0,096 \\
\hline I-Pi & 0,205 & 0,716 & 0,151 & 1,449 & 0,637 & 1,577 & 1,879 & 0,354 & 1,247 \\
\hline DBahA & 0,035 & 0,156 & 0,019 & 0,068 & 0,086 & 0,256 & 0,314 & 0,051 & 0,260 \\
\hline BghiPer & 0,233 & 0,975 & 0,104 & 0,508 & 0,459 & 1,022 & 1,877 & 0,456 & 1,216 \\
\hline 16 HPA & 1,12 & 4,49 & 0,44 & 3,88 & 3,46 & 5,22 & 7,79 & 2,26 & 6,87 \\
\hline$\Sigma$ HPA & 1,72 & 6,23 & 0,56 & 5,40 & 5,37 & 6,68 & 9,57 & 3,21 & 8,98 \\
\hline \%p-terfenil & 73 & 85 & 26 & 100 & 101 & 74 & 74 & 66 & 105 \\
\hline $2,6+3,5$ 2MFe & nd & nd & $\overline{\mathrm{nd}}$ & nd & 0,015 & nd & nd & nd & 0,026 \\
\hline 1,7 2MFe & 0,025 & 0,079 & nd & 0,062 & 0,128 & 0,077 & 0,058 & 0,041 & 0,120 \\
\hline 1,5 $2 \mathrm{MFe}$ & nd & nd & nd & nd & nd & nd & nd & nd & 0,088 \\
\hline Acef & 0,008 & 0,023 & nd & 0,026 & 0,036 & 0,031 & 0,023 & 0,014 & 0,072 \\
\hline $\mathrm{BeFe}$ & nd & 0,017 & nd & 0,012 & 0,028 & 0,024 & 0,014 & 0,015 & 0,047 \\
\hline $\mathrm{I}-\mathrm{Cr}$ & 0,066 & 0,254 & 0,041 & 0,182 & 0,212 & 0,421 & 0,576 & 0,133 & 0,474 \\
\hline DajA & 0,021 & 0,099 & 0,009 & 0,034 & 0,056 & 0,153 & 0,211 & 0,047 & 0,189 \\
\hline Pf & 0,010 & 0,023 & nd & nd & 0,010 & 0,033 & 0,035 & 0,017 & 0,095 \\
\hline $\mathrm{BbCr}$ & 0,017 & 0,047 & nd & 0,008 & 0,021 & 0,083 & 0,101 & 0,027 & 0,155 \\
\hline Pc & nd & 0,028 & 0,013 & nd & nd & 0,011 & 0,058 & 0,008 & nd \\
\hline
\end{tabular}


Resultado de hidrocarbonetos aromáticos, em $\mathrm{ng} \mathrm{m}^{-3}$, para as amostras de material particulado atmosférico (PM 2,5) coletadas no ano de 2011

\begin{tabular}{|c|c|c|c|c|c|c|c|c|c|}
\hline Código & SJ146 & SJ152 & SJ158 & SJ164 & SJ170 & SJ170 & SJ176 & SJ182 & SJ188 \\
\hline Data Início & 26-mai & 1-jun & 7-jun & 13-jun & 19-jun & 19-jun & 25-jun & 1-jul & 7-jul \\
\hline $\mathbf{N}$ & 0,037 & 0,038 & 0,072 & 0,093 & 0,033 & 0,061 & 0,040 & 0,097 & 0,072 \\
\hline $\mathrm{C} 1 \mathrm{~N}$ & 0,018 & 0,019 & 0,068 & 0,092 & 0,018 & 0,042 & 0,021 & 0,102 & 0,051 \\
\hline $\mathrm{C} 2 \mathrm{~N}$ & 0,032 & 0,037 & 0,072 & 0,101 & 0,026 & 0,041 & 0,032 & nd & 0,063 \\
\hline C3N & 0,020 & nd & 0,053 & 0,061 & 0,021 & 0,041 & 0,024 & 0,044 & 0,021 \\
\hline $\mathrm{C} 4 \mathrm{~N}$ & 0,017 & nd & 0,043 & 0,049 & 0,019 & nd & nd & 0,029 & 0,037 \\
\hline ACF & nd & nd & 0,011 & 0,020 & nd & nd & nd & 0,019 & 0,011 \\
\hline ACE & nd & nd & nd & nd & nd & nd & nd & nd & nd \\
\hline $\mathbf{F}$ & nd & nd & 0,009 & 0,015 & nd & nd & nd & 0,011 & 0,011 \\
\hline C1F & 0,009 & nd & 0,022 & 0,025 & 0,009 & nd & 0,012 & 0,019 & 0,014 \\
\hline $\mathrm{C} 2 \mathrm{~F}$ & 0,035 & nd & 0,077 & 0,085 & 0,043 & 0,045 & 0,043 & 0,050 & 0,030 \\
\hline C3F & nd & 0,022 & 0,015 & nd & nd & 0,012 & nd & 0,093 & 0,010 \\
\hline DBT & nd & nd & nd & nd & nd & nd & nd & nd & nd \\
\hline C1DBT & nd & 0,015 & 0,023 & 0,018 & 0,010 & 0,014 & 0,011 & 0,020 & 0,017 \\
\hline C2DBT & 0,026 & 0,059 & 0,084 & 0,052 & 0,028 & 0,053 & 0,042 & 0,050 & 0,035 \\
\hline C3DBT & 0,034 & 0,136 & 0,100 & 0,077 & 0,046 & 0,080 & 0,060 & 0,062 & 0,035 \\
\hline $\mathrm{Fe}$ & 0,062 & 0,058 & 0,142 & 0,200 & 0,087 & 0,060 & 0,064 & 0,134 & 0,058 \\
\hline $\mathrm{C} 1 \mathrm{Fe}$ & 0,045 & 0,073 & 0,130 & 0,148 & 0,062 & 0,062 & 0,056 & 0,079 & 0,046 \\
\hline $\mathrm{C} 2 \mathrm{Fe}$ & 0,072 & 0,123 & 0,174 & 0,173 & 0,075 & 0,089 & 0,074 & 0,073 & 0,050 \\
\hline $\mathrm{C} 3 \mathrm{Fe}$ & 0,050 & 0,095 & 0,138 & 0,124 & 0,059 & 0,073 & 0,067 & 0,060 & 0,066 \\
\hline $\mathrm{C} 4 \mathrm{Fe}$ & 0,027 & 0,048 & 0,071 & 0,103 & 0,034 & 0,033 & 0,047 & 0,017 & 0,044 \\
\hline A & 0,012 & 0,011 & 0,030 & 0,042 & 0,014 & nd & 0,011 & 0,026 & 0,015 \\
\hline FI & 0,126 & 0,140 & 0,238 & 0,263 & 0,249 & 0,125 & 0,111 & 0,192 & 0,078 \\
\hline $\mathbf{P i}$ & 0,126 & 0,225 & 0,277 & 0,284 & 0,208 & 0,144 & 0,116 & 0,173 & 0,062 \\
\hline C1Pi & 0,082 & 0,151 & 0,173 & 0,215 & 0,103 & 0,107 & 0,084 & 0,085 & 0,042 \\
\hline $\mathrm{C} 2 \mathrm{Pi}$ & 0,079 & 0,141 & 0,214 & 0,293 & 0,119 & 0,109 & 0,130 & 0,081 & 0,032 \\
\hline $\mathrm{BaA}$ & 0,133 & 0,169 & 0,356 & 0,508 & 0,135 & 0,086 & 0,091 & 0,210 & 0,083 \\
\hline $\mathrm{Cr}$ & 0,218 & 0,290 & 0,489 & 0,762 & 0,355 & 0,203 & 0,211 & 0,342 & 0,128 \\
\hline $\mathrm{C} 1 \mathrm{Cr}$ & 0,086 & 0,128 & 0,225 & 0,374 & 0,119 & 0,088 & 0,090 & 0,112 & 0,061 \\
\hline $\mathrm{C} 2 \mathrm{Cr}$ & 0,028 & nd & 0,121 & 0,296 & 0,058 & nd & 0,083 & 0,075 & 0,049 \\
\hline $\mathrm{BbFI}$ & 0,772 & 0,762 & 1,822 & 2,243 & 1,270 & 0,770 & 0,789 & 1,084 & 0,615 \\
\hline BkFI & 0,262 & 0,224 & 0,676 & 0,726 & 0,383 & 0,218 & 0,239 & 0,345 & 0,132 \\
\hline $\mathrm{BePi}$ & 0,394 & 0,559 & 0,837 & 0,933 & 0,616 & 0,493 & 0,415 & 0,552 & 0,247 \\
\hline $\mathrm{BaPi}$ & 0,381 & 0,487 & 1,109 & 1,393 & 0,411 & 0,321 & 0,309 & 0,594 & 0,288 \\
\hline Per & 0,069 & 0,049 & 0,216 & 0,252 & 0,079 & 0,042 & 0,066 & 0,089 & 0,070 \\
\hline I-Pi & 0,846 & 1,263 & 1,565 & 1,987 & 1,251 & 1,368 & 0,826 & 1,658 & 0,495 \\
\hline DBahA & 0,137 & 0,107 & 0,208 & 0,376 & 0,217 & 0,188 & 0,157 & 0,281 & 0,081 \\
\hline BghiPer & 0,765 & 0,763 & 1,604 & 2,029 & 1,376 & 1,140 & 0,812 & 1,295 & 0,633 \\
\hline 16 HPA & 3,88 & 4,54 & 8,61 & 10,94 & 5,99 & 4,68 & 3,78 & 6,46 & 2,76 \\
\hline$\Sigma$ HPA & 5,00 & 6,19 & 11,46 & 14,41 & 7,53 & 6,11 & 5,13 & 8,15 & 3,79 \\
\hline \%p-terfenil & 102 & 94 & 102 & 98 & 86 & 94 & 73 & 119 & 86 \\
\hline $2,6+3,5$ 2MFe & nd & 0,008 & 0,018 & 0,019 & nd & nd & 0,008 & 0,016 & nd \\
\hline $1,72 \mathrm{MFe}$ & 0,046 & 0,065 & 0,104 & 0,105 & 0,039 & 0,043 & 0,039 & 0,080 & 0,031 \\
\hline 1,5 2MFe & 0,028 & 0,041 & 0,070 & 0,071 & 0,028 & 0,033 & 0,031 & 0,061 & 0,021 \\
\hline Acef & 0,033 & 0,026 & 0,067 & 0,084 & 0,036 & 0,025 & 0,026 & 0,052 & 0,027 \\
\hline $\mathrm{BeFe}$ & 0,015 & 0,013 & 0,030 & 0,055 & 0,019 & 0,011 & 0,011 & 0,033 & nd \\
\hline $\mathrm{I}-\mathrm{Cr}$ & 0,251 & 0,206 & 0,424 & 0,659 & 0,471 & 0,338 & 0,290 & 0,496 & 0,238 \\
\hline DajA & 0,089 & 0,057 & 0,099 & 0,238 & 0,135 & 0,110 & 0,089 & 0,224 & 0,057 \\
\hline Pf & 0,023 & 0,019 & 0,038 & 0,093 & 0,030 & 0,018 & 0,027 & 0,088 & 0,019 \\
\hline $\mathrm{BbCr}$ & 0,055 & 0,038 & 0,082 & 0,181 & 0,066 & 0,051 & 0,049 & 0,148 & 0,041 \\
\hline Pc & 0,099 & 0,062 & 0,107 & 0,275 & 0,169 & 0,118 & 0,122 & 0,122 & nd \\
\hline
\end{tabular}


Resultado de hidrocarbonetos aromáticos, em $\mathrm{ng} \mathrm{m}^{-3}$, para as amostras de material particulado atmosférico (PM 2,5) coletadas no ano de 2011

\begin{tabular}{|c|c|c|c|c|c|c|c|c|c|}
\hline Código & SJ194 & SJ200 & SJ206 & SJ212 & SJ218 & SJ230 & SJ236 & SJ242 & SJ248 \\
\hline Data Início & 13-jul & 19-jul & 25-jul & 31-jul & 6-ago & 18-ago & 24-ago & 30 -ago & 5-set \\
\hline $\mathbf{N}$ & 0,057 & 0,045 & 0,074 & 0,059 & 0,073 & 0,037 & 0,043 & 0,059 & 0,041 \\
\hline C1N & 0,070 & 0,050 & 0,055 & 0,034 & 0,076 & 0,037 & 0,055 & 0,106 & 0,019 \\
\hline $\mathrm{C} 2 \mathrm{~N}$ & 0,085 & 0,046 & 0,021 & 0,046 & 0,114 & 0,074 & 0,088 & 0,296 & 0,054 \\
\hline C3N & 0,039 & 0,022 & 0,028 & 0,021 & 0,064 & 0,041 & 0,050 & 0,141 & 0,037 \\
\hline C4N & 0,033 & 0,020 & 0,025 & 0,016 & 0,041 & 0,029 & 0,036 & 0,066 & 0,025 \\
\hline ACF & 0,021 & 0,013 & 0,013 & nd & 0,017 & 0,011 & 0,011 & 0,016 & 0,008 \\
\hline ACE & nd & nd & nd & nd & nd & nd & nd & nd & nd \\
\hline $\mathbf{F}$ & 0,014 & nd & 0,015 & nd & 0,021 & 0,013 & 0,013 & 0,030 & 0,008 \\
\hline C1F & 0,024 & 0,011 & 0,016 & 0,010 & 0,032 & 0,021 & 0,023 & 0,043 & 0,017 \\
\hline $\mathrm{C} 2 \mathrm{~F}$ & 0,053 & 0,025 & 0,043 & 0,023 & 0,074 & 0,046 & 0,044 & 0,090 & 0,060 \\
\hline C3F & 0,132 & 0,088 & 0,016 & nd & 0,022 & 0,012 & 0,013 & 0,021 & 0,173 \\
\hline DBT & 0,009 & nd & nd & nd & 0,013 & 0,011 & 0,012 & 0,019 & nd \\
\hline C1DBT & 0,028 & 0,013 & 0,022 & 0,013 & 0,035 & 0,026 & 0,026 & 0,065 & 0,029 \\
\hline C2DBT & 0,057 & 0,035 & 0,048 & 0,025 & 0,069 & 0,067 & 0,059 & 0,141 & 0,096 \\
\hline C3DBT & 0,070 & 0,039 & 0,050 & 0,032 & 0,074 & 0,066 & 0,058 & 0,186 & 0,115 \\
\hline $\mathrm{Fe}$ & 0,143 & 0,043 & 0,111 & 0,023 & 0,180 & 0,101 & 0,089 & 0,235 & 0,115 \\
\hline C1Fe & 0,105 & 0,042 & 0,088 & 0,021 & 0,149 & 0,083 & 0,082 & 0,224 & 0,108 \\
\hline $\mathrm{C} 2 \mathrm{Fe}$ & 0,115 & 0,058 & 0,105 & 0,029 & 0,159 & 0,094 & 0,104 & 0,260 & 0,158 \\
\hline $\mathrm{C} 3 \mathrm{Fe}$ & 0,112 & 0,056 & 0,095 & 0,034 & 0,117 & 0,097 & 0,063 & 0,249 & 0,142 \\
\hline $\mathrm{C} 4 \mathrm{Fe}$ & 0,094 & 0,047 & 0,075 & 0,028 & 0,074 & 0,065 & 0,046 & 0,130 & 0,108 \\
\hline A & 0,036 & 0,017 & 0,034 & nd & 0,035 & 0,024 & 0,019 & 0,045 & 0,019 \\
\hline FI & 0,252 & 0,097 & 0,149 & 0,031 & 0,174 & 0,094 & 0,073 & 0,198 & 0,197 \\
\hline $\mathbf{P i}$ & 0,229 & 0,103 & 0,117 & 0,019 & 0,169 & 0,074 & 0,062 & 0,184 & 0,236 \\
\hline C1Pi & 0,181 & 0,065 & 0,084 & 0,015 & 0,090 & 0,046 & 0,042 & 0,113 & 0,148 \\
\hline $\mathrm{C} 2 \mathrm{Pi}$ & 0,209 & 0,077 & 0,079 & 0,014 & 0,079 & 0,049 & 0,045 & 0,118 & 0,148 \\
\hline $\mathrm{BaA}$ & 0,594 & 0,147 & 0,426 & 0,016 & 0,240 & 0,087 & 0,089 & 0,208 & 0,288 \\
\hline $\mathrm{Cr}$ & 0,786 & 0,263 & 0,423 & 0,039 & 0,357 & 0,165 & 0,176 & 0,300 & 0,613 \\
\hline $\mathrm{C} 1 \mathrm{Cr}$ & 0,433 & 0,119 & 0,261 & 0,022 & 0,201 & 0,082 & 0,083 & 0,208 & 0,177 \\
\hline $\mathrm{C} 2 \mathrm{Cr}$ & 0,206 & 0,059 & 0,130 & 0,055 & 0,117 & 0,110 & 0,084 & 0,215 & 0,100 \\
\hline $\mathrm{BbFI}$ & 2,428 & 0,769 & 2,211 & 0,442 & 2,334 & 0,759 & 0,619 & nd & 1,067 \\
\hline BkFI & 0,492 & 0,146 & 0,574 & 0,091 & 0,510 & 0,580 & 0,468 & 0,622 & 0,324 \\
\hline $\mathrm{BePi}$ & 0,931 & 0,269 & 0,760 & 0,226 & 1,127 & 0,320 & 0,289 & nd & 0,616 \\
\hline $\mathrm{BaPi}$ & 1,104 & 0,260 & 0,959 & 0,116 & 0,900 & 0,253 & 0,196 & 0,273 & 0,444 \\
\hline Per & 0,243 & 0,056 & 0,171 & 0,021 & 0,150 & 0,037 & 0,028 & 0,035 & 0,056 \\
\hline I-Pi & 1,748 & 0,534 & 1,345 & 0,594 & 2,102 & 0,829 & 0,439 & 0,599 & 4,240 \\
\hline DBahA & 0,464 & 0,069 & 0,186 & 0,063 & 0,290 & 0,102 & 0,065 & 0,416 & 0,246 \\
\hline BghiPer & 1,600 & 0,621 & 1,279 & 0,399 & 1,789 & 0,518 & 0,411 & 0,502 & 0,730 \\
\hline 16 HPA & 9,97 & 3,13 & 7,92 & 1,89 & 9,19 & 3,65 & 2,77 & 3,69 & 8,57 \\
\hline$\Sigma$ HPA & 13,20 & 4,33 & 10,09 & 2,58 & 12,07 & 5,06 & 4,10 & 6,41 & 10,96 \\
\hline \%p-terfenil & 72 & 82 & 83 & 64 & 95 & 97 & 87 & 102 & 101 \\
\hline $2,6+3,52 \mathrm{MFe}$ & 0,017 & nd & 0,012 & nd & 0,017 & 0,011 & 0,009 & 0,033 & 0,013 \\
\hline 1,7 2MFe & 0,123 & 0,036 & 0,058 & 0,011 & 0,080 & 0,046 & 0,038 & 0,123 & 0,107 \\
\hline 1,5 2MFe & 0,081 & 0,046 & 0,043 & 0,010 & 0,061 & 0,018 & 0,148 & 0,097 & nd \\
\hline Acef & 0,077 & 0,027 & 0,051 & 0,016 & 0,046 & 0,027 & 0,022 & 0,040 & 0,044 \\
\hline $\mathrm{BeFe}$ & 0,075 & 0,016 & 0,026 & nd & 0,028 & 0,012 & 0,010 & 0,027 & 0,037 \\
\hline $\mathrm{I}-\mathrm{Cr}$ & 0,955 & 0,208 & 0,572 & 0,148 & 0,833 & 0,247 & 0,147 & 0,209 & 0,325 \\
\hline DajA & 0,273 & 0,044 & 0,139 & 0,036 & 0,192 & 0,056 & 0,032 & 0,050 & 0,119 \\
\hline Pf & 0,082 & 0,013 & 0,045 & 0,012 & 0,068 & 0,020 & 0,015 & nd & nd \\
\hline $\mathrm{BbCr}$ & 0,203 & 0,028 & 0,099 & 0,018 & 0,143 & 0,034 & 0,026 & nd & 0,060 \\
\hline Pc & 0,239 & nd & nd & nd & nd & nd & nd & nd & 0,011 \\
\hline
\end{tabular}


Resultado de hidrocarbonetos aromáticos, em $\mathrm{ng} \mathrm{m}^{-3}$, para as amostras de material particulado atmosférico (PM 2,5) coletadas no ano de 2011

\begin{tabular}{|c|c|c|c|c|c|c|c|c|c|}
\hline Código & SJ254 & SJ260 & SJ266 & SJ272 & SJ314 & SJ320 & SJ326 & SJ332 & SJ338 \\
\hline Data Início & 11-set & 17-set & 23-set & 29-set & 10-nov & 16-nov & 22-nov & 28-nov & 4-dez \\
\hline $\mathbf{N}$ & 0,027 & 0,041 & 0,034 & 0,021 & 0,094 & 0,020 & 0,016 & 0,018 & 0,105 \\
\hline C1N & 0,008 & 0,024 & 0,031 & 0,026 & 0,068 & 0,029 & 0,032 & 0,028 & 0,060 \\
\hline $\mathrm{C} 2 \mathrm{~N}$ & 0,015 & 0,029 & 0,033 & 0,030 & 0,062 & 0,027 & 0,043 & 0,033 & 0,042 \\
\hline C3N & nd & 0,012 & 0,015 & 0,013 & nd & nd & nd & nd & nd \\
\hline C4N & nd & 0,010 & 0,016 & nd & nd & nd & nd & nd & nd \\
\hline ACF & nd & nd & 0,009 & 0,008 & 0,011 & nd & nd & nd & nd \\
\hline ACE & nd & nd & nd & nd & nd & nd & nd & nd & nd \\
\hline $\mathbf{F}$ & nd & 0,007 & nd & nd & nd & nd & nd & nd & nd \\
\hline C1F & nd & 0,009 & 0,013 & 0,011 & nd & nd & 0,010 & nd & nd \\
\hline $\mathrm{C} 2 \mathrm{~F}$ & 0,007 & 0,020 & 0,027 & 0,027 & 0,025 & 0,021 & 0,029 & 0,015 & 0,012 \\
\hline C3F & nd & nd & 0,077 & 0,104 & 0,109 & 0,136 & 0,118 & 0,052 & 0,118 \\
\hline DBT & nd & nd & nd & nd & 0,011 & nd & 0,011 & nd & nd \\
\hline C1DBT & nd & 0,014 & 0,022 & 0,018 & 0,020 & 0,018 & 0,027 & 0,015 & 0,013 \\
\hline C2DBT & 0,022 & 0,030 & 0,057 & 0,046 & 0,043 & 0,045 & 0,064 & 0,025 & 0,028 \\
\hline C3DBT & 0,050 & 0,037 & 0,069 & 0,064 & 0,053 & 0,011 & 0,077 & 0,032 & nd \\
\hline $\mathrm{Fe}$ & 0,018 & 0,030 & 0,053 & 0,029 & 0,051 & 0,030 & 0,054 & 0,014 & 0,020 \\
\hline C1Fe & 0,021 & 0,036 & 0,055 & 0,046 & 0,043 & 0,038 & 0,052 & 0,016 & 0,021 \\
\hline $\mathrm{C} 2 \mathrm{Fe}$ & 0,038 & 0,046 & 0,085 & 0,087 & 0,046 & 0,063 & 0,072 & 0,021 & 0,027 \\
\hline $\mathrm{C} 3 \mathrm{Fe}$ & 0,028 & 0,046 & 0,064 & 0,102 & 0,029 & 0,062 & 0,037 & 0,021 & 0,021 \\
\hline $\mathrm{C} 4 \mathrm{Fe}$ & 0,015 & 0,034 & 0,049 & 0,076 & nd & 0,040 & 0,019 & nd & 0,019 \\
\hline A & nd & 0,008 & 0,016 & 0,011 & 0,011 & nd & 0,012 & nd & nd \\
\hline FI & 0,034 & 0,043 & 0,082 & 0,085 & 0,095 & 0,082 & 0,090 & 0,054 & 0,047 \\
\hline $\mathbf{P i}$ & 0,040 & 0,039 & 0,087 & 0,088 & 0,095 & 0,084 & 0,082 & 0,027 & 0,028 \\
\hline C1Pi & 0,023 & 0,021 & 0,053 & 0,059 & 0,038 & 0,057 & 0,038 & nd & 0,012 \\
\hline $\mathrm{C} 2 \mathrm{Pi}$ & 0,024 & 0,023 & 0,045 & 0,073 & 0,043 & 0,078 & 0,045 & nd & nd \\
\hline $\mathrm{BaA}$ & 0,021 & 0,055 & 0,132 & 0,097 & 0,074 & 0,081 & 0,077 & nd & nd \\
\hline $\mathrm{Cr}$ & 0,072 & 0,078 & 0,158 & 0,205 & 0,189 & 0,192 & 0,147 & 0,054 & 0,040 \\
\hline $\mathrm{C} 1 \mathrm{Cr}$ & 0,024 & 0,047 & 0,086 & 0,097 & 0,053 & 0,068 & 0,067 & 0,014 & 0,018 \\
\hline $\mathrm{C} 2 \mathrm{Cr}$ & nd & 0,105 & 0,119 & 0,102 & nd & nd & nd & nd & nd \\
\hline $\mathrm{BbFI}$ & 0,176 & 0,830 & 0,843 & 0,522 & 0,638 & 0,151 & 0,726 & 0,158 & 0,337 \\
\hline BkFI & 0,036 & 0,246 & 0,198 & 0,092 & 0,264 & 0,059 & 0,369 & 0,062 & 0,152 \\
\hline $\mathrm{BePi}$ & 0,130 & 0,385 & 0,315 & 0,200 & 0,315 & 0,143 & nd & 0,090 & 0,282 \\
\hline $\mathrm{BaPi}$ & 0,034 & 0,364 & 0,300 & 0,132 & 0,160 & 0,089 & 0,226 & 0,056 & 0,137 \\
\hline Per & 0,009 & 0,053 & 0,040 & 0,023 & 0,041 & 0,022 & 0,064 & 0,018 & 0,041 \\
\hline I-Pi & 0,844 & 0,987 & 0,691 & 0,663 & 1,370 & 0,076 & 1,807 & 0,115 & 0,525 \\
\hline DBahA & 0,041 & 0,105 & 0,081 & 0,046 & 0,329 & 0,136 & 0,328 & 0,033 & 0,135 \\
\hline BghiPer & 0,262 & 0,680 & 0,617 & 0,322 & 0,417 & 0,233 & 0,551 & 0,113 & 0,816 \\
\hline 16 HPA & 1,61 & 3,51 & 3,30 & 2,32 & 3,80 & 1,23 & 4,48 & 0,70 & 2,34 \\
\hline$\Sigma$ HPA & 2,02 & 4,50 & 4,57 & 3,53 & 4,80 & 2,09 & 5,29 & 1,09 & 3,05 \\
\hline$\%$-terfenil & 89 & 94 & 87 & 101 & 88 & 96 & 72 & 65 & 100 \\
\hline $2,6+3,52 \mathrm{MFe}$ & nd & 0,009 & 0,009 & 0,009 & 0,029 & 0,032 & 0,033 & 0,023 & 0,023 \\
\hline 1,7 2MFe & 0,022 & 0,023 & 0,055 & 0,073 & 0,052 & 0,065 & 0,068 & 0,028 & 0,023 \\
\hline 1,5 2MFe & nd & 0,025 & 0,059 & 0,044 & 0,035 & 0,037 & 0,044 & nd & nd \\
\hline Acef & nd & 0,018 & 0,025 & 0,021 & 0,030 & 0,025 & 0,028 & 0,023 & 0,021 \\
\hline $\mathrm{BeFe}$ & nd & nd & 0,011 & 0,013 & nd & nd & nd & nd & nd \\
\hline $\mathrm{I}-\mathrm{Cr}$ & 0,075 & 0,289 & 0,245 & 0,113 & 0,130 & 0,038 & 0,167 & 0,054 & 0,245 \\
\hline DajA & 0,014 & 0,074 & 0,052 & 0,025 & 0,041 & 0,021 & 0,044 & 0,029 & 0,060 \\
\hline Pf & nd & 0,026 & 0,016 & 0,009 & 0,024 & 0,020 & 0,020 & 0,020 & 0,035 \\
\hline $\mathrm{BbCr}$ & nd & 0,048 & 0,030 & 0,012 & 0,031 & 0,020 & 0,031 & 0,021 & 0,038 \\
\hline Pc & nd & nd & nd & nd & nd & 0,021 & 0,041 & 0,027 & 0,069 \\
\hline
\end{tabular}


Resultado de hidrocarbonetos aromáticos, em $\mathrm{ng} \mathrm{m}^{-3}$, para as amostras de material particulado atmosférico (PM 2,5) coletadas no ano de 2011

\begin{tabular}{lcc}
\hline Código & SJ344 & SJ356 \\
\hline Data Início & $\mathbf{1 0 - d e z}$ & $\mathbf{2 2 - d e z}$ \\
\hline $\mathbf{N}$ & 0,030 & 0,041 \\
C1N & 0,033 & 0,036 \\
C2N & 0,037 & 0,034 \\
C3N & nd & nd \\
C4N & nd & nd \\
ACF & nd & nd \\
ACE & nd & nd \\
F & nd & nd \\
C1F & nd & nd \\
C2F & 0,015 & 0,025 \\
C3F & 0,066 & 0,103 \\
DBT & nd & 0,010 \\
C1DBT & 0,016 & 0,020 \\
C2DBT & 0,033 & 0,047 \\
C3DBT & 0,039 & 0,071 \\
Fe & 0,025 & 0,059 \\
C1Fe & 0,022 & 0,052 \\
C2Fe & 0,028 & 0,078 \\
C3Fe & 0,020 & 0,060 \\
C4Fe & 0,013 & 0,030 \\
A & nd & 0,010 \\
FI & 0,058 & 0,134 \\
Pi & 0,032 & 0,128 \\
C1Pi & 0,022 & 0,071 \\
C2Pi & 0,029 & 0,081 \\
BaA & 0,068 & 0,103 \\
Cr & 0,132 & 0,193 \\
C1Cr & 0,050 & 0,085 \\
C2Cr & nd & nd \\
BbFI & 0,264 & 0,848 \\
BkFI & 0,102 & 0,267 \\
BePi & 0,126 & 0,375 \\
BaPi & 0,071 & 0,215 \\
Per & 0,020 & 0,048 \\
I-Pi & 0,430 & 0,335 \\
DBahA & 0,141 & 0,079 \\
BghiPer & 0,190 & 0,576 \\
\hline 16 HPA & 1,54 & 2,99 \\
$\mathbf{\Sigma}$ HPA & 2,11 & 4,22 \\
\hline \%p-terfenil & 83 & 74 \\
\hline 2,6+3,5 2MFe & 0,022 & 0,035 \\
1,7 2MFe & 0,030 & 0,102 \\
1,5 2MFe & 0,017 & 0,044 \\
Acef & 0,022 & 0,034 \\
BeFe & nd & nd \\
I-Cr & 0,046 & 0,256 \\
DajA & 0,024 & 0,065 \\
Pf & 0,018 & 0,029 \\
BbCr & 0,019 & 0,038 \\
Pc & 0,015 & 0,022 \\
\hline & &
\end{tabular}


Resultado de hidrocarbonetos aromáticos, em $\mathrm{ng} \mathrm{m}^{-3}$, para as amostras de material particulado atmosférico (PM 2,5) coletadas no ano de 2011

\begin{tabular}{|c|c|c|c|c|c|c|c|c|c|}
\hline Código & SE8 & SE12 & SE14 & SE18 & SE20 & SE26 & SE29 & SE34 & SE38 \\
\hline Data Início & 8-jan & 12-jan & 14-jan & 18-jan & 20-jan & 26-jan & 29-jan & 3-fev & 7-fev \\
\hline $\mathbf{N}$ & 0,060 & 0,036 & 0,056 & 0,041 & 0,044 & 0,059 & 0,033 & 0,049 & 0,034 \\
\hline $\mathrm{C} 1 \mathrm{~N}$ & 0,018 & 0,019 & 0,032 & 0,021 & 0,020 & 0,031 & 0,015 & 0,025 & 0,014 \\
\hline $\mathrm{C} 2 \mathrm{~N}$ & 0,032 & nd & 0,046 & nd & 0,023 & 0,028 & nd & nd & 0,027 \\
\hline C3N & 0,022 & 0,011 & 0,032 & 0,009 & nd & nd & 0,011 & 0,014 & nd \\
\hline C4N & 0,024 & 0,017 & 0,032 & nd & nd & nd & 0,015 & 0,011 & nd \\
\hline ACF & nd & nd & nd & nd & nd & nd & nd & nd & nd \\
\hline ACE & nd & nd & nd & nd & nd & nd & nd & nd & nd \\
\hline $\mathbf{F}$ & nd & nd & nd & nd & nd & nd & nd & nd & nd \\
\hline C1F & 0,026 & nd & 0,020 & nd & nd & nd & nd & nd & nd \\
\hline $\mathrm{C} 2 \mathrm{~F}$ & 0,028 & 0,033 & 0,036 & 0,012 & 0,018 & 0,020 & 0,025 & 0,025 & 0,018 \\
\hline C3F & 0,200 & 0,062 & 0,127 & 0,040 & nd & 0,023 & 0,042 & 0,043 & nd \\
\hline DBT & nd & nd & nd & nd & nd & nd & nd & nd & nd \\
\hline C1DBT & 0,011 & 0,011 & 0,014 & nd & nd & nd & 0,008 & nd & 0,009 \\
\hline C2DBT & 0,029 & 0,027 & 0,025 & 0,011 & 0,013 & 0,016 & 0,017 & 0,015 & 0,026 \\
\hline C3DBT & 0,035 & 0,027 & 0,031 & 0,011 & 0,044 & 0,026 & 0,018 & 0,014 & 0,078 \\
\hline $\mathrm{Fe}$ & 0,021 & 0,020 & 0,025 & 0,019 & 0,017 & 0,019 & 0,030 & 0,041 & 0,027 \\
\hline $\mathrm{C} 1 \mathrm{Fe}$ & 0,022 & 0,027 & 0,024 & 0,015 & 0,016 & 0,017 & 0,027 & 0,025 & 0,023 \\
\hline $\mathrm{C} 2 \mathrm{Fe}$ & 0,035 & 0,035 & 0,039 & 0,013 & 0,021 & 0,024 & 0,027 & 0,022 & 0,034 \\
\hline $\mathrm{C} 3 \mathrm{Fe}$ & nd & 0,034 & 0,045 & 0,010 & 0,020 & 0,028 & 0,020 & 0,015 & 0,036 \\
\hline $\mathrm{C} 4 \mathrm{Fe}$ & 0,030 & 0,010 & 0,032 & nd & 0,014 & 0,026 & nd & nd & nd \\
\hline A & nd & nd & nd & nd & nd & nd & nd & nd & nd \\
\hline FI & 0,019 & 0,023 & 0,028 & 0,035 & 0,054 & 0,027 & 0,055 & 0,138 & 0,067 \\
\hline $\mathbf{P i}$ & 0,026 & 0,022 & 0,035 & 0,032 & 0,040 & 0,027 & 0,050 & 0,105 & 0,056 \\
\hline C1Pi & 0,028 & 0,017 & 0,028 & 0,020 & 0,022 & 0,021 & 0,025 & 0,044 & 0,031 \\
\hline $\mathrm{C} 2 \mathrm{Pi}$ & 0,036 & 0,021 & 0,041 & 0,019 & 0,024 & 0,018 & 0,025 & 0,035 & 0,034 \\
\hline $\mathrm{BaA}$ & 0,020 & 0,016 & 0,034 & 0,018 & 0,027 & 0,014 & 0,024 & 0,079 & 0,027 \\
\hline $\mathrm{Cr}$ & 0,027 & 0,032 & 0,063 & 0,037 & 0,088 & 0,039 & 0,057 & 0,149 & 0,091 \\
\hline $\mathrm{C} 1 \mathrm{Cr}$ & 0,023 & 0,014 & 0,030 & nd & 0,025 & 0,011 & 0,013 & 0,032 & 0,023 \\
\hline $\mathrm{C} 2 \mathrm{Cr}$ & 0,042 & nd & 0,026 & nd & nd & nd & nd & nd & 0,013 \\
\hline $\mathrm{BbFI}$ & nd & 0,067 & 0,728 & 0,113 & 0,303 & 0,121 & 0,143 & 0,367 & 0,253 \\
\hline BkFI & 0,024 & 0,019 & 0,216 & 0,032 & 0,083 & 0,025 & 0,040 & 0,130 & 0,065 \\
\hline $\mathrm{BePi}$ & 0,027 & 0,029 & 0,237 & 0,050 & 0,161 & 0,066 & 0,081 & 0,189 & 0,131 \\
\hline $\mathrm{BaPi}$ & 0,026 & 0,024 & 0,182 & 0,042 & 0,161 & 0,053 & 0,069 & 0,215 & 0,101 \\
\hline Per & nd & nd & 0,028 & nd & 0,039 & 0,012 & nd & 0,045 & 0,027 \\
\hline I-Pi & 0,118 & 0,075 & 0,439 & 0,215 & 0,474 & 0,303 & 0,333 & 0,703 & 0,448 \\
\hline DBahA & nd & 0,029 & 0,060 & 0,078 & 0,098 & 0,040 & 0,085 & 0,204 & 0,061 \\
\hline BghiPer & 0,102 & 0,059 & 0,316 & 0,149 & 0,475 & 0,299 & 0,297 & 0,585 & 0,492 \\
\hline 16 HPA & 0,44 & 0,42 & 2,18 & 0,81 & 1,86 & 1,03 & 1,22 & 2,77 & 1,72 \\
\hline$\Sigma$ HPA & 1,11 & 0,82 & 3,11 & 1,04 & 2,32 & 1,39 & 1,58 & 3,32 & 2,25 \\
\hline \%p-terfenil & 89 & 132 & 66 & 118 & 87 & 60 & 125 & 144 & 108 \\
\hline $2,6+3,52 \mathrm{MFe}$ & nd & nd & 0,011 & nd & nd & nd & nd & nd & nd \\
\hline $1,72 \mathrm{MFe}$ & 0,022 & 0,043 & 0,022 & 0,017 & 0,017 & 0,015 & 0,031 & 0,023 & 0,022 \\
\hline 1,5 2MFe & 0,020 & 0,021 & 0,022 & 0,011 & 0,017 & nd & 0,019 & 0,019 & nd \\
\hline Acef & 0,128 & 0,008 & nd & 0,013 & nd & nd & 0,013 & 0,021 & 0,008 \\
\hline $\mathrm{BeFe}$ & 0,127 & nd & nd & nd & nd & nd & nd & 0,013 & nd \\
\hline $\mathrm{I}-\mathrm{Cr}$ & 0,113 & 0,032 & 0,084 & 0,105 & 0,075 & 0,121 & 0,125 & 0,201 & 0,203 \\
\hline DajA & nd & 0,022 & 0,064 & 0,050 & 0,070 & 0,036 & 0,054 & 0,154 & 0,055 \\
\hline Pf & nd & nd & 0,015 & nd & 0,023 & 0,009 & nd & 0,070 & 0,016 \\
\hline $\mathrm{BbCr}$ & nd & 0,014 & 0,029 & 0,031 & 0,041 & 0,016 & 0,030 & 0,101 & 0,023 \\
\hline Pc & nd & 0,019 & 0,055 & 0,026 & 0,078 & 0,031 & 0,019 & 0,037 & 0,012 \\
\hline
\end{tabular}


Resultado de hidrocarbonetos aromáticos, em $\mathrm{ng} \mathrm{m}^{-3}$, para as amostras de material particulado atmosférico (PM 2,5) coletadas no ano de 2011

\begin{tabular}{|c|c|c|c|c|c|c|c|c|c|}
\hline Código & SE40 & SE44 & SE50 & SE56 & SE62 & SE68 & SE74 & SE80 & SE86 \\
\hline Data Início & 9-fev & 13-fev & 19-fev & 25-fev & 3-mar & 9-mar & 15-mar & 21-mar & 27-mar \\
\hline $\mathbf{N}$ & 0,049 & 0,034 & 0,024 & 0,032 & 0,071 & 0,095 & 0,101 & 0,089 & 0,075 \\
\hline C1N & 0,021 & 0,008 & nd & 0,014 & 0,044 & 0,080 & 0,072 & 0,065 & 0,044 \\
\hline $\mathrm{C} 2 \mathrm{~N}$ & nd & 0,024 & 0,041 & 0,027 & 0,043 & 0,075 & 0,111 & 0,067 & 0,051 \\
\hline $\mathrm{C} 3 \mathrm{~N}$ & 0,012 & nd & 0,029 & nd & 0,010 & 0,021 & 0,039 & 0,017 & 0,011 \\
\hline C4N & 0,009 & nd & 0,032 & nd & nd & 0,019 & 0,028 & 0,014 & nd \\
\hline ACF & nd & nd & nd & nd & nd & nd & 0,010 & nd & nd \\
\hline ACE & nd & nd & nd & nd & nd & nd & nd & nd & nd \\
\hline $\mathbf{F}$ & nd & nd & nd & nd & nd & nd & 0,014 & nd & nd \\
\hline C1F & nd & nd & 0,013 & nd & nd & 0,011 & 0,017 & 0,010 & nd \\
\hline $\mathrm{C} 2 \mathrm{~F}$ & 0,024 & 0,019 & nd & 0,012 & 0,032 & 0,034 & 0,039 & 0,038 & 0,030 \\
\hline C3F & 0,026 & nd & 0,085 & 0,050 & nd & nd & 0,016 & nd & nd \\
\hline DBT & nd & nd & nd & nd & 0,008 & nd & 0,011 & nd & nd \\
\hline C1DBT & nd & nd & 0,016 & 0,008 & 0,011 & 0,022 & 0,029 & 0,019 & nd \\
\hline C2DBT & 0,012 & 0,016 & 0,056 & 0,023 & 0,044 & 0,053 & 0,061 & 0,046 & 0,028 \\
\hline C3DBT & 0,013 & 0,044 & 0,076 & 0,063 & 0,051 & 0,068 & 0,066 & 0,059 & 0,040 \\
\hline $\mathrm{Fe}$ & 0,026 & 0,021 & 0,029 & 0,032 & 0,063 & 0,042 & 0,059 & 0,037 & 0,029 \\
\hline C1Fe & 0,017 & 0,017 & 0,033 & 0,023 & 0,039 & 0,047 & 0,055 & 0,040 & 0,024 \\
\hline $\mathrm{C} 2 \mathrm{Fe}$ & 0,015 & 0,022 & 0,064 & 0,032 & 0,050 & 0,053 & 0,074 & 0,047 & 0,034 \\
\hline $\mathrm{C} 3 \mathrm{Fe}$ & 0,012 & 0,022 & 0,048 & 0,035 & 0,046 & 0,061 & 0,083 & 0,050 & 0,034 \\
\hline $\mathrm{C} 4 \mathrm{Fe}$ & nd & 0,018 & 0,037 & 0,028 & 0,037 & 0,044 & 0,038 & 0,043 & 0,024 \\
\hline A & nd & nd & nd & nd & 0,011 & nd & 0,013 & nd & nd \\
\hline FI & 0,040 & 0,039 & 0,039 & 0,062 & 0,038 & 0,033 & 0,048 & 0,028 & 0,061 \\
\hline $\mathbf{P i}$ & 0,038 & 0,031 & 0,039 & 0,050 & 0,050 & 0,037 & 0,032 & 0,037 & 0,065 \\
\hline C1Pi & 0,022 & 0,019 & 0,035 & 0,030 & 0,024 & 0,028 & 0,024 & 0,028 & 0,030 \\
\hline $\mathrm{C} 2 \mathrm{Pi}$ & 0,020 & 0,028 & 0,043 & 0,029 & 0,042 & 0,045 & 0,033 & 0,042 & 0,038 \\
\hline $\mathrm{BaA}$ & 0,023 & 0,018 & 0,036 & 0,034 & 0,035 & 0,017 & 0,023 & 0,028 & 0,024 \\
\hline $\mathrm{Cr}$ & 0,045 & 0,080 & 0,073 & 0,092 & 0,122 & 0,074 & 0,066 & 0,073 & 0,086 \\
\hline $\mathrm{C} 1 \mathrm{Cr}$ & 0,013 & 0,045 & 0,056 & 0,034 & 0,035 & 0,038 & 0,047 & 0,042 & 0,022 \\
\hline $\mathrm{C} 2 \mathrm{Cr}$ & 0,010 & nd & 0,056 & nd & 0,011 & 0,010 & 0,045 & 0,019 & 0,009 \\
\hline $\mathrm{BbFI}$ & 0,152 & 0,447 & 0,394 & 0,357 & 0,379 & 0,183 & 0,284 & 0,165 & 0,171 \\
\hline BkFI & 0,048 & 0,093 & 0,038 & 0,095 & 0,052 & 0,038 & 0,051 & 0,032 & 0,042 \\
\hline $\mathrm{BePi}$ & 0,088 & 0,281 & 0,195 & 0,178 & 0,147 & 0,098 & 0,104 & 0,082 & 0,088 \\
\hline $\mathrm{BaPi}$ & 0,078 & 0,164 & 0,148 & 0,136 & 0,100 & 0,058 & 0,068 & 0,066 & 0,064 \\
\hline Per & nd & 0,032 & 0,022 & 0,029 & 0,017 & 0,011 & 0,012 & 0,010 & 0,012 \\
\hline I-Pi & 0,579 & 0,668 & 0,510 & 0,510 & 0,211 & 0,143 & 0,137 & 0,136 & 0,200 \\
\hline DBahA & 0,153 & 0,111 & 0,108 & 0,082 & 0,036 & 0,030 & 0,029 & 0,026 & 0,041 \\
\hline BghiPer & 0,544 & 0,708 & 0,522 & 0,551 & 0,250 & 0,177 & 0,166 & 0,182 & 0,181 \\
\hline 16 HPA & 1,77 & 2,42 & 1,96 & 2,03 & 1,42 & 0,93 & 1,10 & 0,90 & 1,04 \\
\hline$\Sigma$ HPA & 2,09 & 3,01 & 2,90 & 2,65 & 2,11 & 1,74 & 2,11 & 1,64 & 1,56 \\
\hline \%p-terfenil & 122 & 99 & 104 & 103 & 91 & 115 & 102 & 89 & 94 \\
\hline $2,6+3,5$ 2MFe & nd & nd & nd & nd & nd & nd & nd & nd & nd \\
\hline 1,7 2MFe & 0,016 & 0,015 & 0,039 & 0,028 & 0,033 & 0,044 & 0,033 & 0,036 & 0,022 \\
\hline 1,5 $2 \mathrm{MFe}$ & 0,012 & nd & 0,022 & nd & nd & nd & 0,037 & 0,016 & nd \\
\hline Acef & 0,013 & nd & nd & nd & 0,005 & nd & 0,014 & 0,003 & 0,007 \\
\hline $\mathrm{BeFe}$ & 0,007 & nd & nd & nd & nd & nd & nd & nd & nd \\
\hline $\mathrm{I}-\mathrm{Cr}$ & 0,285 & 0,291 & 0,398 & 0,245 & 0,091 & 0,067 & 0,060 & 0,056 & 0,074 \\
\hline DajA & 0,125 & 0,087 & 0,102 & 0,058 & 0,024 & 0,022 & 0,021 & 0,021 & 0,028 \\
\hline Pf & 0,046 & 0,029 & 0,032 & 0,024 & 0,007 & 0,009 & nd & nd & 0,010 \\
\hline $\mathrm{BbCr}$ & 0,056 & 0,029 & 0,032 & 0,024 & 0,010 & 0,009 & 0,012 & nd & 0,010 \\
\hline Pc & 0,032 & 0,008 & 0,025 & 0,015 & 0,019 & 0,023 & 0,023 & 0,013 & 0,027 \\
\hline
\end{tabular}


Resultado de hidrocarbonetos aromáticos, em $\mathrm{ng} \mathrm{m}^{-3}$, para as amostras de material particulado atmosférico (PM 2,5) coletadas no ano de 2011

\begin{tabular}{|c|c|c|c|c|c|c|c|c|c|}
\hline Código & SE92 & SE98 & SE104 & SE152 & SE164 & SE182 & SE188 & SE200 & SE206 \\
\hline Data Início & $2-a b r$ & 8-abr & 14-abr & 1-jun & 13-jun & 1-jul & 7-jul & 19-jul & 25-jul \\
\hline $\mathbf{N}$ & 0,043 & 0,003 & 0,051 & 0,034 & 0,083 & 0,057 & 0,057 & 0,036 & 0,056 \\
\hline C1N & 0,025 & 0,002 & 0,035 & 0,013 & 0,056 & 0,035 & 0,040 & 0,037 & 0,038 \\
\hline $\mathrm{C} 2 \mathrm{~N}$ & 0,026 & 0,003 & 0,057 & 0,037 & 0,047 & 0,039 & 0,053 & 0,029 & 0,046 \\
\hline $\mathrm{C} 3 \mathrm{~N}$ & 0,009 & 0,002 & 0,025 & nd & 0,028 & 0,014 & 0,019 & nd & 0,014 \\
\hline C4N & nd & 0,001 & 0,018 & nd & 0,028 & 0,012 & 0,022 & nd & 0,013 \\
\hline ACF & nd & nd & 0,008 & nd & nd & nd & nd & 0,010 & nd \\
\hline ACE & nd & nd & nd & nd & nd & nd & nd & nd & nd \\
\hline $\mathbf{F}$ & nd & 0,001 & 0,010 & nd & nd & nd & 0,010 & nd & 0,010 \\
\hline C1F & nd & 0,001 & 0,014 & nd & nd & nd & 0,012 & nd & 0,010 \\
\hline $\mathrm{C} 2 \mathrm{~F}$ & nd & 0,003 & 0,033 & nd & 0,037 & nd & 0,023 & nd & 0,020 \\
\hline C3F & 0,007 & 0,001 & 0,011 & 0,022 & nd & nd & nd & nd & 0,009 \\
\hline DBT & nd & nd & nd & nd & nd & nd & 0,008 & nd & nd \\
\hline C1DBT & 0,012 & 0,002 & 0,016 & nd & nd & nd & 0,014 & nd & 0,012 \\
\hline C2DBT & 0,036 & 0,004 & 0,037 & 0,038 & nd & 0,009 & 0,023 & nd & 0,021 \\
\hline C3DBT & 0,044 & 0,005 & 0,048 & 0,078 & 0,046 & nd & 0,024 & nd & 0,023 \\
\hline $\mathrm{Fe}$ & 0,015 & 0,003 & 0,045 & 0,023 & 0,042 & 0,015 & 0,038 & 0,026 & 0,036 \\
\hline C1Fe & 0,022 & 0,004 & 0,047 & 0,030 & 0,033 & 0,011 & 0,027 & nd & 0,024 \\
\hline $\mathrm{C} 2 \mathrm{Fe}$ & 0,043 & 0,007 & 0,091 & 0,037 & 0,045 & 0,019 & 0,038 & nd & 0,032 \\
\hline $\mathrm{C} 3 \mathrm{Fe}$ & 0,056 & 0,008 & 0,092 & 0,030 & 0,042 & 0,023 & 0,045 & nd & 0,037 \\
\hline $\mathrm{C} 4 \mathrm{Fe}$ & 0,046 & 0,004 & 0,055 & nd & 0,028 & 0,022 & 0,029 & nd & 0,024 \\
\hline A & nd & 0,001 & 0,011 & nd & nd & nd & 0,009 & 0,010 & 0,012 \\
\hline FI & 0,023 & 0,004 & 0,087 & 0,051 & 0,072 & 0,028 & 0,039 & 0,108 & 0,041 \\
\hline $\mathbf{P i}$ & 0,014 & 0,003 & 0,054 & 0,087 & 0,068 & 0,014 & 0,028 & 0,070 & 0,024 \\
\hline C1Pi & 0,013 & 0,003 & 0,037 & 0,075 & 0,046 & nd & 0,018 & nd & 0,017 \\
\hline $\mathrm{C} 2 \mathrm{Pi}$ & 0,015 & 0,002 & 0,045 & 0,067 & 0,053 & nd & 0,021 & nd & 0,014 \\
\hline $\mathrm{BaA}$ & 0,010 & 0,002 & 0,037 & 0,040 & 0,051 & nd & 0,019 & 0,039 & 0,029 \\
\hline $\mathrm{Cr}$ & 0,032 & 0,006 & 0,115 & 0,095 & 0,113 & 0,023 & 0,066 & 0,110 & 0,051 \\
\hline $\mathrm{C} 1 \mathrm{Cr}$ & 0,020 & 0,003 & 0,046 & 0,031 & 0,056 & nd & 0,024 & nd & 0,024 \\
\hline $\mathrm{C} 2 \mathrm{Cr}$ & 0,021 & 0,003 & 0,037 & nd & 0,032 & nd & 0,020 & nd & 0,024 \\
\hline $\mathrm{BbFI}$ & 0,138 & 0,035 & 0,502 & 0,236 & 0,379 & 0,095 & 0,195 & 0,426 & 0,402 \\
\hline BkFI & 0,024 & 0,007 & 0,106 & 0,063 & 0,123 & 0,017 & nd & 0,055 & 0,068 \\
\hline $\mathrm{BePi}$ & 0,049 & 0,014 & 0,199 & 0,117 & 0,198 & 0,045 & 0,071 & 0,131 & 0,138 \\
\hline $\mathrm{BaPi}$ & 0,027 & 0,011 & 0,126 & 0,112 & 0,240 & 0,032 & 0,039 & 0,093 & 0,101 \\
\hline Per & nd & 0,003 & 0,034 & 0,012 & 0,035 & nd & nd & 0,020 & 0,022 \\
\hline I-Pi & 0,070 & 0,034 & 0,390 & 0,198 & 0,424 & 0,087 & 0,061 & 0,219 & 0,362 \\
\hline DBahA & 0,015 & 0,007 & 0,068 & 0,038 & 0,087 & 0,017 & 0,012 & 0,035 & 0,067 \\
\hline BghiPer & 0,077 & 0,033 & 0,368 & 0,213 & 0,447 & 0,101 & 0,089 & 0,212 & 0,356 \\
\hline 16 HPA & 0,49 & 0,15 & 1,98 & 1,19 & 2,13 & 0,49 & 0,66 & 1,45 & 1,61 \\
\hline$\Sigma$ HPA & 0,93 & 0,23 & 2,95 & 1,77 & 2,94 & 0,72 & 1,20 & 1,67 & 2,18 \\
\hline \%p-terfenil & 95 & 100 & 101 & 53 & 98 & 54 & 74 & 80 & 73 \\
\hline $2,6+3,5$ 2MFe & nd & nd & nd & nd & nd & nd & nd & nd & nd \\
\hline $1,72 \mathrm{MFe}$ & 0,022 & 0,004 & 0,037 & 0,015 & 0,022 & 0,010 & 0,015 & 0,025 & 0,012 \\
\hline $1,52 \mathrm{MFe}$ & 0,022 & 0,002 & 0,039 & 0,013 & 0,019 & 0,012 & nd & 0,049 & nd \\
\hline Acef & 0,012 & 0,001 & 0,020 & nd & 0,012 & 0,013 & 0,016 & 0,015 & 0,018 \\
\hline $\mathrm{BeFe}$ & nd & nd & nd & nd & nd & nd & nd & nd & nd \\
\hline $\mathrm{I}-\mathrm{Cr}$ & 0,033 & 0,018 & 0,159 & 0,075 & 0,147 & 0,034 & 0,029 & 0,084 & 0,175 \\
\hline DajA & 0,011 & 0,005 & 0,053 & 0,028 & 0,079 & 0,014 & 0,010 & 0,026 & 0,044 \\
\hline Pf & nd & 0,001 & 0,013 & nd & 0,014 & nd & nd & nd & 0,014 \\
\hline $\mathrm{BbCr}$ & nd & 0,003 & 0,021 & nd & 0,038 & 0,008 & nd & 0,014 & 0,028 \\
\hline Pc & nd & 0,005 & 0,065 & 0,021 & 0,076 & nd & nd & 0,035 & nd \\
\hline
\end{tabular}


Resultado de hidrocarbonetos aromáticos, em $\mathrm{ng} \mathrm{m}^{-3}$, para as amostras de material particulado atmosférico (PM 2,5) coletadas no ano de 2011

\begin{tabular}{|c|c|c|c|c|c|c|c|c|c|}
\hline Código & SE212 & SE218 & SE224 & SE230 & SE236 & SE242 & SE254 & SE260 & SE266 \\
\hline Data Início & 31-jul & 6-ago & 12-ago & 18-ago & 24-ago & 30 -ago & 11-set & 17-set & 23-set \\
\hline $\mathbf{N}$ & 0,062 & 0,030 & 0,034 & 0,028 & 0,044 & 0,058 & 0,032 & 0,037 & 0,027 \\
\hline $\mathrm{C} 1 \mathrm{~N}$ & 0,043 & 0,025 & 0,031 & 0,032 & 0,053 & 0,043 & nd & nd & nd \\
\hline $\mathrm{C} 2 \mathrm{~N}$ & 0,062 & 0,032 & 0,051 & 0,039 & 0,063 & 0,054 & 0,023 & 0,022 & 0,017 \\
\hline C3N & 0,020 & 0,014 & 0,026 & nd & 0,027 & nd & 0,010 & 0,008 & nd \\
\hline $\mathrm{C} 4 \mathrm{~N}$ & 0,015 & 0,016 & 0,024 & nd & 0,031 & nd & 0,008 & nd & nd \\
\hline ACF & 0,010 & nd & 0,009 & 0,010 & 0,009 & 0,010 & nd & nd & nd \\
\hline ACE & nd & nd & nd & nd & nd & nd & nd & nd & nd \\
\hline $\mathbf{F}$ & 0,010 & nd & 0,012 & 0,010 & 0,012 & 0,018 & nd & nd & nd \\
\hline C1F & nd & nd & 0,017 & nd & 0,017 & nd & nd & nd & nd \\
\hline $\mathrm{C} 2 \mathrm{~F}$ & 0,022 & nd & 0,024 & nd & 0,036 & nd & 0,018 & 0,014 & 0,014 \\
\hline C3F & nd & 0,011 & 0,009 & nd & 0,008 & nd & 0,050 & 0,037 & 0,057 \\
\hline DBT & 0,009 & nd & 0,009 & nd & 0,010 & 0,068 & nd & nd & nd \\
\hline C1DBT & 0,014 & 0,013 & 0,024 & nd & 0,021 & nd & 0,008 & nd & nd \\
\hline C2DBT & 0,022 & 0,021 & 0,049 & nd & 0,044 & nd & 0,017 & 0,012 & 0,015 \\
\hline C3DBT & 0,025 & 0,028 & 0,064 & nd & 0,046 & nd & 0,019 & 0,015 & 0,017 \\
\hline $\mathrm{Fe}$ & 0,045 & 0,021 & 0,068 & 0,020 & 0,069 & 0,238 & 0,022 & 0,018 & 0,017 \\
\hline C1Fe & 0,026 & 0,019 & 0,051 & nd & 0,058 & nd & 0,016 & 0,012 & 0,016 \\
\hline $\mathrm{C} 2 \mathrm{Fe}$ & 0,033 & 0,029 & 0,063 & nd & 0,072 & nd & 0,017 & 0,018 & 0,019 \\
\hline $\mathrm{C} 3 \mathrm{Fe}$ & 0,032 & 0,035 & 0,060 & nd & 0,082 & nd & 0,018 & 0,017 & 0,019 \\
\hline $\mathrm{C} 4 \mathrm{Fe}$ & 0,027 & 0,028 & 0,036 & nd & 0,043 & nd & 0,012 & 0,015 & 0,016 \\
\hline A & 0,012 & nd & 0,015 & 0,010 & 0,014 & 0,016 & nd & nd & nd \\
\hline FI & 0,056 & 0,056 & 0,061 & 0,036 & 0,059 & 0,151 & 0,020 & 0,024 & 0,033 \\
\hline $\mathbf{P i}$ & 0,035 & 0,028 & 0,046 & 0,028 & 0,036 & 0,129 & 0,025 & 0,040 & 0,045 \\
\hline C1Pi & 0,019 & 0,020 & 0,026 & nd & 0,022 & nd & 0,011 & 0,023 & 0,019 \\
\hline $\mathrm{C} 2 \mathrm{Pi}$ & 0,019 & 0,020 & 0,029 & nd & 0,025 & nd & 0,010 & 0,018 & 0,019 \\
\hline $\mathrm{BaA}$ & 0,021 & 0,019 & 0,050 & 0,041 & 0,028 & 0,102 & nd & 0,012 & 0,008 \\
\hline $\mathrm{Cr}$ & 0,066 & 0,082 & 0,104 & 0,107 & 0,092 & 0,196 & 0,018 & 0,054 & 0,054 \\
\hline $\mathrm{C} 1 \mathrm{Cr}$ & 0,027 & 0,022 & 0,078 & nd & 0,054 & nd & nd & 0,013 & 0,011 \\
\hline $\mathrm{C} 2 \mathrm{Cr}$ & 0,025 & 0,014 & 0,102 & nd & 0,048 & nd & nd & 0,011 & 0,016 \\
\hline BbFI & 0,497 & 0,458 & 0,982 & 0,729 & 0,352 & 0,441 & 0,075 & 0,230 & 0,166 \\
\hline BkFI & 0,097 & 0,084 & nd & 0,137 & 0,063 & 0,065 & 0,016 & 0,038 & 0,035 \\
\hline $\mathrm{BePi}$ & 0,202 & 0,209 & 0,377 & 0,329 & 0,121 & 0,160 & 0,037 & 0,104 & 0,063 \\
\hline $\mathrm{BaPi}$ & 0,130 & 0,103 & 0,437 & 0,220 & 0,073 & 0,124 & 0,007 & 0,065 & 0,031 \\
\hline Per & 0,039 & 0,027 & 0,103 & 0,059 & 0,017 & 0,055 & nd & 0,009 & nd \\
\hline I-Pi & 0,484 & 0,334 & 0,784 & 0,789 & 0,143 & 0,302 & 0,056 & 0,189 & 0,082 \\
\hline DBahA & 0,067 & 0,055 & 0,150 & 0,150 & 0,029 & 0,049 & 0,009 & 0,037 & 0,014 \\
\hline BghiPer & 0,462 & 0,363 & 0,755 & 0,794 & 0,157 & 0,301 & 0,057 & 0,192 & 0,074 \\
\hline 16 HPA & 2,05 & 1,63 & 3,51 & 3,11 & 1,18 & 2,20 & 0,34 & 0,94 & 0,59 \\
\hline$\Sigma$ HPA & 2,73 & 2,22 & 4,76 & 3,57 & 2,08 & 2,58 & 0,61 & 1,28 & 0,90 \\
\hline \%p-terfenil & 78 & 54 & 85 & 83 & 99 & 99 & 102 & 103 & 100 \\
\hline $2,6+3,52 \mathrm{MFe}$ & nd & nd & nd & nd & nd & 0,183 & nd & nd & nd \\
\hline 1,7 2MFe & 0,014 & 0,009 & 0,027 & 0,017 & 0,027 & 1,542 & 0,008 & 0,009 & 0,010 \\
\hline $1,52 \mathrm{MFe}$ & 0,024 & 0,017 & 0,031 & 0,017 & 0,067 & 0,719 & nd & nd & nd \\
\hline Acef & 0,019 & 0,016 & 0,021 & 0,015 & 0,018 & 0,032 & nd & nd & 0,005 \\
\hline $\mathrm{BeFe}$ & nd & nd & nd & nd & nd & 0,013 & nd & nd & nd \\
\hline $\mathrm{I}-\mathrm{Cr}$ & 0,217 & 0,112 & 0,426 & 0,420 & 0,063 & 0,110 & 0,027 & 0,083 & 0,039 \\
\hline DajA & 0,050 & 0,044 & 0,107 & 0,107 & 0,021 & 0,043 & 0,008 & 0,026 & nd \\
\hline Pf & 0,014 & 0,009 & 0,035 & 0,027 & nd & 0,012 & nd & nd & nd \\
\hline $\mathrm{BbCr}$ & 0,028 & 0,016 & 0,088 & 0,058 & 0,010 & 0,018 & nd & nd & nd \\
\hline Pc & 0,046 & nd & nd & nd & nd & nd & nd & nd & nd \\
\hline
\end{tabular}


Resultado de hidrocarbonetos aromáticos, em $\mathrm{ng} \mathrm{m}^{-3}$, para as amostras de material particulado atmosférico (PM 2,5) coletadas no ano de 2011

\begin{tabular}{|c|c|c|c|c|c|}
\hline Código & SE320 & SE326 & SE350 & SE356 & SE362 \\
\hline Data Início & 16-nov & 22-nov & 16-dez & 22-dez & 28-dez \\
\hline $\mathbf{N}$ & 0,089 & 1,089 & 0,122 & 0,062 & 0,085 \\
\hline C1N & 0,057 & 0,141 & 0,067 & 0,045 & 0,054 \\
\hline $\mathrm{C} 2 \mathrm{~N}$ & 0,046 & 0,041 & nd & 0,040 & 0,039 \\
\hline $\mathrm{C} 3 \mathrm{~N}$ & nd & nd & 0,014 & nd & nd \\
\hline C4N & nd & nd & 0,009 & nd & nd \\
\hline ACF & nd & 0,251 & nd & nd & nd \\
\hline ACE & nd & nd & nd & nd & nd \\
\hline $\mathbf{F}$ & nd & 0,114 & nd & nd & nd \\
\hline C1F & nd & nd & nd & nd & nd \\
\hline $\mathrm{C} 2 \mathrm{~F}$ & nd & nd & nd & 0,012 & 0,014 \\
\hline C3F & 0,071 & 0,136 & 0,106 & 0,045 & 0,077 \\
\hline DBT & nd & 0,026 & nd & nd & nd \\
\hline C1DBT & 0,013 & nd & 0,012 & 0,014 & 0,010 \\
\hline C2DBT & 0,021 & nd & 0,028 & 0,029 & 0,017 \\
\hline C3DBT & 0,035 & 0,017 & 0,034 & 0,037 & nd \\
\hline $\mathrm{Fe}$ & 0,021 & 0,451 & 0,017 & 0,020 & 0,012 \\
\hline C1Fe & 0,019 & 0,030 & 0,019 & 0,017 & nd \\
\hline $\mathrm{C} 2 \mathrm{Fe}$ & 0,016 & nd & 0,033 & 0,020 & nd \\
\hline $\mathrm{C} 3 \mathrm{Fe}$ & nd & nd & 0,029 & 0,013 & nd \\
\hline $\mathrm{C} 4 \mathrm{Fe}$ & nd & nd & 0,014 & nd & nd \\
\hline A & nd & 0,092 & nd & nd & nd \\
\hline FI & 0,039 & 0,260 & 0,014 & 0,071 & 0,025 \\
\hline $\mathbf{P i}$ & 0,019 & 0,228 & 0,015 & 0,044 & nd \\
\hline C1Pi & nd & 0,036 & 0,012 & 0,015 & nd \\
\hline $\mathrm{C} 2 \mathrm{Pi}$ & 0,014 & nd & 0,016 & nd & nd \\
\hline $\mathrm{BaA}$ & 0,018 & 0,082 & nd & nd & nd \\
\hline $\mathrm{Cr}$ & 0,081 & 0,066 & 0,031 & 0,070 & 0,032 \\
\hline $\mathrm{C} 1 \mathrm{Cr}$ & 0,036 & nd & 0,014 & 0,020 & 0,013 \\
\hline $\mathrm{C} 2 \mathrm{Cr}$ & 0,033 & nd & 0,013 & nd & 0,011 \\
\hline $\mathrm{BbFI}$ & 0,148 & 0,104 & 0,076 & 0,208 & 0,088 \\
\hline BkFI & 0,049 & 0,051 & 0,027 & 0,068 & 0,028 \\
\hline $\mathrm{BePi}$ & 0,083 & 0,047 & 0,036 & 0,102 & 0,040 \\
\hline $\mathrm{BaPi}$ & 0,053 & 0,084 & 0,022 & 0,075 & 0,022 \\
\hline Per & 0,018 & 0,027 & nd & 0,022 & 0,012 \\
\hline I-Pi & 0,065 & 0,040 & 0,055 & 0,107 & 0,043 \\
\hline DBahA & 0,025 & 0,019 & 0,010 & 0,030 & 0,021 \\
\hline BghiPer & 0,082 & 0,040 & 0,065 & 0,105 & 0,055 \\
\hline 16 HPA & 0,69 & 2,97 & 0,45 & 0,86 & 0,41 \\
\hline$\Sigma$ HPA & 1,15 & 3,47 & 0,91 & 1,29 & 0,70 \\
\hline \%p-terfenil & 92 & - & 98 & 90 & 85 \\
\hline $2,6+3,52 \mathrm{MFe}$ & 0,023 & $\mathrm{nd}$ & nd & 0,021 & 0,017 \\
\hline 1,7 2MFe & 0,019 & nd & 0,013 & 0,025 & nd \\
\hline 1,5 2MFe & nd & nd & 0,028 & nd & nd \\
\hline Acef & nd & 0,045 & nd & 0,022 & 0,016 \\
\hline $\mathrm{BeFe}$ & nd & nd & nd & nd & nd \\
\hline $\mathrm{I}-\mathrm{Cr}$ & 0,028 & 0,012 & 0,023 & 0,049 & 0,024 \\
\hline DajA & 0,023 & 0,019 & nd & 0,025 & 0,018 \\
\hline Pf & 0,020 & 0,017 & nd & 0,019 & nd \\
\hline $\mathrm{BbCr}$ & 0,019 & 0,017 & nd & 0,020 & 0,016 \\
\hline Pc & 0,023 & 0,018 & nd & 0,017 & 0,019 \\
\hline
\end{tabular}


DADOS DE HPAS EM AMOSTRAS DE ÓLEO 
Resultado de hidrocarbonetos aromáticos, em $\mu \mathrm{g} \mathrm{g}^{-1}$, para as amostras de petróleo e produtos de petróleo.

\begin{tabular}{|c|c|c|c|c|c|c|c|c|c|}
\hline Código & $\mathrm{BB}$ & $\mathrm{BB}$ & $\mathrm{V}$ & $\mathrm{V}$ & $\mathrm{Y}$ & $\mathrm{Y}$ & $\mathrm{U}$ & AA & AA \\
\hline $\mathbf{N}$ & 287 & 256 & 323 & 213 & 665 & 610 & 109 & 378 & 334 \\
\hline C1N & 511 & 446 & 803 & 548 & 2680 & 2506 & 453 & 1296 & 1155 \\
\hline $\mathrm{C} 2 \mathrm{~N}$ & 1017 & 917 & 2626 & 1933 & 3444 & 3124 & 941 & 2013 & 1816 \\
\hline C3N & 684 & 561 & 2361 & 1539 & 2227 & 1912 & 782 & 1646 & 1534 \\
\hline C4N & 363 & 352 & 1231 & 749 & 670 & 605 & 305 & 549 & 520 \\
\hline ACF & nd & nd & nd & nd & nd & nd & nd & 20 & 21 \\
\hline ACE & nd & nd & 16 & 13 & 27 & 27 & nd & 19 & 16 \\
\hline $\mathbf{F}$ & 35 & 32 & 129 & 100 & 170 & 165 & 25 & 60 & 56 \\
\hline C1F & 128 & 104 & 365 & 304 & 419 & 399 & 82 & 115 & 118 \\
\hline $\mathrm{C} 2 \mathrm{~F}$ & 290 & 260 & 706 & 521 & 643 & 610 & 217 & 200 & 205 \\
\hline C3F & 526 & 538 & 1054 & 767 & 656 & 628 & 307 & 258 & 270 \\
\hline DBT & 24 & 22 & 89 & 77 & 31 & 32 & 13 & 13 & 13 \\
\hline C1DBT & 80 & 74 & 227 & 207 & 138 & 140 & 50 & 59 & 67 \\
\hline C2DBT & 118 & 124 & 317 & 243 & 241 & 230 & 53 & 50 & 54 \\
\hline C3DBT & 103 & 96 & 206 & 178 & 199 & 203 & 102 & 78 & 68 \\
\hline $\mathrm{Fe}$ & 113 & 109 & 323 & 302 & 171 & 170 & 107 & 89 & 90 \\
\hline $\mathrm{C} 1 \mathrm{Fe}$ & 230 & 212 & 684 & 575 & 575 & 564 & 260 & 220 & 219 \\
\hline $\mathrm{C} 2 \mathrm{Fe}$ & 331 & 309 & 890 & 758 & 731 & 709 & 380 & 329 & 331 \\
\hline $\mathrm{C} 3 \mathrm{Fe}$ & 300 & 265 & 541 & 444 & 444 & 426 & 274 & 223 & 245 \\
\hline $\mathrm{C} 4 \mathrm{Fe}$ & 224 & 190 & 346 & 281 & 137 & 146 & 109 & 87 & 75 \\
\hline A & nd & nd & 19 & 16 & nd & nd & nd & nd & nd \\
\hline FI & nd & nd & 24 & 25 & nd & nd & 15 & 16 & 13 \\
\hline $\mathrm{Pi}$ & 25 & 20 & 47 & 41 & 28 & 25 & 14 & 14 & 13 \\
\hline C1Pi & 82 & 81 & 147 & 137 & 55 & 55 & 28 & 22 & 27 \\
\hline $\mathrm{C} 2 \mathrm{Pi}$ & 172 & 161 & 239 & 197 & 144 & 142 & 91 & 67 & 71 \\
\hline $\mathrm{BaA}$ & nd & nd & 9 & nd & 9 & nd & nd & nd & nd \\
\hline $\mathrm{Cr}$ & 72 & 62 & 118 & 118 & 45 & 43 & 36 & 17 & 20 \\
\hline $\mathrm{C} 1 \mathrm{Cr}$ & 98 & 90 & 158 & 141 & 78 & 73 & 52 & 24 & 25 \\
\hline $\mathrm{C} 2 \mathrm{Cr}$ & 178 & 167 & 223 & 188 & 77 & 77 & 52 & 31 & 30 \\
\hline $\mathrm{BbFI}$ & 15 & nd & nd & 10 & 12 & 12 & 13 & 10 & 11 \\
\hline BkFI & nd & nd & nd & nd & nd & nd & nd & nd & nd \\
\hline $\mathrm{BePi}$ & 29 & 22 & 29 & 27 & 19 & 17 & 12 & nd & nd \\
\hline $\mathrm{BaPi}$ & 20 & nd & 12 & nd & 9 & 11 & nd & nd & nd \\
\hline Per & 10 & nd & nd & 10 & nd & nd & 11 & nd & nd \\
\hline I-Pi & nd & nd & nd & nd & nd & nd & nd & nd & nd \\
\hline DBahA & nd & nd & nd & nd & nd & nd & nd & nd & nd \\
\hline BghiPer & nd & nd & nd & nd & nd & nd & nd & nd & nd \\
\hline 16 HPA & 567 & 478 & 1020 & 838 & 1136 & 1062 & 319 & 622 & 574 \\
\hline$\Sigma$ HPA & 6063 & 5471 & 14263 & 10663 & 14744 & 13660 & 4893 & 7902 & 7416 \\
\hline $2,6+3,5$ 2MFe & 66 & 54 & 197 & 155 & 111 & 108 & 49 & 27 & 26 \\
\hline $1,72 \mathrm{MFe}$ & 384 & 377 & 980 & 846 & 413 & 401 & 360 & 353 & 355 \\
\hline $1,52 \mathrm{MFe}$ & nd & nd & nd & nd & nd & nd & nd & nd & nd \\
\hline Acef & nd & nd & nd & nd & nd & nd & nd & nd & nd \\
\hline $\mathrm{BeFe}$ & nd & nd & nd & nd & nd & nd & nd & nd & nd \\
\hline $\mathrm{I}-\mathrm{Cr}$ & nd & nd & nd & nd & nd & nd & nd & nd & nd \\
\hline DajA & nd & nd & nd & nd & nd & nd & nd & nd & nd \\
\hline Pf & nd & nd & nd & nd & nd & nd & nd & nd & nd \\
\hline $\mathrm{BbCr}$ & nd & nd & nd & nd & nd & nd & nd & nd & nd \\
\hline Pc & nd & nd & nd & nd & nd & nd & nd & nd & nd \\
\hline Reteno & nd & nd & nd & nd & 13 & 24 & 19 & 47 & 48 \\
\hline
\end{tabular}


Resultado de hidrocarbonetos aromáticos, em $\mu \mathrm{g} \mathrm{g}^{-1}$, para as amostras de petróleo e produtos de petróleo.

\begin{tabular}{|c|c|c|c|c|c|c|c|c|c|}
\hline Código & $\overline{F F}$ & FF & DD & $\mathrm{DD}$ & $Z$ & $\bar{Z}$ & $\mathrm{~W}$ & $\mathrm{~W}$ & $\bar{T}$ \\
\hline $\mathbf{N}$ & 178 & 188 & 574 & 547 & 315 & 386 & 174 & 151 & 227 \\
\hline C1N & 875 & 976 & 1760 & 1610 & 1227 & 1503 & 709 & 638 & 938 \\
\hline $\mathrm{C} 2 \mathrm{~N}$ & 1582 & 1813 & 2211 & 1933 & 2022 & 2477 & 1707 & 1409 & 1771 \\
\hline C3N & 1463 & 1605 & 1256 & 1069 & 1432 & 1886 & 1357 & 1103 & 1572 \\
\hline $\mathrm{C} 4 \mathrm{~N}$ & 586 & 613 & 500 & 420 & 493 & 648 & 519 & 435 & 630 \\
\hline $\mathrm{ACF}$ & 17 & 19 & nd & nd & nd & nd & nd & nd & nd \\
\hline ACE & nd & 12 & 14 & 12 & 11 & 16 & 17 & 14 & nd \\
\hline F & 43 & 46 & 57 & 46 & 64 & 72 & 58 & 52 & 43 \\
\hline C1F & 123 & 133 & 222 & 171 & 187 & 226 & 205 & 171 & 166 \\
\hline $\mathrm{C} 2 \mathrm{~F}$ & 296 & 285 & 477 & 363 & 401 & 443 & 420 & 370 & 361 \\
\hline $\mathrm{C} 3 \mathrm{~F}$ & 422 & 484 & 444 & 379 & 415 & 532 & 478 & 389 & 485 \\
\hline DBT & 38 & 43 & 24 & 18 & 31 & 42 & 13 & 10 & 18 \\
\hline C1DBT & 123 & 126 & 63 & 47 & 95 & 117 & 48 & 40 & 79 \\
\hline C2DBT & 156 & 149 & 82 & 60 & 137 & 167 & 90 & 86 & 137 \\
\hline C3DBT & 107 & 152 & 96 & 71 & 117 & 155 & 108 & 100 & 149 \\
\hline $\mathrm{Fe}$ & 198 & 182 & 234 & 162 & 282 & 336 & 106 & 96 & 111 \\
\hline C1Fe & 497 & 497 & 519 & 373 & 617 & 739 & 369 & 336 & 386 \\
\hline $\mathrm{C} 2 \mathrm{Fe}$ & 740 & 775 & 638 & 424 & 780 & 909 & 540 & 477 & 654 \\
\hline $\mathrm{C} 3 \mathrm{Fe}$ & 591 & 536 & 346 & 250 & 458 & 585 & 388 & 309 & 504 \\
\hline $\mathrm{C} 4 \mathrm{Fe}$ & 190 & 213 & 124 & 90 & 168 & 225 & 122 & 106 & 208 \\
\hline A & nd & nd & nd & nd & 16 & nd & nd & 14 & 11 \\
\hline FI & 15 & nd & nd & nd & nd & nd & 19 & 19 & nd \\
\hline $\mathbf{P i}$ & 22 & 23 & 16 & 13 & 35 & 40 & 17 & 16 & 12 \\
\hline C1Pi & 49 & 49 & 26 & 20 & 54 & 67 & 31 & 26 & 30 \\
\hline $\mathrm{C} 2 \mathrm{Pi}$ & 149 & 143 & 81 & 64 & 149 & 180 & 75 & 67 & 111 \\
\hline $\mathrm{BaA}$ & 12 & 11 & nd & nd & 14 & 9 & nd & 13 & nd \\
\hline $\mathrm{Cr}$ & 55 & 44 & 40 & 31 & 66 & 78 & 23 & 26 & 29 \\
\hline $\mathrm{C} 1 \mathrm{Cr}$ & 80 & 80 & 58 & 42 & 83 & 98 & 41 & 37 & 55 \\
\hline $\mathrm{C} 2 \mathrm{Cr}$ & 67 & 73 & 59 & 48 & 101 & 113 & 50 & 43 & 65 \\
\hline $\mathrm{BbFI}$ & 12 & 11 & 14 & 14 & 15 & 18 & nd & 15 & 11 \\
\hline BkFI & nd & nd & nd & nd & nd & nd & nd & nd & nd \\
\hline $\mathrm{BePi}$ & 16 & 16 & 11 & nd & 19 & 26 & nd & nd & nd \\
\hline $\mathrm{BaPi}$ & nd & 14 & nd & nd & nd & 11 & nd & 12 & nd \\
\hline Per & 10 & nd & nd & nd & nd & 10 & nd & nd & nd \\
\hline I-Pi & nd & nd & nd & nd & nd & nd & nd & nd & nd \\
\hline DBahA & nd & nd & nd & nd & nd & nd & nd & nd & nd \\
\hline BghiPer & nd & nd & nd & nd & nd & nd & nd & nd & nd \\
\hline 16 HPA & 550 & 550 & 950 & 825 & 819 & 963 & 414 & 427 & 444 \\
\hline$\Sigma$ HPA & 8709 & 9312 & 9947 & 8277 & 9804 & 12113 & 7682 & 6581 & 8765 \\
\hline $2,6+3,5$ 2MFe & 73 & 70 & 131 & 89 & 110 & 137 & 88 & 79 & 76 \\
\hline $1,72 \mathrm{MFe}$ & 876 & 874 & 363 & 251 & 717 & 867 & 356 & 317 & 362 \\
\hline $1,52 \mathrm{MFe}$ & nd & nd & nd & nd & nd & nd & nd & nd & nd \\
\hline Acef & nd & nd & nd & nd & nd & nd & nd & nd & nd \\
\hline $\mathrm{BeFe}$ & nd & nd & nd & nd & nd & nd & nd & nd & nd \\
\hline $\mathrm{I}-\mathrm{Cr}$ & nd & nd & nd & nd & nd & nd & nd & nd & nd \\
\hline DajA & nd & nd & nd & nd & nd & nd & nd & nd & nd \\
\hline Pf & nd & nd & nd & nd & nd & nd & nd & nd & nd \\
\hline $\mathrm{BbCr}$ & nd & nd & nd & nd & nd & nd & nd & nd & nd \\
\hline Pc & nd & nd & nd & nd & nd & nd & nd & nd & nd \\
\hline Reteno & 17 & 17 & 16 & 14 & 13 & 14 & 18 & 14 & 13 \\
\hline
\end{tabular}


Resultado de hidrocarbonetos aromáticos, em $\mu \mathrm{g} \mathrm{g}^{-1}$, para as amostras de petróleo e produtos de petróleo.

\begin{tabular}{|c|c|c|c|c|c|c|c|c|c|}
\hline Código & $\mathrm{T}$ & A & A & B & B & C & C & $\mathrm{D}$ & $\mathrm{D}$ \\
\hline $\mathbf{N}$ & 319 & $\overline{14}$ & 20 & 345 & 347 & 284 & 259 & 497 & 517 \\
\hline C1N & 1138 & 42 & 57 & 1572 & 1561 & 1175 & 1102 & 1729 & 1812 \\
\hline $\mathrm{C} 2 \mathrm{~N}$ & 1982 & 266 & 310 & 2729 & 2760 & 2272 & 2146 & 2578 & 2669 \\
\hline C3N & 1747 & 559 & 764 & 2289 & 2257 & 2274 & 2175 & 1822 & 1914 \\
\hline $\mathrm{C} 4 \mathrm{~N}$ & 756 & 1078 & 1361 & 1398 & 1326 & 1374 & 1266 & 997 & 972 \\
\hline $\mathrm{ACF}$ & 18 & nd & nd & 19 & 19 & nd & nd & 19 & 19 \\
\hline ACE & nd & 28 & 29 & 10 & 12 & nd & nd & nd & 10 \\
\hline $\mathbf{F}$ & 47 & nd & 10 & 60 & 60 & 59 & 56 & 97 & 102 \\
\hline C1F & 167 & 206 & 216 & 176 & 166 & 179 & 178 & 217 & 220 \\
\hline $\mathrm{C} 2 \mathrm{~F}$ & 339 & 643 & 684 & 398 & 389 & 393 & 390 & 394 & 403 \\
\hline C3F & 455 & 753 & 851 & 530 & 450 & 557 & 498 & 372 & 356 \\
\hline DBT & 18 & 20 & 21 & 43 & 38 & 54 & 45 & 24 & 18 \\
\hline C1DBT & 73 & 215 & 223 & 125 & 134 & 162 & 166 & 68 & 64 \\
\hline C2DBT & 123 & 342 & 376 & 159 & 175 & 233 & 234 & 86 & 70 \\
\hline C3DBT & 129 & 303 & 300 & 127 & 140 & 208 & 192 & 69 & 59 \\
\hline $\mathrm{Fe}$ & 113 & 73 & 83 & 246 & 259 & 236 & 233 & 246 & 226 \\
\hline C1Fe & 367 & 490 & 552 & 118 & 120 & 620 & 606 & 118 & 104 \\
\hline $\mathrm{C} 2 \mathrm{Fe}$ & 579 & 1168 & 1213 & 919 & 854 & 976 & 945 & 648 & 584 \\
\hline C3Fe & 442 & 1070 & 1167 & 573 & 589 & 555 & 633 & 429 & 375 \\
\hline C4Fe & 191 & 407 & 459 & 252 & 265 & 229 & 252 & 175 & 132 \\
\hline A & 18 & nd & 8 & 26 & 23 & nd & nd & 22 & 23 \\
\hline FI & nd & nd & nd & nd & nd & nd & nd & 11 & nd \\
\hline $\mathbf{P i}$ & 10 & 48 & 41 & 23 & 19 & 24 & 25 & 20 & 18 \\
\hline C1Pi & 28 & 156 & 151 & 82 & 77 & 84 & 90 & 77 & 74 \\
\hline $\mathrm{C} 2 \mathrm{Pi}$ & 101 & 254 & 278 & 162 & 137 & 153 & 138 & 122 & 112 \\
\hline $\mathrm{BaA}$ & nd & 24 & 25 & 14 & 14 & 11 & nd & 11 & 11 \\
\hline $\mathrm{Cr}$ & 25 & 81 & 79 & 72 & 59 & 59 & 56 & 49 & 49 \\
\hline $\mathrm{C} 1 \mathrm{Cr}$ & 50 & 173 & 175 & 110 & 96 & 104 & 109 & 80 & 89 \\
\hline $\mathrm{C} 2 \mathrm{Cr}$ & 57 & 243 & 278 & 165 & 141 & 152 & 160 & 99 & 93 \\
\hline BbFI & 12 & nd & nd & 13 & 12 & nd & nd & 14 & 13 \\
\hline BkFI & nd & nd & nd & nd & nd & nd & nd & nd & nd \\
\hline $\mathrm{BePi}$ & 10 & 33 & 36 & 18 & 16 & 17 & 27 & 18 & 19 \\
\hline $\mathrm{BaPi}$ & nd & 14 & 11 & nd & nd & nd & nd & 9 & 8 \\
\hline Per & nd & nd & nd & nd & nd & nd & nd & nd & nd \\
\hline I-Pi & nd & nd & nd & nd & nd & nd & nd & nd & nd \\
\hline DBahA & nd & nd & nd & nd & nd & nd & nd & nd & nd \\
\hline BghiPer & nd & nd & nd & nd & nd & nd & nd & nd & nd \\
\hline 16 HPA & 560 & 283 & 307 & 827 & 823 & 673 & 629 & 993 & 995 \\
\hline$\Sigma$ HPA & 9311 & 8703 & 9779 & 12772 & 12514 & 12445 & 11980 & 11116 & 11134 \\
\hline $2,6+3,5$ 2MFe & 70 & 117 & 442 & 85 & 83 & 82 & 90 & 89 & 78 \\
\hline $1,72 \mathrm{MFe}$ & 330 & 468 & 494 & 974 & 995 & 585 & 609 & 615 & 537 \\
\hline 1,5 $2 \mathrm{MFe}$ & nd & 434 & 442 & nd & nd & 316 & 329 & nd & nd \\
\hline Acef & nd & nd & nd & nd & nd & nd & nd & nd & nd \\
\hline $\mathrm{BeFe}$ & nd & nd & nd & nd & nd & nd & nd & nd & nd \\
\hline $\mathrm{I}-\mathrm{Cr}$ & nd & nd & nd & nd & nd & nd & nd & nd & nd \\
\hline DajA & nd & nd & nd & nd & nd & nd & nd & nd & nd \\
\hline Pf & nd & nd & nd & nd & nd & nd & nd & nd & nd \\
\hline $\mathrm{BbCr}$ & nd & nd & nd & nd & nd & nd & nd & nd & nd \\
\hline Pc & nd & nd & nd & nd & nd & nd & nd & nd & nd \\
\hline Reteno & 14 & 11 & 20 & nd & nd & nd & nd & 16 & 12 \\
\hline
\end{tabular}


Resultado de hidrocarbonetos aromáticos, em $\mu \mathrm{g} \mathrm{g}^{-1}$, para as amostras de petróleo e produtos de petróleo.

\begin{tabular}{|c|c|c|c|c|c|c|c|c|c|}
\hline Código & $E$ & $\mathrm{E}$ & $\mathrm{F}$ & $\mathrm{F}$ & $\mathrm{G}$ & $\mathrm{G}$ & $\mathrm{H}$ & $\mathrm{H}$ & 1 \\
\hline $\mathbf{N}$ & 270 & 298 & 277 & 230 & 261 & 198 & 275 & 341 & 44 \\
\hline C1N & 1220 & 1331 & 1068 & 923 & 917 & 705 & 1256 & 1516 & 176 \\
\hline $\mathrm{C} 2 \mathrm{~N}$ & 2201 & 2468 & 2145 & 1778 & 1796 & 1381 & 2176 & 2569 & 1433 \\
\hline C3N & 1939 & 2047 & 2002 & 1769 & 2003 & 1736 & 1876 & 2251 & 1336 \\
\hline $\mathrm{C} 4 \mathrm{~N}$ & 124 & 143 & 1457 & 1201 & 1164 & 1067 & 124 & 151 & 830 \\
\hline ACF & 19 & 23 & 14 & 13 & nd & nd & 19 & 21 & nd \\
\hline ACE & nd & nd & nd & nd & nd & nd & nd & nd & 12 \\
\hline $\mathbf{F}$ & 62 & 66 & 42 & 36 & 28 & 29 & 60 & 69 & 70 \\
\hline C1F & 167 & 186 & 156 & 151 & 125 & 106 & 173 & 192 & 194 \\
\hline $\mathrm{C} 2 \mathrm{~F}$ & 377 & 405 & 384 & 318 & 277 & 272 & 349 & 415 & 436 \\
\hline C3F & 400 & 557 & 455 & 386 & 381 & 338 & 454 & 551 & 469 \\
\hline DBT & 49 & 59 & 22 & 18 & 22 & 18 & 46 & 65 & 19 \\
\hline C1DBT & 152 & 169 & 75 & 70 & 92 & 83 & 153 & 203 & 93 \\
\hline C2DBT & 166 & 200 & 137 & 116 & 130 & 119 & 166 & 220 & 131 \\
\hline C3DBT & 159 & 174 & 135 & 113 & 114 & 115 & 150 & 198 & 92 \\
\hline $\mathrm{Fe}$ & 236 & 259 & 104 & 92 & 172 & 154 & 231 & 292 & 320 \\
\hline C1Fe & 605 & 639 & 63 & 57 & 445 & 384 & 556 & 675 & 134 \\
\hline $\mathrm{C} 2 \mathrm{Fe}$ & 820 & 863 & 531 & 465 & 752 & 714 & 814 & 983 & 720 \\
\hline $\mathrm{C} 3 \mathrm{Fe}$ & 506 & 622 & 469 & 475 & 615 & 559 & 618 & 698 & 531 \\
\hline $\mathrm{C} 4 \mathrm{Fe}$ & 214 & 224 & 222 & 193 & 255 & 259 & 212 & 287 & 253 \\
\hline A & 14 & nd & 20 & 14 & nd & nd & nd & 21 & 17 \\
\hline FI & nd & nd & nd & nd & nd & nd & 13 & nd & 13 \\
\hline $\mathbf{P i}$ & 29 & 27 & 10 & 9 & 10 & 11 & 24 & 32 & 62 \\
\hline C1Pi & 58 & 73 & 49 & 41 & 66 & 63 & 60 & 79 & 117 \\
\hline $\mathrm{C} 2 \mathrm{Pi}$ & 175 & 217 & 91 & 87 & 117 & 117 & 178 & 225 & 166 \\
\hline $\mathrm{BaA}$ & 13 & 16 & nd & 7 & 11 & 11 & 10 & 18 & 15 \\
\hline $\mathrm{Cr}$ & 58 & 73 & 27 & 24 & 40 & 39 & 61 & 72 & 81 \\
\hline $\mathrm{C} 1 \mathrm{Cr}$ & 101 & 114 & 57 & 48 & 85 & 83 & 97 & 128 & 116 \\
\hline $\mathrm{C} 2 \mathrm{Cr}$ & 123 & 147 & 78 & 68 & 129 & 122 & 121 & 151 & 129 \\
\hline BbFI & 13 & 15 & 10 & 9 & nd & nd & 15 & 16 & 25 \\
\hline BkFI & nd & nd & nd & nd & nd & nd & nd & nd & nd \\
\hline $\mathrm{BePi}$ & 18 & 21 & 8 & nd & 13 & 13 & 19 & 22 & 32 \\
\hline $\mathrm{BaPi}$ & 11 & 12 & nd & nd & nd & 12 & 12 & nd & 12 \\
\hline Per & nd & nd & nd & nd & nd & nd & nd & nd & nd \\
\hline I-Pi & nd & nd & nd & nd & nd & nd & nd & nd & nd \\
\hline DBahA & nd & nd & nd & nd & nd & nd & nd & nd & nd \\
\hline BghiPer & nd & nd & nd & nd & nd & nd & nd & nd & nd \\
\hline 16 HPA & 726 & 787 & 504 & 434 & 523 & 454 & 719 & 883 & 670 \\
\hline$\Sigma$ HPA & 10302 & 11445 & 10110 & 8710 & 10022 & 8707 & 10316 & 12462 & 8078 \\
\hline $2,6+3,52 \mathrm{MFe}$ & 80 & 86 & 61 & 55 & 62 & 57 & 79 & 94 & 121 \\
\hline $1,72 \mathrm{MFe}$ & 968 & 1080 & 323 & 278 & 446 & 401 & 948 & 1194 & 610 \\
\hline $1,52 \mathrm{MFe}$ & nd & nd & nd & nd & 271 & 237 & nd & nd & nd \\
\hline Acef & nd & nd & nd & nd & nd & nd & nd & nd & nd \\
\hline $\mathrm{BeFe}$ & nd & nd & nd & nd & nd & nd & nd & nd & nd \\
\hline $\mathrm{I}-\mathrm{Cr}$ & nd & nd & nd & nd & nd & nd & nd & nd & nd \\
\hline DajA & nd & nd & nd & nd & nd & nd & nd & nd & nd \\
\hline Pf & nd & nd & nd & nd & nd & nd & nd & nd & nd \\
\hline $\mathrm{BbCr}$ & nd & nd & nd & nd & nd & nd & nd & nd & nd \\
\hline $\mathrm{Pc}$ & nd & nd & nd & nd & nd & nd & nd & nd & nd \\
\hline Reteno & 19 & 20 & 10 & nd & nd & nd & 17 & 22 & nd \\
\hline
\end{tabular}


Resultado de hidrocarbonetos aromáticos, em $\mu \mathrm{g} \mathrm{g}^{-1}$, para as amostras de petróleo e produtos de petróleo.

\begin{tabular}{|c|c|c|c|c|c|c|c|c|c|}
\hline Código & 1 & $\mathrm{~J}$ & $\mathrm{~J}$ & $\mathrm{~K}$ & $\mathrm{~K}$ & $\mathrm{~L}$ & $\bar{L}$ & $\bar{M}$ & $\mathrm{M}$ \\
\hline $\mathbf{N}$ & 72 & 156 & 180 & 175 & 207 & 172 & 176 & 228 & 243 \\
\hline C1N & 242 & 663 & 743 & 953 & 1107 & 743 & 757 & 1100 & 1178 \\
\hline $\mathrm{C} 2 \mathrm{~N}$ & 1818 & 1195 & 1349 & 1881 & 2080 & 1330 & 1348 & 2060 & 2283 \\
\hline C3N & 1611 & 950 & 1044 & 1684 & 1955 & 1281 & 1333 & 1776 & 1816 \\
\hline C4N & 992 & 522 & 591 & 1159 & 1216 & 748 & 782 & 1166 & 1208 \\
\hline ACF & nd & nd & nd & 16 & nd & nd & nd & 17 & 18 \\
\hline ACE & 16 & nd & nd & nd & 10 & nd & nd & 11 & 12 \\
\hline F & 79 & 31 & 25 & 42 & 53 & 31 & 38 & 54 & 58 \\
\hline C1F & 208 & 79 & 79 & 120 & 139 & 180 & 173 & 147 & 155 \\
\hline $\mathrm{C} 2 \mathrm{~F}$ & 481 & 180 & 180 & 320 & 323 & 482 & 457 & 383 & 370 \\
\hline $\mathrm{C} 3 \mathrm{~F}$ & 472 & 69 & 73 & 410 & 405 & 572 & 511 & 441 & 414 \\
\hline DBT & 21 & nd & nd & 38 & 38 & nd & nd & 41 & 41 \\
\hline C1DBT & 89 & 34 & 33 & 128 & 131 & 42 & 45 & 144 & 131 \\
\hline C2DBT & 133 & 52 & 48 & 160 & 159 & 109 & 113 & 178 & 174 \\
\hline C3DBT & 94 & 59 & 35 & 135 & 136 & 113 & 107 & 168 & 172 \\
\hline $\mathrm{Fe}$ & 320 & 109 & 115 & 212 & 223 & 104 & 97 & 237 & 217 \\
\hline C1Fe & 132 & 39 & 37 & 100 & 99 & 364 & 345 & 126 & 113 \\
\hline $\mathrm{C} 2 \mathrm{Fe}$ & 713 & 300 & 326 & 725 & 762 & 672 & 612 & 876 & 818 \\
\hline $\mathrm{C} 3 \mathrm{Fe}$ & 563 & 200 & 238 & 533 & 533 & 514 & 438 & 665 & 600 \\
\hline $\mathrm{C} 4 \mathrm{Fe}$ & 223 & 76 & 94 & 242 & 242 & 171 & 160 & 262 & 246 \\
\hline A & 13 & nd & 13 & 20 & 18 & nd & nd & 22 & 19 \\
\hline FI & 16 & nd & nd & nd & 12 & nd & nd & nd & nd \\
\hline $\mathbf{P i}$ & 62 & 11 & 8 & 19 & 20 & 20 & 9 & 24 & 24 \\
\hline C1Pi & 104 & 26 & 24 & 75 & 68 & 55 & 52 & 97 & 78 \\
\hline $\mathrm{C} 2 \mathrm{Pi}$ & 155 & 43 & 41 & 125 & 111 & 97 & 84 & 165 & 147 \\
\hline $\mathrm{BaA}$ & 12 & nd & nd & 14 & 16 & nd & nd & 15 & 14 \\
\hline $\mathrm{Cr}$ & 72 & 39 & 36 & 53 & 53 & 15 & 14 & 64 & 60 \\
\hline $\mathrm{C} 1 \mathrm{Cr}$ & 105 & 40 & 41 & 93 & 89 & 44 & 40 & 115 & 98 \\
\hline $\mathrm{C} 2 \mathrm{Cr}$ & 136 & 46 & 41 & 144 & 141 & 67 & 64 & 158 & 136 \\
\hline $\mathrm{BbFI}$ & 24 & nd & nd & 11 & 13 & nd & nd & 14 & 12 \\
\hline BkFI & nd & nd & nd & nd & nd & nd & nd & nd & nd \\
\hline $\mathrm{BePi}$ & 36 & nd & 11 & 15 & 14 & nd & nd & 20 & 18 \\
\hline $\mathrm{BaPi}$ & 12 & nd & nd & nd & nd & nd & nd & nd & nd \\
\hline Per & nd & nd & nd & nd & nd & nd & nd & nd & nd \\
\hline I-Pi & nd & nd & nd & nd & nd & nd & nd & nd & nd \\
\hline DBahA & nd & nd & nd & nd & nd & nd & nd & nd & nd \\
\hline BghiPer & nd & nd & nd & nd & nd & nd & nd & nd & nd \\
\hline $16 \mathrm{HPA}$ & 700 & 345 & 378 & 563 & 624 & 343 & 335 & 687 & 675 \\
\hline$\Sigma$ HPA & 9028 & 4916 & 5408 & 9603 & 10374 & 7927 & 7756 & 10776 & 10870 \\
\hline $2,6+3,5$ 2MFe & 122 & 30 & 32 & 74 & 78 & 97 & 89 & 92 & 82 \\
\hline 1,7 2MFe & 585 & 228 & 230 & 846 & 863 & 273 & 251 & 992 & 876 \\
\hline 1,5 $2 \mathrm{MFe}$ & nd & nd & nd & nd & nd & 243 & 222 & nd & nd \\
\hline Acef & nd & nd & nd & nd & nd & nd & nd & nd & nd \\
\hline BeFe & nd & nd & nd & nd & nd & nd & nd & nd & nd \\
\hline $\mathrm{I}-\mathrm{Cr}$ & nd & nd & nd & nd & nd & nd & nd & nd & nd \\
\hline DajA & nd & nd & nd & nd & nd & nd & nd & nd & nd \\
\hline Pf & nd & nd & nd & nd & nd & nd & nd & nd & nd \\
\hline $\mathrm{BbCr}$ & nd & nd & nd & nd & nd & nd & nd & nd & nd \\
\hline Pc & nd & nd & nd & nd & nd & nd & nd & nd & nd \\
\hline Reteno & nd & nd & nd & 9 & 9 & nd & nd & nd & nd \\
\hline
\end{tabular}


Resultado de hidrocarbonetos aromáticos, em $\mu \mathrm{g} \mathrm{g}^{-1}$, para as amostras de petróleo e produtos de petróleo.

\begin{tabular}{|c|c|c|c|c|c|c|c|c|c|}
\hline Código & $\mathrm{N}$ & $\mathrm{N}$ & 0 & 0 & $\mathrm{P}$ & $\mathrm{P}$ & $\bar{Q}$ & $\mathrm{Q}$ & $\mathrm{R}$ \\
\hline $\mathrm{N}$ & 457 & 463 & 649 & 481 & 602 & 669 & 193 & 164 & 313 \\
\hline C1N & 870 & 897 & 2082 & 1685 & 2416 & 2689 & 785 & 655 & 1463 \\
\hline $\mathrm{C} 2 \mathrm{~N}$ & 1243 & 1167 & 3083 & 2681 & 3969 & 4580 & 1895 & 1533 & 2764 \\
\hline C3N & 1374 & 1418 & 2391 & 2293 & 3299 & 3667 & 1406 & 1192 & 2966 \\
\hline $\mathrm{C} 4 \mathrm{~N}$ & 884 & 894 & 202 & 222 & 1487 & 1719 & 770 & 772 & 1519 \\
\hline $\mathrm{ACF}$ & nd & nd & nd & nd & nd & nd & nd & nd & nd \\
\hline ACE & nd & nd & nd & nd & nd & nd & 13 & 13 & nd \\
\hline $\mathrm{F}$ & 24 & 27 & 59 & 48 & 141 & 148 & 70 & 62 & 64 \\
\hline C1F & 104 & 115 & 204 & 188 & 415 & 391 & 189 & 177 & 237 \\
\hline $\mathrm{C} 2 \mathrm{~F}$ & 278 & 271 & 383 & 390 & 771 & 765 & 492 & 416 & 539 \\
\hline $\mathrm{C} 3 \mathrm{~F}$ & 371 & 404 & 424 & 432 & 710 & 662 & 466 & 465 & 608 \\
\hline DBT & 34 & 37 & 18 & 18 & 14 & 17 & 12 & 11 & 50 \\
\hline C1DBT & 55 & 59 & 80 & 73 & 90 & 95 & 53 & 46 & 167 \\
\hline C2DBT & 83 & 87 & 114 & 108 & 134 & 115 & 113 & 102 & 249 \\
\hline C3DBT & 76 & 86 & 118 & 99 & 133 & 109 & 130 & 104 & 196 \\
\hline $\mathrm{Fe}$ & 219 & 230 & 108 & 99 & 427 & 434 & 116 & 108 & 307 \\
\hline $\mathrm{C} 1 \mathrm{Fe}$ & 366 & 397 & 352 & 352 & 1190 & 1186 & 80 & 79 & 915 \\
\hline $\mathrm{C} 2 \mathrm{Fe}$ & 440 & 541 & 522 & 540 & 1506 & 1502 & 559 & 528 & 1312 \\
\hline $\mathrm{C} 3 \mathrm{Fe}$ & 371 & 407 & 394 & 397 & 981 & 937 & 399 & 415 & 810 \\
\hline $\mathrm{C} 4 \mathrm{Fe}$ & 183 & 174 & 147 & 175 & 286 & 287 & 154 & 128 & 310 \\
\hline A & nd & nd & nd & nd & nd & nd & 18 & 19 & nd \\
\hline FI & 44 & nd & nd & nd & nd & nd & 14 & 11 & nd \\
\hline $\mathrm{Pi}$ & 222 & nd & 12 & 10 & 22 & 19 & 21 & 15 & 24 \\
\hline C1Pi & 39 & 40 & 18 & 24 & 93 & 106 & 60 & 44 & 83 \\
\hline $\mathrm{C} 2 \mathrm{Pi}$ & 63 & 70 & 54 & 76 & 170 & 188 & 84 & nd & 173 \\
\hline $\mathrm{BaA}$ & nd & nd & nd & nd & nd & nd & nd & 8 & nd \\
\hline $\mathrm{Cr}$ & 41 & 48 & 23 & 19 & 89 & 89 & 30 & 22 & 70 \\
\hline $\mathrm{C} 1 \mathrm{Cr}$ & 48 & 57 & 36 & 36 & 141 & 146 & 55 & 47 & 122 \\
\hline $\mathrm{C} 2 \mathrm{Cr}$ & 78 & 71 & 41 & 49 & 169 & 164 & 69 & 58 & 176 \\
\hline BbFI & nd & nd & nd & 9 & nd & nd & 12 & 11 & nd \\
\hline BkFI & nd & nd & nd & nd & nd & nd & nd & nd & nd \\
\hline $\mathrm{BePi}$ & 10 & 12 & nd & nd & 24 & 29 & nd & nd & 27 \\
\hline $\mathrm{BaPi}$ & nd & nd & nd & nd & nd & nd & nd & 9 & nd \\
\hline Per & nd & nd & nd & nd & nd & nd & 11 & 10 & nd \\
\hline I-Pi & nd & nd & nd & nd & nd & nd & nd & nd & nd \\
\hline DBahA & nd & nd & nd & nd & nd & nd & nd & nd & nd \\
\hline BghiPer & nd & nd & nd & nd & nd & nd & nd & nd & nd \\
\hline $16 \mathrm{HPA}$ & 1007 & 768 & 851 & 666 & 1283 & 1359 & 487 & 443 & 779 \\
\hline$\Sigma$ HPA & 7978 & 7971 & 11517 & 10502 & 19281 & 20712 & 8267 & 7224 & 15465 \\
\hline $2,6+3,52 \mathrm{MFe}$ & 40 & 45 & 88 & 95 & 510 & 484 & 88 & 83 & 429 \\
\hline 1,7 2MFe & 227 & 245 & 260 & 261 & 721 & 682 & 405 & 370 & 721 \\
\hline $1,52 \mathrm{MFe}$ & 252 & 279 & nd & nd & 510 & 484 & nd & nd & 429 \\
\hline Acef & nd & nd & nd & nd & nd & nd & nd & nd & nd \\
\hline $\mathrm{BeFe}$ & nd & nd & nd & nd & nd & nd & nd & nd & nd \\
\hline $\mathrm{I}-\mathrm{Cr}$ & nd & nd & nd & nd & nd & nd & nd & nd & nd \\
\hline DajA & nd & nd & nd & nd & nd & nd & nd & nd & nd \\
\hline Pf & nd & nd & nd & nd & nd & nd & nd & nd & nd \\
\hline $\mathrm{BbCr}$ & nd & nd & nd & nd & nd & nd & nd & nd & nd \\
\hline Pc & nd & nd & nd & nd & nd & nd & nd & nd & nd \\
\hline Reteno & nd & nd & 17 & 13 & nd & nd & nd & nd & nd \\
\hline
\end{tabular}


Resultado de hidrocarbonetos aromáticos, em $\mu \mathrm{g} \mathrm{g}^{-1}$, para as amostras de petróleo e produtos de petróleo.

\begin{tabular}{|c|c|c|c|c|c|c|c|}
\hline Código & $\mathrm{R}$ & $S$ & $\mathrm{~S}$ & $\mathrm{CC}$ & $\mathrm{CC}$ & $\mathrm{EE}$ & $\mathrm{EE}$ \\
\hline $\mathbf{N}$ & 258 & 134 & 122 & 935 & 1002 & 13 & 10 \\
\hline C1N & 1467 & 600 & 553 & 1175 & 1292 & 84 & 78 \\
\hline $\mathrm{C} 2 \mathrm{~N}$ & 2879 & 1170 & 1068 & 995 & 1073 & 388 & 358 \\
\hline C3N & 2727 & 945 & 892 & 475 & 522 & 597 & 496 \\
\hline $\mathrm{C} 4 \mathrm{~N}$ & 1436 & 576 & 524 & 279 & 276 & 762 & 747 \\
\hline ACF & nd & nd & nd & 10 & 13 & nd & nd \\
\hline ACE & nd & nd & nd & 16 & 18 & 19 & 17 \\
\hline $\mathbf{F}$ & 65 & 32 & 34 & 25 & 26 & 69 & 65 \\
\hline C1F & 247 & 71 & 82 & 35 & 34 & 175 & 166 \\
\hline $\mathrm{C} 2 \mathrm{~F}$ & 554 & 189 & 231 & 48 & 48 & 339 & 311 \\
\hline $\mathrm{C} 3 \mathrm{~F}$ & 705 & 204 & 259 & nd & nd & 329 & 292 \\
\hline DBT & 48 & 10 & 10 & nd & nd & 26 & 25 \\
\hline C1DBT & 172 & 34 & 36 & 11 & 14 & 91 & 73 \\
\hline C2DBT & 231 & 43 & 48 & 17 & 20 & 104 & 96 \\
\hline C3DBT & 218 & 51 & 49 & nd & nd & 81 & 73 \\
\hline $\mathrm{Fe}$ & 309 & 120 & 127 & 21 & 21 & 135 & 115 \\
\hline C1Fe & 900 & 49 & 53 & nd & nd & 30 & 26 \\
\hline $\mathrm{C} 2 \mathrm{Fe}$ & 1365 & 324 & 362 & 26 & 27 & 477 & 405 \\
\hline C3Fe & 816 & 227 & 292 & 23 & 26 & 367 & 328 \\
\hline $\mathrm{C} 4 \mathrm{Fe}$ & 276 & 80 & 99 & 10 & 11 & 164 & 136 \\
\hline A & nd & 11 & nd & 10 & 10 & 20 & 16 \\
\hline FI & nd & nd & 22 & 8 & 9 & 14 & 12 \\
\hline $\mathbf{P i}$ & 25 & 9 & 48 & nd & nd & 15 & 13 \\
\hline C1Pi & nd & 29 & 26 & 9 & nd & 65 & 62 \\
\hline $\mathrm{C} 2 \mathrm{Pi}$ & 170 & 48 & 49 & nd & nd & 112 & 100 \\
\hline $\mathrm{BaA}$ & nd & nd & nd & nd & nd & 11 & 10 \\
\hline $\mathrm{Cr}$ & 63 & 39 & 43 & nd & nd & 30 & 26 \\
\hline $\mathrm{C} 1 \mathrm{Cr}$ & 130 & 46 & 52 & nd & nd & 54 & 45 \\
\hline $\mathrm{C} 2 \mathrm{Cr}$ & 170 & 45 & 69 & 8 & nd & 64 & 56 \\
\hline $\mathrm{BbFI}$ & nd & nd & 9 & nd & nd & 11 & 11 \\
\hline BkFI & nd & nd & nd & nd & nd & nd & nd \\
\hline $\mathrm{BePi}$ & 25 & 12 & 12 & nd & nd & 11 & 10 \\
\hline $\mathrm{BaPi}$ & nd & nd & nd & nd & nd & nd & nd \\
\hline Per & nd & nd & nd & nd & nd & nd & nd \\
\hline I-Pi & nd & nd & nd & nd & nd & nd & nd \\
\hline DBahA & nd & nd & nd & nd & nd & nd & nd \\
\hline BghiPer & nd & nd & nd & nd & nd & nd & nd \\
\hline $16 \mathrm{HPA}$ & 721 & 345 & 405 & 1025 & 1098 & 337 & 297 \\
\hline$\Sigma$ HPA & 15255 & 5099 & 5174 & 4135 & 4441 & 4657 & 4179 \\
\hline $2,6+3,52 \mathrm{MFe}$ & 430 & 39 & 44 & nd & nd & 35 & 29 \\
\hline $1,72 \mathrm{MFe}$ & 710 & 231 & 260 & 22 & 23 & 435 & 372 \\
\hline $1,52 \mathrm{MFe}$ & 430 & nd & nd & nd & nd & nd & nd \\
\hline Acef & nd & nd & nd & nd & nd & nd & nd \\
\hline $\mathrm{BeFe}$ & nd & nd & nd & nd & nd & nd & nd \\
\hline $\mathrm{I}-\mathrm{Cr}$ & nd & nd & nd & nd & nd & nd & nd \\
\hline DajA & nd & nd & nd & nd & nd & nd & nd \\
\hline $\mathrm{Pf}$ & nd & nd & nd & nd & nd & nd & nd \\
\hline $\mathrm{BbCr}$ & nd & nd & nd & nd & nd & nd & nd \\
\hline Pc & nd & nd & nd & nd & nd & nd & nd \\
\hline Reteno & nd & nd & nd & nd & nd & 24 & 21 \\
\hline
\end{tabular}


DADOS DE AROMÁTICOS EM AMOSTRAS SEDIMENTO 
Resultado de hidrocarbonetos aromáticos, em $\mathrm{ng}^{-1}$, para as amostras sedimento coletadas na Baia de Guanabara.

\begin{tabular}{|c|c|c|c|c|c|c|}
\hline Código & P1 & P2 & P3 & P4 & P5 & P6 \\
\hline $\mathbf{N}$ & 7,64 & 16,75 & 5,73 & 7,64 & 6,28 & nd \\
\hline C1N & 9,15 & 13,71 & 11,52 & 14,19 & 10,37 & 1,04 \\
\hline $\mathrm{C} 2 \mathrm{~N}$ & 8,73 & 118,50 & 24,01 & 13,54 & 16,95 & 4,71 \\
\hline C3N & 5,21 & 212,03 & 25,53 & 8,81 & 16,67 & 3,29 \\
\hline $\mathrm{C} 4 \mathrm{~N}$ & 6,87 & 348,39 & 49,05 & 12,29 & 24,30 & 10,53 \\
\hline ACF & 10,13 & 362,88 & 50,33 & 10,18 & 33,58 & 11,17 \\
\hline ACE & 1,81 & 80,30 & 2,97 & 5,61 & 2,19 & nd \\
\hline $\mathbf{F}$ & 2,98 & 85,76 & 12,16 & 9,68 & 9,18 & 1,42 \\
\hline C1F & 5,49 & 255,73 & 33,26 & 15,53 & 25,06 & 11,64 \\
\hline $\mathrm{C} 2 \mathrm{~F}$ & 23,72 & 468,38 & 120,75 & 56,87 & 102,57 & 41,34 \\
\hline C3F & 56,69 & 877,40 & 186,20 & 102,11 & 144,16 & 95,26 \\
\hline DBT & 2,31 & 125,61 & 13,09 & 8,96 & 9,04 & 3,83 \\
\hline C1DBT & 7,17 & 511,06 & 45,74 & 17,56 & 28,13 & 13,00 \\
\hline C2DBT & 24,15 & 1495,59 & 141,40 & 42,48 & 88,25 & 39,07 \\
\hline C3DBT & 40,35 & 1970,35 & 174,83 & 46,98 & 101,95 & 61,67 \\
\hline $\mathrm{Fe}$ & 22,95 & 439,63 & 69,68 & 126,34 & 52,12 & 21,50 \\
\hline C1Fe & 38,06 & 1498,32 & 140,61 & 88,38 & 114,63 & 41,14 \\
\hline $\mathrm{C} 2 \mathrm{Fe}$ & 64,34 & 2181,90 & 236,00 & 113,68 & 172,28 & 70,48 \\
\hline $\mathrm{C} 3 \mathrm{Fe}$ & 47,24 & 1654,54 & 195,07 & 68,11 & 121,77 & 68,91 \\
\hline $\mathrm{C} 4 \mathrm{Fe}$ & 19,63 & 910,61 & 93,54 & 31,35 & 62,00 & 52,68 \\
\hline A & 8,40 & 390,19 & 60,27 & 30,81 & 34,19 & 10,63 \\
\hline FI & 119,97 & 3055,01 & 240,46 & 315,92 & 148,36 & 77,88 \\
\hline $\mathbf{P i}$ & 102,62 & 4067,79 & 302,34 & 266,62 & 145,00 & 97,97 \\
\hline C1Pi & 77,75 & 4211,88 & 282,56 & 164,84 & 153,63 & 81,94 \\
\hline $\mathrm{C} 2 \mathrm{Pi}$ & 43,13 & 2285,02 & 175,31 & 80,03 & 102,21 & 88,76 \\
\hline $\mathrm{BaA}$ & 87,10 & 2382,15 & 190,52 & 186,11 & 124,15 & 68,80 \\
\hline $\mathrm{Cr}$ & 71,80 & 1977,33 & 142,54 & 156,39 & 100,37 & 59,22 \\
\hline $\mathrm{C} 1 \mathrm{Cr}$ & 44,75 & 1943,49 & 174,32 & 82,84 & 118,13 & 74,80 \\
\hline $\mathrm{C} 2 \mathrm{Cr}$ & 23,74 & 871,10 & 122,90 & 37,87 & 90,90 & 78,52 \\
\hline $\mathrm{BbFI}$ & 125,52 & 2632,55 & 362,45 & 213,68 & 224,31 & 107,96 \\
\hline BkFI & 39,41 & 1074,80 & 108,51 & 62,73 & 67,74 & 37,91 \\
\hline $\mathrm{BePi}$ & 58,96 & 1358,00 & 164,42 & 89,62 & 97,36 & 50,90 \\
\hline $\mathrm{BaPi}$ & 90,37 & 1919,64 & 232,63 & 125,70 & 144,14 & 58,70 \\
\hline Per & 18,18 & 466,75 & 56,61 & 33,03 & 36,48 & 28,98 \\
\hline I-Pi & 85,52 & 1814,26 & 239,95 & 126,44 & 162,40 & 35,67 \\
\hline DBahA & 26,17 & 464,71 & 80,77 & 38,08 & 52,19 & 9,62 \\
\hline BghiPer & 69,25 & 1645,36 & 196,72 & 92,04 & 119,16 & 30,63 \\
\hline 16 HPA & 872 & 22409 & 2298 & 1774 & 1425 & 629 \\
\hline$\Sigma$ HPA & 1497 & 46187 & 4765 & 2903 & 3062 & 1552 \\
\hline \%p-terfenil & 79 & 106 & 86 & 77 & 91 & 111 \\
\hline $2,6+3,52 \mathrm{MFe}$ & 10,63 & 247,70 & 24,84 & 18,44 & 27,24 & 9,82 \\
\hline 1,7 2MFe & 29,91 & 542,66 & 86,66 & 50,53 & 80,64 & 45,24 \\
\hline 1,5 2MFe & 28,74 & 757,32 & 102,03 & 53,60 & 81,96 & 47,18 \\
\hline Acef & 9,41 & 333,70 & 48,06 & 11,77 & 29,43 & 7,93 \\
\hline $\mathrm{BeFe}$ & 13,25 & 499,44 & 48,37 & 26,11 & 23,61 & 9,08 \\
\hline $\mathrm{I}-\mathrm{Cr}$ & 16,00 & 230,93 & 51,56 & 23,90 & 33,11 & 20,26 \\
\hline DajA & 20,56 & 291,44 & 74,05 & 21,16 & 41,28 & 14,90 \\
\hline Pf & 12,49 & 139,18 & 34,32 & 16,17 & 19,44 & 19,70 \\
\hline $\mathrm{BbCr}$ & 17,50 & 252,64 & 50,54 & 18,56 & 32,51 & 16,66 \\
\hline Pc & 13,73 & 218,17 & 40,26 & 12,54 & 24,91 & 10,61 \\
\hline
\end{tabular}


Resultado de hidrocarbonetos aromáticos, em $\mathrm{ng}^{-1}$, para as amostras sedimento coletadas na Baia de Guanabara.

\begin{tabular}{|c|c|c|c|c|c|}
\hline Código & P7 & P8 & P9 & P10 & P11 \\
\hline $\mathbf{N}$ & 2,08 & 2,14 & 7,77 & 13,25 & 4,45 \\
\hline C1N & 5,12 & 4,78 & 5,98 & 12,08 & 6,11 \\
\hline $\mathrm{C} 2 \mathrm{~N}$ & 6,19 & 6,70 & 31,54 & 12,15 & 7,28 \\
\hline C3N & 5,26 & 4,25 & 27,65 & 5,72 & 5,14 \\
\hline $\mathrm{C} 4 \mathrm{~N}$ & 6,17 & 10,19 & 43,81 & 6,15 & 9,82 \\
\hline ACF & 2,29 & 12,46 & 250,90 & 4,11 & 19,08 \\
\hline ACE & nd & nd & 4,61 & 2,03 & 1,27 \\
\hline $\mathbf{F}$ & 1,19 & 2,62 & 27,01 & 4,04 & 3,93 \\
\hline C1F & 4,12 & 8,66 & 42,03 & 6,48 & 6,67 \\
\hline $\mathrm{C} 2 \mathrm{~F}$ & 12,82 & 2,89 & 111,83 & 14,94 & 26,69 \\
\hline C3F & 28,04 & 58,40 & 281,18 & 34,78 & 60,63 \\
\hline DBT & 1,21 & 2,57 & 13,28 & 3,25 & 3,25 \\
\hline C1DBT & 4,27 & 10,88 & 45,03 & 6,59 & 10,15 \\
\hline C2DBT & 9,09 & 28,32 & 234,97 & 14,87 & 32,90 \\
\hline C3DBT & 10,89 & 33,58 & 458,58 & 13,95 & 40,92 \\
\hline $\mathrm{Fe}$ & 4,71 & 13,31 & 100,86 & 41,41 & 44,61 \\
\hline C1Fe & 9,39 & 30,86 & 257,08 & 44,63 & 54,67 \\
\hline $\mathrm{C} 2 \mathrm{Fe}$ & 14,66 & 50,43 & 559,34 & 53,18 & 88,82 \\
\hline $\mathrm{C} 3 \mathrm{Fe}$ & 9,59 & 41,81 & 490,11 & 32,31 & 67,02 \\
\hline C4Fe & 4,00 & 21,08 & 193,34 & 12,48 & 37,16 \\
\hline A & 2,43 & 8,43 & 93,94 & 17,36 & 19,66 \\
\hline FI & 26,82 & 58,92 & 499,31 & 210,71 & 236,75 \\
\hline $\mathbf{P i}$ & 22,35 & 62,46 & 683,86 & 188,10 & 240,49 \\
\hline C1Pi & 16,35 & 62,12 & 1320,78 & 124,64 & 188,11 \\
\hline $\mathrm{C} 2 \mathrm{Pi}$ & 10,37 & 45,29 & 1043,64 & 62,38 & 123,83 \\
\hline $\mathrm{BaA}$ & 15,29 & 45,69 & 810,16 & 185,05 & 225,99 \\
\hline $\mathrm{Cr}$ & 14,76 & 44,31 & 745,39 & 151,72 & 185,42 \\
\hline $\mathrm{C} 1 \mathrm{Cr}$ & 9,59 & 47,23 & 957,81 & 74,23 & 124,69 \\
\hline $\mathrm{C} 2 \mathrm{Cr}$ & 7,82 & 33,45 & 498,18 & 33,01 & 70,29 \\
\hline $\mathrm{BbFI}$ & 34,66 & 100,92 & 1428,42 & 215,42 & 279,16 \\
\hline BkFI & 8,44 & 32,50 & 555,52 & 69,12 & 91,52 \\
\hline $\mathrm{BePi}$ & 13,69 & 45,07 & 590,10 & 94,88 & 120,51 \\
\hline $\mathrm{BaPi}$ & 16,22 & 61,02 & 1280,94 & 155,25 & 183,52 \\
\hline Per & 28,02 & 51,89 & 219,21 & 39,40 & 45,26 \\
\hline I-Pi & 27,13 & 74,91 & 1065,46 & 137,52 & 176,89 \\
\hline DBahA & 10,27 & 22,67 & 270,12 & 44,29 & 51,88 \\
\hline BghiPer & 18,69 & 54,60 & 904,24 & 92,65 & 141,70 \\
\hline 16 HPA & 207 & 597 & 8729 & 1532 & 1906 \\
\hline$\Sigma$ HPA & 424 & 1197 & 16154 & 2234 & 3036 \\
\hline \%p-terfenil & 84 & 94 & 107 & 81 & 74 \\
\hline $2,6+3,5$ 2MFe & 2,28 & 6,43 & 66,26 & 8,05 & 11,88 \\
\hline 1,7 2MFe & 8,70 & 28,55 & 146,25 & 22,60 & 44,88 \\
\hline 1,5 2MFe & 6,57 & 30,28 & 198,27 & 20,77 & 42,18 \\
\hline Acef & 2,02 & 9,49 & 123,71 & 5,24 & 14,47 \\
\hline $\mathrm{BeFe}$ & 2,66 & 9,84 & 184,26 & 21,49 & 32,65 \\
\hline $\mathrm{I}-\mathrm{Cr}$ & 8,72 & 17,07 & 165,91 & 23,73 & 33,24 \\
\hline DajA & 13,94 & 16,38 & 221,39 & 27,81 & 39,09 \\
\hline Pf & 6,37 & 9,47 & 109,63 & 18,90 & 18,46 \\
\hline $\mathrm{BbCr}$ & 7,97 & 13,73 & 214,56 & 27,22 & 27,41 \\
\hline $\mathrm{Pc}$ & 7,66 & 13,78 & 162,98 & 20,55 & 21,70 \\
\hline
\end{tabular}

